BNL-81352-2008

\title{
2007 SITE ENVIRONMENTAL REPORT
}

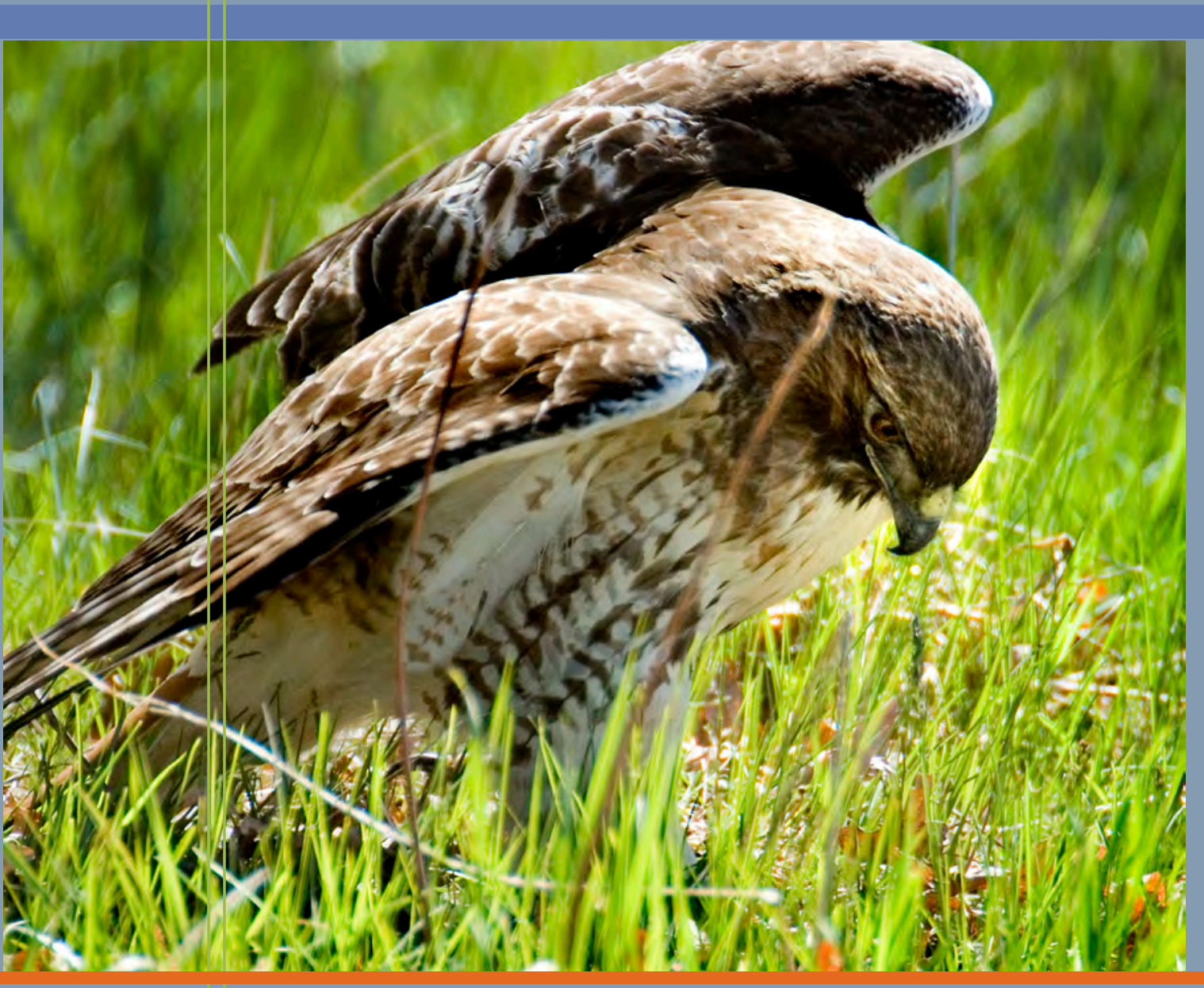

\author{
Volume 1
}

BROOKHAVEN NATIONAL LABORATORY 


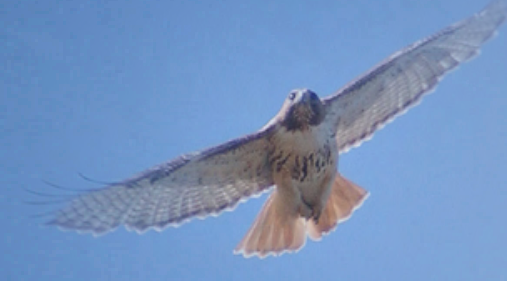

\section{ABOUT THE COVER}

A total of 216 species of birds have been identified at Brookhaven National Laboratory (BNL) since 1948. Approximately 85 species are known to nest on site, some of which are New York State threatened, endangered, or species of special concern. Chapter 6 of this report discusses habitat management and protection efforts of the laboratory's various bird populations.

The beautiful photo of a Red-tailed hawk (Buteo jamaicencis) on the cover of this report was taken by BNL photographer, Roger Stoutenburgh. The red-tailed hawk, a bird of prey, is one of nine species of Buteo inhabiting the United States and is protected by the migratory Bird Treaty Act.

The Brookhaven National Laboratory 2007 Site Environmental Report is a public document that is distributed to various U.S. Department of Energy sites, local libraries, and local regulators and stakeholders. The report is available to the general public on the internet at http://www.bnl.gov/ewms/ser/. A summary of the report is also available and is accompanied by a compact disk containing the full report. To obtain a copy of the summary and CD, please write or call:

Brookhaven National Laboratory

Environmental and Waste Management Services Division

Attention: SER Project Coordinator

Building 120

P.O. Box 5000

Upton, NY 11973-5000

(631) 344-3711 


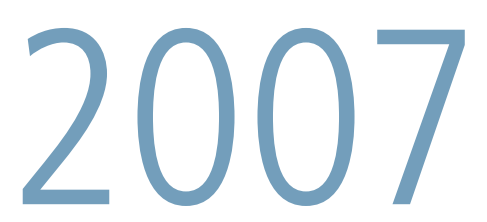

\title{
SITE ENVIRONMENTAL REPORT BROOKHAVEN NATIONAL LABORATORY
}

\author{
Volume I
}

\author{
October 2008
}

Prepared by

Brookhaven Science Associates, LLC

For the U.S. Department of Energy

Under Contract No. DE-AC02-98CH10886

Brookhaven National Laboratory

Brookhaven Science Associates, LLC

P.O. Box 5000

Upton, NY 11973-5000

EXPLORING EARTH'S MYSTERIES

...PROTECTING ITS FUTURE 


\section{DISCLAIMER}

This report was prepared as an account of work sponsored by an agency of the United States Government. Neither the United States Government nor any agency thereof, nor any of their employees, nor any of their contractors, subcontractors, or their employees, makes any warranty, express or implied, or assumes any legal liability or responsibility for the accuracy, completeness, or usefulness of any information, apparatus, product, or process disclosed, or represents that its use would not infringe on privately owned rights. Reference herein to any specific commercial product, process, or service by trade name, trademark, manufacturer, or otherwise, does not necessarily constitute or imply its endorsement, recommendation, or favoring by the United States Government or any agency, contractor, or subcontractor thereof. The views and opinions of authors expressed herein do not necessarily state or reflect those of the United States Government or any agency, contractor, or subcontractor thereof.

Printed in the United States of America

Available from

National Technical Information Service

U.S. Department of Commerce

5285 Port Royal Road

Springfield, VA 22161

\section{8}

PRINTED ON RECYCLED PAPER 


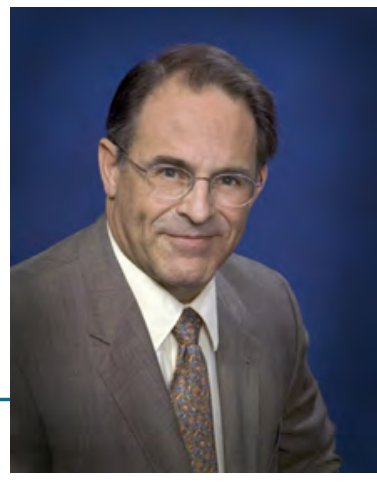

A MESSAGE FROM

THE LABORATORY DIRECTOR

BNL's environmental performance in 2007 continued to be a success, and that performance is key in enabling us to accomplish our scientific goals. We were recognized with eight national or regional environmental awards, including the prestigious White House Closing the Circle Award for expanding our EMS by voluntary participating in environmental improvement programs and our first Silver Level Award from the Office of the Federal Environmental Executive for electronics recycling. In addition, we received an Environmental Outreach Award from the National Environmental Performance Track Program, and a Long Island Transportation Management Inc., 2007 Commuter Choice Leadership Award. These accomplishments are proof that our commitment to environmentally responsible operations remains strong.

In 2007, BNL's Environmental Management System received recertification, with 24 examples of our continual improvement highlighted by the auditors. In addition, our nationally recognized Pollution Prevention Program continued to save the Laboratory money and helped reduce or reuse millions of pounds of waste.

As we address the remaining legacy issues under the Environmental Restoration Program, we will continue to openly communicate with the community, regulators, employees, and other interested parties on our environmental issues and cleanup progress. We know that the Laboratory's future as a world leader in science research depends in great part on the trust and cooperation of our neighbors.

Signature on file

Samuel H. Aronson, Laboratory Director 


\section{Executive Summary}

Brookhaven National Laboratory (BNL) prepares an annual Site Environmental Report (SER) in accordance with DOE Order 231.1A, Environment, Safety and Health Reporting of the U.S. Department of Energy. The report is written to inform the public, regulators, employees, and other stakeholders of the Laboratory's environmental performance during the calendar year in review. Volume I of the SER summarizes environmental data; environmental management performance; compliance with applicable DOE, federal, state, and local regulations; and performance in restoration and surveillance monitoring programs. BNL has prepared annual SERs since 1971 and has documented nearly all of its environmental history since the Laboratory's inception in 1947.

Volume II of the SER, the Groundwater Status Report, also is prepared annually to report on the status of and evaluate the performance of groundwater treatment systems at the Laboratory. Volune II includes detailed technical summaries of groundwater data and its interpretation, and is intended for internal BNL users, regulators, and other technically oriented stakeholders. A brief summary of the information contained in Volume II is included in this volume in Chapter 7, Groundwater Protection.

Both reports are available in print and as downloadable files on the BNL web page at http://www. bnl.gov/ewms/ser/. An electronic version on compact disc is distributed with each printed report. In addition, a summary of Volume I is prepared each year to provide a general overview of the report, and is distributed with a compact disc containing the-length report.

BNL is operated and managed for DOE's Office of Science by Brookhaven Science Associates (BSA), a partnership formed by Stony Brook University and Battelle Memorial Institute. For more than 60 years, the Laboratory has played a lead role in the DOE Science and Technology mission and continues to contribute to the DOE missions in Energy Resources, Environmental Quality, and National Security. BNL manages its world-class scientific research with particular sensitivity to environmental issues and community concerns. The Laboratory's motto, "Exploring Life’s Mysteries...Protecting its Future," and its Environmental, Safety, Security and Health Policy reflect the commitment of BNL's management to fully integrate environmental stewardship into all facets of its mission and operations.

\section{BNL'S INTEGRATED SAFETY MANAGEMENT SYSTEM, ISO 14001, AND OHSAS 18001}

The Laboratory's Integrated Safety Management System (ISMS) integrates management of environment (i.e., environmental protection and pollution prevention), safety, and health issues into all work planning. BNL's ISMS ensures that the Laboratory integrates DOE's five Core Functions and seven Guiding Principles into all work processes. These integrated safety processes contributed to BNL's achievement of registration under both the International Organization for Standardization (ISO) 14001 Standard (for the Laboratory's Environmental Management System) and the Occupational Safety and Health Assessment Series (OHSAS) 18001 standard (for BNL's Safety and Health Program). Both standards require an organiza- 
tion to develop a policy, create plans to implement the policy, implement the plans, check progress and take correction actions, and review the system periodically to ensure its continuing suitability, adequacy, and effectiveness.

One of BNL's highest priorities is ensuring that the Laboratory's environmental commitment is as strong as its passion for discovery. In 2001, an Environmental Management System (EMS) was established at BNL to ensure that environmental issues are systematically identified, controlled, and monitored. The EMS also provides mechanisms for responding to changing environmental conditions and requirements, reporting on environmental performance, and reinforcing continual environmental improvement. The cornerstone of the Laboratory's EMS is BNL's Environment, Safety, Security, and Health (ESSH) Policy. This policy makes clear the Laboratory's commitments to environmental stewardship, the safety of its employees, and the security of the site. Specific environmental commitments in the policy include compliance, pollution prevention, conservation, community outreach, and continual improvement. The policy is posted throughout the Laboratory and on the BNL website at http://www.bnl.gov/ ESHQ/ESSH.asp. It is also included in all training programs for new employees, guests, and contractors.

The Laboratory's EMS was designed to meet the rigorous requirements of the globally recognized ISO 14001 Environmental Management Standard. BNL was the first laboratory under the DOE Office of Science to become officially registered to this standard. Annual independent audits, which are required in order to maintain the registration, are conducted to validate that the Laboratory's EMS is being maintained and to identify evidence of continual improvement. In 2007, an EMS surveillance audit determined that BNL continues to conform to the Standard. During the audit, 24 examples of BNL's continual improvement were highlighted, including the Laboratory's link between institutional- and division-level objectives and targets, "very well done” internal audit records and documentation, and improved management reviews. The auditors identified one minor nonconformance in
"Nonconformity, corrective action and preventative action" and four opportunities for improvement, one each in Emergency Preparedness and Response; Objectives, Targets and Programs; Control of Documents; and Operational Control. A corrective action plan was prepared to track the minor nonconformances to closure.

The Laboratory's strong Pollution Prevention (P2) Program is an essential element for the successful implementation of BNL's EMS. The P2 Program reflects the national and DOE pollution prevention goals and policies, and represents an ongoing effort to make pollution prevention and waste minimization an integral part of the Laboratory's operating philosophy. Pollution prevention and waste reduction goals have been incorporated as performance measures into the DOE contract with BSA and into BNL's ESSH Policy. The overall goal of the P2 Program is to create a systems approach that integrates pollution prevention and waste minimization, resource conservation, recycling, and affirmative procurement into all planning and decision making. In January 2007, Executive Order 13423 was signed, establishing federal requirements for: energy efficiency and conservation, renewable energy, fleet management, electronic stewardship, water conservation, toxic chemical use reduction, recycling, sustainable buildings, and purchasing environmentally preferred products. Although most of these requirements have already been incorporated within the Laboratory's $\mathrm{P} 2$ program, the new order will direct its future course. Six P2 proposals, submitted by employees to BNL's P2 Council, were funded in 2007, for a combined investment of approximately $\$ 10,000$. The anticipated annual savings from these projects is estimated at $\$ 38,000$, for an average payback period of less than one year. Initiatives to reduce, recycle, and reuse 14.6 million pounds of industrial, sanitary, hazardous, and radiological waste through the $\mathrm{P} 2$ program saved over \$2.9 million in 2007.

BNL was accepted into the EPA's Performance Track (PTrack) Program in 2004. This program recognizes top environmental performance among participating U.S. facilities of all types and is considered the "gold standard" for facility-based environmental performance. The 
program requires that facilities commit to several improvement goals for a 3-year period and report on the progress of these goals annually. In 2007, the Laboratory completed its first set of goals under the PTrack Program:

- BNL's land and habitat conservation was significantly increased. A total of 42 acres of land was recovered, surpassing the original goal to recover 30 acres.

- The Laboratory continued its efforts to reduce radioactive air emissions from the Brookhaven Linac Isotope Producer (BLIP). In total, emissions were reduced by 34 percent, surpassing the original goal of 30 percent.

- BNL surpassed its original goal to remove more than 30 tons of ozone-depleting substances (ODS) by eliminating 35.5 tons of Class I ODS from 2003 through 2006.

- The Laboratory did not achieve its original goal of an 80 percent reduction in mercury inventory because the original inventory of mercury in storage was overestimated. By the end of 2006, 47 percent of the mercury inventory had been disposed. BNL continued to eliminate sources of mercury in 2007, achieving a 60 percent reduction by the end of the year.

In April 2007, BNL reapplied for continued membership to the PTrack program. Four new goals were established: energy reduction, transportation energy reduction, toxic release reductions, and establishing an electronics procurement program.

Chapter 2 of this report describes the elements and implementation of BNL's EMS in further detail.

\section{BNL'S ENVIRONMENTAL MANAGEMENT PROGRAM}

BNL's Environmental Management Program consists of several Laboratory-wide and facility-specific environmental monitoring and surveillance programs. These programs identify potential pathways of public and environmental exposure and evaluate the impacts BNL activities may have on the environment. An overview of the Laboratory's environmental programs and a summary of performance for 2007 follows:

\section{Compliance Monitoring Program}

BNL has an extensive program in place to ensure compliance with all applicable environmental regulatory and permit requirements. The Laboratory must comply with more than 100 sets of federal, state, and local environmental regulations, numerous site-specific permits, equivalency permits for the operation of 14 groundwater remediation systems, and several other binding agreements. In 2007, BNL complied with the majority of these requirements, and instances of noncompliance were reported to regulatory agencies and corrected expeditiously.

Ten external environmental audits were conducted in 2007. The New York State Department of Environmental Conservation (NYSDEC) conducted inspections of air compliance at the Central Steam Facility (CSF), several outfalls at the Sewage Treatment Plant (STP) regulated by the State Pollutant Discharge Elimination System (SPDES), BNL's Major Petroleum Facility (MPF), and chemical bulk storage facilities. The Suffolk County Department of Health Services (SCDHS) conducted inspections of the BNL potable water supply, a quarterly inspection of the STP, and several SPDES-regulated outfalls. No formal notices of violation or enforcement actions were issued as a result of these inspections.

The Laboratory took immediate corrective actions to address three conditions identified during the NYSDEC inspection of the MPF. The corrective actions included: the submittal of design specifications/plans for the replacement of the secondary containment system for tanks 5 and 6, repair of a malfunctioning alarm system, and the need for an additional cover stone on several secondary containment systems to prevent liner damage. In addition, an inspection of BNL's diesel tank farm and underground gasoline storage facilities identified three conditions that needed corrective action. They included: application of the proper color coding for an underground storage tank, inspections and repair of two high-level alarms at the diesel tank farm, and noting both the design and working capabilities of each tank at the diesel tank farm. All conditions were corrected in 2007. 
Two issues that required corrective action were identified during an inspection by NYSDEC of BNL's chemical bulk storage facilities. These included: peeling and blistering paint observed on a tank, and tank labels that did not include the working capacity of each tank. The issues were corrected in accordance with the NYSDEC directive.

Compliance monitoring in 2007 showed that emissions of nitrogen oxides, carbon monoxide, and sulfur dioxide from the CSF were all within permit limits. Opacity excursions were noted in the first and second quarters of 2007. The first excursions were due to soot blowing operations, which are performed to maintain boiler efficiency. The excursions were determined to be isolated events after an extended idle period which allowed excess soot to accumulate while nominal volumes of oil were burned to keep the boiler warm. Opacity excursions noted in the second quarter were caused by a mechanical malfunction of the calibration shutter in the transmissometer optical head assembly, which was subsequently replaced.

Approximately 1,168 pounds of ozone-depleting refrigerants were recovered from refrigeration equipment for recycling on site or made available for use by other DOE facilities or federal agencies. These reductions included the removal of forty-seven 17-pound Halon 1211 portable fire extinguishers as excess property due to changes in operations or through replacement.

Monitoring of the potable water supply showed that all drinking water quality requirements were met. Groundwater monitoring at the MPF continued to demonstrate that current oil storage and transfer operations are not affecting groundwater quality. With the exception of four minor permit excursions at the STP, liquid effluents discharged to surface water and groundwater met all applicable SPDES permit requirements. The four SPDES permit limit excursions reported were for nitrogen. Abnormally low flow conditions and decreased nutrients in the waste have been identified as the most likely causes of the increased nitrogen levels. Enzymes are now added at the plant to enhance denitrification of the effluent by the biological organisms during treatment.
The Laboratory continues to reduce the number and severity of spills on site. In 2007, the total number of spills was reduced by 22 percent, from 27 spills in 2006 to 21 spills in 2007. Twelve spills were 5 gallons or less, but were reportable because they reached the soil. The remaining nine spills were small-volume releases either to containment areas or to other impermeable surfaces. All releases were cleaned up or addressed to the satisfaction of NYSDEC. Measures employed to help reduce spills include: replacing petroleum-based lubricants and fluids with vegetable-based products, installing stainless steel-reinforced hydraulic lines on various pieces of equipment, and training staff in proper spill-response techniques.

Chapter 3 of this report describes BNL's Compliance Program and status in further detail.

\section{Air Quality Program}

BNL monitors radioactive emissions at three facilities on site to ensure compliance with the requirements of the Clean Air Act (CAA). During 2007, Laboratory facilities released a total of 2,536 curies of radioactive gases. EPA regulations require continuous monitoring of all sources that have the potential to deliver an annual radiation dose greater than 0.1 mrem to a member of the public; all other facilities capable of delivering any radiation dose require periodic confirmatory sampling. Although the dose to the public is less than 0.1 mrem and monitoring is not required by EPA, the BLIP is continuously monitored. Oxygen-15 (half-life: 122 seconds) and carbon-11 (half-life: 20.48 minutes) emitted from the BLIP constituted more than 99.9 percent of radiological air emissions on site in 2007. The combined emissions were approximately 43 percent lower than in 2006, primarily due to operation at lower power levels in 2007.

Monitoring was also conducted at one other active facility, the Target Processing Laboratory (TPL), and one inactive facility, the High Flux Beam Reactor (HFBR). Releases from the TPL in 2007 continued to be very small $(0.038 \mu \mathrm{Ci})$. Tritium releases from the HFBR in 2007 continued a downward trend, as emissions dropped to 1.33Ci compared to releases in 2006 of $4.03 \mathrm{Ci}$. 
The Laboratory conducts ambient radiological air monitoring to verify local air quality and assess possible environmental and health impacts from BNL operations. Air monitoring stations around the perimeter of the site measure tritium and gross alpha and beta airborne activity. Results for 2007 continued to demonstrate that on-site radiological air quality was consistent with off-site measurements and with results from locations in New York State that are not located near radiological facilities.

Various state and federal regulations governing nonradiological releases require facilities to conduct periodic or continuous emission monitoring to demonstrate compliance with emission limits. The CSF is the only BNL facility that requires monitoring. Two of the four boilers at the CSF, specifically 6 and 7, are equipped with continuous emission monitors to measure opacity and nitrogen oxide $\left(\mathrm{NO}_{\mathrm{x}}\right)$ emissions. In 2007, there were no exceedances of the $\mathrm{NO}_{\mathrm{x}}$ emission standards for either boiler. Opacity levels cannot exceed 20 percent, except for one 6-minute period per hour of not more than 27 percent opacity. During the first quarter of 2007, all of the Boiler 6 opacity measurements that exceeded the opacity limit occurred during the first soot blowing cycle after a long idle period, during which the boiler was only warmed with nominal volumes of oil. Second quarter Boiler 6 opacity exceedances were the result of a calibration shutter malfunction. Opacity deviations ceased when the transmissometer optical head assembly was replaced. Changes in the sequence of the soot blowing cycle for Boiler 6 that were made in August 2005 have proven effective in eliminating most opacity exceedances due to soot blowing. Similar changes made to the soot blowing cycle on Boiler 7, after the installation of a new soot blowing controller in March 2006, have also been successful in eliminating soot blowing opacity exceedances from this boiler.

Because natural gas prices were lower than residual fuel oil prices from May through November 2007, BNL used natural gas for most heating and cooling needs during these months. As a result, annual facility emissions of particulate matter, nitrogen oxides, and sulfur dioxide were considerably lower than in years when residual fuel oil was predominantly used.

Chapter 4 of this report describes BNL's Air Quality Program and monitoring data in further detail.

\section{Water Quality Surveillance Program}

BNL discharges treated wastewater into the headwaters of the Peconic River via the STP, and non-contact cooling water and storm water runoff to groundwater via recharge basins. Some wastewater may contain very low levels of radiological, organic, or inorganic contaminants. Monitoring, pollution prevention, and careful operation of treatment facilities ensure that these discharges comply with all applicable requirements and that the public, employees, and the environment are protected.

To assess the potential impact of discharges on the water quality of the Peconic River, surface water monitoring is conducted at several locations upstream and downstream of the STP point-source discharge. The Carmans River, located to the west of BNL, is monitored as a geographical control location for comparative purposes, as it is not affected by Laboratory operations. In 2007, the average gross alpha and beta activity levels in the STP discharge were well below drinking water standards (DWS). While the frequency of detectable levels of tritium declined in 2007, the average concentration was slightly higher than in 2006, resulting in an increase in releases to the Peconic River. The maximum concentration released was approximately 9.2 percent of the drinking water standard and was only detected in the effluent. The average concentration was $57.4 \mathrm{pCi} / \mathrm{L}$, which is less than 20 percent of the minimum detection limit (MDL). Throughout 2007, tritium was never detected in the influent to the STP, only the effluent. The only explanation for this observation is that tritium released to the STP in late 2006 continued to be released in early January. An investigation to ascertain the tritium source did not reveal any single source of high-concentration tritium, but did identify several low-concentration sources. The lowconcentration releases are expected to continue, as facilities such as the HFBR and Brookhaven 
Medical Research Reactor (BMRR) are placed into routine surveillance mode and piping and tank systems are drained and dried out. The STP effluent continued to show no detection of cesium-137 (Cs-137), strontium-90 (Sr-90), or other gamma-emitting nuclides attributable to BNL operations. Acetone was the only volatile organic compound (VOC) detected in the STP effluent at concentrations at or near the detection limit. The maximum concentration detected was $4.2 \mathrm{ug} / \mathrm{L}$, which is less than 15 percent of the generic limit of $50 \mu \mathrm{g} / \mathrm{L}$ imposed by NYSDEC. Nitrogen as nitrate was confirmed in the STP effluent through the environmental surveillance monitoring program at concentrations that exceeded the SPDES permit limits.

On-site recharge basins are used for the discharge of "clean" wastewater streams, including once-through cooling water, storm water runoff, and cooling tower blow-down, and are suitable for direct replenishment of the groundwater aquifer. Radiological analyses in 2007 showed that the low levels of gross alpha and beta activity detected in most of the basins were attributable to naturally occurring radionuclides, such as potassium-40, and not to BNL operations. Tritium was detected in a single sample collected at Basin HT-W at very low levels $(430 \mathrm{pCi} / \mathrm{L})$. Considering the low level of detection and analytical method uncertainties, positive identification of tritium in the sample was questionable.

In 2007, nonradiological analyses of the recharge basins showed low concentrations of VOCs, including disinfection byproducts generated by the use of chlorine for the control of bacteria and algae in cooling water systems. Acetone was also detected above the MDL for most recharge basins. Due to the common use of acetone in analytical laboratories and the finding of acetone in the contract analytical laboratory control samples, positive identification is suspect. Lead was detected in two samples and was likely due to the presence of suspended particulate in the samples. Remediation of the CSF outfall for lead contamination was completed and the site was restored in 2007 at a MDL of $0.2 \mu \mathrm{g} / \mathrm{L}$.

Along the Peconic River, several locations are monitored for radiological and nonradiologi- cal parameters to access overall water quality. Radiological data from Peconic River surface water sampling in 2007 showed very low concentrations of gross alpha and gross beta activity. The average concentrations from off-site and control locations were indistinguishable from BNL on-site levels, and all detected levels were below the applicable DWS. No gammaemitting radionuclides attributable to Laboratory operations were detected either upstream or downstream of the STP. Tritium was detected in a single water sample collected downstream of the STP discharge in May, although the detection is questionable due to the fact that tritium was not detected in the STP discharge during this period. Aluminum, copper, iron, and zinc were present at some locations both upstream and downstream of the STP point-source discharge at concentrations that exceeded the NYS Ambient Water Quality Standards. Mercury was not detected in any water samples in 2007.

Chapter 5 of this report describes BNL's Water Quality Surveillance Program and monitoring data in further detail.

\section{Natural and Cultural Resource Management Program}

The BNL Natural Resource Management Program was designed to promote stewardship of the natural resources found on site and to integrate natural resource management and protection with the Laboratory's scientific mission. The goals of the program include protecting and monitoring the ecosystem, conducting research, and communicating with the public, stakeholders, and staff members regarding environmental issues. Precautions are taken to protect and enhance habitats and natural resources at BNL. Activities to eliminate or minimize negative effects on sensitive or critical species (such as the eastern tiger salamander, eastern hognose snake, and banded sunfish) are incorporated into procedures or into specific program or project plans. Restoration efforts continue to remove pollutant sources that could contaminate habitats. In some cases, habitats are enhanced to improve survival or increase populations. The Laboratory also monitors and manages other wildlife populations, such as white-tailed deer and wild turkey. 
BNL conducts routine monitoring of flora and fauna to assess the impact, if any, of past and present activities on the Laboratory's natural resources. Generally, deer sampled on site contain higher concentrations of Cs-137 than deer sampled from more than 1 mile off site. This is most likely because on-site deer consume small amounts of contaminated soil and graze on vegetation growing in soil where elevated Cs-137 levels are known to exist. The maximum onsite concentration in 2007 was 17 times lower than the highest level reported in 2006, and is much lower than the highest level ever reported (1996). The low levels in samples taken in 2007 indicate the effectiveness of cleanup actions across the site. The New York State Department of Health (NYSDOH) has reviewed the potential public health risk associated with the low levels of Cs-137 in on-site deer and determined that neither hunting restrictions or formal health advisories are warranted. Testing of deer bones for Sr-90 indicated background levels. Sr-90 is present in the environment at background levels as a result of worldwide fallout from nuclear weapons testing. BNL will continue to test for Sr-90 in bone to develop baseline information.

In an effort to restore fish populations, the Laboratory suspended most on-site fish sampling in 2001. The reluctance to sample fish continued in 2006, due to impacts of the Peconic River cleanup project and drought conditions in 2005. In 2006, four fish were sampled on site; although due to the size of the fish, only metals analyses could be performed. Routine annual on-site sampling of fish resumed in 2007. Cs-137 was detected at low levels in all samples from the Peconic River system and appears to be declining compared with historic values. The cleanup of both on-and off-site portions of the Peconic River in 2004 and 2005 removed approximately 88 percent of Cs-137 in the sediment that was co-located with mercury. Natural decay and the removal of this contamination are expected to result in further deceases.

Non-radiological analysis of fish continued in 2007. Due to their small size, fish taken on site were analyzed for mercury only, due to its known health effects. The mercury in on-site samples ranged from $0.13 \mathrm{mg} / \mathrm{kg}$ in a brown bullhead to $1.35 \mathrm{mg} / \mathrm{kg}$ in a pumpkinseed. This compares to a range of $0.46 \mathrm{mg} / \mathrm{kg}$ to 0.62 $\mathrm{mg} / \mathrm{kg}$ in fish taken in 2006. The larger range in the 2007 on-site data is due to a larger sample size and larger range in fish. Off-site Peconic River samples ranged from less than the MDL in a brown bullhead to $1.04 \mathrm{mg} / \mathrm{kg}$ in a largemouth bass. Mercury levels were less than the $1.0 \mathrm{mg} / \mathrm{kg}$ consumption standard set by the U.S. Food and Drug Administration in all but a few fish. The average of all fish from the Peconic River was $0.32 \mathrm{mg} / \mathrm{kg}$, which is slightly above the U.S. EPA criterion for freshwaters. Low levels of pesticides were also detected in off-site fish samples, but did not exceed any standards and do not pose any health impact to humans or animals that might consume the fish. PCBs have been found in fish and sediment at BNL and periodically at other locations in the Peconic River. However, the cleanup of the Peconic River, which was completed in 2005, removed most PCBs within the sediments. PCB testing will be discontinued in fish samples in 2008 except for fish taken on site to continue to document the effectiveness of the Peconic River cleanup.

Annual sampling of sediment, vegetation, and freshwater in the Peconic River and a control location on the Carmans River was conducted in 2007. Low levels of Cs-137 were documented in sediment and vegetation. On- and off-site aquatic vegetation and sediments contained low levels of Cs-137, metals, pesticides, and PCBs, in amounts that were consistent with levels detected in previous years.

Under the Peconic River remediation project, sediment from the Peconic River was remediated to remove mercury and associated contaminants from the river. This project was completed in the summer of 2005. Sampling results for 2007 showed that 97 percent of samples analyzed at 16 on-site locations and 14 off-site locations met the cleanup goal of $2.0 \mathrm{mg} / \mathrm{kg}$. One sample exceeded the goal in June and two samples exceeded the goal in August. Further evaluation will include additional sediment and surface water sampling in 2008.

Water column sampling for mercury and methylmercury was performed at 20 Peconic River sampling locations and one reference 
location on the Connetquot River in 2007. Concentrations of mercury were less than the respective 2003 Peconic River pre-cleanup concentrations. Mercury samples collected from the Peconic River upstream and downstream of the STP effluent indicate that concentrations are higher upstream of the STP. Methylmercury concentrations detected in June 2007 were generally higher than the June 2003 Peconic River pre-cleanup concentrations, and August 2007 concentrations were lower than values detected in August 2003. Methylmercury samples collected from the STP effluent indicate that the STP is not a significant contributing source.

Wetland monitoring results showed that vegetation restoration along the Peconic River was at 92 percent over 64 monitoring transects with less than 1 percent coverage of invasive species. Monitoring of invasive species will continue until 2008, at which time BNL will evaluate all wetland restoration and invasive species surveys and control operations since the completion of the Peconic River cleanup in 2005.

BNL sponsors a variety of educational and outreach activities involving natural resources. These programs are designed to help participants understand the ecosystem and to foster interest in science. Wildlife programs are conducted at BNL in collaboration with DOE, local agencies, colleges, and high schools. Ecological research is also conducted on site to update the current natural resource inventory, gain a better understanding of the ecosystem, and guide management planning. In 2007, the Environmental and Waste Management Services Division (EWMSD) hosted 16 interns and one faculty member who worked on a variety of projects including: surveying dragonflies and damselflies, radio tracking turtles, analyzing the water chemistry of coastal plain ponds, investigating turtle and amphibian diseases, investigating the loss of the southern leopard frog on Long Island, genetics of resident gray and red fox at BNL, and population health of the banded sunfish. The Foundation for Ecological Research in the Northeast (FERN) hosted two undergraduate interns who assisted in the development of Freshwater Wetland Health Monitoring Protocols. The monitoring protocols are available on the FERN website at www.fern-li.org .

The goal of BNL's Cultural Resource Management Program (CRMP) is to ensure the proper stewardship of BNL and DOE historic resources. Additional goals include maintaining compliance with various historic preservation and archeological laws and regulations, and ensuring the availability of resources to Laboratory personnel and the public for research and interpretation. Cultural resource management activities performed in 2007 include: identifying additional equipment artifacts associated with the HFBR and the BGRR, and electronically scanning the diary of a World War I soldier for website posting. Outreach activities consisted of providing presentations on Laboratory cultural resources and tours of the WWI trenches to several small groups, and participating in local fairs.

Chapter 6 of this report describes BNL's natural and cultural resources in further detail.

\section{Groundwater Protection Management Program}

BNL's extensive groundwater monitoring well network is used to evaluate progress in restoring groundwater quality, to comply with regulatory permit requirements, to monitor active research and support facilities, and to assess the quality of groundwater that enters and exits the site. The Laboratory monitors research and support facilities where there is a potential for environmental impact, as well as areas where past waste handling practices or accidental spills have already degraded groundwater quality. In 2007, the Laboratory collected groundwater samples from 850 on- and off-site monitoring wells during 2,289 individual sampling events.

Under the environmental surveillance program, 10 active research and support facilities were monitored during 2007. Although no new impacts to groundwater quality have been discovered since 2001, groundwater quality continues to be impacted from past releases at two facilities: the former g-2 experiment within the Alternating Gradient Synchrotron (AGS) facility, and the Upton service station facility. Tritium continues to be detected at concentrations above the $20,000 \mathrm{pCi} / \mathrm{L}$ DWS in wells monitoring the g-2 source area. Although tritium concentrations have shown a steady decline over the past 
4 years, monitoring data suggest that the continued release of tritium from the source area is due to residual tritium being flushed out of the unsaturated zone close to the water table by natural water table fluctuations. The amount of tritium entering the groundwater is expected to decrease over time, due to this flushing mechanism and by natural radioactive decay. Tritium levels in the groundwater at the BLIP were less than the 20,000 pCi/L DWS during all of 2007. In early 2007, a Record of Decision (ROD) was signed by DOE and EPA for the g-2 and BLIP tritium source areas. The ROD requires continued routine inspection and maintenance of the impermeable caps at the source area, groundwater surveillance of the source areas, and monitoring the g-2 tritium plume until it attenuates to less than the $20,000 \mathrm{pCi} / \mathrm{L}$ DWS. VOCs associated with historical petroleum and solvent spills continue to be detected in the groundwater at concentrations above the applicable DWS at the Upton service station facility. These low levels of VOCs are expected to decrease over time by means of natural attenuation.

The primary mission of the Laboratory's Long Term Response Actions (LTRA) program is to operate and maintain groundwater treatment systems and prevent additional groundwater contamination from migrating off site. BNL continues to make significant progress in restoring groundwater on site. During 2007, 198 pounds of VOCs and approximately $5.2 \mathrm{mCi}$ of Sr-90 were removed from the groundwater, and more than 1.2 billion gallons of treated groundwater were returned to the aquifer. Data from the groundwater monitoring networks and treatment systems is monitored and analyzed on a continuous basis. During 2007, it was determined that two groundwater treatment systems, the Chemical Holes Sr-90 System and the Airport System, required modifications in the form of additional extraction wells to ensure the complete capture of the plumes and the ability to achieve the cleanup goals. In addition, based on the triggering of an OU III ROD contingency, the HFBR Pump and Recharge System was reactivated and enhanced with an additional extraction well. The Laboratory's groundwater cleanup goals include minimizing plume growth and reducing contaminant concentrations in the Upper Glacial aquifer to below Maximum Contaminant Level (MCL) standards by 2030. For the Chemical/Animal Holes area, MCLs must be reached by 2040 . VOC levels in the Magothy aquifer must meet MCLs by 2065. For the Sr-90 plumes associated with the BGRR/WCF, MCLs must be reached by 2070. The cleanup objectives will be met by a combination of active treatment and natural attenuation. The LTRA program uses an extensive network of monitoring wells to track the progress that the groundwater treatment systems are making toward plume remediation.

Chapter 7 of this report provides an overview of this program, and the SER Volume II, Groundwater Status Report, provides a detailed description, data, and maps relating to all groundwater monitoring performed in 2007.

\section{Radiological Dose Assessment Program}

BNL routinely assesses its operations to ensure that any potential radiological dose to members of the public, BNL workers, and the environment is "As Low As Reasonably Achievable” (ALARA). The potential radiological dose is calculated as the largest possible dose to a hypothetical Maximally Exposed Individual (MEI) at the BNL site boundary. For dose assessment purposes, the pathways include direct radiation exposure, inhalation, ingestion, immersion, and skin absorption. Radiological dose assessments at the Laboratory have consistently shown that the "effective dose equivalent" from operations is well below the EPA and DOE regulatory dose limits for the public and the environment. The dose impact from all BNL activities in 2007 was found to be insignificantly above natural background radiation levels.

To measure direct radiation from Laboratory operations, 49 thermoluminescent dosimeters (TLDs) are placed on site and 15 TLDs are placed in surrounding communities. In 2007, the average doses from all TLDs showed there was no additional contribution to dose from BNL operations above natural background radiation. The annual on-site external dose from all potential sources, including cosmic and terrestrial radiation, was $70 \pm 12$ mrem $(700 \pm 120$ 
$\mu \mathrm{Sv})$, and the annual off-site external dose was $64 \pm 10$ mrem $(640 \pm 100 \mu \mathrm{Sv})$. Both on- and off-site dose measurements include the contribution from natural terrestrial and cosmic background radiation.

The effective dose to the MEI from air emissions was 5.96E-2 mrem $(0.60 \mu \mathrm{Sv})$. The ingestion pathway dose was estimated as 3.02 mrem (30 $\mu \mathrm{Sv}$ ) from consumption of deer meat and 0.08 mrem $(0.7 \mu \mathrm{Sv})$ from consumption of fish caught in the vicinity of the Laboratory. The total annual dose to the MEI from all pathways was estimated as 3.16 mrem (32 $\mu \mathrm{Sv})$. The dose from the air inhalation pathway attributable to BNL operations was less than 1 percent of EPA's annual regulatory dose limit of 10 mrem (100 $\mu \mathrm{Sv}$ ), and the total dose was less than 4 percent of DOE's annual dose limit of 100 mrem (1,000 $\mu \mathrm{Sv})$ from all pathways. Doses to aquatic and terrestrial biota were also evaluated and found to be well below the regulatory limits.

As a part of the National Emission Standards for Hazardous Air Pollutants (NESHAPs) review process at BNL, any source that has the potential to emit radioactive materials is evaluated for regulatory compliance. In 2007, two NESHAPs compliance reviews were performed: research using radiotracers in Room 9-830 in the Medical Department and remediation activities at the waste loading dock. Both assessments showed no significant dose impacts from these activities.

Chapter 8 of this report describes the BNL Radiological Dose Assessment Program and monitoring data in further detail.

\section{Quality Assurance Program}

The multilayered components of the BNL Quality Assurance (QA) Program ensure that all analytical data reported in this document are reliable and of high quality, and that all environmental monitoring data meet quality assurance and quality control objectives. Samples are collected and analyzed in accordance with EPA methods and standard operating procedures that are designed to ensure samples are representative and the resulting data are reliable and defensible. Quality control in the analytical laboratories is maintained through daily instru- ment calibrations, efficiency and background checks, and testing for precision and accuracy. Data are verified and validated as required by project-specific quality objectives before being used to support decision making.

In 2007, the Laboratory used five off-site contract analytical laboratories to analyze environmental samples: General Engineering Lab (GEL), H2M Lab, Test American (TA), Chemtex Lab, and Brooks Rand. All analytical laboratories were certified by New York State for the tests they performed for BNL, and were subject to oversight that included state and national performance evaluation (PE) testing, review of QA programs, and audits.

Four of the contract analytical laboratories (GEL, TA, H2M, and Brooks Rand) participated in several national and state PE testing programs in 2007. The fifth contractor, Chemtex Laboratory, did not participate in PE testing because there is no testing program for the specific analytes Chemtex analyzed. Each of the participating laboratories took part in at least one testing program, and several laboratories participated in multiple programs. Results of the tests provide information on the quality of a laboratory's analytical capabilities. The testing was conducted by Environmental Resource Associates (ERA), the National Voluntary Laboratory Accreditation Program (NVLAP), the voluntary Mixed Analyte Performance Evaluation Program (MAPEP), and the NYSDOH Environmental Laboratory Accreditation Program (ELAP).

As part of DOE's Integrated Contract Procurement Team Program, TA and GEL were audited during 2007. During the audits, errors are categorized into Priority I and Priority II findings. Priority I status indicates a problem that can result in unusable data or a finding that the contract analytical laboratory cannot adequately perform services for DOE. Priority II status indicates problems that do not result in unusable data and do not indicate that the contract analytical laboratory cannot adequately perform services for DOE .

In 2007, there were no Priority I findings for GEL. TA had two Priority I findings. The results of the TA audit included two Priority I findings (one radiological and one waste man- 
agement) and 18 Priority II findings: 11 radiological, 2 QA management system findings, 1 waste management finding, 3 inorganic findings, and 1 Laboratory Information Management System (LIMS) finding. The two Priority I findings against their radiological analysis and waste management departments indicated that the Technical Director of the radiochemistry department did not have the appropriate education/and or technical background and that the implementation of the radiation protection program had systematic failures and a lack of accountability of the radiological inventory. Based on these findings, it was necessary to suspend sending samples for radiological analyses until the TA facility successfully closed these issues with DOE. In July 2007, DOE issued a letter stating that a re-audit of the facility resulted in the closing of the Priority I findings and BNL was authorized to ship BNL samples to TA. The results of the GEL audit included 13 Priority II findings: two quality assurance management system findings, three organic findings, three inorganic findings, four radiological findings, and one waste management finding. Corrective action plans were submitted to DOE by both contract analytical laboratories to document that procedures were put in place to correct these findings. Based on the audits, the analytical data met DOE's criteria for acceptable status.

Based on the data reviews, data validations, and results of the independent PE assessments, the chemical and radiological results reported in this 2007 SER are of acceptable quality. Chapter 9 of this report describes the BNL Quality Assurance/Quality Control Program in further detail. 
A Note from the Editor

Throughout the Site Environmental Report, there are many references to Brookhaven National Laboratory (BNL), the U.S. Department of Energy (DOE), and the U.S. Environmental Protection Agency (EPA). These acronyms, and others that are explained in each chapter, are used interchangeably with their spelled-out forms as an aid to readers. Also, Appendix A opens with a list of acronyms and their meanings. 


\section{SITE ENVIRONMENTAL REPORT TEAM}

The SER Team realizes that many other employees contributed to this report and thanks everyone for their assistance.

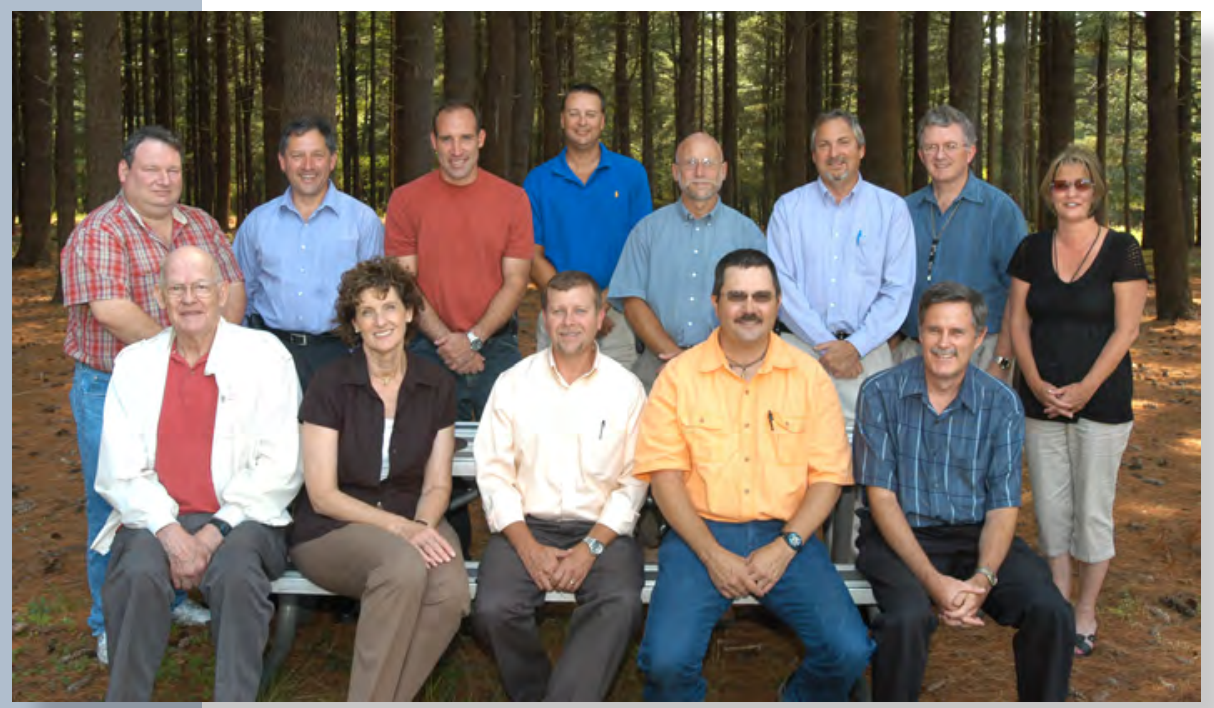

The SER Team

(Back row, left to right) John Burke, Robert Lee, Jason Remien, William Dorsch, Robert Howe, George Goode, Douglas Paquette, and Karen Ratel (Front row, left to right) Arland Carsten, Patricia Yalden, John Selva, Timothy Green, and Jeffrey Williams (Balwan Hooda and Kathleen Robinson not pictured)
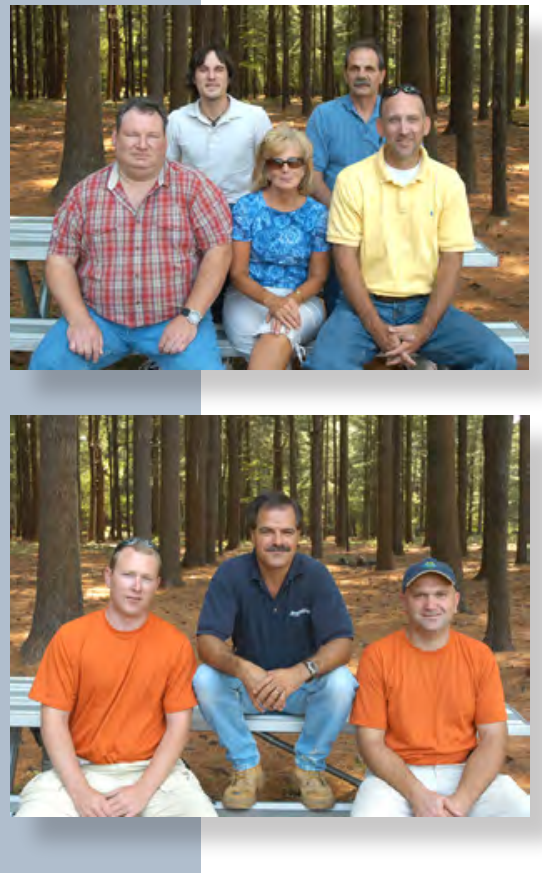

The Environmental Information Management Services Group

(Back row, left to right)

Andrew Rohkohl, and Frank Tramontano

(Front row, left to right)

John Burke, Susan Young, and Brian Foley

The Environmental and Waste Management Services Division Field Sampling Team

(From left to right) James Milligan, Lawrence Lettieri, and Robert Metz

(Richard Lagattolla not pictured) 


\section{Acknowledgments}

The production of the BNL 2007 Site Environmental Report (SER), Volume I, required the knowledge, skill, experience, and cooperation of many people and organizations at the Laboratory. The lead authors, co-authors, and other contributing staff involved in producing the report and Summary are listed below.

LEAD CHAPTER AUTHORS

ENVIRONMENTAL AND WASTE MANAGEMENT

SERVICES DIVISION

$\begin{array}{cc}\text { EXECUTIVE SUMMARY } & \text { Karen Ratel } \\ \text { CHAPTER } 1 & \text { Karen Ratel } \\ \text { CHAPTER } 2 & \text { John Selva } \\ \text { CHAPTER } 3 & \text { Robert Lee } \\ \text { CHAPTER } 4 & \text { Jeffrey Willi } \\ \text { CHAPTER } 5 & \text { Robert Lee } \\ \text { ENVIRONMENTAL AND wASTE MANAG } \\ \text { SERVICES DIVISION } \\ \text { Arland Carsten, Consultant } \\ \text { Mark Davis } \\ \text { George Goode } \\ \text { Jennifer Higbie } \\ \text { Richard Lagattolla } \\ \text { Lawrence Lettieri } \\ \text { Robert Metz } \\ \text { Peter Pohlot } \\ \text { Jason Remien } \\ \text { Glen Todzia }\end{array}$

$\begin{aligned} \text { CHAPTER 6 } & \text { Timothy Green } \\ \text { CHAPTER 7 } & \begin{array}{l}\text { Douglas Paquette } \\ \text { William Dorsch }\end{array} \\ \text { CHAPTER } 8 & \text { Balwan Hooda } \\ \text { CHAPTER 9 } & \text { John Burke } \\ \text { SER SUMMARY } & \text { Karen Ratel }\end{aligned}$

CO-AUTHORS AND KEY CONTRIBUTORS

BIOLOGY DEPARTMENT

Richard Setlow

COMMUNITY, EDUCATION, GOVERNMENT

AND PUBLIC AFFAIRS

Jeanne D'Ascoli

Peter Genzer

ENVIRONMENTAL RESTORATION

Robert Howe

PLANT ENGINEERING DIVISION

Edward Phillips

Barbara Pierce

Mark Toscano

RADIOLOGICAL CONTROL DIVISION

Charles Schaefer

SER PROJECT COORDINATOR

Karen Ratel, Environmental and Waste Management Services Division

EDITOR

Kathleen Robinson, Information Services Division

DESIGNER

Patricia Yalden, Media \& Communications and Production Services

"Thank you" to the staff and management of the following organizations who assisted the authors in the preparation of this report by providing technical peer reviews, sample and data collection, maps and diagrams, and other support necessary to make this report possible.

\footnotetext{
Community, Education, Government

and Public Affairs Directorate

Environment, Safety \& Health Directorate

Environmental and Waste Management Services Division

Environmental Information Management System Group
}

\author{
Environmental Restoration Group \\ Information Services Division \\ Media \& Communications and Production Services \\ Plant Engineering Division \\ Radiological Control Division
}




\section{Contents}

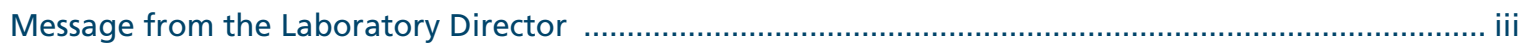

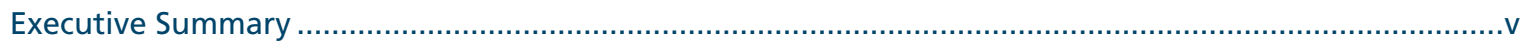

Acknowledgments .................................................................................................................

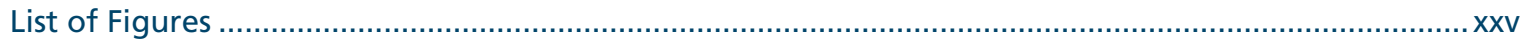

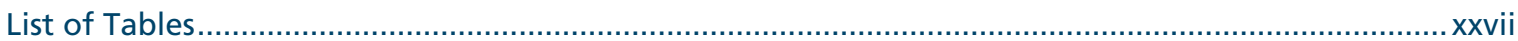

\section{CHAPTER 1: INTRODUCTION}

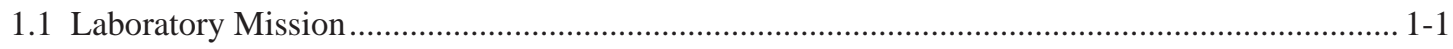

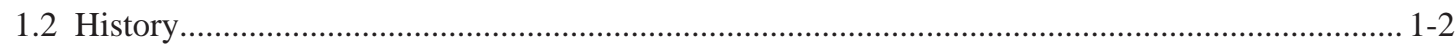

1.3 Research and Discoveries ............................................................................................... 1-4

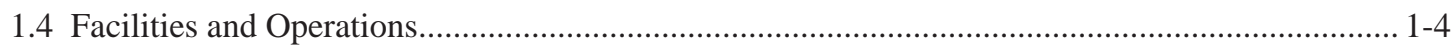

1.5 Location, Local Population, and Local Economy ........................................................................ 1-5

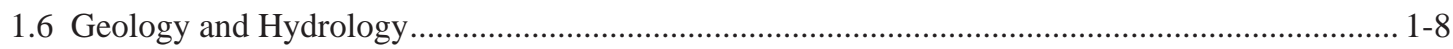

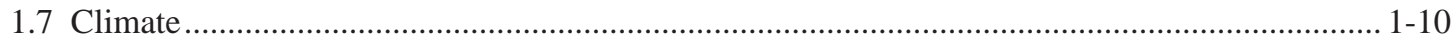

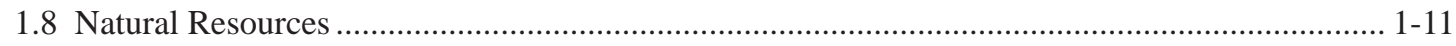

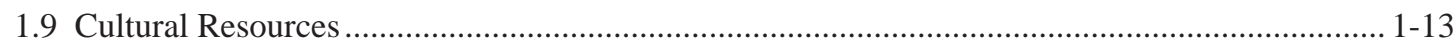

References and Bibliography ................................................................................................ 1-13

\section{CHAPTER 2: ENVIRONMENTAL MANAGEMENT SYSTEM}

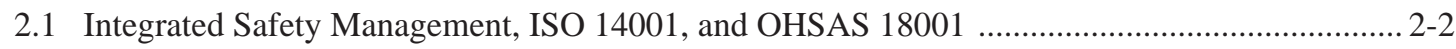

2.2 Environmental, Safety, Security, and Health Policy ……......................................................... 2-5

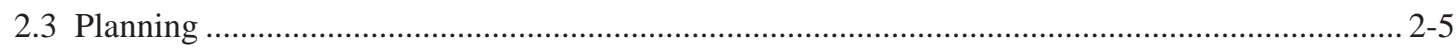

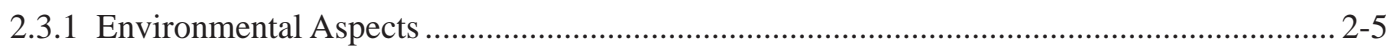

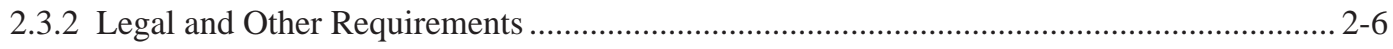

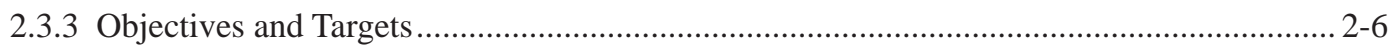

2.3.4 Environmental Management Programs ............................................................................. 2-6

2.3.4.1 Compliance....................................................................................................... 2-7

2.3.4.2 Groundwater Protection ...................................................................................... 2-7

2.3.4.3 Waste Management ............................................................................................ 2-7

2.3.4.4 Pollution Prevention and Minimization .............................................................. 2-8

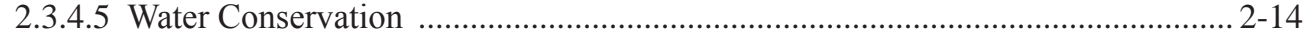

2.3.4.6 Energy Management and Conservation ................................................................ 2-15

2.3.4.7 Natural and Cultural Resource Management Programs ........................................... 2-17

2.3.4.8 Environmental Restoration..................................................................................... 2-18

2.3.4.9 EPA Performance Track Program...................................................................... 2-19

2.4 Implementing the Environmental Management System.................................................................. 2-21 
2.4.1 Structure and Responsibility ........................................................................................ 2-21

2.4.2 Communication and Community Involvement ............................................................. 2-21

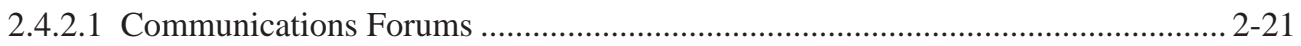

2.4.2.2 Community Involvement in Cleanup Projects ....................................................... 2-22

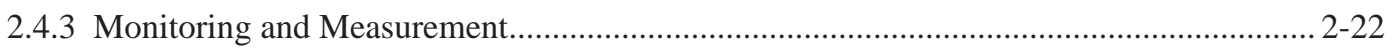

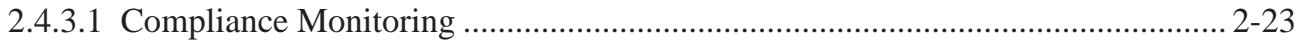

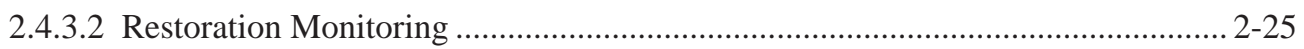

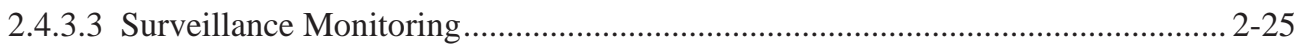

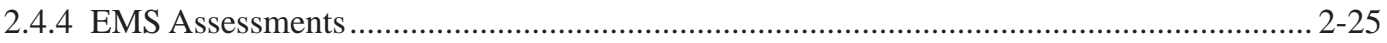

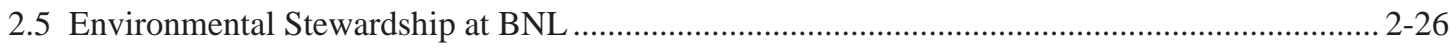

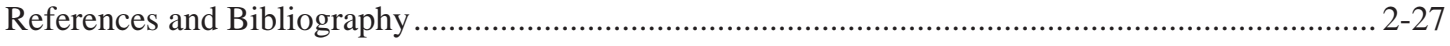

\section{CHAPTER 3: COMPLIANCE STATUS}

3.1 Compliance with Requirements ......................................................................................... 3-1

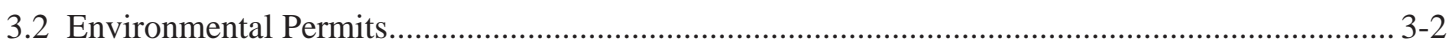

3.2.1 Existing Permits........................................................................................................... 3-2

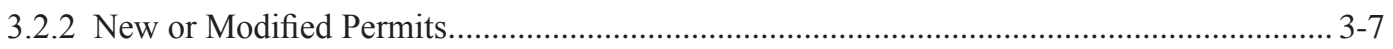

3.2.2.1 Wild Scenic Recreational Rivers Act ………......................................................... 3-7

3.2.2.2 Air Emissions Permits ........................................................................................ 3-7

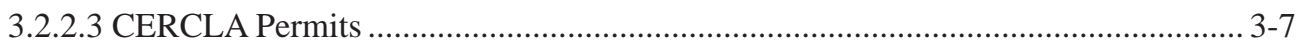

3.3 NEPA Assessments ......................................................................................................... 3-7

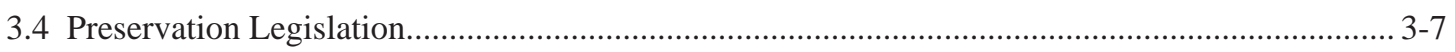

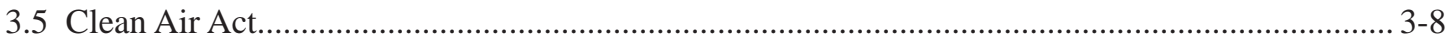

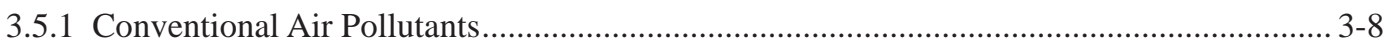

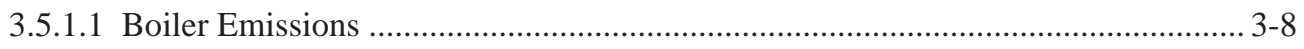

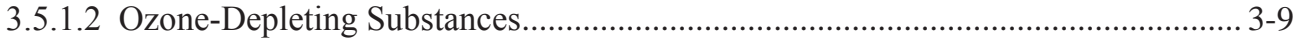

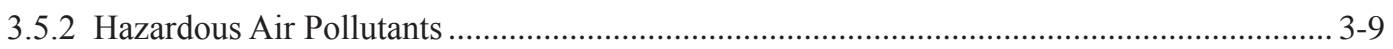

3.5.2.1 Maximum Available Control Technology ................................................................ 3-9

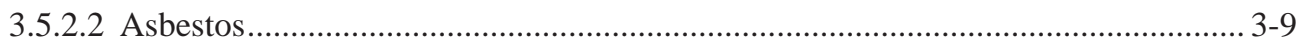

3.5.2.3 Radioactive Airborne Emissions .......................................................................... 3-9

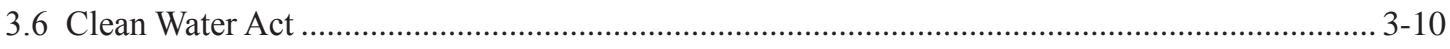

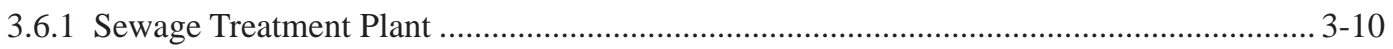

3.6.1.1 Chronic Toxicity Testing ......................................................................................... 3-14

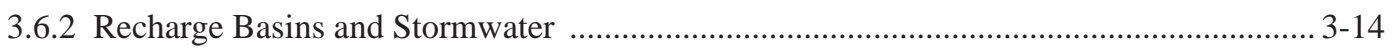

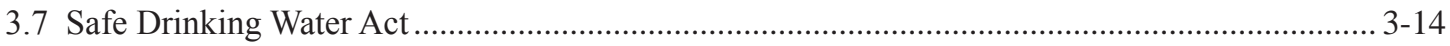

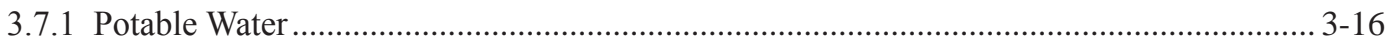

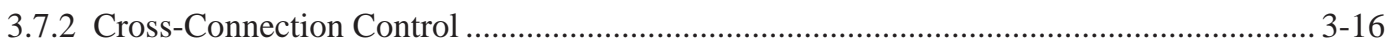

3.7.3 Underground Injection Control..................................................................................... 3-18

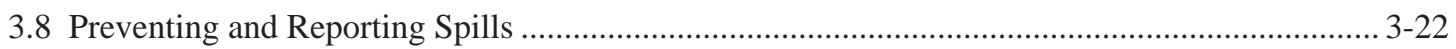

3.8.1 Preventing Oil Pollution and Spills ............................................................................... 3-22 


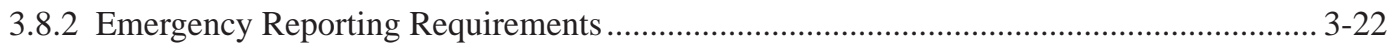

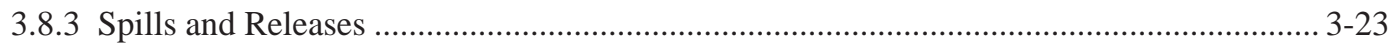

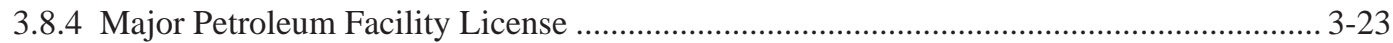

3.8.5 Chemical Bulk Storage ............................................................................................. 3-25

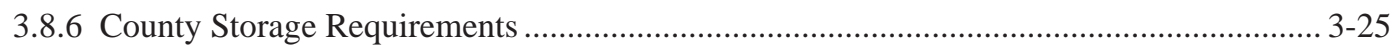

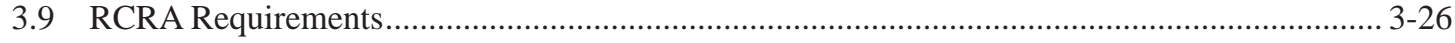

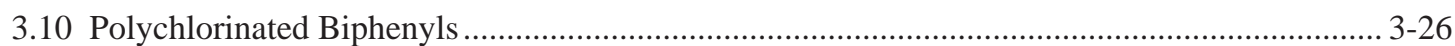

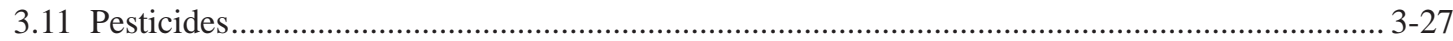

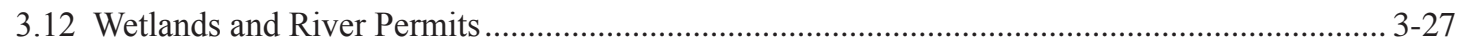

3.13 Endangered Species Act................................................................................................ 3-27

3.14 External Audits and Oversight ……………….................................................................. 3-28

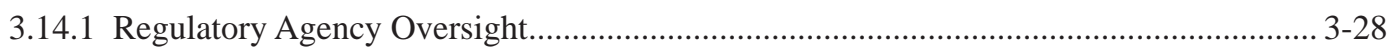

3.14.2 DOE Assessments/Inspections..................................................................................... 3-29

3.14.2.1 Environmental Multi-Topic Assessment............................................................... 3-30

3.14.2.2 Nevada Test Site Inspection......................................................................... 3-31

3.15 Enforcement Actions and Agreements ................................................................................... 3-31

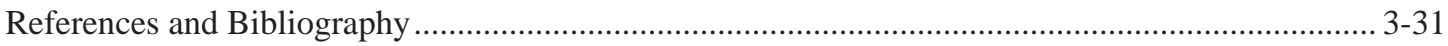

\section{CHAPTER 4: AIR QUALITY}

4.1 Radiological Emissions........................................................................................................... 4-1

4.1.1 Brookhaven Medical Research Reactor.......................................................................... 4-1

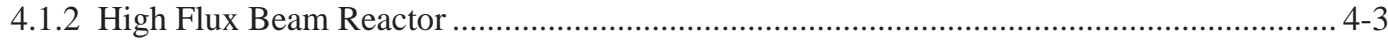

4.1.3 Brookhaven Linac Isotope Producer ................................................................................. 4-4

4.1.4 Evaporator Facility ....................................................................................................... 4-4

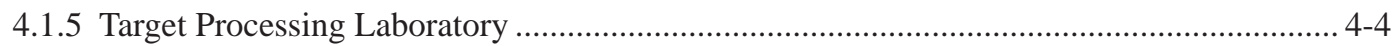

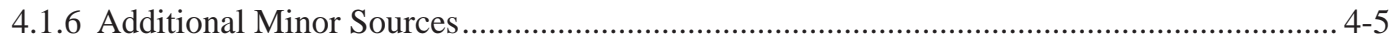

4.1.7 Nonpoint Radiological Emission Sources ……….......................................................... 4-5

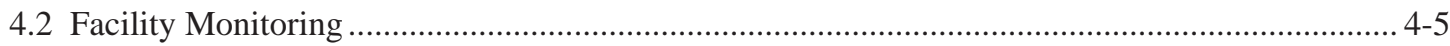

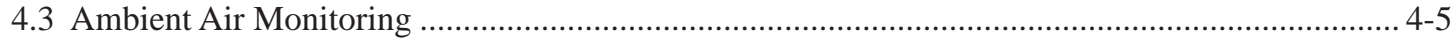

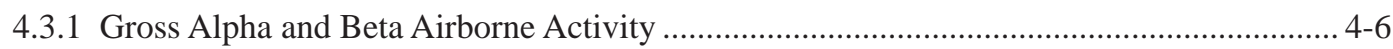

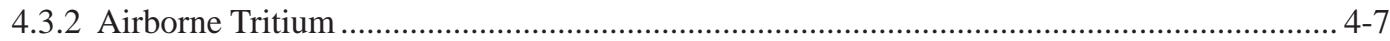

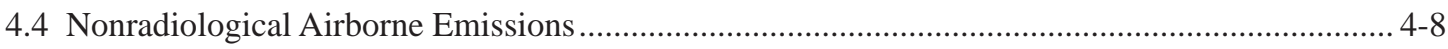

References and Bibliography ………….................................................................................... 4-10

\section{CHAPTER 5: WATER QUALITY}

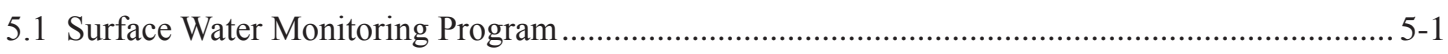

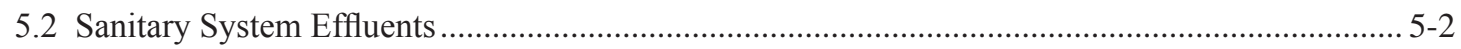

5.2.1 Sanitary System Effluent-Radiological Analyses .............................................................. 5-3

5.2.2 Sanitary System Effluent-Nonradiological Analyses ........................................................ 5-7

5.3 Process-Specific Wastewater....................................................................................................... 5-8 


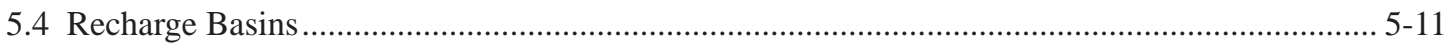

5.4.1 Recharge Basins - Radiological Analyses ....................................................................... 5-12

5.4.2 Recharge Basins - Nonradiological Analyses .................................................................. 5-13

5.4.3 Stormwater Assessment ................................................................................................ 5-13

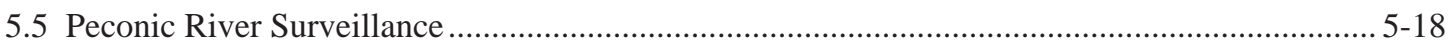

5.5.1 Peconic River - Radiological Analyses ......................................................................... 5-18

5.5.2 Peconic River - Nonradiological Analyses ............................................................ 5-20

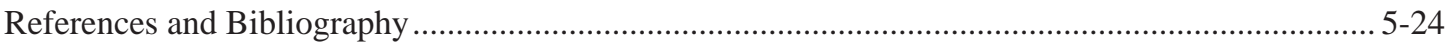

\section{CHAPTER 6: NATURAL AND CULTURAL RESOURCES}

6.1 Natural Resource Management Program ..................................................................................... 6-1

6.1.1 Identification and Mapping ................................................................................................ 6-1

6.1.2 Habitat Protection and Enhancement.............................................................................. 6-2

6.1.2.1 Salamander Protection Efforts......................................................................................... 6-3

6.1.2.2 Eastern Box Turtle.................................................................................................. 6-3

6.1.2.3 Other Species......................................................................................................... 6-4

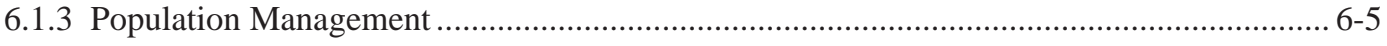

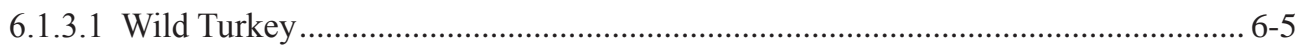

6.1.3.2 White-Tailed Deer ………………………………................................................. 6-5

6.1.4 Compliance Assurance and Potential Impact Assessment..................................................... 6-6

6.2 Upton Ecological and Research Reserve .................................................................................. 6-6

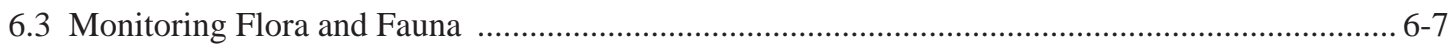

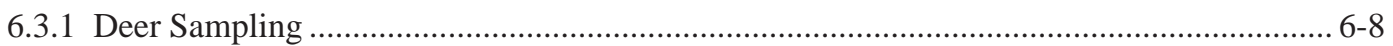

6.3.1.1 Cs-137 in White-Tailed Deer............................................................................ 6-8

6.3.1.2 Strontium-90 in Deer Bone .................................................................................. 6-13

6.3.2 Small Mammal Sampling …………………………...................................................... 6-13

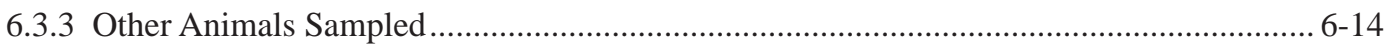

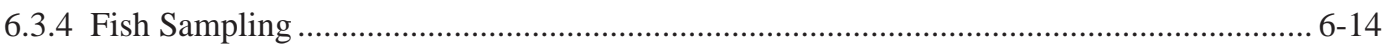

6.3.4.1 Radiological Analysis of Fish .......................................................................... 6-14

6.3.4.2 Fish Population Assessment ......................................................................... 6-15

6.3.4.3 Nonradiological Analysis of Fish ............................................................................. 6-15

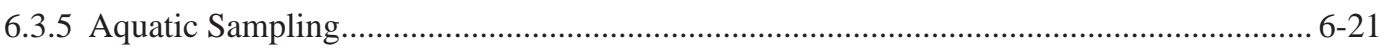

6.3.5.1 Radiological Analysis................................................................................................ 6-21

6.3.5.2 Metals in Aquatic Samples ................................................................................ 6-24

6.3.5.3 Pesticides and PCBs in Aquatic Samples ........................................................... 6-24

6.3.6 Peconic River Post-Cleanup Monitoring ............................................................................ 6-24

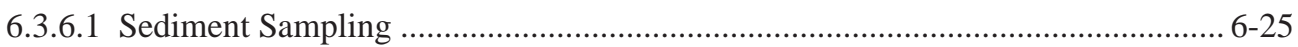

6.3.6.2 Water Column Sampling ...................................................................................... 6-26

6.3.6.3 Fish Sampling ............................................................................................ 6-26

6.3.6.4 Wetland Sampling ........................................................................................ 6-26 


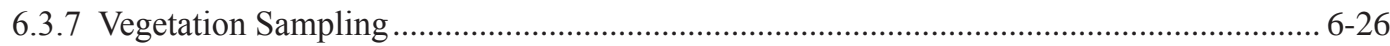

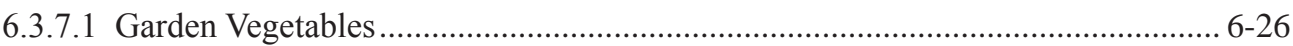

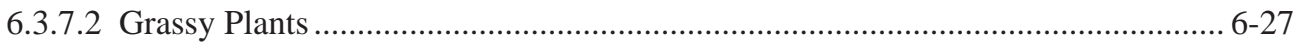

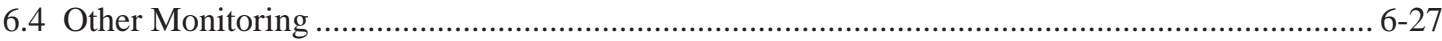

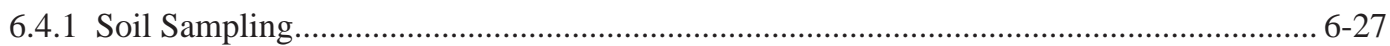

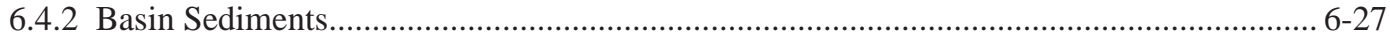

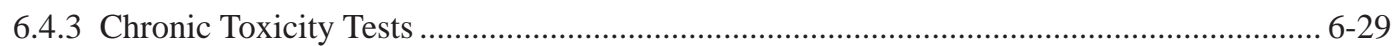

6.4.4 Radiological and Mercury Monitoring of Precipitation ....................................................... 6-29

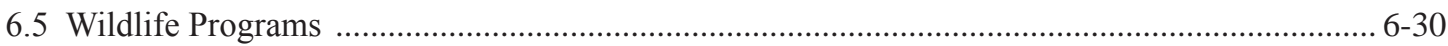

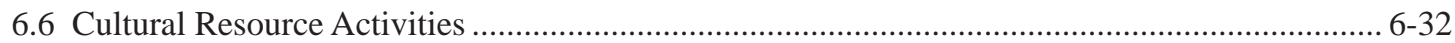

References and Bibliography ..................................................................................................... 6-32

\section{CHAPTER 7: GROUNDWATER PROTECTION}

7.1 The BNL Groundwater Protection Management Program............................................................... 7-1

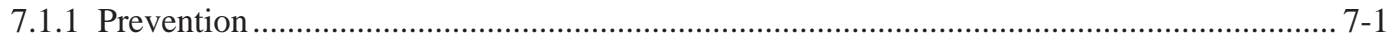

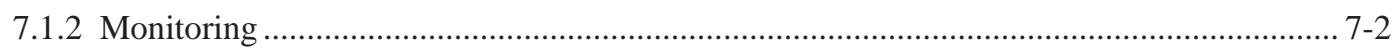

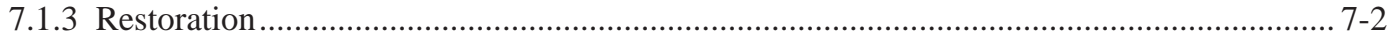

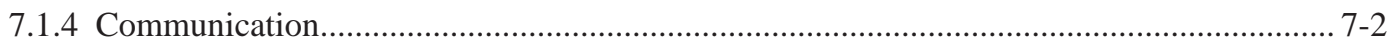

7.2 Groundwater Protection Performance ..........................................................................................

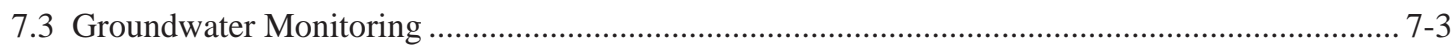

7.4 Supplemental Monitoring of Water Supply Wells ...................................................................... $7-3$

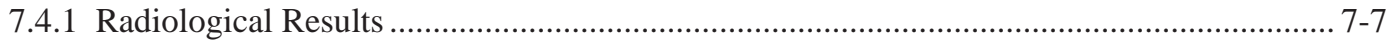

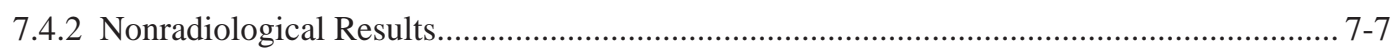

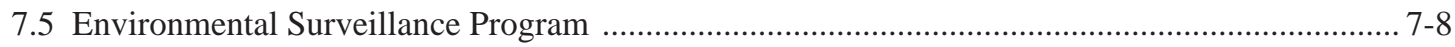

7.6 Long Term Response Actions Groundwater Monitoring Program ............................................... 7-9

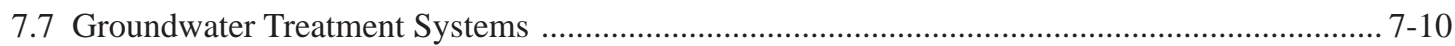

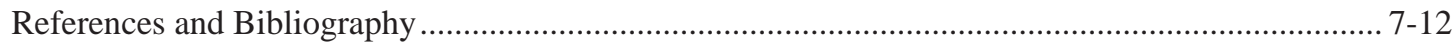

\section{CHAPTER 8: RADIOLOGICAL DOSE ASSESSMENT}

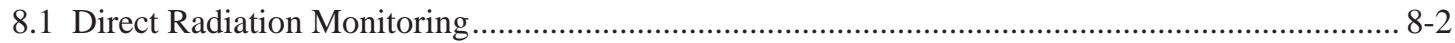

8.1.1 Ambient Monitoring ....................................................................................................... 8-2

8.1.2 Facility Area Monitoring ……..................................................................................... 8-4

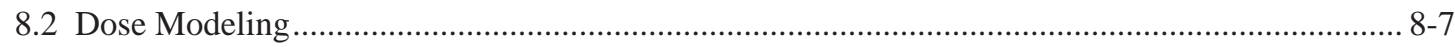

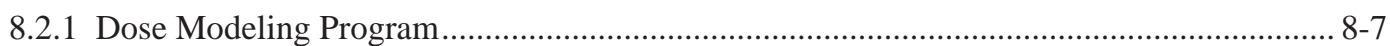

8.2.2 Dose Calculation Methods and Pathways............................................................................ 8-9

8.2.2.1 Maximally Exposed Individual ........................................................................ 8-9

8.2.2.2 Effective Dose Equivalent................................................................................. 8-9

8.2.2.3 Dose Calculation: Fish Ingestion ........................................................................ 8-9

8.2.2.4 Dose Calculation: Deer Meat Ingestion ............................................................. 8-9

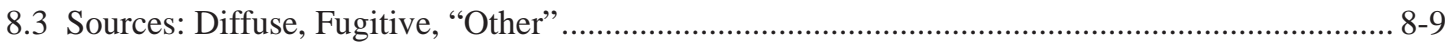


8.3.1 Medical Department ................................................................................................... 8-10

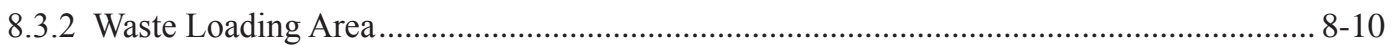

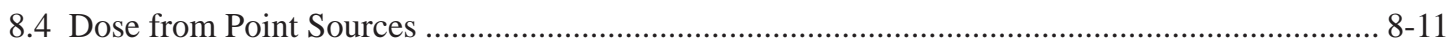

8.4.1 Brookhaven Linac Isotope Producer ……….................................................................... 8-11

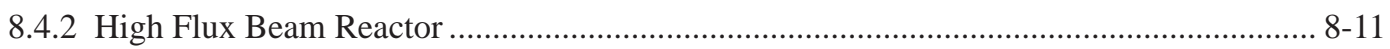

8.4.3 Brookhaven Medical Research Reactor.............................................................................. 8-11

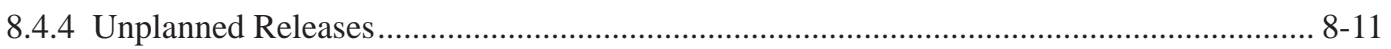

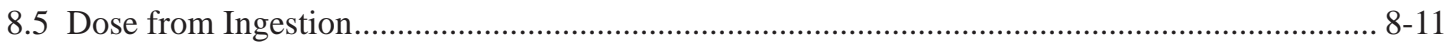

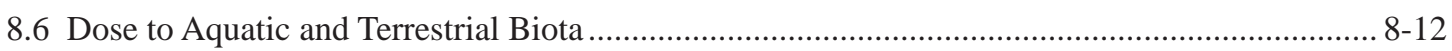

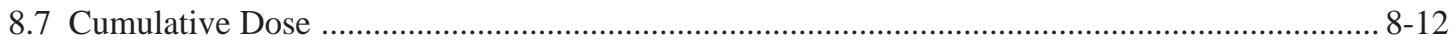

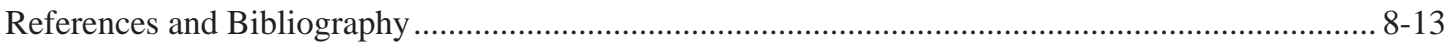

\section{CHAPTER 9: QUALITY ASSURANCE}

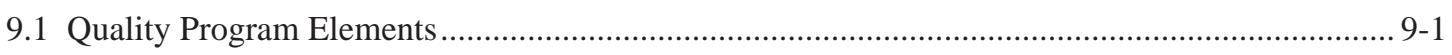

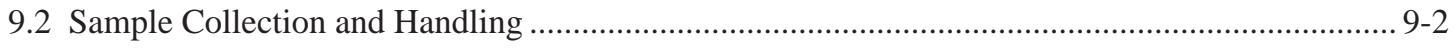

9.2.1 Field Sample Handling ............................................................................................... 9-3

9.2.1.1 Custody and Documentation ..................................................................................

9.2.1.2 Preservation and Shipment ..................................................................................... 9-3

9.2.2 Field Quality Control Samples ....................................................................................... 9-3

9.2.3 Tracking and Data Management ........................................................................................ 9-5

9.3 Sample Analysis.............................................................................................................. 9-5

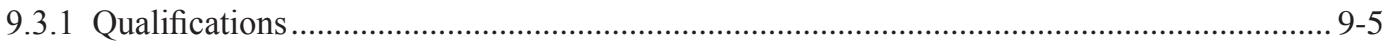

9.4 Verification and Validation of Analytical Results ...................................................................... 9-5

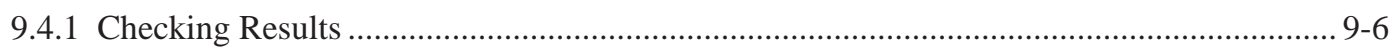

9.5 Contract Analytical Laboratory QA/QC ……......................................................................... 9-6

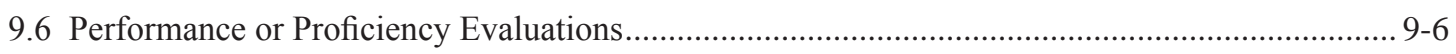

9.6.1 Summary of Test Results ............................................................................................... 9-7

9.6.1.1 Radiological Assessments .................................................................................. 9-7

9.6.1.2 Nonradiological Assessments .............................................................................. 9-7

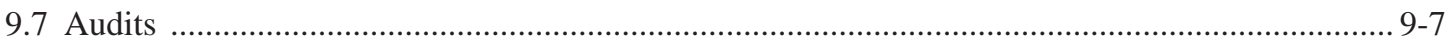

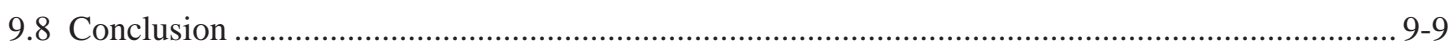

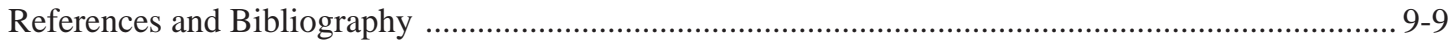

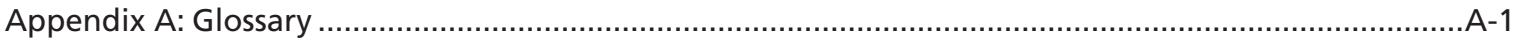

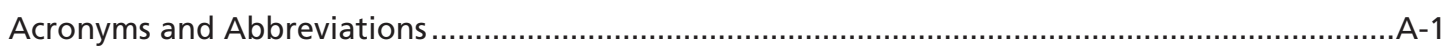

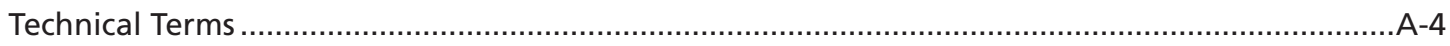

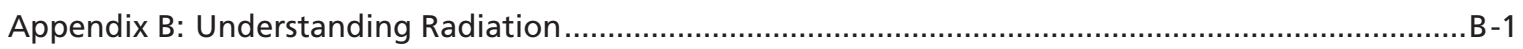

Appendix C: Units of Measure and Half-Life Periods ...................................................................... -1

Appendix D: Federal, State, and Local Laws and Regulations Pertinent to BNL..................................... 


\section{List of Figures}

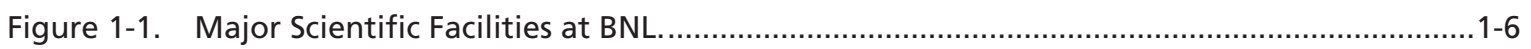

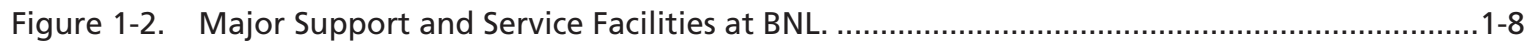

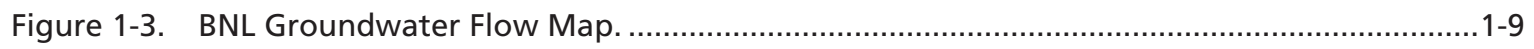

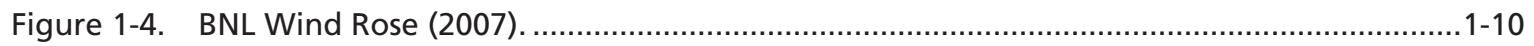

Figure 1-5. BNL 2007 Monthly Mean Temperature versus 59-Year Monthly Average.......................1-11

Figure 1-6. BNL 2007 Annual Mean Temperature Trend (59 Years). ............................................1-11

Figure 1-7. BNL 2007 Monthly Precipitation versus 59-Year Monthly Average.................................1-12

Figure 1-8. BNL 2007 Annual Precipitation Trend (59 Years)....................................................... 1-12

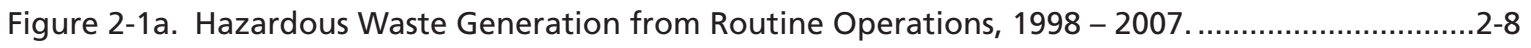

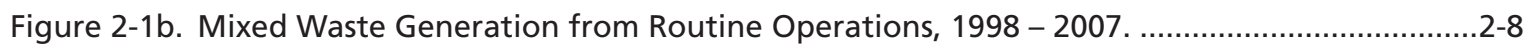

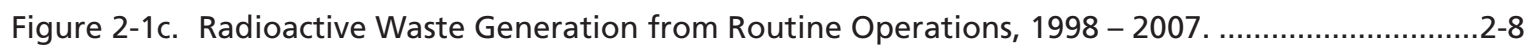

Figure 2-1d. Hazardous Waste Generation from ER and Nonroutine Operations, $1998-2007$.............2-9

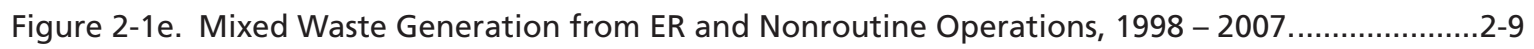

Figure 2-1f. Radioactive Waste Generation from ER and Nonroutine Operations, $1998-2007$...........2-9

Figure 2-2. BNL Water Consumption Trend, 1998-2007..........................................................16

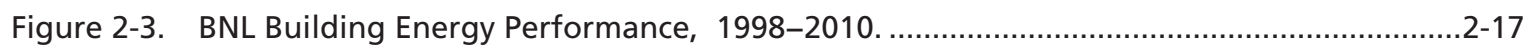

Figure 3-1. Maximum Concentrations of Copper Discharged from the BNL Sewage Treatment Plant, 2003-2007.

Figure 3-2. Maximum Concentrations of Iron Discharged from the BNL Sewage Treatment Plant, 2003-2007.

Figure 3-3. Maximum Concentrations of Lead Discharged from the BNL Sewage Treatment Plant, 2003-2007.

Figure 3-4. Maximum Concentrations of Mercury Discharged from the BNL Sewage Treatment Plant, 2003-2007.

Figure 3-5. Maximum Concentrations of Nickel Discharged from the BNL Sewage Treatment Plant, 2003-2007...

Figure 3-6. Maximum Concentrations of Silver Discharged from the BNL Sewage Treatment Plant, 2003-2007.

Figure 3-7. Maximum Concentrations of Zinc Discharged from the BNL Sewage Treatment Plant, 2003-2007.

Figure 4-1. Air Emission Release Points Subject to Monitoring ...................................................

Figure 4-2. High Flux Beam Reactor Tritium Emissions, Ten-Year Trend (1998-2007)........................4-3

Figure 4-3. BNL On-Site Ambient Air Monitoring Stations...........................................................4-6

Figure 4-4. Airborne Gross Beta Concentration Trend Recorded at Station P7..............................4-8

Figure 5-1. Schematic of BNL's Sewage Treatment Plant (STP) . ...................................................5-2

Figure 5-2. Tritium Concentrations in Effluent from the BNL Sewage Treatment Plant (2007). ...........5-4

Figure 5-3. Sewage Treatment Plant/Peconic River Annual Average Tritium Concentrations (1993-2007). . 5-6

Figure 5-4. Tritum Released to the Peconic River, 15-Year Trend (1993-2007) ..................................5-6

Figure 5-5. Cesium-137 in the BNL Sewage Treatment Plant Influent and Effluent (1993-2007). ........5-6 


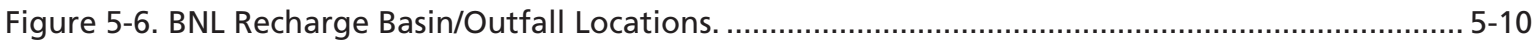

Figure 5-7. Schematic of Potable Water Use and Flow at BNL............................................... 5-11

Figure 5-8. Sampling Stations for Surface Water, Fish, and Shellfish............................................ 5-19

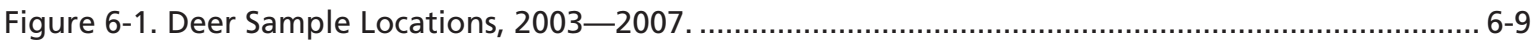

Figure 6-2. Comparison of Cs-137 Average Concentrations in Deer, 2007....................................6-12

Figure 6-3. Trend of Cs-137 Concentrations in Deer Meat at BNL and Within 1 Mile of BNL,

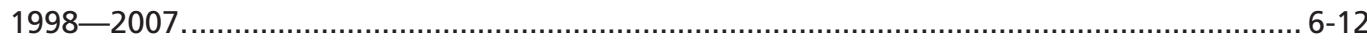

Figure 7-1. Groundwater Flow and Water Table Elevation (December 2007) with Supply and Remediation Wells Shown

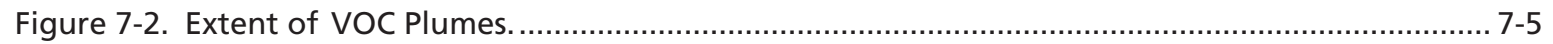

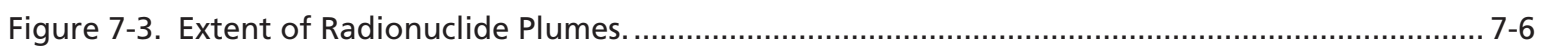

Figure 7-4. Locations of BNL Groundwater Remediation Systems. ............................................... 7-11

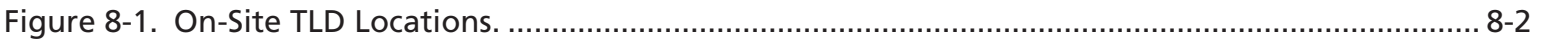

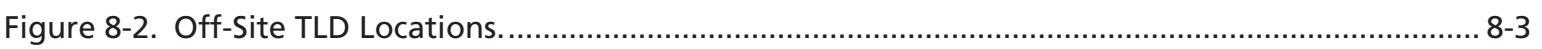

Figure 9-1. Flow of Environmental Monitoring QA/QC Program Elements........................................ 9-2

Figure 9-2. Summary of Scores in the Radiological Proficiency Evaluation Programs. .......................... 9-8

Figure 9-3. Summary of Scores in the Nonradiological Proficiency Evaluation Programs...................... 9-8 


\section{List of Tables}

Table 2-1 Elements of the Environmental Management System (EMS) and their Relationship to OHSAS 18001 and Integrated Safety Management (ISM) - Review of EMS

Implementation at BNL.

Table 2-2. BNL Pollution Prevention, Waste Reduction, and Recycling Programs. .......................... 2-10

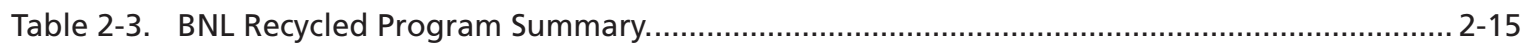

Table 2-4. Summary of BNL 2007 Environmental Restoration Activities. ........................................... 2-19

Table 2-5. Summary of BNL 2007 Sampling Program Sorted by Media........................................... 2-23

Table 3-1. Federal, State, and Local Environmental Statutes and Regulations Applicable to BNL....... 3-2

Table 3-2. BNL Environmental Permits.................................................................................... 3-5

Table 3-3. Analytical Results for Wastewater Discharges to Sewage Treatment Plant Outfall 001.... 3-11

Table 3-4. Analytical Results for Wastewater Discharges to Outfalls 002, $005-008$, and 010.......... 3-15

Table 3-5. Potable Water Wells and Potable Distribution System: Analytical Results (Maximum Concentration, Minimum pH Value)

Table 3-6. Potable Water Wells: Analytical Results for Principal Organic Compounds, Synthetic Organic Chemicals, Pesticides, and Micro-Extractables.................................. 3-19

Table 3-7. Summary of Chemical and Oil Spill Reports. .................................................... 3-24

Table 3-8. Existing Agreements and Enforcement Actions Issued to BNL, with Status. ...................3-30

Table 4-1. Airborne Radionuclide Releases from Monitored Facilities. ........................................ 4-3

Table 4-2. Gross Activity in Facility Air Particulate Filters. .................................................... 4-7

Table 4-3. Gross Activity Detected in Ambient Air Monitoring Particulate Filters............................. 4-7

Table 4-4. Ambient Airborne Tritium Measurements in 2007. ................................................. 4-8

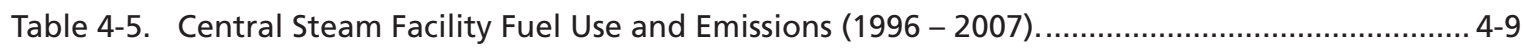

Table 5-1. Tritium and Gross Activity in Water at the BNL Sewage Treatment Plant (STP). ................. 5-5

Table 5-2. Gamma-Emitting Radionuclides and Sr-90 in Water at the BNL Sewage Treatment Plant... 5-8

Table 5-3. BNL Sewage Treatment Plant (STP) Water Quality and Metals Analytical Results. .............. 5-9

Table 5-4. Radiological Analysis of Samples from On-Site Recharge Basins at BNL.......................... 5-12

Table 5-5. Water Quality Data for BNL On-Site Recharge Basin Samples...................................... 5-14

Table 5-6. Metals Analysis of Water Samples from BNL On-Site Recharge Basins. ........................... 5-15

Table 5-7. Radiological Results for Surface Water Samples from the Peconic and Carmans Rivers..... 5-20

Table 5-8. Water Quality Data for Surface Water Samples Collected along the Peconic and

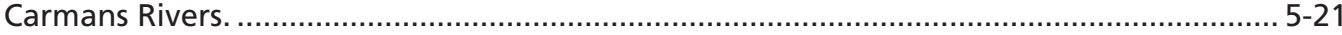

Table 5-9. Metals Analysis in Surface Water Samples Collected along the Peconic and Carmans Rivers.

Table 6-1. New York State Threatened, Endangered, Exploitably Vulnerable, and Species of Special Concern at BNL.

Table 6-2. Radiological Analyses of Deer Tissue (Flesh, Liver, Bone) .......................................... 6-10

Table 6.3. Radiological Analyses of Fish from the Peconic River System...................................... 6-15

Table 6-4. Metals Analyses of Fish from the Peconic River System and Carmans River, Lower Lake. .. 6-16

Table 6-5. Pesticide and PCB Analyses of Fish from the Peconic River System and Carmans River, Lower Lake. 
Table 6-6. Radiological Analyses of Aquatic Vegetation and Sediment from the Peconic River and Carmans River System, Lower Lake.

Table 6-7. Metals Analyses of Aquatic Vegetation and Sediment from the Peconic River System and Carmens River, Lower Lake.

Table 6-8. Radiological Analyses of Garden Vegetables, Grassy Vegetation, and Associated Soils..... 6-27

Table 6-9. Metals Analyses of Basin Sediment....................................................................... $6-28$

Table 6-10. Semi-Volatile Organic Compounds Analyses of Basin Sediments. .................................... 6-29

Table 7-1. Summary of BNL Groundwater Monitoring Program, 2007. ...................................... 7-2

Table 7-2. Potable Well Radiological Analytical Results. ............................................................. 7-7

Table 7-3. Potable Water Supply Wells Water Quality Data......................................................... 7-8

Table 7-4. Total Metals Concentration Data for Potable Water Supply Well Samples. ......................... 7-9

Table 7-5. BNL Groundwater Remediation Systems Treatment Summary for 1997 through 2007..... 7-12

Table 8-1. On-Site Direct Ambient Radiation Measurements........................................................... 8-4

Table 8-2. Off-Site Direct Radiation Measurements....................................................................... 8-6

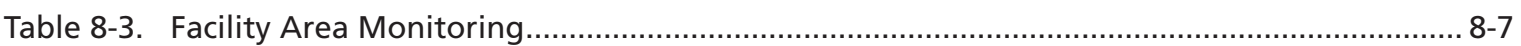

Table 8-4. MEI Effective Dose Equivalent From Facilities or Routine Processes. ................................... 8-8

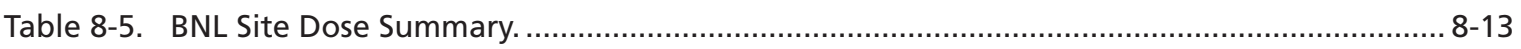




\section{Introduction}

Established in 1947, Brookhaven National Laboratory (BNL) is a multi-program national laboratory managed for the U.S. Department of Energy by Brookhaven Science Associates (BSA), a partnership formed by Stony Brook University and Battelle Memorial Institute. BSA has been managing and operating the Laboratory under a performance-based contract with DOE since 1998. From 1947 to 1998, BNL was operated by Associated Universities Incorporated. Prior to 1947, the site operated as Camp Upton, a U.S. Army training camp, which was active from 1917 to 1920 during World War I and from 1940 to 1946 during World War II.

$B N L$ is one of 10 national laboratories under DOE's Office of Science, which provides most of the Laboratory's research dollars and direction. BNL has a history of outstanding scientific achievements. For over 60 years, Laboratory researchers have successfully worked to envision, construct, and operate large and innovative scientific facilities and use the data generated to make advances in many fields. Under BSA's management, new programs in place at BNL emphasize improved environmental, safety, security, and health performance.

\subsection{LABORATORY MISSION}

BNL's broad mission is to carry out basic and applied research in long-term programs in a safe and environmentally sound manner with the cooperation, support, and appropriate involvement of its scientific and local communities. The fundamental elements of the Laboratory's role in support of DOE's strategic missions in energy resources, environmental quality, and national security are:

- To conceive, design, construct, and operate complex, leading-edge, user-oriented research facilities in response to the needs of DOE and the international community of users.

- To conduct safe, secure, and environmentally sound operations and promote mutually beneficial relationships with its stakeholders.

- To carry out basic and applied research in long-term, high-risk programs at the frontier of science.

- To develop advanced technologies that address national needs and to transfer them to other organizations and to the commercial sector.

- To disseminate technical knowledge to educate future generations of scientists and engineers, to maintain technical currency in the nation's workforce, and to encourage scientific awareness in the general public.

BNL's Environmental, Safety, Security, and Health (ESSH) Policy is the Laboratory's commitment to continual improvement in ESSH performance. Under this policy, the Laboratory's goals are to protect the environment, conserve resources, and prevent pollution; maintain a safe workplace by planning work and performing it safely; provide security for people, property, information, computing systems, and facilities; protect human health within our boundaries and in the surrounding community; achieve and maintain compliance with applicable ESSH requirements; maintain an open, proactive, and constructive relationship with employees, neighbors, regulators, DOE, and other stakeholders; and continually improve ESSH performance. 
In 2001, BNL was the first DOE Office of Science National Laboratory to be registered under the prestigious International ISO 14001 environmental management standard. In addition, in December 2006, BNL was the first DOE Laboratory to achieve full registration under the Occupational Health and Safety Assessment Series (OHSAS) 18001 Standard. These programs are described in detail in Chapter 2 of this report. Registration to these standards was maintained throughout 2007.

\subsection{HISTORY}

BNL was founded in 1947 by the Atomic Energy Commission (AEC), which was a predecessor to the present DOE. AEC provided the initial funding for BNL's research into peaceful uses of the atom. The objective was to promote basic research in the physical, chemical, biological, and engineering aspects of the atomic sciences. The result was the creation of a regional laboratory to design, construct, and operate large scientific machines that individual institutions could not afford to develop on their own.

Although BNL no longer operates any research reactors, the Laboratory's first major scientific facility was the Brookhaven Graphite Research Reactor (BGRR), which was the first peace-time reactor to be constructed in the United States following World War II. The reactor's primary mission was to produce neutrons for scientific experimentation in the fields of medicine, biology, chemistry, physics, and nuclear technology. The BGRR operated from 1950 to 1968 and is currently being decommissioned and will be dismantled. The BGRR will undergo long-term routine inspection and surveillance when decommissioning is complete.

The BGRR's research capacity was replaced and surpassed in 1965 by the High Flux Beam Reactor (HFBR). The HFBR was used solely for scientific research and provided neutrons for experiments in materials science, chemistry, biology, and physics. For more than 30 years, the HFBR was one of the premier neutron beam reactors in the world. In 1997, workers discovered that a leak in the HFBR spent fuel storage pool had been releasing tritium to the groundwater (see Chapter 7 for further details). In November
1999, the Secretary of Energy decided that the HFBR would be permanently shut down. Since that time, actions have taken place to prepare the HFBR for permanent decontamination and dismantling. A proposed plan and schedule for its decommissioning has been presented for public comment. All spent fuel from the HFBR has been removed and transported off site.

Medical research at BNL began in 1950 with the opening of one of the first hospitals devoted to nuclear medicine. It was followed by the Medical Research Center in 1958 and the Brookhaven Medical Research Reactor (BMRR) in 1959. The BMRR was the first nuclear reactor in the nation to be constructed specifically for medical research. Due to a reduction of research funding, the BMRR was shut down in December 2000. All spent fuel from the BMRR has been removed and transported off site, and the facility is currently in a "cold" shutdown mode as a radiological facitity. The Brookhaven Linac Isotope Producer (BLIP) was built in 1973. It creates radioactive forms of ordinary chemical elements that can be used alone or incorporated into radiotracers for use in nuclear medicine research or for clinical diagnosis and treatment. BNL's Center for Translational Neuroimaging (CTN) uses brain-imaging tools, including positron emission tomography (PET) and magnetic resonance imaging (MRI) equipment, to research causes of, and treatments for, brain diseases such as drug addiction, appetite disorders, attention deficit disorder, and neurodegenerative disease. The development of PET and MRI also has helped facilitate the development of new drugs for physicians worldwide to treat patients for cancer and heart disease.

High-energy particle physics research at BNL began in 1952 with the Cosmotron, the first particle accelerator to achieve billion-electron-volt energies. Work at the Cosmotron resulted in a Noble Prize in 1957. After 14 years of service, the Cosmotron ceased operation and was dismantled due to design limitations that restricted the energies it could achieve. The Alternating Gradient Synchrotron (AGS), a much larger particle accelerator, became operational in 1960. The AGS allowed scientists to accelerate 
protons to energies that yielded many discoveries of new particles and phenomena, for which BNL researchers were awarded three Nobel Prizes in physics. The AGS receives protons from BNL's linear accelerator (Linac), designed and built in the late 1960s as a major upgrade to the AGS complex. The Linac's purpose is to provide accelerated protons for use at AGS facilities and BLIP. The AGS booster, constructed in 1991, further enhanced the capabilities of the AGS, enabling it to accelerate protons and heavy ions to even higher energies. The Tandem Van de Graaff accelerator began operating in 1970 and is the starting point of the chain of accelerators that provide ions of gold, other heavy metals, and protons for experiments at the Relativistic Heavy Ion Collider (RHIC).

RHIC began operation in 2000. Inside this two-ringed particle accelerator, two beams of gold ions, heavy metals, or protons circulating at nearly the speed of light, collide head-on, releasing large amounts of energy. RHIC is used to study what the universe may have looked like in the first few moments after its creation, offering insights into the fundamental forces and properties of matter. Planned upgrades to RHIC will expand the facility's research. The first upgrade, RHIC II, will increase the collider's collision rate and improve the sensitivity of the large detectors it uses. Another planned upgrade, the eRHIC, will add a high-energy electron ring to create the world's only electron-heavy ion collider, which physicists expect will probe a new form of matter.

The NASA Space Radiation Laboratory (NSRL) became operational in 2003. It is jointly managed by DOE's Office of Science and NASA's Johnson Space Center. The NSRL uses heavy ions extracted from the AGS booster to produce beams of radiation similar to radiation that would be encountered by astronauts on long missions. Studies are conducted to assess risks and test protective measures. The NSRL is one of the few facilities in the world that can simulate the harsh cosmic and solar radiation environment found in space.

The National Synchrotron Light Source (NSLS) uses a linear accelerator and booster synchrotron to guide charged particles in orbit inside two electron storage rings for use in a wide range of physical and biological experiments. The NSLS produces beams of very intense light in the $\mathrm{x}$-ray, ultraviolet, and infrared spectra, allowing scientists to study the structure of proteins, investigate the properties of new materials, and understand the fate of chemicals in the environment. Although the current NSLS has been continually updated since its commissioning in 1982, today the practical limits of its performance have been reached. A new synchrotron, NSLS-II, is planned for completion in the next decade and will be the highest resolution light source in the world, further expanding the ability to probe structures on the nanoscale. Site preparation for this new facility will commence in 2009.

The Laboratory's Research Support Building (RSB) was completed in 2006, and provides administrative and support functions in a single location for employees and visiting scientists. The RSB is rated as "green" or environmentally friendly, according to a scoring system developed by the U.S. Green Building Council's Leadership in Energy \& Environment Design (LEED) Program. The RSB also surpasses New York State requirements for energy efficiency by 15 percent.

Construction of the Center for Functional Nanomaterials (CFN) began in 2005 and was completed in May 2007. The CFN provides state-of-the-art capabilities for the fabrication and study of nanoscale materials, with an emphasis on atomic-level tailoring to achieve desired properties and functions. Nanoscience has the potential to bring about and accelerate new technologies in energy distribution, drug delivery, sensors, and industrial processes. The CFN is a science-based user facility, used for developing strong scientific programs while offering broad access to its capabilities and collaboration through an active user program. It is one of five Nanoscale Science Research Centers funded by DOE's Office of Science and supports the Laboratory's goal of leadership in the development of advanced materials and processes for energy applications.

Past operations and research at the BNL site dating back to the early 1940s when it was 
Camp Upton have resulted in localized environmental contamination. As a result, the Laboratory was added to the federal Comprehensive Environmental Response, Compensation and Liability Act (CERCLA) National Priorities List of contaminated sites in 1989. One of 27 sites on Long Island identified for priority cleanup, BNL has made significant progress toward improving environmental operations and remediating past contamination. DOE will continue to fund cleanup projects until the Laboratory is restored and removed from the National Priorities List. Major accomplishments in cleanup activities at BNL are discussed further throughout this report.

\subsection{RESEARCH AND DISCOVERIES}

BNL conducts research in nuclear and highenergy physics, the physics and chemistry of materials, environmental science, alternative energy sources, nuclear nonproliferation, neurosciences, medical imaging, and structural biology. Approximately 2,700 scientists, engineers, technicians, and support staff work at the Laboratory, and more than 3,500 guest researchers from around the world visit the site each year to participate in scientific collaborations. BNL's world-class research facilities are also available to university, industrial, and government personnel.

To date, six Nobel Prizes have been awarded for discoveries made wholly or partly at BNL. Some significant discoveries and developments made at the Laboratory include L-dopa, used to treat Parkinson's disease; the first synthesis of human insulin; the use of x-rays and neutrons to study biological specimens; the radionuclide thallium-201, used in millions of cardiac stress tests each year; the radionuclide technetium99, also used to diagnose heart disease; x-ray angiography for noninvasive cardiac imaging; and research on solar neutrinos and how they change form as they move through space; magnetically-levitated (maglev) trains; energy technologies studies; and researching pollutioneating bacteria.

Examples of current research at the Laboratory include the investigation of new nanostructures and nanoparticles; the development of high-temperature superconductors; novel states of matter being revealed at RHIC; medical imaging techniques to investigate the brain mechanisms underlying drug addiction, psychiatric disorders, and metabolism; new methods of understanding the earth's climate; and research into how infections begin.

\subsection{FACILITIES AND OPERATIONS}

Most of the Laboratory's principal facilities are located near the center of the site. The developed area is approximately 1,650 acres:

- 500 acres originally developed by the Army (as part of Camp Upton) and still used for offices and other operational buildings

- 200 acres occupied by large, specialized research facilities

- 550 acres used for outlying facilities, such as the Sewage Treatment Plant, research agricultural fields, housing facilities, and fire breaks

- 400 acres of roads, parking lots, and connecting areas

The balance of the site, approximately 3,600 acres, is mostly wooded and represents the native pine barrens ecosystem.

The major scientific facilities at BNL are briefly described in Figure 1-1. Additional facilities, shown in Figure 1-2 and briefly described below, support BNL's science and technology mission by providing basic utility and environmental services.

- Central Chilled Water Plant. This plant provides chilled water sitewide for air conditioning and process refrigeration via underground piping. The plant has a large refrigeration capacity and reduces the need for local refrigeration plants and air conditioning.

- Central Steam Facility (CSF). This facility provides high-pressure steam for facility and process heating sitewide. Either natural gas or fuel oil can be used to produce the steam, which is conveyed to other facilities through underground piping. Condensate is collected and returned to the CSF for reuse, to conserve water and energy.

- Fire Station. The Fire Station houses six response vehicles. The BNL Fire Rescue 
Group provides on-site fire suppression, emergency medical services, hazardous material response, salvage, and property protection. The Fire Rescue Group can respond within 5 minutes to emergencies in the core area of the Laboratory and within 8 minutes to emergencies in the outer areas (RHIC and eastern portions of the site).

- Major Petroleum Facility (MPF). This facility provides reserve fuel for the CSF during times of peak operation. With a total capacity of 2.3 million gallons, the MPF primarily stores No. 6 fuel oil. The 1997 conversion of CSF boilers to burn natural gas as well as oil has significantly reduced the Laboratory's reliance on oil as a sole fuel source when other fuels are more economical.

- Sewage Treatment Plant (STP). This plant treats sanitary and certain process wastewater from BNL facilities prior to discharge into the Peconic River, similar to the operations of a municipal sewage treatment plant. The plant has a design capacity of 3 million gallons per day. Effluent is monitored and controlled under a permit issued by the New York State Department of Environmental Conservation (NYSDEC).

- Waste Concentration Facility (WCF). This facility was previously used for the receipt, processing, and volume reduction of aqueous radioactive waste. At present, the WCF houses equipment and auxiliary systems required for operation of the liquid lowlevel radioactive waste storage and pump systems.

- Waste Management Facility (WMF). This facility is a state-of-the-art complex for managing the wastes generated from BNL's research and operations activities. The facility was built with advanced environmental protection systems and features, and began operation in December 1997.

- Water Treatment Plant (WTP). The potable water treatment plant has a capacity of 5 million gallons per day. Potable water is obtained from six on-site wells. Three wells located along the western boundary of the site are treated with a lime soften- ing process to remove naturally occurring iron. The plant is also equipped with dual air-stripping towers to ensure that volatile organic compounds (VOCs) are at or below New York State drinking water standards. Three wells located along the eastern section of the developed site are treated with carbon to ensure that VOC levels meet New York State drinking water standards. BNL's potable water met all drinking water standards in 2007.

\subsection{LOCATION, LOCAL POPULATION, AND LOCAL ECONOMY}

BNL is located on Long Island, 60 miles east of New York City. The Laboratory's 5,265-acre site is near Long Island's geographic center and is part of the Town of Brookhaven, the largest township (both in area and population) in Suffolk County. The Laboratory is one of the five largest, high-technology employers on Long Island, with approximately 2,700 employees that include scientists, engineers, technicians, and administrative personnel. More than 75 percent of BNL employees live in Suffolk County. In addition, BNL annually hosts an estimated 3,500 visiting scientists, more than 30 percent of whom are from New York State universities and businesses. The visiting scientists and sometimes their families, as well as visiting students, reside in apartments and dormitories on site or in nearby communities.

An independent Suffolk County Planning Commission report concluded that BNL's spending for operations, procurement, payroll, construction, medical benefits, and technology transfer spreads throughout Long Island's economy, making BNL vital to the local economic health, as well as to New York State (Kamer 2006). In 2007, BNL purchased \$40.2 million worth of supplies and services from Long Island businesses. Approximately $\$ 13.8$ million was spent on 467 purchases in Nassau County, and \$26.4 million was spent on 2,786 purchases in Suffolk County. BNL's total annual budget in 2007 was approximately $\$ 510.2$ million, of which approximately 55.6 percent, or $\$ 283.8$ million, was spent on employee salaries, wages, and fringe benefits. 


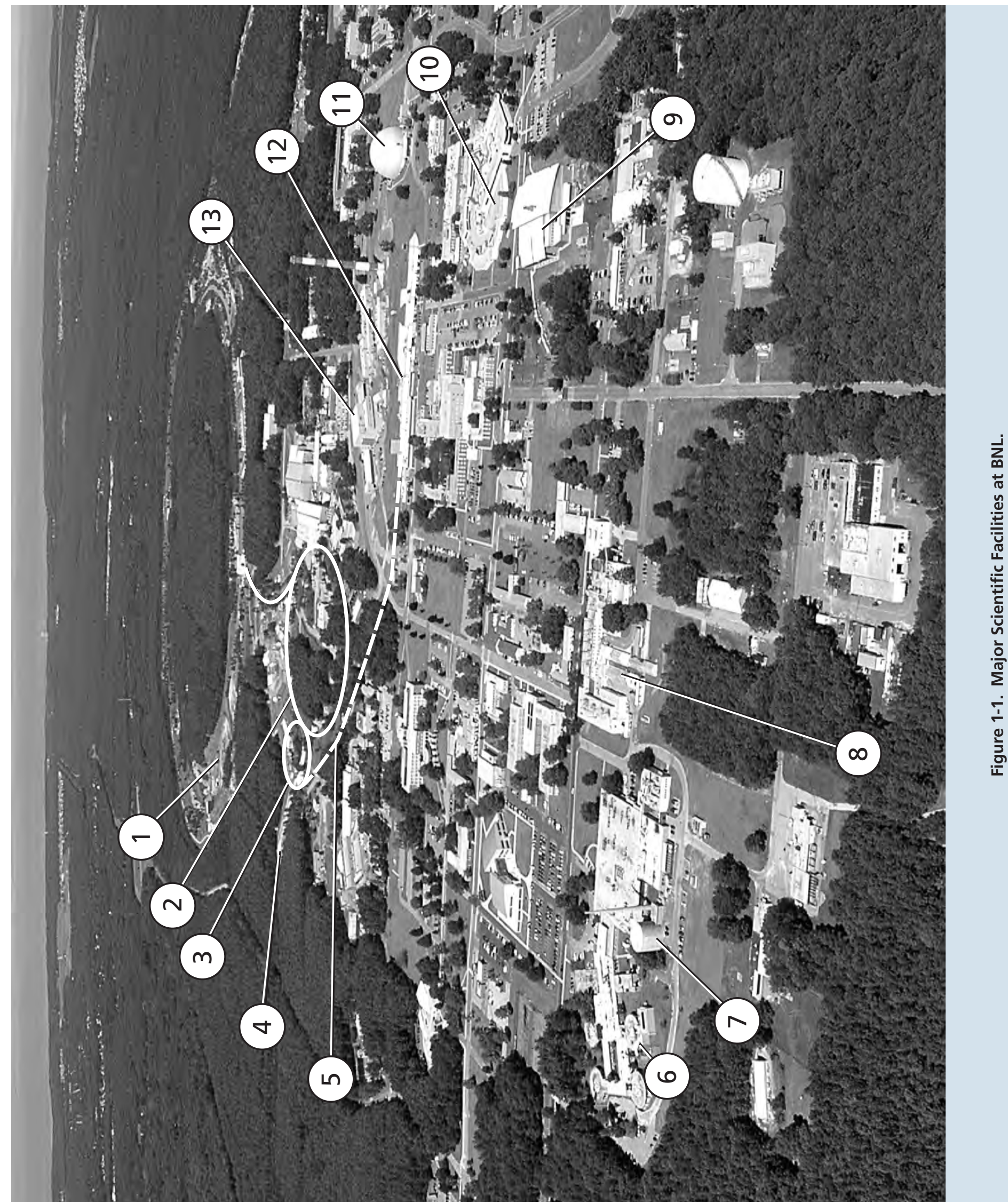




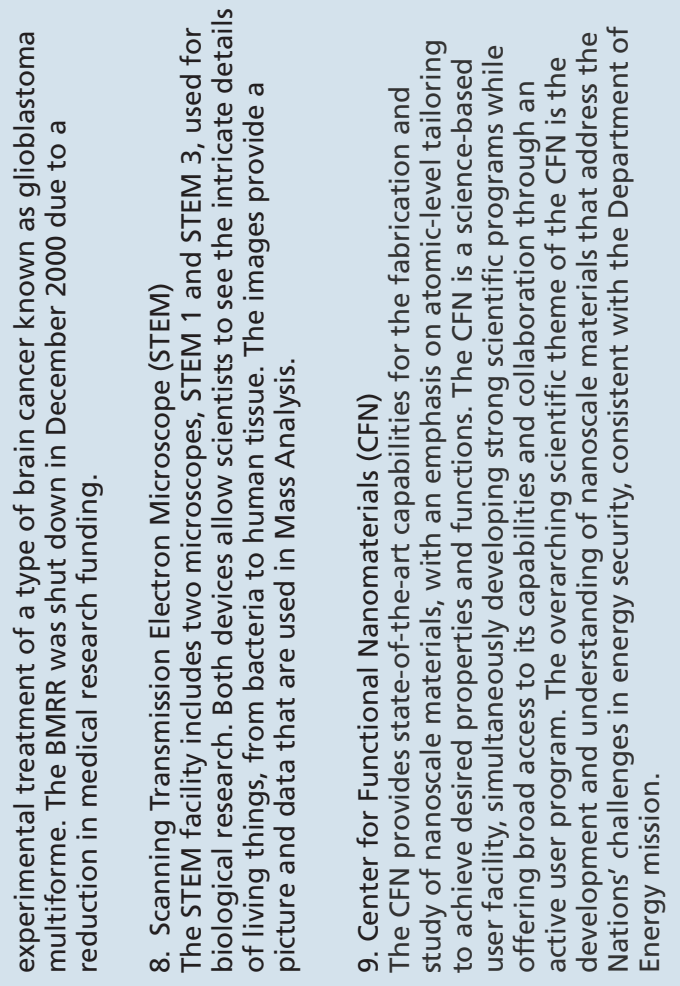

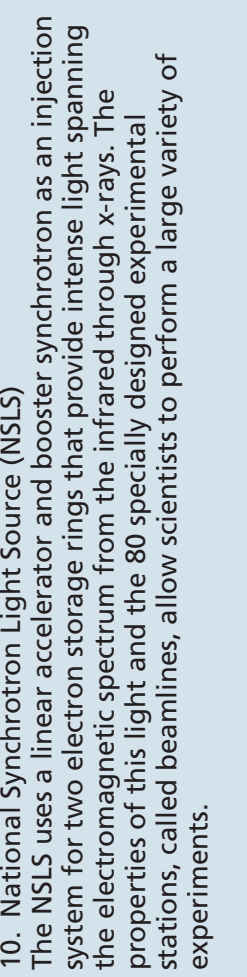

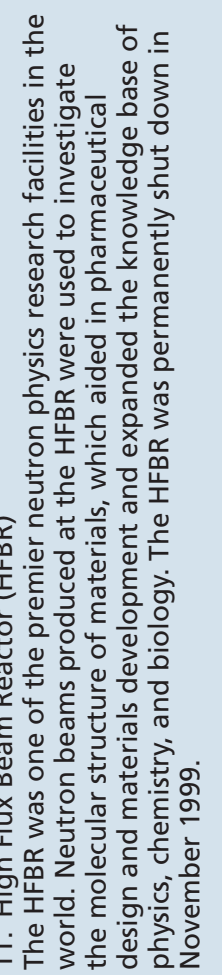

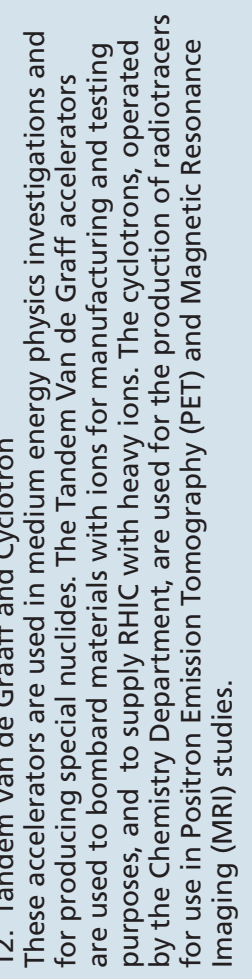

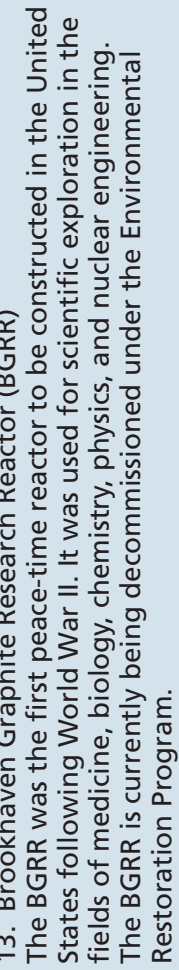

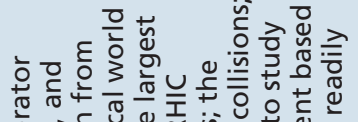

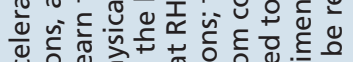

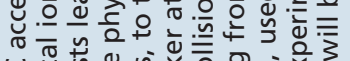

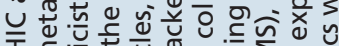

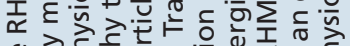

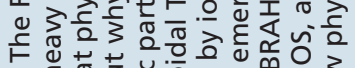

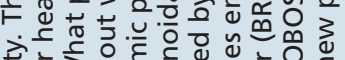

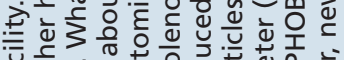

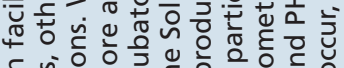

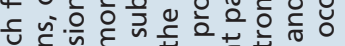

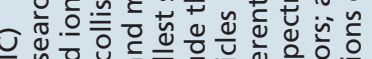

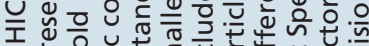

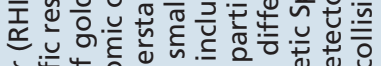

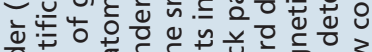

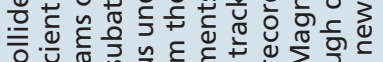

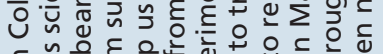

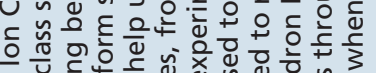

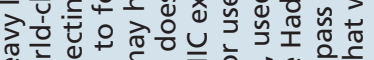

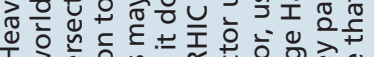
エ

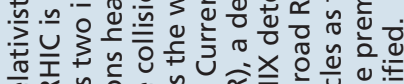

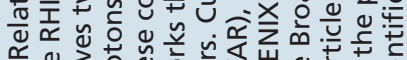

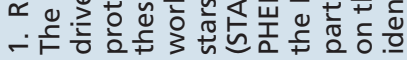

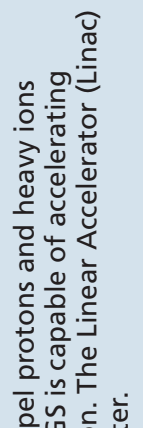

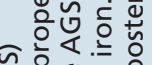
(3)

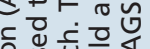
政

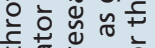

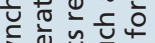

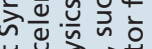

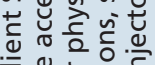

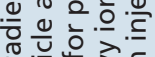
는 는 을으응 웅 $=\pi \frac{1}{0}$ 을 政政

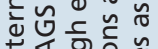
중

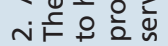

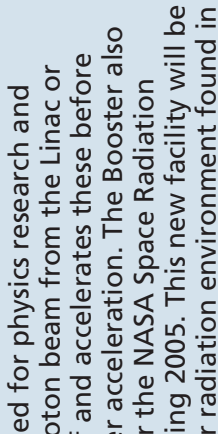

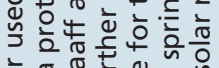

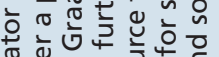

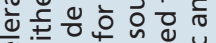

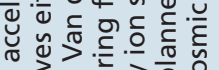
흘 ह ये 웅

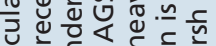
ป

ธ艹 屯ั

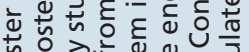

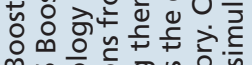

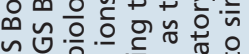

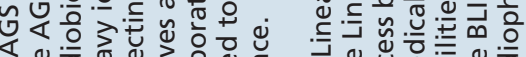
mト
ఏำ 을 包官。导

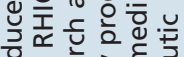

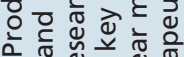
ब 会

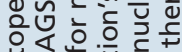

응 ᅯ

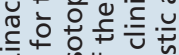

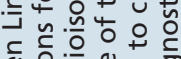

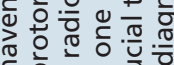

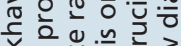

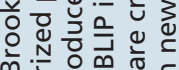

ตำ 은

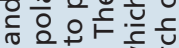

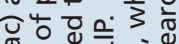

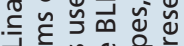

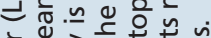

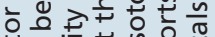

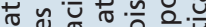

는 응 응 윽눅

बู प흘

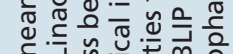

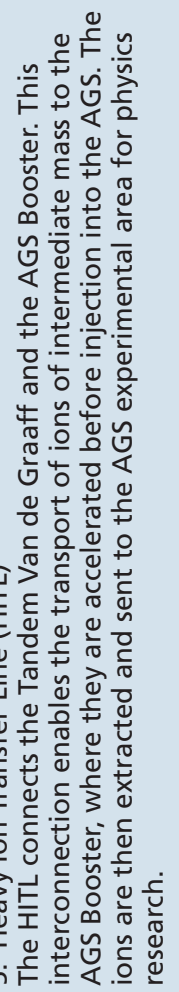

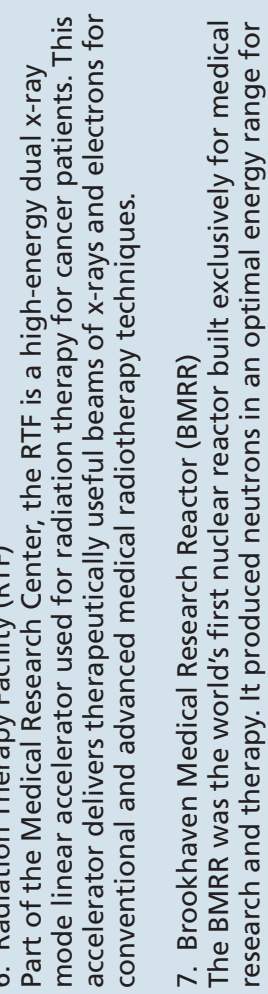




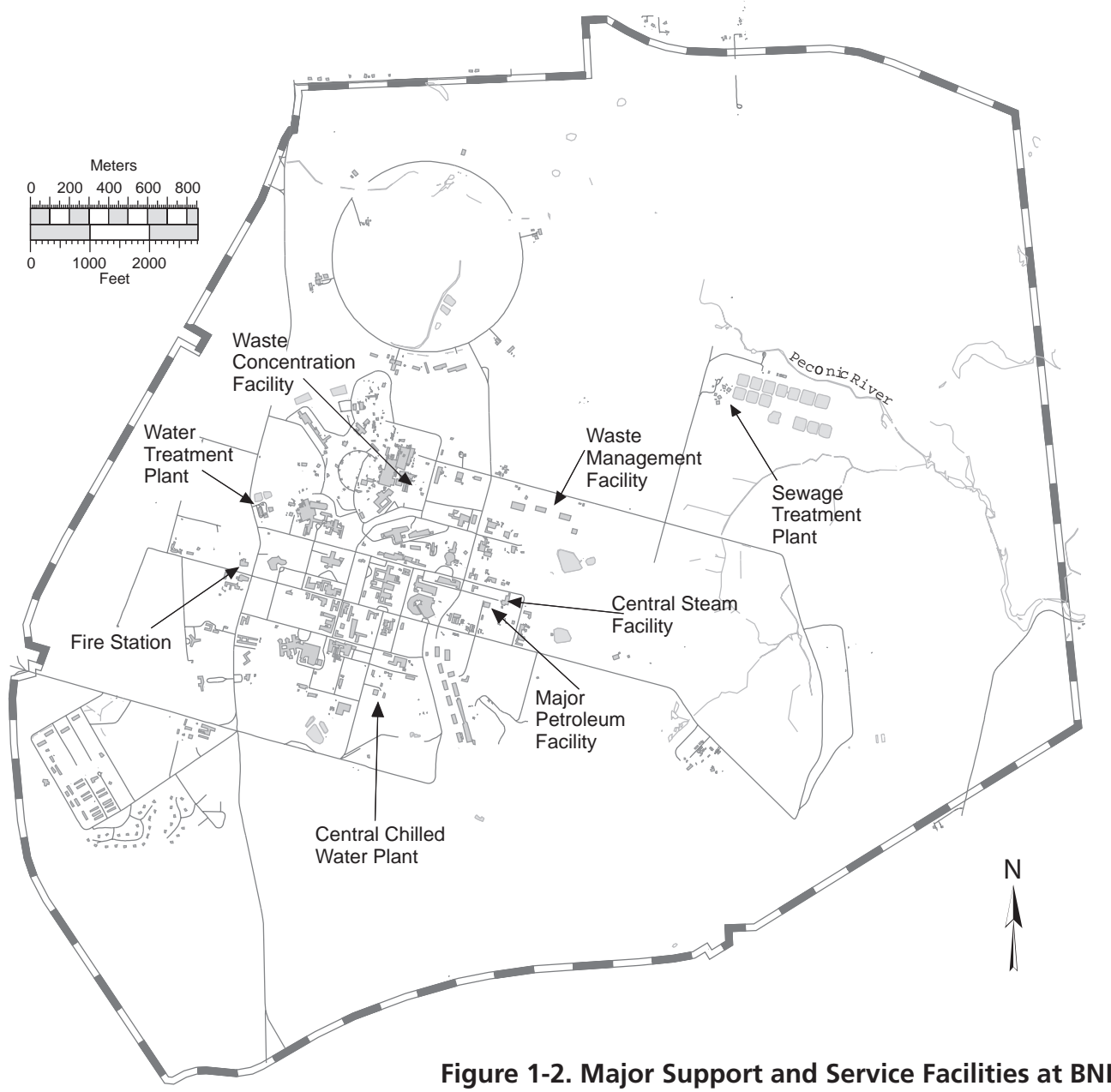

\subsection{GEOLOGY AND HYDROLOGY}

BNL is situated on the western rim of the shallow Peconic River watershed. The marshy areas in the northern and eastern sections of the site are part of the headwaters of the Peconic River. Depending on the height of the water table relative to the base of the riverbed, the Peconic River both recharges to, and receives water from, the underlying upper glacial aquifer. In times of sustained drought, the river water recharges to the groundwater; with normal to above-normal precipitation, the river receives water from the aquifer.

In general, the terrain of the BNL site is gently rolling, with elevations varying between 44 and 120 feet above mean sea level. Depth to groundwater from the land surface ranges from 5 feet near the Peconic River to about 80 feet in the higher elevations of the central and western portions of the site. Studies of Long Island hydrology and geology in the vicinity of the Laboratory indicate that the uppermost Pleistocene deposits, composed of highly permeable glacial sands and gravel, are between 120 and 250 feet thick (Warren et al. 1968, Scorca et al. 1999). Water penetrates these deposits readily, and there is little direct runoff into surface streams unless precipitation is intense. The sandy deposits store large quantities of water in the Upper Glacial aquifer. On average, about half of the annual precipitation is lost to the atmosphere through evapotranspiration and the other half percolates through the soil to recharge the groundwater (Koppelman 1978).

The Long Island Regional Planning Board and Suffolk County have identified the Laboratory site as overlying a deep-flow recharge zone for Long Island groundwater (Koppelman 1978). Precipitation and surface water that recharge within this zone have the potential to 


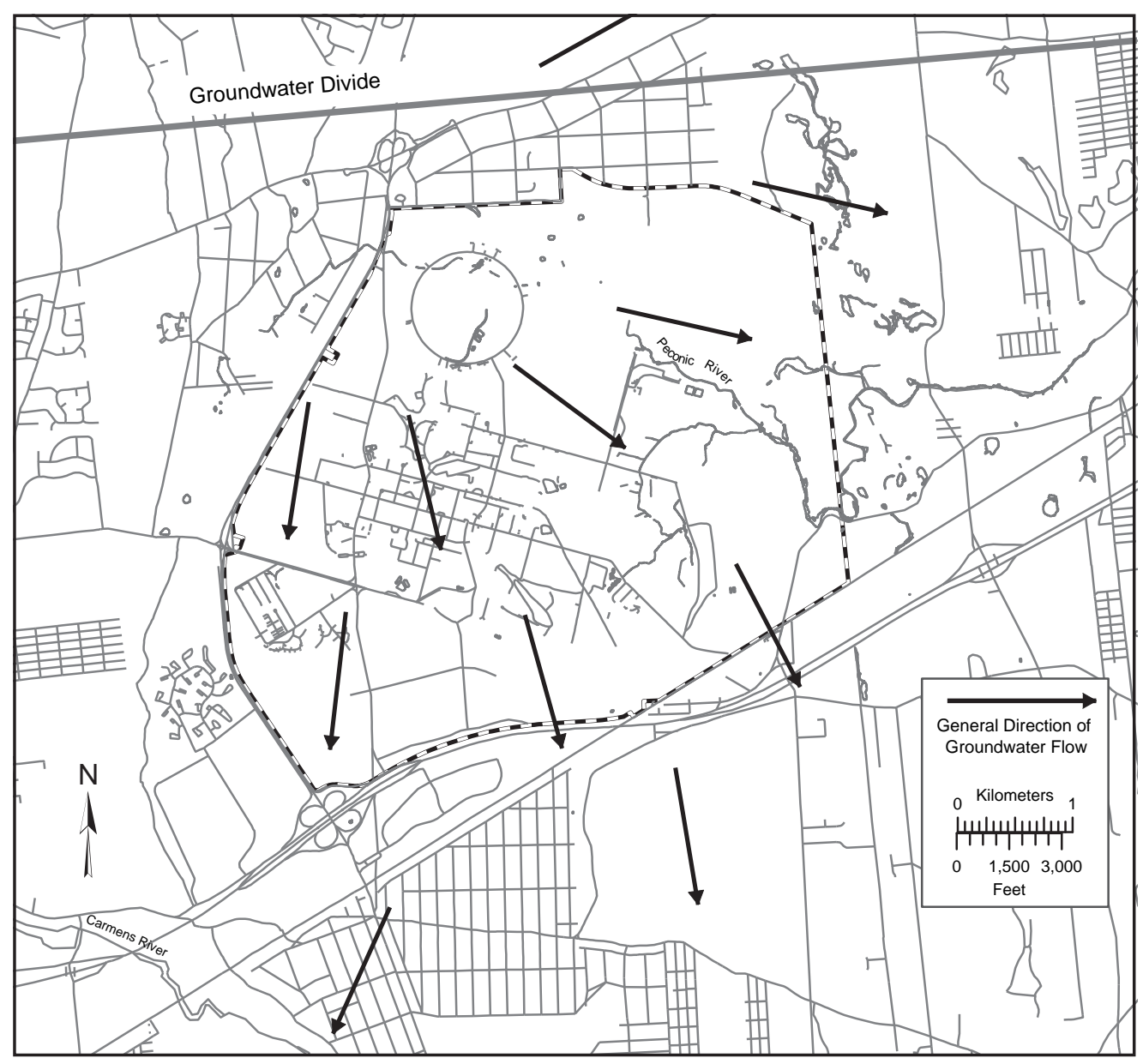

Figure 1-3. BNL Groundwater Flow Map.

replenish the Magothy and Lloyd aquifer systems lying below the Upper Glacial aquifer. It has been estimated that up to two-fifths of the recharge from rainfall moves into the deeper aquifers. The extent to which groundwater on site contributes to deep-flow recharge has been confirmed through the use of an extensive network of shallow and deep wells installed at BNL and surrounding areas (Geraghty \& Miller 1996). This groundwater system is the primary source of drinking water for both on- and offsite private and public supply wells and has been designated a sole source aquifer system by the Environmental Protection Agency (EPA).

During 2007, the Laboratory used approximately 1.15 million gallons of groundwater per day to meet potable water needs and heating and cooling requirements. Approximately 75 percent of the water pumped from BNL supply wells is returned to the aquifer through on-site recharge basins and permitted discharges to the Peconic River. Under normal hydrologic conditions, most of the water discharged to the river recharges to the Upper Glacial aquifer before leaving the site. Human consumption, evaporation (cooling tower and wind losses), and sewer line losses account for the remaining 25 percent. An additional 3.4 million gallons of groundwater were pumped each day from remediation wells. This water is treated to remove contaminants and is then returned to the aquifer by way of recharge basins or injection wells.

Groundwater flow directions across the BNL site are influenced by natural drainage systems: eastward along the Peconic River, southeast toward the Forge River, and south toward the Carmans River (Figure 1-3). Pumping from on-site supply wells affects the direction and speed of groundwater flow, especially in the central, developed areas of the site. The main groundwater 

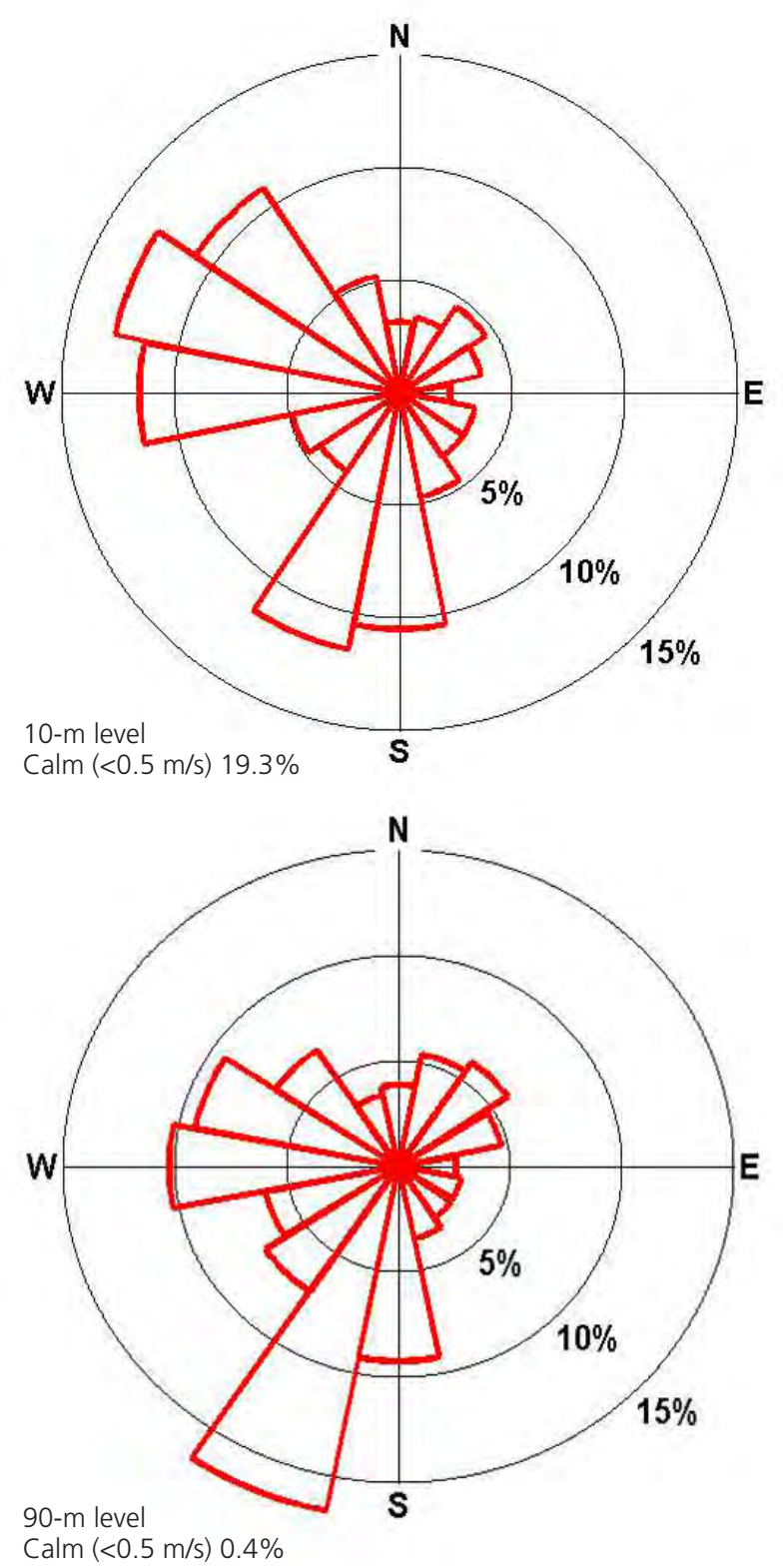

Explanation: The arrows formed by the wedges indicate wind direction. Each concentric circle represents a 5 percent frequency; that is, how often the wind came from that direction. The wind direction was measured at heights of 10 and 90 meters. This diagram indicates that the predominant wind direction was from the south at the 10-m level and south-southwest at the 90-m level.

Figure 1-4. BNL Wind Rose (2007).

divide on Long Island is aligned generally eastwest and lies approximately one-half mile north of the Laboratory. Groundwater north of the divide flows northward and ultimately discharges to the Long Island Sound. Groundwater south of the divide flows east and south, discharging to the Peconic River, Peconic Bay, south shore streams, Great South Bay, and Atlantic Ocean. The regional groundwater flow system is discussed in greater detail in Stratigraphy and Hydrologic Conditions at the Brookhaven National Laboratory and Vicinity (Scorca et al. 1999). In most areas at BNL, the horizontal velocity of groundwater is approximately 0.75 to 1.2 feet per day (Geraghty \& Miller 1996). In general, this means that groundwater travels for approximately 20 to 22 years as it moves from the central, developed area of the site to the Laboratory's southern boundary.

\subsection{CLIMATE}

The Meteorological Group at BNL has been recording weather data on site since 1949. The Laboratory is broadly influenced by continental and maritime weather systems. Locally, the Long Island Sound, Atlantic Ocean, and associated bays influence wind directions and humidity and provide a moderating influence on extreme summer and winter temperatures. The prevailing ground-level winds at BNL are from the southwest during the summer, from the northwest during the winter, and about equally from those two directions during the spring and fall (Nagle 1975, 1978). Figure 1-4 shows the 2007 annual wind rose for BNL, which depicts the annual frequency distribution of wind speed and direction, measured at an on-site meteorological tower at heights of 33 feet (10 meters) and 300 feet ( 90 meters) above land surface.

The average monthly temperature in the area for 2007 was 53.9 degrees Fahrenheit $\left({ }^{\circ} \mathrm{F}\right)$. The average yearly temperature for the area was $51.7^{\circ} \mathrm{F}$. While that temperature was slightly above normal, it did not nearly reach the record-breaking yearly temperature of $53.2^{\circ} \mathrm{F}$ set in 2006. Figures 1-5 and 1-6 show the 2007 monthly mean temperatures and the historical annual mean temperatures, respectively.

With a total annual precipitation of 45.33 inches, 2007 was a dry year in contrast to 2006, which brought 61.59 inches of precipitation to the area. Figures 1-7 and 1-8 show the 2007 monthly and the 59-year annual precipitation data. Snowfall for the 2006-2007 winter season was 9.5 inches, well below the 31.2 inches of average yearly snowfall for Long Island, and about 


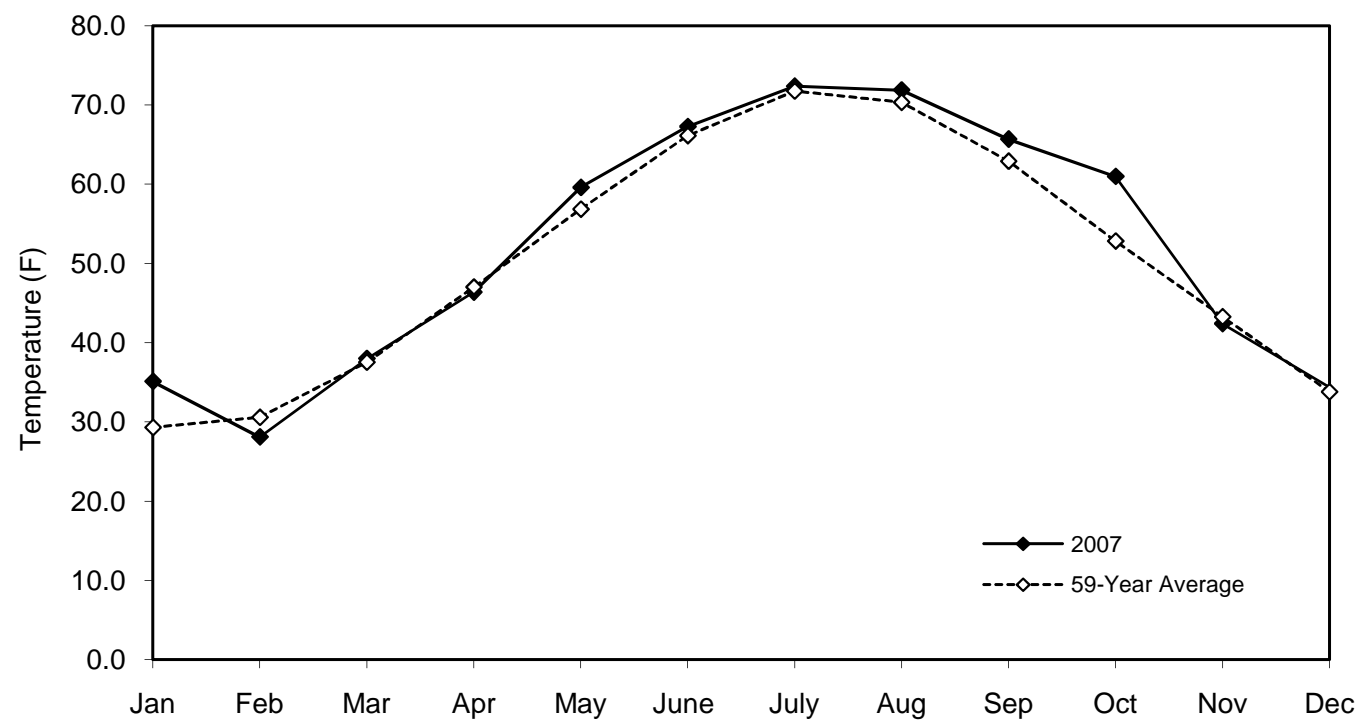

Figure 1-5. BNL 2007 Monthly Mean Temperature versus 59-Year Monthly Average.

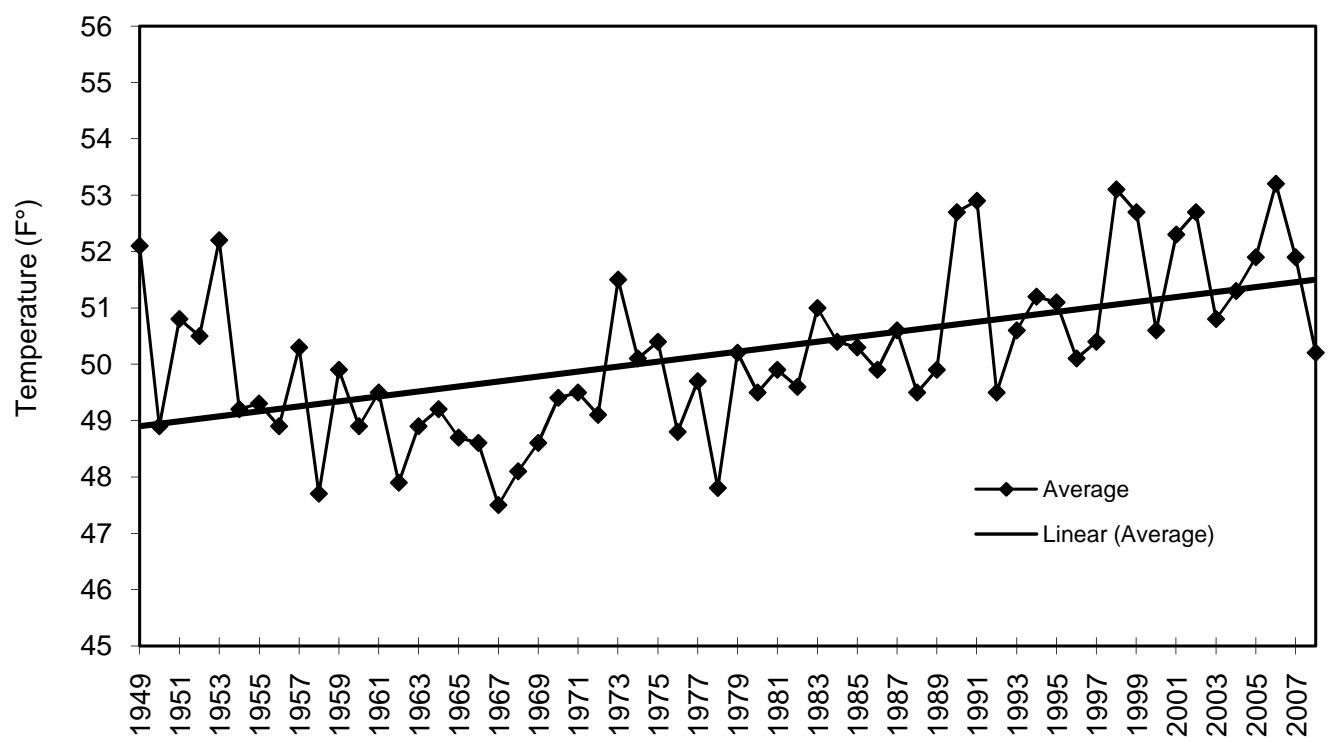

Figure 1-6. BNL 2007 Annual Mean Temperature Trend (59 Years).

10 times less than the record high snowfall of 90.8 inches, set in the 1995-1996 snow season.

\subsection{NATURAL RESOURCES}

The Laboratory is located in the oak/chestnut forest region of the Coastal Plain and constitutes about 5 percent of the 100,000-acre New York State-designated region on Long Island known as the Central Pine Barrens. The section of the Peconic River running through
BNL is designated as "scenic" under the New York State Wild, Scenic, and Recreational River System Act of 1972. Due to the general topography and porous soil, the land is very well drained and there is little surface runoff or open standing water. However, depressions form numerous small, pocket wetlands with standing water on a seasonal basis (vernal pools), and there are six regulated wetlands on site. Thus, a mosaic of wet and dry areas cor- 


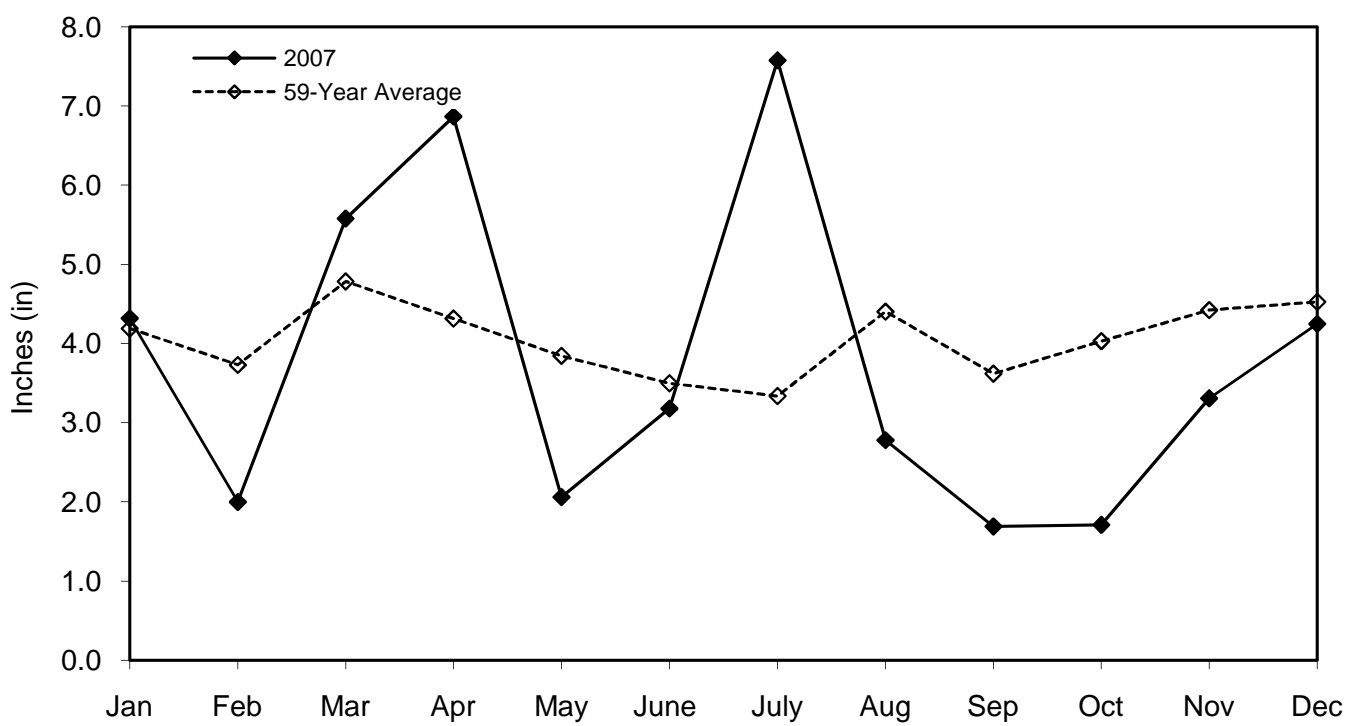

Figure 1-7. BNL 2007 Monthly Precipitation versus 59-Year Monthly Average.

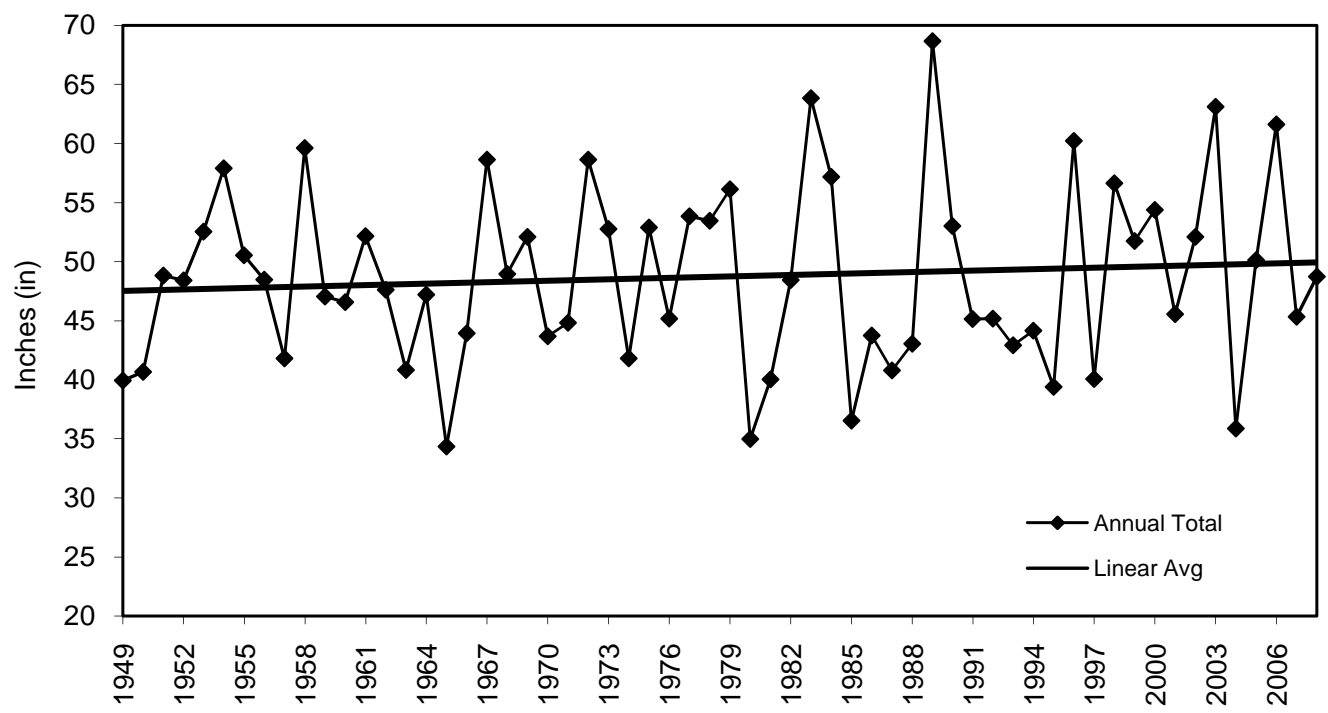

Figure 1-8. BNL 2007 Annual Precipitation Trend (59 Years).

relates with variations in topography and depth to the water table.

Vegetation on site is in various stages of succession, which reflects a history of disturbances to the area. For example, when Camp Upton was constructed in 1917, the site was entirely cleared of its native pines and oaks. Although portions of the site were replanted in the 1930s, portions were cleared again in 1940 when Camp Upton was reactivated by the U.S. Army. Other past disturbances include fire, local flooding, and draining. Current operations minimize dis- turbances to the more natural areas of the site.

More than 230 plant species have been identified at the Laboratory, including two species that are threatened in New York State and two that are classified as rare. Fifteen animal species identified on site include a number that are protected in New York State, as well as species common to mixed hardwood forests and open grassland habitats. At least 85 species of birds have been observed nesting on site, and more than 200 transitory bird species have been documented visiting the site. (BNL is located within 
the Atlantic Flyway, with scrub/shrub habitats that offer food and rest to migratory songbirds.) Permanently flooded retention basins and other watercourses support amphibians and aquatic reptiles. Thirteen amphibian and 12 reptile species have been identified at BNL. Recent ecological studies have confirmed 26 breeding sites for the New York State endangered eastern tiger salamander in ponds and recharge basins. Ten species of fish have been identified as endemic to the site, including the banded sunfish and the swamp darter, both of which are threatened in New York State. Two types of butterflies that are protected in New York State are believed to breed on site due to the presence of their preferred habitat and host plants, and a New York State threatened damselfly was found on site in 2005. To eliminate or minimize any negative effects that Laboratory operations might cause to these species, precautions are in place to protect the on-site habitats and natural resources.

In November 2000, DOE established the Upton Ecological and Research Reserve at BNL. The 530-acre Upton Reserve (10 percent of the Laboratory's property) is on the eastern portion of the site, in the Core Preservation Area of the Central Pine Barrens. The Upton Reserve creates a unique ecosystem of forests and wetlands that provides habitats for plants, mammals, birds, reptiles, and amphibians. From 2000 to 2004, funding provided by DOE under an InterAgency Agreement between DOE and the U.S. Fish \& Wildlife Services was used to conduct resource management programs for the conservation, enhancement, and restoration of wildlife and habitat in the reserve. In 2005, management was transitioned to the Foundation for Ecological Research in the Northeast (FERN). The Laboratory continues to utilize the Upton Reserve Technical Advisory Group, made up of local land management agencies, to assist BNL and FERN with technical expertise and help determine natural resource management policy for the Laboratory and the Upton Reserve. Management of the Upton Reserve falls within the scope of BNL's Natural Resource Management Plan, and the area will continue to be managed for its key ecological values and as an area for ecological research. Additional information re- garding the Upton Reserve and the Laboratory's natural resources can be found in Chapter 6 of this report.

\subsection{CULTURAL RESOURCES}

The Laboratory is responsible for ensuring compliance with historic preservation requirements. BNL's Cultural Resource Management Plan was developed to identify, assess, and document the Laboratory's historic and cultural resources. These resources include World War I trenches; Civilian Conservation Corps features; World War II buildings; and historic structures, programs, and discoveries associated with highenergy physics, research reactors, and other science conducted at BNL. The Laboratory currently has three facilities classified as eligible for listing on the National Register of Historic Places: the Brookhaven Graphite Research Reactor complex, the High Flux Beam Reactor complex, and the World War I training trenches associated with Camp Upton.

\section{REFERENCES AND BIBLIOGRAPHY}

BNL. 2003. Natural Resource Management Plan for Brookhaven National Laboratory. Brookhaven National Laboratory, Upton, NY.

BNL. 2005. Cultural Resource Management Plan for Brookhaven National Laboratory. Brookhaven National Laboratory, Upton, NY.

DOE Order 231.1.A. 2003. Environment, Safety and Health Reporting. U.S. Department of Energy, Washington, DC.

Geraghty and Miller, Inc. 1996. Regional Groundwater Model, Brookhaven National Laboratory, Upton, New York. A Report to Brookhaven National Laboratory. November 1996.

Kamer, Pearl M. 2006. The Economic Impact of Brookhaven National Laboratory on the New York State. Suffolk County Planning Commission, Suffolk County Department of Planning. October 2005.

Koppelman, L.E. 1978. The Long Island Comprehensive Waste Treatment Management Plan (Long Island 208 Study), Vol. I and II. Long Island Regional Planning Board, Hauppauge, NY. July 1978.

Nagle, C.M. 1975. Climatology of Brookhaven National Laboratory: 1949-1973. BNL-50466. Brookhaven National Laboratory, Upton, NY. November 1975.

Nagle, C.M. 1978. Climatology of Brookhaven National Laboratory: 1974-1977. BNL-50857. Brookhaven National Laboratory, Upton, NY. May 1978. 


\section{CHAPTER 1: INTRODUCTION}

NYCRR. Title 27. Wild, Scenic, and Recreational River Systems Act. Article 15 and subsequent updates. New York State Department of Environmental Conservation, Albany, NY.

Scorca, M.P., W.R. Dorsch, and D.E. Paquette. 1999. Stratigraphy and Hydrologic Conditions at the Brookhaven National Laboratory and Vicinity, Suffolk County, New York, 1994-97. U.S. Geological Survey Water Resources Investigations Report 99-4086. 55 pp.

Warren, M.A., W. deLaguna, and N.J. Lusczynski.1968. Hydrology of Brookhaven National Laboratory and Vicinity, Suffolk County, New York. U.S. Geological Survey Bulletin, 1156-C. 


\section{Environmental Management System}

One of Brookhaven National Laboratory's (BNL) highest priorities is ensuring that its environmental commitment is as strong as its passion for discovery. The contractor operating the Laboratory on behalf of DOE, Brookhaven Science Associates (BSA), takes environmental stewardship very seriously. As part of its commitment to environmentally responsible operations, BSA has established the BNL Environmental Management System (EMS). One measure of an effective EMS is recognition of good environmental performance. In 2007, BNL was recognized with eight national or regional environmental awards. DOE awarded BNL three Pollution Prevention and Environmental Stewardship Accomplishment Awards for EMS, composting, and recycling efforts. For voluntary efforts in EMS, Performance Track, and the National Partnership for Environmental Priorities program, BNL received the Pollution Prevention Star Award and White House Closing the Circle Award. Further, BNL received its first Silver Level Award for Electronics Recycling from the Office of the Federal Environmental Executive. Finally, the Laboratory received the Environmental Outreach Award from the National Environmental Performance Track Program, and the Long Island Transportation Management Inc. 2007 Commuter Choice Leadership award.

An EMS ensures that environmental issues are systematically identified, controlled, and monitored. Moreover, an EMS provides mechanisms for responding to changing environmental conditions and requirements, reporting on environmental performance, and reinforcing continual improvement. The Laboratory's EMS was designed to meet the rigorous requirements of the globally recognized International Organization for Standardization (ISO) 14001 Environmental Management Standard, with additional emphasis on compliance, pollution prevention, and community involvement.

Annual audits are required to maintain EMS registration. Recertification audits of the entire EMS occur every three years. In 2007, an EMS Recertification Audit determined that BNL remains in conformance with the ISO 14001: 2004 Standard.

BNL continued its strong support of the Pollution Prevention Program, which seeks ways to eliminate waste and toxic materials. In 2007, pollution prevention projects resulted in more than $\$ 2.9$ million in cost avoidance or savings and resulted in the reduction or reuse of approximately 14.6 million pounds of waste. Also in 2007, the BNL Pollution Prevention Council funded six new proposals or special projects, investing approximately \$10,000. Anticipated annual savings from the projects are estimated at approximately $\$ 38,000$, for an average payback period of less than 1 year. The ISO 14001-registered EMS and the nationally recognized Pollution Prevention Program continue to contribute to the Laboratory's success in promoting pollution prevention.

BNL continues to address legacy issues under the Environmental Restoration Program and openly communicates with neighbors, regulators, employees, and other interested parties on environmental issues and cleanup progress on site and off site. 


\subsection{INTEGRATED SAFETY MANAGEMENT, ISO 14001, AND OHSAS 18001}

The Laboratory's Integrated Safety Management System (ISMS) integrates environment, safety, and health management into all work planning. The integrated safety processes within the ISMS contributed to BNL achieving ISO 14001 and Occupational Safety and Health Assessment Series (OHSAS) 18001 registrations.

The ISO 14001 Standard is globally recognized and defines the structure of an organization's EMS for purposes of improving environmental performance. OHSAS 18001 mirrors the ISO14001 structure. The processbased structure of the ISO 14001 and OHSAS 18001 standards are based on the "Plan-DoCheck-Act” improvement cycle. Both standards require an organization to develop a policy, create plans to implement the policy, implement the plans, check progress and take corrective actions, and review the system periodically to ensure its continuing suitability, adequacy, and effectiveness. To gain registration to the ISO 14001 and OHSAS 18001 standards, an organization must comply with the set of requirements listed and described in Table 2-1. Table 2-1 also defines where these requirements fit into the ISMS structure.

BNL's EMS was officially registered to the ISO 14001 Standard in July 2001 and was the first DOE Office of Science Laboratory to obtain third-party registration to this globally recognized environmental standard. BNL was also officially registered to the OHSAS 18001 Standard in 2006, and was again the first DOE Office of Science Laboratory to achieve this registration. Each certification requires the Laboratory to undergo annual audits by an accredited registrar to assure that the system is maintained.

In 2007, an EMS and OHSAS Certification Audit determined that BNL remains in conformance with the ISO 14001 and OHSAS 18001 standards. In their recommendation for

Table 2-1. Elements of the Environmental Management System (EMS) and their Relationship to OHSAS 18001 and Integrated Safety Management (ISM) - Review of EMS Implementation at BNL.

\begin{tabular}{l|l|l}
\hline ISO 14001 EMS Clause & OHSAS 18001 Clause & ISM Guiding Principle and Core Function \\
\hline 4.2 Environmental policy & 4.2 OH\&S policy & $\begin{array}{l}\text { Core function 1: Define the scope of work } \\
\text { Guiding principle 1: Line manager clearly responsible } \\
\text { for ES\&H }\end{array}$ \\
\hline
\end{tabular}

The Environmental, Safety, Security, and Health Policy is a statement of BNL's intentions and principles regarding overall environmental, safety, security, and health performance. It provides a framework for planning and action. In the policy, BNL has reaffirmed its commitment to the environment, safety, security, health, compliance, the community, and continual improvement.

\begin{tabular}{l|l|l}
\hline 4.3.1 Environmental aspects & 4.3.1 Planning for hazard identification, risk as- Core function 2: Identify and analyze hazards associa-
\end{tabular} sessment, and risk control ted with the work

Guiding principle 5: Identify ES\&H standards and requirements

When operations have an environmental aspect, BNL implements the EMS to minimize or eliminate any potential impact. The Laboratory evaluates its operations, identifies the aspects of operations that can impact the environment, and determines which of those potential impacts are significant. BNL has determined that the following aspects of its operations are significant and have the potential to affect the environment:

\begin{tabular}{l|l|l}
\hline - Waste generation & $\begin{array}{l}\text { - Natural resource usage - power and water } \\
\text { consumption } \\
\text { - Atmospheric emissions }\end{array}$ & $\begin{array}{l}\text { - Disturbances to endangered species/protected } \\
\text { - Liquid effluents }\end{array}$ \\
$\begin{array}{l}\text { - Storagitats } \\
\text { - Haterials or use of chemicals and radioactive } \\
\text { - Environmental noise }\end{array}$ & $\begin{array}{l}\text { - Soil activation } \\
\text { - Historical contamination }\end{array}$ \\
\hline 4.3.2 Legal and other requirements & 4.3 .2 Legal and other requirements & $\begin{array}{l}\text { Core function 2: Identify and analyze hazards associa- } \\
\text { ted with the work } \\
\text { Guiding principle 5: Identify ES\&H standards and re- } \\
\text { quirements }\end{array}$ \\
\hline
\end{tabular}

The Laboratory has implemented and continues to improve the Standards Based Management System (SBMS), a BNL web-based system designed to deliver Laboratory-level requirements and guidance to all staff. New or revised requirements (e.g., new regulations) are analyzed to determine their applicability and to identify any actions required to achieve compliance. This may involve developing or revising BNL documents or operating procedures, implementing administrative controls, providing training, installing engineered controls, or increasing monitoring. 
Table 2-1. Elements of the Environmental Management System (EMS) and their Relationship to OHSAS 18001 and Integrated Safety Management (ISM) - Review of EMS Implementation at BNL(continued).

\begin{tabular}{l|l|l}
\hline ISO 14001 EMS Clause & OHSAS 18001 Clause & ISM Guiding Principle and Core Function \\
\hline 4.3.3 Objectives Targets and Programs & 4.3 .3 Objectives & $\begin{array}{l}\text { Core function 1: Define the scope of work } \\
\text { Guiding principle 5: Identify ES\&H standards and re- } \\
\text { quirements }\end{array}$ \\
\hline
\end{tabular}

The Performance Based Management System is designed to develop, align, balance, and implement the Laboratory's strategic objectives, including environmental objectives. Objectives and targets are developed by fiscal year (FY). The following objectives and targets in FY07 included:

- Continually improving the EMS

- Improving compliance in targeted areas

- Integrating pollution prevention into work planning
- Improving communications, trust, and relationships with stakeholders on environmental programs and issues

- Fully implementing the BNL Groundwater Protection Management Program
- Ensuring responsible stewardship of natural and historical resources on site

- Implementing environmental restoration projects efficiently

Organizations within BNL develop action plans detailing how they will achieve their objectives and targets and commit the necessary resources to successfully implement both Laboratory-wide programs and facility-specific programs. BNL has implemented a Pollution Prevention Program to conserve resources and minimize waste generation. The Laboratory also has a budgeting system designed to ensure that priorities are balanced and that resources essential to the implementation and control of the EMS are provided.

\begin{tabular}{l|l|l}
\hline $\begin{array}{l}\text { 4.4.1 Resources, roles, responsibilities and } \\
\text { authority }\end{array}$ & 4.4.1 Structure and responsibility & $\begin{array}{l}\text { Core function 1: Define the scope of work } \\
\text { Guiding principle 1: Line manager is clearly responsible } \\
\text { for ES\&H } \\
\text { Guiding principle 2: Clear ES\&H roles and responsibilities } \\
\text { Guiding principle 4: Balanced priorities }\end{array}$ \\
\hline
\end{tabular}

All employees at BNL have specific roles and responsibilities in key areas, including environmental protection. Environmental and waste management technical support personnel assist the line organizations with developing and meeting their environmental responsibilities. Every Laboratory employee is required to develop a Roles, Responsibilities, Accountabilities, and Authorities (R2A2) document signed by the employee, their supervisor, and the supervisor's manager. Specifics on environment, safety, and health performance expectations are included in these documents.

\begin{tabular}{l|l|l}
\hline 4.4.2 Competence, training, and awareness & 4.4.2 Training, awareness, and competence & $\begin{array}{l}\text { Core function 4: Perform work within controls } \\
\text { Guiding principle 3: Competence commensurate with } \\
\text { responsibilities }\end{array}$ \\
\hline
\end{tabular}

Extensive training on EMS requirements has been provided to staff whose responsibilities include environmental protection. BNL's training program includes general environmental awareness for all employees; regulatory compliance training for selected staff; and specific courses for managers, internal assessors, EMS implementation teams, and operations personnel whose work can impact the environment.

\begin{tabular}{l|l|l}
\hline 4.4.3 Communication & 4.4.3 Consultation and communication & $\begin{array}{l}\text { Core function 4: Perform work within controls } \\
\text { Core function 5: Provide feedback on adequacy of con- } \\
\text { trols and continue to improve safety management } \\
\text { Guiding principle 2: Clear ES\&H roles and responsibilities }\end{array}$ \\
\hline
\end{tabular}

BNL continues to improve processes for internal and external communications on environmental issues. The Laboratory solicits input from interested parties such as community members, activists, civic organizations, elected officials, and regulators. This is accomplished primarily through the Citizens Advisory Committee and the Brookhaven Executive Roundtable. At the core of the communication and community involvement programs are the Environmental Safety, Security, and Health Policy and the Community Involvement Plan.

\begin{tabular}{l|l|l}
\hline 4.4.4 Documentation & 4.4.4 Documentation & $\begin{array}{l}\text { Core function 2: Identify and analyze hazards associ- } \\
\text { ated with the work } \\
\text { Guiding principle 6: Hazard controls tailored to work } \\
\text { Guiding Principle 7: Operations authorization }\end{array}$ \\
\hline
\end{tabular}

BNL has a comprehensive, up-to-date set of Laboratory-wide environmental documents describing the EMS. Using the SBMS, staff can access detailed information on regulatory requirements, Laboratory-wide procedures, and manuals on how to control processes and perform their work in a way that protects the environment. The SBMS has improved the quality, usability, and communication of Laboratory-level requirements.

\begin{tabular}{l|l|l}
\hline 4.4.5 Control of documents & 4.4.5 Document and data control & $\begin{array}{l}\text { Core function 4: Perform work within controls } \\
\text { Guiding principle 6: Hazard controls tailored to work }\end{array}$ \\
\hline
\end{tabular}

The SBMS includes a comprehensive document control system to ensure effective management of procedures and other requirements documents. When facilities require additional procedures to control their work, document control protocols are implemented to ensure that workers have access to the most current versions of procedures. 
Table 2-1. Elements of the Environmental Management System (EMS) and their Relationship to OHSAS 18001 and Integrated Safety Management (ISM) - Review of EMS Implementation at BNL(concluded).

\begin{tabular}{l|l|l}
\hline ISO 14001 EMS Clause & OHSAS 18001 Clause & ISM Guiding Principle and Core Function \\
\hline 4.4 .6 Operational control & 4.4 .6 Operational control & $\begin{array}{l}\text { Core function 2: Identify and analyze hazards associ- } \\
\text { ated with the work } \\
\text { Core function 3: Develop and implement hazard controls } \\
\text { Core function 4: Perform work within controls } \\
\text { Guiding principle 5: Identify ES\&H standards and re- } \\
\text { quirements } \\
\text { Guiding principle 6: Hazard controls tailored to work } \\
\text { Guiding principle 7: Operations authorization }\end{array}$ \\
\hline
\end{tabular}

Operations at BNL are evaluated for the adequacy of current controls to prevent impacts to the environment. As needed, additional administrative or engineered controls are identified, and plans for upgrades and improvements are developed and implemented.

\begin{tabular}{l|l|l}
\hline 4.4.7 Emergency preparedness and response & 4.4 .7 Emergency preparedness and response & $\begin{array}{l}\text { Core function 2: Identify and analyze hazards associ- } \\
\text { ated with the work } \\
\text { Core function 3: Develop and implement hazard controls } \\
\text { Guiding principle 6: Hazard controls tailored to work }\end{array}$ \\
\hline
\end{tabular}

BNL has an Emergency Preparedness and Response Program and specialized staff to provide timely response to hazardous materials or other environmental emergencies. This program includes procedures for preventing, as well as responding to, emergencies.

\begin{tabular}{l|l|l}
\hline 4.5.1 Monitoring and measurement & 4.5.1 Performance measurement and monitoring & $\begin{array}{l}\text { Core function 5: Provide feedback on adequacy of con- } \\
\text { trols and continue to improve safety }\end{array}$ \\
\hline
\end{tabular}

Effluent and emission monitoring helps ensure the effectiveness of controls, adherence to regulatory requirements, and timely identification and implementation of corrective measures. BNL has a comprehensive, Laboratory-wide Environmental Monitoring Program. Monitoring results are reported to regulatory agencies and are summarized annually in the Site Environmental Report. In addition, BNL tracks and trends its progress and performance in achieving environmental objectives and performance measures.

\begin{tabular}{l|l|l}
\hline 4.4.2 Evaluation of compliance & NA & $\begin{array}{l}\text { Core function 5: Provide feedback on adequacy of con- } \\
\text { trols and continue to improve safety }\end{array}$ \\
\hline
\end{tabular}

Specific environmental legislation and regulations are evaluated and assessed on a program- or facility-specific basis. BNL has established a documented procedure for periodically evaluating its compliance with relevant environmental regulations. This procedure is often integrated in an organization's environmental, safety, and health inspection process, which is performed in a prioritized fashion by a team of experts including one on environmental regulatory issues. Periodically, the environmental support organizations will perform a regulatory assessment in a particular topical area to verify the compliance status of multiple organizations throughout the Laboratory. Lastly, external regulatory agencies and/or technical experts may conduct independent audits of compliance.

\begin{tabular}{l|l|l}
\hline $\begin{array}{l}\text { 4.5.3 Nonconformance, corrective action, and } \\
\text { preventative action }\end{array}$ & $\begin{array}{l}4.5 .2 \text { Accidents, incidents, non-conformances, } \\
\text { and corrective and preventative action }\end{array}$ & $\begin{array}{l}\text { Core function 5: Provide feedback on adequacy of con- } \\
\text { trols and continue to improve safety }\end{array}$
\end{tabular}

BNL continues to improve processes that identify and correct problems. A Lessons Learned Program to prevent recurrences, a Laboratory-wide SelfAssessment Program, and an electronic web-based assessment and action tracking system have been implemented.

\begin{tabular}{l|l|l}
\hline 4.5.2 Control of records & 4.5.3 Records and records management & $\begin{array}{l}\text { Core function 2: Identify and analyze hazards associ- } \\
\text { ated with the work } \\
\text { Guiding principle 6: Hazard controls tailored to work } \\
\text { Guiding principle 7: Operations authorization }\end{array}$ \\
\hline
\end{tabular}

EMS-related records, including audit and training records, are maintained to ensure integrity, facilitate retrieval, and protect them from loss.

\begin{tabular}{l|l|l}
\hline 4.5 .5 Internal audit & 4.5 .4 Audit & $\begin{array}{l}\text { Core function 5: Provide feedback on adequacy of con- } \\
\text { trols and continue to improve safety }\end{array}$ \\
\hline
\end{tabular}

To periodically verify that the EMS is operating as intended, audits are conducted. These audits, which are part of the Laboratory-wide Self-Assessment Program, are designed to ensure that any nonconformance to the ISO 14001 Standard is identified and addressed. An independent accredited registrar also conducts ISO 14001 registration audits. In addition, compliance with regulatory requirements is verified through routine inspections, operational evaluations, and periodic audits.

\begin{tabular}{l|l|l}
\hline 4.6 Management review & 4.6 Management review & $\begin{array}{l}\text { Core function 5: Provide feedback on adequacy of con- } \\
\text { trols and continue to improve safety } \\
\text { Guiding principle 1: Line manager clearly responsible } \\
\text { for ES\&H }\end{array}$ \\
\hline
\end{tabular}

In addition to audits, a management review process has been established to involve top management in the overall assessment of environmental performance, the EMS, and progress toward achieving environmental goals. This review also identifies, as necessary, the need for changes to, and continual improvement of, the EMS. 
continued certification, auditors from NSF-International Strategic Registrations, Ltd. highlighted 24 examples of BNL's continual improvement, some of which include the Laboratory's link between institutional- and division-level objectives and targets, "very well done” internal audit records and documentation, and improved management reviews. The auditors also identified one EMS minor nonconformance in "Nonconformity, corrective action and preventative action" and four EMS opportunities for improvement, one each in Emergency Preparedness and Response; Objectives, Targets and Programs; Control of Documents; and Operational Control. A corrective action plan was prepared to track the minor nonconformances to closure.

\subsection{ENVIRONMENTAL, SAFETY, SECURITY, AND HEALTH POLICY}

The cornerstone of an EMS is a commitment to environmental protection at the highest levels of an organization. BNL's environmental commitments are incorporated into a comprehensive Environmental, Safety, Security, and Health (ESSH) Policy. The policy, issued and signed by the Laboratory Director, makes clear the Laboratory's commitment to environmental stewardship, the safety of the public and BNL employees, and the security of the site. The policy continues as a statement of the Laboratory's intentions and principles regarding overall environmental performance. It provides a framework for planning and action and is included in employee, guest, and contractor training programs. The ESSH Policy is posted throughout the Laboratory and on the BNL website at http://www.bnl.gov. The goals and commitments focusing on compliance, pollution prevention, community outreach, and continual improvement include:

- ENVIRONMENT: We protect the environment, conserve resources, and prevent pollution.

- Safety: We maintain a safe workplace, and we plan our work and perform it safely. We take responsibility for the safety of ourselves, coworkers, and guests.

- SECURITY: We protect people, property, information, computing systems, and facilities.

- HEALTH: We protect human health within our boundaries and in the surrounding community.

- COMPLIANCE: We achieve and maintain compliance with applicable ESSH requirements.

- COMmUNITY: We maintain open, proactive, and constructive relationships with our employees, neighbors, regulators, DOE, and our other stakeholders.

- CONTINUAL IMPROVEMENT: We continually improve ESSH performance.

\subsection{PLANNING}

The planning requirements of the ISO 14001 Standard require BNL to identify the environmental aspects and impacts of its activities, products, and services; to evaluate applicable legal and other requirements; to establish objectives and targets; and to create action plans to achieve the objectives and targets.

\subsubsection{Environmental Aspects}

An "environmental aspect" is any element of an organization's activities, products, and services that can interact with the environment. As required by the ISO 14001 Standard, BNL evaluates its operations, identifies the aspects that can impact the environment, and determines which of those impacts are significant. The Laboratory's criteria for significance are based on actual and perceived impacts of its operations and on regulatory requirements. BNL utilizes several processes to identify and review environmental aspects. Key among these is the Process Assessment Procedure. This is an evaluation that is documented on a Process Assessment Form, which consists of a written process description, a detailed process flow diagram, a regulatory determination of all process inputs and outputs, identification of pollution prevention opportunities, and identification of any assessment, prevention, and control measures that should be considered. Environmental professionals work closely with Laboratory personnel to ensure that environmental requirements are integrated into each process. Aspects and impacts are evaluated annually to ensure that they continue to reflect stakeholder concerns and changes in regulatory requirements. 
In 2007, BNL focused on work with engineered nanomaterials, following the completion of a new Center for Functional Nanomaterial Research. In September 2005, a DOE Policy (456.1) had been released establishing a framework by which all DOE labs would work safely with engineered nanomaterials. In response, BNL has worked in conjunction with other DOE Nanoscale Science Research Centers (NSRCs) to develop a consensus document, "Approach to Nanomaterial ESH," that establishes the best available controls for worker and environmental protection. The document uses the precautionary principal to manage the uncertain risk associated with engineered nanomaterials. The Laboratory has since performed an extensive review of its work with engineered nanomaterials to ensure that the controls identified in the document have been implemented. The procedure requires rigorous environmental controls to prevent the release of engineered nanomaterials to the environment. BNL added work with engineered nanomaterials to its list of significant environmental aspects in 2007 and continues to inform the community on its management efforts.

\subsubsection{Legal and Other Requirements}

To implement the compliance commitments of the ESSH Policy and to meet its legal requirements, BNL has systems in place to review changes in federal, state, or local environmental regulations and to communicate those changes to affected staff. Laboratory-wide procedures for documenting these reviews and recording the actions required to ensure compliance are available to all staff through BNL's web-based Standards-Based Management System (SBMS) subject areas.

\subsubsection{Objectives and Targets}

The establishment of environmental objectives and targets is accomplished through a Performance Based Management System. This system is designed to develop, align, balance, and implement the Laboratory's strategic objectives, including environmental objectives. The system drives BNL's improvement agenda by establishing a prioritized set of key objectives, called the Performance Evaluation Management Plan. Annually, BSA works closely with DOE to clearly define expectations and performance measures. Factors for selecting environmental priorities include:

- Significant environmental aspects

- Risk and vulnerability (primarily, threat to the environment)

- Legal requirements (laws, regulations, permits, enforcement actions, and memorandums of agreement)

- Commitments (in the ESSH Policy) to regulatory agencies, and to the public

- Importance to DOE, the public, employees, and other stakeholders

Laboratory-level objectives and targets are developed on a fiscal year (FY) schedule. In FY07 (October 1, 2006 through September 30, 2007), BNL's environmental objectives included:

- Continually improving the EMS

- Improving compliance in targeted areas

- Integrating pollution prevention into work planning

- Improving communications, trust, and relationships with stakeholders on environmental programs and issues

- Fully implementing the BNL Groundwater Protection Management Program

- Ensuring responsible stewardship of natural and historical resources on site

- Implementing environmental restoration projects efficiently

\subsubsection{Environmental Management Programs}

Each organization within BNL develops an action plan detailing how they will achieve their environmental objectives and targets and commit the resources necessary to successfully implement both Laboratory-wide and facility-specific programs. BNL has a budgeting system designed to ensure that priorities are balanced and to provide resources essential to the implementation and control of the EMS. The Laboratory continues to review, develop, and fund important environmental programs to further integrate environmental stewardship into all facets of its missions. 


\subsubsection{Compliance}

BNL has an extensive program to ensure that the Laboratory remains in full compliance with all applicable environmental regulatory requirements and permits. Legislated compliance is outlined by the Clean Air Act, National Emission Standards for Hazardous Air Pollutants (NESHAPs), Clean Water Act (e.g., State Pollutant Discharge Elimination System (SPDES)), Safe Drinking Water Act (SDWA), Resource Conservation and Recovery Act (RCRA), and other programs. Other compliance initiatives at the Laboratory involve special projects, such as upgrading petroleum and chemical storage tank facilities, upgrading the sanitary sewer system, closing underground injection control devices, retrofitting or replacing air conditioning equipment refrigerants, and managing legacy waste. See Chapter 3 for a list of regulatory programs to which BNL subscribes, and a thorough discussion of these programs and their status.

\subsubsection{Groundwater Protection}

BNL's Groundwater Protection Management Program is designed to prevent negative impacts to groundwater and to restore groundwater quality by integrating pollution prevention efforts, monitoring groundwater restoration projects, and communicating performance. The Laboratory has also developed a Groundwater Protection Contingency Plan that defines an orderly process for quickly taking corrective actions in response to unexpected monitoring results. Key elements of the groundwater program are full, timely disclosure of any off-normal occurrences, and regular communication on the performance of the program. Chapter 7 and SER Volume II, Groundwater Status Report, provide additional details about this program, its performance, and monitoring results for 2007.

\subsubsection{Waste Management}

As a byproduct of the world-class research it conducts, BNL generates a large range of wastes. These wastes include materials common to many businesses and industries, such as aerosol cans, batteries, paints, and oils. However, the Laboratory's unique scientific activities also generate waste streams that are subject to addi- tional regulation and special handling, including radioactive, hazardous, and mixed waste.

Collecting, storing, transporting, and disposing of waste generated at the Laboratory is the responsibility of BNL's Waste Management Facility (WMF). This modern facility was designed for handling hazardous, industrial, radioactive, and mixed waste and is comprised of three staging areas: a facility for hazardous waste, regulated by RCRA; a mixed-waste building for material that is both hazardous and radioactive; and a reclamation building for radioactive material. The RCRA and mixed-waste buildings are managed under a permit issued by the New York State Department of Environmental Conservation (NYSDEC). These buildings are used for short-term storage of waste before it is packaged or consolidated for off-site shipment to permitted treatment and disposal facilities. In 2007, BNL generated the following types and quantities of waste from routine operations:

- Hazardous waste: 4.1 tons

- Mixed waste: $31 \mathrm{ft}^{3}$

- Radioactive waste: 6,796 $\mathrm{ft}^{3}$

Hazardous waste from routine operations in 2007 remained fairly steady with respect to 2006 generation rates, as shown in Figure 2-1a. The increase in mixed waste generation, as shown in $2-1 b$, is attributed to activities within the Collider-Accelerator Department. As shown in Figure 2-1c, the radioactive waste quantity for routine operations also increased, but remained below quantities typically generated in previous years. This increase is attributed to increased funding and resulting operations within the high-energy nuclear physics program. Wastes generated from nonroutine or one-time events and wastes generated from environmental restoration activities are not included in the figures.

Routine operations are defined as ongoing industrial and experimental operations. BNL is currently cleaning up facilities and areas containing radioactive and chemical contamination resulting from long-past operations. Waste recovered through restoration and decommissioning activities is managed by the Environmental Restoration (ER) Project, with assistance from BNL's Environmental and Waste Management Services Division (EWMSD). 
In 2007, EWMSD continued surveillance and maintenance operations for the Brookhaven Medical Research Reactor (BMRR) and began working on removing some of the equipment and components from the former Hot Laundry and Decontamination Facility in Building 650. Waste generation activity associated with the BMRR and the Decontamination Facility is reflected in the nonroutine waste values. Nonroutine waste typically includes construction and demolition waste, environmental restoration waste, legacy waste, lead-painted debris, lead shielding, and polychlorinated biphenyl (PCB) waste. Figures 2-1d through 2-1f show wastes generated under the ER Program, as well as nonroutine operations. Waste generation from these activities has varied significantly from year to year. This was expected, as environmental restoration activities moved from remedial investigations and feasibility studies to remedial actions, which have changed annually based on the progress of the Laboratory's cleanup schedule. Nonroutine hazardous waste generation increased in 2007 due to activities to remove lead from the former skeet range.

\subsubsection{Pollution Prevention and Minimization}

The BNL Pollution Prevention (P2) Program is an essential element for the successful accomplishment of the Laboratory's broad mission. The P2 Program reflects the national and DOE pollution

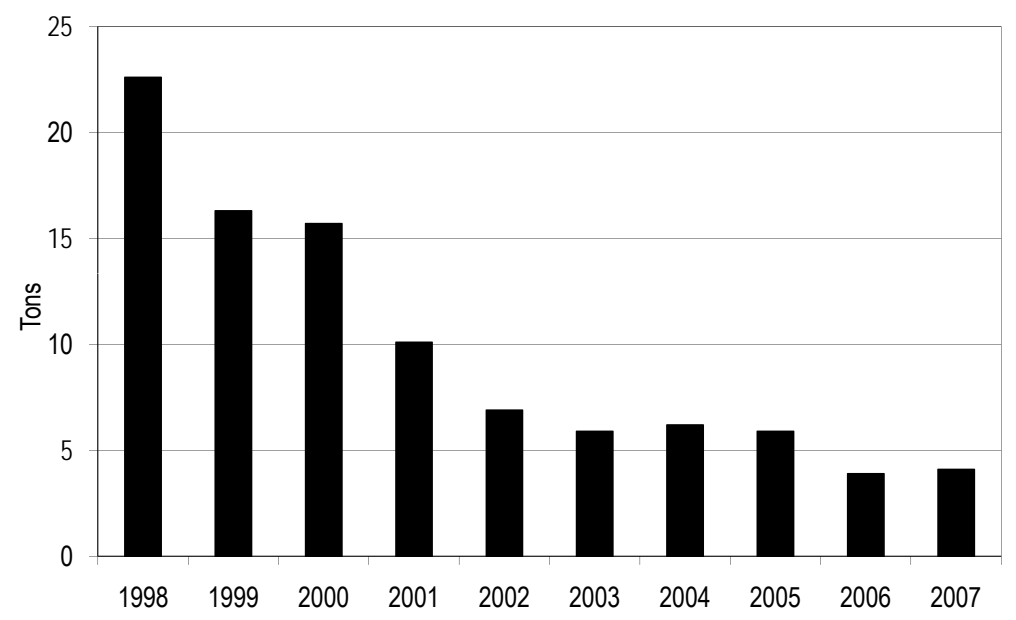

Figure 2-1a. Hazardous Waste Generation from Routine Operations, $1998-2007$.

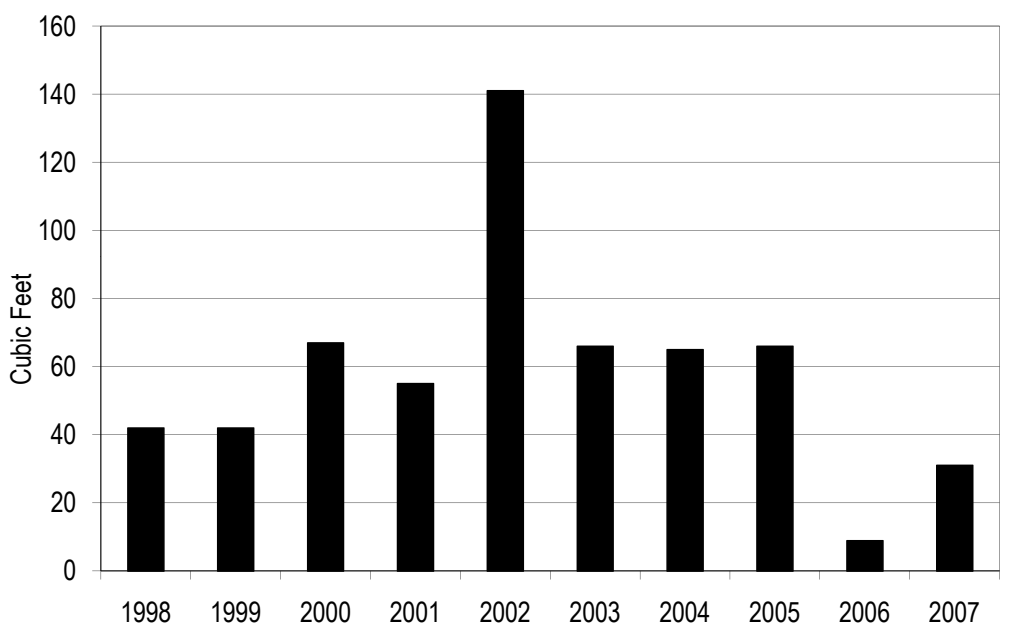

Figure 2-1b. Mixed Waste Generation from Routine Operations, $1998-2007$.

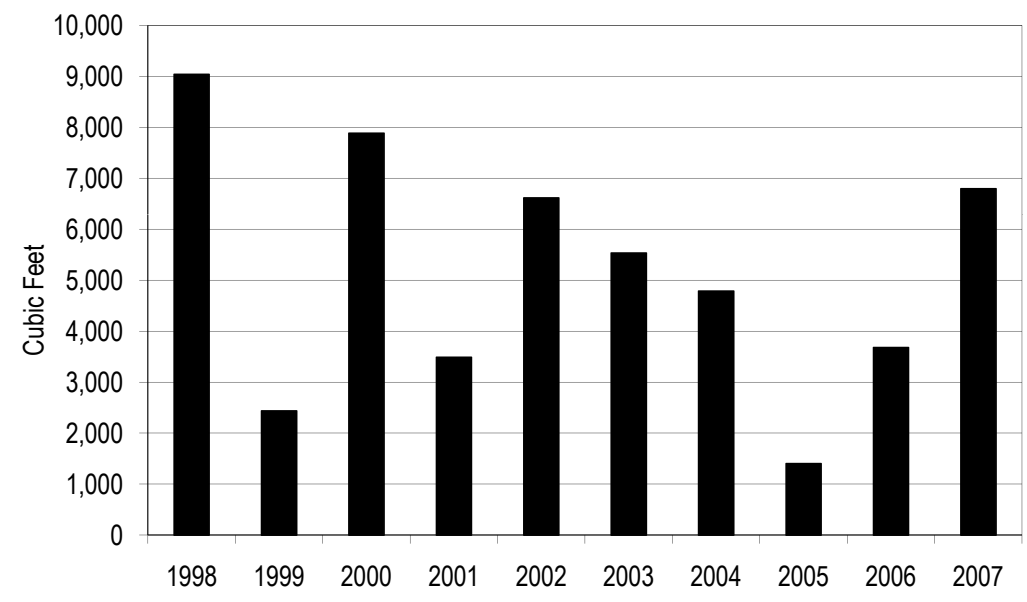

Figure 2-1c. Radioactive Waste Generation from Routine Operations, 1998 - 2007. 


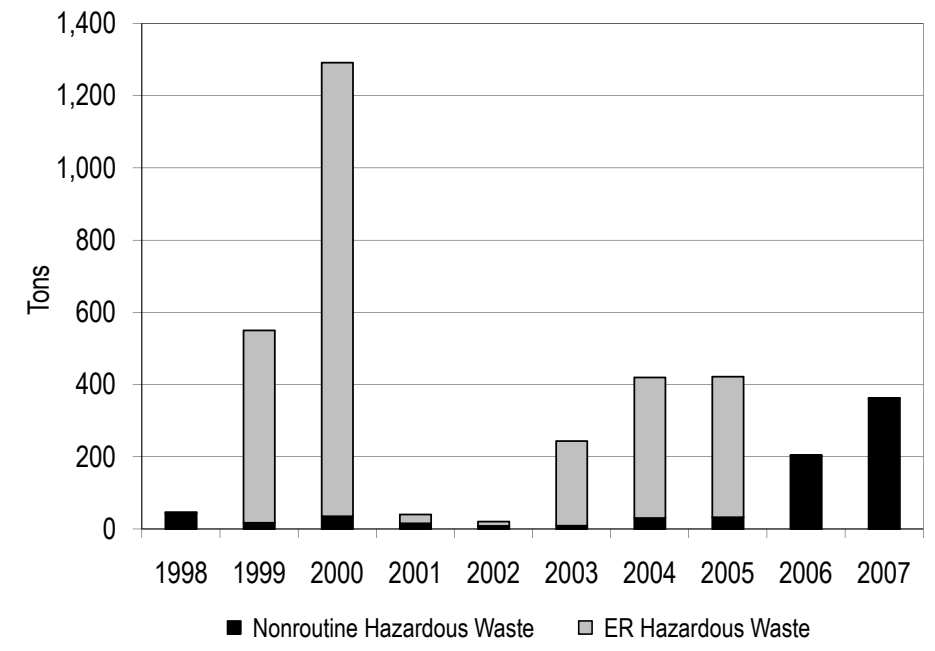

Figure 2-1d. Hazardous Waste Generation from ER and Nonroutine Operations, 1998 - 2007.

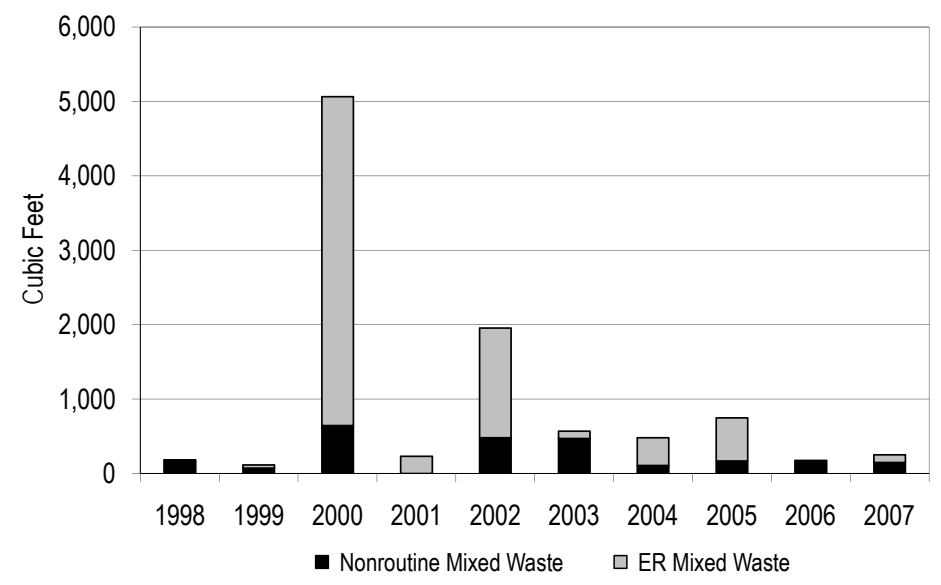

Figure 2-1e. Mixed Waste Generation from ER and Nonroutine Operations, $1998-2007$.

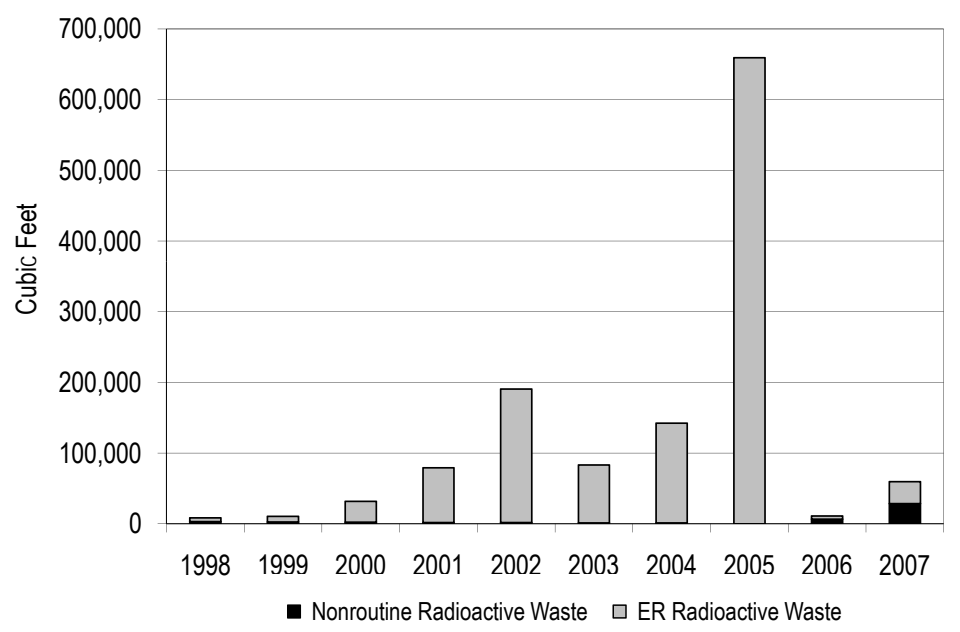

Figure 2-1f. Radioactive Waste Generation from ER and Nonroutine Operations, 1998 - 2007. prevention goals and policies, and represents an ongoing effort to make pollution prevention and waste minimization an integral part of the Laboratory's operating philosophy.

In January 2007, Executive Order 13423 was signed, establishing federal requirements for: energy efficiency and conservation, renewable energy, fleet management, electronic stewardship, water conservation, toxic chemical use reduction, recycling, sustainable buildings, and purchasing environmentally preferred products. These requirements will direct the future of BNL's P2 program and, as discussed below, most have already been incorporated within its program.

Pollution prevention and waste reduction goals have been incorporated into the DOE contract with BSA, into BNL's ESSH Policy, and into the Performance Evaluation Management Plan associated with the Laboratory's operating contract with BSA. Key elements of the P2 Program include:

- Eliminate or reduce emissions, effluents, and waste at the source where possible, and ensure that they are "as low as reasonably achievable" (i.e., uphold the E-ALARA policy)

- Procure environmentally preferable products (known as "affirmative procurement”)

- Conserve natural resources and energy

- Reuse and recycle materials

- Achieve or exceed BNL/ DOE waste minimization, $\mathrm{P} 2$, recycling, and affirmative procurement goals 
- Comply with applicable requirements (e.g., New York State Hazardous Waste Reduction Goal, Executive Orders, etc.)

- Reduce waste management costs

- Identify funding mechanisms for evaluating and implementing P2 opportunities

- Implement P2 projects

- Improve employee and community awareness of P2 goals, plans, and progress

Nineteen P2 proposals were submitted to the BNL P2 Council for funding in fiscal year 2007. Six proposals were funded, for a combined investment of slightly less than $\$ 10,000$. The anticipated annual savings from these projects is estimated at $\$ 38,218$, for an average payback period of less than 1 year.

The BNL P2 and recycling programs have achieved significant reductions in waste generated by routine operations, as shown in Figures 2-1a through $2-1 c$. This continues a positive trend and is further evidence that pollution prevention planning is well integrated into the Laboratory's work planning process. These positive trends are also driven by the EMS emphasis on preventing pollution and establishing objectives and targets to reduce environmental impacts.

Table 2-2 describes the P2 projects implemented through 2007 and provides the number of pounds of materials reduced, reused, or recycled, as well as the estimated cost benefit of each project.

The implementation of pollution prevention opportuni-

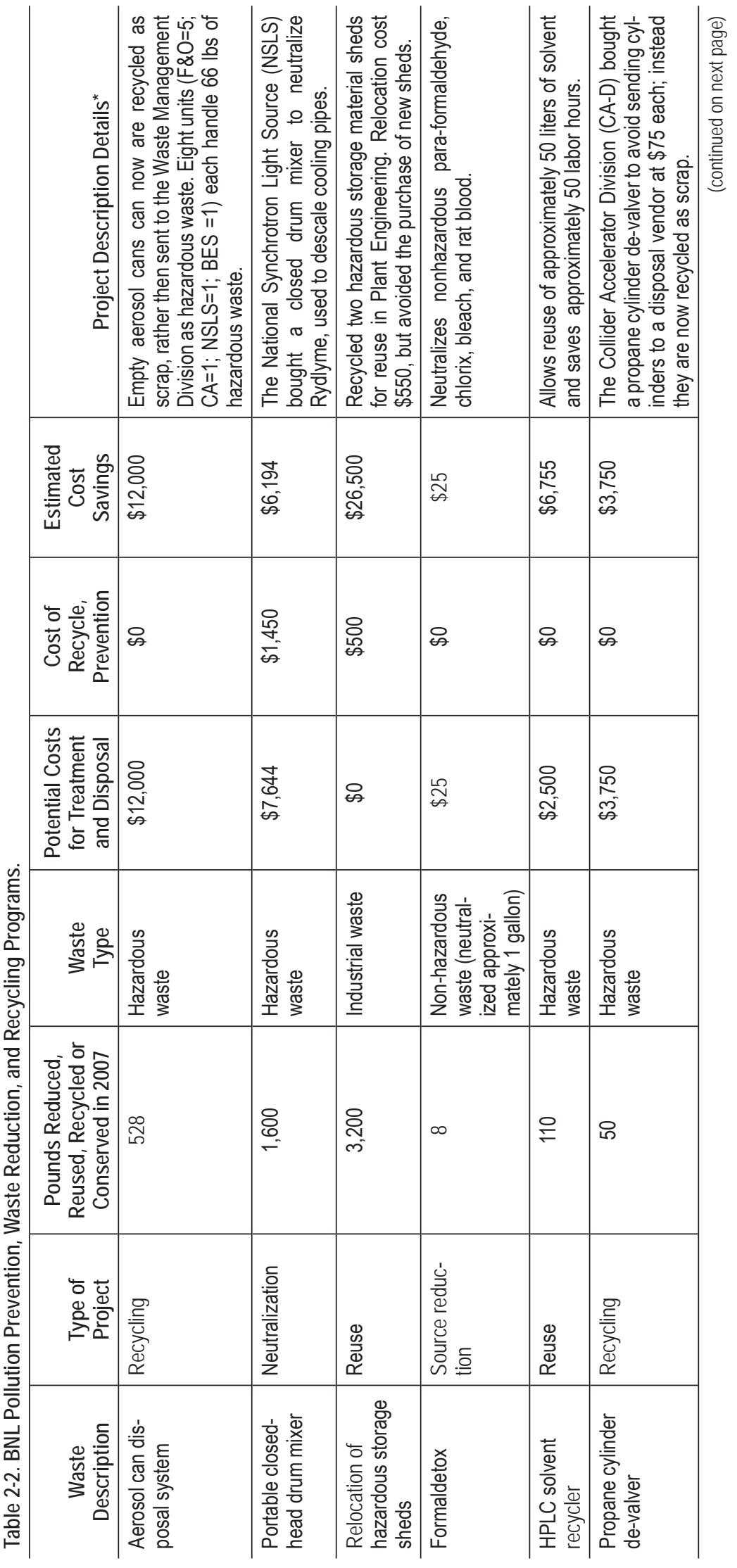


CHAPTER 2: ENVIRONMENTAL MANAGEMENT SYSTEM

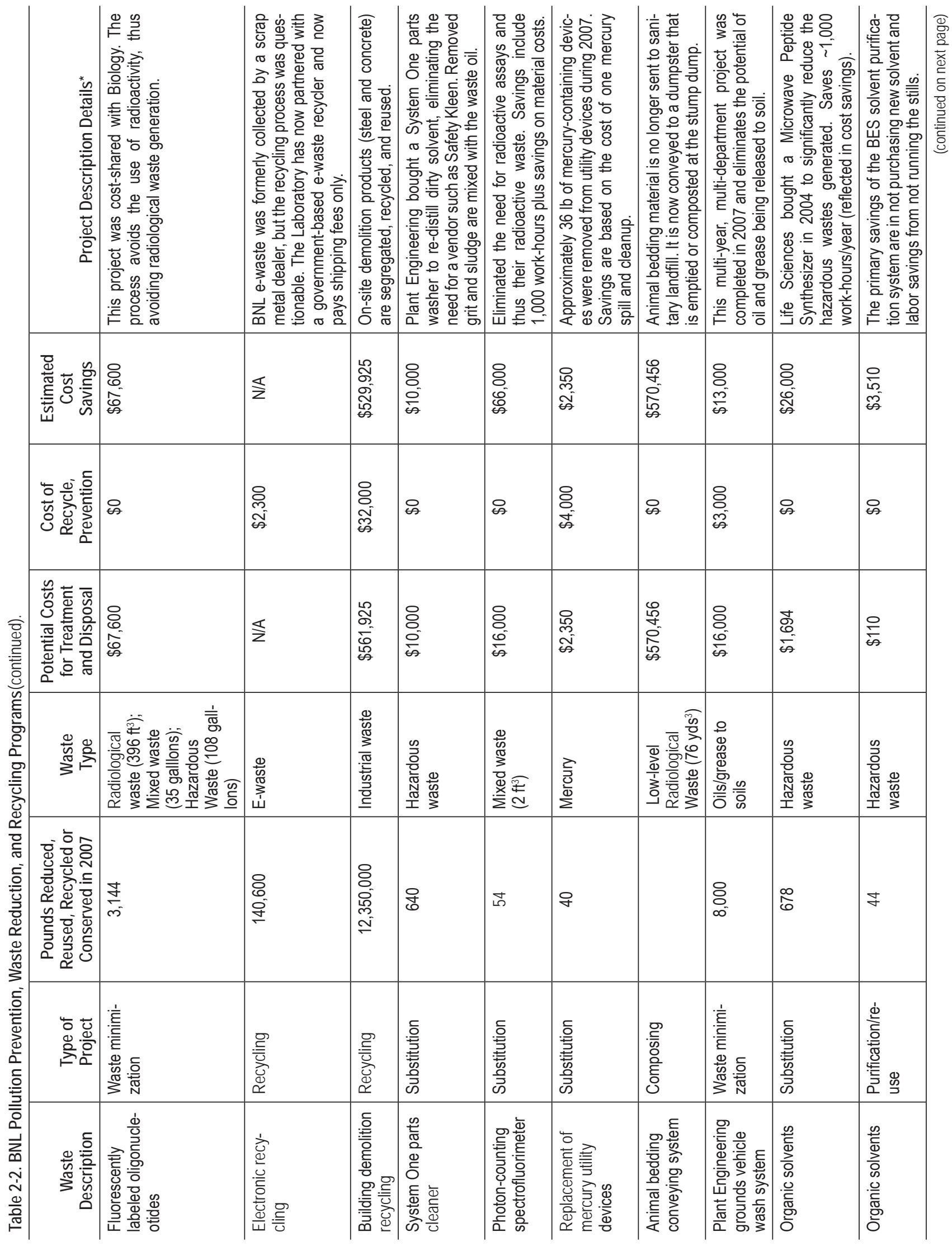


CHAPTER 2: ENVIRONMENTAL MANAGEMENT SYSTEM

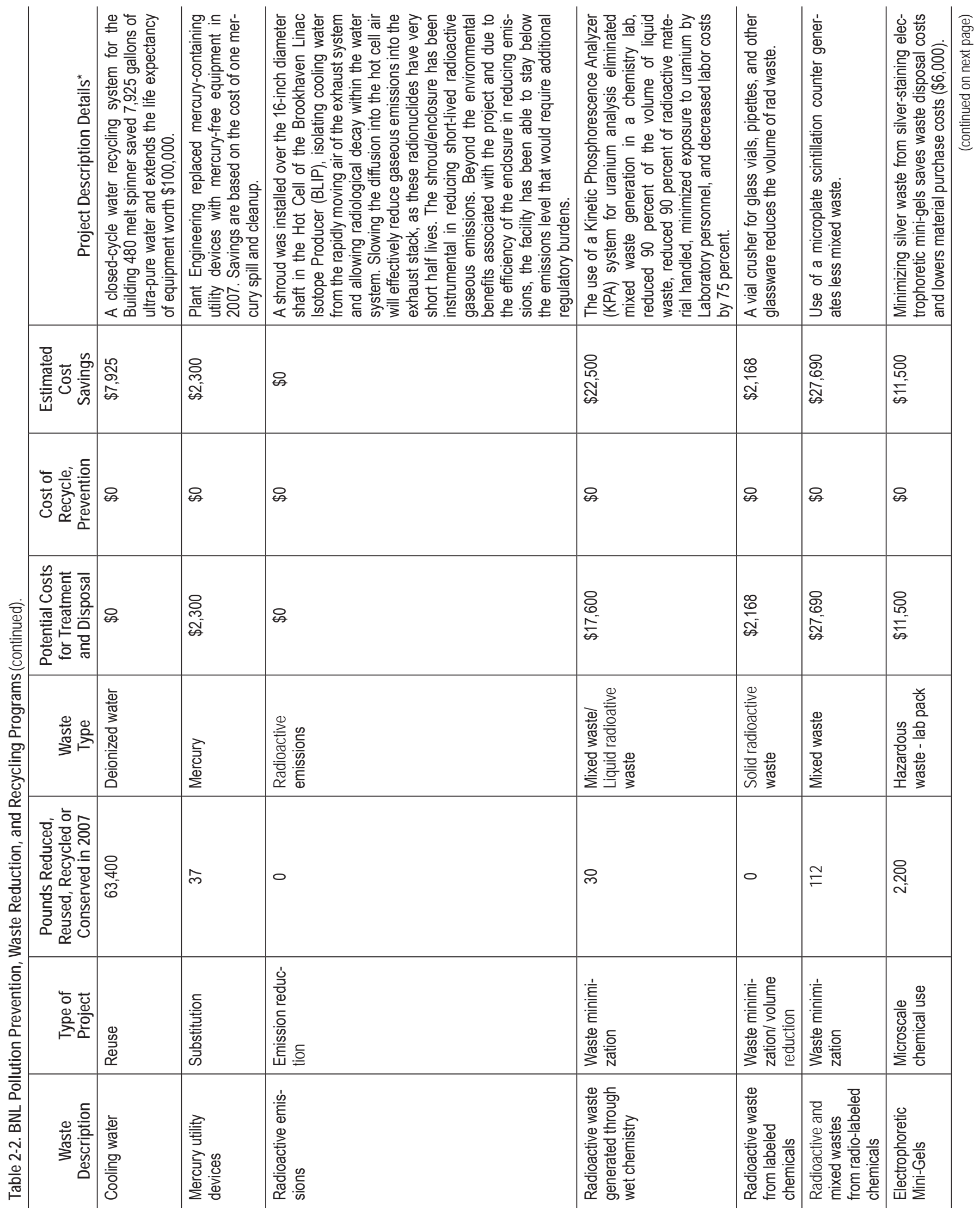




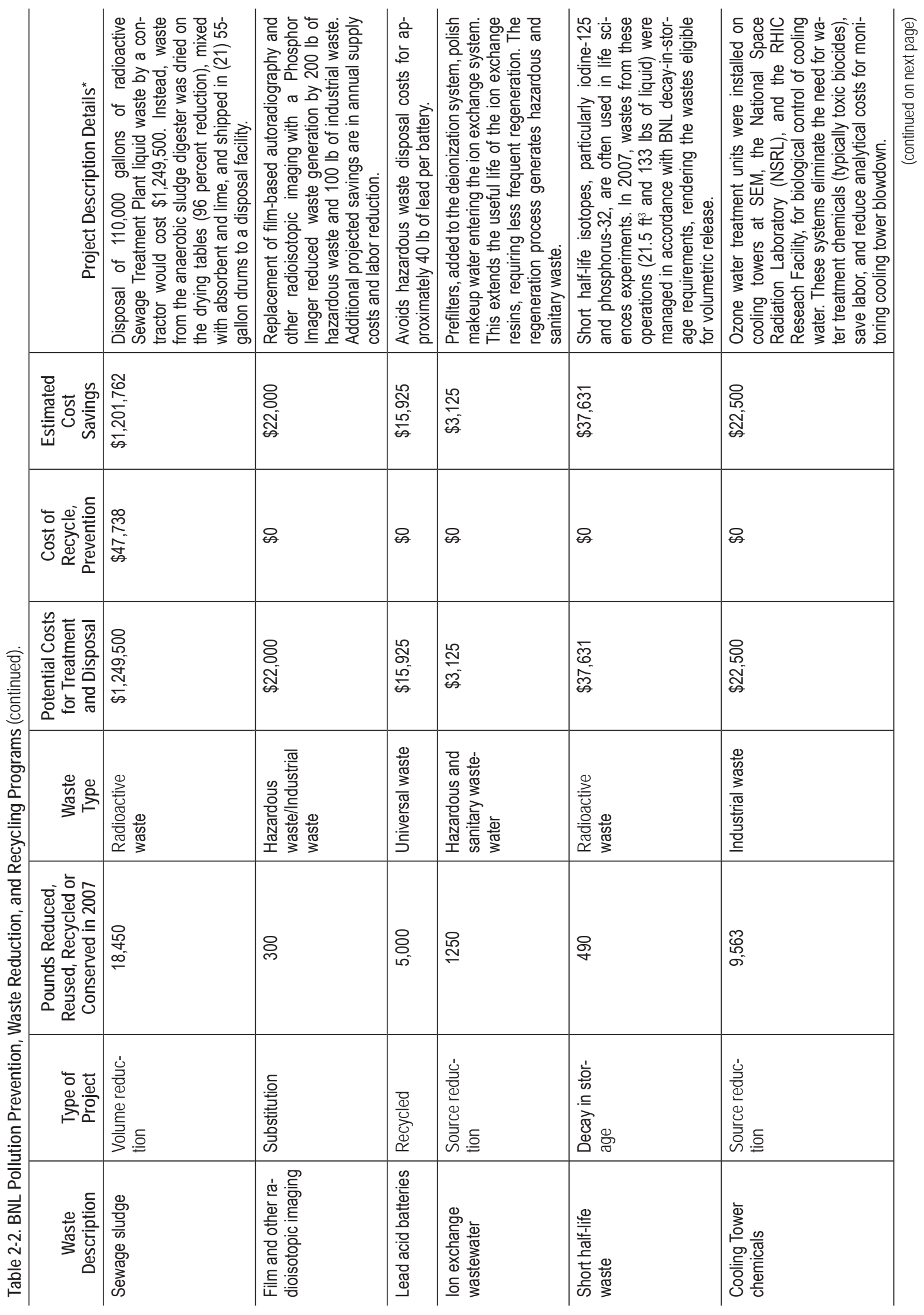




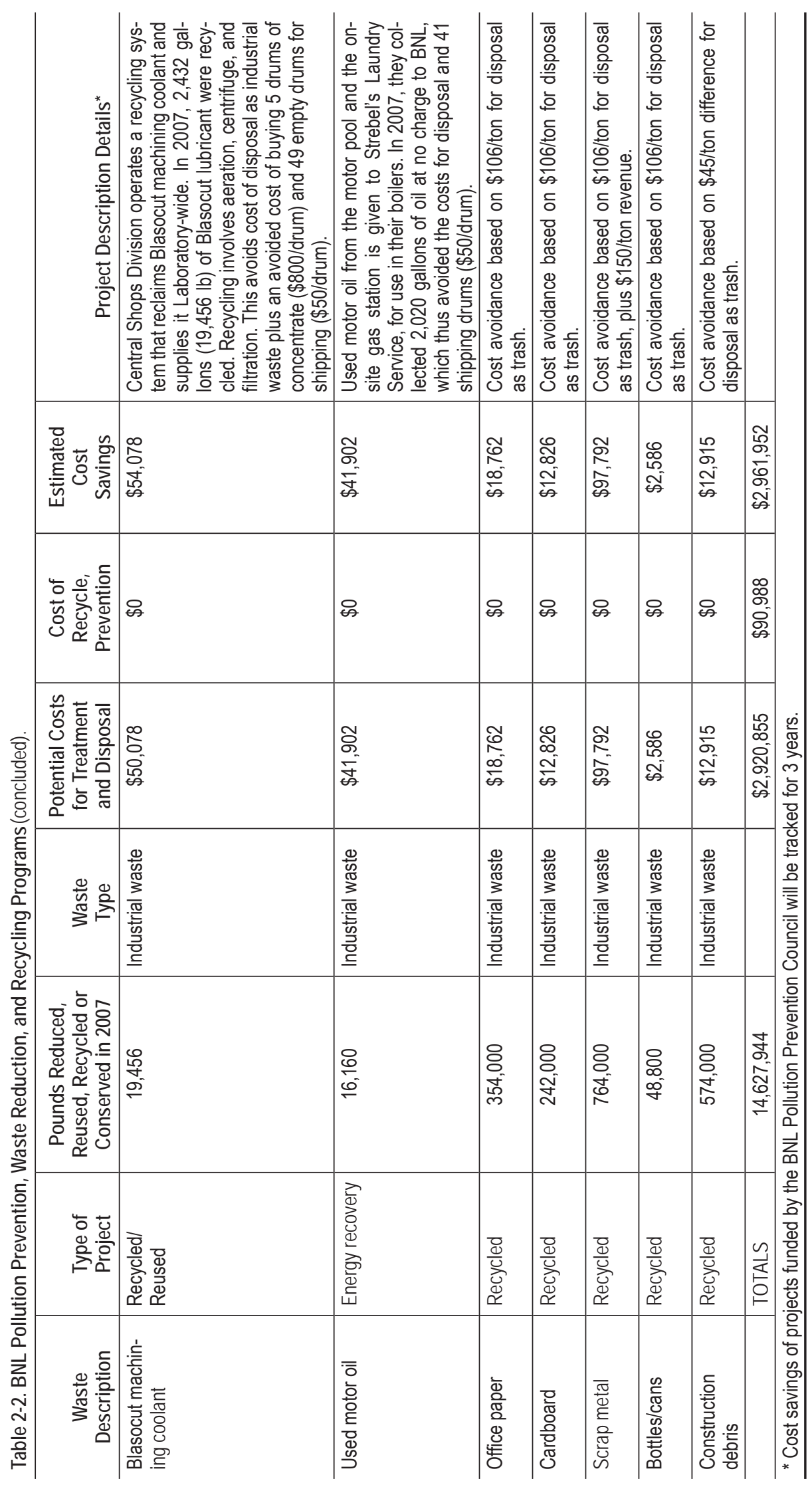

ties, recycling programs, and conservation initiatives has significantly reduced both waste volumes and management costs. In 2007, these efforts resulted in more than \$2.9 million in cost avoidance or savings and approximately 14.6 million pounds of materials being reduced, recycled, or reused.

The Laboratory also has an active and successful solid waste recycling program, which involves all employees. In 2007, BNL collected more than 175 tons of office paper for recycling. Cardboard, bottles and cans, construction debris, motor oil, scrap metals, lead, automotive batteries, electronic scrap, fluorescent light bulbs, drill press machine coolant, and antifreeze were also recycled. Table 2-3 shows the total number of tons (or units) of the materials recycled in 2007.

\subsubsection{Water Conservation}

BNL's water conservation program has achieved dramatic reductions in water use since the mid 1990s. The Laboratory continually evaluates water conservation as part of facility upgrades or new construction initiatives. These efforts include more efficient and expanded use of chilled water for cooling and heating/ventilation and air conditioning (HVAC) systems, and reuse of oncethrough cooling water for other systems such as cooling towers. The goal is to reduce the consumption of potable water and reduce the possible impact of clean water discharges on 


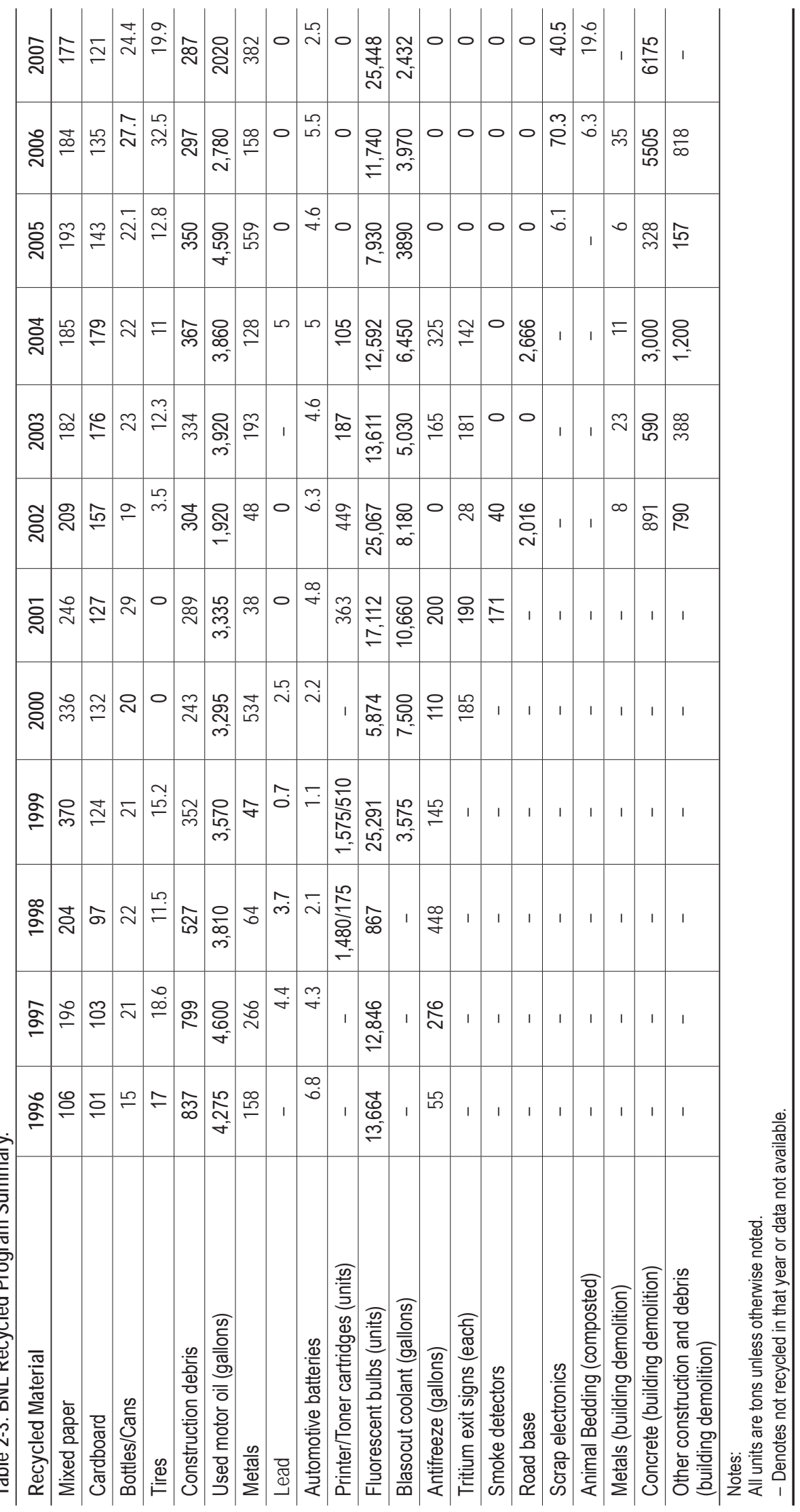

Sewage Treatment Plant (STP) operations. Figure 2-2 shows the 10-year trend of water consumption. In 2007, BNL reduced its water use by more than 11 percent, compared to the previous year. In each of the past 4 years, the water consumption total was less than half the 1998 total—a reduction of nearly a half-billion gallons per year.

\subsubsection{Energy Management and Conservation}

Since 1979, the Laboratory's Energy Management Group has been working to reduce energy use and costs by identifying cost-effective, energyefficient projects, monitoring energy use and utility bills, and assisting in obtaining the least expensive energy sources possible. The group is responsible for developing, implementing, and coordinating BNL's Energy Management Plan and assisting DOE in meeting the energy goals in DOE Order 430.2B and the Secretary's Transformational Energy Action Management (TEAM) initiative.

The Laboratory has more than 4 million square feet of building space. Many BNL scientific experiments use particle beams generated and accelerated by electricity, with the particles controlled and aligned by large electromagnets. In 2007, the Laboratory used approximately 233 million kilowatt hours $(\mathrm{kWh})$ of electricity, 3 million gallons of fuel oil, 36 thousand gallons of propane, and 163 million $\mathrm{ft}^{3}$ of natural gas. Fuel oil and 


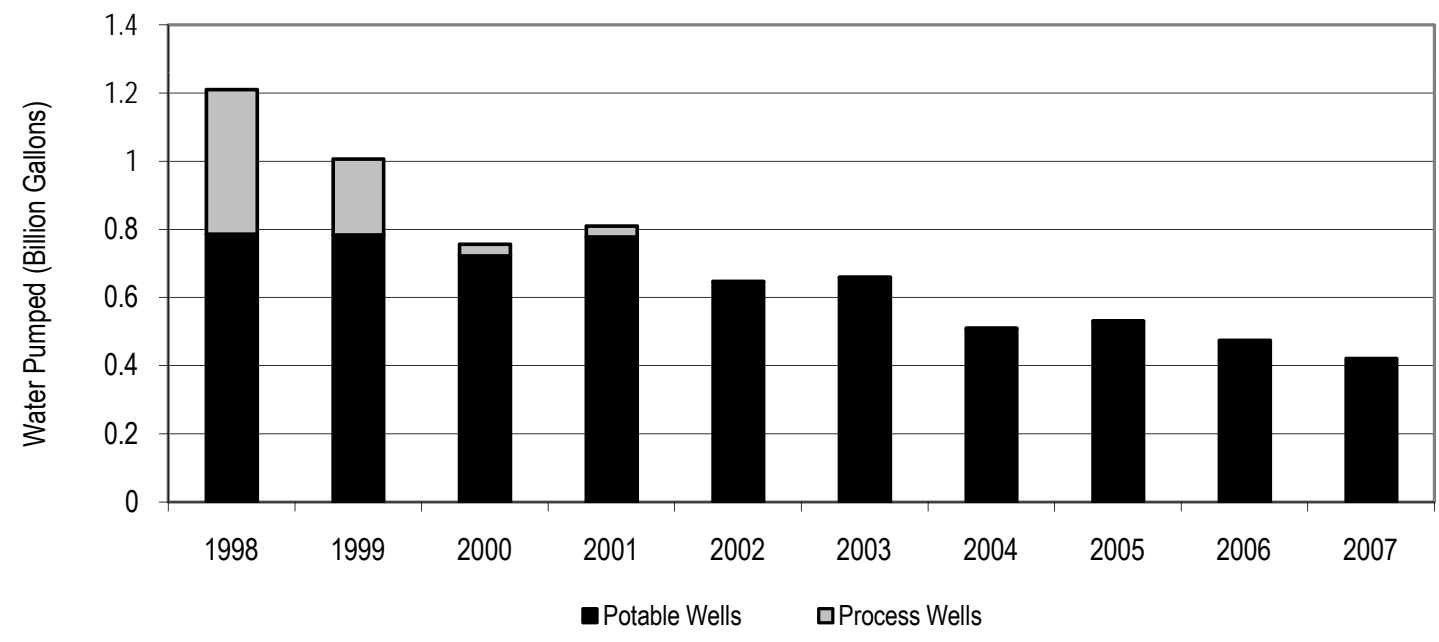

Figure 2-2. BNL Water Consumption Trend, 1998-2007.

natural gas produce steam at the Central Steam Facility (CSF). Due to market conditions, fuel oil and natural gas were used whenever each respective fuel was least expensive. Additional information on natural gas and fuel oil use can be found in Chapter 4 .

BNL is a participant in the New York Independent System Operator (NYISO) Special Case Resource (SCR) Program, which is an electric load reduction curtailment program. Through this program, the Laboratory has agreed to reduce electrical demand during critical days throughout the summer when NYISO expects customer demand to meet or exceed the available supply. In return, BNL receives a rebate for each megawatt reduced on each curtailment day. No curtailment days were requested in 2007, in part due to mild weather. However, mere participation in this program produced a rebate of $\$ 55,000$. The Laboratory continues to keep electric loads at a minimum during the summer, by scheduling operations at RHIC to avoid peak demand periods. This scheduling allowed BNL to save nearly \$4 million in electric costs in 2007 and greatly helps maintain the reliability of the Long Island Power Authority (LIPA) electric system to meet all of its users' needs.

BNL also maintains a contract with the New York Power Authority (NYPA) that resulted in an overall cost avoidance of \$20.4 million in 2007. The Laboratory will continue to seek alternative energy sources to meet its future en- ergy needs, support federally required "green" initiatives, and reduce energy costs. In 2007, the Laboratory purchased a portion of "green energy" for the newly constructed Research Support Building, avoiding 265,000 lbs of $\mathrm{CO}_{2}$. In addition, biofuels were used in several applications.

In 2007, a solar heating system for the BNL swimming pool began operation. This small project was the first step toward meeting the Laboratory's energy needs with renewable sources. To reduce energy use at non-research facilities, other activities also were undertaken in 2007. These activities included:

- The process was begun for a site-wide Energy Savings Performance Contract (ESPC) audit that will strive to reduce energy usage throughout the Laboratory. This is still in the preliminary evaluation stage, but BNL anticipates significant energy savings from this effort.

- 25 MW of demand was rescheduled to avoid coinciding with the utility summer peak, saving several million dollars in electricity charges.

- \$30,000 in Federal Energy Management Program funding was obtained to demonstrate a solar hot water combination system at the Brookhaven Center.

- Work continued in the replacment of aging, inefficient T-40 fluorescent lighting fixtures with new, efficient T-8 and T-5 units; two to three hundred fixtures are typically replaced annually, saving tens of thousands 


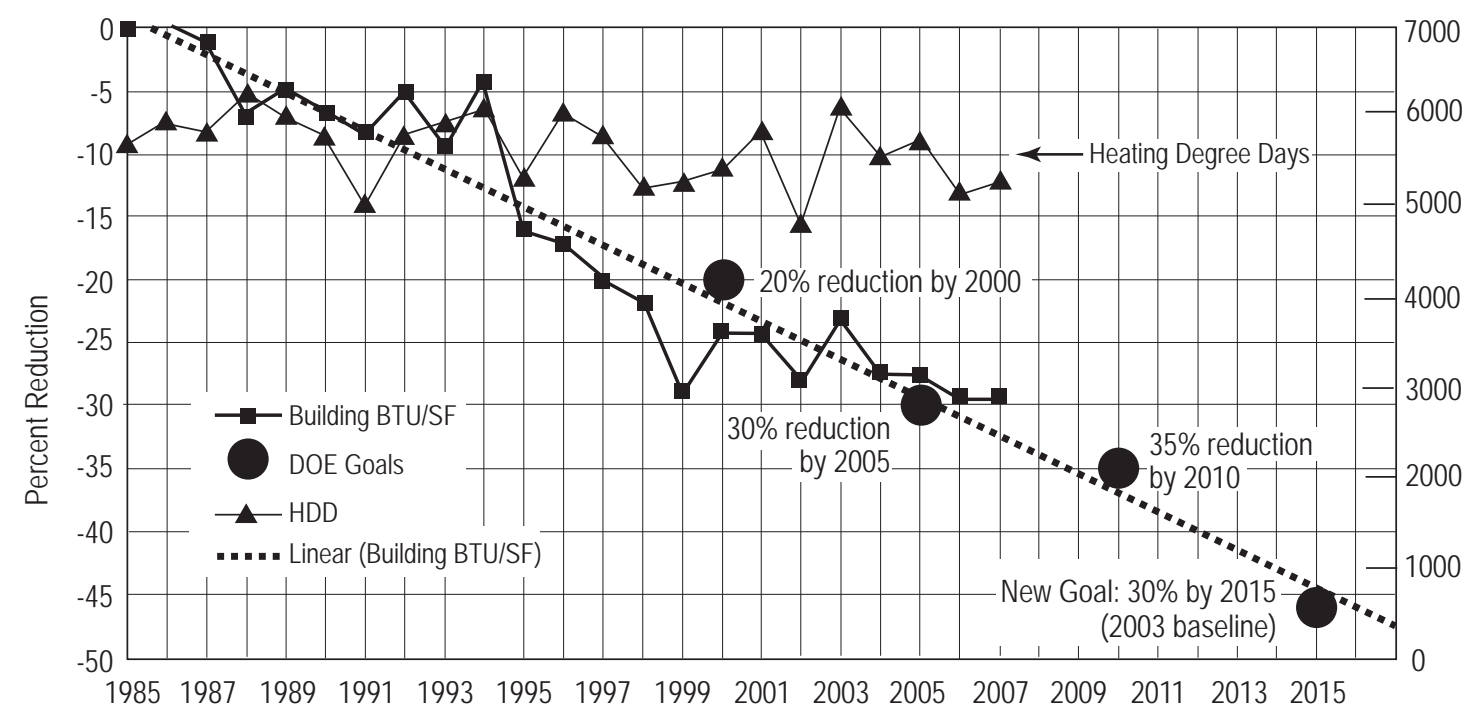

Figure 2-3. BNL Building Energy Performance, 1998-2010.

of kWhs and reducing costs by several thousand dollars.

- Due to aggressive conservation in various buildings, BNL's overall facilities energy usage for FY07 was approximately 8.3 percent less than in FY05, saving over \$1.2 million.

- Water consumption for FY07 was 53 million gallons less than in FY06, saving approximately $\$ 20,000$ in operational costs.

- Efficient fuel purchasing strategies (buying and storing oil and burning the least expensive fuel) saved $\$ 420,000$, compared to purchasing only oil as it is consumed.

- The Laboratory's Research Support Building was completed and received a Leadership in Energy and Environmental Design (LEED) silver certification.

- The Center for Functional Nanomaterials was completed, and is also expected to receive LEED silver certification.

- Nearly 25,000 gge (gasoline gallon equivalents) of natural gas were used in place of gasoline for the Laboratory's vehicle fleet.

The National Energy Conservation Policy Act, as amended by the Federal Energy Management Improvement Act of 1988 and the Energy Policy Acts of 1992 and 2005, requires federal agencies to apply energy conservation measures and to improve federal building design to reduce energy consumption per square foot. Current goals are to reduce energy consumption per square foot, relative to 2003, by 2 percent per year from FY06 - FY15. In 2007, an Executive Order increased the target reduction to 3 percent per year, which is a 30 percent reduction by the end of FY2015. Further, DOE Order 430.2B and the Secretary's TEAM initiative have set even more stringent requirements, including renewable energy and transportation fuels that go significantly beyond the previous goal of a 30 percent reduction by 2005, compared to 1985 . BNL's energy use per square foot in 2007 was 29.4 percent less than in 1985 (see Figure 2-3) and 8.3 percent less than 2003. It is important to note that energy use for buildings and facilities at the Laboratory is largely weather dependent.

\subsubsection{Natural and Cultural Resource Management Programs}

BNL continues to enhance its Natural Resource Management Program in cooperation with the Foundation for Ecological Research in the Northeast (FERN) and the Upton Ecological and Research Reserve. The Laboratory also continues to enhance its Cultural Resource Management Program. A BNL Cultural Resource Management Plan has been developed to identify and manage properties that are determined to be eligible or potentially eligible for inclusion on the National Register of Historic Places. See Chapter 6 for further information about these programs. 


\subsubsection{Environmental Restoration}

The Comprehensive Environmental Response, Compensation and Liability Act (CERCLA), commonly known as Superfund, was enacted by Congress in 1980. As part of CERCLA, EPA established the National Priorities List, which identifies sites where cleanup of past contamination is required. BNL was placed on the list with 27 other Long Island sites, 12 of which are in Suffolk County.

Each step of the CERCLA cleanup process is reviewed and approved by DOE, EPA, and NYSDEC, under an Interagency Agreement (IAG) contract. This agreement was formalized in 1992. Although not a formal signatory of the IAG, the Suffolk County Department of Health Services (SCDHS) also plays a key role in the review process. Most of the contamination at the Laboratory is associated with past accidental spills and outmoded practices for handling, storing, and disposing of chemical and radiological material.

BNL follows the CERCLA process, which includes the following steps:

- Conduct a Remedial Investigation to characterize the nature and extent of contamination and assess the associated risks

- Prepare a Feasibility Study and Proposed Plan to identify and evaluate remedial action alternatives and present the proposed best alternative

- Issue a Record of Decision (ROD), which is the remedy/corrective action agreed to by DOE, EPA, and NYSDEC

- Perform the Remedial Design/Remedial Action, which includes final design, construction specifications, and carrying out the remedy selected

In 2007, work planning continued for the Brookhaven Graphite Research Reactor (BGRR) decommissioning project. In accordance with the requirements of $10 \mathrm{CFR}$ 830, BNL completed the development of the Documented Safety Analysis (DSA), which was approved by DOE. The DSA is a critical document for the BGRR pile removal. Other progress related to the BGRR project included finalizing the Remedial Design/Remedial Action (RD/RA) Work Plan for the graphite pile removal, the development and regulatory review of the RD/RA Work Plans for removal of the biological shield and installation of an engineered cap.

Progress associated with the High Flux Beam Reactor (HFBR) decommissioning project in 2007 included: finalization of the HFBR Feasibility Study describing remedial alternatives and presenting a comparative analysis of the alternatives; working with regulators to finalize the Proposed Remedial Action Plan (PRAP); and preparations for the commencement of the public comment period for the PRAP, including two information sessions and a public meeting.

A final Action Memorandum was issued for the removal action involving the cleanup of the Waste Loading Area (WLA). The WLA is an area along the eastern boundary of the former Hazardous Waste Management Facility (HWMF). The remediation of this area (approximately two acres) was transferred to the HFBR project scope in 2005. Cleanup of the WLA using the dose-based cleanup goal and methodology specified for the former HWMF in the Operable Unit I ROD began in 2007.

The productive operation and maintenance (O\&M) of the Laboratory's groundwater treatment systems removed approximately 200 pounds of solvents and $5 \mathrm{mCi}$ of Strontium-90 (Sr-90) from the sole source aquifer in 2007. Since the operation of the first treatment system in 1996, a cumulative total of approximately 5,900 pounds of solvents and $17 \mathrm{mCi}$ of Sr-90 have been cleaned-up. Other progress included the installation of four additional extraction wells to supplement the existing 57 wells to ensure that all cleanup objectives will be met. Post-cleanup monitoring of the Peconic River surface water, sediment, fish, and wetland vegetation continued with the issuance of an Annual Monitoring Report. The groundwater systems operate in accordance with the O\&M manuals, while the Peconic and surface soil cleanup areas are monitored via the OU I Soils and OU V Long-Term Monitoring and Maintenance Plan. Institutional controls are also monitored and maintained for the cleanup areas in accordance with the RODs to help ensure the remedies remain protective. An annual 
evaluation of these controls is submitted to the regulators.

Following the resolution of public comments, a ROD was signed for the g-2 Tritium Source Area and Groundwater Plume, the Brookhaven Linac Isotope Producer (BLIP), and the Former Underground Storage Tanks area. Table 2-4 provides a description of each operable unit and a summary of environmental restoration actions taken. See Chapter 7 and SER Volume II, Groundwater Status Report, for further details.

\subsubsection{EPA Performance Track Program}

BNL was accepted into the EPA's Performance Track (PTrack) Program in 2004.

This program recognizes top environmental performance among participating U.S. facilities of all types, sizes, and complexity, both public and private. It is considered the "gold standard" for facility-based environmental performance-a standard that participating members strive to attain as they "meet or exceed their performance commitment." Under this program, partners provide leadership in many areas, including preventing pollution at its source. The PTrack Program requires that sites commit to several improvement goals for a 3-year period and report on the progress of the goals annually. In 2007, BNL completed its first set of goals under the PTrack program. Below are brief descriptions of the goals and their progress.

Table 2-4. Summary of BNL 2007 Environmental Restoration Activities.

\begin{tabular}{|c|c|c|}
\hline Project & Description & Environmental Restoration Program Actions \\
\hline Soil Projects & $\begin{array}{l}\text { Operable Unit (OU) I } \\
\text { OU II } \\
\text { OU VII }\end{array}$ & $\begin{array}{l}\text { - Performed monitoring and maintenance of institutional controls for cleanup areas. An annual evaluation } \\
\text { of compliance with the controls was submitted to the regulators. } \\
\text { - Initiated remediation of radiologically-contaminated soil at the Waste Loading area, including rail ship- } \\
\text { ments for disposal. }\end{array}$ \\
\hline \multirow[t]{4}{*}{$\begin{array}{l}\text { Groundwater } \\
\text { Projects }\end{array}$} & OU III & $\begin{array}{l}\text { - Continued operations of } 14 \text { groundwater treatment systems that treat volatile organic compounds } \\
\text { (VOCs) and strontium-90 (Sr-90). } \\
\text { - Four groundwater treatment systems continued pulse pumping due to low VOC concentrations in the } \\
\text { groundwater near the pumping wells. } \\
\text { - One groundwater treatment system and } 11 \text { individual extraction wells were placed in standby mode. } \\
\text { - Due to the detection of hexavalent chromium above the standard in a localized area at the Building } 96 \\
\text { VOC plume, a design modification for one of the pumping wells was submitted to regulators for treat- } \\
\text { ment of chromium using ion exchange resin. A State Pollutant Discharge Elimination System (SPDES) } \\
\text { Equivalency Permit for the planned discharge of the treated effluent was issued by the New York State } \\
\text { Department of Environmental Conservation (NYSDEC). Preparation of an alternative evaluation to } \\
\text { address the high level of VOCs in the silt zone was initiated. One Building } 96 \text { groundwater treatment } \\
\text { system extraction well was placed back into service. } \\
\text { - Continued monitoring of the High Flux Beam Reactor (HFBR) tritium plume. As a result of triggering the } \\
\text { contingency at Weaver Drive in late } 2006 \text { with a detection of tritium above the } 20,000 \text { pCi/L drinking } \\
\text { water standard, a fourth groundwater extraction well was installed and began operation in late } 2007 . \\
\text { - Based on preliminary groundwater modeling of recent Sr-90 concentrations in the Waste Concentration } \\
\text { Facility (WCF) plume, it was determined that several additional extraction wells will be necessary in } \\
\text { order to achieve the cleanup goals. } \\
\text { - Installed and began operation of two additional extraction wells for the Sr-90 Chemical Holes plume, } \\
\text { and one additional extraction well for the Airport plume. } \\
\text { - Following concurrence from NYSDEC, the Record of Decision (ROD) for the g-2 Tritium Groundwater } \\
\text { Plume, the Brookhaven LINAC Isotope Producer (BLIP), and former Underground Storage Tanks } \\
\text { Proposed Remedial Action Plan was signed by DOE and EPA. } \\
\text { - During } 2007,1.2 \text { billion gallons of groundwater were treated and } 198 \text { pounds of VOCs were removed. } \\
\text { Since the first groundwater treatment system started operating in December } 1996, \text { approximately } \\
5,900 \text { pounds of VOCs have been removed from more than } 12.8 \text { billion gallons of groundwater. }\end{array}$ \\
\hline & OU IV & - Continued groundwater monitoring. \\
\hline & OU VI & $\begin{array}{l}\text { - Continued operation of a groundwater treatment system to treat ethylene dibromide that has migrated } \\
\text { beyond BNL property in Manorville. }\end{array}$ \\
\hline & $\begin{array}{l}\text { Groundwater } \\
\text { Monitoring }\end{array}$ & $\begin{array}{l}\text { - Completed the BNL } 2007 \text { Groundwater Status Report. } \\
\text { - Collected and analyzed 2,289 groundwater samples from } 850 \text { monitoring wells. } \\
\text { - Updated the Environmental Monitoring Plan. }\end{array}$ \\
\hline
\end{tabular}


Table 2-4. Summary of BNL 2007 Environmental Restoration Activities (concluded).

\begin{tabular}{|c|c|c|}
\hline Project & Description & Environmental Restoration Program Actions \\
\hline Peconic River & OU V & $\begin{array}{l}\text { - Performed second year of long-term post-cleanup monitoring of Peconic River surface water, sedi- } \\
\text { ment, fish, and wetland vegetation (including phragmities removal). } \\
\text { - Issued Final } 2006 \text { Peconic River Monitoring Report and submitted the draft } 2007 \text { report to regulators } \\
\text { for review. }\end{array}$ \\
\hline \multirow[t]{3}{*}{ Reactors } & $\begin{array}{l}\text { Brookhaven Graphite } \\
\text { Research Reactor } \\
\text { (BGRR) }\end{array}$ & $\begin{array}{l}\text { - Completed Graphite Pile inspections. } \\
\text { - Detailed Planning for Graphite Pile and Bioshield removal. } \\
\text { - Documented Safety Analysis and Technical Safety Requirements approved by DOE. } \\
\text { - Completed Building } 701 \text { preparatory work including: overhaul of overhead crane; high-bay ventilation } \\
\text { - system modification; and perimeter fencing installation. } \\
\text { - Awarded contract for Graphite Pile and BioShield removal in December } 2007 .\end{array}$ \\
\hline & $\begin{array}{l}\text { High Flux Beam } \\
\text { Reactor (HFBR) }\end{array}$ & $\begin{array}{l}\text { - Continued long-term surveillance and maintenance activities. } \\
\text { - Installed Building } 750 \text { leak detection system. } \\
\text { - Removed combustible material from reactor building in accordance with Fire Hazards Analysis recom- } \\
\text { mendations. } \\
\text { - Developed revised Nuclear Safety Basis documentation and submitted to DOE. } \\
\text { - Commenced remediation of the Waste Loading area. } \\
\text { - Commenced detailed planning for the removal and disposal of the control rod blades and beam plugs. }\end{array}$ \\
\hline & $\begin{array}{l}\text { Brookhaven Medical } \\
\text { Research Reactor } \\
\text { (BMRR) (Project } \\
\text { managed by the BNL } \\
\text { Environmental and } \\
\text { Waste Management } \\
\text { Services Division) }\end{array}$ & $\begin{array}{l}\text { - Continued surveillance and maintenance activities at the BMRR. } \\
\text { - Planned for the removal of the resin vessels from the primary coolant water purification system. }\end{array}$ \\
\hline $\begin{array}{l}\text { Buildings } \\
810 / 811\end{array}$ & $\begin{array}{l}\text { Radiological Liquid } \\
\text { Processing Facility }\end{array}$ & - Removed and disposed of two inactive above-ground 25,000-gal radioactive liquid storage tanks. \\
\hline Building 801 & $\begin{array}{l}\text { Inactive Radiological } \\
\text { Liquid Holdup Facility }\end{array}$ & - Removed piping containing mercury from outlet of two inactive radiological liquid holdup tanks. \\
\hline Building 650 & $\begin{array}{l}\text { Inactive Radiological } \\
\text { Decon Facility }\end{array}$ & $\begin{array}{l}\text { - Removed lead melter, contaminated glove boxes, contaminated water in drains, and contaminated HVAC } \\
\text { ductwork. Pumped standing water and scraped contaminated sludge from the floor of the basement. }\end{array}$ \\
\hline
\end{tabular}

- Increase BNL's land and habitat conservation. BNL surpassed its original goal of 30 acres and recovered a total of 42 acres of land, including 15 acres recovered during a prescribed burn conducted in October 2006. Prescribed burns improve the health of the forest and allow for forest re-growth by removing dead vegetation, eliminating underbrush and leaf litter, and opening the forest floor to new growth. The Laboratory will continue its stewardship efforts by returning lands to their native states as opportunities arise, minimizing use of non-native vegetation in landscaping, and managing on-site wildlife.

- Reduce Radioactive Air Emissions. BNL continued to evaluate and reduce, where possible, radioactive air emissions from the BLIP. In total, emissions were reduced by 34 percent, surpassing the original goal of 30 percent. These efforts included construc- tion of a Lucite enclosure to retain evaporative losses from the target facility. In 2007, a barometric damper was installed to reduce the pressure differential across the target enclosure, which also reduces evaporative emissions. The effectiveness of this change will continue to be assessed.

- Reduce BNL's use of ozone-depleting substances (ODS), specifically Class I ODS. BNL surpassed its original goal by more than 5.5 tons of ODS by eliminating 35.5 tons of Class I ODS from 2003 through 2006. The Laboratory will continue to remove Class I and II refrigerants as obsolete $\mathrm{A} / \mathrm{C}$ and refrigeration systems are replaced.

- Reduce BNL's hazardous materials use. BNL did not achieve its original goal of an 80 percent reduction in mercury inventory, primarily because the estimate of the amount of mercury in storage was high. By the end of 2006, 47 percent of the mercury 
inventory had been disposed. In 2007, the Laboratory continued to eliminate unneeded sources of mercury and achieved a 60 percent reduction by the end of the year. BNL will continue to remove and dispose of mercury, especially elemental mercury, as opportunities arise and as older projects close.

In April 2007, BNL reapplied for continued membership to the PTrack program. Four new goals were established and accepted: energy reduction, transportation energy reduction, reductions in toxic releases through effective biosolids management, and establishing an electronics procurement program focused on purchasing computers that are registered under the Electronic Procurement Environmental Assessment Tool.

\subsection{IMPLEMENTING THE ENVIRONMENTAL MANAGEMENT SYSTEM}

\subsubsection{Structure and Responsibility}

All employees at BNL have clearly defined roles and responsibilities in key areas, including environmental protection. Employees are required to develop their own Roles, Responsibilities, Accountabilities, and Authorities (R2A2) document to sign and be signed by two levels of supervision. BSA has clearly defined expectations for management and staff which must be included in this document. Under the BSA performance-based management model, senior management must communicate their expectation that all line managers and staff take full responsibility for their actions and be held accountable for ESSH performance. Environmental and waste management technical support personnel assist the line organizations with identifying and carrying out their environmental responsibilities. The Environmental Compliance Representative Program, initiated in 1998, is an effective means of integrating environmental planning and pollution prevention into the work planning processes of the line organizations. A comprehensive training program for staff, visiting scientists, and contractor personnel is also in place, thus ensuring that all personnel are aware of their ESSH responsibilities.

\subsubsection{Communication and Community Involvement}

Communication and community involvement are commitments under BNL's EMS. The Laboratory maintains relationships with its employees, key stakeholders, neighbors, elected officials, regulators, and other community members. The goals are to provide an understanding of BNL's science and operations, including environmental stewardship and restoration activities, and to incorporate community input in the Laboratory's decision making.

BNL staff participates in: on- and off-site meetings, which include discussions, talks, presentations, and roundtables; workshops; canvassing surrounding neighborhoods; Laboratory tours; and informal information sessions and formal public meetings held during public comment periods.

\subsubsection{Communication Forums}

To facilitate effective dialogue between BNL and key stakeholders, several forums for communication and involvement have been established:

- The Brookhaven Executive Roundtable (BER), established in 1997 by DOE's Brookhaven Site Office, meets routinely to update local, state, and federal elected officials and regulatory agencies on environmental and operational issues, as well as on scientific discoveries and initiatives.

- The Community Advisory Council (CAC), established by BNL in 1998, advises the Laboratory Director on issues related to the Laboratory that are important to the community. The CAC is composed of approximately 30 member organizations representing business, civic, education, employee, community, environmental, and health organizations. The CAC meets monthly in sessions that are open to the public, and sets its own agenda in cooperation with the Laboratory.

- BNL’s Envoy Program educates employee volunteers regarding Laboratory issues and provides a link to local community organizations. Feedback shared by envoys helps BNL gain a better understanding of local community concerns. 
- The Speakers’ Bureau provides speakers for educational and other organizations interested in the Laboratory.

- BNLs Summer Sunday tours enable the Laboratory to educate the public by featuring different facilities and program areas.

- The Laboratory participates in various annual events, such as a week-long celebration in honor of Earth Day, the Heckscher State Park Spring Festival, and the Longwood Fair.

- Lunchtime tours are held once a month and offer employees the opportunity to learn about activities outside the scope of their jobs.

- The Laboratory's research, history, and natural environment, as well as cleanup projects, have all been topics covered under BNL's lunchtime talks. Periodically, bag lunch meetings are held with employees on specific topics of interest or concern, such as health benefits or wildlife management.

- BNL issues press releases; publishes Laboratory Link, a bi-monthly update on BNL science and events; and the Bulletin, a weekly employee newsletter.

- The Laboratory maintains an informative website at http://www.bnl.gov, where these publications, as well as extensive information about BNL's science and operations, past and present, are posted. In addition, employees and the community can subscribe to the Laboratory's e-mail update service at http://lists.bnl.gov/mailman/ listinfo/bnl-announce-1.

\subsubsection{Community Involvement in Cleanup Projects}

In 2007, BNL stakeholders were updated on the progress of the environmental cleanup projects through presentations given at the monthly CAC and BER meetings, including:

- A presentation on the Laboratory's Annual Groundwater Report provided the CAC with information on the communication processes related to groundwater remediation, the protection and monitoring of the groundwater, the operational status of treatment systems, the progress toward achiev- ing cleanup goals, and proposed actions in response to monitoring data.

- The 2006 monitoring report on the Peconic River (OU V) was shared with the CAC in two detailed presentations. The presentations included data on sediment, surface water, fish, and wetlands sampling. It also included information on sampling, data evaluation, data transmission, and implementation of follow-up actions.

- As a follow-up to the comments provided in 2006 by the CAC on the Proposed Remedial Action Plan for the g-2 Tritium Source area and plume, the Laboratory briefed the CAC on how their comments and those received from other stakeholders were incorporated into the ROD.

- The CAC was updated periodically on the development of possible remedies for the decommissioning of the HFBR in an effort to provide them with up-to-date information when the final Proposed Remedial Action Plan was released.

- A presentation on the activities at the BGRR was given to the CAC. Work plans and schedules for removal of the pile, and preparatory activities including overhauling the overhead crane, removal of physical interferences, and identifying remote equipment, were discussed. A detailed description of an inspection of the pile and its findings was also provided.

Working closely with elected officials, regulatory agency representatives, community members, and employees, DOE and BNL openly shared information and provided feedback on how that input was used.

\subsubsection{Monitoring and Measurement}

The Laboratory monitors effluents and emissions to ensure the effectiveness of controls, adherence to regulatory requirements, and timely identification and implementation of corrective measures. BNL's Environmental Monitoring Program is a comprehensive, sitewide program that identifies potential pathways for exposure of the public and employees, evaluates what impact activities have on the environment, and ensures compliance with environmental per- 
mit requirements. The monitoring program is reviewed and revised, as necessary or on an annual basis, to reflect changes in permit requirements, changes in facility-specific monitoring activities, or the need to increase or decrease monitoring based on a review of previous analytical results.

As required under DOE Order 450.1, Environmental Protection Program, BNL prepares an Environmental Monitoring Plan, Triennial Update (BNL 2007), which outlines annual sampling goals by media and frequency. The plan uses the EPA Data Quality Objective approach for documenting the decisions associated with the monitoring program. In addition to the required triennial update, an annual electronic update is also prepared.
As shown in Table 2-5, in 2007 there were 8,632 sampling events of groundwater, potable water, precipitation, air, plants and animals, soil, sediment, and discharges under the Environmental Monitoring Program. Specific sampling programs for the various media are described further in Chapters 3 through 8.

The Environmental Monitoring Program addresses three components: compliance, restoration, and surveillance monitoring.

\subsubsection{Compliance Monitoring}

Compliance monitoring is conducted to ensure that wastewater effluents, air emissions, and groundwater monitoring data comply with regulatory and permit limits issued under the federal Clean Air Act, Clean Water Act, Oil

Table 2-5. Summary of BNL 2007 Sampling Program Sorted by Media.

\begin{tabular}{|c|c|c|}
\hline Environmental Media & $\begin{array}{l}\text { No. of } \\
\text { Sampling Events* }\end{array}$ & Purpose \\
\hline Groundwater & $\begin{array}{l}2,049 \mathrm{ER} \\
256 \mathrm{ES} / \mathrm{C}\end{array}$ & $\begin{array}{l}\text { Groundwater is monitored to evaluate impacts from past and present operations on groundwater } \\
\text { quality, under the Environmental Restoration, Environmental Surveillance, and Compliance sam- } \\
\text { pling programs. See Chapter } 7 \text { and SER Volume II, Groundwater Status Report for further detail. }\end{array}$ \\
\hline On-Site Recharge Basins & 71 & $\begin{array}{l}\text { Recharge basins used for wastewater and stormwater disposal are monitored in accordance with } \\
\text { discharge permit requirements and for environmental surveillance purposes. See Chapter } 5 \text { for } \\
\text { further detail. }\end{array}$ \\
\hline Potable Water & $\begin{array}{l}43 \mathrm{ES} \\
181 \mathrm{C}\end{array}$ & $\begin{array}{l}\text { Potable water wells and the BNL distribution system are monitored routinely for chemical and } \\
\text { radiological parameters to ensure compliance with Safe Drinking Water Act requirements. In ad- } \\
\text { dition, samples are collected under the Environmental Surveillance Program to ensure the source } \\
\text { of the Laboratory's potable water is not impacted by contamination. See Chapters } 3 \text { and } 7 \text { for } \\
\text { further detail. }\end{array}$ \\
\hline $\begin{array}{l}\text { Sewage Treatment Plant } \\
\text { (STP) }\end{array}$ & 439 & $\begin{array}{l}\text { The STP influent and effluent and several upstream and downstream Peconic River stations are } \\
\text { monitored routinely for organic, inorganic, and radiological parameters to assess BNL impacts. } \\
\text { The number of samples taken depends on flow. For example, samples are scheduled for collec- } \\
\text { tion at Station } \mathrm{HQ} \text { monthly, but if there is no flow, samples can not be collected. See Chapters } 3 \\
\text { and } 5 \text { for further detail. }\end{array}$ \\
\hline Precipitation & 16 & $\begin{array}{l}\text { Precipitation samples are collected from two locations to determine if radioactive emissions have } \\
\text { impacted rainfall, and to monitor worldwide fallout from nuclear testing. The data are also used, } \\
\text { along with wind speed, wind direction, temperature, and atmospheric stability to help model atmo- } \\
\text { spheric transport and diffusion of radionuclides. See Chapter } 4 \text { for further detail. }\end{array}$ \\
\hline Air - Tritium & 381 & $\begin{array}{l}\text { Silica gel cartridges are used to collect atmospheric moisture for subsequent tritium analysis. } \\
\text { These data are used to assess environmental tritium levels. See Chapter } 4 \text { for further detail. }\end{array}$ \\
\hline Air - Particulate & $\begin{array}{l}459 \text { ES/C } \\
53 \text { NYSDOH }\end{array}$ & $\begin{array}{l}\text { Samples are collected to assess impacts from BNL operations and to facilitate reporting of emis- } \\
\text { sions to regulatory agencies. Samples are also collected for the New York State Department of } \\
\text { Health Services (NYSDOH) as part of their program to assess radiological air concentrations } \\
\text { statewide. See Chapter } 4 \text { for further detail. }\end{array}$ \\
\hline Air - Charcoal & 53 & $\begin{array}{l}\text { Samples are collected to assess impacts from BNL operations and to facilitate reporting of emis- } \\
\text { sions to regulatory agencies. See Chapter } 4 \text { for further detail. }\end{array}$ \\
\hline Fauna & 144 & $\begin{array}{l}\text { Fish, deer, and small mammals are monitored to assess impacts on wildlife associated with past } \\
\text { or current BNL operations. See Chapter } 6 \text { for further detail. }\end{array}$ \\
\hline
\end{tabular}


Table 2-5. Summary of BNL 2007 Sampling Program Sorted by Media (concluded).

\begin{tabular}{|c|c|c|}
\hline Environmental Media & $\begin{array}{c}\text { No. of } \\
\text { Sampling Events* }\end{array}$ & Purpose \\
\hline Flora & 13 & $\begin{array}{l}\text { Vegetation is sampled to assess possible uptake of contaminants by plants and fauna, since } \\
\text { the primary pathway from soil contamination to fauna is via ingestion. See Chapter } 6 \text { for further } \\
\text { detail. }\end{array}$ \\
\hline Soils & 78 & $\begin{array}{l}\text { Soil samples are collected as part of the Natural Resource Management Program to assess fau- } \\
\text { nal uptake, during Environmental Restoration investigative work, during the closure of drywells } \\
\text { and underground tanks, and as part of preconstruction background sampling. }\end{array}$ \\
\hline Miscellaneous & 312 & $\begin{array}{l}\text { Samples are collected periodically from potable water fixtures and dispensers, manholes, spills, } \\
\text { to assess process waters, and to assess sanitary discharges. }\end{array}$ \\
\hline $\begin{array}{l}\text { Groundwater Treatment } \\
\text { Systems and Remediation } \\
\text { Monitoring }\end{array}$ & 2027 & $\begin{array}{l}\text { Samples are collected from groundwater treatment systems and as long-term monitoring after } \\
\text { remediation completion under the Comprehensive Environmental Response, Compensation, and } \\
\text { Liability Act program. The Laboratory has } 14 \text { operating groundwater treatment systems. See } \\
\text { Chapter } 7 \text { for details. }\end{array}$ \\
\hline Vehicle Monitor Checks & 248 & $\begin{array}{l}\text { Materials leaving the Laboratory pass through the on-site vehicle monitor that detects if radioac- } \\
\text { tive materials are present. Any radioactive material discovered is properly disposed of through the } \\
\text { Waste Management Program. The vehicle monitor is checked on a daily basis. }\end{array}$ \\
\hline $\begin{array}{l}\text { State Pollutant Discharge } \\
\text { Elimination System (SPDES) }\end{array}$ & 244 & $\begin{array}{l}\text { Samples are collected to ensure that the Laboratory complies with the requirements of the } \\
\text { New York State Department of Environmental Conservation (NYSDEC)- issued SPDES permit. } \\
\text { Samples are collected at the STP, recharge basins, and four process discharge sub-outfalls to } \\
\text { the STP. }\end{array}$ \\
\hline Flow Charts & 546 & $\begin{array}{l}\text { Flowcharts are exchanged weekly as part of BNL's SPDES permit requirements to report dis- } \\
\text { charge flow at the recharge basin outfalls. }\end{array}$ \\
\hline Floating Petroleum Checks & 110 & $\begin{array}{l}\text { Tests are performed on select petroleum storage facility monitoring wells to determine if floating } \\
\text { petroleum products are present. The number of wells and frequency of testing is determined } \\
\text { by NYSDEC licensing requirements (e.g., Major Petroleum Facility), NYSDEC spill response } \\
\text { requirements (e.g., Motor Pool area), or other facility-specific sampling and analysis plans. }\end{array}$ \\
\hline Radiological Monitor Checks & 661 & $\begin{array}{l}\text { Daily instrumentation checks are conducted on the radiation monitors located in Buildings } 569 \\
\text { and } 592 \text {. These monitors are located } 30 \text { minutes upstream and at the STP. Monitoring at these } \\
\text { locations allows for diversion of wastes containing radionuclides before they are discharged to } \\
\text { the Peconic River. }\end{array}$ \\
\hline $\begin{array}{l}\text { Quality Assurance/Quality } \\
\text { Control Samples (QA/QC) }\end{array}$ & 248 & $\begin{array}{l}\text { To ensure that the concentrations of contaminants reported in the Site Environmental Report are } \\
\text { accurate, additional samples are collected. These samples detect if contaminants are introduced } \\
\text { during sampling, transportation, or analysis of the samples. QA/QC samples are also sent to the } \\
\text { contract analytical laboratories to ensure their processes give valid, reproducible results. }\end{array}$ \\
\hline $\begin{array}{l}\text { Total number of sampling } \\
\text { events }\end{array}$ & 8632 & $\begin{array}{l}\text { The total number of sampling events includes all samples identified in the Environmental } \\
\text { Monitoring Plan (BNL 2007), as well as samples collected to monitor Environmental Restoration } \\
\text { projects, air and water treatment system processes, and by the Environmental and Waste } \\
\text { Management Services Division Field Sampling Team as special requests. The number does not } \\
\text { include samples taken by Waste Management personnel, waste generators, or Environmental } \\
\text { Compliance Representatives for waste characterization purposes. }\end{array}$ \\
\hline \multicolumn{2}{|c|}{$\begin{array}{l}\text { Notes: } \\
\text { *A sampling event is the collection of samples from a } \\
\text { single georeferenced location. Multiple samples for dif- } \\
\text { ferent analyses (i.e., tritium, gross alpha, gross beta, } \\
\text { and volatile organic compounds) can be collected dur- } \\
\text { ing a single sample event. }\end{array}$} & $\begin{array}{l}\mathrm{C}=\text { Compliance } \\
\mathrm{ER}=\text { Environmental Restoration } \\
\mathrm{ES}=\text { Environmental Surveillance }\end{array}$ \\
\hline
\end{tabular}

Pollution Act, Safe Drinking Water Act, and the New York State equivalents. Included in compliance monitoring are the following:

- Air emissions monitoring is conducted at reactors, accelerators, and other radiological emission sources, as well as the CSF.
Real-time, continuous emission monitoring equipment is installed and maintained at some of these facilities, as required by permits and other regulations. At other facilities, samples are collected and analyzed periodically to ensure compliance with 
regulatory requirements. Analytical data are routinely reported to the permitting authority. See Chapters 3 and 4 for details.

- Wastewater monitoring is performed at the point of discharge to ensure that the effluent complies with release limits in the Laboratory's SPDES permits. Twenty-four point-source discharges are monitored under the BNL program: 12 under the ER Program and 12 under the SPDES permit. As required by permit conditions, samples are collected daily, weekly, monthly, or quarterly and monitored for organic, inorganic, and radiological parameters. Monthly reports that provide analytical results and an assessment of compliance for that reporting period are filed with the permitting agency. See Chapter 3, Section 3.6 for details.

- Groundwater monitoring is also performed in accordance with permit requirements. Specifically, monitoring of groundwater is required under the Major Petroleum Facility License for the CSF and the RCRA permit for the WMF. Extensive groundwater monitoring is also conducted under the Long Term Response Actions Program, as required under the RODs for many of the OUs or Areas of Concern (see Chapter 7 and SER Volume II, Groundwater Status Report, for details). Additionally, to ensure that the Laboratory maintains a safe drinking water supply, BNL's potable water supply is monitored as required by the SDWA, which is administered by the SCDHS.

\subsubsection{Restoration Monitoring}

Restoration monitoring is performed to determine the overall impact of past operations, to delineate the real extent of contamination, and to ensure that Removal Actions are effective and remedial systems are performing as designed under CERCLA and RCRA.

This program typically involves collecting soil and groundwater samples to determine the lateral and vertical extent of the contaminated area. Samples are analyzed for organic, inorganic, and radiological contaminants, and the analytical results are compared with guidance, standards, cleanup goals, or background concentrations. Areas where impacts have been confirmed are fully characterized and, if necessary, remediated to mitigate continuing impacts. Follow-up monitoring of groundwater is conducted in accordance with a ROD with the regulatory agencies (see Chapter 7 and SER Volume II, Groundwater Status Report, for details).

\subsubsection{Surveillance Monitoring}

Pursuant to DOE Order 450.1, surveillance monitoring is performed in addition to compliance monitoring, to assess potential environmental impacts that could result from routine facility operations. The BNL Surveillance Monitoring Program involves collecting samples of ambient air, surface water, groundwater, flora, fauna, and precipitation. Samples are analyzed for organic, inorganic, and radiological contaminants. Additionally, data collected using thermoluminescent dosimeters (devices to measure radiation exposure) strategically positioned on and off site are routinely reviewed under this program. Control samples (also called background or reference samples) are collected on and off the site to compare Laboratory results to areas that could not have been affected by BNL operations.

The monitoring programs can be broken down further by the relevant law or requirement (e.g., Clean Air Act) and even further by specific environmental media and type of analysis. The results of monitoring and the analysis of the monitoring data are the subject of the remaining chapters of this report. Chapter 3 summarizes environmental requirements and compliance data, Chapters 4 through 8 give details on media-specific monitoring data and analysis, and Chapter 9 provides supporting information for understanding and validating the data shown in this report.

\subsubsection{EMS Assessments}

To periodically verify that the Laboratory's EMS is operating as intended, audits are conducted as part of BNL's Self-Assessment Program. The audits are designed to ensure that any nonconformance to the ISO 14001 Standard is identified and addressed. In addition, compliance with regulatory requirements is verified 
through routine inspections, operational evaluations, and focused compliance audits. BNL's Self-Assessment Program consists of several processes:

- Self-assessment is the systematic evaluation of internal processes and performance. The approach for the environmental self-assessment program includes evaluating programs and processes within organizations that have environmental aspects. Conformance to the Laboratory's EMS requirements is verified, progress toward achieving environmental objectives is monitored, operations are inspected to verify compliance with regulatory requirements, and the overall effectiveness of the EMS is evaluated. BNL environmental staff routinely participate in these assessments. Laboratory management conducts assessments to evaluate BNL environmental performance from a programmatic perspective, to determine if there are Laboratory-wide issues that require attention, and to facilitate the identification and communication of "best management" practices used in one part of the Laboratory that could improve performance in other parts. BNL management also routinely evaluates progress on key environmental improvement projects. The Laboratory and DOE periodically perform assessments to facilitate the efficiency of assessment activities and ensure that the approach to performing the assessments meets DOE expectations.

- Independent assessments are performed by BNL staff members who do not have line responsibility for the work processes involved, to ensure that operations are in compliance with Laboratory requirements. These assessments verify the effectiveness and adequacy of management processes (including self-assessment programs) at the division, department, directorate, and Laboratory levels. Special investigations are also conducted to identify the root causes of problems, as well as corrective actions and lessons learned.

The Laboratory's Self-Assessment Program is augmented by programmatic, external audits conducted by DOE. BSA staff and subcontrac- tors also perform periodic independent reviews. An independent third party conducts ISO 14001 registration audits of BNL's EMS. The Laboratory is also subject to extensive oversight by external regulatory agencies (see Chapter 3 for details). Results of all assessment activities related to environmental performance are included, as appropriate, throughout this report.

\subsection{ENVIRONMENTAL STEWARDSHIP AT BNL}

BNL has unprecedented knowledge of its potential environmental vulnerabilities and current operations due to ongoing process evaluations, the work planning and control system, and the management systems for groundwater protection, environmental restoration, and information management. Compliance assurance programs have improved the Laboratory's compliance status and pollution prevention projects have reduced costs, minimized waste generation, and reused and recycled significant quantities of materials.

BNL is openly communicating with neighbors, regulators, employees, and other interested parties on environmental issues and progress. To regain and maintain stakeholder trust, the Laboratory will continue to deliver on commitments and demonstrate improvements in environmental performance. The Site Environmental Report is an important communication mechanism, as it summarizes BNL's environmental programs and performance each year. Additional information about the Laboratory's environmental programs is available on BNL's website at http://www.bnl. gov. The Laboratory continues to pursue other ways to communicate timely data in a more user-friendly, visual manner.

BNL's EMS is viewed as exemplary within DOE. Due to external recognition of the Laboratory's knowledge and unique experience implementing the EMS program, several DOE facilities and private universities have invited BNL to extend its outreach activities and share its experiences, lessons learned, and successes. The Laboratory's environmental programs and projects have been recognized with international, national, and regional awards.

Audits have consistently observed a high level of management involvement, commitment, and 
support for environmental protection and the EMS. Audits and EMS management reviews have noted the following improvements made since BSA began managing BNL:

- The EMS has been strengthened, integrated with other Laboratory management systems, and formalized.

- Line ownership for environmental stewardship has been established, key roles and responsibilities have been identified and clarified, and expectations have been made explicit.

- A comprehensive environmental training program has been implemented.

- From the process evaluation project, BNL has improved its understanding of environmental aspects, waste streams, and applicable requirements.

- There is much greater formality with regard to control of EMS documents, manuals, and procedures. Procedures and requirements have been updated, and environmental management programs have been improved.

- The Laboratory has been very successful in achieving its environmental goals. There have been successes in ISO 14001 registration and recertification, compliance improvements (e.g., facility modifications, implementation of SBMS, enhanced operational controls), and increased environmental knowledge and awareness on the part of management, employees, contractors, and visitors.

- Communication on environmental issues has improved, occurs at the highest levels of management, and reporting is more formal. Managers are better informed about environmental aspects, issues, and performance.

- Core EMS teams representing many organizations have been formed. A consensus process is used to develop the system, improving acceptance and support.

- There has been strong implementation of the EMS throughout the organizations, and cultural change has been notable.

For more than 50 years, the unique, leading-edge research facilities and scientific staff at BNL have made many innovative scientific contributions possible. Today, BNL continues its research mission while focusing on cleaning up and protecting the environment. The Laboratory's environmental motto, which was generated in an employee suggestion contest, is "Exploring Earth's Mysteries ... Protecting Its Future," reflects the Laboratory's desire to balance world-class research with environmentally responsible operations.

\section{REFERENCES AND BIBLIOGRAPHY}

BNL. 2005. Community Involvement Policy and Plan. Brookhaven National Laboratory, Upton, NY.

BNL. 2003a. BNL Energy Management Plan. Brookhaven National Laboratory, Upton, NY.

BNL. 2003b. Natural Resource Management Plan for Brookhaven National Laboratory. BNL-71870-2003. Brookhaven National Laboratory, Upton, NY.

BNL. 2003c. Wildland Fire Management Plan for Brookhaven National Laboratory. BNL-71629-2003. Brookhaven National Laboratory, Upton, NY.

BNL. 2006. BNL Environmental Monitoring Plan 2006, Triennial Update. Brookhaven National Laboratory, Upton, NY.

DOE Order 450.1. 2003. Environmental Protection Program. U.S. Department of Energy, Washington, DC. Jan. 15. 2003.

EPA/DOE. 1998. Memorandum of Agreement by and between the Environmental Protection Agency and the United States Department of Energy. March 23, 1998.

ISO. 2004. ISO 14001, Environmental Management Systems - Specification with Guidance for Use. First Edition. International Organization for Standardization. Geneva, Switzerland. 
Intentionally Left Blank 


\section{Compliance Status}

Brookhaven National Laboratory (BNL) is subject to more than 100 sets offederal, state, and local environmental regulations; numerous site-specific permits; 18 equivalency permits for operation of 14 groundwater remediation systems; and several other binding agreements. In 2007, the Laboratory operated in compliance with most of the requirements defined in these governing documents. Instances of noncompliance were reported to regulatory agencies and corrected expeditiously. Routine inspections conducted during the year found no significant instances of noncompliance; however, minor deficiencies were noted during inspections conducted by the New York State Department of Environmental Conservation.

Emissions of nitrogen oxides, carbon monoxide, and sulfur dioxide from the Central Steam Facility were all within permit limits. Opacity excursions were noted in the first and second quarters of 2007. Approximately 1,168 pounds of ozone-depleting refrigerants were recovered for recycling on site or made available for use by other DOE facilities or other federal agencies. These reductions included removal of forty-seven 17-pound Halon 1211 fire extinguishers. Monitoring BNL's potable water system showed that all drinking water requirements were met. During 2007, most of the liquid effluents discharged to surface water and groundwater met applicable New York State Pollutant Discharge Elimination System permit requirements. Four minor excursions above permit limits were reported for the year. All four occurred at the Sewage Treatment Plant and were due to slightly elevated levels of nitrogen. The permit excursions were reported to the New York State Department of Environmental Conservation and the Suffolk County Department of Health Services. Groundwater monitoring at the Major Petroleum Facility continued to demonstrate that current oil storage and transfer operations are not affecting groundwater quality.

Laboratory efforts to minimize spills of materials continued in 2007. There were 12 reportable spills of petroleum products, antifreeze, or chemicals. While the number of reportable spills increased in 2007 as compared to 2006, there were 20 percent fewer total number of spills (21 compared to 27). All releases were cleaned up to the satisfaction of the New York State Department of Environmental Conservation.

The Laboratory participated in 10 environmental audits by external regulatory agencies in 2007. These audits included inspections of petroleum and chemical storage, Sewage Treatment Plant operations, other regulated outfalls and recharge basins, and the potable water system, and the Major Petroleum Facility. Immediate corrective actions were taken to address all issues raised during these inspections. No formal enforcement actions were taken in 2007.

\subsection{COMPLIANCE WITH REQUIREMENTS}

The federal, state, and local environmental statutes and regulations that BNL operates under are summarized in Table 3-1, along with a dis- 
cussion of the Laboratory's compliance status with each. A list of all applicable environmental regulations is contained in Appendix D.

\subsection{ENVIRONMENTAL PERMITS}

\subsubsection{Existing Permits}

Many processes and facilities at BNL operate under permits issued by environmental regulatory agencies. Table 3-2 provides a complete list of the existing permits, some of which are briefly described below.

- State Pollutant Discharge Elimination System (SPDES) permit, issued by New York
State Department of Environmental Conservation (NYSDEC)

- Major Petroleum Facility (MPF) license, issued by NYSDEC

- Resource Conservation and Recovery Act (RCRA) permit issued by NYSDEC for the Waste Management Facility

- Registration certificate from NYSDEC for tanks storing bulk quantities of hazardous substances

- Seven radiological emission authorizations issued by the United States Environmental Protection Agency (EPA) under the National

Table 3-1. Federal, State, and Local Environmental Statutes and Regulations Applicable to BNL.

\begin{tabular}{|c|c|c|c|}
\hline $\begin{array}{l}\text { Regulator: } \\
\text { Codified Regulation }\end{array}$ & Regulatory Program Description & Compliance Status & $\begin{array}{l}\text { Report } \\
\text { Sections }\end{array}$ \\
\hline $\begin{array}{l}\text { EPA: } \\
40 \text { CFR } 300 \\
40 \text { CFR } 302 \\
40 \text { CFR } 355 \\
40 \text { CFR } 370\end{array}$ & $\begin{array}{l}\text { The Comprehensive Environmental Response, Compensation } \\
\& \text { Liability Act (CERCLA) provides the regulatory framework } \\
\text { for remediation of releases of hazardous substances and re- } \\
\text { mediation (including decontamination and decommissioning, } \\
\text { D\&D) of inactive hazardous waste disposal sites. Regulators } \\
\text { include EPA, DOE, and the New York State Department of } \\
\text { Environmental Conservation (NYSDEC). }\end{array}$ & $\begin{array}{l}\text { In 1989, BNL entered into a tri-party agreement with EPA, } \\
\text { NYSDEC, and DOE. BNL site remediation is conducted by } \\
\text { the Environmental Restoration Program in accordance with } \\
\text { milestones established under this agreement. In 2005, BNL } \\
\text { completed the restoration portion of the cleanup project and } \\
\text { entered the surveillance and maintenance mode. Reactor D\&D } \\
\text { will continue under the CERCLA program in } 2008 \text {. }\end{array}$ & 2.3.4.8 \\
\hline $\begin{array}{l}\text { Council for Env. } \\
\text { Quality: } \\
\text { 40 CFR 1500-1508 } \\
\text { DOE: } \\
10 \text { CFR } 1021\end{array}$ & $\begin{array}{l}\text { The National Environmental Policy Act (NEPA) requires fed- } \\
\text { eral agencies to follow a prescribed process to anticipate the } \\
\text { impacts on the environment of proposed major federal actions } \\
\text { and alternatives. DOE codified its implementation of NEPA in } \\
10 \text { CFR } 1021 .\end{array}$ & $\begin{array}{l}\text { BNL is in full compliance with NEPA requirements. The Laboratory } \\
\text { has established sitewide procedures for implementing the NEPA } \\
\text { requirements. }\end{array}$ & 3.3 \\
\hline $\begin{array}{l}\text { Advisory Council } \\
\text { on Historic } \\
\text { Preservation: } \\
36 \text { CFR } 60 \\
36 \text { CFR } 63 \\
36 \text { CFR } 79 \\
36 \text { CFR } 800 \\
16 \text { USC } 470\end{array}$ & $\begin{array}{l}\text { The National Historic Preservation Act (NHPA) identifies, } \\
\text { evaluates, and protects historic properties eligible for listing } \\
\text { in the National Register of Historic Places, commonly known } \\
\text { as the National Register. Such properties can be archeologi- } \\
\text { cal sites or historic structures, documents, records, or objects. } \\
\text { NHPA is administered by state historic preservation offices } \\
\text { (SHPOs; in New York State, NYSHPO). } \\
\text { At BNL, structures that may be subject to NHPA include the } \\
\text { High Flux Beam Reactor (HFBR), the Brookhaven Graphite } \\
\text { Research Reactor (BGRR) complex, World War I training } \\
\text { trenches near the Relativistic Heavy lon Collider project, and } \\
\text { the former Cosmotron building. }\end{array}$ & $\begin{array}{l}\text { The HFBR, BGRR complex, and World War I trenches are } \\
\text { eligible for inclusion in the National Register. The former } \\
\text { Cosmotron building was identified as potentially eligible in an } \\
\text { April } 1991 \text { letter from NYSHPO. Any proposed activities involv- } \\
\text { ing these facilities must be identified through the NEPA process } \\
\text { and evaluated to determine if the action would affect the fea- } \\
\text { tures that make the facility eligible. Some actions required for } \\
\text { D\&D of the BGRR were determined to affect its eligibility, and } \\
\text { mitigative actions are proceeding according to a Memorandum } \\
\text { of Agreement between DOE and NYSHPO. BNL has a Cultural } \\
\text { Resource Management Plan to ensure compliance with cul- } \\
\text { tural resource regulations. }\end{array}$ & 3.4 \\
\hline $\begin{array}{l}\text { EPA: } \\
40 \text { CFR } 50-0 \\
40 \text { CFR } 82 \\
\text { NYSDEC: } \\
6 \text { NYCRR 200-257 } \\
6 \text { NYCRR } 307\end{array}$ & $\begin{array}{l}\text { The Clean Air Act (CAA) and the NY State Environmental } \\
\text { Conservation Laws regulate the release of air pollutants through } \\
\text { permits and air quality limits. Emissions of radionuclides are } \\
\text { regulated by EPA, via the National Emission Standards for } \\
\text { Hazardous Air Pollutants (NESHAPs) authorizations. }\end{array}$ & $\begin{array}{l}\text { All air emission sources are incorporated into the BNL Title V } \\
\text { permit or have been exempted under the New York State air } \\
\text { program, which is codified under the New York Codes, Rules, } \\
\text { and Regulations (NYCRR). }\end{array}$ & 3.5 \\
\hline $\begin{array}{l}\text { EPA: } \\
40 \text { CFR 109-140 } \\
40 \text { CFR 230, } 231 \\
40 \text { CFR 401, } 403 \\
\text { NYSDEC: } \\
6 \text { NYCRR } 700-703 \\
6 \text { NYCRR } 750\end{array}$ & $\begin{array}{l}\text { The Clean Water Act (CWA) and NY State Environmental } \\
\text { Conservation Laws seek to improve surface water quality by } \\
\text { establishing standards and a system of permits. Wastewater } \\
\text { discharges are regulated by NYSDEC permits through the } \\
\text { State Pollutant Discharge Elimination System (SPDES). }\end{array}$ & $\begin{array}{l}\text { At BNL, permitted discharges include treated sanitary waste, } \\
\text { and cooling tower and stormwater discharges. With the excep- } \\
\text { tion of four excursions, these discharges met the SPDES per- } \\
\text { mit limits in } 2007 \text {. }\end{array}$ & 3.6 \\
\hline
\end{tabular}


Table 3-1. Federal, State, and Local Environmental Statutes and Regulations Applicable to BNL (continued).

\begin{tabular}{|c|c|c|c|}
\hline $\begin{array}{l}\text { Regulator: } \\
\text { Codified Regulation }\end{array}$ & Regulatory Program Description & Compliance Status & $\begin{array}{l}\text { Report } \\
\text { Sections }\end{array}$ \\
\hline $\begin{array}{l}\text { EPA: } \\
40 \text { CFR 141-149 } \\
\text { NYSDOH: } \\
10 \text { NYCRR } 5\end{array}$ & $\begin{array}{l}\text { The Safe Drinking Water Act (SDWA) and New York State } \\
\text { Department of Health (NYSDOH) standards for public water } \\
\text { supplies establish minimum drinking water standards and } \\
\text { monitoring requirements. SDWA requirements are enforced by } \\
\text { the Suffolk County Department of Health Services (SCDHS). }\end{array}$ & $\begin{array}{l}\text { BNL maintains a sitewide public water supply. This water sup- } \\
\text { ply met all primary drinking water standards as well as opera- } \\
\text { tional and maintenance requirements in } 2007 \text {. }\end{array}$ & 3.7 \\
\hline $\begin{array}{l}\text { EPA: } \\
40 \text { CFR } 112 \\
40 \text { CFR } 300 \\
40 \text { CFR } 302 \\
40 \text { CFR } 355 \\
40 \text { CFR } 370 \\
40 \text { CFR } 372\end{array}$ & $\begin{array}{l}\text { The Oil Pollution Act, the Emergency Planning and } \\
\text { Community Right-to-KnowAct (EPCRA), and the Superfund } \\
\text { Amendment Reauthorization Act (SARA) require facilities } \\
\text { with large quantities of petroleum products or chemicals to } \\
\text { prepare emergency plans and report their inventories to EPA, } \\
\text { the state, and local emergency planning groups. }\end{array}$ & $\begin{array}{l}\text { Since some facilities at BNL store or use chemicals or petro- } \\
\text { leum in quantities exceeding threshold planning quantities, } \\
\text { BNL is subject to these requirements. BNL fully complies with } \\
\text { all reporting and emergency planning requirements. }\end{array}$ & $\begin{array}{l}3.8 .1 \\
3.8 .2 \\
3.8 .3\end{array}$ \\
\hline $\begin{array}{l}\text { EPA: } \\
40 \text { CFR } 280 \\
\text { NYSDEC: } \\
6 \text { NYCRR 595-597 } \\
6 \text { NYCRR 611-613 } \\
\text { SCDHS: } \\
\text { SCSC Article } 12\end{array}$ & $\begin{array}{l}\text { Federal, state, and local regulations govern the storage of } \\
\text { chemicals and petroleum products to prevent releases of } \\
\text { these materials to the environment. Suffolk County Safety } \\
\text { Codes (SCSC) are more stringent than the federal and state } \\
\text { regulations. }\end{array}$ & $\begin{array}{l}\text { The regulations require that these materials be managed in } \\
\text { facilities equipped with secondary containment, overfill protec- } \\
\text { tion, and leak detection. BNL complies with all federal and state } \\
\text { requirements and has achieved conformance to county codes. }\end{array}$ & $\begin{array}{l}3.8 .4 \\
3.8 .5 \\
3.8 .6\end{array}$ \\
\hline $\begin{array}{l}\text { EPA: } \\
40 \text { CFR } 260-280 \\
\text { NYSDEC: } \\
6 \text { NYCRR } 360-372\end{array}$ & $\begin{array}{l}\text { The Resource Conservation Recovery Act (RCRA) and } \\
\text { New York State Solid Waste Disposal Act govern the gen- } \\
\text { eration, storage, handling, and disposal of hazardous wastes. }\end{array}$ & $\begin{array}{l}\text { BNL is defined as a large-quantity generator of hazardous } \\
\text { waste and has a permitted waste management facility. }\end{array}$ & 3.9 \\
\hline $\begin{array}{l}\text { EPA: } \\
40 \text { CFR } 700-763\end{array}$ & $\begin{array}{l}\text { The Toxic Substances Control Act (TSCA) regulates the } \\
\text { manufacture, use, and distribution of all chemicals. }\end{array}$ & $\begin{array}{l}\text { BNL manages all TSCA-regulated materials, including PCBs, } \\
\text { in compliance with all requirements. }\end{array}$ & 3.10 \\
\hline $\begin{array}{l}\text { EPA: } \\
40 \text { CFR 162-171 } \\
\text { NYSDEC: } \\
6 \text { NYCRR } 320 \\
6 \text { NYCRR } 325-329\end{array}$ & $\begin{array}{l}\text { The Federal Insecticide, Fungicide, and Rodenticide Act } \\
\text { (FIFRA) and corresponding NY State regulations govern the } \\
\text { manufacture, use, storage, and disposal of pesticides and her- } \\
\text { bicides, as well as the pesticide containers and residuals. }\end{array}$ & $\begin{array}{l}\text { BNL employs NY State-certified pesticide applicators to apply } \\
\text { pesticides and herbicides. Each applicator attends training as } \\
\text { needed to maintain current certification, and files an annual re- } \\
\text { port to the state detailing the types and quantity of pesticides } \\
\text { applied. }\end{array}$ & 3.11 \\
\hline $\begin{array}{l}\text { DOE: } \\
10 \text { CFR } 1022 \\
\text { NYSDEC: } \\
6 \text { NYCRR } 663 \\
6 \text { NYCRR } 666\end{array}$ & $\begin{array}{l}\text { DOE regulations require its facilities to comply with floodplain/ } \\
\text { wetland review requirements. The New York State Fresh } \\
\text { Water Wetlands and Wild, Scenic, and Recreational Rivers } \\
\text { rules govern development in the state's natural waterways. } \\
\text { Development or projects within a half-mile of regulated waters } \\
\text { must have NYSDEC permits. }\end{array}$ & $\begin{array}{l}\text { BNL is in the Peconic River watershed and has several jurisdic- } \\
\text { tional wetlands; consequently, development of locations in the } \\
\text { north and east of the site requires NYSDEC permits and review } \\
\text { for compliance under DOE wetland/floodplain regulations. In } \\
\text { 2007, there were two projects permitted under the NYS Fresh } \\
\text { Water Program. }\end{array}$ & 3.12 \\
\hline $\begin{array}{l}\text { U.S. Fish \& Wildlife } \\
\text { Service: } \\
50 \text { CFR } 17 \\
\text { NYSDEC: } \\
6 \text { NYCRR } 182\end{array}$ & $\begin{array}{l}\text { The Endangered Species Act and corresponding New York } \\
\text { State regulations prohibit activities that would jeopardize the } \\
\text { continued existence of an endangered or threatened species, } \\
\text { or cause adverse modification to a critical habitat. }\end{array}$ & $\begin{array}{l}\text { BNL is host to numerous species of flaura and fauna. Many } \\
\text { species have been categorized by NYS as endangered, } \\
\text { threatened, or of special concern. BNL's Natural Resource } \\
\text { Management Plan outlines activities to protect these vulner- } \\
\text { able species and their habitats (see Chapter } 6 \text { ). }\end{array}$ & 3.13 \\
\hline $\begin{array}{l}\text { DOE: } \\
\text { Manual 231.1-1A }\end{array}$ & $\begin{array}{l}\text { The Environment, Safety, and Health Reporting program ob- } \\
\text { jective is to ensure timely collection, reporting, analysis, and } \\
\text { dissemination of information on environment, safety, and } \\
\text { health issues as required by law or regulations or as needed } \\
\text { to ensure that DOE is kept fully informed on a timely basis } \\
\text { about events that could adversely affect the health and safety } \\
\text { of the public, workers, the environment, the intended purpose } \\
\text { of DOE facilities, or the credibility of the Department. Included } \\
\text { in the order are the requirements for the Occurrence Reporting } \\
\text { and Processing of Operations Program (ORPS). }\end{array}$ & $\begin{array}{l}\text { BNL prepares an annual Site Environmental Report and } \\
\text { provides data for DOE to prepare annual NEPA summaries } \\
\text { and other Safety, Fire Protection, and Occupational Health } \\
\text { and Safety Administration (OSHA) reports. BNL developed } \\
\text { the ORPS Subject Area for staff and management who per- } \\
\text { form specific duties related to discovery, response, notifica- } \\
\text { tion, investigation, and reporting of occurrences to BNL and } \\
\text { DOE management. The ORPS Subject Area is supported by: } \\
\text { Occurrence Reporting Program Description, Critiques Subject } \\
\text { Area, Occurrence Categorizer's Procedure, and the ORPS } \\
\text { Office Procedure. }\end{array}$ & $\begin{array}{l}\text { All chap- } \\
\text { ters }\end{array}$ \\
\hline
\end{tabular}


Table 3-1. Federal, State, and Local Environmental Statutes and Regulations Applicable to BNL (concluded).

\begin{tabular}{|c|c|}
\hline $\begin{array}{l}\text { Regulator: } \\
\text { Codified Regulation }\end{array}$ & Regulatory Program Description \\
\hline $\begin{array}{l}\text { DOE: } \\
\text { Order } 414.1 \\
10 \text { CFR 830, } \\
\text { Subpart A } \\
\text { Policy } 450.5\end{array}$ & $\begin{array}{l}\text { The Quality Assurance (QA) program objective is to establish } \\
\text { an effective management system using the performance re- } \\
\text { quirements of this Order, coupled with technical standards, } \\
\text { where appropriate, to ensure: senior management provides } \\
\text { planning, organization, direction, control, and support to } \\
\text { achieve DOE objectives; line organizations achieve and main- } \\
\text { tain quality while minimizing safety and health risks and envi- } \\
\text { ronmental impacts and maximizing reliability and performance; } \\
\text { line organizations have a basic management system in place } \\
\text { supporting this Order; and each DOE element reviews, evalu- } \\
\text { ates, and improves its overall performance and that of its con- } \\
\text { tractors using a rigorous assessment process based on an } \\
\text { approved QA Program. }\end{array}$ \\
\hline
\end{tabular}

\begin{tabular}{|c|c|}
\hline $\begin{array}{l}\text { DOE: } \\
\text { Order } 435.1\end{array}$ & $\begin{array}{l}\text { The Radioactive Waste Management Program objective is to } \\
\text { ensure that all DOE radioactive waste is managed in a man- } \\
\text { ner that protects workers, public health and safety, and the } \\
\text { environment. Order } 435.1 \text { requires all DOE organizations that } \\
\text { generate radioactive waste to implement a waste certification } \\
\text { program. DOE Laboratories must develop a Radioactive Waste } \\
\text { Management Basis (RWMB) Program Description, which in- } \\
\text { cludes exemption and timeframe requirements for staging and } \\
\text { storing radioactive wastes, both routine and nonroutine. }\end{array}$ \\
\hline
\end{tabular}

DOE: $\quad$ The Environmental Protection Program objective is to imple-

Order 450.1 ment sound stewardship practices that protect the air, water, land, and other natural and cultural resources affected by DOE (former Order 5400.1) and Order $450.1 \mathrm{~A}$ operations, in a cost-effective manner, meeting or exceeding applicable environmental; public health; and resource protection laws, regulations, and DOE requirements. DOE facilities meet this objective by implementing an Environmental Management System (EMS) that is part of an Integrated Safety Management System (ISMS). Other components include establishing sound environmental monitoring programs to comply with former DOE Order 5400.1. The Site Based Management System (SBMS) provides staff with procedural guidance. In 2007, Order 450.1A was finalized and requires all federal agencies and contractors to include the goals of Executive Order 13423 in their EMS. These goals include energy and water conservation, renewable energy, use of alternate fuels and other "green" initiatives.

DOE: $\quad$ To protect members of the public and the environment against Order 5400.5, $\quad$ undue risk from radiation, the Radiation Protection of the Change 2 Public and Environment Program establishes standards and requirements for operations of DOE and DOE contractors.

\section{Compliance Status}

BNL has a Quality Management (QM) system to implement quality management methodology throughout its management systems and associated processes to:

1) plan and perform Laboratory operations reliably and effectively to minimize the impact on the safety and health of humans and on the environment; 2) standardize processes and support continuous improvement in all aspects of Laboratory operations; and 3) enable the delivery of products and services that meet customers' requirements and expectations. Having a comprehensive program ensures that all environmental monitoring data meet QA and quality control requirements. Samples are collected and analyzed using standard operating procedures, to ensure representative samples and reliable, defensible data. Quality control in the analytical labs is maintained through daily instrument calibration, efficiency and background checks, and testing for precision and accuracy. Data are verified and validated according to project-specific quality objectives before they are used to support decision making.

The BNL Waste Certification Program Plan (WCPP) in the RWMB Program Description defines the radioactive waste management program's structure, logic, and methodology for waste certification. New or modified operations or activities that do not fall within the scope of the RWMB Program Description must be documented and approved before implementation. BNL's RWMB Program Description describes the BNL policies, procedures, plans, and controls demonstrating that BNL has the management systems, administrative controls, and physical controls to comply with DOE Order 435.1.

BNL's EMS was officially registered to the ISO 14001:1996 standard in 2001 and recertified to the revised standard in 2004. In June 2007, a surveillance audit was conducted that found the BNL EMS to be robust. The BNL ISMS Program Description presents the Laboratory's approach to integrating environment, safety, and health (ES\&H) requirements into the processes for planning and conducting work at the Laboratory. It describes BNL's programs, including the SBMS, for accomplishing work safely and provides the road map of the systems and processes. In accordance with Order 450.1A, BNL has included many of the Executive Order objectives in its Objectives and Targets for 2008.

BNL uses the guidance values provided in DOE Order 5400.5 to ensure that effluents and emissions do not affect the environment or public and worker safety and health, and to ensure that all doses meet the "As Low As Reasonably Achievable" (ALARA) policy.
Report Sections

Chapter 9

2.3 .4

Notes:

CFR = Code of Federal Regulations

NYCRR = New York Codes, Rules, and Regulations

SCSC = Suffolk County Sanitary Code 
Table 3-2. BNL Environmental Permits.

\begin{tabular}{|c|c|c|c|c|c|c|}
\hline Issuing Agency & $\begin{array}{l}\text { Bldg. or } \\
\text { Facility }\end{array}$ & Process/Permit Description & Permit ID No. & $\begin{array}{l}\text { Expiration or } \\
\text { Completion }\end{array}$ & $\begin{array}{l}\text { Emission } \\
\text { Unit ID }\end{array}$ & Source ID \\
\hline EPA - NESHAPS & 510 & Calorimeter Enclosure & BNL-689-01 & None & NA & NA \\
\hline EPA - NESHAPS & 705 & Building Ventilation & BNL-288-01 & None & NA & NA \\
\hline EPA - NESHAPS & 820 & Accelerator Test Facility & BNL-589-01 & None & NA & NA \\
\hline EPA - NESHAPS & AGS & AGS Booster - Accelerator & BNL-188-01 & None & NA & NA \\
\hline EPA - NESHAPS & $\mathrm{RHIC}$ & Accelerator & BNL-389-01 & None & NA & NA \\
\hline EPA - SDWA & BNL & Underground Injection Control & NYU500001 & $11-F e b-11$ & NA & NA \\
\hline NYSDEC - Air Equivalency & 517 & Middle Road System & $1-51-009$ & NA & NA & NA \\
\hline NYSDEC - Air Equivalency & 518 & South Boundary System & $1-51-009$ & NA & NA & NA \\
\hline NYSDEC - Air Equivalency & 598 & OU I Remediation System & $1-52-009$ & NA & NA & NA \\
\hline NYSDEC - Air Equivalency & 539 & Western South Boundary System & $1-52-009$ & NA & NA & NA \\
\hline NYSDEC - Air Equivalency & TR 867 & T-96 Remediation System & $1-52-009$ & NA & NA & NA \\
\hline NYSDEC - SPDES Equivalency & 517 & Middle Road System & $1-51-009$ & NA & NA & NA \\
\hline NYSDEC - SPDES Equivalency & 518 & South Boundary System & $1-51-009$ & NA & NA & NA \\
\hline NYSDEC - SPDES Equivalency & 539 & West South Boundary System & $1-52-009$ & NA & NA & NA \\
\hline NYSDEC - SPDES Equivalency & 598 & OU I Remediation System & $1-52-009$ & 31-Oct-06 & NA & NA \\
\hline NYSDEC - SPDES Equivalency & 598 & Tritium Remediation System & $1-52-009$ & 04-May-11 & NA & NA \\
\hline NYSDEC - SPDES Equivalency & 670 & Sr-90 Treatment System & None & 25-Feb-13 & NA & NA \\
\hline NYSDEC - SPDES Equivalency & TR 829 & Carbon Tetrachloride System & None & NA & NA & NA \\
\hline NYSDEC - SPDES Equivalency & OS-4 & Airport/LIPA Treatment System & None & NA & NA & NA \\
\hline NYSDEC - SPDES Equivalency & OS-2 & Industrial Park East Treatment System & None & NA & NA & NA \\
\hline NYSDEC - SPDES Equivalency & OS-5 & North St./North St. East Treatment System & None & NA & NA & NA \\
\hline NYSDEC - SPDES Equivalency & OS-6 & Ethylene Di-Bromide Treatment System & None & 01-Aug-09 & NA & NA \\
\hline NYSDEC - SPDES Equivalency & 855 & Sr-90 Treatment System - BGRR/WCF & None & 01-Jan-10 & NA & NA \\
\hline NYSDEC - SPDES Equivalency & TR 867 & T-96 Remediation System & $1-52-009$ & 09-Mar-13 & NA & NA \\
\hline NYSDEC - Hazardous Substance & BNL & Bulk Storage Registration Certificate & $1-000263$ & 27-Jul-09 & NA & NA \\
\hline NYSDEC - LI Well Permit & BNL & Domestic Potable/Process Wells & $1-4722-00032 / 00113$ & 13-Sep-08 & NA & NA \\
\hline NYSDEC - Air Quality & 197 & Lithographic Printing Presses & $1-4722-00032 / 00115$ & 06-Jan-07 & U-LITHO & $19709-10$ \\
\hline NYSDEC - Air Quality & 423 & Metal Parts Cleaning Tanks & $1-4722-00032 / 00115$ & 06-Jan-07 & U-METAL & 42308 \\
\hline NYSDEC - Air Quality & 423 & Gasoline Storage and Fuel Pumps & $1-4722-00032 / 00115$ & 06-Jan-07 & U-FUELS & $42309-10$ \\
\hline NYSDEC - Air Quality & 423 & Motor Vehicle A/C Servicing & $1-4722-00032 / 00115$ & 06-Jan-07 & U-MVACS & MVAC1\&2 \\
\hline NYSDEC - Air Quality & 244 & Paint Spray Booth & $1-4722-00032 / 00115$ & 06-Jan-07 & U-45801 & $244-02$ \\
\hline NYSDEC - Air Quality & 244 & Flammable Liquid Storage Cabinet & $1-4722-00032 / 00115$ & 06-Jan-07 & U-45801 & $244 \mathrm{AE}$ \\
\hline NYSDEC - Air Quality & 479 & Metal Parts Cleaning Tank & $1-4722-00032 / 00115$ & 06-Jan-07 & U-METAL & 47908 \\
\hline NYSDEC - Air Quality & 479 & Metal Parts Cleaning Tank & $1-4722-00032 / 00115$ & 06-Jan-07 & U-METAL & $47906^{\star *}$ \\
\hline NYSDEC - Air Quality & 490 & Milling Machine/Block Cutter & $1-4722-00032 / 00115$ & 06-Jan-07 & U-49003 & $49003^{\star *}$ \\
\hline NYSDEC - Air Quality & 490 & Lead Alloy Melting & $1-4722-00032 / 00115$ & 06-Jan-07 & U-49003 & $49004^{\star *}$ \\
\hline NYSDEC - Air Quality & 498 & Aqueous Cleaning Facility & $1-4722-00032 / 00115$ & 06-Jan-07 & U-METAL & 49801 \\
\hline
\end{tabular}


Table 3-2. BNL Environmental Permits (concluded).

\begin{tabular}{|c|c|c|c|c|c|c|}
\hline Issuing Agency & $\begin{array}{l}\text { Bldg. or } \\
\text { Facility }\end{array}$ & Process/Permit Description & Permit ID No. & $\begin{array}{l}\text { Expiration or } \\
\text { Completion }\end{array}$ & $\begin{array}{l}\text { Emission } \\
\text { Unit ID }\end{array}$ & Source ID \\
\hline NYSDEC - Air Quality & $535 B$ & Plating Tanks & $1-4722-00032 / 00115$ & 06-Jan-07 & U-INSIG & 53501 \\
\hline NYSDEC - Air Quality & $535 B$ & Etching Machine & $1-4722-00032 / 00115$ & 06-Jan-07 & U-INSIG & 53502 \\
\hline NYSDEC - Air Quality & $535 B$ & Printed Circuit Board Process & $1-4722-00032 / 00115$ & 06-Jan-07 & U-INSIG & 53503 \\
\hline NYSDEC - Air Quality & 610 & Combustion Unit & $1-4722-00032 / 00115$ & 06-Jan-07 & U-61005 & 61005 \\
\hline NYSDEC - Air Quality & 610 & Combustion Unit & $1-4722-00032 / 00115$ & 06-Jan-07 & U-61006 & 61006 \\
\hline NYSDEC - Air Quality & 610 & Combustion Unit & $1-4722-00032 / 00115$ & 06-Jan-07 & U-61007 & 61007 \\
\hline NYSDEC - Air Quality & 610 & Metal Parts Cleaning Tray & $1-4722-00032 / 00115$ & 06-Jan-07 & U-METAL & 61008 \\
\hline NYSDEC - Air Quality & 610 & Combustion Unit & $1-4722-00032 / 00115$ & 06-Jan-07 & U-61005 & $6101 \mathrm{~A}$ \\
\hline NYSDEC - Air Quality & 630 & Gasoline Storage and Fuel Pumps & $1-4722-00032 / 00115$ & 06-Jan-07 & U-FUELS & $63001-03$ \\
\hline NYSDEC - Air Quality & 820 & Metal Parts Cleaning Tank & $1-4722-00032 / 00115$ & 06-Jan-07 & U-METAL & $82001^{\star \star}$ \\
\hline NYSDEC - Air Quality & 902 & Epoxy Coating/Curing Exhaust & $1-4722-00032 / 00115$ & 06-Jan-07 & U-COILS & 90206 \\
\hline NYSDEC - Air Quality & 903 & Metal Parts Cleaning Tank & $1-4722-00032 / 00115$ & 06-Jan-07 & U-METAL & 90304 \\
\hline NYSDEC - Air Quality & $919 \mathrm{~B}$ & Electroplating Operation & $1-4722-00032 / 00115$ & 06-Jan-07 & U-INSIG & 91904 \\
\hline NYSDEC - Air Quality & 922 & Metal Parts Cleaning Tank & $1-4722-00032 / 00115$ & 06-Jan-07 & U-METAL & $92202-03^{\star *}$ \\
\hline NYSDEC - Air Quality & 922 & Electroplating Operation & $1-4722-00032 / 00115$ & 06-Jan-07 & U-INSIG & 92204 \\
\hline NYSDEC - Air Quality & 923 & Electronic Equipment Cleaning & $1-4722-00032 / 00115$ & 06-Jan-07 & U-METAL & $9231 \mathrm{~A}$ \\
\hline NYSDEC - Air Quality & 923 & Parts Drying Oven & $1-4722-00032 / 00115$ & 06-Jan-07 & U-METAL & 9231B \\
\hline NYSDEC - Air Quality & 924 & Magnet Coil Production Press & $1-4722-00032 / 00115$ & 06-Jan-07 & U-INSIG & 92402 \\
\hline NYSDEC - Air Quality & 924 & Vapor/Ultrasonic Degreasing Unit & $1-4722-00032 / 00115$ & 06-Jan-07 & U-METAL & 92404 \\
\hline NYSDEC - Air Quality & Site & Halon 1211 Portable Extinguishers & $1-4722-00032 / 00115$ & 06-Jan-07 & U-HALON & $\mathrm{H} 1211$ \\
\hline NYSDEC - Air Quality & Site & Halon 1301 Fire Suppression Systems & $1-4722-00032 / 00115$ & 06-Jan-07 & U-HALON & H1301 \\
\hline NYSDEC - Air Quality & Site & Packaged A/C Units & $1-4722-00032 / 00115$ & 06-Jan-07 & U-RFRIG & PKG01-02 \\
\hline NYSDEC - Air Quality & Site & Reciprocating Chillers & $1-4722-00032 / 00115$ & 06-Jan-07 & U-RFRIG & REC01-52 \\
\hline NYSDEC - Air Quality & Site & Rotary Screw Chillers & $1-4722-00032 / 00115$ & 06-Jan-07 & U-RFRIG & ROTO1-11 \\
\hline NYSDEC - Air Quality & Site & Split A/C Units & $1-4722-00032 / 00115$ & 06-Jan-07 & U-RFRIG & SPL01-02 \\
\hline NYSDEC - Air Quality & Site & Centrifugal Chillers & $1-4722-00032 / 00115$ & 06-Jan-07 & U-RFRIG & CEN01-24 \\
\hline NYSDEC - Hazardous Waste & WMF & Waste Management & $1-4722-00032 / 00102$ & 19-Nov-16 & NA & NA \\
\hline NYSDEC - Natural Resources & RHIC & Construction of New Recharge Basin & $1-4722-00032 / 00129$ & 01-May-07 & NA & NA \\
\hline NYSDEC - Natural Resources & RHIC & Construct 9C/7C Alcove Building & $1-4722-00032 / 00137$ & 01-May-07 & NA & NA \\
\hline NYSDEC - NESHAPS & REF & Radiation Effects/Neutral Beam & BNL-789-01 & None & NA & NA \\
\hline NYSDEC - NESHAPS & RTF & Radiation Therapy Facility & BNL-489-01 & None & NA & NA \\
\hline NYSDEC - Water Quality & CSF & Major Petroleum Facility & $1-1700$ & 31-Mar-09 & NA & NA \\
\hline NYSDEC - Water Quality & STP & STP and Recharge Basins & NY-0005835 & 01-Mar-10 & NA & NA \\
\hline NYSDEC - Water Quality & 1010 & Install A/C @ 1010A and 1012A & $1-4722-00032 / 00139$ & 31-May-12 & NA & NA \\
\hline NYSDEC - Water Quality & 1004 & Installation of Blockhouse & $1-4722-00032 / 00140$ & Pending & NA & NA \\
\hline $\begin{array}{l}\text { Notes: } \\
\text { A/C = Air Conditioning } \\
\text { AGS = Alternating Gradient Synchr } \\
\text { BGRR = Brookhaven Graphite Res } \\
\text { EPA = Environmental Protection Ag } \\
\text { LIPA = Long Island Power Authority } \\
\text { NA = Not Applicable } \\
\text { NESHAPS = National Emission Sta }\end{array}$ & ch Reactor & ardous Air Pollutants & $\begin{array}{l}\text { NYSDEC }=\text { New York Stat } \\
\text { NA }=\text { Not Applicable } \\
\text { OU = Operable Unit } \\
\text { Sr-90 = Strontium-90 } \\
\text { STP = Sewage Treatment } \\
\text { WCF = Waste Concentrati }\end{array}$ & $\begin{array}{l}\text { Iant } \\
\text { n Facility }\end{array}$ & ironmental Con & servation \\
\hline
\end{tabular}


Emission Standards for Hazardous Air Pollutants (NESHAPs)

- Air emissions permit issued by NYSDEC under Title V of the Clean Air Act Amendments authorizing the operation of 39 facilities

- Four permits issued by NYSDEC for construction activities within the Peconic River corridor

- An EPA Underground Injection Control (UIC) Area permit for the operation of 90 UIC wells

- Permit for the operation of six domestic water supply wells, issued by NYSDEC

- Fifteen equivalency permits for the operation of 12 groundwater remediation systems installed under the Interagency Agreement (Federal Facility Agreement under the Comprehensive Environmental Response, Compensation and Liability Act [CERCLA])

\subsubsection{New or Modified Permits}

\subsubsection{Wild Scenic Recreational Rivers Act}

The Laboratory applied for two new permits under the New York State Wild Scenic and Recreational Rivers Act in 2007. These permits were for construction activities located within one-half mile of the Peconic River. The first activity included the installation of air conditioning systems at Buildings 1010A and 1012A in the Relativistic Heavy Ion Collider (RHIC) ring area, and the second activity was the relocation of a block house to Building 1004 and installation of antennae at Building 1012 and 1002. Also in 2007, work was completed under two prior permits, the first for the construction of a new facility at Building 1009C, and the second for the construction of a new recharge basin in the center of the RHIC Ring.

\subsubsection{Air Emissions Permits}

Air emissions permits are granted by NYSDEC. The Title V permit consolidates all applicable federal and state requirements for BNL's regulated emission sources into a single document. The Laboratory has a variety of nonradioactive air emission sources covered under the permit that are subject to federal or state regulations. Section 3.5 describes the more significant sources and the methods used by
BNL to comply with the applicable regulatory requirements. In June 2006, an application to renew the Laboratory's Title $\mathrm{V}$ operating permit was submitted to NYSDEC. The application included numerous changes to reflect the removal of certain processes previously included in the permit, as well as the addition of new processes.

Air emissions permits are also issued as "equivalency" permits for the installation and operation of groundwater remediation systems under CERCLA, or as changes to the BNL Title V operating permit. During 2007, no CERCLA air equivalency permits were issued or revised.

\subsubsection{CERCLA Permits}

In an effort to improve the efficiency of the groundwater treatment system installed for removing contaminants from the T-96 area, a SPDES-Equivalency permit was obtained for the discharge of treated water from this system to an existing recharge basin. This discharge is being treated with activated carbon for volatile organic compound (VOC) removal and with ion-exchange resins for the removal of metals.

\subsection{NEPA ASSESSMENTS}

The National Environmental Policy Act (NEPA) regulations require federal agencies to evaluate the effects of proposed major federal activities on the environment. The prescribed evaluation process ensures that the proper level of environmental review is performed before an irreversible commitment of resources is made.

During 2007, environmental evaluations were completed for 91 proposed projects. Of these, 87 were considered minor actions requiring no additional documentation. The four remaining projects were addressed by submitting notification forms to DOE, which determined that those projects were covered by existing Categorical Exclusions per 10 CFR 1021 or fell within the scope of a previous environmental assessment.

\subsection{PRESERVATION LEGISLATION}

The Laboratory is subject to several cultural resource laws, most notably the National Historic Preservation Act and the Archeological Resource Protection Act. These laws require agencies to consider the effects of proposed federal actions 
on historic structures, objects, and documents, as well as cultural or natural places important to Native Americans or other ethnic groups.

BNL has three structures or sites that are eligible for listing on the National Register of Historic Places: the Brookhaven Graphite Research Reactor complex, the High Flux Beam Reactor complex, and the World War I Army training trenches associated with Camp Upton. An annual Department of Interior questionnaire regarding historic and cultural resources was submitted in March 2007. Additional activities associated with historic preservation compliance are described in Chapter 6.

\subsection{CLEAN AIR ACT}

The objectives of the Clean Air Act (CAA), which is administered by EPA and NYSDEC, are to improve or maintain regional ambient air quality through operational and engineering controls on stationary or mobile sources of air pollution. Both conventional and hazardous air pollutants are regulated under the CAA.

\subsubsection{Conventional Air Pollutants}

The Laboratory has a variety of conventional, nonradioactive air emission sources that are subject to federal or state regulations. The following subsections describe the more significant sources and the methods used by BNL to comply with the applicable regulatory requirements.

\subsubsection{Boiler Emissions}

BNL has four boilers (Nos. 1A, 5, 6, and 7) at the Central Steam Facility (CSF) that are subject to NYSDEC Reasonably Available Control Technology requirements. Three of the boilers can burn either residual fuel oil or natural gas; Boiler 1A burns fuel oil only. In 2007, low nitrogen residual fuel oil (i.e., below 0.3 percent) was the predominant fuel burned in all four boilers. For boilers with maximum operating heat inputs greater than or equal to $50 \mathrm{MMBtu} / \mathrm{hr}$ (14.6 MW), the requirements establish emission standards for oxides of nitrogen $\left(\mathrm{NO}_{\mathrm{x}}\right)$. Boilers with a maximum operating heat input between 50 and $250 \mathrm{MMBtu} / \mathrm{hr}$ (14.6 and 73.2 MW) can demonstrate compliance using periodic emission tests or by using continuous emission monitoring equipment. Emission tests conducted in 1995 and again in 2006 confirmed that boilers 1A and 5, both in this size category, met the $\mathrm{NO}_{\mathrm{x}}$ emission standards when burning residual fuel oil with low nitrogen content. To ensure continued compliance, an outside contract analytical laboratory analyzes composite samples (collected quarterly) of fuel deliveries. The analyses conducted in 2007 confirmed that the fuel-bound nitrogen content met these requirements. Compliance with the $0.30 \mathrm{lbs} / \mathrm{MMBtu} \mathrm{NO}_{\mathrm{x}}$ emission standards for boilers 6 and 7 was demonstrated by continuous emission monitoring of the flue gas. In 2007, $\mathrm{NO}_{\mathrm{x}}$ emissions from Boilers 6 and 7 averaged $0.155 \mathrm{lbs} / \mathrm{MMBtu}$ and $0.115 \mathrm{lbs} / \mathrm{MMBtu}$, respectively, and there were no known exceedances of the $\mathrm{NO}_{\mathrm{x}}$ emission standard for either boiler.

The Laboratory also maintains continuous opacity monitors for boilers 6 and 7. These monitors measure the transmittance of light through the exhaust gas and report this measurement in percent attenuated. Opacity limitations state that no facility may emit particulates such that the opacity exceeds 20 percent, calculated in 6-minute averages, except for one period not to exceed 27 percent in any one hour. To maintain boiler efficiency, soot that accumulates on the boiler tubes must be removed. This is accomplished by passing a mixture of high-pressure steam and air through the boiler using a series of blowers. In 2007, BNL reported five periods during the first calendar quarter and 22 periods during the second calendar quarter when opacity measurements for Boiler 6 exceeded the 6-minute 20 percent average during soot blowing operations. The opacity exceedances measured during the first quarter were isolated events that occurred after an extended idle period of approximately two months. During this period, excess soot accumulated while nominal volumes of oil were burned to keep the boiler warm. When the boiler was returned to normal operation, opacity excursions were noted during the initial soot blowing events. The deviations from the opacity standard recorded during the second quarter were caused by mechanical malfunction of the calibration shutter in the transmissometer optical head assembly. Opacity readings returned to normal when the optical head assembly was replaced. 


\subsubsection{Ozone-Depleting Substances}

Refrigerant:

The Laboratory's preventative maintenance program requires regular inspection and maintenance of refrigeration and air conditioning equipment that contains ozone-depleting substances such as R-11, R-12, and R-22. All refrigerant recovery and recycling equipment is certified to meet refrigerant evacuation levels specified by 40 CFR 82.158. As a matter of standard practice at BNL, if a refrigerant leak is found, technicians will either immediately repair the leak or isolate it and prepare a work order for the needed repairs. This practice exceeds the leak repair provisions of 40 CFR 82.156. In 2007, approximately 369 pounds of R-22 were recovered and recycled from refrigeration equipment that was serviced.

Halon: Halon 1211 and 1301 are extremely efficient fire suppressants, but are being phased out due to their effect on the earth's ozone layer. In 1998, the Laboratory purchased equipment to comply with the halon recovery and recycling requirements of the CAA, 40 CFR 82 Subpart $\mathrm{H}$. When portable fire extinguishers or fixed systems are removed from service and when halon cylinders are periodically tested, BNL technicians use halon recovery and recycling devices, to comply with the CAA provisions.

In 2007, BNL declared forty-seven 17-pound Halon 1211 portable fire extinguishers as excess property. The Laboratory is arranging to transfer these 47 extinguishers, along with 120 portable Halon 1211 extinguishers that were declared excess property in 2006, to the Department of Defense Ozone Depletion Substance (ODS) Reserve. This transfer will be made in accordance with the Class I Ozone Depleting Substances Disposition Guidelines prepared by the DOE Office of Environmental Policy and Guidance. The portable extinguishers became excess property due to changes in operations or when they were replaced by ABC dry-chemical or clean agent FE-36 extinguishers.

\subsubsection{Hazardous Air Pollutants}

In 1970, the CAA established standards to protect the general public from hazardous air pollutants that may lead to death or an increase in irreversible or incapacitating illnesses. The NESHAPs program was established in 1977 and the governing regulations were updated significantly in 1990. EPA developed NESHAPS to limit the emission of 189 toxic air pollutants. The program includes a list of regulated contaminants, a schedule for implementing control requirements, aggressive technology-based emission standards, industry-specific requirements, special permitting provisions, and a program to address accidental releases. The following subsections describe BNL's compliance with NESHAPs regulations.

\subsubsection{Maximum Available Control \\ Technology}

Based on the Laboratory's periodic review of Maximum Available Control Technology (MACT) standards, it has been determined that none of the existing, proposed, or newly promulgated MACT standards apply to the emissions from existing permitted operations or the anticipated emissions from proposed activities and operations at BNL.

\subsubsection{Asbestos}

In 2007, the Laboratory notified the EPA Region II office regarding removal of materials containing asbestos. During the year, 350 linear feet of pipe insulation, 10,303 $\mathrm{ft}^{2}$ of floor tile, 2,250 $\mathrm{ft}^{2} \mathrm{of}$ asbestos-containing roofing material, and $3,542 \mathrm{ft}^{2}$ of mineral board siding were removed and disposed of according to EPA requirements.

\subsubsection{Radioactive Airborne Emissions}

Emissions of radiological contaminants are evaluated and, if necessary, monitored to ensure that they do not impact the environment or people working or residing at or near the Laboratory. A full description of this monitoring conducted in 2007 is provided in Chapter 4. BNL transmitted all data pertaining to radioactive air emissions and dose calculations to EPA in fulfillment of the June 30 annual reporting requirement. As in past years, the maximum off-site dose due to airborne radioactive emissions from the Laboratory continued to be far below the 10 mrem $(100 \mu \mathrm{Sv})$ annual dose limit specified in 40 CFR 61 Subpart H, (see Chapters 4 and 8 
for more information on the estimated air dose). Using EPA modeling software, the dose to the hypothetical maximally exposed individual resulting from BNL's airborne emissions was 0.06 mrem $(0.8 \mu \mathrm{Sv})$ in 2007.

\subsection{CLEAN WATER ACT}

The disposal of wastewater generated by Laboratory operations is regulated under the Clean Water Act (CWA) as implemented by NYSDEC and under DOE Order 5400.5, Radiation Protection of the Public and the Environment. The goals of the CWA are to achieve a level of water quality that promotes the propagation of fish, shellfish, and wildlife; to provide waters suitable for recreational purposes; and to eliminate the discharge of pollutants into surface waters. New York State was delegated CWA authority in 1975. NYSDEC has issued a SPDES permit to regulate wastewater effluents at the Laboratory. This permit was renewed in May 2005, and specifies monitoring requirements and effluent limits for nine of 12 outfalls, as described below. See Figure 5-7 in Chapter 5 for the locations of BNL outfalls.

- Outfall 001 is used to discharge treated effluent from the STP to the Peconic River.

- Outfalls 002, 002B, 003, 005, 006A, 006B, 008, 010, 011, and 012 are recharge basins used to discharge cooling tower blowdown, once-through cooling water, and/or stormwater. NYSDEC does not require BNL to monitor Outfalls 003, 011, and 012.

- Outfall 007 receives backwash water from the potable Water Treatment Plant filter building.

- Outfall 009 consists of numerous subsurface and surface wastewater disposal systems (e.g., drywells) that receive predominantly sanitary waste and steam- and air-compressor condensate discharges. NYSDEC does not require monitoring of this outfall.

Each month, the Laboratory prepares Discharge Monitoring Reports that describe monitoring results, evaluate compliance with permit limitations, and identify corrective measures taken to address permit excursions. These reports are submitted to the NYSDEC central and regional offices and the Suffolk County Depart- ment of Health Services (SCDHS). Details of the monitoring program conducted for the groundwater treatment systems and of SPDES equivalency permit performance are provided in SER Volume II, Groundwater Status Report.

In 2007, NYSDEC initiated a comprehensive review of the BNL SPDES permit. This review required the complete characterization of all permitted outfalls and a review of the discharges received by each outfall. Wastewater samples were collected from each outfall and analyzed for a full series of chemical and biological contaminants. The data were submitted to NYSDEC in August. No unexpected contaminants were identified through these analyses. In an effort to better understand the release of mercury to the Peconic River, wastewater samples collected from Outfall 001 were analyzed following EPA method 1631, a relatively new method that permits the analysis of mercury to the part-per-trillion level. These data show that the Sewage Treatment Plant (STP) effluent routinely contains mercury at levels at or below 100 parts-per-trillion.

\subsubsection{Sewage Treatment Plant}

Sanitary and process wastewater generated by BNL operations is conveyed to the STP for processing before discharge to the Peconic River. The STP provides tertiary treatment (settlement/ sedimentation, biological reduction of organic matter, and reduction of nitrogen). Chapter 5 provides a detailed description of the treatment process.

A summary of SPDES monitoring results for the STP discharge at Outfall 001 is provided in Table 3-3. The relevant SPDES permit limits are also shown. The Laboratory monitors the STP discharge for more than 100 parameters monthly and more than 200 parameters quarterly. BNL's overall compliance with effluent limits was greater than 99 percent in 2007. There were four excursions of the SPDES permit limits, all for total nitrogen: two occurred in February, one in September, and one in November. In all four cases, the effluent concentrations for total nitrogen were just above the Laboratory's SPDES limit of $10 \mathrm{ppm}$, with discharges of 11.6, 11.4, 11.2, and $11.1 \mathrm{ppm}$, respectively. All other parameters were within permit limits. 
Table 3-3. Analytical Results for Wastewater Discharges to Sewage Treatment Plant Outfall 001.

\begin{tabular}{|c|c|c|c|c|c|c|}
\hline Analyte & $\begin{array}{c}\text { Low } \\
\text { Report }\end{array}$ & $\begin{array}{l}\text { High } \\
\text { Report }\end{array}$ & Min. Monitoring. Freq. & SPDES Limit & Exceedances & $\begin{array}{c}\% \\
\text { Compliance }^{*}\end{array}$ \\
\hline Max. temperature $\left({ }^{\circ} \mathrm{F}\right)$ & 45 & 79 & Daily & 90 & 0 & 100 \\
\hline $\mathrm{pH}(\mathrm{SU})$ & 6.1 & 7.7 & Continuous Recorder & $\operatorname{Min} 5.8, \operatorname{Max} .9 .0$ & 0 & 100 \\
\hline Avg. 5-Day BOD (mg/L) & $<2$ & $<2$ & Twice Monthly & 10 & 0 & 100 \\
\hline Max. 5-Day BOD (mg/L) & $<2$ & $<2$ & Twice Monthly & 20 & 0 & 100 \\
\hline \% BOD Removal & $>90$ & $>97$ & Monthly & 85 & 0 & 100 \\
\hline Avg. TSS (mg/L) & $<0.6$ & 1.8 & Twice Monthly & 10 & 0 & 100 \\
\hline Max. TSS (mg/L) & $<0.6$ & 2.3 & Twice Monthly & 20 & 0 & 100 \\
\hline \% TSS Removal & $>95$ & $>99$ & Monthly & 85 & 0 & 100 \\
\hline Settleable solids (ml/L) & 0 & 0 & Daily & 0.1 & 0 & 100 \\
\hline Ammonia nitrogen (mg/L) & 0.1 & 0.39 & Twice Monthly & 2 & 0 & 100 \\
\hline Total nitrogen (mg/L) & 4 & $11.6(a)$ & Twice Monthly & 10 & 4 & 86 \\
\hline Total phosphorus (mg/L) & 1.02 & 2.09 & Twice Monthly & NA & 0 & 100 \\
\hline Cyanide ( $\mu \mathrm{g} / \mathrm{L})$ & $<1.5$ & 2.1 & Twice Monthly & 100 & 0 & 100 \\
\hline Copper (mg/L) & 0.042 & 0.124 & Twice Monthly & 0.15 & 0 & 100 \\
\hline Iron (mg/L) & 0.102 & 0.278 & Twice Monthly & 0.37 & 0 & 100 \\
\hline Lead (mg/L) & $<0.001$ & 0.002 & Twice Monthly & 0.019 & 0 & 100 \\
\hline Mercury (mg/L) & $<0.00003$ & 0.00015 & Twice Monthly & 0.0008 & 0 & 100 \\
\hline Methylene chloride $(\mu \mathrm{g} / \mathrm{L})$ & $<2$ & 2.76 & Twice Monthly & 5 & 0 & 100 \\
\hline Nickel (mg/L) & 0.008 & 0.022 & Twice Monthly & 0.11 & 0 & 100 \\
\hline Silver (mg/L) & $<0.001$ & 0.003 & Twice Monthly & 0.015 & 0 & 100 \\
\hline Toluene ( $\mu \mathrm{g} / \mathrm{L})$ & 0.38 & $<1$ & Twice Monthly & 5 & 0 & 100 \\
\hline Zinc (mg/L) & 0.024 & 0.076 & Twice Monthly & 0.1 & 0 & 100 \\
\hline 1,1,1-trichloroethane $(\mu \mathrm{g} / \mathrm{L})$ & $<1$ & $<1$ & Twice Monthly & 5 & 0 & 100 \\
\hline 2-butanone ( $\mu \mathrm{g} / \mathrm{L})$ & $<5$ & $<5$ & Twice Monthly & 50 & 0 & 100 \\
\hline PCBs ( $\mu g / L)$ & $<0.0463$ & $<0.0463$ & Quarterly & NA & 0 & 100 \\
\hline Max. Flow (MGD) & 0.21 & 0.82 & Continuous Recorder & 2.3 & 0 & 100 \\
\hline Avg. Flow (MGD) & 0.25 & 0.44 & Continuous Recorder & NA & 0 & 100 \\
\hline Avg. Fecal Coliform (MPN/100 ml) & $<2$ & $<2$ & Twice Monthly & 200 & 0 & 100 \\
\hline Max. Fecal Coliform (MPN/100 ml) & $<2$ & $<2$ & Twice Monthly & 400 & 0 & 100 \\
\hline $\begin{array}{l}\text { Notes: } \\
\text { See Chapter } 5 \text {, Figure } 5-6 \text { for location of } \\
\text { * } \% \text { Compliance }=\text { total no. samples - } \\
\text { samples } \times 100 \\
\text { BOD = Biological Oxygen Demand } \\
\text { MGD = Million Gallons per Day } \\
\text { MPN = Most Probable Number }\end{array}$ & $\begin{array}{l}\text { fall } 001 \text {. } \\
\text { no. exceeda }\end{array}$ & es/total no. of & $\begin{array}{l}\text { NA = Not Applicable } \\
\text { SU = Standard Unit } \\
\text { TSS = Total Suspended S } \\
\text { (a) Two permit exceedano } \\
\text { in September, and on } \\
\text { Please refer to Section } 3 .\end{array}$ & $\begin{array}{l}\text { lids } \\
\text { n of the total nitrogen lin } \\
1 \text { for explanations of th }\end{array}$ & $\begin{array}{l}\text { its were reported, tv } \\
\text { ese permit exceeda }\end{array}$ & in February, one \\
\hline
\end{tabular}

The Laboratory has been investigating the potential sources of elevated nitrogen concentrations observed at the STP. Abnormally low flow conditions and decreased nutrients in the waste have been identified as the most likely causes of the increased nitrogen levels in the discharge. To address this issue, enzymes are now added at the plant to enhance denitrifica- tion of the effluent by the biological organisms during treatment. BNL will continue to monitor nitrogen levels at the STP very closely, to ensure that effluent limits are met in the future. Figures 3-1 through 3-7 plot 5-year trends for the monthly concentrations of copper, iron, lead, mercury, nickel, silver, and zinc in the STP discharge. 
Figure 3-1. Maximum Concentrations of Copper Discharged from the BNL Sewage Treatment Plant, 2003-2007.

Figure 3-2. Maximum Concentrations of Iron Discharged from the BNL Sewage Treatment Plant, 2003-2007.

Figure 3-3. Maximum Concentrations of Lead Discharged from the BNL

Sewage Treatment Plant, 2003-2007.
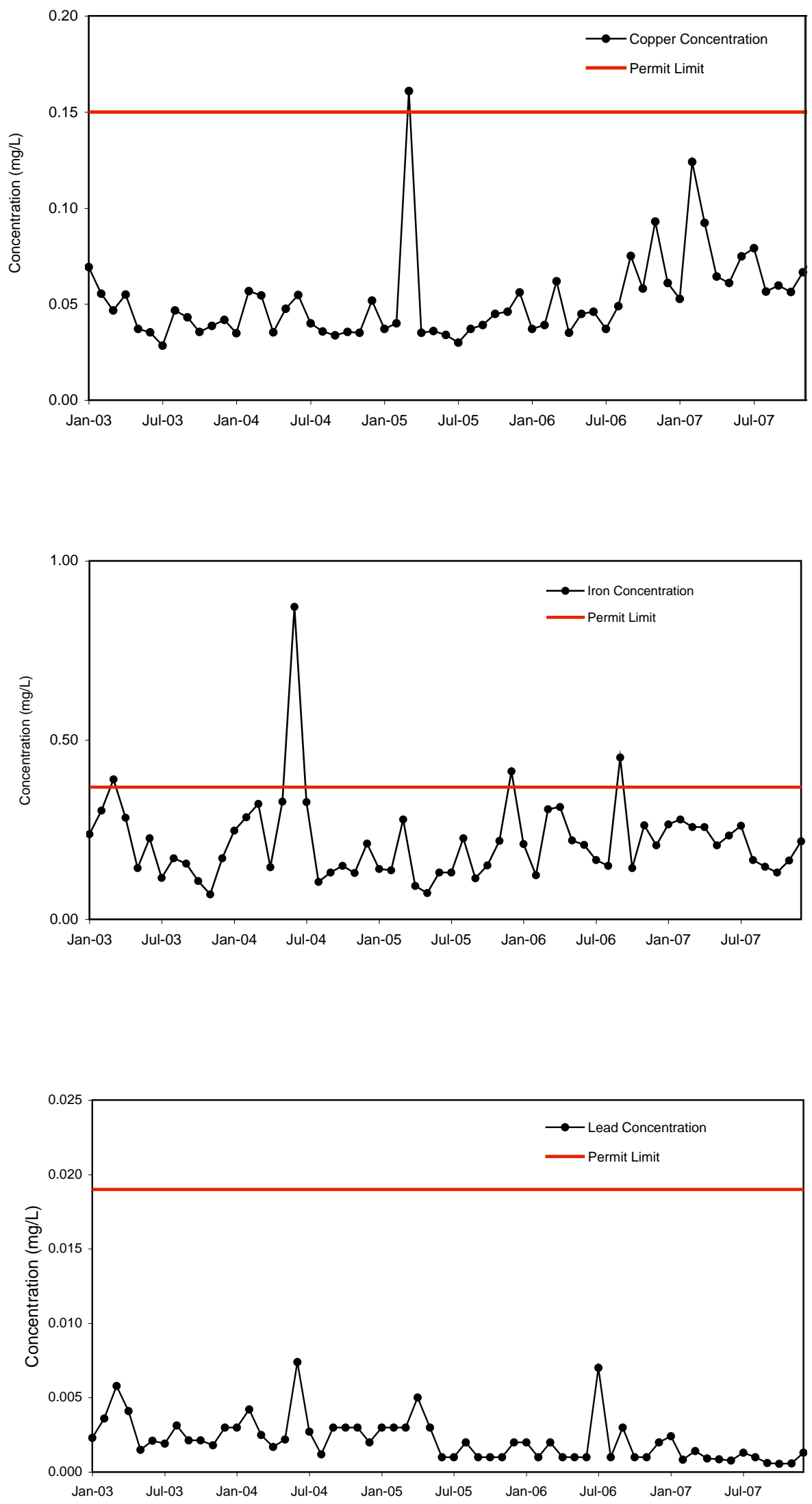


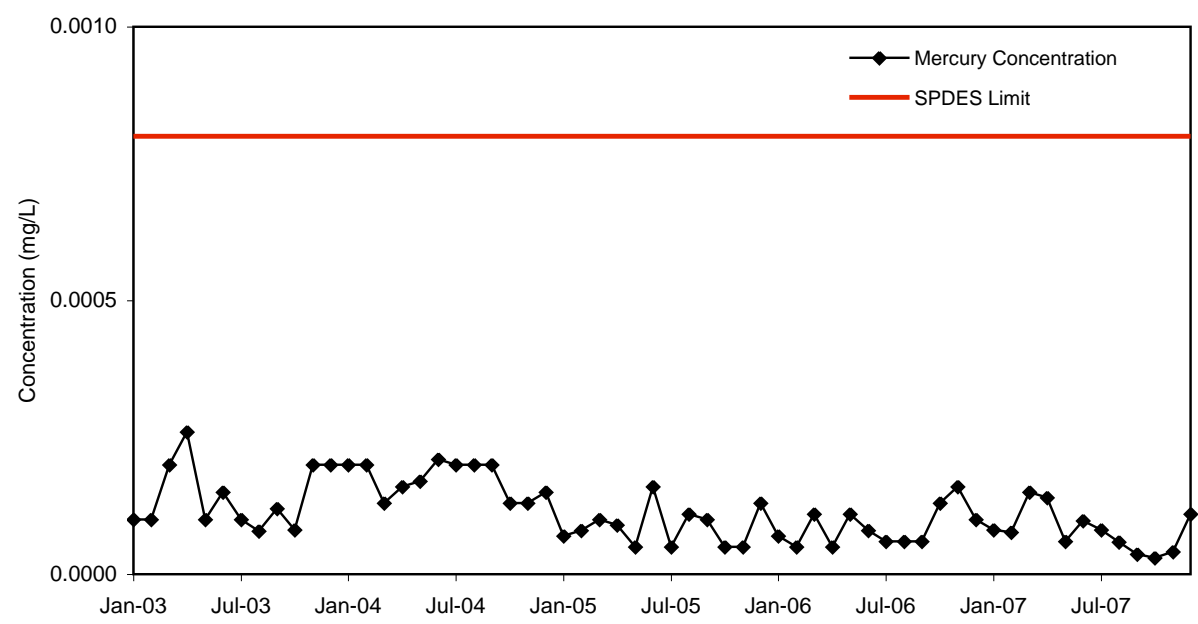

Figure 3-4. Maximum Concentrations of Mercury Discharged from the BNL Sewage Treatment Plant, 2003-2007.

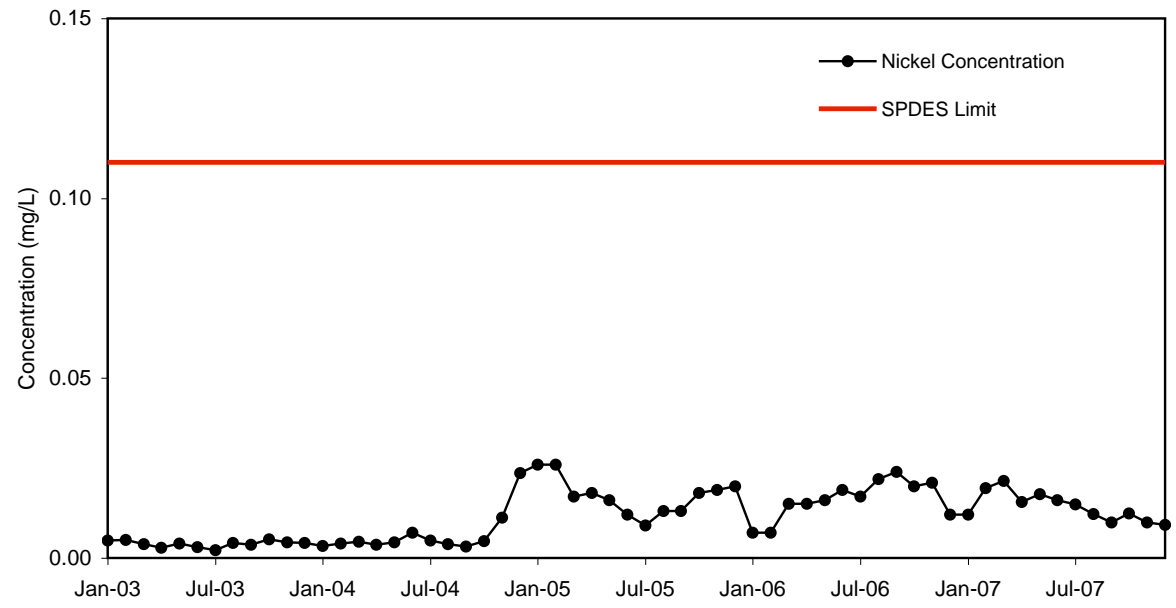

Figure 3-5. Maximum Concentrations of Nickel Discharged from the BNL Sewage Treatment Plant, 2003-2007.

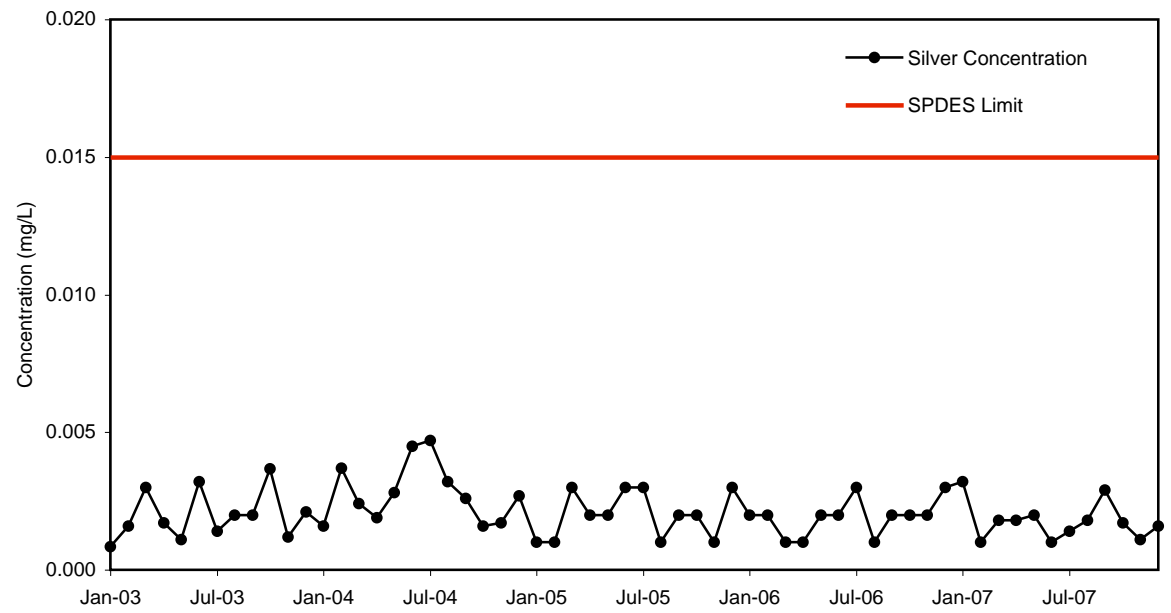

Figure 3-6. Maximum Concentrations of Silver Discharged from the BNL Sewage Treatment Plant, 2003-2007. 
Note:

Per New York State Department of Environmental Conservation guidance, the concentrations of zinc exhibited in the effluent during February and June of 2003 and 2004 and November 2005 were not considered in violation of the State Pollutant Discharge Elimination System effluent limit of $0.1 \mathrm{mg} / \mathrm{L}$, due to rounding off of significant figures.

Figure 3-7. Maximum Concentrations of Zinc Discharged from the BNL Sewage Treatment Plant, 2003-2007.

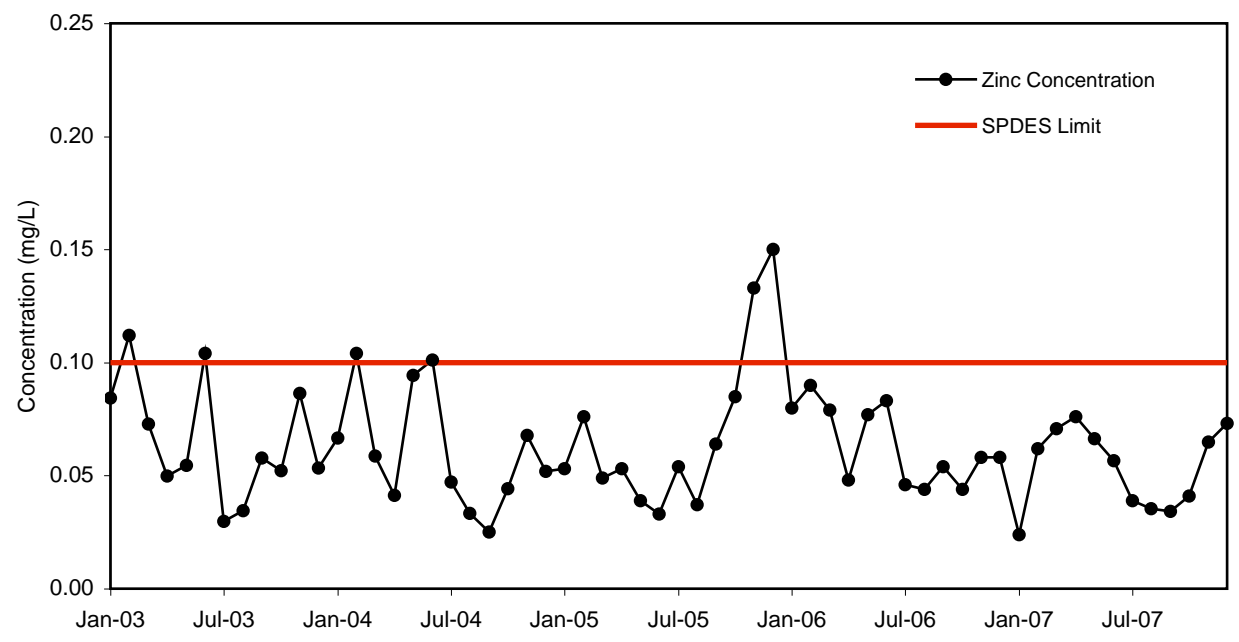

\subsubsection{Chronic Toxicity Testing}

The Laboratory's SPDES permit requires that "whole effluent toxicity" (WET) tests be conducted to ensure that chemicals present in the STP effluent are not toxic to aquatic organisms. BNL's chronic toxicity testing program began in 1993 and continued through 2003. Toxicity testing was postponed in 2004, but was restarted in March 2005 as stipulated in the 2005 SPDES permit renewal. Under the WET testing provisions, samples are collected and tested quarterly. The program consists of 7-day chronic toxicity testing on two freshwater organisms: water fleas and fathead minnows. In each test, sets of 10 of these organisms are exposed to varying concentrations of the STP effluent (100, 50, 25, 12.5, and 6.25 percent) for 7 days. During testing, the growth rate of the fish and rate of reproduction for the water flea are measured and compared to untreated organisms (i.e., controls). The test results are submitted to NYSDEC for review.

Since tests conducted in 2006 continued to be inconclusive to determine the toxic effects on freshwater organisms, testing was continued in 2007. Changes to the testing program in 2007 included using synthetic fresh water modified to the hardness of the Peconic River as a dilution water source. This change was necessitated by inconsistencies in water characteristics from the Water Treatment Plant. Tests were performed in March, June, September, and December. Minnows exhibited no acute or chronic toxicity in all tests conducted in 2007. For the water flea, minor impacts on reproduction rates were observed in one of the four tests conducted (December). Because the observed impacts were minor (only evident in one of the four test concentrations tested), no further toxicity reduction was required. Testing will continue in 2008.

\subsubsection{Recharge Basins and Stormwater}

Water discharged to Outfalls 002 through 008 and Outfalls 010 through 012 recharges to groundwater, replenishing the underlying aquifer. Monitoring requirements for each of these discharges vary, depending on the type of wastewater received and the type of cooling water treatment reagents used. Table 3-4 summarizes the monitoring requirements and performance results for 2007. Review of the data shows that all discharges were in full compliance with SPDES requirements. No permit excursions were recorded at any of these outfalls in 2007.

\subsection{SAFE DRINKING WATER ACT}

The extraction and distribution of drinking water is regulated under the federal Safe Drinking Water Act (SDWA). In New York State, implementation of the SDWA is delegated to the New York State Department of Health (NYS$\mathrm{DOH}$ ) and administered locally by SCDHS. Because BNL provides potable water to more than 25 full-time residents, it is subject to the same requirements as a municipal water supplier. Monitoring requirements are prescribed annually by SCDHS, and a Potable Water Sampling and Analysis Plan (Chaloupka 2007) is prepared by BNL to comply with these requirements. 
CHAPTER 3: COMPLIANCE STATUS

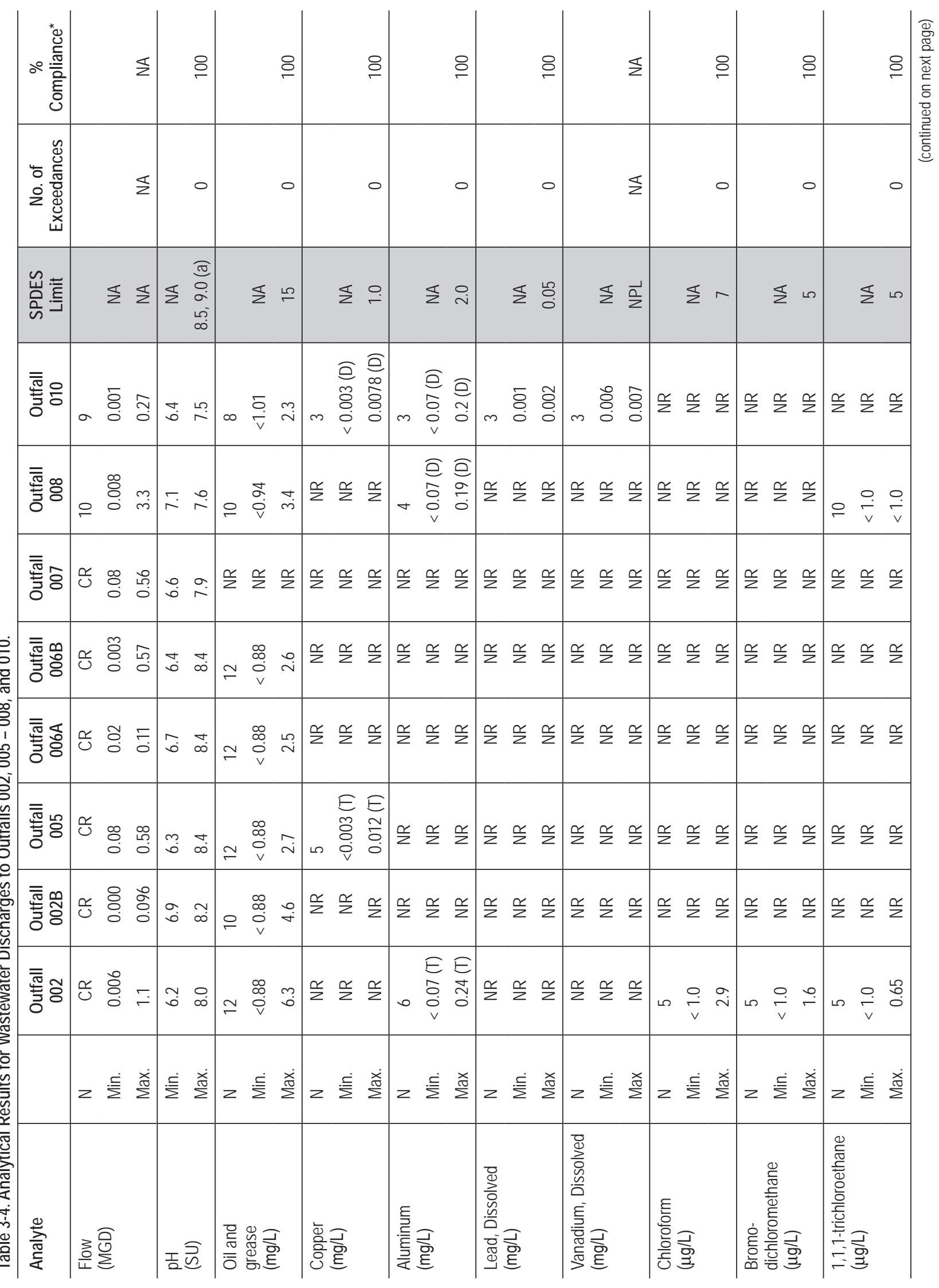




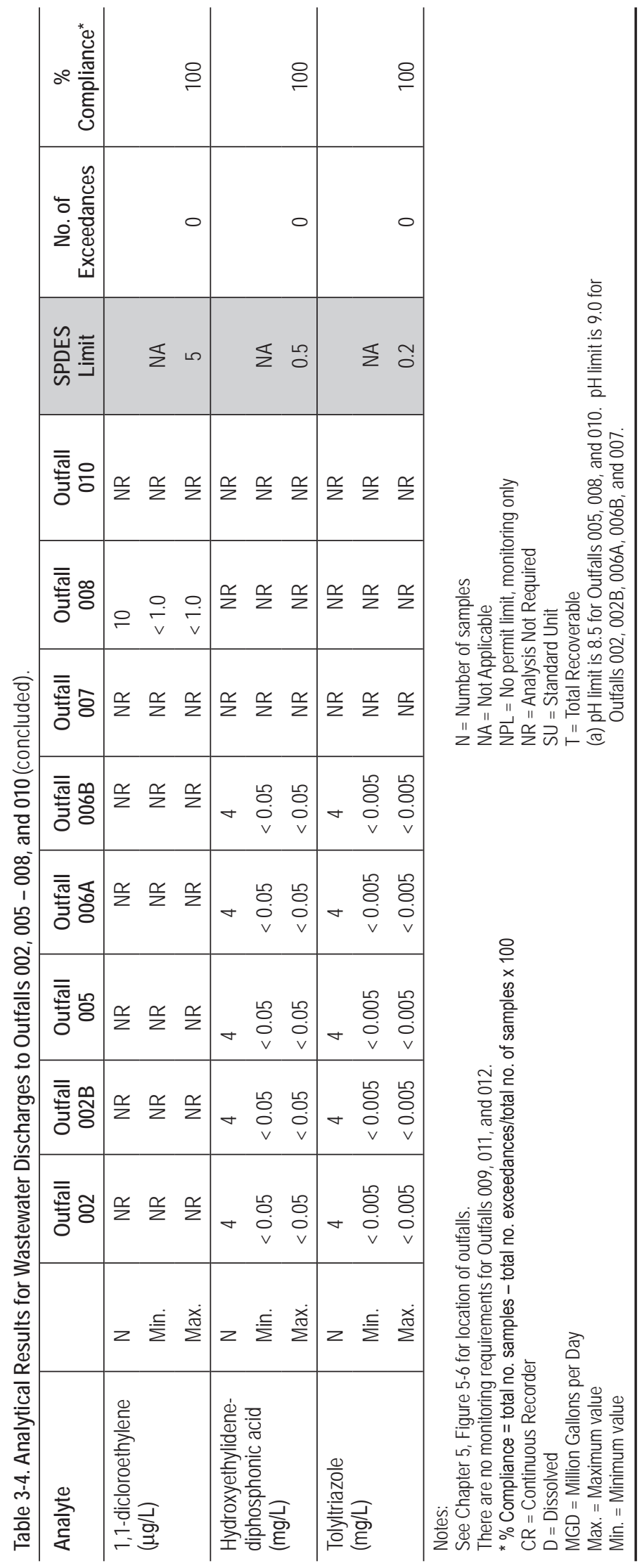

\subsubsection{Potable Water}

The Laboratory maintains six water supply wells for on-site distribution of potable water. As required by NYSDOH regulations, BNL monitors the potable wells regularly for bacteria, inorganics, organics, and pesticides. The Laboratory also voluntarily monitors drinking water supplies for radiological contaminants yearly. Tables 3-5 and 3-6 provide the potable water supply monitoring data for 2007. In 2007, only iron and color exceeded New York State Drinking Water Standards (NYS DWS), in samples collected from three of the wells (wells 4, 6 and 7) before distribution. Groundwater from these three wells is treated to reduce naturally occurring iron. Treatment at the Water Treatment Plant effectively reduces these levels to below DWS limits. To ensure that BNL's water supply continually meets NYS DWS, groundwater is also treated with activated carbon or air stripping to remove VOCs. At the point of consumption, drinking water complied with all DWS during 2007. Chapter 7 provides additional data on environmental surveillance tests performed on potable wells. This additional testing goes beyond the minimum SDWA testing requirements.

To ensure that BNL drinking-water consumers are informed about the quality of Laboratory-produced potable water, BNL annually publishes a Consumer Confidence Report (CCR) by the May deadline required by the SDWA. This report provides information regarding BNL's source water, supply system, the analytical tests conducted, and the detected contaminants as compared to federal drinking water standards. The CCR also describes the measures the Laboratory takes to protect its water source and limit consumer exposure to contaminants. The CCR is distributed as a special edition of the Laboratory's weekly newsletter to all BNL employees and on-site residents, and it is also available electronically at http://www.bnl.gov/bnlweb/pubaf/water/reports. htm and http://www.bnl.gov/bnlweb/pubaf/bulletin.asp.

\subsubsection{Cross-Connection Control}

The SDWA requires that public water suppliers implement practices to protect the water supply from sanitary hazards. One of the safety require- 
Table 3-5. Potable Water Wells and Potable Distribution System: Analytical Results (Maximum Concentration, Minimum pH Value).

\begin{tabular}{|c|c|c|c|c|c|c|c|c|}
\hline Compound & $\begin{array}{c}\text { Well } \\
\text { No. } 4\end{array}$ & $\begin{array}{c}\text { Well } \\
\text { No. } 6\end{array}$ & $\begin{array}{c}\text { Well } \\
\text { No. } 7\end{array}$ & $\begin{array}{c}\text { Well } \\
\text { No. } 10\end{array}$ & $\begin{array}{c}\text { Well } \\
\text { No. } 11\end{array}$ & $\begin{array}{c}\text { Well } \\
\text { No. } 12\end{array}$ & $\begin{array}{c}\text { Potable } \\
\text { Distribution } \\
\text { Sample }\end{array}$ & $\begin{array}{l}\text { NYS } \\
\text { DWS }\end{array}$ \\
\hline \multicolumn{9}{|l|}{ Water Quality Indicators } \\
\hline Ammonia (mg/L) & $<0.10$ & $<0.10$ & $<0.10$ & $<0.10$ & $<0.10$ & $<0.10$ & $<0.10$ & SNS \\
\hline Chlorides (mg/L) & 39 & 22.8 & 25.6 & 17.2 & 17.3 & 27 & 30.3 & 250 \\
\hline Color (units) & $20^{*}$ & $50^{*}$ & $30^{*}$ & $<5$ & $<5$ & $<5$ & $<5$ & 15 \\
\hline Conductivity ( $\mu \mathrm{mhos} / \mathrm{cm})$ & 210 & 196 & 248 & 139 & 298 & 283 & 175 & SNS \\
\hline Cyanide ( $\mu \mathrm{g} / \mathrm{L})$ & $<10$ & $<10$ & $<10$ & $<10$ & $<10$ & $<10$ & $<10$ & SNS \\
\hline MBAS (mg/L) & $<0.08$ & $<0.08$ & $<0.08$ & $<0.08$ & $<0.08$ & $<0.08$ & $<0.08$ & SNS \\
\hline Nitrates (mg/L) & 0.19 & 0.17 & 0.28 & 0.43 & 0.48 & 0.46 & 0.28 & 10 \\
\hline Nitrites (mg/L) & 0.12 & $<0.10$ & $<0.10$ & $<0.10$ & $<0.10$ & $<0.10$ & $<0.10$ & 1.0 \\
\hline Odor (units) & 0 & 0 & 0 & 0 & 0 & 0 & 0 & 3 \\
\hline pH (Standard Units) & 5.4 & 5.4 & 5.5 & 5.7 & 5.7 & 6.0 & 6.9 & SNS \\
\hline Sulfates (mg/L) & 9.5 & 9.9 & 10.6 & 6.5 & 9.4 & 9.5 & 11.1 & 250 \\
\hline Total coliform & ND & 1 & ND & ND & ND & ND & ND & Negative \\
\hline \multicolumn{9}{|l|}{ Metals } \\
\hline Antimony ( $\mu \mathrm{g} / \mathrm{L})$ & $<5.90$ & $<5.90$ & $<5.90$ & $<5.90$ & $<5.90$ & $<5.90$ & $<5.90$ & 6.0 \\
\hline Arsenic $(\mu \mathrm{g} / \mathrm{L})$ & $<3.00$ & $<3.00$ & $<3.00$ & $<3.00$ & $<3.00$ & $<3.00$ & $<3.00$ & 50 \\
\hline Barium (mg/L) & $<0.2$ & $<0.2$ & $<0.2$ & $<0.2$ & $<0.2$ & $<0.2$ & $<0.2$ & 2.0 \\
\hline Beryllium ( $\mu \mathrm{g} / \mathrm{L})$ & $<3.0$ & $<3.0$ & $<3.0$ & $<3.0$ & $<3.0$ & $<3.0$ & $<3.0$ & 4.0 \\
\hline Cadmium ( $\mu \mathrm{g} / \mathrm{L})$ & $<5.0$ & $<5.0$ & $<5.0$ & $<5.0$ & $<5.0$ & $<5.0$ & $<5.0$ & 5.0 \\
\hline Chromium (mg/L) & $<0.010$ & $<0.010$ & $<0.010$ & $<0.010$ & $<0.010$ & $<0.010$ & $<0.010$ & 0.1 \\
\hline Fluoride (mg/L) & $<0.10$ & $<0.10$ & $<0.10$ & $<0.10$ & $<0.10$ & $<0.10$ & $<0.10$ & 2.2 \\
\hline Iron (mg/L) & $1.46^{*}$ & $3.33^{*}$ & $2.1^{*}$ & 0.03 & 0.02 & 0.02 & 0.1 & 0.3 \\
\hline Lead ( $\mu \mathrm{g} / \mathrm{L})$ & $<1.0$ & $<1.0$ & $<1.0$ & $<1.0$ & $<1.0$ & $<1.0$ & $<1.0$ & 15 \\
\hline Manganese (mg/L) & 0.154 & 0.114 & 0.072 & $<0.010$ & $<0.010$ & $<0.010$ & 0.043 & 0.3 \\
\hline Mercury ( $\mu g / L)$ & $<0.20$ & $<0.20$ & $<0.20$ & $<0.20$ & $<0.20$ & $<0.20$ & $<0.20$ & 2.0 \\
\hline Nickel (mg/L) & $<0.040$ & $<0.040$ & $<0.040$ & $<0.040$ & $<0.040$ & $<0.040$ & $<0.040$ & SNS \\
\hline Selenium ( $\mu \mathrm{g} / \mathrm{L})$ & $<5.00$ & $<5.00$ & $<5.00$ & $<5.00$ & $<5.00$ & $<5.00$ & $<5.00$ & 50.0 \\
\hline Sodium (mg/L) & 21.2 & 13.0 & 15.1 & 10.8 & 12.3 & 15.0 & 18.5 & SNS \\
\hline Silver $(\mu \mathrm{g} / \mathrm{L})$ & $<10$ & $<10$ & $<10$ & $<10$ & $<10$ & $<10$ & $<10$ & 100 \\
\hline Thallium ( $\mu \mathrm{g} / \mathrm{L})$ & $<1.90$ & $<1.90$ & $<1.90$ & $<1.90$ & $<1.90$ & $<1.90$ & $<1.90$ & 2.0 \\
\hline Zinc (mg/L) & 0.02 & 0.03 & $<0.020$ & $<0.020$ & $<0.020$ & $<0.020$ & $<0.020$ & 5.0 \\
\hline \multicolumn{9}{|l|}{ Radioactivity } \\
\hline Gross alpha activity (pCi/L) & $<1.43$ & $1.97 \pm 1.24$ & $<1.97$ & $<0.98$ & $2.37 \pm 1.23$ & $<1.52$ & NR & 15.0 \\
\hline Gross beta activity (pCi/L) & $<2.57$ & $<2.75$ & $<2.59$ & $<1.95$ & $2.78 \pm 1.07$ & $2.99 \pm 1.80$ & NR & (a) \\
\hline Strontium-90 (pCi/L) & $<0.66$ & $<0.77$ & $<0.75$ & $<0.40$ & $<0.75$ & $<0.75$ & NR & 8.0 \\
\hline Tritium (pCi/L) & $<370$ & $<370$ & $<370$ & $<370$ & $<370$ & $<370$ & NR & 20,000 \\
\hline
\end{tabular}


Table 3-5. Potable Water Wells and Potable Distribution System: Analytical Results (Maximum Concentration, Minimum pH Value) (concluded).

\begin{tabular}{|c|c|c|c|c|c|c|c|c|}
\hline Compound & $\begin{array}{c}\text { Well } \\
\text { No. } 4\end{array}$ & $\begin{array}{r}\text { Well } \\
\text { No. } 6 \\
\end{array}$ & $\begin{array}{c}\text { Well } \\
\text { No. } 7\end{array}$ & $\begin{array}{c}\text { Well } \\
\text { No. } 10\end{array}$ & $\begin{array}{c}\text { Well } \\
\text { No. } 11\end{array}$ & $\begin{array}{c}\text { Well } \\
\text { No. } 12\end{array}$ & $\begin{array}{c}\text { Potable } \\
\text { Distribution } \\
\text { Sample }\end{array}$ & $\begin{array}{l}\text { NYS } \\
\text { DWS }\end{array}$ \\
\hline \multicolumn{9}{|l|}{ Other } \\
\hline Alkalinity (mg/L) & 11.8 & 7.4 & 14.2 & 22.9 & 16.2 & 19.4 & 25.6 & SNS \\
\hline Asbestos (M. fibers/L) & NR & NR & NR & NR & NR & NR & $<0.20$ & 7 \\
\hline Calcium (mg/L) & 5.2 & 4.2 & 5.9 & 8.1 & 6.5 & 8.5 & 10.1 & SNS \\
\hline HAA5 (mg/L) & NR & NR & NR & NR & NR & NR & $<0.002$ & $0.06^{\star *}$ \\
\hline Residual chlorine - MRDL (mg/L) & NR & NR & NR & NR & NR & NR & 0.6 & 4.0 \\
\hline TTHM (mg/L) & NR & NR & NR & NR & NR & NR & 0.01 & $0.08^{\star *}$ \\
\hline $\begin{array}{l}\text { Notes: } \\
\text { See Figure 7-3 for well locations. } \\
\text { HAA5 = Five Haloacetic Acids } \\
\text { MBAS = Methylene Blue Active Substa } \\
\text { MRDL = Maximum Residual Disinfecta } \\
\text { NA = Not Analyzed due to well shutdo } \\
\text { ND = Not Detected } \\
\text { NR = Analysis Not Required } \\
\text { NYS DWS = New York State Drinking } \\
\text { SNS = Drinking Water Standard Not S } \\
\text { TTHM = Total Trihalomethanes }\end{array}$ & $\begin{array}{l}\text { es } \\
\text { Level } \\
\text { ter Standard } \\
\text { ified }\end{array}$ & & & \multicolumn{5}{|c|}{$\begin{array}{l}\text { * Water from these wells is treated at the Water Treatment Plant for color and } \\
\text { iron reduction prior to site distribution. } \\
\text { ** Limit imposed on distribution samples only. } \\
\text { (a) The drinking water standard was changed from } 50 \mathrm{pCi} / \mathrm{L} \text { (concentration } \\
\text { based) to } 4 \text { mrem/yr (dose based) in late } 2003 \text {. Gross beta activity does no } \\
\text { identify specific radionuclides; therefore, a dose equivalent can not be cal- } \\
\text { culated. No specific nuclides were detected; therefore, compliance with the } \\
\text { requirement is demonstrated. }\end{array}$} \\
\hline
\end{tabular}

ments is to rigorously prevent cross-connections between the potable water supply and facility piping systems that may contain hazardous substances. Cross-connection control is the installation of control devices (e.g., double-check valves, reduced pressure zone valves, etc.) at the interface between a facility and the domestic water main. Cross-connection control devices are required at all facilities where hazardous materials are used in a manner that could result in their introduction into the domestic water system, especially under low-pressure conditions. In addition, secondary cross-connection controls at the point of use are recommended, to protect users within a specific facility from hazards that might be posed by intra-facility operations.

The Laboratory maintains approximately 200 cross-connection control devices at interfaces to the potable water main, and secondary control devices at the point of use. Approximately 188 cross-connection control units were tested at BNL in 2007, including primary and secondary devices. If a problem with a cross-connection device is encountered during testing, the device is repaired and retested to ensure proper function. Copies of the cross-connection device test reports are filed with the SCDHS annually.

\subsubsection{Underground Injection Control}

Underground Injection Control wells are regulated under the SDWA. At the Laboratory, UICs include drywells, cesspools, septic tanks, and leaching pools, all of which are classified by EPA as Class V injection wells. Proper management of UIC devices is vital for protecting underground sources of drinking water. In New York State, the UIC program is implemented through EPA, because NYSDEC has not adopted UIC regulatory requirements. (Note: New York State regulates the discharges of pollutants to cesspools under the SPDES program.) Under EPA's UIC program, all Class V injection wells must be included in an inventory maintained with the agency. In 2007, two new storm water drywells were installed for the local control of flooding, and six were closed in accordance with EPA and SCDHS requirements.

In addition to the UICs maintained for routine Laboratory discharges of sanitary waste and stormwater, UICs also are maintained at several on- and off-site treatment facilities used for groundwater remediation. Contaminated groundwater is treated and then returned to the aquifer via drywells, injection wells, or recharge basins. Discharges to these UICs are "authorized by rule" rather than by permit. 
Table 3-6. Potable Water Wells: Analytical Results for Principal Organic Compounds, Synthetic Organic Chemicals, Pesticides, and Micro-Extractables.

\begin{tabular}{|c|c|c|c|c|c|c|c|c|}
\hline \multirow[b]{2}{*}{ Compound } & $\begin{array}{c}\text { WTP } \\
\text { Effluent }\end{array}$ & $\begin{array}{l}\text { Well } \\
\text { No. } 4\end{array}$ & $\begin{array}{c}\text { Well } \\
\text { No. } 6\end{array}$ & $\begin{array}{l}\text { Well } \\
\text { No. } 7\end{array}$ & $\begin{array}{c}\text { Well } \\
\text { No. } 10\end{array}$ & $\begin{array}{c}\text { Well } \\
\text { No. } 11\end{array}$ & $\begin{array}{c}\text { Well } \\
\text { No. } 12\end{array}$ & \multirow[t]{2}{*}{$\begin{array}{l}\text { NYS } \\
\text { DWS }\end{array}$} \\
\hline & \multicolumn{7}{|c|}{$-\mu \mathrm{g} / \mathrm{L}$} & \\
\hline Dichlorodifluoromethane & $<M D L$ & $<M D L$ & $<M D L$ & $<M D L$ & $<M D L$ & $<M D L$ & $<M D L$ & 5 \\
\hline Chloromethane & $<\mathrm{MDL}$ & $<M D L$ & $<M D L$ & $<\mathrm{MDL}$ & $<\mathrm{MDL}$ & $<M D L$ & $<M D L$ & 5 \\
\hline Vinyl Chloride & $<\mathrm{MDL}$ & $<M D L$ & $<M D L$ & $<\mathrm{MDL}$ & $<M D L$ & $<M D L$ & $<\mathrm{MDL}$ & 2 \\
\hline Bromomethane & $<\mathrm{MDL}$ & $<M D L$ & $<M D L$ & $<\mathrm{MDL}$ & $<\mathrm{MDL}$ & $<\mathrm{MDL}$ & $<M D L$ & 5 \\
\hline Chloroethane & $<M D L$ & $<M D L$ & $<M D L$ & $<M D L$ & $<M D L$ & $<M D L$ & $<\mathrm{MDL}$ & 5 \\
\hline Trichlorofluoromethane & $<M D L$ & $<M D L$ & $<M D L$ & $<M D L$ & $<M D L$ & $<M D L$ & $<M D L$ & 5 \\
\hline 1,1-dichloroethene & $<\mathrm{MDL}$ & $<M D L$ & $<\mathrm{MDL}$ & $<\mathrm{MDL}$ & $<\mathrm{MDL}$ & $<\mathrm{MDL}$ & $<\mathrm{MDL}$ & 5 \\
\hline Methylene Chloride & $<\mathrm{MDL}$ & $<M D L$ & $<\mathrm{MDL}$ & $<\mathrm{MDL}$ & $<\mathrm{MDL}$ & $<\mathrm{MDL}$ & $<M D L$ & 5 \\
\hline trans-1,2-dichloroethene & $<M D L$ & $<M D L$ & $<\mathrm{MDL}$ & $<\mathrm{MDL}$ & $<\mathrm{MDL}$ & $<M D L$ & $<M D L$ & 5 \\
\hline 1,1-dichloroethane & $<\mathrm{MDL}$ & $<\mathrm{MDL}$ & $<\mathrm{MDL}$ & $<\mathrm{MDL}$ & $<\mathrm{MDL}$ & $<\mathrm{MDL}$ & $<\mathrm{MDL}$ & 5 \\
\hline cis-1,2-dichloroethene & $<M D L$ & $<M D L$ & $<M D L$ & $<M D L$ & $<M D L$ & $<M D L$ & $<M D L$ & 5 \\
\hline 2,2-dichloropropane & $<\mathrm{MDL}$ & $<\mathrm{MDL}$ & $<\mathrm{MDL}$ & $<\mathrm{MDL}$ & $<\mathrm{MDL}$ & $<\mathrm{MDL}$ & $<\mathrm{MDL}$ & 5 \\
\hline Bromochloromethane & $<\mathrm{MDL}$ & $<\mathrm{MDL}$ & $<\mathrm{MDL}$ & $<\mathrm{MDL}$ & $<\mathrm{MDL}$ & $<\mathrm{MDL}$ & $<\mathrm{MDL}$ & 5 \\
\hline 1,1,1-trichloroethane & $<\mathrm{MDL}$ & $<M D L$ & $<M D L$ & $<\mathrm{MDL}$ & $<\mathrm{MDL}$ & $<M D L$ & $<M D L$ & 5 \\
\hline Carbon Tetrachloride & $<\mathrm{MDL}$ & $<\mathrm{MDL}$ & $<\mathrm{MDL}$ & $<\mathrm{MDL}$ & $<\mathrm{MDL}$ & $<\mathrm{MDL}$ & $<\mathrm{MDL}$ & 5 \\
\hline 1,1-dichloropropene & $<\mathrm{MDL}$ & $<M D L$ & $<M D L$ & $<\mathrm{MDL}$ & $<M D L$ & $<M D L$ & $<M D L$ & 5 \\
\hline 1,2-dichloroethane & $<\mathrm{MDL}$ & $<\mathrm{MDL}$ & $<\mathrm{MDL}$ & $<\mathrm{MDL}$ & $<\mathrm{MDL}$ & $<\mathrm{MDL}$ & $<\mathrm{MDL}$ & 5 \\
\hline Trichloroethene & $<\mathrm{MDL}$ & $<M D L$ & $<\mathrm{MDL}$ & $<\mathrm{MDL}$ & $<\mathrm{MDL}$ & $<\mathrm{MDL}$ & $<\mathrm{MDL}$ & 5 \\
\hline 1,2-dichloropropane & $<\mathrm{MDL}$ & $<\mathrm{MDL}$ & $<\mathrm{MDL}$ & $<\mathrm{MDL}$ & $<\mathrm{MDL}$ & $<\mathrm{MDL}$ & $<\mathrm{MDL}$ & 5 \\
\hline Dibromomethane & $<\mathrm{MDL}$ & $<M D L$ & $<\mathrm{MDL}$ & $<M D L$ & $<\mathrm{MDL}$ & $<\mathrm{MDL}$ & $<\mathrm{MDL}$ & 5 \\
\hline trans-1,3-dichloropropene & $<\mathrm{MDL}$ & $<M D L$ & $<\mathrm{MDL}$ & $<\mathrm{MDL}$ & $<\mathrm{MDL}$ & $<\mathrm{MDL}$ & $<M D L$ & 5 \\
\hline cis-1,3-dichloropropene & $<\mathrm{MDL}$ & $<M D L$ & $<M D L$ & $<\mathrm{MDL}$ & $<\mathrm{MDL}$ & $<\mathrm{MDL}$ & $<M D L$ & 5 \\
\hline 1,1,2-trichloroethane & $<\mathrm{MDL}$ & $<\mathrm{MDL}$ & $<\mathrm{MDL}$ & $<\mathrm{MDL}$ & $<\mathrm{MDL}$ & $<\mathrm{MDL}$ & $<\mathrm{MDL}$ & 5 \\
\hline 1,3-dichloropropane & $<M D L$ & $<M D L$ & $<\mathrm{MDL}$ & $<\mathrm{MDL}$ & $<\mathrm{MDL}$ & $<\mathrm{MDL}$ & $<M D L$ & 5 \\
\hline Chlorobenzene & $<\mathrm{MDL}$ & $<\mathrm{MDL}$ & $<\mathrm{MDL}$ & $<\mathrm{MDL}$ & $<\mathrm{MDL}$ & $<\mathrm{MDL}$ & $<\mathrm{MDL}$ & 5 \\
\hline 1,1,1,2-tetrachloroethane & $<\mathrm{MDL}$ & $<\mathrm{MDL}$ & $<M D L$ & $<\mathrm{MDL}$ & $<\mathrm{MDL}$ & $<M D L$ & $<\mathrm{MDL}$ & 5 \\
\hline Bromobenzene & $<\mathrm{MDL}$ & $<M D L$ & $<\mathrm{MDL}$ & $<\mathrm{MDL}$ & $<\mathrm{MDL}$ & $<M D L$ & $<M D L$ & 5 \\
\hline 1,2,3-trichloropropane & $<\mathrm{MDL}$ & $<\mathrm{MDL}$ & $<\mathrm{MDL}$ & $<\mathrm{MDL}$ & $<\mathrm{MDL}$ & $<M D L$ & $<\mathrm{MDL}$ & 5 \\
\hline 2-chlorotoluene & $<\mathrm{MDL}$ & $<M D L$ & $<M D L$ & $<\mathrm{MDL}$ & $<\mathrm{MDL}$ & $<M D L$ & $<\mathrm{MDL}$ & 5 \\
\hline 4-chlorotoluene & $<\mathrm{MDL}$ & $<\mathrm{MDL}$ & $<\mathrm{MDL}$ & $<\mathrm{MDL}$ & $<\mathrm{MDL}$ & $<\mathrm{MDL}$ & $<\mathrm{MDL}$ & 5 \\
\hline 1,3-dichlorobenzene & $<\mathrm{MDL}$ & $<M D L$ & $<M D L$ & $<\mathrm{MDL}$ & $<M D L$ & $<M D L$ & $<\mathrm{MDL}$ & 5 \\
\hline 1,4-dichlorobenzene & $<\mathrm{MDL}$ & $<\mathrm{MDL}$ & $<\mathrm{MDL}$ & $<\mathrm{MDL}$ & $<\mathrm{MDL}$ & $<\mathrm{MDL}$ & $<\mathrm{MDL}$ & 5 \\
\hline 1,2-dichlorobenzene & $<M D L$ & $<M D L$ & $<M D L$ & $<\mathrm{MDL}$ & $<M D L$ & $<M D L$ & $<\mathrm{MDL}$ & 5 \\
\hline 1,2,4-trichlorobenzene & $<\mathrm{MDL}$ & $<M D L$ & $<M D L$ & $<\mathrm{MDL}$ & $<\mathrm{MDL}$ & $<M D L$ & $<M D L$ & 5 \\
\hline
\end{tabular}


Table 3-6. Potable Water Wells: Analytical Results for Principal Organic Compounds, Synthetic Organic Chemicals, Pesticides, and Micro-Extractables(continued).

\begin{tabular}{|c|c|c|c|c|c|c|c|c|}
\hline \multirow[b]{2}{*}{ Compound } & $\begin{array}{l}\text { WTP } \\
\text { Effluent }\end{array}$ & $\begin{array}{l}\text { Well } \\
\text { No. } 4\end{array}$ & $\begin{array}{l}\text { Well } \\
\text { No. } 6\end{array}$ & $\begin{array}{l}\text { Well } \\
\text { No. } 7\end{array}$ & $\begin{array}{l}\text { Well } \\
\text { No. } 10\end{array}$ & $\begin{array}{l}\text { Well } \\
\text { No. } 11\end{array}$ & $\begin{array}{l}\text { Well } \\
\text { No. } 12\end{array}$ & \multirow[t]{2}{*}{$\begin{array}{l}\text { NYS } \\
\text { DWS }\end{array}$} \\
\hline & & & & $-\mu \mathrm{g} / \mathrm{L}$ & & & & \\
\hline Hexachlorobutadiene & $<M D L$ & $<M D L$ & $<M D L$ & $<M D L$ & $<M D L$ & $<M D L$ & $<\mathrm{MDL}$ & 5 \\
\hline Tetrachloroethene & $<M D L$ & $<M D L$ & $<M D L$ & $<M D L$ & $<M D L$ & $<M D L$ & $<\mathrm{MDL}$ & 5 \\
\hline 1,1,2,2-Tetrachloroethane & $<M D L$ & $<M D L$ & $<M D L$ & $<\mathrm{MDL}$ & $<\mathrm{MDL}$ & $<\mathrm{MDL}$ & $<\mathrm{MDL}$ & 5 \\
\hline 1,2,3-trichlorobenzene & $<M D L$ & $<M D L$ & $<M D L$ & $<\mathrm{MDL}$ & $<\mathrm{MDL}$ & $<\mathrm{MDL}$ & $<\mathrm{MDL}$ & 5 \\
\hline Benzene & $<M D L$ & $<M D L$ & $<M D L$ & $<M D L$ & $<\mathrm{MDL}$ & $<\mathrm{MDL}$ & $<\mathrm{MDL}$ & 5 \\
\hline Toluene & $<M D L$ & $<M D L$ & $<M D L$ & $<M D L$ & $<\mathrm{MDL}$ & $<\mathrm{MDL}$ & $<M D L$ & 5 \\
\hline Ethylbenzene & $<M D L$ & $<M D L$ & $<M D L$ & $<M D L$ & $<M D L$ & $<M D L$ & $<M D L$ & 5 \\
\hline m,p-xylene & $<M D L$ & $<M D L$ & $<M D L$ & $<M D L$ & $<\mathrm{MDL}$ & $<M D L$ & $<M D L$ & 5 \\
\hline o-xylene & $<M D L$ & $<M D L$ & $<M D L$ & $<\mathrm{MDL}$ & $<\mathrm{MDL}$ & $<\mathrm{MDL}$ & $<\mathrm{MDL}$ & 5 \\
\hline Styrene & $<M D L$ & $<M D L$ & $<M D L$ & $<\mathrm{MDL}$ & $<\mathrm{MDL}$ & $<\mathrm{MDL}$ & $<M D L$ & 5 \\
\hline Isopropylbenzene & $<M D L$ & $<M D L$ & $<M D L$ & $<M D L$ & $<\mathrm{MDL}$ & $<M D L$ & $<M D L$ & 5 \\
\hline n-propylbenzene & $<M D L$ & $<M D L$ & $<M D L$ & $<\mathrm{MDL}$ & $<\mathrm{MDL}$ & $<\mathrm{MDL}$ & $<M D L$ & 5 \\
\hline 1,3,5-trimethylbenzene & $<M D L$ & $<M D L$ & $<M D L$ & $<\mathrm{MDL}$ & $<M D L$ & $<\mathrm{MDL}$ & $<M D L$ & 5 \\
\hline tert-butylbenzene & $<M D L$ & $<M D L$ & $<M D L$ & $<\mathrm{MDL}$ & $<M D L$ & $<\mathrm{MDL}$ & $<M D L$ & 5 \\
\hline 1,2,4-trimethylbenzene & $<M D L$ & $<M D L$ & $<M D L$ & $<M D L$ & $<M D L$ & $<M D L$ & $<\mathrm{MDL}$ & 5 \\
\hline sec-butylbenzene & $<M D L$ & $<M D L$ & $<M D L$ & $<\mathrm{MDL}$ & $<\mathrm{MDL}$ & $<\mathrm{MDL}$ & $<\mathrm{MDL}$ & 5 \\
\hline 4-Isopropyltoluene & $<M D L$ & $<M D L$ & $<M D L$ & $<\mathrm{MDL}$ & $<\mathrm{MDL}$ & $<\mathrm{MDL}$ & $<\mathrm{MDL}$ & 5 \\
\hline n-butylbenzene & $<M D L$ & $<M D L$ & $<M D L$ & $<\mathrm{MDL}$ & $<\mathrm{MDL}$ & $<\mathrm{MDL}$ & $<\mathrm{MDL}$ & 5 \\
\hline Chloroform & 5.6 & 3.7 & 23.4 & 1.5 & 1.4 & 1.6 & 0.5 & 50 \\
\hline Bromodichloromethane & 4.8 & $<M D L$ & 2.5 & $<\mathrm{MDL}$ & 0.6 & $<\mathrm{MDL}$ & $<\mathrm{MDL}$ & 50 \\
\hline Dibromochloromethane & 5.5 & $<M D L$ & 0.5 & $<M D L$ & $<\mathrm{MDL}$ & $<M D L$ & $<\mathrm{MDL}$ & 50 \\
\hline Bromoform & $<\mathrm{MDL}$ & $<M D L$ & $<M D L$ & $<\mathrm{MDL}$ & $<\mathrm{MDL}$ & $<\mathrm{MDL}$ & $<\mathrm{MDL}$ & 50 \\
\hline Methyl tert-butyl ether & $<M D L$ & $<M D L$ & $<M D L$ & $<\mathrm{MDL}$ & $<\mathrm{MDL}$ & $<\mathrm{MDL}$ & $<M D L$ & 50 \\
\hline Lindane & NR & $<M D L$ & $<M D L$ & $<\mathrm{MDL}$ & $<\mathrm{MDL}$ & $<\mathrm{MDL}$ & $<M D L$ & 0.2 \\
\hline Heptachlor & NR & $<M D L$ & $<M D L$ & $<\mathrm{MDL}$ & $<\mathrm{MDL}$ & $<M D L$ & $<M D L$ & 0.4 \\
\hline Aldrin & NR & $<M D L$ & $<M D L$ & $<\mathrm{MDL}$ & $<\mathrm{MDL}$ & $<\mathrm{MDL}$ & $<M D L$ & 5 \\
\hline Heptachlor Epoxide & NR & $<M D L$ & $<M D L$ & $<\mathrm{MDL}$ & $<\mathrm{MDL}$ & $<M D L$ & $<M D L$ & 0.2 \\
\hline Dieldrin & NR & $<\mathrm{MDL}$ & $<\mathrm{MDL}$ & $<\mathrm{MDL}$ & $<\mathrm{MDL}$ & $<\mathrm{MDL}$ & $<\mathrm{MDL}$ & 5 \\
\hline Endrin & NR & $<M D L$ & $<\mathrm{MDL}$ & $<\mathrm{MDL}$ & $<\mathrm{MDL}$ & $<\mathrm{MDL}$ & $<\mathrm{MDL}$ & 0.2 \\
\hline Methoxychlor & NR & $<M D L$ & $<\mathrm{MDL}$ & $<\mathrm{MDL}$ & $<\mathrm{MDL}$ & $<\mathrm{MDL}$ & $<\mathrm{MDL}$ & 40 \\
\hline Toxaphene & NR & $<\mathrm{MDL}$ & $<\mathrm{MDL}$ & $<\mathrm{MDL}$ & $<\mathrm{MDL}$ & $<\mathrm{MDL}$ & $<\mathrm{MDL}$ & 3 \\
\hline Chlordane & NR & $<\mathrm{MDL}$ & $<M D L$ & $<\mathrm{MDL}$ & $<\mathrm{MDL}$ & $<\mathrm{MDL}$ & $<\mathrm{MDL}$ & 2 \\
\hline Total PCB's & NR & $<\mathrm{MDL}$ & $<\mathrm{MDL}$ & $<\mathrm{MDL}$ & $<\mathrm{MDL}$ & $<\mathrm{MDL}$ & $<\mathrm{MDL}$ & 0.5 \\
\hline 2,4,5,-TP (Silvex) & NR & $<\mathrm{MDL}$ & $<\mathrm{MDL}$ & $<\mathrm{MDL}$ & $<\mathrm{MDL}$ & $<\mathrm{MDL}$ & $<\mathrm{MDL}$ & 10 \\
\hline Dinoseb & NR & $<\mathrm{MDL}$ & $<M D L$ & $<\mathrm{MDL}$ & $<\mathrm{MDL}$ & $<\mathrm{MDL}$ & $<\mathrm{MDL}$ & 50 \\
\hline Dalapon & NR & $<M D L$ & $<M D L$ & $<\mathrm{MDL}$ & $<\mathrm{MDL}$ & $<\mathrm{MDL}$ & $<\mathrm{MDL}$ & 50 \\
\hline
\end{tabular}


Table 3-6. Potable Water Wells: Analytical Results for Principal Organic Compounds, Synthetic Organic Chemicals, Pesticides, and Micro-Extractables (concluded).

\begin{tabular}{|c|c|c|c|c|c|c|c|c|}
\hline \multirow[b]{2}{*}{ Compound } & $\begin{array}{c}\text { WTP } \\
\text { Effluent }\end{array}$ & $\begin{array}{l}\text { Well } \\
\text { No. } 4\end{array}$ & $\begin{array}{l}\text { Well } \\
\text { No. } 6\end{array}$ & $\begin{array}{l}\text { Well } \\
\text { No. } 7\end{array}$ & $\begin{array}{l}\text { Well } \\
\text { No. } 10\end{array}$ & $\begin{array}{c}\text { Well } \\
\text { No. } 11\end{array}$ & $\begin{array}{c}\text { Well } \\
\text { No. } 12\end{array}$ & \multirow[t]{2}{*}{$\begin{array}{l}\text { NYS } \\
\text { DWS }\end{array}$} \\
\hline & \multicolumn{7}{|c|}{$\mu \mathrm{g} / \mathrm{L}$} & \\
\hline Picloram & NR & $<M D L$ & $<M D L$ & $<M D L$ & $<M D L$ & $<\mathrm{MDL}$ & $<M D L$ & 50 \\
\hline Dicamba & NR & $<M D L$ & $<M D L$ & $<\mathrm{MDL}$ & $<M D L$ & $<\mathrm{MDL}$ & $<M D L$ & 50 \\
\hline Pentachlorophenol & NR & $<M D L$ & $<M D L$ & $<M D L$ & $<M D L$ & $<\mathrm{MDL}$ & $<M D L$ & 1 \\
\hline Hexachlorocyclopentadiene & NR & $<M D L$ & $<M D L$ & $<M D L$ & $<M D L$ & $<\mathrm{MDL}$ & $<M D L$ & 5 \\
\hline Bis(2-ethylhexyl)Phthalate & NR & $<M D L$ & $<M D L$ & $<M D L$ & $<M D L$ & $<\mathrm{MDL}$ & $<M D L$ & 50 \\
\hline Bis(2-ethylhexyl)Adipate & NR & $<M D L$ & $<M D L$ & $<\mathrm{MDL}$ & $<M D L$ & $<\mathrm{MDL}$ & $<M D L$ & 50 \\
\hline Hexachlorobenzene & NR & $<M D L$ & $<\mathrm{MDL}$ & $<M D L$ & $<M D L$ & $<\mathrm{MDL}$ & $<M D L$ & 5 \\
\hline Benzo(A)Pyrene & NR & $<M D L$ & $<\mathrm{MDL}$ & $<M D L$ & $<M D L$ & $<\mathrm{MDL}$ & $<M D L$ & 50 \\
\hline Aldicarb Sulfone & NR & $<M D L$ & $<M D L$ & $<M D L$ & $<M D L$ & $<\mathrm{MDL}$ & $<M D L$ & SNS \\
\hline Aldicarb Sulfoxide & NR & $<\mathrm{MDL}$ & $<\mathrm{MDL}$ & $<M D L$ & $<M D L$ & $<\mathrm{MDL}$ & $<M D L$ & SNS \\
\hline Aldicarb & NR & $<\mathrm{MDL}$ & $<\mathrm{MDL}$ & $<M D L$ & $<M D L$ & $<\mathrm{MDL}$ & $<M D L$ & SNS \\
\hline Oxamyl & NR & $<\mathrm{MDL}$ & $<\mathrm{MDL}$ & $<M D L$ & $<M D L$ & $<\mathrm{MDL}$ & $<M D L$ & 50 \\
\hline 3-Hydroxycarbofuran & NR & $<\mathrm{MDL}$ & $<\mathrm{MDL}$ & $<\mathrm{MDL}$ & $<M D L$ & $<\mathrm{MDL}$ & $<M D L$ & 50 \\
\hline Carbofuran & NR & $<M D L$ & $<M D L$ & $<M D L$ & $<M D L$ & $<\mathrm{MDL}$ & $<M D L$ & 40 \\
\hline Carbaryl & NR & $<M D L$ & $<M D L$ & $<\mathrm{MDL}$ & $<M D L$ & $<\mathrm{MDL}$ & $<M D L$ & 50 \\
\hline Methomyl & NR & $<M D L$ & $<M D L$ & $<\mathrm{MDL}$ & $<M D L$ & $<\mathrm{MDL}$ & $<M D L$ & 50 \\
\hline Glyphosate & NR & $<\mathrm{MDL}$ & $<M D L$ & $<\mathrm{MDL}$ & $<M D L$ & $<\mathrm{MDL}$ & $<M D L$ & 50 \\
\hline Diquat & NR & $<\mathrm{MDL}$ & $<M D L$ & $<\mathrm{MDL}$ & $<M D L$ & $<\mathrm{MDL}$ & $<M D L$ & 50 \\
\hline 1,2-dibromoethane (EDB) & NR & $<\mathrm{MDL}$ & $<M D L$ & $<M D L$ & NA & $<\mathrm{MDL}$ & $<M D L$ & 0.05 \\
\hline 1,2-dibromo-3-chloropropane & NR & $<\mathrm{MDL}$ & $<M D L$ & $<M D L$ & NA & $<\mathrm{MDL}$ & $<M D L$ & 0.2 \\
\hline $2,4,-D$ & NR & $<M D L$ & $<\mathrm{MDL}$ & $<M D L$ & $<M D L$ & $<\mathrm{MDL}$ & $<M D L$ & 50 \\
\hline Alachlor & NR & $<M D L$ & $<\mathrm{MDL}$ & $<M D L$ & $<M D L$ & $<\mathrm{MDL}$ & $<M D L$ & 2 \\
\hline Simazine & NR & $<\mathrm{MDL}$ & $<\mathrm{MDL}$ & $<M D L$ & $<M D L$ & $<\mathrm{MDL}$ & $<M D L$ & 50 \\
\hline Atrazine & NR & $<\mathrm{MDL}$ & $<\mathrm{MDL}$ & $<M D L$ & $<M D L$ & $<\mathrm{MDL}$ & $<M D L$ & 3 \\
\hline Metolachlor & NR & $<\mathrm{MDL}$ & $<\mathrm{MDL}$ & $<\mathrm{MDL}$ & $<\mathrm{MDL}$ & $<\mathrm{MDL}$ & $<\mathrm{MDL}$ & 50 \\
\hline Metribuzin & NR & $<\mathrm{MDL}$ & $<\mathrm{MDL}$ & $<\mathrm{MDL}$ & $<\mathrm{MDL}$ & $<\mathrm{MDL}$ & $<\mathrm{MDL}$ & 50 \\
\hline Butachlor & NR & $<\mathrm{MDL}$ & $<\mathrm{MDL}$ & $<\mathrm{MDL}$ & $<\mathrm{MDL}$ & $<\mathrm{MDL}$ & $<\mathrm{MDL}$ & 50 \\
\hline Endothall & NR & $<\mathrm{MDL}$ & $<\mathrm{MDL}$ & $<\mathrm{MDL}$ & $<\mathrm{MDL}$ & $<\mathrm{MDL}$ & $<\mathrm{MDL}$ & 100 \\
\hline Propachlor & NR & $<\mathrm{MDL}$ & $<\mathrm{MDL}$ & $<\mathrm{MDL}$ & $<\mathrm{MDL}$ & $<\mathrm{MDL}$ & $<\mathrm{MDL}$ & 50 \\
\hline $\begin{array}{l}\text { Notes: } \\
\text { See Chapter } 7 \text {, Figure } 7-3 \text { for well } \\
\text { For compliance determination with } \\
\text { table water samples were analy } \\
\text { annually for other organics by } \\
\text { laboratory. } \\
\text { The minimum detection limits for } \\
\text { Minimum detection limits for syn } \\
\text { compound-specific, and in all ca } \\
\text { Health drinking water standard. }\end{array}$ & $\begin{array}{l}\text { State Depar } \\
\text { rly for Princ } \\
\text { Inc., a New } \\
\text { organic com } \\
\text { inic chemica } \\
\text { ss than the }\end{array}$ & $\begin{array}{l}\text { of Health } \\
\text { Organic Co } \\
\text { State-certi } \\
\text { d analytes } \\
\text { dd micro-ex } \\
\text { ork State }\end{array}$ & $\begin{array}{l}\text { lards, po- } \\
\text { unds and } \\
\text { contractor } \\
0.5 \mu \mathrm{g} / \mathrm{L} \text {. } \\
\text { ables are } \\
\text { irtment of }\end{array}$ & $\begin{array}{c}<\mathrm{MDL}=\mathrm{L} \\
\text { question } \\
\mathrm{NA}=\text { Not av } \\
\mathrm{NR}=\text { Analys } \\
\text { SNS = Drink } \\
\text { NYS DWS } \\
\text { WTP = Wate }\end{array}$ & $\begin{array}{l}\text { han the Mi } \\
\text { e } \\
\text { t Required } \\
\text { Vater Standa } \\
\text { York State } \\
\text { atment Plan }\end{array}$ & $\begin{array}{l}\text { ot Specified } \\
\text { ing Water S }\end{array}$ & it for the & yte in \\
\hline
\end{tabular}


Under the "authorized by rule” requirements, a separate inventory is maintained for these treatment facilities and is periodically updated whenever a new device is added or closed.

\subsection{PREVENTING AND REPORTING SPILLS}

Federal, state, and local regulations are in place to address the management of storage facilities containing chemicals, petroleum, and other hazardous materials. The regulations include specifications for the design of storage facilities, requirements for written plans relating to unplanned releases, and requirements for reporting any releases that do occur. BNL's compliance with these regulations is described below.

\subsubsection{Preventing Oil Pollution and Spills}

As required by the Oil Pollution Act, BNL maintains a Spill Prevention Control and Countermeasures (SPCC) Plan as a condition of its license to store petroleum fuel. The SPCC Plan is part of the Laboratory's emergency preparedness program and outlines mitigating and remedial actions that would be taken in the event of a major petroleum release. The plan also provides information regarding release prevention measures, the design of storage facilities, and maps detailing storage facility locations. The SPCC Plan is filed with NYSDEC, EPA, and DOE, and was updated in October 2007 (Chaloupka 2007). BNL remained in full compliance with the SPCC requirements in 2007.

In July 2002, EPA adopted significant changes to the SPCC regulations that extended the requirements to previously unregulated facilities and provided some relief to existing covered facilities. These changes, among others, included extending the plan update deadline from 3 to 5 years, and specifying that containers smaller than 55 gallons need not be counted toward reaching SPCC applicability. In October 2007,
BNL's deadline for updating and implementing its SPCC plan was once again extended by EPA, this time to February 2009. Although the Laboratory has recently updated its SPCC Plan ahead of schedule, the plan will be reviewed again prior to the February 2009 deadline to ensure it complies with all SPCC requirements.

BNL also maintains a Facility Response Plan (FRP) (Lee 2006) that outlines emergency response procedures to be implemented in the event of a worst-case discharge of oil. In October 2005, EPA reviewed the Laboratory's FRP and responded with numerous comments. The revised FRP was approved by EPA in September 2006. Updates to the plan were published in 2007 to ensure all telephone notification lists remained current.

\subsubsection{Emergency Reporting Requirements}

The Emergency Planning and Community Right-to-Know Act (EPCRA) and Title III of the Superfund Amendments and Reauthorization Act (SARA) require that facilities report inventories (i.e., Tier II Report) and releases (i.e., Tier III Report) of certain chemicals that exceed specific release thresholds. These reports are submitted to the local emergency planning committee and the state emergency response commission. Community Rightto-Know requirements are codified under 40 CFR Parts 355, 370, and 372. Table 3-1 summarizes the applicability of the regulations to BNL. The Laboratory complied with these requirements in 2007 through the submittal of reports under EPCRA Sections 302, 303, 311, and 312. In 2007, through the Tier III report, BNL reported releases of lead ( 16,483 pounds), mercury ( 95 pounds), PCBs ( 40 pounds), benzo(g,h,i)perylene ( $<1$ pound), and polycyclic aromatic compounds ( $<1$ pound). "Releases" of lead, PCBs, and mercury were

\begin{tabular}{|l|l|c|c|c|}
\hline \multicolumn{5}{|c|}{ Applicability of EPCRA to BNL } \\
\hline EPCRA 302-303 & Planning Notification & YES [X] & NO [ ] & NOT REQUIRED [ ] \\
\hline EPCRA 304 & EHS Release Notification & YES [ ] & NO [ ] & NOT REQUIRED [X] \\
\hline EPCRA 311-312 & MSDS/Chemical Inventory & YES [X] & NO [ ] & NOT REQUIRED [ ] \\
\hline EPCRA 313 & TRI Reporting & YES [X] & NO [ ] & NOT REQUIRED [ ] \\
\hline
\end{tabular}


predominantly in the form of shipments of waste for off-site recycling or disposal. Releases of benzo(g,h,i)perylene and polycyclic aromatic compounds were as byproducts of the combustion of fuel oils. In 2007, there were no releases of "extremely hazardous substances" reportable under Part 304.

\subsubsection{Spills and Releases}

When a spill of hazardous material occurs, Laboratory and contractor personnel are required to immediately notify the on-site Fire Rescue Group, whose members are trained to respond to such releases. The initial step in spill response is to contain and control any release and to notify additional response personnel (i.e., BNL environmental professionals, industrial hygienists, etc.). Environmental professionals reporting to the scene assess the spill for environmental impact and determine if it is reportable to regulatory agencies. Any release of petroleum products to soil must be reported to both NYSDEC and SCDHS, and any release affecting surface water must also be reported to the EPA National Response Center. In addition, a release of more than 5 gallons of petroleum product to impermeable surfaces or containment areas must be reported to NYSDEC and SCDHS. Spills of chemicals in quantities greater than the CERCLA-reportable limits must be reported to the EPA National Response Center, NYSDEC, and SCDHS. Remediation of the spill is conducted, as necessary, to prevent impacts to the environment, minimize human health exposures, and restore the site.

During 2007, there were 21 spills, twelve of which met regulatory agency reporting criteria. The remaining nine spills were small-volume releases either to containment areas or to other impermeable surfaces that did not exceed a reportable quantity. Four of the seven reported releases involved small volumes of ethylene glycol spilled from employee- or Laboratoryowned vehicles. Four releases were from hydraulic systems on BNL-owned and -operated equipment. In all cases, the releases were 5 gallons or less, but because they reached the soil they were reportable in New York State, which has a "zero tolerance" level for releases of pe- troleum products to soil or water. There was one spill of hydraulic fluid from a non BNL-operated vehicle and a spill of waste motor oil that an employee had brought on-site for disposal at the public service station. Again, since these spills impacted soils they were reportable to the NYSDEC. There were two spills associated with elevator or hydraulic lift systems. The first spill was discovered when a vehicle lift began to malfunction at Building 423. The second spill occurred during replacement of the elevator lift system in Building 1005. Table 3-7 summarizes each of the reportable incidents, including a description of the cause and corrective actions taken. There were no spills reportable through the DOE Occurrence Reporting and Processing System (ORPS), a system for identifying, categorizing, notifying, investigating, analyzing, and reporting to DOE events or conditions discovered on site. In addition, there were no environmental events reported through ORPS in 2007.

The Laboratory continues its successful reductions in the number and severity of spills on site. In 2007, the total number of spills was reduced by 22 percent, from 27 spills in 2006 . Measures employed to achieve this reduction included: replacing petroleum-based lubricants and fluids with vegetable-based products, installing stainless steel-reinforced hydraulic lines on various pieces of equipment, and training staff in proper spill-response techniques.

\subsubsection{Major Petroleum Facility License}

The storage of 2.3 million gallons of fuel oil (principally No. 6 oil) subjects the Laboratory to Major Petroleum Facility (MPF) licensing by NYSDEC. The fuel is used at the CSF to produce high pressure steam to heat and cool BNL facilities and is stored in six tanks ranging from 300,000 to 600,000 gallons. In March 2007, the Laboratory obtained a renewed license to operate the MPF. The license renewal was based on, among other factors, the history of spills and discharges, the history of compliance with the applicable provisions of 6 NYCRR Parts 613 and 614, review of submitted plans and inspections of the facility, and compliance with license conditions. During 2007, BNL remained in full 
Table 3-7. Summary of Chemical and Oil Spill Reports.

\begin{tabular}{|c|c|c|c|}
\hline $\begin{array}{l}\text { Spill No. } \\
\text { and Date }\end{array}$ & $\begin{array}{l}\text { Material and } \\
\text { Quantity }\end{array}$ & $\begin{array}{l}\text { ORPS } \\
\text { Report }\end{array}$ & Source/Cause and Corrective Actions \\
\hline $\begin{array}{l}07-02 \\
02 / 07 / 07\end{array}$ & $\begin{array}{l}\text { Ethylene Glycol/ } \\
\text { Water } \\
1 / 2 \text { gallon }\end{array}$ & No & $\begin{array}{l}\text { A Laboratory vehicle leaked antifreeze onto the parking lot of Building } 50 \text {. Speedy dry was used to absorb } \\
\text { the fluid and the car was sent to the vehicle maintenance shop for repair. All wastes were containerized } \\
\text { for off-site disposal. }\end{array}$ \\
\hline $\begin{array}{l}07-03 \\
04 / 20 / 07\end{array}$ & $\begin{array}{l}\text { Hydraulic Fluid } \\
1 \text { quart }\end{array}$ & No & $\begin{array}{l}\text { While using a front-end loader to clear brush, a stump became wedged between the bucket and the } \\
\text { ground, resulting in damage to a hydraulic hose. The loader was immediately secured and shut down. } \\
\text { Impacted soils were removed and containerized for off-site disposal. }\end{array}$ \\
\hline $\begin{array}{l}07-04 \\
05 / 03 / 07\end{array}$ & $\begin{array}{l}\text { Hydraulic Fluid } \\
1 / 2 \text { cup }\end{array}$ & No & $\begin{array}{l}\text { During retrieval of a roll-off trailer, a Town of Brookhaven vehicle spilled approximately } 1 / 2 \text { cup of hy- } \\
\text { draulic fluid to the ground. The spill was caused by an overfilled reservoir. The reservoir was drained to } \\
\text { remove excess fluid, and the impacted soil was removed for off-site disposal. }\end{array}$ \\
\hline $\begin{array}{l}07-05 \\
05 / 17 / 07\end{array}$ & $\begin{array}{l}\text { Hydraulic Fluid } \\
2 \text { gallons }\end{array}$ & No & $\begin{array}{l}\text { While mowing the lawn outside of Building } 750 \text {, the lawn mower developed a leak from the valve spool. } \\
\text { Examination of the valve spool showed that one of the hose fittings loosened due to vibration. The hose } \\
\text { connection was repaired, and the impacted soils were excavated and containerized for off-site disposal. }\end{array}$ \\
\hline $\begin{array}{l}07-06 \\
05 / 18 / 07\end{array}$ & $\begin{array}{l}\text { Biobased } \\
\text { Hydraulic Fluid } \\
25 \text { gallons }\end{array}$ & No & $\begin{array}{l}\text { During examination of the vehicle lifts in Building 423, vehicle lift } 2 \text { was noted as not operating properly. } \\
\text { Further examination by the repair contractor revealed a leak in the buried piping, and the piping was } \\
\text { then repaired. The hydraulic fluid was vegetable oil-based; therefore, the New York State Department of } \\
\text { Environmental Conservation did not require the remediation of the impacted soils. }\end{array}$ \\
\hline $\begin{array}{l}07-07 \\
06 / 03 / 07\end{array}$ & $\begin{array}{l}\text { Ethylene Glycol/ } \\
\text { Water } \\
1 \text { gallon }\end{array}$ & No & $\begin{array}{l}\text { A privately operated limousine developed an antifreeze leak due to a failed water pump. The vehicle was } \\
\text { towed from the BNL site for repair, and the spilled fluid was absorbed with speedy dry and containerized } \\
\text { for off-site disposal. }\end{array}$ \\
\hline $\begin{array}{l}07-08 \\
06 / 06 / 07\end{array}$ & $\begin{array}{l}\text { Waste Engine } \\
\text { Oil } \\
3 \text { gallons }\end{array}$ & No & $\begin{array}{l}\text { A BNL employee brought a container of waste oil from home to dispose of at the local service station. The } \\
\text { container was transferred from his personal vehicle to a laboratory pick-up truck. The container was not } \\
\text { secured in the back of the truck, and it fell over and split open. The oil spilled into the back of the truck, } \\
\text { out of the rear door, and onto pavement and soil. Speedy dry and sand were used to absorb the spilled } \\
\text { oil. All contaminated media was collected and containerized for off-site disposal. }\end{array}$ \\
\hline $\begin{array}{l}07-11 \\
08 / 07 / 07\end{array}$ & $\begin{array}{l}\text { Ethylene Glycol/ } \\
\text { Water } \\
1 / 2 \text { gallon }\end{array}$ & No & $\begin{array}{l}\text { The water pump in a BNL-operated vehicle failed, resulting in a release of antifreeze to the parking lot of } \\
\text { Building 423. The vehicle was awaiting repair at the time of release. Speedy dry was used to remediate } \\
\text { the release, which was later collected and containerized for off-site disposal. }\end{array}$ \\
\hline $\begin{array}{l}07-13 \\
08 / 29 / 07\end{array}$ & $\begin{array}{l}\text { Ethylene Glycol/ } \\
\text { Water } \\
1 / 2 \text { gallon }\end{array}$ & No & $\begin{array}{l}\text { The lower radiator hose of a Laboratory vehicle failed, resulting in a release of antifreeze to the parking } \\
\text { lot at Building } 599 \text {. Speedy dry was used to absorb the spilled fluid, which was later collected for off-site } \\
\text { disposal. The vehicle was sent to the vehicle maintenance shop for repair. }\end{array}$ \\
\hline $\begin{array}{l}07-15 \\
09 / 19 / 07\end{array}$ & $\begin{array}{l}\text { Hydraulic Fluid } \\
30 \text { gallons }\end{array}$ & No & $\begin{array}{l}\text { During replacement of the elevator hydraulic system in Building } 1005 \text {, a release of hydraulic fluid was } \\
\text { discovered. The fluid was found in the interstitial space of the hydraulic cylinder and the exterior casing. } \\
\text { The elevator casing was partially submerged in groundwater and the oil was found floating on the surface } \\
\text { of the water. All oil was contained between the outside casing and the water. The oil was removed by } \\
\text { pumping and by flooding the casing with water, causing the oil to spill out the top where it was collected. } \\
\text { All oil and contaminated water was containerized for off-site disposal. The new hydraulic system includes } \\
\text { a secondary containment sock to prevent future releases in the event of a casing leak. }\end{array}$ \\
\hline $\begin{array}{l}07-17 \\
10 / 22 / 07\end{array}$ & $\begin{array}{l}\text { Hydraulic Fluid } \\
5 \text { gallons }\end{array}$ & No & $\begin{array}{l}\text { A new front-end loader leaked oil on the ground during its initial use. Examination of the unit showed } \\
\text { that the hose connections at the control box were loose, probably due to vibration during shipping. The } \\
\text { contaminated soils were containerized for off-site disposal. }\end{array}$ \\
\hline $\begin{array}{l}07-19 \\
12 / 10 / 07\end{array}$ & $\begin{array}{l}\text { Hydraulic Fluid } \\
1 \text { gallon }\end{array}$ & No & $\begin{array}{l}\text { A hydraulic hose on the garbage truck failed resulting in a release of hydraulic oil to parking areas near } \\
\text { Buildings } 488 \text { and } 902 \text {. Due to wet weather, the oil flowed into a storm water catch basin and was dis- } \\
\text { charged to a low-lying area near Building } 904 \text {. The spill was remediated by using spill absorbents. All } \\
\text { contaminated media was collected and containerized for off-site disposal. }\end{array}$ \\
\hline
\end{tabular}

Note:

* Release is reportable to DOE under the requirements of DOE Order 231.1A, Occurrence Reporting and Processing.

compliance with the MPF license requirements, which include monitoring groundwater in the vicinity of the six active, aboveground storage tanks. The license also requires BNL to inspect the storage facilities monthly and test the tank leak detection systems, high-level monitoring, and secondary containment. Tank integrity is also checked periodically. Groundwater 
monitoring consists of monthly checks for the presence of floating products and twice-yearly analyses for VOCs and semi-volatile organic compounds (SVOCs). In 2007, no VOCs, SVOCs, or floating products attributable to MPF activities were detected. See SER Volume II, Groundwater Status Report, for additional information on groundwater monitoring results.

In 2007, engineering plans were prepared for the complete upgrade of the secondary containment basin for tanks 5 and 6 and were submitted to NYSDEC for approval. As part of the upgrade work, the tanks were emptied, all related piping and supports were removed, and the cathodic protection system for the tanks was temporarily de-energized to facilitate replacement of the containment system. The approved plans will be implemented in 2008.

In November, NYSDEC conducted its annual inspection of the Major Oil Storage Facility. Three conditions that required corrective action were identified: the submittal of design specifications/plans for the replacement of the secondary containment system for tanks 5 and 6, repair of a malfunctioning alarm system located at the steam plant truck off-loading area, and the need for an additional cover stone on several of the secondary containment systems to prevent liner damage. In addition, an inspection of the Laboratory's diesel tank farm and underground gasoline storage facilities identified three conditions that required corrective action. They included reapplication of the proper color coding for an underground storage tank containing \#2 fuel oil, inspection and repair of two high-level alarms at the diesel tank farm that failed to function properly during manual activation, and noting both the design and working capacities of each tank at the diesel tank farm. All conditions were corrected in accordance with NYSDEC directives prior to the end of calendar year 2007.

\subsubsection{Chemical Bulk Storage}

Title 6 of the Official Compilation of the Codes, Rules and Regulations of the State of New York (NYCRR), Part 597, requires that all aboveground tanks larger than 185 gallons and all underground tanks that store specific chemi- cals be registered with NYSDEC. The Laboratory holds a Hazardous Substance Bulk Storage Registration Certificate for eight tanks. Seven of the tanks store treatment chemicals for potable water (sodium hydroxide and sodium hypochlorite) and one tank stores gallium trichloride, formerly required in physics experiments. The tanks range in capacity from 200 to 1,200 gallons. These tanks are also regulated under Suffolk County Sanitary Code (SCSC) Article 12 (SCDHS 1993) and are managed in accordance with BNL procedures designed to conform to Suffolk County requirements.

NYSDEC conducted an inspection of the Chemical Bulk Storage (CBS) facilities in November 2007. During this inspection, two issues were identified that required corrective action: peeling and blistering paint observed on the west end plate of Tank 637-01 located in Potable Well House \#12, and tank labels that did not include the working capacity of each tank. The issues were corrected in accordance with the NYSDEC directive.

\subsubsection{County Storage Requirements}

Article 12 of the Suffolk County Sanitary Code regulates the storage and handling of toxic and hazardous materials in aboveground or underground storage tanks, drum storage facilities, piping systems, and transfer areas. Article 12 specifies design criteria to prevent environmental impacts resulting from spills or leaks and specifies administrative requirements such as identification, registration, and spill reporting procedures. In 1987, the Laboratory entered into a voluntary Memorandum of Agreement with SCDHS, in which DOE and BNL agreed to conform to the environmental requirements of Article 12.

Currently, there are 348 active storage facilities at BNL for wastewater, chemicals, and fuel (some fuel facilities are regulated under the MPF license), as well as storage facilities used to support BNL research. An additional 37 storage facilities are temporarily out of service. The Laboratory has two active storage facilities associated with environmental restoration activities conducted under the CERCLA program; these are not regulated under Article 12. 
BNL has an ongoing program to upgrade or replace existing storage facilities, to ensure that the information provided to SCDHS for all registered storage facilities is accurate, and to ensure that new or modified storage facilities are designed and reviewed for full conformance with Article 12 regulations. In 2007, the Laboratory continued to provide SCDHS with updated information regarding several registered tanks, including the results of annual cathodic protection testing and a request to abandon the Building $801 \mathrm{D}$ and $\mathrm{F}$ tanks, which was approved by SCDHS. In addition, design plans and specifications for two new diesel generator tank systems at Buildings 515 and 912A were prepared and submitted to SCDHS for approval. Both systems were designed to fully conform to SCSC Article 12 requirements for aboveground storage.

In October 2007, a representative from SCDHS conducted an inspection of the Laboratory's underground storage tanks at the motor pool, which services the site's government vehicle fleet, and at Upton Industries, a full-service gas station and car repair garage. The purpose of this inspection was routine surveillance of registered storage facilities to verify compliance with SCSC Article 12 requirements. Some deficiencies and other concerns that required corrective action were observed during the inspections. These deficiencies included a malfunctioning leak detection sensor in two piping fill/sumps, two high-level alarms that could not be demonstrated when manually activated, insufficient seals on three tank interstitial space probe risers/caps, and deficiencies in inspection records and scheduled repairs. All deficiencies identified were addressed to Suffolk County's satisfaction, including the development of a procedure and training of personnel on the appropriate management and inspection of underground storage tank systems.

\subsection{RCRA REQUIREMENTS}

The Resource Conservation and Recovery Act regulates hazardous wastes that, if mismanaged, could present risks to human health or the environment. The regulations are designed to ensure that hazardous wastes are managed from the point of generation to final disposal. In New
York State, EPA delegates the RCRA program to NYSDEC, with EPA retaining an oversight role. Because the Laboratory may generate greater than $1,000 \mathrm{Kg}$ (2,200 pounds) of hazardous waste in a month, it is considered a largequantity generator and has a RCRA permit to store hazardous wastes for up to one year before shipping them off site to licensed treatment and disposal facilities. As noted in Chapter 2, BNL also has a number of satellite accumulation and 90-day waste storage areas.

Mixed wastes are materials that are both hazardous (under RCRA guidelines) and radioactive. The Federal Facilities Compliance Act (1992) requires that DOE work with local regulators to develop a site treatment plan to manage mixed waste. Development of the plan has two purposes: to identify available treatment technologies and disposal facilities (federal or commercial) that are able to manage mixed waste produced at federal facilities, and to develop a schedule for treating and disposing of these waste streams.

BNL's Site Treatment Plan is updated annually and submitted to NYSDEC for review. The updated plan documents the current mixed waste inventory and describes efforts undertaken to seek new commercial treatment and disposal outlets for various waste streams. Treatment options for all of the mixed waste now in storage have been identified. The Laboratory anticipates that it will continue to manage mixed wastes within its permitted one-year storage limitation, and will continue to maintain and update its Site Treatment Plan as a reporting mechanism, should waste types or treatment facility availability change in the future

\subsection{POLYCHLORINATED BIPHENYLS}

The storage, handling, and use of polychlorinated biphenyls (PCBs) are regulated under the Toxic Substance and Control Act. Capacitors manufactured before 1970 that are believed to be oil filled are handled as if they contain PCBs, even when that cannot be verified from the manufacturer's records. All equipment containing PCBs must be inventoried, except for capacitors containing less than 3 pounds of dielectric fluid and items with a concentration of PCB source 
material of less than 50 parts per million. Certain PCB-containing articles or PCB containers must be labeled. The inventory is updated by July 1 of each year. The Laboratory responds to any PCB spill in accordance with standard emergency response procedures. BNL was in compliance with the regulatory requirements in 2007.

The Laboratory has aggressively approached reductions in its PCB inventory. By replacing and disposing of 55 large capacitors from the Collider-Accelerator Department in 2007, the inventory was reduced an additional 44 percent. Since 2003, BNL has reduced its PCB inventory by more than 90 percent.

\subsection{PESTICIDES}

The storage and application of pesticides (insecticides, rodenticides, herbicides, and algicides) are regulated under the Federal Insecticide, Fungicide and Rodenticide Act. Pesticides are used at the Laboratory to control undesirable insects, mice, and rats; bacteria in cooling towers; and to maintain certain areas free of vegetation (e.g., around fire hydrants and inside secondary containment berms). Insecticides are also applied to agricultural research fields and in greenhouses on site. Herbicide use is minimized wherever possible (e.g., through spot treatment of weeds). All pesticides are applied by BNL-employed, New York State-certified applicators. By February 1, each applicator files an annual report with NYSDEC detailing insecticide, rodenticide, algicide, and herbicide use for the previous year. The Laboratory was in full compliance with the legislated requirements in 2007.

\subsection{WETLANDS AND RIVER PERMITS}

As noted in Chapter 1, portions of the BNL site are situated on the Peconic River floodplain. Portions of the Peconic River are listed by NYSDEC as "scenic" under the Wild, Scenic, and Recreational River Systems Act. The Laboratory also has six areas regulated as wetlands and a number of vernal (seasonal) pools. Construction or modification activities performed within these areas require permits from NYSDEC.

Activities that could require review under the BNL Natural and Cultural Resource Manage- ment Programs are identified during the NEPA process (see Section 3.3). In the preliminary design stages of a construction project, design details required for the permit application process are specified. These design details ensure that the construction activity will not negatively affect the area, or if it does, that the area will be restored to its original condition. When design is near completion, permit applications are filed. During and after construction, the Laboratory must comply with the permit conditions.

In 2007, two projects were granted permits under this program. These projects included the installation of air conditioning for instrument houses at multiple locations at the Relativistic Heavy Ion Collider (RHIC), and the construction of a block house at the 4 o'clock area at RHIC. Final photos for a recharge basin built under an earlier permit were submitted in 2007, along with the permit completion notice to close the permit.

\subsection{ENDANGERED SPECIES ACT}

In 2006, the Laboratory updated its list of endangered, threatened, and species of special concern (see Table 6-1 in Chapter 6). Although the tiger salamander is no longer the only state endangered species found at BNL, it is the most notable and best-studied species on site. Tiger salamanders are listed as endangered in New York State because populations have declined due to habitat loss through development, road mortality during breeding migration, introduction of predatory fish into breeding sites, historical collection for the bait and pet trade, water level fluctuations, pollution, and general disturbance of breeding sites. The Laboratory adopted and implemented the BNL Natural Resource Management Plan (NRMP) in December 2003. One component of the plan formalizes the strategy and actions needed to protect 22 confirmed tiger salamander breeding locations on site. The strategy includes identifying and mapping habitats, monitoring breeding conditions, improving breeding sites, and controlling activities that could negatively affect breeding. A multi-year study of three ponds was begun in 2004 to gain a better understanding of the habitat requirements and salamander movement. 
The banded sunfish and swamp darter are found in the Peconic River drainage areas at BNL. Both are listed as threatened species within New York State. Eastern Long Island has the only known remaining populations of these fish in New York. Measures taken or being taken by the Laboratory to protect the banded sunfish and swamp darter and their habitat include: eliminating, reducing, or controlling pollutant discharges; reducing nitrogen loading in the Peconic River; monitoring populations and water quality to ensure that habitat remains viable; maintaining adequate flow to the river to enable the fish to survive drought; and minimizing disturbances to the river and adjacent banks.

Three butterfly species that are endangered, threatened, or of special concern have been historically documented at the Laboratory; these include the frosted elfin, persius duskywing, and mottled duskywing. None have been documented in recent surveys. Habitat for the frosted elfin and persius duskywing exists on Laboratory property and mottled duskywing is likely to exist on site; therefore, the management of habitat and surveys for the three butterflies has been added to the NRMP.

Surveys for damselflies and dragonflies conducted annually during the summer months confirmed the presence of one of the three threatened species of damselffies expected to be found on site. In June 2005, the pine-barrens bluet (Enallagma recurvatum), a threatened species, was documented at one of the many coastal plain ponds located at BNL.

The Laboratory is also home to 14 species that are listed as species of special concern. Such species have no protection under the state endangered species laws, but may be protected under other state and federal laws (e.g., Migratory Bird Treaty Act). New York State monitors species of special concern and manages their populations and habitats, where practical, to ensure that they do not become threatened or endangered. Species of special concern found at BNL include the mottled duskywing butterfly, marbled salamander, eastern spadefoot toad, spotted turtle, eastern box turtle, eastern hognose snake, worm snake, horned lark, whip-poor-will, vesper sparrow, grasshopper sparrow, and Cooper's hawk.
The management efforts for the tiger salamander also benefit the marbled salamander. At present, no additional protective measures are planned for the eastern box turtle or spotted turtle, as little activity occurs within their known habitat at the Laboratory. Radio telemetry work on the spotted turtle was carried out in 2004 - 2006, and a basic understanding of their movement and habitat needs was developed. Radio telemetry work on the eastern box turtle was completed in the summers of 2006 and 2007 at one of the many ponds at BNL in order to assess the amount of territory overlap in this species. This was completed to assess the potential for disease transmission between individuals of this species. A radio telemetry study on the eastern hognose snake was completed in 2005, resulting in greater understanding of this species' habitat needs and its movement between habitats. BNL continues to evaluate bird populations as part of the management strategy outlined in the NRMP. In addition to the bird species mentioned above, 18 other bird species listed as species of special concern and two federally threatened species have been observed during spring and fall migrations.

The Laboratory has 20 plant species that are protected under state law. One is an endangered plant, the crested fringed orchid; two are threatened plants, the stiff goldenrod and stargrass; and two are rare plants, the narrow-leafed bush clover and long-beaked bald-rush. The other 15 species are considered to be "exploitably vulnerable,” meaning that they may become threatened or endangered if factors that result in population declines continue. These plants are currently sheltered at BNL due to the large areas of undeveloped pine-barren habitat on site. As outlined in the NMRP, locations of these rare plants must be determined, populations estimated, and management requirements established. In an effort to locate and document rare plants, BNL is working with a botanist to assess the flora found at BNL. See Chapter 6 for further details.

\subsection{EXTERNAL AUDITS AND OVERSIGHT}

\subsubsection{Regulatory Agency Oversight}

A number of federal, state, and local agencies oversee BNL activities. In addition to ex- 
ternal audits and oversight, the Laboratory has a comprehensive self-assessment program, as described in Chapter 2. In 2007, BNL was inspected by federal, state, or local regulators on 10 occasions and SCDHS continued to maintain a part-time, on-site inspector who provided periodic oversight of BNL activities. These inspections included:

- Air Compliance. NYSDEC inspected the Laboratory in September 2007 to verify compliance with permit requirements. This inspection focused on operations at the CSF. No compliance issues were identified.

- Potable Water. In July, SCDHS collected samples and conducted its annual inspection of the BNL potable water system. No issues were identified.

- Sewage Treatment Plant. SCDHS conducts quarterly inspections of the Laboratory's STP, to evaluate operations and sample the effluent. In 2007, no performance or operational issues were identified. In November, NYSDEC also inspected the STP and other SPDES regulated outfalls; no issues were identified.

- Recharge Basins. SCDHS inspected several of the SPDES-regulated outfalls and collected samples. No issues were identified.

- Major Petroleum Facility. The annual NYSDEC inspection of the MPF was conducted in November. See Section 3.8.4 for a discussion of the issues identified.

- Chemical Bulk Storage Facilities. The CBS facilities are inspected periodically by NYSDEC. The inspection was conducted in November (see Section 3.8.5).

- Hazardous Waste. NYSDEC did not perform its annual review of the BNL Hazardous Waste Program.

\subsubsection{DOE Assessments/Inspections}

In 2007, BNL underwent several reviews by DOE, most notably an assessment of the BNL Integrated Safety Management System by the Headquarters office. During July and August 2007, the DOE Office of Environment, Safety and Health (ES\&H) evaluations (HS-64), within the Office of Health, Safety and Security (HSS), inspected ES\&H program implementation at
BNL. The inspection team concluded in their report, "Inspection of ES\&H Programs at BNL" (HSS Report), that significant improvement was evident in all areas reviewed since the 2000 ES\&H inspection. However, further work is needed in core functions (CF) 3 - Develop and Implement Hazard Controls, CF 4 - Perform Work within Controls, and CF 5 - Feedback and Improvement. The HSS Report identified nine site-specific findings. BSA/BNL has responsibility for developing corrective actions for seven of the findings and the DOE-Brookhaven Site Office (BHSO) has responsibility for two findings. The Laboratory has prepared a comprehensive Corrective Action Plan (CAP) to address the findings identified from the HSS inspection. The HSS Report also identified 18 opportunities for improvement. Many of these were incorporated as part of the corrective actions outlined in this ES\&H corrective action plan.

Beyond the findings, opportunities for improvement, and analysis of ongoing corrective action plans, the Laboratory reviewed the Validation Appendices attached to the HSS Report, to identify unmitigated hazards or situations that present an unacceptable immediate risk to workers, public health, or the environment. In all, 17 compensatory actions were identified to address unmitigated hazards.

Given the Laboratory's past success in using an integrated project approach to safety improvement, the ES\&H CAP was incorporated into the Integrated Safety Management (ISM)/ Safety Improvement Project with a specific Work Breakdown Structure (WBS) designation, and managed as a part of the overall project. The ES\&H CAP portion of the project WBS will be updated as corrective actions are completed and tracked to closure in the BNL Assessment Tracking System (ATS) as Assessment No. 4015.

In September 2007, the DOE Chicago Support Center, in coordination with the BHSO, reviewed the BNL Hazardous Waste Management Program. One specific issue and two general issues were identified during this review and required corrective action: 1 ) when a release of oil was discovered during the replacement of an elevator hydraulic system in Building 1005, the 
Table 3-8. Existing Agreements and Enforcement Actions Issued to BNL, with Status.

\begin{tabular}{|c|c|c|c|c|}
\hline $\begin{array}{l}\text { Number } \\
\text { Agreements }\end{array}$ & Title & Parties & $\begin{array}{l}\text { Effective } \\
\text { Date }\end{array}$ & Status \\
\hline No Number & Suffolk County Agreement & $\begin{array}{l}\text { SCDHS, } \\
\text { DOE, } \\
\text { and BNL }\end{array}$ & $\begin{array}{l}\text { Originally } \\
\text { signed on } \\
09 / 23 / 87\end{array}$ & $\begin{array}{l}\text { This Agreement was developed to ensure that the } \\
\text { storage and handling of toxic and hazardous mate- } \\
\text { rials at BNL conform to the environmental and tech- } \\
\text { nical requirements of Suffolk County codes. }\end{array}$ \\
\hline No Number & $\begin{array}{l}\text { Federal Facilities Compliance } \\
\text { Agreement on Mixed Wastes }\end{array}$ & $\begin{array}{l}\text { NYSDEC } \\
\text { and DOE }\end{array}$ & $\begin{array}{l}1992 \\
\text { (updated } \\
\text { annually) }\end{array}$ & $\begin{array}{l}\text { The Federal Facilities Compliance Act (FFCA) re- } \\
\text { quires that a site treatment plan to manage mixed } \\
\text { wastes be written and updated annually. BNL is in } \\
\text { compliance with this requirement. }\end{array}$ \\
\hline $\begin{array}{l}\text { II-CERCLA- } \\
\text { FFA-00201 }\end{array}$ & $\begin{array}{l}\text { Federal Facility Agreement } \\
\text { under the Comprehensive } \\
\text { Environmental Response, } \\
\text { Compensation and Liability } \\
\text { Act (CERCLA) Section } 120 \\
\text { (also known as the Interagency } \\
\text { Agreement or "IAG" of the } \\
\text { Environmental Restoration } \\
\text { Program). }\end{array}$ & $\begin{array}{l}\text { EPA, DOE, } \\
\text { and NYSDEC }\end{array}$ & $05 / 26 / 92$ & $\begin{array}{l}\text { Provides the framework, including schedules, for } \\
\text { assessing the extent of contamination and con- } \\
\text { ducting the BNL cleanup. Work is performed either } \\
\text { as an Operable Unit or a Removal Action. The IAG } \\
\text { integrates the requirements of CERCLA, Resource } \\
\text { Conservation and Recovery Act (RCRA), and the } \\
\text { National Environmental Policy Act (NEPA). While } \\
\text { all clean-up actions were completed in 2005, BNL } \\
\text { continues to perform surveillance and maintenance } \\
\text { of operating remediation systems. All systems op- } \\
\text { erated as required in } 2007 \text {. }\end{array}$ \\
\hline \multicolumn{5}{|c|}{ Notices of Violation/Enforcement Actions } \\
\hline \multicolumn{5}{|l|}{ None } \\
\hline \multicolumn{5}{|c|}{$\begin{array}{l}\text { Notes: } \\
\text { EPA = Environmental Protection Agency } \\
\text { NYSDEC = New York State Department of Environmental Conservation } \\
\text { SCDHS = Suffolk County Department of Health Services }\end{array}$} \\
\hline
\end{tabular}

change in conditions should have been noted on the work permit; 2) inspection reports did not document instances when no concerns were found during an inspection; and 3) BNL does not document the "all's clear" condition when conducting inspections of work spaces. A Corrective Action Plan was prepared to address these conditions and is being implemented.

The DOE BHSO also continued to oversee Laboratory programs and observed BNL's multi-topic programmatic assessment. In 2007, the Environmental and Waste Management Services Division (EWMSD) simplified its assessment, conducting a review of issues identified during regulatory inspections and the required self-assessments (e.g., annual certifications), and performing a review of tank inspection records. The rationale for this means of assessing BNL organizations was to reduce the impact, in time and resources, on both the assessors and those being assessed. In addition, the Laboratory also underwent its annual Nevada Test Site (NTS) inspection in order to maintain its waste shipment certification. The results of these assessments and the inspection are summarized below. In addition to the formal assessments, BHSO staff perform routine surveillance assessments of BNL operations to ensure that work is conducted in accordance with regulatory requirements.

\subsubsection{Environmental Multi-Topic Assessment}

In 2007, the EWMSD conducted an assessment of compliance activities associated with liquid effluents, radiological and nonradiological air emissions, and the storage of hazardous and nonhazardous materials. However, in lieu of performing a new assessment, routine inspections and reports were reviewed. Annually, the Laboratory undergoes a minimum of 10 regulatory compliance inspections and performs numerous self-evaluations of operations to ensure compliance with regulatory requirements. These inspections and self-evaluations include:

- Annual and semi-annual certifications of air emission requirements 
- Annual NESHAPs evaluation and preparation of the annual NESHAPs report

- Annual internal review of major oil storage and chemical bulk storage facilities

- Quarterly inspections of the STP by SCDHS

- Annual NYSDEC and SCDHS inspections of waste water discharges permitted under the SPDES

- Annual NYSDEC inspections of chemical bulk storage (as defined by 6 NYCRR Part 596) and the major oil storage facilities

- Annual NYSDEC air emissions inspections

- Annual NYSDEC inspections of hazardous waste operations for RCRA compliance

- Annual SCDHS potable water inspections

In addition to the activities identified above, in 2007 the Laboratory was requested by NYSDEC to conduct a comprehensive review and sampling of all waste water discharges permitted under the SPDES permit. Based on the findings of these inspections or data gaps not covered during these reviews, supplemental reviews were also conducted of wastewater discharges contributing to Outfall 006B, mercurybearing wastewater streams, and tank inspection records. All Laboratory organizations were reviewed during this assessment in one or more categories. Three nonconformances, 13 "observations," and four opportunities for improvement were identified through this assessment. Corrective actions for all nonconformances and observations were developed and are being tracked through the Laboratory's Assessment Tracking System.

\subsubsection{Nevada Test Site Inspection}

As part of the NTS waste certification process, random unannounced inspections by the NTS Maintenance and Operations Contractor are conducted. In September 2007, BNL's Waste Management Program was inspected to assess its waste shipments to NTS. One corrective action was issued. The issue was corrected, and BNL continues to be a certified NTS waste generator.

\subsection{ENFORCEMENT ACTIONS AND AGREEMENTS}

No consent orders were issued to the Laboratory in 2007. All former enforcement actions have been closed. BNL and DOE have determined that the Laboratory has fully complied with the terms and conditions listed in these actions, and have submitted supporting documentation to the regulatory agencies. All regulatory agreements are listed in Table 3-8, along with a summary of their status.

\section{REFERENCES AND BIBLIOGRAPHY}

BNL. 1997. BNL Site Treatment Plan. Brookhaven National Laboratory, Upton, NY.

BNL. 2003. Natural Resource Management Plan for Brookhaven National Laboratory. Brookhaven National Laboratory, Upton, NY.

Chaloupka, W. 2007. Brookhaven National Laboratory Spill Prevention Control and Countermeasure Plan. Brookhaven National Laboratory, Upton, NY.

Chaloupka, W. 2007. Brookhaven National Laboratory 2007 Annual Potable Water Sampling Plan. Brookhaven National Laboratory, Upton, NY.

DOE Order 5400.5. 1990. Radiation Protection of the Public and the Environment. U.S. Department of Energy, Washington, DC. Change 2: 1-7-93.

DOE Policy 450.4. 1996. Safety Management System Policy. U.S. Department of Energy, Washington, DC. 1015-96.

EPA. 2000. Federal Facilities Agreement under CERCLA 120. Administrative Docket Number II-CERCLA-FFA00201.

Lee, R. 2006. Brookhaven National Laboratory, Facility Response Plan. Brookhaven National Laboratory, Upton, NY.

Lee, R. Brookhaven National Laboratory, Programmatic Self-Assessment Report for 2007, Multi-Topic Environmental Assessment, September 2007, Brookhaven National Laboratory, Upton, NY.

SCDHS. 1993. Suffolk County Sanitary Code Article 12: Toxic and Hazardous Material Storage and Handling Controls. Suffolk County Department of Health Services, NY. 
Intentionally Left Blank 


\section{Air Quality}

Brookhaven National Laboratory (BNL) monitors both radioactive and nonradioactive emissions at several facilities on site to ensure compliance with the requirements of the Clean Air Act. In addition, the Laboratory conducts ambient air monitoring to verify local air quality and assess possible environmental impacts from Laboratory operations.

During 2007, BNL facilities released a total of 2,536 curies of short-lived radioactive gases. Oxygen-15 and carbon-11 emitted from the Brookhaven Linac Isotope Producer constituted more than 99.9 percent of the site's radiological air emissions.

Since natural gas prices were comparatively lower than residual fuel prices from May through November in 2007, the Central Steam Facility used natural gas to meet most of the heating and cooling needs of the Laboratory's major facilities during this period. As a result, annual facility emissions of particulate matter and sulfur dioxide were considerably lower in 2007 than in the years 2004 to 2005, when residual fuel satisfied more than 99.9 percent of BNL's major facility heating and cooling needs.

\subsection{RADIOLOGICAL EMISSIONS}

Federal air quality laws and DOE regulations that govern the release of airborne radioactive material include 40 CFR 61 Subpart H: National Emission Standards for Hazardous Air Pollutants (NESHAPs) - part of the Clean Air Act (CAA), and DOE Order 5400.5, Radiation Protection of the Public and the Environment. Under NESHAPs Subpart H, facilities that have the potential to deliver an annual radiation dose of greater than 0.1 mrem $(1 \mu \mathrm{Sv})$ to a member of the public must be continuously monitored for emissions. Facilities capable of delivering radiation doses below that limit require periodic, confirmatory monitoring. Although not required, BNL has one facility that is continuously monitored, the Brookhaven Linac Isotope Producer (BLIP). Periodic monitoring is conducted at one active facility, the Target Processing Laboratory (TPL), and one inactive facility, the High Flux Beam Reactor (HFBR). Figure 4-1 indicates the locations of these monitored facilities, and Table 4-1 presents the airborne release data from each of these facilities during 2007. Annual emissions from monitored facilities are discussed in the following sections of this chapter. Also discussed is a fourth inactive facility, the Evaporator Facility, which was periodically monitored in past years. The associated radiation dose estimates are presented in Chapter 8, Table 8-4.

\subsubsection{Brookhaven Medical Research Reactor}

In August 2000, DOE announced that the Brookhaven Medical Research Reactor (BMRR) would be permanently shut down due to a reduction of research funding. Until it stopped operating in late December 2000, the BMRR was fueled with enriched uranium, moderated and cooled by "light” (ordinary) water, and was operated intermittently at power levels up to $3 \mathrm{MW}$, thermal. Air from the interior of the containment building was used to cool the neutron reflector surrounding the core of the reactor vessel. As air was drawn through the reflector, it was exposed to a neutron field, resulting in activation of the argon fraction of the air. This produced argon-41 (Ar-41), an inert, radioactive gas (half-life 1.8 hours). After passage through the reflector, the air was routed through a roughing filter and a high-efficiency 


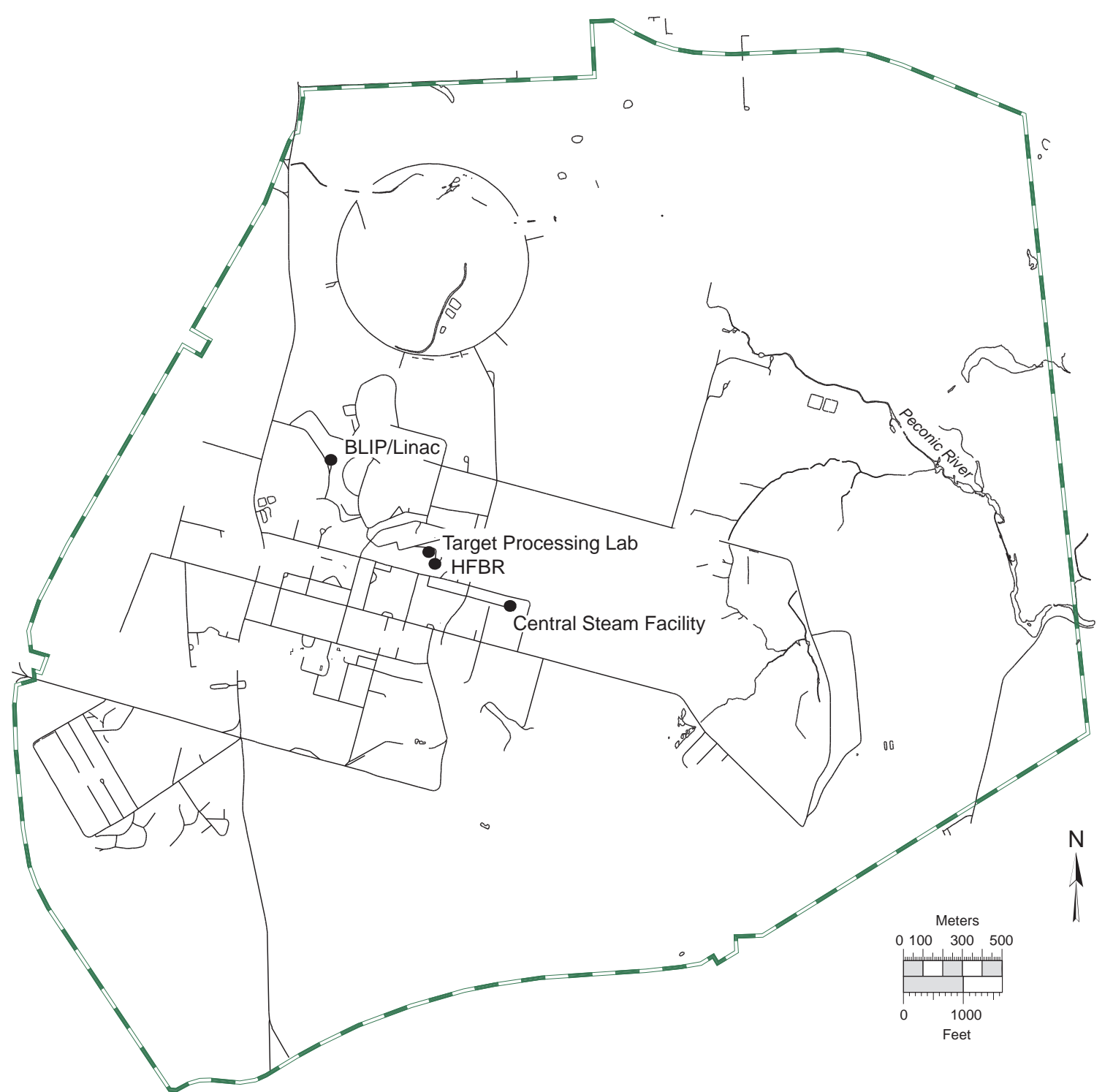

Figure 4-1. Air Emission Release Points Subject to Monitoring.

particulate air (HEPA) filter to remove any particulate matter. Charcoal filters were also used to remove radioiodines produced during the fission process. Following filtration, the air was exhausted to the atmosphere through a $150-\mathrm{ft}$ stack adjacent to the reactor containment building. This air was continuously monitored for Ar-41 emissions.

After the BMRR stopped operating, continuous Ar-41 monitoring was reduced to periodic, semi-annual monitoring to confirm that radionuclide concentrations remained below detection limits. In January 2003, the remaining fuel was removed from the BMRR reactor vessel, eliminating the last significant source for radio- nuclide emissions. The sole remaining BMRR emission source was evaporation of the cooling water, which contained the radioactive isotope tritium (H-3, half-life 12.3 years), produced by neutron activation when the BMRR operated. In January 2005, EPA approved BNL's petition to discontinue emissions monitoring at the BMRR. As a result, sample collection was stopped in 2006 and all removable radioactive materials were shipped off site to a disposal facility.

In 2007, the BMRR remained in a "cold" shutdown mode as a radiological facility. During regular periodic inspections of the facility, tritium samples were collected to quantify the tritium content in the humid air enclosed within 
the facility. Tritium concentrations inside the building were very low and did not pose any dose risk.

\subsubsection{High Flux Beam Reactor}

When the HFBR operated, "heavy" water was used as a neutron moderator and fuel coolant. Heavy water, or $\mathrm{D}_{2} \mathrm{O}$, is water composed of a nonradioactive isotope of hydrogen known as deuterium. When exposed to neutron fields generated inside a reactor vessel, deuterium becomes activated and produces radioactive tritium. As a result of the transfer of fuel elements from the reactor, the spent fuel storage pool contained tritiated heavy water (HTO) from the HFBR system. In 1997, a plume of tritiated groundwater was traced back to a leak in the pool. Consequently, the HFBR was put in standby mode, the pool was pumped out, and the HTO from the pool was properly disposed of as radioactive waste. The pool was then repaired and double lined in accordance with Suffolk County Article 12 regulations (SCDHS 1993) and remained empty while the facility was in a standby mode.

The HFBR continued in standby mode until November 1999, when DOE declared that it was to be permanently shut down. Residual
Table 4-1. Airborne Radionuclide Releases from Monitored Facilities.

\begin{tabular}{|c|c|c|c|}
\hline Facility & Nuclide & Half-Life & Ci Released \\
\hline HFBR & Tritium & 12.3 years & $1.33 \mathrm{E}+0$ \\
\hline \multirow[t]{3}{*}{ BLIP } & Carbon-11 & 20.4 minutes & $8.37 \mathrm{E}+2$ \\
\hline & Oxygen-15 & 122 seconds & $1.70 \mathrm{E}+3$ \\
\hline & Tritium & 12.3 years & 4.92E-2 \\
\hline \multirow{4}{*}{$\begin{array}{l}\text { TPL - } \\
\text { Bldg. } 801\end{array}$} & Antimony-124 & 60 days & 2.70E-11 \\
\hline & Arsenic-74 & 17.8 days & 5.34E-10 \\
\hline & Germanium-68 & 270.8 days & 3.60E-8 \\
\hline & Selenium-75 & 119.8 days & $9.31 \mathrm{E}-10$ \\
\hline \multicolumn{3}{|l|}{ Total } & $2.54 \mathrm{E}+3$ \\
\hline \multicolumn{4}{|c|}{$\begin{array}{l}\text { Notes: } \\
\mathrm{Ci}=3.7 \mathrm{E}+10 \mathrm{~Bq} \\
\mathrm{BLIP}=\mathrm{Brookhaven} \text { Linac Isotope Producer } \\
\text { HFBR = High Flux Beam Reactor (operations were terminated in } \\
\text { November 1999) } \\
\text { TPL = Target Processing Laboratory }\end{array}$} \\
\hline
\end{tabular}

tritium in water in the reactor vessel and piping systems continues to diffuse into the building's air through valve seals and other system penetrations, though emission rates are much lower than during the years of operation (Figure 4-2).

The increase in emissions in 2003 was attributed to evaporative losses when HTO remaining in the reactor core was pumped out for ap-

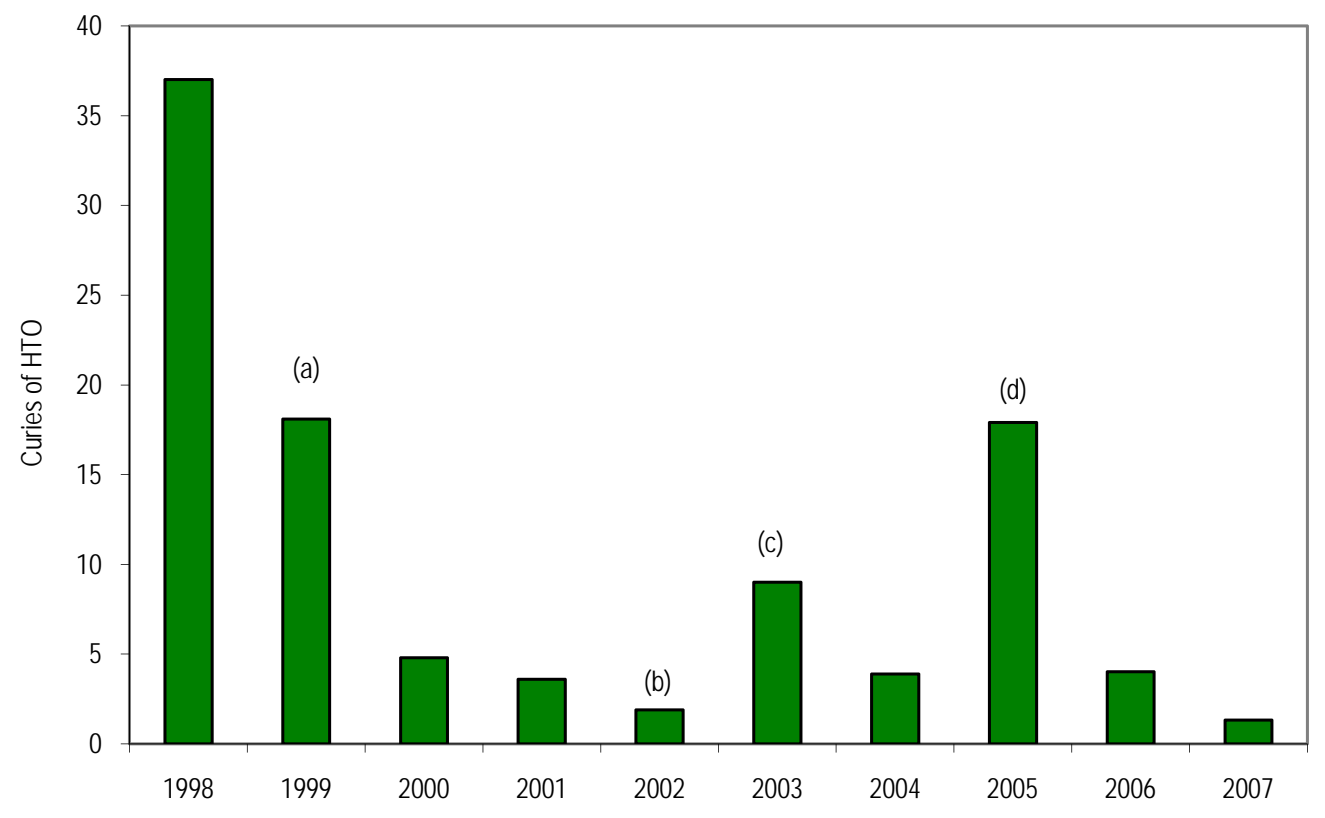

Figure 4-2. High Flux Beam Reactor Tritium Emissions, Ten-Year Trend (1998-2007). 
proved disposal. In 2004, the downward trend in emissions resumed: the level dropped from 9.0 Ci (the 2003 value) to $3.94 \mathrm{Ci}$. In 2005, tritium emissions climbed to $17.9 \mathrm{Ci}$, apparently due to evaporation of residual heavy water through an open drain-tank vent line. In 2006, tritium emissions dropped to $4.03 \mathrm{Ci}$, a level consistent with 2004 emissions. In 2007, the downward trend continued, as tritium emissions fell to $1.33 \mathrm{Ci}$. The air emissions from the HFBR facility have been monitored since 2002 via air sampling of the building at a frequency of one week per month.

\subsubsection{Brookhaven Linac Isotope Producer}

Protons from the Linear Accelerator (Linac) are sent via an underground beam tunnel to the BLIP, where they strike various metal targets to produce new radionuclides for medical diagnostics. The activated metal targets are transferred to the TPL in Building 801 for separation and shipment to various radiopharmaceutical research laboratories. During irradiation, the targets become hot and are cooled by a continuously recirculating water system. The cooling water also becomes activated during the process, producing secondary radionuclides. The most significant of these radionuclides are oxygen-15 (O-15, half-life 122 seconds) and carbon-11 (C-11, half-life 20.48 minutes). Both of these isotopes are released as gaseous, airborne emissions through the facility's 33-ft stack. Emissions of these radionuclides are dependent on the current and energy of the proton beam used to manufacture the radioisotopes.

In 2007, BLIP operated over a period of 20 weeks, during which, $837 \mathrm{Ci}$ of $\mathrm{C}-11$ and 1,698 $\mathrm{Ci}$ of $\mathrm{O}-15$ were released. Tritium produced from activation of the target cooling water was also released, but in a much smaller quantity, $4.92 \mathrm{E}-02$ Ci. Combined emissions of C-11 and O-15 were roughly 43 percent lower than in 2006, primarily due to operation at lower power levels in 2007.

\subsubsection{Evaporator Facility}

In the past, liquid waste generated on site that contained residual radioactivity was accumulated at the Waste Concentration Facility (WCF) in Building 811. At this facility, reverse osmosis was used to remove suspended solids and a high percentage of radionuclides from the liquid. Because tritium is an isotope of hydrogen, it could not be removed from aqueous wastes. The tritiated water that remained following waste concentration was transferred to the Evaporator Facility in Building 802B, where it was converted to steam and released as an airborne emission. The Evaporator Facility was constructed primarily to reduce the amount of tritiated water released to the Peconic River through the BNL Sewage Treatment Plant (STP). Emissions from the Evaporator Facility were previously directed to the same stack used by the HFBR to exhaust building air. This method was preferable to releases to surface water because there was virtually no potential for the airborne emissions to influence groundwater (the primary drinking water source on Long Island), and the potential for the released tritium to contribute to an off-site dose was minimized by atmospheric dispersion.

No aqueous waste has been processed at the WCF since 2001. As a result, the Evaporator Facility has not been used and has produced no emissions of tritiated water vapor. Because generation rates of aqueous wastes containing residual radioactivity are expected to remain low, it is no longer cost effective to process the waste in the same manner. Wastes are now solidified and sent to an approved off-site disposal facility. As a result, planning is underway to decommission the Evaporator Facility. Subject to funding availability, the plans also call for demolishing the Building 802B stack and decontaminating the WCF.

\subsubsection{Target Processing Laboratory}

As mentioned in Section 4.1.3, metal targets irradiated at the BLIP are transported to the TPL in Building 801, where isotopes are chemically extracted for radiopharmaceutical production. Airborne radionuclides released during the extraction process are drawn through multistage HEPA and charcoal filters and then vented to the HFBR stack. The types of radionuclides that are released depend on the isotopes chemically extracted from the irradiated metal targets, which may change from year to year. Annual radionuclide quantities released from this facility are very small, typically in the $\mu \mathrm{Ci}$ to $\mathrm{mCi}$ range. In 2007, the 
total release from the TPL was $0.038 \mu \mathrm{Ci}$. See Table 4-1 for details of the radionuclides released in 2007.

\subsubsection{Additional Minor Sources}

Several research departments at BNL use designated fume hoods for work that involves small quantities of radioactive materials (in the $\mu \mathrm{Ci}$ to $\mathrm{mCi}$ range). The work typically involves labeling chemical compounds and transferring material between containers using pipettes. Due to the use of HEPA filters and activated charcoal filters, the nature of the work conducted, and the small quantities involved, these operations have a very low potential for atmospheric releases of any significant quantities of radioactive materials. Compliance with NESHAPs Subpart $\mathrm{H}$ is demonstrated through the use of an inventory system that allows an upper estimate of potential releases to be calculated. Facilities that demonstrate compliance in this way include Buildings 463, 490, 490A, 510, $535,555,725,801$, and 830 , where research is conducted in the fields of biology, medicine, high energy physics, chemistry, applied and materials science, advanced technology, and environmental sciences. See Table 8-4 in Chapter 8 for the calculated dose from these facility emissions.

\subsubsection{Nonpoint Radiological Emission Sources}

Nonpoint radiological emissions from a variety of diffuse sources were evaluated in 2007 for compliance with NESHAPs Subpart

$\mathrm{H}$. Diffuse sources evaluated included planned research, environmental restoration, and waste management activities. The EPA-approved CAP88-PC dose modeling computer program was used to calculate the possible dose to members of the public from each of the planned activities. The evaluations determined whether NESHAPs permitting and continuous monitoring requirements were applicable, or whether periodic confirmatory sampling was needed to ensure compliance with Subpart H standards for radionuclide emissions. Chapter 8 discusses the NESHAPs evaluations of the research, environmental restoration, and waste management activities that occurred in 2007.

\subsection{FACILITY MONITORING}

In the past, potential sources of radioactive emissions have been monitored at the BMRR, HFBR, Evaporator Facility, TPL, and BLIP. Because the BMRR and HFBR are permanently shut down and the Evaporator Facility has not processed any aqueous wastes since 2001, no particulate sampling was conducted at these facilities in 2007.

The samplers in the TPL exhaust duct and the exhaust stack for BLIP are equipped with glassfiber filters that capture samples of airborne particulate matter generated at these facilities (see Figure 4-3 for locations). The filters are collected and analyzed weekly for gross alpha and beta activity. Particulate filter analytical results for gross alpha and beta activity are reported in Table 4-2. The average gross alpha and beta airborne activity levels for samples collected from the BLIP exhaust stack were 0.0893 and 1.2197 $\mathrm{pCi} / \mathrm{m}^{3}$, respectively. Annual average gross alpha and beta airborne activity levels for samples collected from the TPL were 0.0031 and 0.0348 $\mathrm{pCi} / \mathrm{m}^{3}$, respectively.

\subsection{AMBIENT AIR MONITORING}

As part of the Environmental Monitoring Program, air monitoring stations are in place around the perimeter of the BNL site (see Figure 4-3 for locations). Samples are collected using equipment at six blockhouse stations and three pole-mounted, battery-powered silica-gel samplers. The blockhouses are fenced to control access and protect costly sampling equipment. In 2003, the number of pole-mounted samplers used for airborne tritium monitoring was reduced from 16 to three because historical air surveillance data revealed that tritium concentrations at most sampling stations were below minimum detection limits (MDL).

At each blockhouse, vacuum pumps draw air through columns where particulate matter is captured on a glass-fiber filter. Particulate filters are collected weekly and are analyzed for gross alpha and beta activity using a gas-flow proportional counter. Also, water vapor for tritium analysis is collected on silica-gel absorbent material for processing by liquid scintillation analysis. In 2007, silica-gel samples were collected every two weeks. 


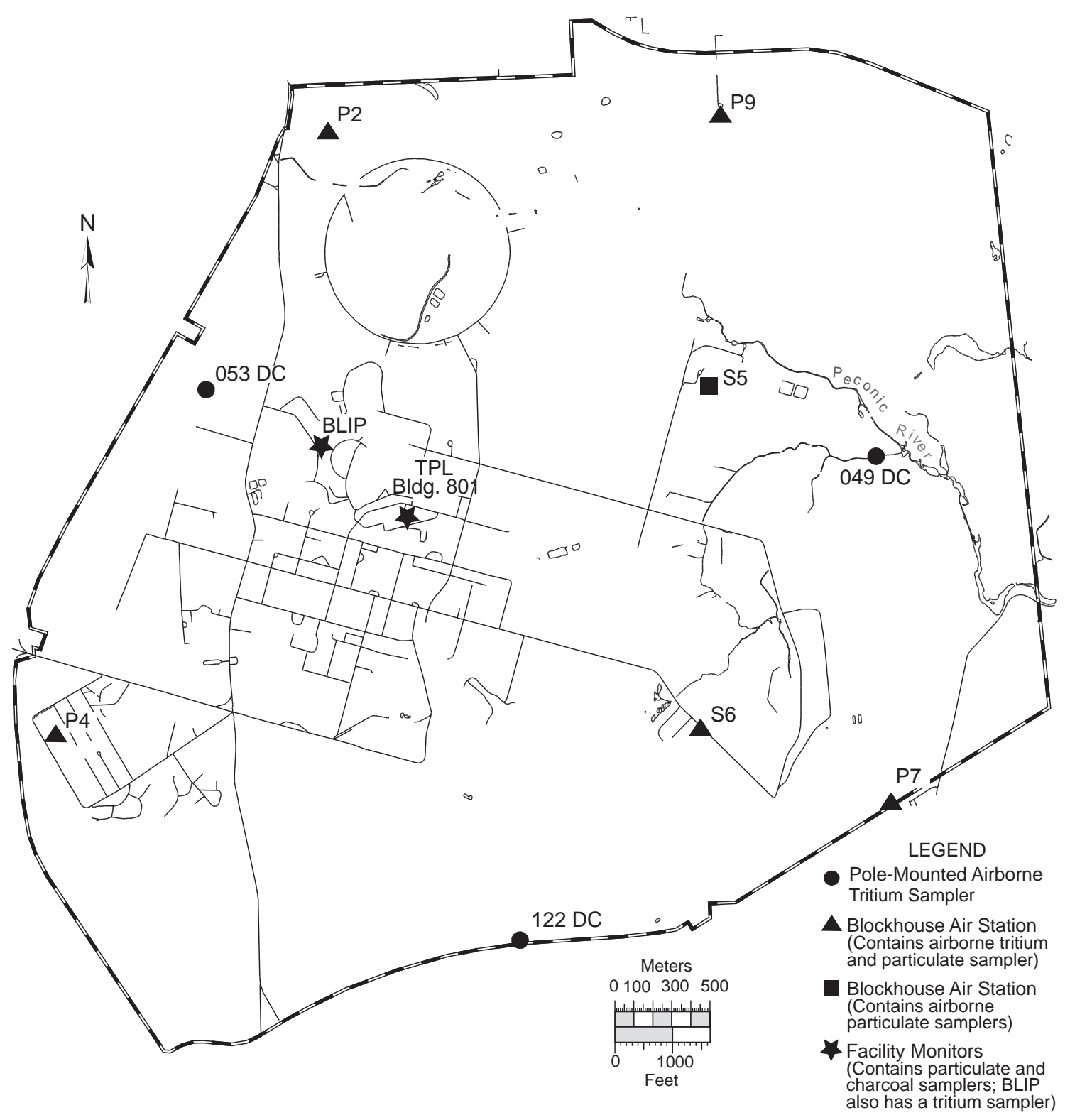

Figure 4-3. BNL On-Site Ambient Air Monitoring Stations.

\subsubsection{Gross Alpha and Beta Airborne Activity}

Particulate filter analytical results for gross alpha and beta airborne activity are reported in Table 4-3. Validated samples are those not rejected due to equipment malfunction or other factors (e.g., sample air volumes were not acceptable). The annual average gross alpha and beta airborne activity levels for the six monitoring stations were 0.0014 and $0.0149 \mathrm{pCi} / \mathrm{m}^{3}$, respectively. Annual gross beta activity trends recorded at Station P7 are plotted in Figure 4-4. The results for this location are typical for the site. The trend shows seasonal variation in activity within a range that is representative of natural background levels. The New York State Department of Health (NYSDOH) received duplicate filter samples that were collected at Station P7 using a sampler they provided. These samples were collected weekly and analyzed by the NYSDOH laboratory for gross beta activity only. The analytical results NYSDOH found were comparable to the Station P7 samples analyzed by GEL Laboratories, an analytical laboratory contracted by BNL. New York State's analytical results for gross beta activity at BNL were between 0.0035 and $0.0181 \mathrm{pCi} / \mathrm{m}^{3}$, with 
Table 4-2. Gross Activity in Facility Air Particulate Filters.

\begin{tabular}{|c|c|c|c|}
\hline \multirow{2}{*}{\multicolumn{2}{|c|}{ Facility Monitor }} & Gross Alpha & Gross Beta \\
\hline & & \multicolumn{2}{|c|}{$-\left(\mathrm{pCi} / \mathrm{m}^{3}\right)$} \\
\hline \multirow[t]{4}{*}{ BLIP } & $\mathrm{N}$ & 51 & 51 \\
\hline & Max. & $0.2410 \pm 0.1200$ & $2.5900 \pm 0.4880$ \\
\hline & Avg. & $0.0893 \pm 0.0925$ & $1.2197 \pm 0.2424$ \\
\hline & MDL & $0.1380^{*}$ & $0.2501^{*}$ \\
\hline \multirow[t]{4}{*}{ TPL - Bldg. 801} & $\mathrm{~N}$ & 51 & 51 \\
\hline & Max. & $0.0186 \pm 0.0040$ & $0.1440 \pm 0.0096$ \\
\hline & Avg. & $0.0031 \pm 0.0018$ & $0.0348 \pm 0.0048$ \\
\hline & MDL & $0.0021^{*}$ & $0.0041^{*}$ \\
\hline \multicolumn{4}{|c|}{$\begin{array}{l}\text { Notes: } \\
\text { See Figure 4-3 for sample station locations. } \\
\text { All values shown with a } 95 \% \text { confidence interval. } \\
\text { BLIP = Brookhaven Linac Isotope Producer } \\
\text { MDL = Minimum Detection Limit } \\
\text { N = Number of validated samples collected } \\
\text { TPL = Target Processing Laboratory } \\
\text { *Average MDL for all samples taken at this location }\end{array}$} \\
\hline
\end{tabular}

an average concentration of $0.0093 \mathrm{pCi} / \mathrm{m}^{3}$.

BNL results ranged from 0.0061 to 0.0218

$\mathrm{pCi} / \mathrm{m}^{3}$, with an average concentration of 0.0139 $\mathrm{pCi} / \mathrm{m}^{3}$. As part of a statewide monitoring program, NYSDOH also collects air samples in Albany, New York, a control location with no potential to be influenced by nuclear facility emissions. In 2007, NYSDOH reported that airborne gross beta activity at that location varied between 0.0037 and $0.0225 \mathrm{pCi} / \mathrm{m}^{3}$, and the average concentration was $0.0113 \mathrm{pCi} / \mathrm{m}^{3}$. Sample results measured at the Laboratory generally fell within this range, demonstrating that on-site radiological air quality was consistent with that observed at locations in New York State not located near radiological facilities.

\subsubsection{Airborne Tritium}

Airborne tritium in the form of HTO is monitored throughout the BNL site. In addition to the five blockhouses containing tritium samplers, three pole-mounted monitors used for tritium sampling are located at or near the property boundary (see Figure 4-3 for locations). Observed concentrations of tritium at the sampling stations in 2007 were comparable to concentrations observed in 2006. Table 4-4 lists the number of validated samples collected at each location, the maximum value observed, and the
Table 4-3. Gross Activity Detected in Ambient Air Monitoring Particulate Filters.

\begin{tabular}{|c|c|c|c|}
\hline \multicolumn{2}{|c|}{$\begin{array}{l}\text { Sample } \\
\text { Station }\end{array}$} & \multirow{2}{*}{$\begin{array}{c}\text { Gross Alpha } \\
52\end{array}$} & Gross Beta \\
\hline \multirow[t]{4}{*}{ P2 } & $\mathrm{N}$ & & 52 \\
\hline & $\operatorname{Max}$ & $0.0056 \pm 0.0013$ & $0.0224 \pm 0.0017$ \\
\hline & Avg. & $0.0016 \pm 0.0006$ & $0.0156 \pm 0.0015$ \\
\hline & MDL & $0.0005^{\star}$ & $0.0009^{*}$ \\
\hline \multirow[t]{4}{*}{ P4 } & $\mathrm{N}$ & 46 & 46 \\
\hline & Max & $0.0032 \pm 0.0008$ & $0.0263 \pm 0.0018$ \\
\hline & Avg. & $0.0013 \pm 0.0006$ & $0.0166 \pm 0.0015$ \\
\hline & MDL & $0.0005^{\star}$ & $0.0009 *$ \\
\hline \multirow[t]{4}{*}{ P7 } & $\mathrm{N}$ & 52 & 52 \\
\hline & Max & $0.0055 \pm 0.0009$ & $0.0218 \pm 0.0017$ \\
\hline & Avg. & $0.0013 \pm 0.0005$ & $0.0139 \pm 0.0013$ \\
\hline & MDL & $0.0004^{*}$ & $0.0008^{*}$ \\
\hline \multirow[t]{4}{*}{ P9 } & $\mathrm{N}$ & 53 & 53 \\
\hline & Max & $0.0054 \pm 0.0013$ & $0.0243 \pm 0.0022$ \\
\hline & Avg. & $0.0016 \pm 0.0006$ & $0.0157 \pm 0.0015$ \\
\hline & MDL & $0.0005^{\star}$ & $0.0009^{*}$ \\
\hline \multirow[t]{4}{*}{ S5 } & $\mathrm{N}$ & 50 & 50 \\
\hline & Max & $0.0035 \pm 0.0009$ & $0.0271 \pm 0.0022$ \\
\hline & Avg. & $0.0011 \pm 0.0005$ & $0.0131 \pm 0.0013$ \\
\hline & MDL & $0.0004^{*}$ & $0.0008^{*}$ \\
\hline \multirow[t]{4}{*}{ S6 } & $\mathrm{N}$ & 51 & 51 \\
\hline & Max & $0.0054 \pm 0.0010$ & $0.0267 \pm 0.0021$ \\
\hline & Avg. & $0.0013 \pm 0.0006$ & $0.0150 \pm 0.0014$ \\
\hline & MDL & $0.0005^{\star}$ & $0.0009 *$ \\
\hline \multicolumn{2}{|c|}{ Grand Average } & $0.0014 \pm 0.0001$ & $0.0149 \pm 0.0005$ \\
\hline \multicolumn{4}{|c|}{$\begin{array}{l}\text { See Figure 4-3 for sample station locations. } \\
\text { All values shown with a } 95 \% \text { confidence interval. } \\
\text { MDL = Minimum Detection Limit } \\
N=\text { Number of validated samples collected }\end{array}$} \\
\hline
\end{tabular}

annual average concentration. Validated samples are those not rejected due to equipment malfunction or other factors (e.g., a battery failure in the sampler, frozen or supersaturated silica gel, insufficient sample volumes, or the loss of sample during preparation at the contract analytical laboratory). Airborne tritium samples were collected every two weeks from each sampling station during 2007. The average tritium concentrations at all of the sampling locations were less than the typical MDL, which ranged from 


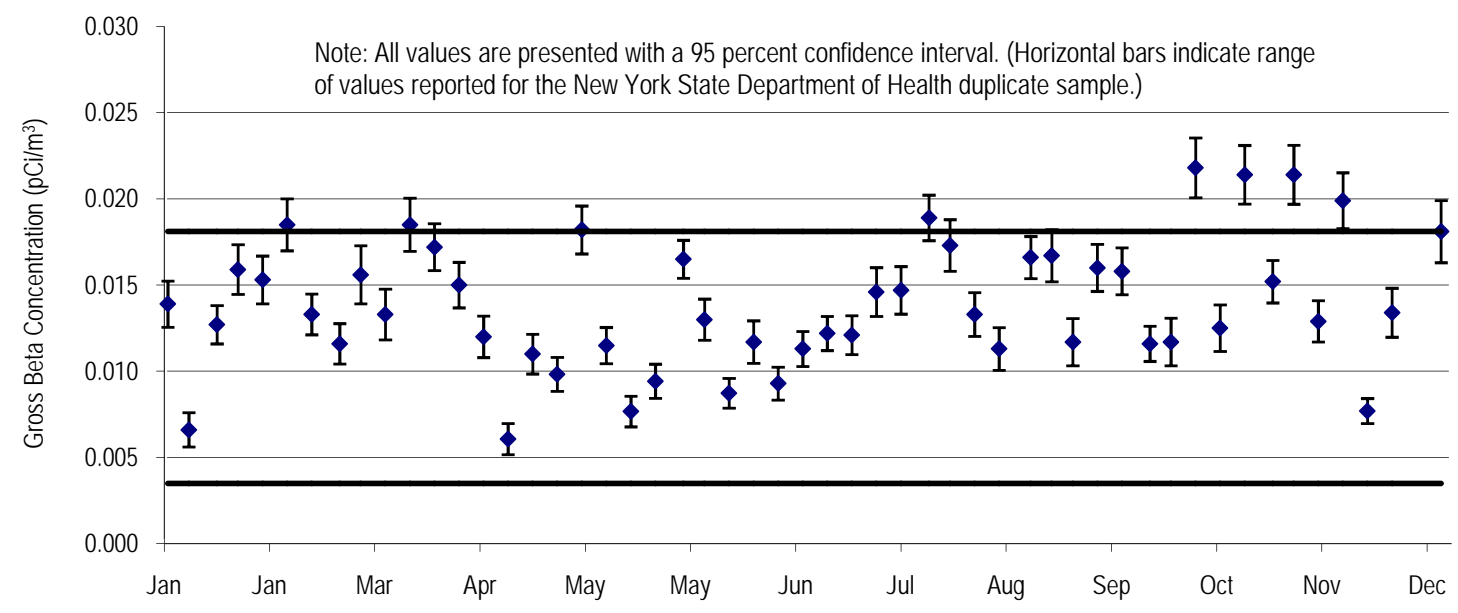

Figure 4-4. Airborne Gross Beta Concentration Trend Recorded at Station P7.

2.0 to $10.0 \mathrm{pCi} / \mathrm{m}^{3}$. The collected data demonstrate that there were no significant differences in ambient tritium concentrations on site or at the site boundary.

\subsection{NONRADIOLOGICAL AIRBORNE EMISSIONS}

Various state and federal regulations governing nonradiological releases require facilities to conduct periodic or continuous emission monitoring to demonstrate compliance with emission limits. The Central Steam Facility (CSF) is the only BNL facility that requires monitoring for nonradiological emissions. The Laboratory has several other emission sources subject to state and federal regulatory requirements that do not require emission monitoring (see Chapter 3 for more details). The CSF supplies steam for heating and cooling to major BNL facilities through an underground steam distribution and condensate grid. The location of the CSF is shown in Figure 4-1. The combustion units at the CSF are designated as Boilers 1A, 5, 6, and 7. Boiler 1A, which was installed in 1962, has a heat input of 16.4 MW (56.7 million British thermal units [MMBtu] per hour). Boiler 5, installed in 1965, has a heat input of 65.3 MW (225 MMBtu/hr). The newest units, Boilers 6 and 7, were installed in 1984 and 1996, and each has a heat input of 42.6 MW (147 MMBtu/hr). For perspective, Keyspan's Northport, New York power station has four utility-sized turbine/generator boilers, each with a maximum rated heat input of 1,082 MW (3,695 MMBtu/hr).
Because of their design, heat inputs, and dates of installation, Boilers 6 and 7 are subject to Title 6 of the New York Code, Rules, and Regulations (NYCRR) Part 227-2, and the Federal New Source Performance Standard (40 CFR 60 Subpart Db: Standards of Performance for Industrial-Commercial-Institutional Steam Boilers). These boilers are equipped with continuous emission monitors to measure nitrogen oxides $\left(\mathrm{NO}_{\mathrm{x}}\right)$ and Boiler 7 is equipped with a continu-

Table 4-4. Ambient Airborne Tritium Measurements in 2007.

\begin{tabular}{|c|c|c|c|c|}
\hline \multirow{2}{*}{$\begin{array}{c}\begin{array}{c}\text { Sample } \\
\text { Station }\end{array} \\
049\end{array}$} & \multirow{2}{*}{$\begin{array}{c}\begin{array}{c}\text { Wind } \\
\text { Sector }\end{array} \\
E\end{array}$} & \multirow{2}{*}{$\begin{array}{c}\begin{array}{c}\text { Validated } \\
\text { Samples }\end{array} \\
19\end{array}$} & \multicolumn{2}{|c|}{$\begin{array}{l}\text { Maximum Average } \\
-\left(\mathrm{pCi} / \mathrm{m}^{3}\right)-\end{array}$} \\
\hline & & & $25.8 \pm 5.9$ & $3.4 \pm 3.6$ \\
\hline 053 & NW & 25 & $12.1 \pm 8.4$ & $1.8 \pm 3.5$ \\
\hline 122 & SSE & 21 & $14.7 \pm 3.6$ & $3.0 \pm 4.5$ \\
\hline P2 & NNW & 17 & $11.5 \pm 4.3$ & $2.4 \pm 2.9$ \\
\hline P4 & WSW & 25 & $6.7 \pm 5.3$ & $1.8 \pm 3.1$ \\
\hline P7 & ESE & 26 & $16.9 \pm 4.0$ & $2.4 \pm 3.1$ \\
\hline P9 & NE & 25 & $37.7 \pm 7.1$ & $2.7 \pm 3.0$ \\
\hline S6 & SE & 26 & $11.3 \pm 3.4$ & $1.9 \pm 3.1$ \\
\hline \multicolumn{4}{|c|}{ Grand Average } & $2.4 \pm 0.7$ \\
\hline \multicolumn{5}{|c|}{$\begin{array}{l}\text { Notes: } \\
\text { See Figure } 4-3 \text { for station locations. } \\
\text { Wind sector is the downwind direction of the sample station from the } \\
\text { HFBR stack. } \\
\text { All values reported with a } 95 \% \text { confidence interval. } \\
\text { Typical minimum detection limit for tritium is between } 1.0 \text { and } \\
9.0 \mathrm{pCi} / \mathrm{m}^{3} \text {. } \\
\text { DOE Order } 5400.5 \text { Air Derived Concentration Guide is } 100,000 \mathrm{pCi} / \mathrm{m}^{3} \text {. }\end{array}$} \\
\hline
\end{tabular}


ous opacity monitor to comply with Subpart Db opacity monitoring requirements. After a new continuous opacity monitor for Boiler 6 was voluntarily brought online in 2004, emissions on both boilers are now continuously monitored for opacity. To measure combustion efficiency, the boilers are also monitored for carbon dioxide $\left(\mathrm{CO}_{2}\right)$. Continuous emission monitoring results from the two boilers are reported quarterly to EPA and the New York State Department of Environmental Conservation.

From May 1 to September 15 (the peak ozone period), compliance with the $0.30 \mathrm{lbs} / \mathrm{MMBtu}$ (129 ng/J) NO emission standard for No. 6 oil and the $0.20 \mathrm{lbs} / \mathrm{MMBtu}(86 \mathrm{ng} / \mathrm{J}) \mathrm{NO}_{\mathrm{x}}$ emission standard for No. 2 oil and natural gas is demonstrated by calculating the 24-hour average emission rate from continuous emission monitoring system readings and comparing the value to the emission standard. During the remainder of the year, the calculated 30-day rolling average emission rate is used to establish compliance. Boiler 6 and 7 opacity levels are recorded as 6-minute averages. Measured opacity levels cannot exceed 20 percent opacity, except for one 6-minute period per hour of not more than 27 percent opacity. In 2007, there were no measured exceedances of the $\mathrm{NO}_{\mathrm{x}}$ emission standards for either boiler. During the year, all of the Boiler 6 opacity measurements that exceeded the opacity limit during the first quarter occurred during the first soot blowing cycle after a long idle period where the boiler was only warmed with nominal volumes of oil. Second quarter Boiler 6 opacity exceedances that were the result of a calibration shutter malfunction ceased when the transmissometer optical head assembly was replaced. Changes in the sequence of the soot blowing cycle for Boiler 6 that were made in August 2005 have proven effective in eliminating most opacity exceedances due to soot blowing. Similar changes made to the soot blowing cycle on Boiler 7 after the installation of a new soot blowing controller in March 2006 have also been successful in eliminating soot blowing opacity exceedances from this boiler. While there are no regulatory requirements to continuously monitor opacity

\begin{tabular}{|c|c|c|c|c|c|c|c|c|c|c|}
\hline \multicolumn{7}{|c|}{ Annual Fuel Use and Fuel Heating Values } & \multicolumn{4}{|c|}{ Emissions } \\
\hline Year & $\begin{array}{l}\text { No. } 6 \text { Oil } \\
\left(10^{3} \text { gals }\right)\end{array}$ & $\begin{array}{l}\text { Heating } \\
\text { Value } \\
\text { (MMBtu) }\end{array}$ & $\begin{array}{l}\text { No. } 2 \text { Oil } \\
\left(10^{3} \text { gals }\right)\end{array}$ & $\begin{array}{l}\text { Heating } \\
\text { Value } \\
\text { (MMBtu) }\end{array}$ & $\begin{array}{l}\text { Natural Gas } \\
\qquad\left(10^{6} \mathrm{ft}^{3}\right)\end{array}$ & $\begin{array}{l}\text { Heating } \\
\text { Value } \\
\text { (MMBtu) }\end{array}$ & TSP & $\mathrm{NO}_{\mathrm{x}}$ & $\mathrm{SO}_{2}$ & VOCs \\
\hline 1996 & $4,782.55$ & 703,991 & 52.77 & 7,388 & 0.00 & 0 & 14.0 & 104.9 & 109.0 & 0.7 \\
\hline 1997 & $3,303.43$ & 484,613 & 10.23 & 1,432 & 190.65 & 194,463 & 13.7 & 83.5 & 75.1 & 1.0 \\
\hline 1998 & 354.28 & 52,283 & 9.44 & 1,322 & 596.17 & 608,093 & 2.7 & 75.1 & 8.9 & 1.7 \\
\hline 1999 & 682.76 & 78,335 & 2.77 & 388 & 614.98 & 627,280 & 5.1 & 53.5 & 16.7 & 1.8 \\
\hline 2000 & $2,097.32$ & 309,317 & 0.82 & 115 & 342.40 & 349,248 & 9.5 & 81.6 & 45.0 & 1.2 \\
\hline 2001 & $3,645.10$ & 538,847 & 3.40 & 476 & 103.96 & 106,039 & 17.5 & 80.4 & 77.8 & 0.8 \\
\hline 2002 & $2,785.04$ & 407,518 & 0.29 & 41 & 220.62 & 225,030 & 15.4 & 62.4 & 53.8 & 1.0 \\
\hline 2003 & $4,290.94$ & 628,765 & 402.06 & 56,288 & 0.98 & 1,000 & 22.8 & 75.3 & 107.1 & 0.6 \\
\hline 2004 & $4,288.76$ & 628,063 & 2.45 & 343 & 0.11 & 109 & 16.4 & 81.9 & 104.7 & 2.4 \\
\hline 2005 & $4,206.12$ & 618,590 & 0.87 & 122 & 0.00 & 0 & 15.2 & 80.4 & 93.1 & 2.4 \\
\hline 2006 & $2,933.00$ & 432,430 & 0.22 & 30 & 191.35 & 195,177 & 11.8 & 66.9 & 66.3 & 2.2 \\
\hline 2007 & $2,542.85$ & 374,432 & 0.00 & 0 & 263.04 & 268,301 & 9.7 & 77.3 & 59.3 & 2.2 \\
\hline \multicolumn{3}{|c|}{ Permit Limit (in tons) } & & & & & 113.3 & 159.0 & 445.0 & 39.7 \\
\hline \multicolumn{11}{|c|}{$\begin{array}{l}\text { Notes: } \\
\mathrm{NO}_{\mathrm{x}}=\text { Oxides of Nitrogen } \\
\mathrm{SO}_{2}=\text { Sulfur Dioxide } \\
\mathrm{TSP}=\text { Total Suspended Particulates } \\
\text { VOCs = Volatile Organic Compounds }\end{array}$} \\
\hline
\end{tabular}


for Boilers $1 \mathrm{~A}$ and 5 , surveillance monitoring of visible stack emissions is a condition of BNL's Title V operating permit. Daily observations of stack gases recorded by CSF personnel throughout the year showed no visible emissions, with opacity levels better than the regulatory limits established for these boilers.

To satisfy continuous emissions monitoring system quality assurance requirements of the Laboratory's Title V operating permit, a relative accuracy test audit (RATA) of the Boilers 6 and 7 continuous emissions monitoring systems for $\mathrm{NO}_{\mathrm{x}}$ and $\mathrm{CO}_{2}$ is normally performed during the fourth quarter each year. The scheduled RATA was suspended until the week of January 14, 2008, after the initial test run of the Boiler 6 continuous emissions monitoring system was interrupted on December 19 by the failure of the test contractor's data logger. The results of the RATA completed on January 16, 2008 demonstrated that Boiler 6 and $7 \mathrm{NO}_{\mathrm{x}}$ and $\mathrm{CO}_{2}$ continuous emissions monitoring systems met RATA acceptance criteria, which are defined in 40 CFR 60 Appendix B Specifications 2, and 3. In 2007, residual fuel prices from the middle of May to November exceeded those of natural gas. As a result, natural gas was used to supply more than 90 percent of the heating and cooling needs of BNL's major facilities during these months. Natural gas supplied approximately 42 percent of major facility heating and cooling needs for the year. By comparison, in 2004 and 2005, residual fuel satisfied more than 99.9 percent of the major facility heating and cooling needs. Consequently, 2007 emissions of particulates, $\mathrm{NO}_{\mathrm{x}}$, and sulfur dioxide $\left(\mathrm{SO}_{2}\right)$ were 5.5 , 3.1, and 33.8 tons less than the respective totals for 2005. All emissions were well below the respective permit limits of 113.3, 159, and 445 tons. Table 4-5 shows fuel use and emissions since 1996.

\section{REFERENCES AND BIBLIOGRAPHY}

40 CFR 60 Subpart Db. Standards of Performance for Industrial-Commercial-Institutional Steam Boilers. 52 FR 47842, Dec. 16, 1987, as amended 72 FR 32742, June 13, 2007.

40 CFR 61 Subpart H. National Emission Standards for Emissions of Radionuclides Other Than Radon From Department of Energy Facilities. 54 FR 51695, Dec. 15, 1989, as amended at 67 FR 57166, Sept. 9, 2002.

DOE Order 5400.5. 1990. Radiation Protection of the Public and the Environment. U.S. Department of Energy, Washington, DC. Change 2: 1-7-93.

NYCRR Part 227-2. Title 6. Reasonably Available Control Technology for Oxides of Nitrogen. New York State Department of Environmental Conservation, Albany, NY. Amended 1-28-04.

Shlein, Bernard, et al., eds. 1998. Handbook of Health Physics and Radiological Health, Third Edition. Williams and Wilkins, Baltimore, MD.

SCDHS. 1993. Suffolk County Sanitary Code Article 12: Toxic and Hazardous Material Storage and Handling Controls. Suffolk County Department of Health Services, New York.

USC Title 42, Chapter 85. Air Pollution Prevention and Control (Clean Air Act), 1990. 


\section{Water Quality}

Wastewater generated from Brookhaven National Laboratory (BNL) operations is discharged to surface waters via the Sewage Treatment Plant and to groundwater via recharge basins. Some wastewater may contain very low levels of radiological, organic, or inorganic contaminants. Monitoring, pollution prevention, and vigilant operation of treatment facilities ensure that these discharges comply with all applicable requirements and that the public, employees, and environment are protected.

Analytical data for 2007 show that the average gross alpha and beta activity levels in the Sewage Treatment Plant discharge were within the typical range of historical levels and were well below drinking water standards. While the frequency of detectable levels of tritium declined in 2007, the average concentration was slightly higher than in 2006, resulting in an increase in releases to the Peconic River. The maximum concentration of tritium released was approximately 9.2 percent of the drinking water standard. In all cases, tritium was only detected in the effluent. The average concentration was $57.4 \mathrm{pCi} / \mathrm{L}$, which is less than 20 percent of the minimum detection limit. Analysis of the Sewage Treatment Plant effluent continued to show no detection of cesium-137, strontium-90, or other gamma-emitting nuclides attributable to BNL operations. Tritium was detected in a single sample collected downstream of the Sewage Treatment Plant discharge, in May. There were no other radionuclides detected along the Peconic River in 2007.

Nonradiological monitoring of the Sewage Treatment Plant effluent showed that, except for isolated incidents of noncompliance, organic and inorganic parameters were within State Pollutant Discharge Elimination System effluent limitations or other applicable standards. Inorganic data from Peconic River samples collected upstream, downstream, and at control locations demonstrated that elevated amounts of aluminum and iron detected in the river are associated with natural sources.

Examination of analytical data for discharges to recharge basins shows that the average concentrations of gross alpha and beta activity were within typical ranges and that there were no gamma-emitting radionuclides detected. There was a single, low detection of tritium in the discharge to Recharge Basin HT-W, which receives once-through cooling water and cooling tower blow down. The maximum concentration detected was $430 \mathrm{pCi} / \mathrm{L}$, which is approximately 2 percent of the drinking

5.1 SURFACE WATER MONITORING PROGRAM

Treated wastewater from the BNL Sewage Treatment Plant (STP) is discharged into the headwaters of the Peconic River. This discharge is permitted under the New York State Department of Environmental Conservation (NYSDEC) State Pollutant Discharge Elimination
System (SPDES) Program. Effluent limits are based on the water quality standards established by NYSDEC, as well as historical operational data. To assess the impact of wastewater discharge on the quality of the river, surface water is monitored at several locations upstream and downstream of the discharge point. Monitor- 
ing Station HY (see Figure 5-8), on site but upstream of all Laboratory operations, provides information on the background water quality of the Peconic River. The Carmans River is monitored as a geographic control location for comparative purposes, as it is not affected by operations at BNL or within the Peconic River watershed.

On the Laboratory site, the Peconic River is an intermittent stream. Off-site flow occurs only during periods of sustained precipitation, typically in the spring. Off-site flow in 2007 was persistent through mid September, due to a wet spring. When flow ceased, standing water was continuous throughout the year. The following sections describe BNL's surface water monitoring and surveillance program.

\subsection{SANITARY SYSTEM EFFLUENTS}

The STP effluent (Outfall 001) is a discharge point authorized under a SPDES permit issued by NYSDEC. Figure 5-1 shows a schematic of the STP and its sampling locations. The Lab- oratory's STP treatment process includes four principle steps: 1) aerobic oxidation for secondary removal of biological matter and nitrification of ammonia, 2) secondary clarification, 3) sand filtration for final solids removal, and 4) ultraviolet disinfection for bacterial control prior to discharge to the Peconic River. Tertiary treatment for nitrogen removal is also provided by controlling the oxygen levels in the aeration tanks. During the aeration process (Step 1), the oxygen levels are allowed to drop to the point where microorganisms use nitrate-bound oxygen for respiration; this liberates nitrogen gas and consequently reduces the concentration of nitrogen in the STP discharge.

Nitrogen is an essential nutrient in biological systems that, in high concentrations, can cause excessive aquatic vegetation growth. During the night (when photosynthesis does not occur), aquatic plants use oxygen in the water. Too much oxygen uptake by aquatic vegetation deprives a water system of oxygen needed by fish and other aquatic organisms for survival. Limit-

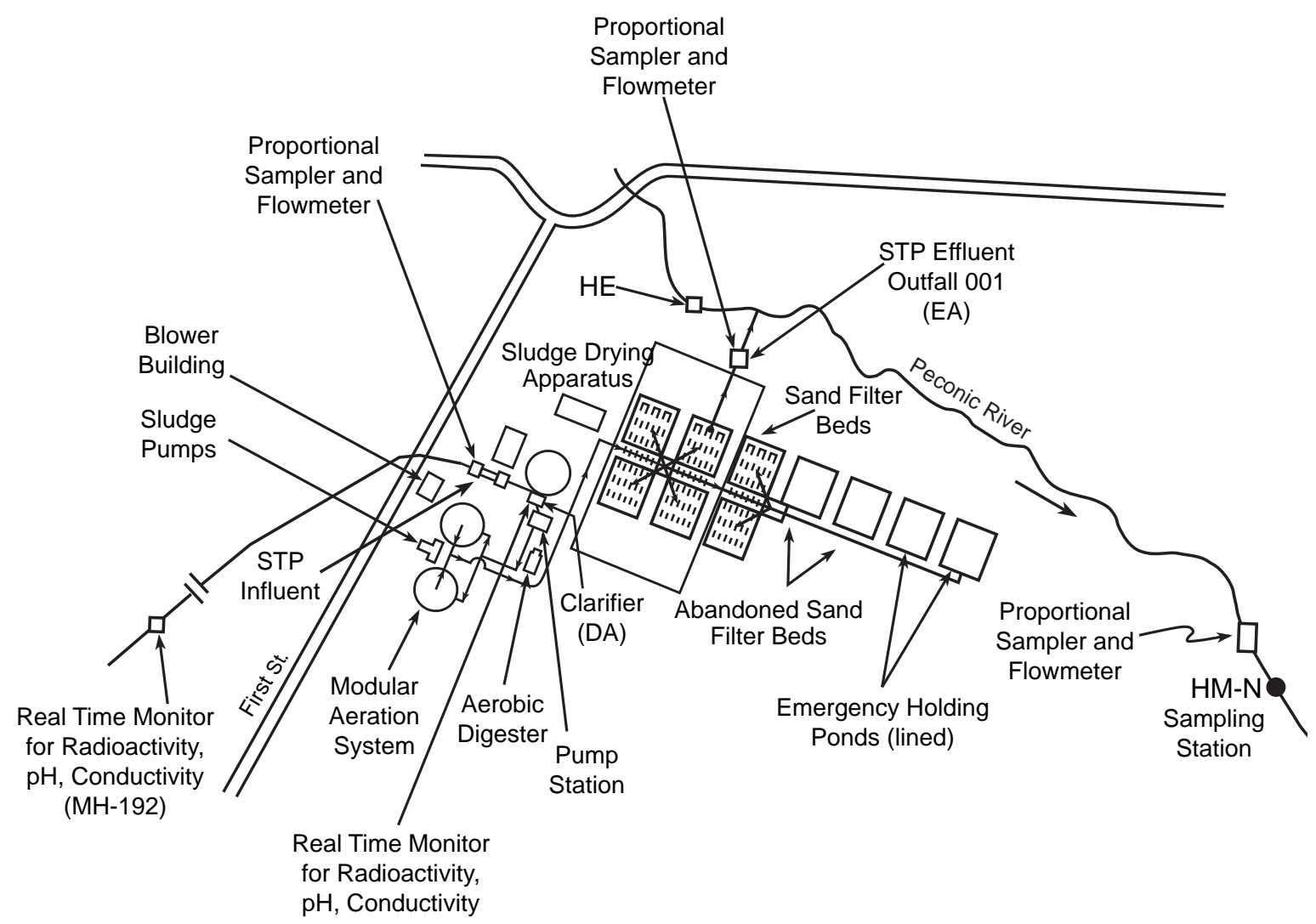

Figure 5-1. Schematic of BNL's Sewage Treatment Plant (STP). 
ing the concentration of nitrogen in the STP discharge helps keep plant growth in the Peconic River in balance with the nutrients provided by natural sources.

Real-time monitoring of the sanitary waste stream for radioactivity, $\mathrm{pH}$, and conductivity takes place at two locations. The first site (MH-192, see Figure 5-1) is approximately 1.1 miles upstream of the STP, providing at least 30 minutes' warning to the STP operators if wastewater is en route that may exceed SPDES limits or BNL effluent release criteria (which are more stringent than DOE-specified levels). The second site is at the point where the STP influent enters the treatment process (formerly the influent to the primary clarifier), as shown in Figure 5-1.

Based on the data collected by the real-time monitoring systems, any influent to the STP that may not meet SPDES limits or BNL effluent release criteria (whichever is more stringent) is diverted to two double-lined holding ponds. The total combined capacity of the two holding ponds exceeds 6 million gallons, or approximately 18 days of flow. Diversion continues until the effluent's water quality meets the permit limits or release criteria. If wastewater is diverted to the holding ponds, it is tested and evaluated against the requirements for release. If necessary, the wastewater is treated and then reintroduced into the STP at a rate that ensures compliance with SPDES permit limits for nonradiological parameters or BNL effluent release criteria for radiological parameters. In 2007, the STP influent was diverted in April to permit draining of the chilled water storage tank. Due to the accumulation of algae and other biological growths in the chilled water system, the system had to be drained and cleaned. Analysis of the chilled water showed it contained high levels of iron, which would have resulted in violation of the Laboratory's SPDES permit if it was drained in an uncontrolled fashion. The diverted wastewater is being held, pending treatment for the removal of iron.

Solids separated in the clarifier are pumped to an aerobic digester for continued biological solids reduction. Sludge is periodically emptied into solar/heat lamp-powered drying beds, where it is dried to a solid cake. Historically, the dried sludge contained very low levels (less than $0.5 \mathrm{pCi} / \mathrm{g}$ ) of radioactivity, such as residual levels of cobalt-60 (Co-60: half-life 5.2 years) from sewage releases. However, recent analysis of the sludge showed it to be free of radiological contamination. The dried sludge is placed in containers for off-site disposal at an authorized facility.

In an effort to reduce the inventory of accumulated sludge residing at the plant, in 2007 the Laboratory contracted with Mineral Processing Services Inc. and Geotube to condition and ready the sludge for disposal. Conditioning of the sludge included adding coagulants and flocculants to the liquid sludge to aid in the separation of the free liquid in the sludge from the solids. Separation was accomplished using Geotubes, large bags constructed of a geotextile fabric that effectively filters out the water while retaining the solids. The filtered water was pumped back to the head of the treatment process for treatment and discharge. The solids retained in the Geotubes continue to air dry and ultimately will be mixed with sand from the sand filter beds and disposed of off site as part of continuing maintenance.

\subsubsection{Sanitary System Effluent-Radiological Analyses}

Wastewater at the STP is sampled at the former output of the primary clarifier, Station DA (see Figure 5-1) and at the Peconic River Outfall (Station EA). At each location, samples are collected on a flow-proportional basis; that is, for every 1,000 gallons of water treated, approximately 4 fluid ounces of sample are collected and composited into a 5-gallon collection container. These samples are analyzed for gross alpha and gross beta activity and for tritium concentrations. In 2007, samples were collected three times weekly. Samples collected from these locations are also composited and analyzed monthly for gamma-emitting radionuclides and strontium-90 (Sr-90: half-life 29 years).

Although the Peconic River is not used as a direct source of potable water, the Laboratory applies the stringent Safe Drinking Water Act 


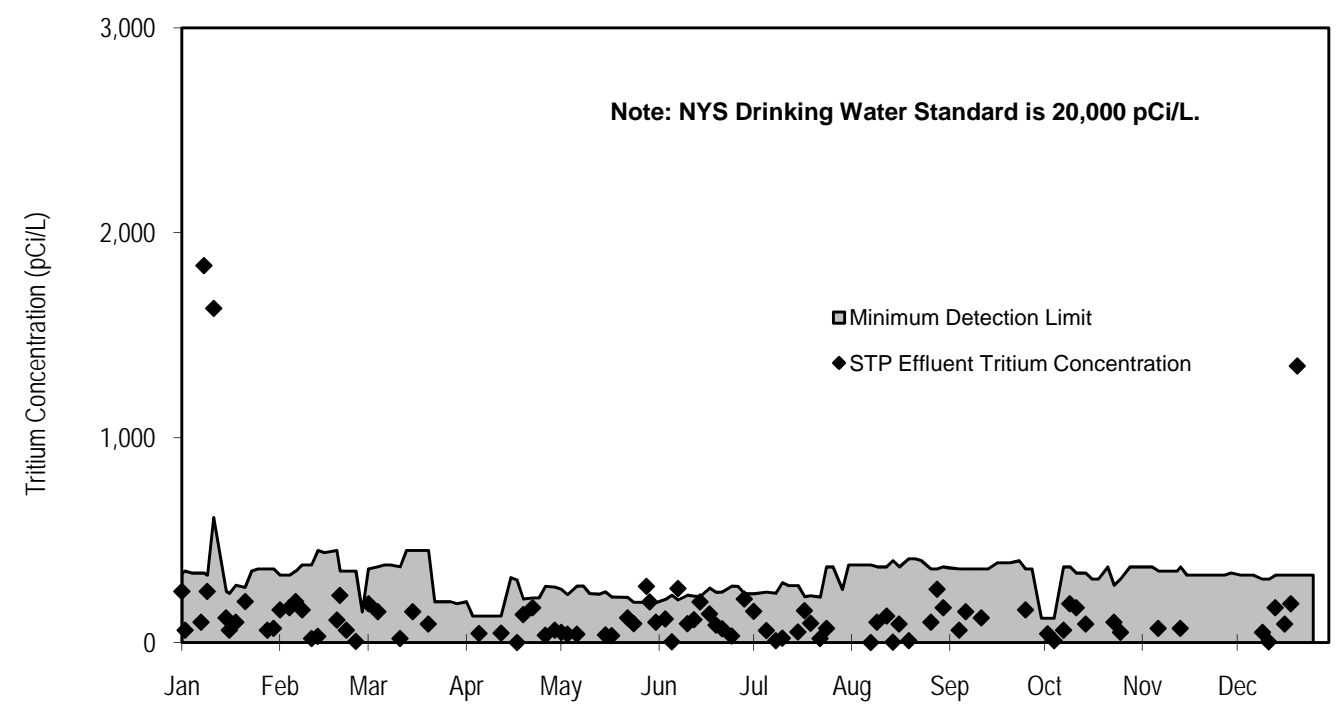

Figure 5-2. Tritium Concentrations in Effluent from the BNL Sewage Treatment Plant (2007).

(SDWA) standards for comparison purposes when monitoring the effluent, in lieu of DOE wastewater criteria. Under the SDWA, water standards are based on a 4 mrem $(40 \mu \mathrm{Sv})$ dose limit. The SDWA specifies that no individual may receive an annual dose greater than 4 mrem from radionuclides that are beta or photon emitters. Beta/photon emitters include up to 168 individual radioisotopes. The Laboratory performs radionuclide-specific gamma analysis to ensure compliance with this standard. The SDWA annual average gross alpha activity limit is $15 \mathrm{pCi} / \mathrm{L}$, including radium-226 (Ra226: half-life 1,600 years), but excluding radon and uranium. Other SDWA-specified drinking water limits are $20,000 \mathrm{pCi} / \mathrm{L}$ for tritium (H-3: half-life 12.3 years), 8 pCi/L for $\mathrm{Sr}-90$, $5 \mathrm{pCi} / \mathrm{L}$ for Ra-226 and radium-228 (Ra-228: half-life 5.75 years), and $30 \mu \mathrm{g} / \mathrm{L}$ for uranium. Gross activity (alpha and beta) measurements are used as a screening tool for detecting the presence of radioactivity. Table $5-1$ shows the monthly gross alpha and beta activity data and tritium concentrations for the STP influent and effluent during 2007. Annual average gross alpha and beta activity levels in the STP effluent were $0.4 \pm 0.1 \mathrm{pCi} / \mathrm{L}$ and $5.1 \pm 0.4 \mathrm{pCi} / \mathrm{L}$, respectively. These concentrations remain essentially unchanged from year to year. Control location data (Carmans River Station $\mathrm{HH}$; see Figure 5-8 ) show average gross alpha and beta levels of $0.5 \pm 0.7 \mathrm{pCi} / \mathrm{L}$ and $1.6 \pm 1.0$ $\mathrm{pCi} / \mathrm{L}$, respectively (see Table 5-7). The average concentrations of gross alpha and beta activity upstream of BNL were $5.8 \pm 10 \mathrm{pCi} / \mathrm{L}$ and $3.9 \pm 4.7 \mathrm{pCi} / \mathrm{L}$, respectively.

Tritium detected at the STP originates from either High Flux Beam Reactor (HFBR) sanitary system releases, or from small, infrequent batch releases that meet BNL discharge criteria, from other facilities. Although the HFBR is no longer operating, tritium continues to be released from the facility at very low concentrations, due to off-gassing. When the HFBR was operating, air within the reactor building contained higher levels of tritium in the form of water vapor. The water was absorbed by many porous surfaces and materials, which slowly liberate the tritiated moisture as it is replaced by untritiated water. Once tritium is in the air stream, it condenses as a component of water vapor in the air conditioning or air compressor units and is discharged in these wastewater streams. To minimize the quantity of tritium released to the STP, efforts have been made to capture most of the air compressor condensate collected on the HFBR equipment level. A plot of the 2007 tritium concentrations recorded in STP effluent is presented in Figure 5-2. A 15-year trend plot of annual average tritium concentrations measured in the STP discharge is shown in Figure 5-3. The annual average con- 
Table 5-1. Tritium and Gross Activity in Water at the BNL Sewage Treatment Plant (STP).

\begin{tabular}{|c|c|c|c|c|c|c|c|c|}
\hline & & Flow (a) & Trit & $m(p C i / L)$ & Gross A & $a(p C i / L)$ & Gross B & $(p C i / L)$ \\
\hline & & (Liters) & $\max$. & avg. & $\max$. & avg. & $\max$. & avg. \\
\hline January & influent & $2.48 \mathrm{E}+7$ & $<270$ & $4.1 \pm 83$ & $2.0 \pm 1.2$ & $0.8 \pm 0.3$ & $6.4 \pm 1.2$ & $5.0 \pm 0.6$ \\
\hline & effluent & $2.46 \mathrm{E}+7$ & $1840 \pm 420$ & $463.2 \pm 317.1$ & $<1.5$ & $0.2 \pm 0.2$ & $5.6 \pm 1.5$ & $4.4 \pm 0.4$ \\
\hline February & influent & $2.63 \mathrm{E}+7$ & $<420$ & $19.2 \pm 81.1$ & $<3.2$ & $0.8 \pm 0.2$ & $7.8 \pm 1.7$ & $5.1 \pm 0.7$ \\
\hline & effluent & $2.26 \mathrm{E}+7$ & $<350$ & $90.2 \pm 52.4$ & $<1.5$ & $0.5 \pm 0.2$ & $7.1 \pm 1.4$ & $5.2 \pm 0.6$ \\
\hline March & influent & $3.05 E+7$ & $<450$ & $-31.5 \pm 61.6$ & $<1.6$ & $0.7 \pm 0.2$ & $7.7 \pm 1.4$ & $5.2 \pm 0.7$ \\
\hline & effluent & $2.90 \mathrm{E}+7$ & $<360$ & $-29.8 \pm 73.6$ & $1.5 \pm 1.0$ & $0.6 \pm 0.2$ & $7.8 \pm 1.5$ & $5.3 \pm 0.7$ \\
\hline April & influent & $2.79 \mathrm{E}+7$ & $<218$ & $21.2 \pm 46.5$ & $<2.9$ & $0.4 \pm 0.2$ & $7.1 \pm 1.3$ & $4.7 \pm 0.9$ \\
\hline & effluent & $2.81 \mathrm{E}+7$ & $<219$ & $17.4 \pm 43.6$ & $<1.1$ & $0.2 \pm 0.2$ & $22.5 \pm 1.9$ & $5.7 \pm 2.8$ \\
\hline May & influent & $2.95 E+7$ & $<282$ & $43.8 \pm 37$ & $8.8 \pm 2.8$ & $1.3 \pm 1.3$ & $14.0 \pm 1.3$ & $7.7 \pm 1.3$ \\
\hline & effluent & $2.56 \mathrm{E}+7$ & $274 \pm 125$ & $63.4 \pm 48.4$ & $<1.6$ & $0.2 \pm 0.2$ & $27.5 \pm 1.7$ & $6.5 \pm 3.6$ \\
\hline June & influent & $3.79 \mathrm{E}+7$ & $<231$ & $70.2 \pm 57.9$ & $<2.0$ & $0.6 \pm 0.3$ & $11.2 \pm 2.1$ & $7.2 \pm 1.0$ \\
\hline & effluent & $2.92 \mathrm{E}+7$ & $264 \pm 132$ & $104.4 \pm 48$ & $1.4 \pm 0.9$ & $0.4 \pm 0.4$ & $11.4 \pm 2.0$ & $6.8 \pm 1.2$ \\
\hline July & influent & $4.97 \mathrm{E}+7$ & $<291$ & $61.4 \pm 50.9$ & $2.9 \pm 1.8$ & $0.3 \pm 0.6$ & $13.0 \pm 2.4$ & $5.9 \pm 1.3$ \\
\hline & effluent & $3.94 \mathrm{E}+7$ & $<225$ & $46 \pm 36.4$ & $1.4 \pm 0.9$ & $0.3 \pm 0.3$ & $7.6 \pm 1.5$ & $6.2 \pm 0.5$ \\
\hline August & influent & $5.14 \mathrm{E}+7$ & $<360$ & $65 \pm 70.4$ & $<1.3$ & $0.6 \pm 0.2$ & $6.3 \pm 1.3$ & $3.9 \pm 0.6$ \\
\hline & effluent & $4.00 \mathrm{E}+7$ & $<360$ & $28 \pm 64.5$ & $<1.2$ & $0.2 \pm 0.2$ & $5.2 \pm 1.2$ & $4.1 \pm 0.4$ \\
\hline September & influent & $4.14 \mathrm{E}+7$ & $<360$ & $-100.5 \pm 64.2$ & $1.5 \pm 0.9$ & $0.5 \pm 0.3$ & $6.4 \pm 1.3$ & $4.4 \pm 0.8$ \\
\hline & effluent & $3.11 E+7$ & $<360$ & $-36.4 \pm 89.9$ & $1.7 \pm 1.0$ & $0.5 \pm 0.3$ & $6.4 \pm 1.4$ & $4.3 \pm 0.9$ \\
\hline October & influent & $4.04 \mathrm{E}+7$ & $<280$ & $-2 \pm 65.6$ & $2.3 \pm 1.3$ & $0.5 \pm 0.4$ & $6.3 \pm 1.5$ & $4.5 \pm 0.6$ \\
\hline & effluent & $3.06 \mathrm{E}+7$ & $<370$ & $25.1 \pm 51.2$ & $<1.7$ & $0.5 \pm 0.3$ & $5.8 \pm 1.3$ & $4.0 \pm 0.6$ \\
\hline November & influent & $3.49 \mathrm{E}+7$ & $<310$ & $-68.6 \pm 56.4$ & $<2.1$ & $0.5 \pm 0.3$ & $6.5 \pm 1.4$ & $4.4 \pm 0.7$ \\
\hline & effluent & $2.67 \mathrm{E}+7$ & $<350$ & $-65.7 \pm 45.7$ & $<1.4$ & $0.4 \pm 0.3$ & $5.8 \pm 1.3$ & $4.1 \pm 0.4$ \\
\hline December & influent & $4.13 \mathrm{E}+7$ & $<360$ & $-46.3 \pm 70.4$ & $2.3 \pm 1.1$ & $0.5 \pm 0.4$ & $6.4 \pm 1.3$ & $5.2 \pm 0.3$ \\
\hline & effluent & $2.41 \mathrm{E}+7$ & $1350 \pm 280$ & $107.6 \pm 209.8$ & $<1.7$ & $0.4 \pm 0.3$ & $5.2 \pm 1.0$ & $5.1 \pm 0.4$ \\
\hline Annual Avg. & influent & & & $4.9 \pm 19.6$ & & $0.6 \pm 0.1$ & & $5.2 \pm 0.3$ \\
\hline & effluent & & & $57.4 \pm 180.3$ & & $0.4 \pm 0.1$ & & $5.1 \pm 0.4$ \\
\hline Total Release & & $3.51 E+8$ & & $20.1 \mathrm{mCi}$ & & $0.14 \mathrm{mCi}$ & & $1.8 \mathrm{mCi}$ \\
\hline Average MDL & & & & 353 & & 1.4 & & 1.9 \\
\hline SDWA Limit ( & & & & 20,000 & & 15 & & (b) \\
\hline $\begin{array}{l}\text { Notes: } \\
\text { All values are re } \\
\text { Negative numbe } \\
\text { To convert value } \\
\text { MDL = Minimum } \\
\text { SDWA = Safe D } \\
\text { (a) Effluent valı } \\
\text { (b) The drinking } \\
\text { identify spe }\end{array}$ & $\begin{array}{l}\text { with a } 95 \% \\
\text { ar when the } \\
\text { pCi to } \mathrm{Bq}, \mathrm{c} \\
\text { tion Limit } \\
\text { Water Act } \\
\text { ater than inf } \\
\text { standards v } \\
\text { lionuclides, }\end{array}$ & $\begin{array}{l}\text { nce interval. } \\
\text { red value is Ic } \\
\text { y } 27.03 \text {. } \\
\text { alues occur w } \\
\text { anged from } 5 \\
\text { equivalent ca }\end{array}$ & $\begin{array}{l}\text { ir than backgrou } \\
\text { ill water that had } \\
\text { oi/L (concentrat } \\
\text { ot be calculated }\end{array}$ & $\begin{array}{l}\text { see Appendix B for } \\
\text { n diverted to the ho } \\
\text { based) to } 4 \mathrm{mrem} / \mathrm{y} \\
\text { the values in the tab }\end{array}$ & $\begin{array}{l}\text { ription). } \\
\text { ponds is test } \\
\text { se based) in } 2\end{array}$ & $\begin{array}{l}\text { treated (if ne } \\
\text { As gross b }\end{array}$ & $\begin{array}{l}\text { ry), and releas } \\
\text { tivity does not }\end{array}$ & \\
\hline
\end{tabular}


Figure 5-3.

Sewage Treatment Plant/

Peconic River Annual Average Tritium Concentrations

(1993-2007).

Figure 5-4. Tritum Released to the Peconic River, 15-Year Trend (1993-2007).
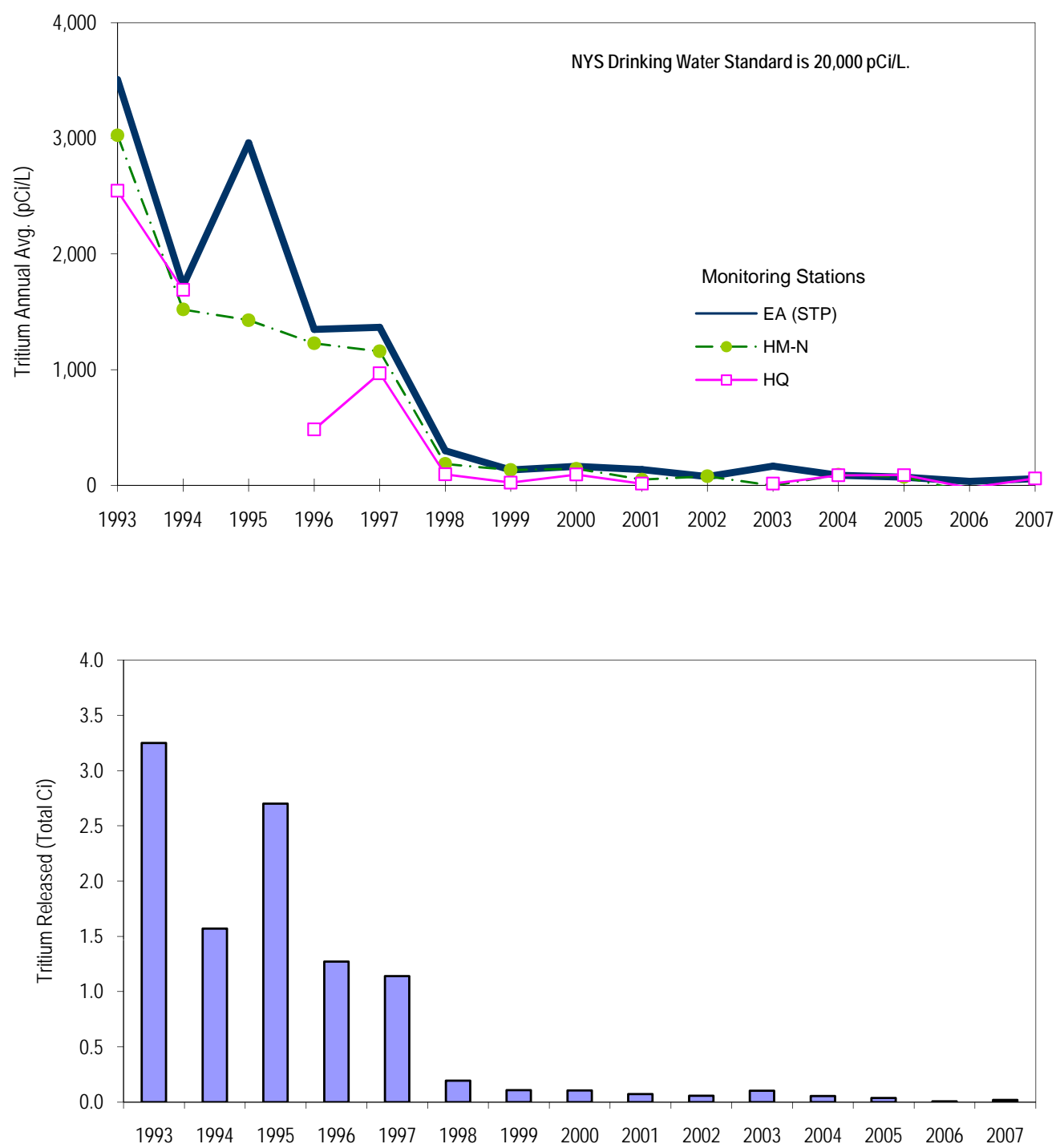

Figure 5-5.

Cesium-137 in the BNL Sewage Treatment Plant Influent and Effluent (1993-2007).

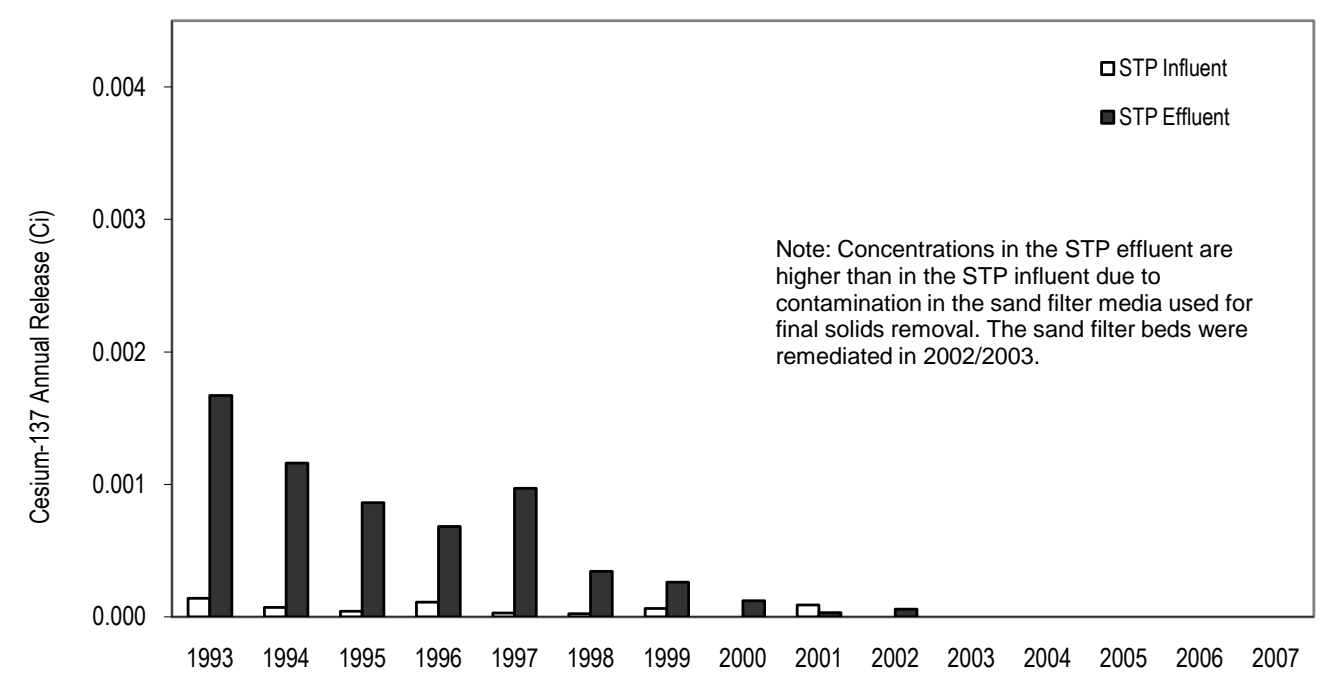


centration trend has been declining since 1995.

In 2007, a total of $0.021 \mathrm{Ci} \mathrm{(21} \mathrm{mCi)} \mathrm{of} \mathrm{tritium}$ was released during the year (see Figure 5-4). The annual average tritium concentration, as measured in the STP effluent (EA, Outfall 001), was $57.4 \pm 180.3 \mathrm{pCi} / \mathrm{L}$. While the average concentration is higher than that recorded in 2006, the frequency of tritium detections was lower in 2007. The 2007 average value is approximately 16 percent of the average minimum detection limit (MDL) of $353 \mathrm{pCi} / \mathrm{L}$. The maximum concentration detected in the STP discharge (see Figure 5-2) was $1,840 \pm 420 \mathrm{pCi} / \mathrm{L}$. The maximum concentration occurred in January and was associated with a release that occurred in December 2006. An investigation to ascertain the tritium source did not reveal any single source of high-concentration tritium, but did identify several low-concentration sources, which when combined, resulted in this observation. Low-concentration releases of this magnitude are expected to continue as facilities such as the HFBR and the Brookhaven Medical Research Reactor (BMRR) are placed into routine surveillance mode and piping and tank systems are drained and dried out.

In total, tritium was detected on five separate days in the STP effluent. Two events, which occurred in January, were likely associated with a release reported in December 2006. Tritium was not detected in the influent on these days, and its presence in the effluent was probably the result of residual in the plant slowly bleeding out. On one event in May and another in June, the concentration detected was lower than the typical minimum detection limit, but greater than the detection limit on that specific day. The level of uncertainty associated with these two samples was high, and it was suspected that the result was overstated. The last detection of tritium occurred in December and it was detected only in the effluent and for only one day. There have been many instances of false positive results reported by the analytical laboratories; the isolated December result was likely a false positive.

Table 5-2 presents the gamma spectroscopy analytical data for anthropogenic radionuclides historically detected in the monthly STP wastewater composite samples. In 2007, there were no gamma-emitting nuclides detected in the STP effluent, which is consistent with data reported for 2003-2006 (see Figure 5-5). No Sr-90 was detected in 2007.

\subsubsection{Sanitary System Effluent-Nonradiological Analyses}

In addition to the compliance monitoring discussed in Chapter 3, effluent from the STP is also monitored for nonradiological contaminants under the BNL Environmental Surveillance Program. Data are collected for field-measured parameters such as temperature, specific conductivity, $\mathrm{pH}$, and dissolved oxygen, as well as inorganic parameters such as chlorides, nitrates, sulfates, and metals. Composite samples of the STP effluent are collected using a flow-proportional refrigerated sampling device (ISCO Model 3700RF) and are then analyzed by contract analytical laboratories. Samples are analyzed for 23 inorganic elements and for anions, semivolatile organic compounds (SVOCs), pesticides, and herbicides. In addition, grab samples are collected monthly from the STP effluent and analyzed for 38 different volatile organic compounds (VOCs). Daily influent and effluent logs are maintained by the STP operators for flow, $\mathrm{pH}$, temperature, and settleable solids, as part of routine monitoring of STP operations.

Table 5-3 summarizes the water quality and inorganic analytical results for the STP samples. Comparing the effluent data to the SPDES effluent limits (or New York State Ambient Water Quality Standards [NYS AWQS], as appropriate) shows that most of the analytical parameters were within SPDES effluent permit limits (see also the compliance data in Chapter 3). Only total nitrogen was detected in the effluent at concentrations exceeding the SPDES permit limits. This is consistent with the data reported in Chapter 3. Nitrogen is a byproduct of the sanitary treatment process. Efforts to control nitrogen in the past have included adding enzymes and bacterial cultures to the treatment process, as well as increasing the period of low dissolved oxygen to enhance the de-nitrificaton step. These efforts have had limited success. Additional emphasis will be placed on nitrogen control in 2008. 
Table 5-2. Gamma-Emitting Radionuclides and Sr-90 in Water at the BNL Sewage Treatment Plant.

\begin{tabular}{|c|c|c|c|c|c|c|c|}
\hline & & $\begin{array}{c}\text { Flow } \\
\text { (Liters) }\end{array}$ & Co-60 & Cs-137 & $\begin{array}{l}\mathrm{Be}-7 \\
(\mathrm{pCi} / \mathrm{L})\end{array}$ & $\mathrm{Na}-22$ & $\begin{array}{r}\text { Sr-90 } \\
\end{array}$ \\
\hline \multirow[t]{2}{*}{ January } & influent & $2.48 \mathrm{E}+7$ & ND & ND & ND & ND & ND \\
\hline & effluent & $2.46 \mathrm{E}+7$ & ND & ND & ND & ND & ND \\
\hline \multirow[t]{2}{*}{ February } & influent & $2.63 E+7$ & ND & ND & ND & ND & ND \\
\hline & effluent & $2.26 \mathrm{E}+7$ & ND & ND & ND & ND & ND \\
\hline \multirow[t]{2}{*}{ March } & influent & $3.05 E+7$ & ND & ND & ND & ND & ND \\
\hline & effluent & $2.90 \mathrm{E}+7$ & ND & ND & ND & ND & ND \\
\hline \multirow[t]{2}{*}{ April } & influent & $2.79 \mathrm{E}+7$ & ND & ND & ND & ND & ND \\
\hline & effluent & $2.81 \mathrm{E}+7$ & ND & ND & ND & ND & ND \\
\hline \multirow[t]{2}{*}{ May } & influent & $2.95 \mathrm{E}+7$ & ND & ND & ND & ND & ND \\
\hline & effluent & $2.56 \mathrm{E}+7$ & ND & ND & ND & ND & ND \\
\hline \multirow[t]{2}{*}{ June } & influent & $3.79 \mathrm{E}+7$ & ND & ND & ND & ND & ND \\
\hline & effluent & $2.92 \mathrm{E}+7$ & ND & ND & ND & ND & ND \\
\hline \multirow[t]{2}{*}{ July } & influent & $4.97 \mathrm{E}+7$ & ND & ND & ND & ND & ND \\
\hline & effluent & $3.94 \mathrm{E}+7$ & ND & ND & ND & ND & ND \\
\hline \multirow[t]{2}{*}{ August } & influent & $5.14 \mathrm{E}+7$ & ND & ND & ND & ND & ND \\
\hline & effluent & $4.00 \mathrm{E}+7$ & ND & ND & ND & ND & ND \\
\hline \multirow[t]{2}{*}{ September } & influent & 4.14E+7 & ND & ND & ND & ND & ND \\
\hline & effluent & $3.11 \mathrm{E}+7$ & ND & ND & ND & ND & ND \\
\hline \multirow[t]{2}{*}{ October } & influent & $4.04 \mathrm{E}+7$ & ND & ND & ND & ND & ND \\
\hline & effluent & $3.06 \mathrm{E}+7$ & ND & ND & ND & ND & ND \\
\hline \multirow[t]{2}{*}{ November } & influent & $3.49 \mathrm{E}+7$ & ND & ND & ND & ND & ND \\
\hline & effluent & $2.67 \mathrm{E}+7$ & ND & ND & ND & ND & ND \\
\hline \multirow[t]{2}{*}{ December } & influent & $4.13 E+7$ & ND & ND & ND & ND & ND \\
\hline & effluent & $2.41 \mathrm{E}+7$ & ND & ND & ND & ND & ND \\
\hline \multicolumn{3}{|c|}{ Total Release to the Peconic River (mCi) } & 0 & 0 & 0 & 0 & 0 \\
\hline \multicolumn{3}{|c|}{ DOE Order 5400.5 DCG (pCi/L) } & 5,000 & 3,000 & 50,000 & 10,000 & 1,000 \\
\hline \multicolumn{3}{|c|}{ Dose limit of 4 mrem EDE (pCi/L) } & 100 & 200 & 6,000 & 400 & 8 \\
\hline \multicolumn{8}{|c|}{$\begin{array}{l}\text { Notes: } \\
\text { No BNL-derived radionuclides were dete } \\
\text { To convert values from pCi to Bq, divide } \\
\text { DCG = Derived Concentration Guide } \\
\text { EDE = Effective Dose Equivalent } \\
\text { ND = Not Detected }\end{array}$} \\
\hline
\end{tabular}

In 2007, acetone was the only VOC detected in the STP effluent at concentrations at or near the detection limit. Other VOCs were sporadically detected at concentrations much less than the method detection limit (typically $<1 \mathrm{ppb}$ ) and much less than the NYS AWQS. Acetone is a common solvent used in the contract analytical laboratory and is typically found in background levels in laboratories. The maximum concentration detected was $4.2 \mu \mathrm{g} / \mathrm{L}$. Although there are no SPDES limits or AWQS specified for acetone, NYSDEC imposes a generic limit of $50 \mu \mathrm{g} / \mathrm{L}$ for unlisted organic compounds. The amounts detected in BNL samples were less than 15 percent of that generic limit.

\subsection{PROCESS-SPECIFIC WASTEWATER}

Wastewater that may contain constituents above SPDES permit limits or ambient water quality discharge standards must be held by the 
Table 5-3. BNL Sewage Treatment Plant (STP) Water Quality and Metals Analytical Results.

\begin{tabular}{|c|c|c|c|c|c|c|c|c|c|c|c|}
\hline \multirow[b]{2}{*}{ ANALYTE } & \multirow[b]{2}{*}{ Units } & \multicolumn{4}{|c|}{ STP Influent } & \multicolumn{4}{|c|}{ STP Effluent } & \multirow{2}{*}{$\begin{array}{l}\text { SPDES Limit } \\
\text { or AWQS (1) }\end{array}$} & \multirow{2}{*}{$\begin{array}{c}\text { Comment or } \\
\text { Qualifier }\end{array}$} \\
\hline & & $\mathrm{N}$ & Min. & Max. & Avg. & $\mathrm{N}$ & Min. & Max. & Avg. & & \\
\hline $\mathrm{pH}$ & SU & $\mathrm{CM}$ & 6.6 & 8.2 & NA & 176 & 6.2 & 7.5 & NA & $5.8-9.0$ & \\
\hline Conductivity & $\mu \mathrm{S} / \mathrm{cm}$ & $\mathrm{CM}$ & NR & NR & NR & 176 & 178 & 817 & 346 & SNS & \\
\hline Temperature & ${ }^{\circ} \mathrm{C}$ & $\mathrm{CM}$ & NR & NR & NR & 176 & 2.7 & 26.3 & 14.9 & SNS & \\
\hline Dissolved Oxygen & $\mathrm{mg} / \mathrm{L}$ & $\mathrm{NM}$ & NM & NM & NM & 176 & 6.8 & 15.1 & 9.9 & SNS & \\
\hline Chlorides & $\mathrm{mg} / \mathrm{L}$ & 12 & 38.5 & 90.3 & 59.3 & 12 & 35.0 & 193.0 & 74.0 & SNS & \\
\hline Nitrate (as N) & $\mathrm{mg} / \mathrm{L}$ & 12 & 0.5 & 3.1 & 1.8 & 12 & 1.7 & 11.1 & 7.0 & 10 & Total N \\
\hline Sulfates & $\mathrm{mg} / \mathrm{L}$ & 12 & 9.0 & 19.9 & 16.8 & 12 & 14.0 & 20.0 & 17.4 & 250 & GA \\
\hline Aluminum & $\mu \mathrm{g} / \mathrm{L}$ & 12 & 59.6 & 373.0 & 197.1 & 12 & 15.5 & $<68$ & $<68$ & 100 & Ionic \\
\hline Antimony & $\mu \mathrm{g} / \mathrm{L}$ & 12 & 0.3 & $<5$ & $<5$ & 12 & 0.3 & $<5$ & $<5$ & 3 & GA \\
\hline Arsenic & $\mu \mathrm{g} / \mathrm{L}$ & 12 & 2.5 & $<5$ & $<5$ & 12 & 1.7 & $<5$ & $<5$ & 150 & Dissolved \\
\hline Barium & $\mu \mathrm{g} / \mathrm{L}$ & 12 & 27.0 & 83.9 & 53.9 & 12 & 9.4 & 24.1 & 15.6 & 1000 & GA \\
\hline Beryllium & $\mu \mathrm{g} / \mathrm{L}$ & 12 & $<1$ & $<2$ & $<2$ & 12 & $<1$ & $<10$ & $<10$ & 11 & Acid Soluble \\
\hline Cadmium & $\mu \mathrm{g} / \mathrm{L}$ & 12 & 0.2 & $<1$ & $<1$ & 12 & 0.2 & $<1$ & $<1$ & 1.1 & Dissolved \\
\hline Calcium & $\mathrm{mg} / \mathrm{L}$ & 12 & 8.3 & 17.5 & 12.1 & 12 & 7.5 & 18.4 & 13.6 & SNS & \\
\hline Chromium & $\mu \mathrm{g} / \mathrm{L}$ & 12 & 2.5 & 7.4 & $<5$ & 12 & $<1$ & 6.7 & $<5$ & 34.4 & Dissolved \\
\hline Cobalt & $\mu \mathrm{g} / \mathrm{L}$ & 12 & 0.6 & 1.7 & $<1$ & 12 & 0.3 & $<5$ & $<5$ & 5 & Acid Soluble \\
\hline Copper & $\mu \mathrm{g} / \mathrm{L}$ & 12 & 52.7 & 312.0 & 162.4 & 12 & 37.9 & 102.0 & 60.4 & 150 & SPDES \\
\hline Iron & $\mathrm{mg} / \mathrm{L}$ & 12 & 0.8 & 6.0 & 2.5 & 12 & 0.1 & 0.3 & 0.2 & 0.37 & SPDES \\
\hline Lead & $\mu \mathrm{g} / \mathrm{L}$ & 12 & 3.9 & 43.4 & 14.3 & 12 & 0.6 & $<3$ & $<3$ & 19 & SPDES \\
\hline Magnesium & $\mathrm{mg} / \mathrm{L}$ & 12 & 2.5 & 5.2 & 3.9 & 12 & 2.6 & 5.1 & 3.8 & SNS & \\
\hline Manganese & $\mu \mathrm{g} / \mathrm{L}$ & 12 & 32.6 & 82.0 & 57.4 & 12 & 1.5 & 7.2 & 3.4 & 300 & $\mathrm{GA}$ \\
\hline Mercury & $\mu \mathrm{g} / \mathrm{L}$ & 12 & 0.1 & 0.3 & $<0.2$ & 12 & $<0.06$ & $<1$ & $<1$ & 0.8 & SPDES \\
\hline Nickle & $\mu \mathrm{g} / \mathrm{L}$ & 12 & 4.3 & 22.6 & 9.6 & 12 & 7.3 & 20.2 & 12.9 & 110 & SPDES \\
\hline Potassium & $\mathrm{mg} / \mathrm{L}$ & 12 & 3.6 & 7.4 & 6.0 & 12 & 3.5 & 8.1 & 5.1 & SNS & \\
\hline Selenium & $\mu \mathrm{g} / \mathrm{L}$ & 12 & 0.6 & $<5$ & $<5$ & 12 & 0.5 & $<5$ & $<5$ & 4.6 & Dissolved \\
\hline Silver & $\mu \mathrm{g} / \mathrm{L}$ & 12 & 0.2 & $<2$ & $<2$ & 12 & 0.5 & 1.8 & 1.0 & 15 & SPDES \\
\hline Sodium & $\mathrm{mg} / \mathrm{L}$ & 12 & 28.7 & 62.9 & 43.1 & 12 & 30.0 & 119.0 & 51.2 & SNS & \\
\hline Thallium & $\mu \mathrm{g} / \mathrm{L}$ & 12 & 0.4 & $<5$ & $<5$ & 12 & $<0.4$ & $<5$ & $<5$ & 8 & Acid Soluble \\
\hline Vanadium & $\mu \mathrm{g} / \mathrm{L}$ & 12 & $<1$ & 16.5 & $<5$ & 12 & 2.6 & 11.4 & 5.1 & 14 & Acid Soluble \\
\hline Zinc & $\mu \mathrm{g} / \mathrm{L}$ & 12 & 42.6 & 201.0 & 111.9 & 12 & 28.9 & 93.2 & 56.4 & 100 & SPDES \\
\hline \multicolumn{12}{|c|}{$\begin{array}{l}\text { Notes: } \\
\text { See Figure 5-2 for locations of the STP influent and effluent monitoring locations. } \\
\text { All analytical results were generated using total recoverable analytical techniques. } \\
\text { For Class C Ambient Water Quality Standards (AWQS), the solubility state for the metal } \\
\text { is provided. } \\
\text { (1) Unless otherwise provided, the reference standard is NYSDEC Class C Surface Water } \\
\text { Ambient Water Quality Standards (AWQS). } \\
\text { (a) The conductivity, temperature, and dissolved oxygen values reported are based on } \\
\text { analyses of daily grab samples. } \\
\text { AWQS = Ambient Water Qualty Standards } \\
\text { CM = Continuously monitored }\end{array}$} \\
\hline
\end{tabular}

generating facility and be characterized to determine the appropriate means of disposal. The analytical results are compared with the appropriate discharge limit, and the wastewater is released to the sanitary system only if the volume and concentration of contaminants in the discharge would not jeopardize the quality of the STP effluent and, subsequently, the Peconic River. 
The Laboratory's SPDES permit includes requirements for quarterly sampling and analysis of process-specific wastewater discharged from printed-circuit-board fabrication operations conducted in Building 535B, metal cleaning operations in Building 498, cooling tower discharges from Building 902, and boiler blowdown from satellite boilers in Buildings 244 and 423. These operations are monitored for contaminants such as metals, cyanide, VOCs, and SVOCs. In 2007, analyses of these waste streams showed that, although several operations contributed contaminants to the STP in concentrations exceeding SPDES-permitted levels, these discharges did not affect the quality of the STP effluent.
Process wastewaters that were not expected to be of consistent quality because they were not routinely generated were held for characterization before release to the site sewer system. The process wastewaters typically included purge water from groundwater sampling, heat exchanger cleaning wastewater, wastewater generated as a result of restoration activities, and other industrial wastewaters. To determine the appropriate disposal method, samples were analyzed for contaminants specific to the process. The analyses were then reviewed and the concentrations were compared to the SPDES effluent limits and BNL's effluent release criteria. If the concentrations were within limits, authorization for sewer system discharge was granted; if

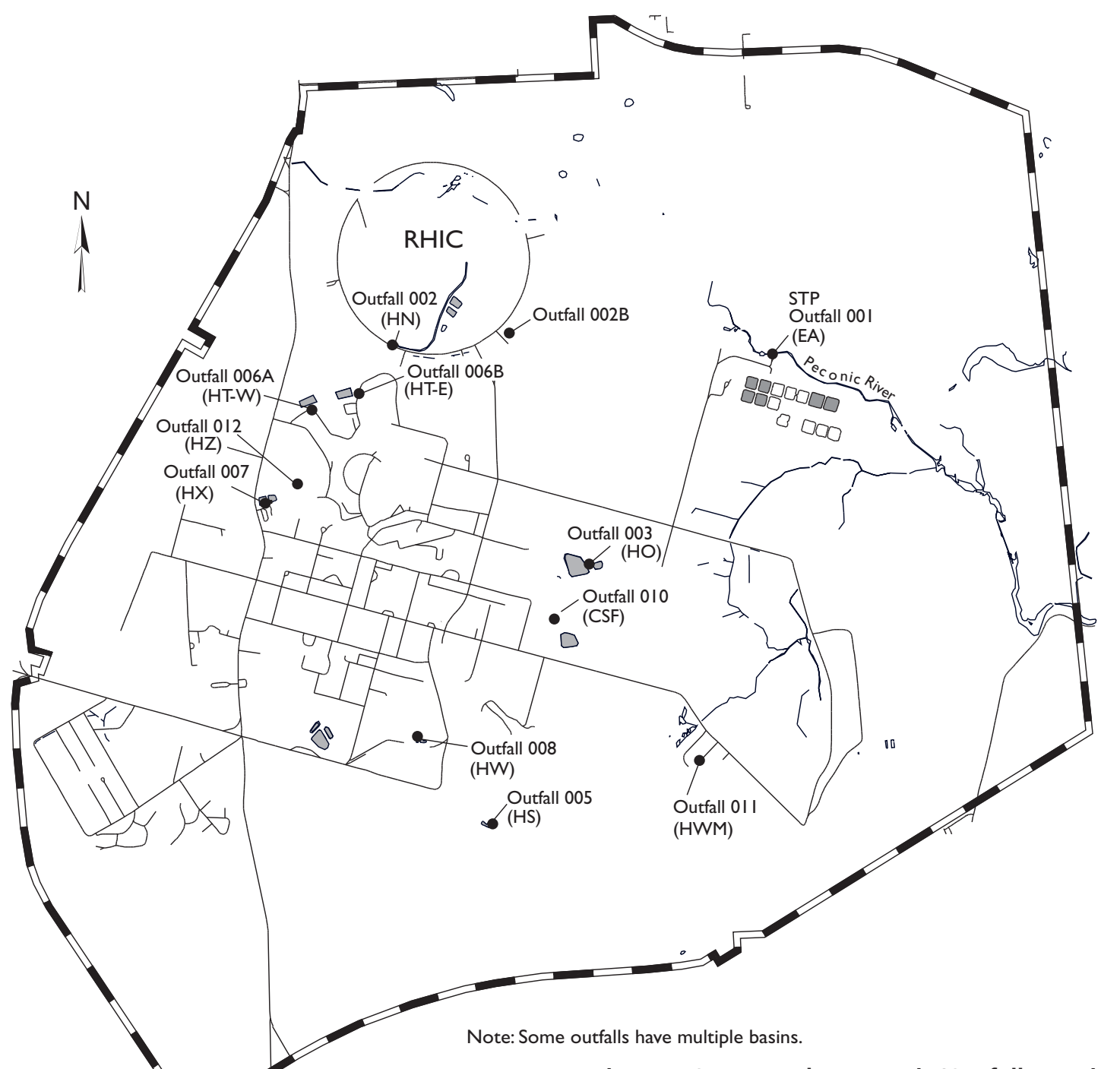

Figure 5-6. BNL Recharge Basin/Outfall Locations. 
not, alternate means of disposal were used. Any waste that contained elevated levels of hazardous or radiological contaminants in concentrations that exceeded Laboratory effluent release criteria was sent to the BNL Waste Management Facility for proper management and off-site disposal.

BNL maintains a Central Chilled Water Facility that provides recirculated refrigerated water for cooling. This water is used for cooling processes such as heat exchangers used at research facilities, computer equipment, and for comfort cooling in buildings. To provide cost-effective cooling, the facility stores 3.2 million gallons of cold water. The cold water is generated during overnight hours when electricity rates are lower. In April 2007, the chilled water system underwent maintenance to remove accumulated sediment and provide access for inspection. The water was drained to the sanitary sewer, but due to high iron levels, the sewer was diverted and the water was collected in hold-up ponds for treatment and release at a later date. By controlling this release, the Laboratory ensured its effluent continually met the SPDES release limits.

\subsection{RECHARGE BASINS}

Recharge basins are used for the discharge of "clean" wastewater streams, including oncethrough cooling water, stormwater runoff, and cooling tower blowdown. With the exception of elevated temperature and increased natural sediment content, these wastewaters are suitable for direct replenishment of the groundwater aquifer. Figure 5-6 shows the locations of the Laboratory's discharges to recharge basins (also called “outfalls” under BNL's SPDES permit). Figure 5-7 presents an overall schematic of potable water use at the Laboratory. Eleven recharge basins are used for managing oncethrough cooling water, cooling tower blowdown, and stormwater runoff:

- Basins HN, HT-W, and HT-E receive oncethrough cooling water discharges generated at the Alternating Gradient Synchrotron (AGS) and Relativistic Heavy Ion Collider (RHIC), as well as cooling tower blowdown and stormwater runoff.

- Basin HS receives predominantly stormwater runoff, once-through cooling water from

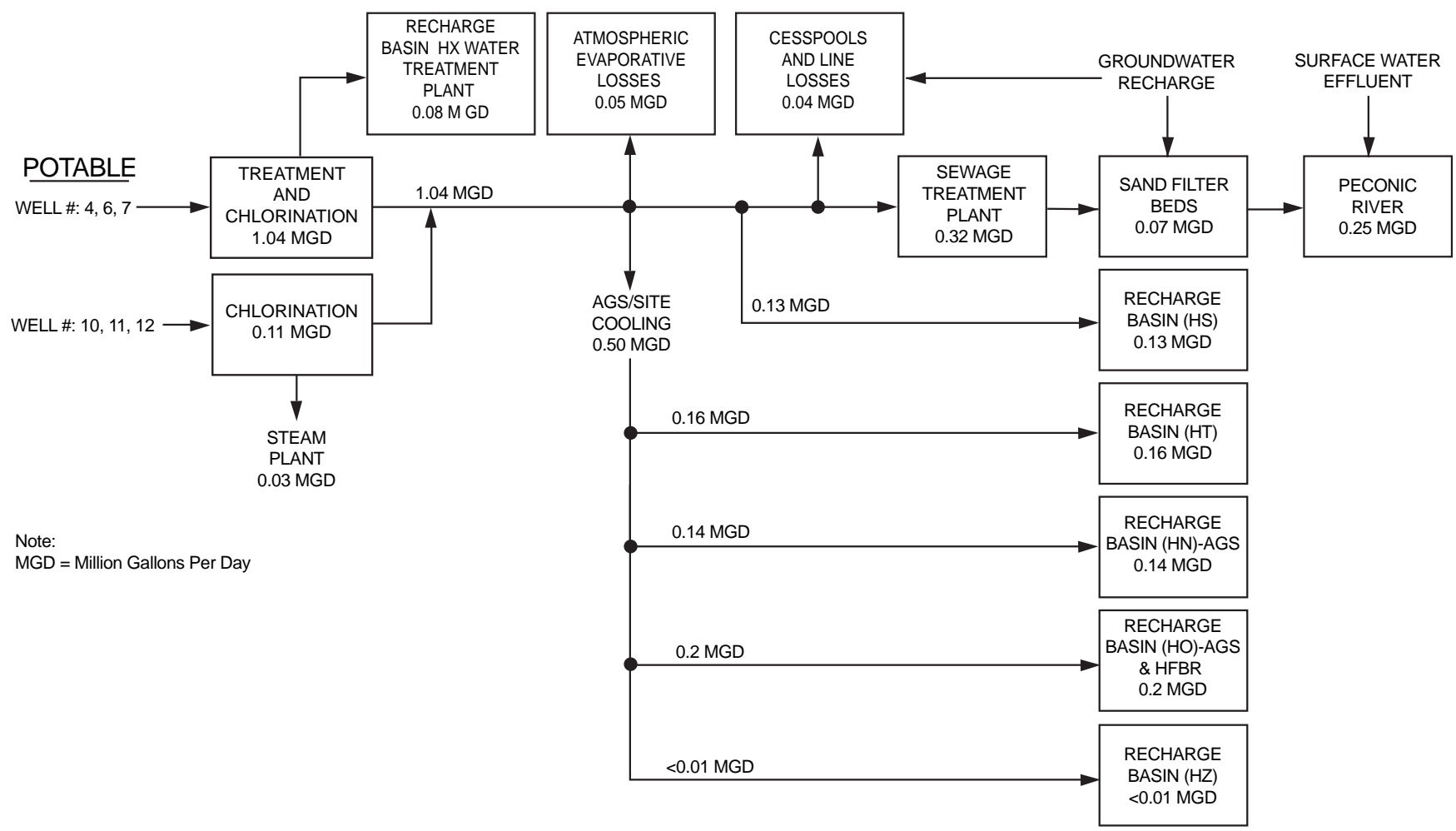

Figure 5-7. Schematic of Potable Water Use and Flow at BNL. 
Table 5-4. Radiological Analysis of Samples from On-Site Recharge Basins at BNL.

\begin{tabular}{|c|c|c|c|c|}
\hline \multicolumn{2}{|l|}{ Basin } & Gross Alpha & $\begin{array}{c}\text { Gross Beta } \\
-\quad(\mathrm{pCi} / \mathrm{L})\end{array}$ & Tritium \\
\hline \multicolumn{2}{|r|}{ No. of samples } & 4 & 4 & 4 \\
\hline \multirow[t]{2}{*}{$\mathrm{HN}$} & $\max$. & $<4.2$ & $5.5 \pm 2.2$ & $<450$ \\
\hline & avg. & $1.3 \pm 1.8$ & $2.9 \pm 1.7$ & $14.4 \pm 47.9$ \\
\hline \multirow[t]{2}{*}{$\mathrm{HO}$} & $\max$. & $<1.2$ & $<2.53$ & $<350$ \\
\hline & avg. & $0.4 \pm 0.3$ & $1.3 \pm 0.8$ & $142.7 \pm 121.6$ \\
\hline \multirow[t]{2}{*}{ HS } & $\max$. & $2.8 \pm 1.3$ & $2.5 \pm 1.1$ & $<360$ \\
\hline & avg. & $1.6 \pm 1.2$ & $1.6 \pm 0.8$ & $22.5 \pm 71.7$ \\
\hline \multirow[t]{2}{*}{ HT-E } & $\max$. & $<67$ (a) & $14 \pm 20(a)$ & $<440$ \\
\hline & avg. & $9.0 \pm 17.0$ & $7.8 \pm 7.1$ & $87.5 \pm 124.3$ \\
\hline \multirow[t]{2}{*}{ HT-W } & $\max$. & $<68$ (a) & $<44(\mathrm{a})$ & $430 \pm 250$ \\
\hline & avg. & $8.7 \pm 16.6$ & $3.4 \pm 3.6$ & $131.1 \pm 232.4$ \\
\hline \multirow[t]{2}{*}{ HW } & $\max$. & $4.3 \pm 4.7$ & $3.2 \pm 2.9$ & $<220$ \\
\hline & avg. & $1.7 \pm 1.7$ & $1.9 \pm 1.0$ & $0.0 \pm 84.1$ \\
\hline \multirow[t]{2}{*}{$\mathrm{HZ}$} & $\max$. & $1.8 \pm 0.8$ & $1.8 \pm 0.9$ & $<248$ \\
\hline & avg. & $0.7 \pm 0.9$ & $1.2 \pm 0.4$ & $24.8 \pm 92.4$ \\
\hline \multicolumn{2}{|c|}{ SDWA Limit } & 15 & (a) & 20,000 \\
\hline
\end{tabular}

Notes:

See Figure 5-7 for the locations of recharge basins/outfalls.

All values reported with a $95 \%$ confidence interval.

Negative numbers occur when the measured value is lower than

background (see Appendix $B$ for description).

To convert values from $\mathrm{pCi}$ to $\mathrm{Bq}$, divide by 27.03

The drinking water standard was changed from $50 \mathrm{pCi} / \mathrm{L}$ (concentration

based) to $4 \mathrm{mrem} / \mathrm{yr}$ (dose based) in 2003. As gross beta activity

does not identify specific radionuclides, a dose equivalent of this value cannot be calculated.

MDL = Minimum Detection Limit

SDWA = Safe Drinking Water Act

(a) Due to high solids content, the minimum detection limit for several samples was very high. sively for discharging stormwater runoff.

These areas include Basin HW in the warehouse area, Basin CSF at the Central Steam Facility (CSF), Basin HW-M at the former Hazardous Waste Management Facility (HWMF), and Basin HZ near Building 902. Each of the recharge basins is a permitted point-source discharge under the Laboratory's SPDES permit. Where required by the permit, the discharge to the basin is equipped with a flow monitoring station; weekly recordings of flow are collected, along with measurements of $\mathrm{pH}$. The specifics of the SPDES compliance monitoring program are provided in Chapter 3. To supplement that monitoring program, samples are also routinely collected and analyzed under BNL's Environmental Surveillance Program for radioactivity, VOCs, metals, and anions. During 2007, water samples were collected from all basins listed above, except recharge basin HX at the Water Treatment Plant (exempted by NYSDEC from sampling due to documented non-impact to groundwater) and the recharge basin at the former HWMF, as there are no longer any operations that could lead to the contamination of runoff.

\subsubsection{Recharge Basins - Radiological Analyses}

Discharges to the recharge basins were sampled throughout the year for subsequent analyses for gross alpha and beta activity, gamma-emitting radionuclides, and tritium. These results are presented in Table 5-4. These data show that low levels of alpha and beta activity were detected in most of the basins. Activities ranged from nondetectable to $4.3 \pm 4.7 \mathrm{pCi} / \mathrm{L}$ for gross alpha activity, and from nondetectable to $14 \pm 20 \mathrm{pCi} / \mathrm{L}$ for gross beta activity. Lowlevel detections of gross alpha and beta activity are attributable to very low levels of naturally occurring radionuclides, such as potassium40 (K-40: half-life 1.3E+09 years). Additionally, the presence of dissolved solids results in analytical data with very high detection limits and very high uncertainties, such as the case with the gross beta result, reported above. The contract analytical laboratory reported no gamma-emitting nuclides attributable to BNL operations in any discharges to recharge basins 
in 2007. Tritium was detected in a single sample collected at Basin HT-W, at very low levels $(430 \pm 250 \mathrm{pCi} / \mathrm{L})$ and with high levels of uncertainty (58 percent). This basin receives cooling water and stormwater discharges from the Collider-Accelerator complex.

\subsubsection{Recharge Basins - Nonradiological Analyses}

To determine the overall impact of the recharge basin discharges on the environment, the nonradiological analytical results were compared to groundwater discharge standards promulgated under Title 6 of the New York Codes, Rules, and Regulations (NYCRR), Part 703.6. Samples were collected quarterly for water quality parameters, metals, and VOCs, and analyzed by a contract analytical laboratory. Field-measured parameters ( $\mathrm{pH}$, conductivity, and temperature) were routinely monitored and recorded. The water quality and metals analytical results are summarized in Tables 5-5 and 5-6, respectively.

Low concentrations of disinfection byproducts were periodically detected. Sodium hypochlorite and bromine, used to control algae in cooling towers, lead to the formation of VOCs including bromoform, chloroform, dibromochloromethane, and dichlorobromomethane. The maximum concentration detected in any of the recharge basins was $10.4 \mu \mathrm{g} / \mathrm{L}$ of bromoform in recharge basin HT-E. Acetone was the only other analyte detected above the MDL for most recharge basins, ranging from nondetectable to a maximum of $10.0 \mu \mathrm{g} / \mathrm{L}$. In most instances, acetone was also found as a contaminant in the contract analytical laboratory, as evidenced by detections in blank samples.

The analytical data in Tables 5-5 show that chlorides and sodium are found in high concentrations in basins that receive significant roadway runoff. Salting of roads in the winter is the cause of these observations. The data in Table 5-6 show that all parameters, except for aluminum, iron, cobalt, manganese, and lead, complied with the respective water quality or groundwater discharge standards (GDS). With the exception of cobalt and single detections of iron and lead, the metals were only detected at concentrations above the discharge standard in the total recoverable sample. Iron, manganese, and aluminum are natural components of soil and readily dissolve when water samples are acidified for preservation. Iron is also naturally present in Long Island groundwater at concentrations that exceed the New York State GDS. Filtration of samples resulted in aluminum, manganese, and iron concentrations that were less than the NYS AWQS or GDS, as appropriate. As these metals are in particulate form, they pose no threat to groundwater quality, because the recharge basin acts as a natural filter, trapping the particles before they reach groundwater. Cobalt was detected in most filtered water samples and is being attributed to the filter media, since it was absent in most of the unfiltered water samples.

Lead was detected in two water samples: one from the CSF outfall and one from Basin HZ. The single detection of lead (230 ppb) from the CSF outfall was likely due to suspended particulate. Remediation of lead-contaminated soils at the CSF outfall was completed in 2006 and post-excavation soil samples showed all areas to have lead levels lower than the clean-up goal of $400 \mathrm{ppm}$, as documented in the "Central Steam Facility Storm Water Outfall Remediation Closeout Report” dated February 21, 2007 (Remien, 2007). Also, a second, smaller area of contamination that had been discovered at a section of broken pipe just upstream of the CSF outfall was remediated in early 2007. A single sample collected at Basin $\mathrm{HZ}$ also had a lead concentration that exceeded the effluent standard. All subsequent HZ samples had lead concentrations that were much less than the standard, so the cause of this observation is unknown, but is likely due to particulate contamination of the sample.

\subsubsection{Stormwater Assessment}

All recharge basins receive stormwater runoff. Stormwater at BNL is managed by collecting runoff from paved surfaces, roofs, and other impermeable surfaces and directing it to recharge basins via underground piping and abovegrade vegetated swales. Recharge basin HS receives most of the stormwater runoff from the central, developed portion of the 
Table 5-5. Water Quality Data for BNL On-Site Recharge Basin Samples.

\begin{tabular}{|c|c|c|c|c|c|c|c|c|c|c|c|}
\hline \multirow{2}{*}{ ANALYTE } & \multicolumn{9}{|c|}{ Recharge Basin } & \multirow{3}{*}{$\begin{array}{l}\text { NYSDEC } \\
\text { Effluent } \\
\text { Standard }\end{array}$} & \multirow{3}{*}{$\begin{array}{c}\text { Typical } \\
\text { MDL }\end{array}$} \\
\hline & & \multirow{2}{*}{$\begin{array}{c}\begin{array}{c}\mathrm{HN} \\
(\mathrm{RHIC})\end{array} \\
4\end{array}$} & \multirow{2}{*}{$\begin{array}{c}\begin{array}{c}\mathrm{HO} \\
(\mathrm{AGS})\end{array} \\
4\end{array}$} & \multirow{2}{*}{$\begin{array}{r}\text { HS } \\
(\mathrm{s})\end{array}$} & \multirow{2}{*}{$\begin{array}{c}\begin{array}{c}\text { HT-W } \\
\text { (Linac) }\end{array} \\
4\end{array}$} & \multirow{2}{*}{$\begin{array}{c}\begin{array}{c}\text { HT-E } \\
\text { (AGS/HFBR) }\end{array} \\
4\end{array}$} & \multirow{2}{*}{$\begin{array}{c}\text { HW } \\
(\mathrm{s})\end{array}$} & \multirow{2}{*}{$\begin{array}{c}\text { CSF } \\
(\mathrm{s})\end{array}$} & \multirow{2}{*}{$\begin{array}{r}\mathrm{HZ} \\
(\mathrm{s}) \\
4\end{array}$} & & \\
\hline No. & samples & & & & & & & & & & \\
\hline \multirow[t]{2}{*}{$\mathrm{pH}(\mathrm{SU})$} & $\min$. & 6.2 & 6.5 & 7.3 & 6.9 & 6.6 & 7.2 & 6.4 & 6.6 & \multirow{2}{*}{$6.5-8.5$} & \multirow{2}{*}{ NA } \\
\hline & $\max$ & 7.6 & 7.6 & 7.6 & 7.8 & 7.6 & 7.4 & 7.4 & 7.7 & & \\
\hline \multirow{3}{*}{$\begin{array}{l}\text { Conductivity } \\
(\mu \mathrm{S} / \mathrm{cm})\end{array}$} & $\min$. & 12 & 135 & 72 & 56 & 105 & 38 & 40 & 111 & \multirow{3}{*}{ SNS } & \multirow{3}{*}{ NA } \\
\hline & $\max$ & 1117 & 172 & 311 & 8583 & 16866 & 222 & 6269 & 246 & & \\
\hline & avg. & 416 & 157 & 157 & 2259 & 4526 & 92 & 1616 & 197 & & \\
\hline \multirow{3}{*}{$\begin{array}{l}\text { Temperature } \\
\left({ }^{\circ} \mathrm{C}\right)\end{array}$} & $\min$. & 2.2 & 5.3 & 2.1 & 3.2 & 3.5 & 0.2 & 0.8 & 5.4 & \multirow{3}{*}{ SNS } & \multirow{3}{*}{ NA } \\
\hline & $\max$ & 15.9 & 22.6 & 19.8 & 12.2 & 13.8 & 24.9 & 24.2 & 21.0 & & \\
\hline & avg. & 9.0 & 15.8 & 9.9 & 8.4 & 8.8 & 12.7 & 13.5 & 14.7 & & \\
\hline \multirow{3}{*}{$\begin{array}{l}\text { Dissolved } \\
\text { oxygen } \\
\text { (mg/L) }\end{array}$} & $\min$. & 7.6 & 8.8 & 9.4 & 10.6 & 9.9 & 8.9 & 9.0 & 9.3 & \multirow{3}{*}{ SNS } & \multirow{3}{*}{ NA } \\
\hline & $\max$. & 13.2 & 12.1 & 13.8 & 11.8 & 11.1 & 14.1 & 13.1 & 16.2 & & \\
\hline & avg. & 10.5 & 10.0 & 11.3 & 11.3 & 10.4 & 10.8 & 10.4 & 11.7 & & \\
\hline \multirow{3}{*}{$\begin{array}{l}\text { Chlorides } \\
\text { (mg/L) }\end{array}$} & $\min$. & 34.6 & 29.0 & 5.9 & 3.6 & 16.1 & 1.5 & 1.0 & 15.8 & \multirow{3}{*}{500} & \multirow{3}{*}{4} \\
\hline & $\max$. & 340.0 & 30.2 & 65.4 & 1880.0 & 8370.0 & 2680.0 & 1060.0 & 37.2 & & \\
\hline & avg. & 124.0 & 29.6 & 29.2 & 490.9 & 2153.3 & 671.9 & 268.8 & 28.9 & & \\
\hline \multirow{3}{*}{$\begin{array}{l}\text { Sulfates } \\
(\mathrm{mg} / \mathrm{L})\end{array}$} & $\min$. & 8.8 & 9.6 & 2.9 & 3.3 & 6.7 & 2.0 & 2.2 & 7.9 & \multirow{3}{*}{500} & \multirow{3}{*}{4} \\
\hline & $\max$. & 18.7 & 10.5 & 19.2 & 47.6 & 41.7 & 29.3 & 9.9 & 12.9 & & \\
\hline & avg. & 12.0 & 10.1 & 9.7 & 18.4 & 26.3 & 9.0 & 4.5 & 11.2 & & \\
\hline \multirow{3}{*}{$\begin{array}{l}\text { Nitrate as } \\
\text { nitrogen } \\
(\mathrm{mg} / \mathrm{L})\end{array}$} & $\min$ & 0.2 & 0.3 & 0.1 & 0.3 & 0.3 & 0.2 & 0.2 & 0.2 & 10 & 1 \\
\hline & $\max$. & 0.6 & 0.3 & 0.7 & 1.2 & 0.7 & 0.3 & 0.5 & 0.7 & 10 & 1 \\
\hline & avg. & 0.4 & 0.3 & 0.4 & 0.6 & 0.5 & 0.3 & 0.3 & 0.4 & & \\
\hline Notes: & & & & & & & & & & & \\
\hline $\begin{array}{l}\text { See Figure 5-7 fo } \\
\text { AGS/HFBR = Alt } \\
\text { Beam Reactor } \\
\text { CSF = Central St } \\
\text { Linac = Linear Ac } \\
M D L=\text { Minimum }\end{array}$ & $\begin{array}{l}\text { he locations } \\
\text { lating Gradi } \\
\text { m Facility } \\
\text { lerator } \\
\text { tection Lim }\end{array}$ & $\begin{array}{l}\text { s of recharg } \\
\text { ient Synchr }\end{array}$ & $\begin{array}{l}\text { asins. } \\
\text { o/High Flux }\end{array}$ & & & $\begin{array}{l}\text { NA = Not Applical } \\
\text { NYSDEC = New } \\
\text { Conservation } \\
\text { RHIC = Relativisti } \\
\text { SNS = Effluent St } \\
\text { (s) = stormwater }\end{array}$ & $\begin{array}{l}\text { le } \\
\text { ork State D } \\
\text { Heavy Ion } \\
\text { adard Not }\end{array}$ & $\begin{array}{l}\text { artment of } \\
\text { ollider } \\
\text { ecified }\end{array}$ & ironmenta & & \\
\hline
\end{tabular}

Laboratory site. Basins HN, HZ, HT-W, and HT-E receive runoff from the Collider-Accelerator complex. Basin HO receives runoff from the Brookhaven Graphite Research Reactor (BGRR) and HFBR areas. Basin CSF receives runoff from the CSF area and along Cornell Avenue east of Railroad Avenue. Basin HW receives runoff from the warehouse area, and $\mathrm{HW}$-M receives runoff from the fenced area at the former HWMF. 
CHAPTER 5: WATER QUALITY

\begin{tabular}{|c|c|c|c|c|c|c|c|c|c|}
\hline & 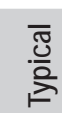 & | & $\stackrel{i}{i}$ & 요 & i̊ & i & $\stackrel{i}{i}$ & $\stackrel{\text { i }}{ }$ & - \\
\hline 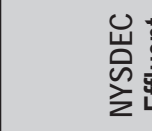 & & & in & ఏ్ & in & : & $\sum_{i n}^{\infty}$ & 요 & مـ \\
\hline 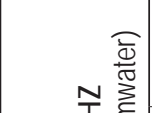 & ४ & $m$ & 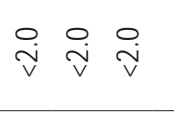 & 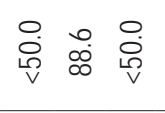 & 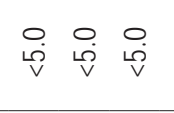 & 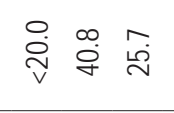 & 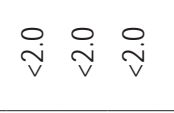 & 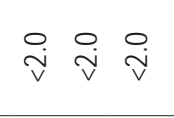 & $\hat{0} \stackrel{0}{\circ} \stackrel{0}{\dot{\theta}}$ \\
\hline 彭 & $\vdash$ & + & 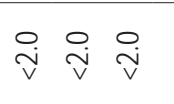 & 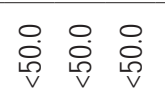 & 웁 웁 입 & 守 $\vec{\forall}$ 守 & 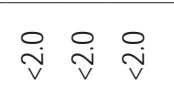 & 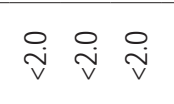 & 웝 운 \\
\hline 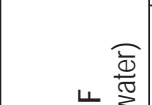 & 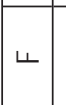 & $m$ & 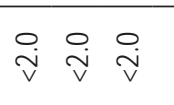 & 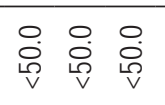 & 웅 & 守 家 & 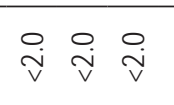 & 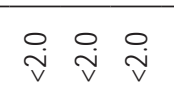 & $\stackrel{\infty}{\sim} \stackrel{\infty}{\exists}$ \\
\hline U人 & $\vdash$ & $\diamond$ & $\stackrel{\circ}{\sim} \underset{\sim}{\sim} \stackrel{\sim}{\sim}$ & 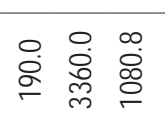 & 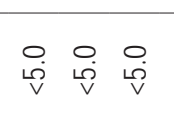 & 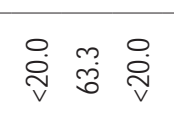 & 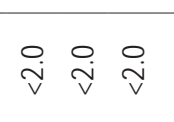 & 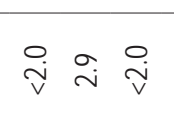 & m \\
\hline $3 \frac{\pi}{3}$ & $\sqcup$ & $\sim$ & $\stackrel{\leftrightarrow}{\mathrm{V}} \stackrel{\mathrm{V}}{\mathrm{V}} \stackrel{\mathrm{V}}{\mathrm{V}}$ & $\begin{array}{l}0 \\
\stackrel{0}{0}\end{array}$ & 압 압 & $\begin{array}{l}\circ \\
\text { ¿ें } \\
\text { vi }\end{array}$ & $\stackrel{\stackrel{\sim}{v}}{\stackrel{\sim}{v}} \stackrel{\circ}{\vec{v}}$ & 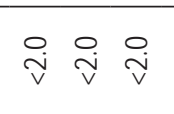 & $\stackrel{\leftrightarrow}{\rightarrow} \stackrel{9}{\stackrel{9}{ }}$ 字 \\
\hline 至言 & $\vdash$ & $\diamond$ & 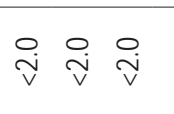 & 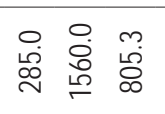 & 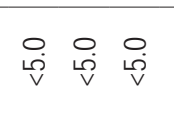 & 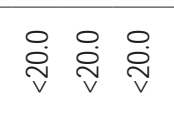 & 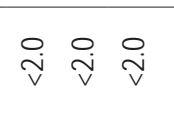 & 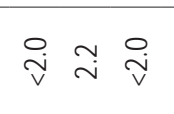 & 항 \\
\hline 38 & 4 & $m$ & 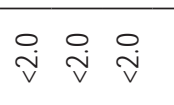 & 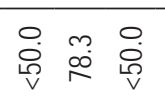 & 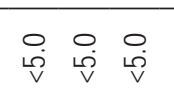 & 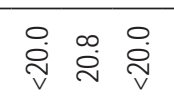 & 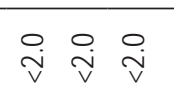 & $\stackrel{\circ}{\vec{v}} \stackrel{\mathrm{v}}{\mathrm{v}} \stackrel{\mathrm{v}}{\mathrm{v}}$ & g: \\
\hline 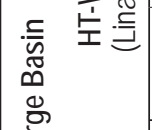 & $\vdash$ & $\diamond$ & 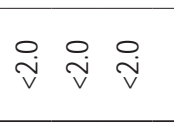 & 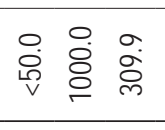 & 압 웁 & 율 芦 & 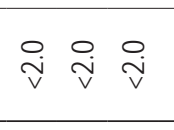 & 업 욤 & 숭압 \\
\hline 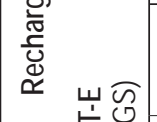 & ч & m & $\stackrel{i}{i} \stackrel{i}{v} \stackrel{\dot{v}}{v}$ & 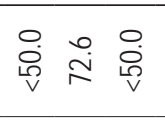 & نำ & 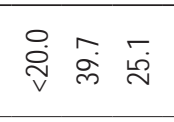 & 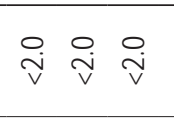 & $\stackrel{\sim}{\mathrm{v}} \stackrel{\circ}{\mathrm{i}} \stackrel{\mathrm{v}}{\mathrm{v}}$ & 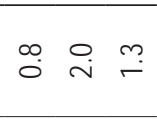 \\
\hline 皇苞 & $\vdash$ & $\diamond$ & 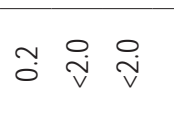 & 웅용ㅇㅁㅇ & 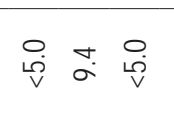 & 울 占 & 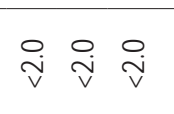 & 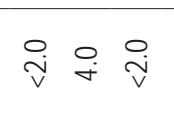 & 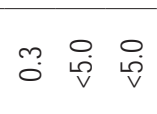 \\
\hline 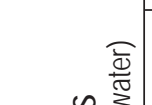 & $\sqcup$ & $m$ & 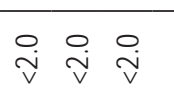 & 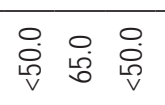 & 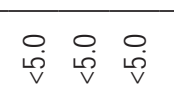 & 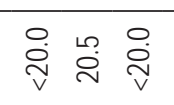 & $\stackrel{\circ}{i} \underset{v}{\sim} \stackrel{i}{v}$ & $\stackrel{\circ}{i} \stackrel{\sim}{v} \stackrel{i}{v}$ & 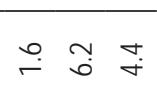 \\
\hline 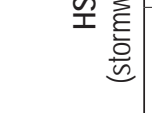 & $\vdash$ & $\diamond$ & 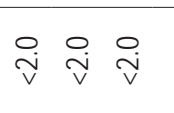 & 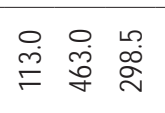 & 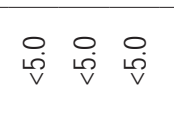 & 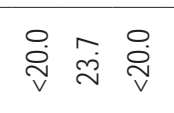 & $\stackrel{\circ}{i} \stackrel{\sim}{\sim} \stackrel{i}{\sim}$ & $\stackrel{\leftrightarrow}{\vec{V}} \stackrel{\stackrel{\sim}{v}}{\stackrel{\mathcal{V}}{v}}$ & m. \\
\hline ○⿹ & ४ & $\sim$ & $\stackrel{\mathrm{v}}{\mathrm{v}} \stackrel{\mathrm{v}}{\mathrm{v}} \stackrel{\mathrm{v}}{\mathrm{v}}$ & 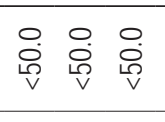 & 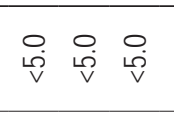 & 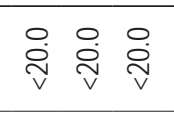 & $\stackrel{ }{i} \stackrel{\circ}{i} \stackrel{i}{v}$ & $\stackrel{\circ}{i} \stackrel{\sim}{v} \stackrel{\sim}{v}$ & œ ન્ન \\
\hline 至是 & $\vdash$ & $\diamond$ & $\stackrel{\circ}{i} \underset{v}{\stackrel{v}{v}}$ & 总总怘 & 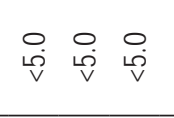 & 월 每 & 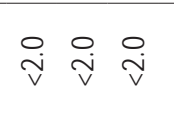 & 웝 원 & $\begin{array}{lll}m & 0 \\
0 & \infty & 0 \\
0\end{array}$ \\
\hline 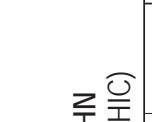 & ч & $m$ & 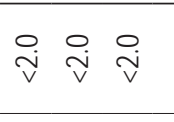 & 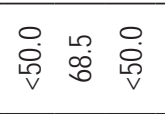 & 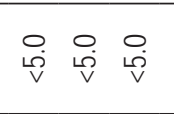 & 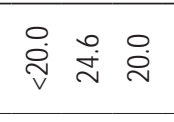 & 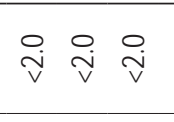 & $\stackrel{\circ}{\vec{v}} \stackrel{\mathrm{v}}{\mathrm{v}} \stackrel{\mathrm{v}}{\mathrm{v}}$ & 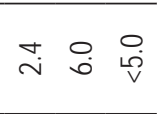 \\
\hline$\overline{\mathbf{I}} \underline{\underline{\underline{I}}}$ & $\vdash$ & $\diamond$ & $\stackrel{\sim}{\mathrm{V}} \stackrel{\mathrm{V}}{\mathrm{v}} \stackrel{\mathrm{V}}{\mathrm{V}}$ & 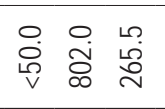 & 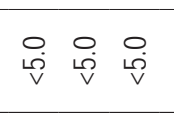 & 율 $\stackrel{\sim}{\sim} \stackrel{\sim}{\sim}$ & 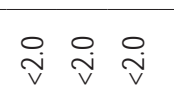 & 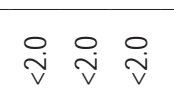 & mi \\
\hline $\mid \overrightarrow{\vec{E}}$ & 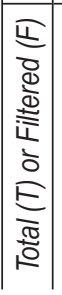 & 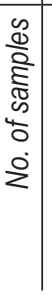 & 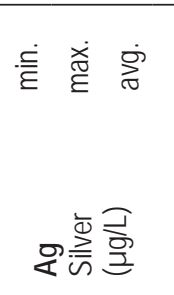 & 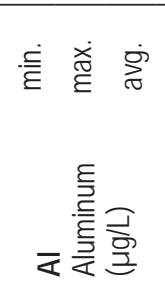 & 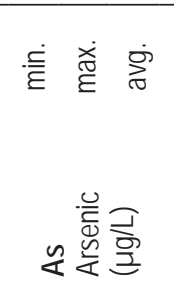 & 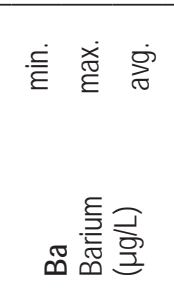 & 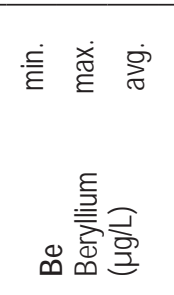 & 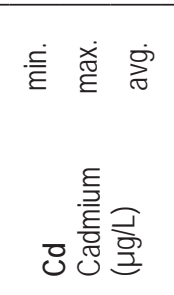 & 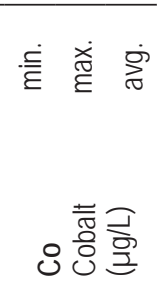 \\
\hline
\end{tabular}




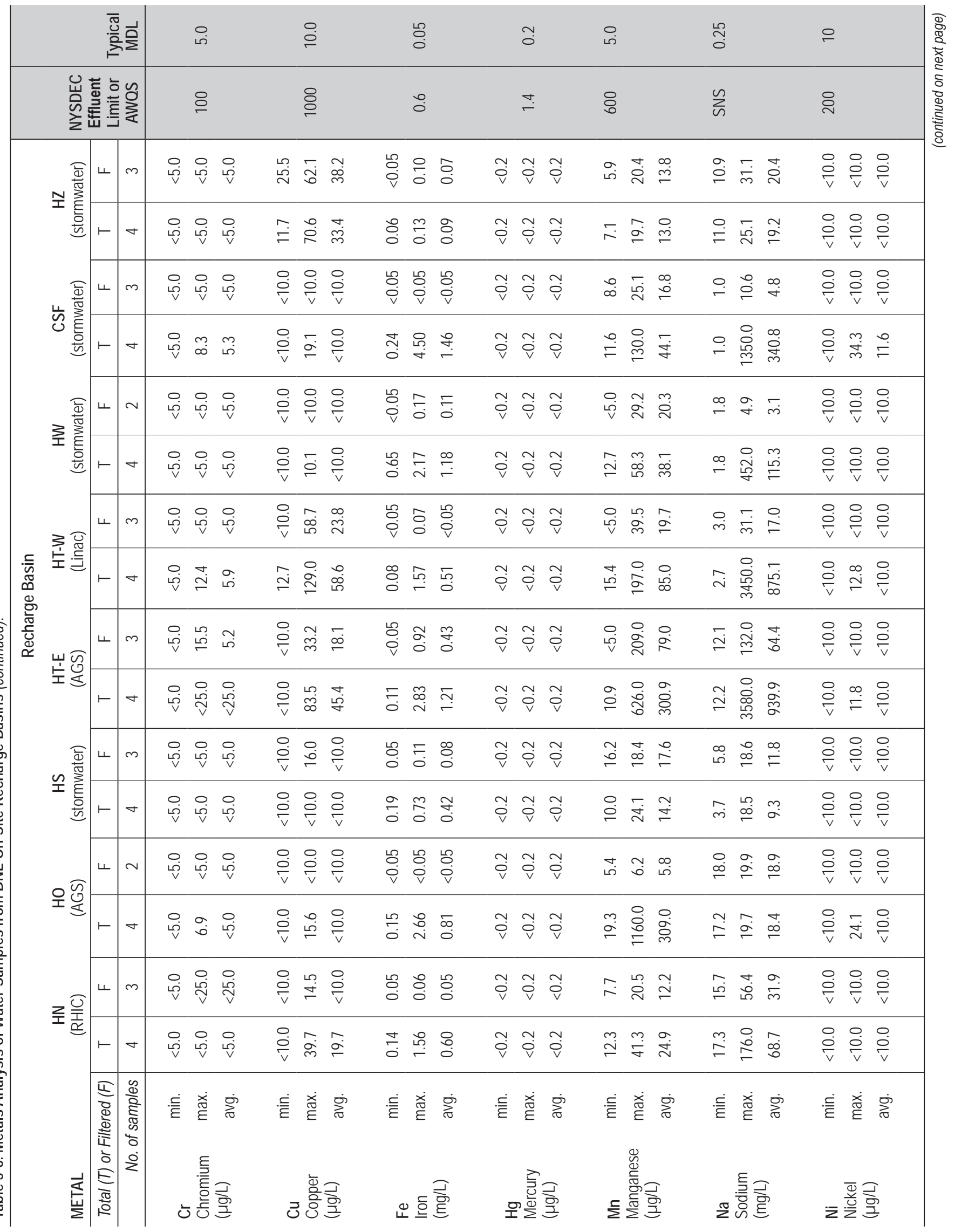




\begin{tabular}{|c|c|c|c|c|c|c|c|c|c|}
\hline & \multicolumn{2}{|c|}{ 를밀 } & $\stackrel{\circ}{\text { m. }}$ & 웅 & 웅. & 운 & 우 & 우 & \multirow{7}{*}{ 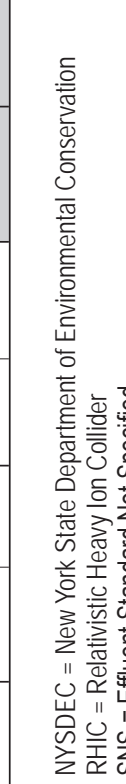 } \\
\hline \multicolumn{3}{|c|}{ 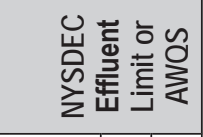 } & 요 & 0 & ㄱ & $\sum_{\infty}^{\infty}$ & 管 & ৪ి & \\
\hline$N \stackrel{\overline{\overline{\bar{m}}}}{\frac{\bar{\pi}}{3}}$ & ४ & $m$ & 일 & 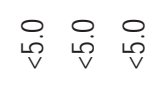 & 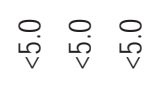 & 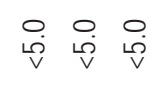 & 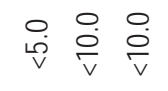 & 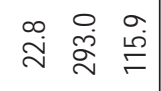 & \\
\hline 章 & $\vdash$ & $\nabla$ & $\stackrel{\oplus}{\dot{v}} \stackrel{\sim}{i}$ & 일 ○् & $\begin{array}{l}\circ \\
\text { ํं }\end{array}$ & 일 일 & 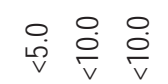 & 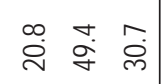 & \\
\hline$\stackrel{\overline{\bar{d}}}{\bar{d}}$ & 4 & $m$ & 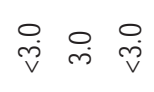 & 입 & 입 & 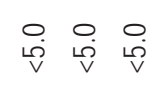 & 입 & 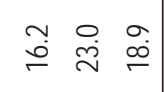 & \\
\hline U. & $\vdash$ & $\nabla$ & 일 & 암 & 입 & 입 & 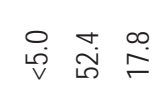 & 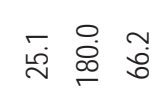 & \\
\hline $3 \stackrel{\overline{\bar{d}}}{\frac{\bar{\pi}}{3}}$ & 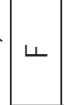 & $\sim$ & 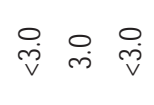 & 일 울 & 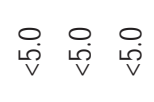 & 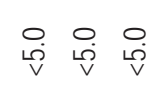 & ○ें & 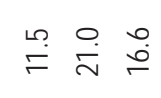 & \\
\hline 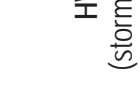 & $\vdash$ & $\nabla$ & 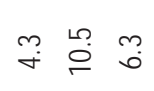 & 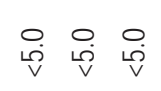 & 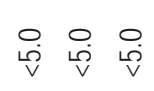 & 웅 & 요 & 용 悬 & \\
\hline 30 & $\sqcup$ & $m$ & $\stackrel{\circ}{\circ} \stackrel{\circ}{\stackrel{\rho}{v}} \stackrel{\dot{v}}{ }$ & 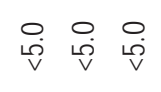 & 입 입 & 입 & 입 & 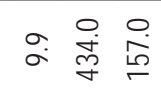 & \\
\hline 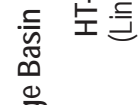 & $\vdash$ & $\nabla$ & 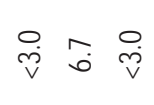 & 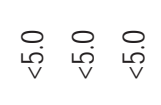 & 일 & 일 & 요 & 志 & \\
\hline 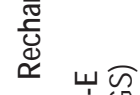 & ४ & $m$ & $\stackrel{\circ}{\circ} \stackrel{\circ}{\stackrel{p}{v}}$ & $\begin{array}{lll}0 & 0 & 0 \\
\stackrel{v}{v} & \stackrel{v}{v}\end{array}$ & 잉 & 일 웅 & 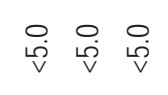 & 芯 & 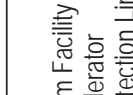 \\
\hline & $\vdash$ & $\nabla$ & 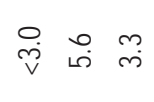 & 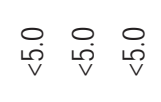 & $\begin{array}{lll}\circ & \infty \\
\stackrel{\leftrightarrow}{v} & 0 & \stackrel{\rho}{v}\end{array}$ & 일 일 & 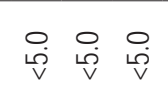 & 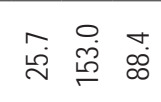 & 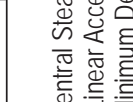 \\
\hline 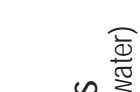 & $\sqcup$ & $m$ & 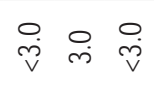 & 입 임 & 입 & 吕 吕 & 입 & 일 怘 & \\
\hline I & $\vdash$ & $\nabla$ & 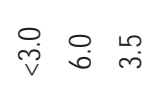 & 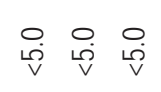 & 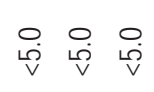 & $\begin{array}{l}\circ \\
\dot{v}\end{array}$ & ㅇ. & స. & \\
\hline & $\sqcup$ & $\sim$ & 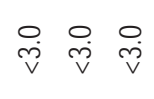 & 일 00 & 입 00 & 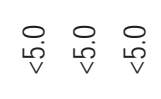 & 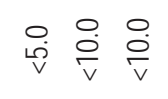 & $\begin{array}{lll}O & O \\
\stackrel{\vec{v}}{\circ} & \stackrel{\vec{v}}{\vec{v}}\end{array}$ & \\
\hline & $\vdash$ & $\nabla$ & 일 & 일 울 & 일 울 & 일 일 & 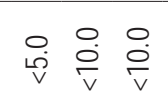 & 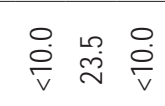 & \\
\hline$z \frac{\widehat{O}}{T}$ & $\sqcup$ & $m$ & 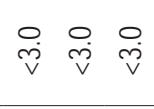 & 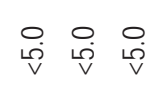 & $\begin{array}{l}\circ \\
\stackrel{\leftrightarrow}{\dot{v}} \stackrel{\circ}{\dot{v}}\end{array}$ & $\begin{array}{lll}\circ & 0 \\
\dot{v} & \stackrel{v}{v} & \stackrel{v}{v}\end{array}$ & $\begin{array}{l}\circ \\
\dot{v}\end{array}$ & 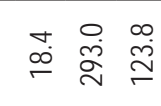 & 产 \\
\hline & $\vdash$ & $\nabla$ & 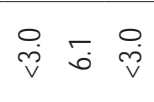 & 일 울 & 암 암 & $\begin{array}{ll}\circ & 0 \\
\stackrel{\leftrightarrow}{v} & \stackrel{\leftrightarrow}{v}\end{array}$ & 입 تુ & 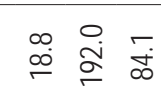 & 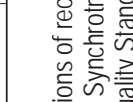 \\
\hline$\stackrel{\overrightarrow{5}}{\stackrel{\overrightarrow{5}}{\mathrm{w}}}$ & 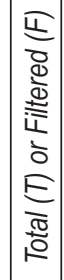 & 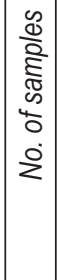 & 용 丞 & 的衰完 & 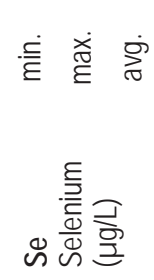 & $F \stackrel{\text { 熹 }}{F}$ & 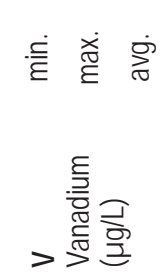 & 는 亭 & 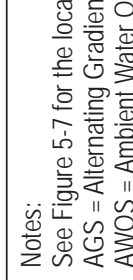 \\
\hline
\end{tabular}


Stormwater runoff at the Laboratory typically has elevated levels of inorganics and low $\mathrm{pH}$. The inorganics are attributable to high sediment content and the natural occurrence of these elements in native soil. In an effort to further protect the quality of stormwater runoff, BNL has finalized formal procedures for managing and maintaining outdoor work and storage areas. The requirements include covering areas to prevent contact with stormwater, conducting an aggressive maintenance and inspection program, and restoring these areas when operations cease. Soil samples are also routinely collected from the recharge basins to ensure these discharges are not compromising the quality of the basins. These data are reported in Chapter 6 .

\subsection{PECONIC RIVER SURVEILLANCE}

Several locations are monitored along the Peconic River to assess the overall water quality of the river and assess any impact from BNL discharges. Sampling points along the Peconic River are identified in Figure 5-8. In total, 10 stations (three upstream and seven downstream of the STP) were regularly sampled in 2007. A sampling station along the Carmans River $(\mathrm{HH})$ was also monitored as a geographic control location, not affected by Laboratory operations or within the Peconic River watershed. All locations were routinely monitored for radiological and nonradiological parameters. The sampling stations are located as follows:

Upstream sampling stations

- HY, on site immediately east of the William Floyd Parkway

- HV, on site just east of the 10:00 o'clock Experimental Hall in the RHIC Ring

- HE, on site approximately $20 \mathrm{ft}$ upstream of the STP outfall (EA)

\section{Downstream sampling stations}

- HM-N, on site 0.5 mile downstream of the STP outfall

- HM-S, on site on a typically dry tributary of the Peconic River

- HQ, on site 1.2 miles downstream of the STP outfall at the site boundary

- HA, first station downstream of the BNL boundary, 3.1 miles from the STP outfall
- Donahue’s Pond, off site, 4.3 miles downstream of the STP outfall. (Note: In 2007, one of the four samples was collected at former station $\mathrm{HC}$, due to access problems at Donahue's Pond. The two sites are very near one another, one within the pond and the other at the outflow from the pond.)

- Forge Pond, off site

- Swan Pond, off site, not within the influence of BNL discharges

\section{Control location \\ - HH, Carmans River}

\subsubsection{Peconic River - Radiological Analyses}

Radionuclide measurements were performed on surface water samples collected from the Peconic River at all 10 locations. Routine samples at Stations HM-N and HQ were collected once per month. All other stations were sampled quarterly unless conditions (such as no water flow) prevented collection. Stations HE, HM$\mathrm{N}$, and HQ have been equipped with Parshall flumes that allow automated flow-proportional sampling and volume measurements. All other sites were sampled by collecting instantaneous grab samples, as flow allowed.

The radiological data from Peconic River surface water sampling in 2007 are summarized in Table 5-7. Radiological analysis of water samples collected both upstream and downstream of the STP discharge had very low concentrations of gross alpha and gross beta activity. While the downstream maximum concentrations were slightly higher than the upstream, the average concentration was similar at all locations. The average concentrations from off-site and control locations were indistinguishable from BNL on-site levels. All detected levels were below the applicable DWS. No gamma-emitting radionuclides attributable to Laboratory operations were detected either upstream or downstream of the STP. Tritium was detected in a single water sample collected downstream of the STP discharge at Station HM-N, in May. Since tritium was not detected in the STP discharge during this period, this detection is questionable.

Monitoring for Sr-90 was performed at all Peconic River stations in 2007. Strontium-90 was 


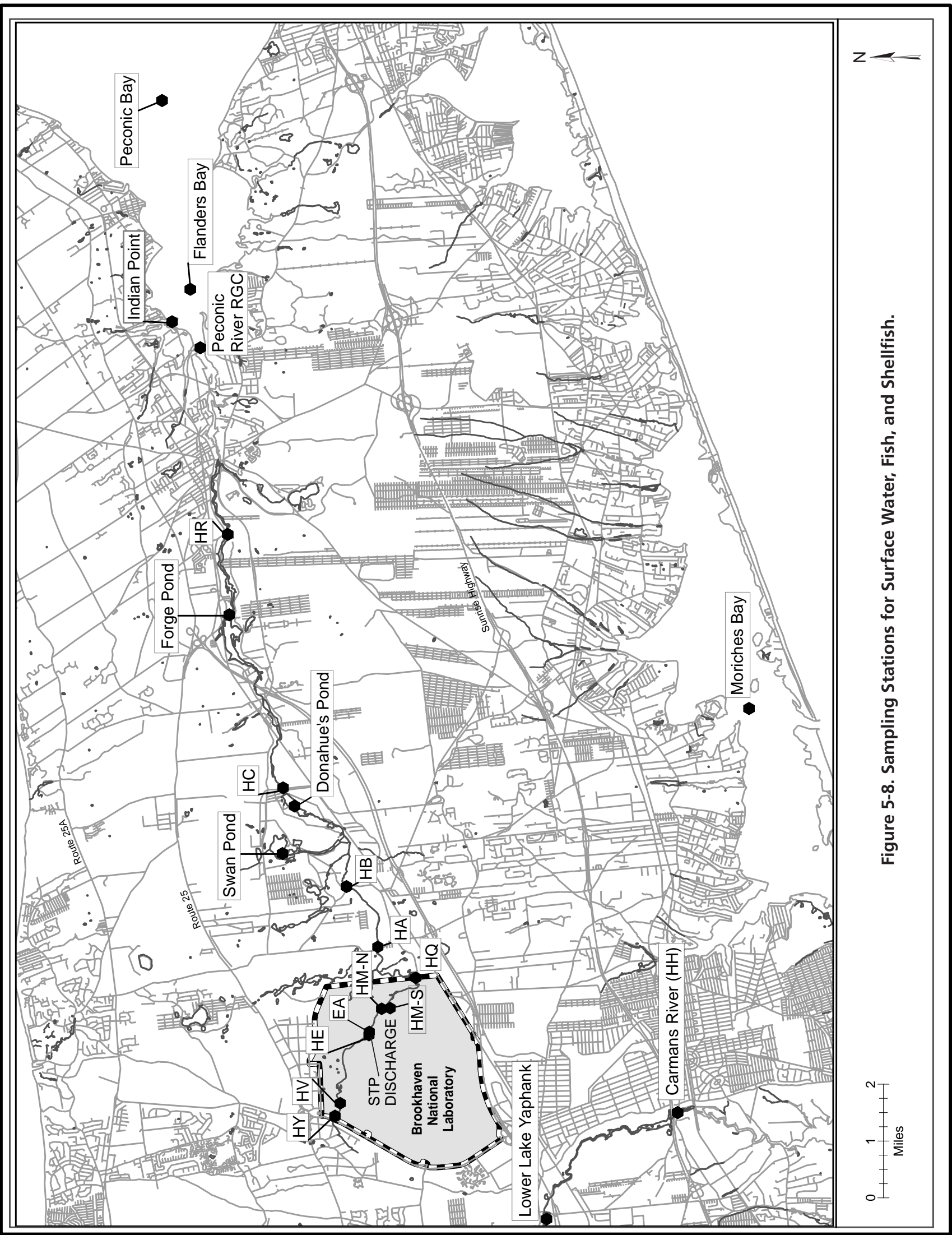




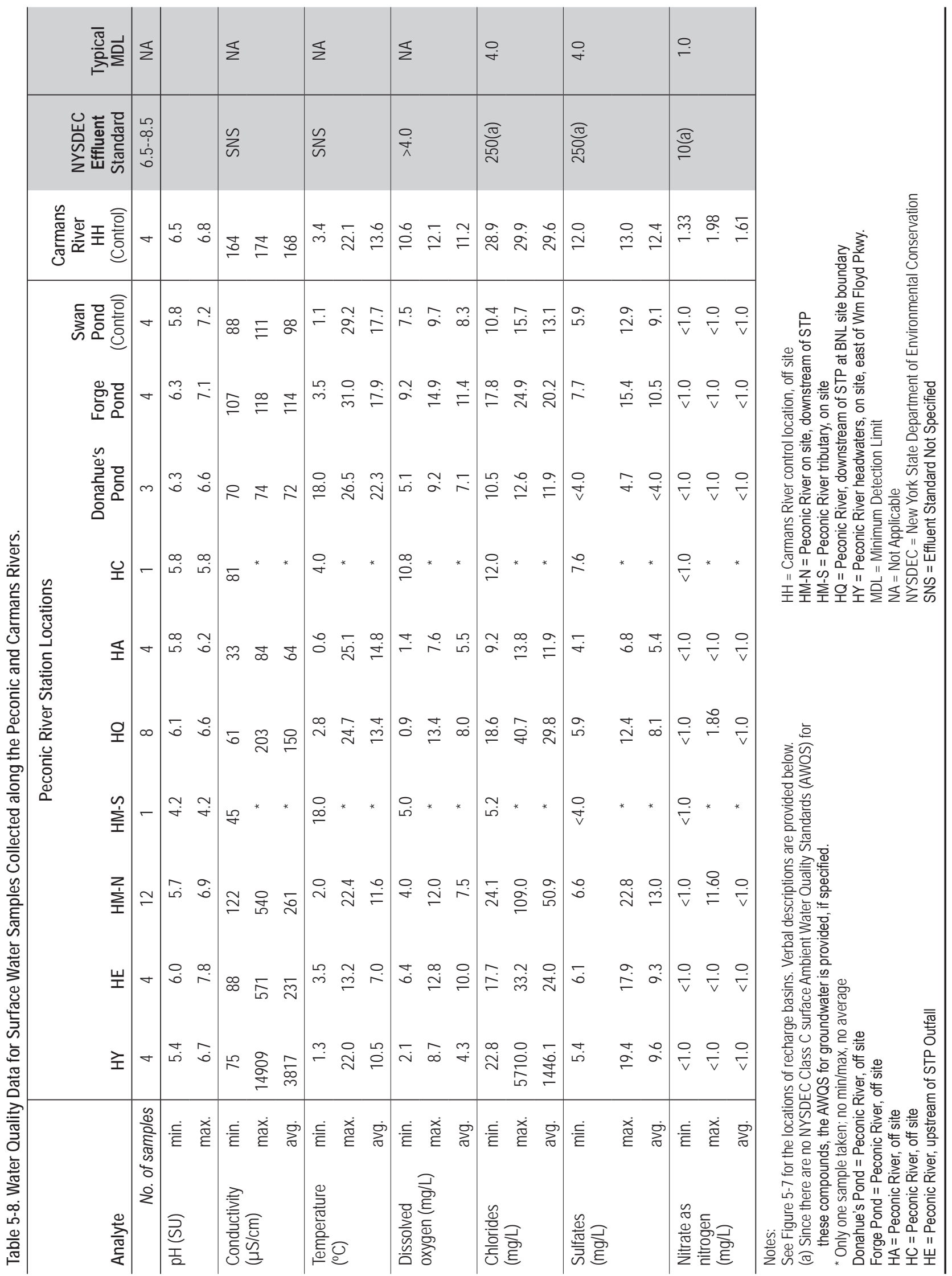




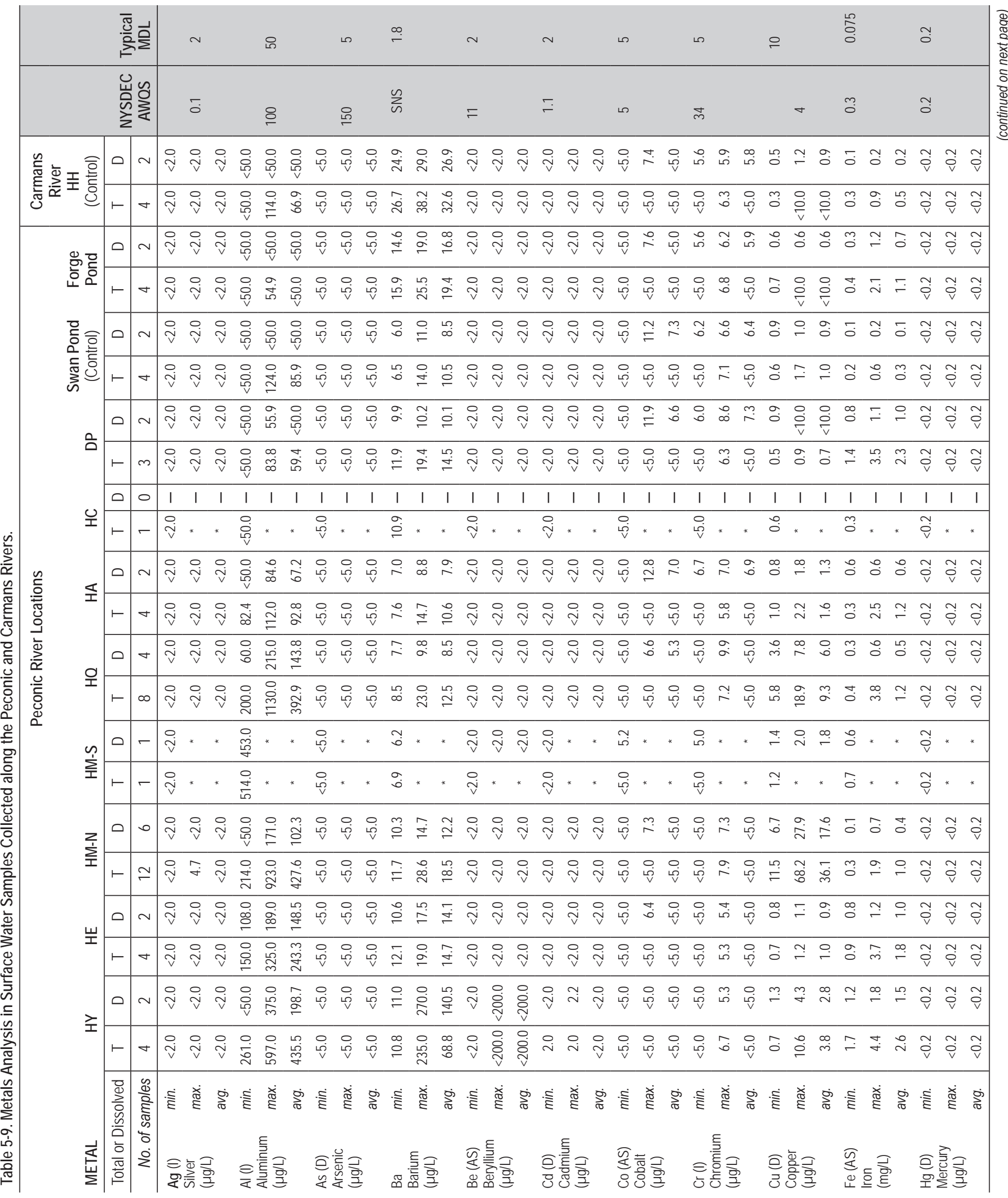


$m$

เ

เ

เ

เก

으 궁

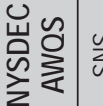

告

ָู

$\stackrel{4}{A}$

告

$\stackrel{\circ}{+}$

$\infty$

サ

मे

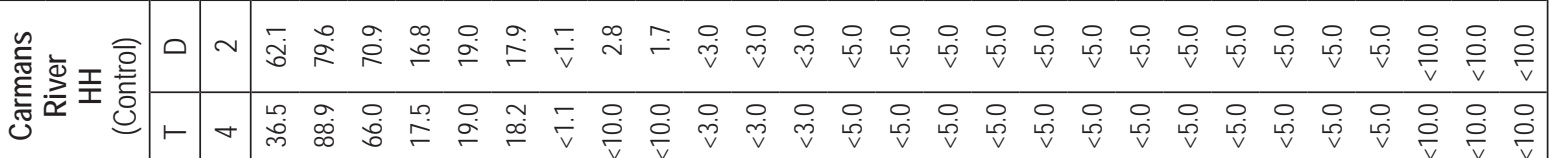

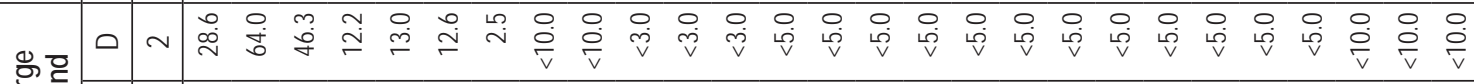

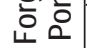

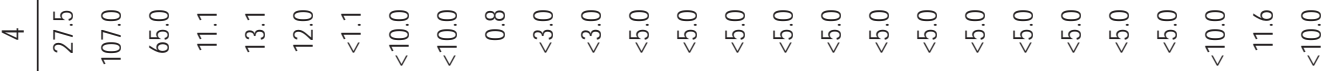

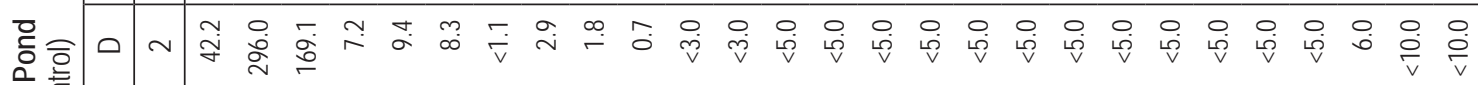

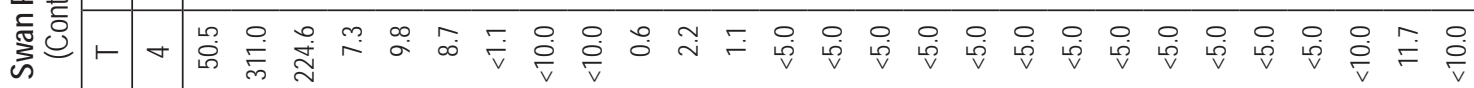

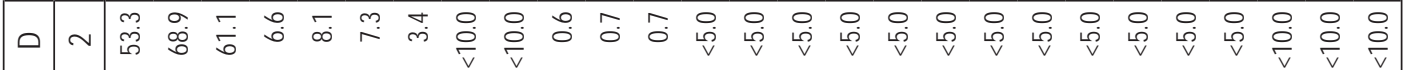

ถ

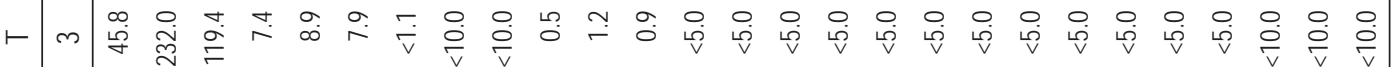

-

오

- 0 I l

1

I

๑ $\sim$

告

เั

* $\frac{\vec{v}}{\mathrm{i}}$

* $\stackrel{\circ}{\mathrm{v}}$

ㅇำ

욤

올

它

\begin{tabular}{ll}
1 & 1 \\
\hline &
\end{tabular}

조

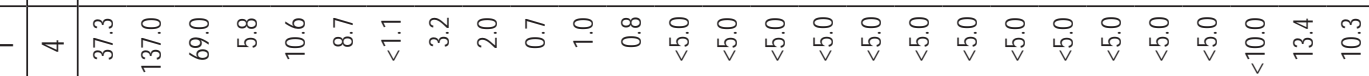

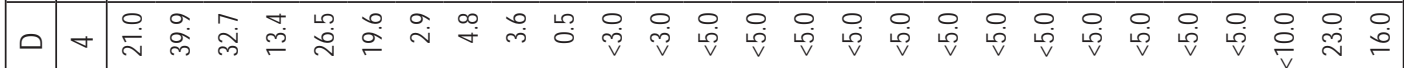

오

实

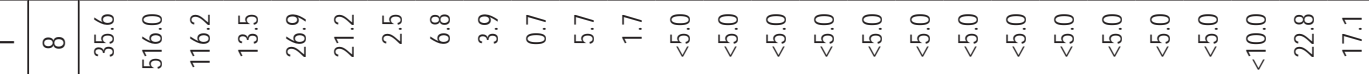

$\omega$ ๑

ָ̃

主

$-\rightarrow$

\&

$\stackrel{\infty}{i}$

*

\%

옴

* * ㅇ․

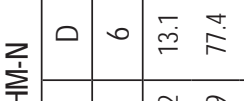

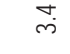

$\stackrel{\overbrace{}}{\sim}$

* $\stackrel{\infty}{0}$

* 임

* 임

* * 유

* * 암

* * $\stackrel{\llcorner}{\rightarrow}$

至

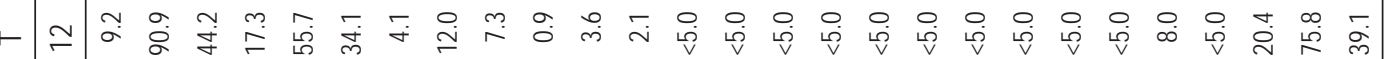

๑ $\sim$ م

뽀

- $\rightarrow$ 岇

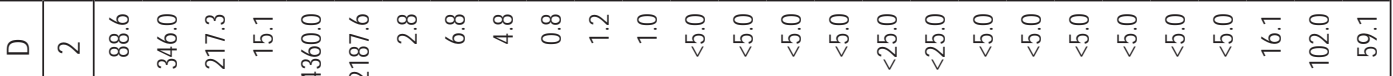

主

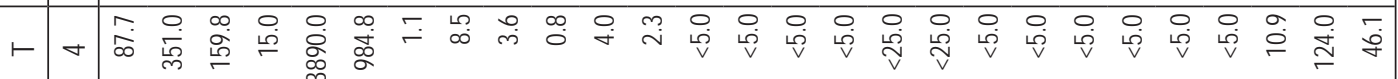

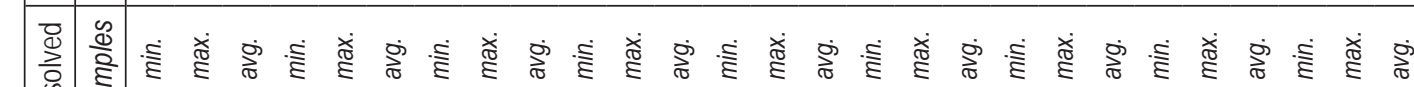

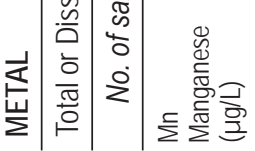

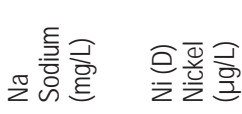

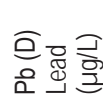

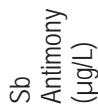

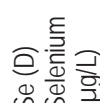

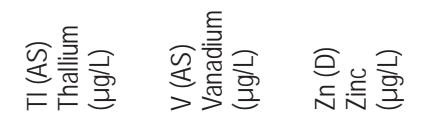

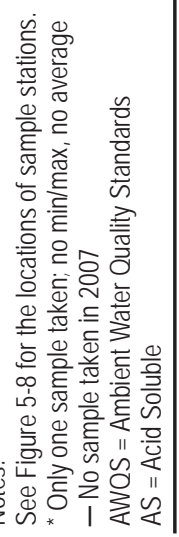


As spring rains mix with decaying matter, these acids decrease the already low $\mathrm{pH}$ of precipitation, resulting in a $\mathrm{pH}$ as low as 4.2 Standard Units. A discussion of precipitation monitoring is provided in Chapter 6 (see Section 6.7 for more detail).

Ambient water quality standards for metallic elements are based on their solubility state. Certain metals are only biologically available to aquatic organisms if they are in a dissolved or ionic state, whereas other metals are toxic in any form (i.e., dissolved and particulate combined). In 2007, the BNL monitoring program continued to assess water samples for both the dissolved and particulate form. Dissolved concentrations were determined by filtering the samples prior to acid preservation and analysis. Examination of the metals data showed that aluminum, copper, iron, lead, and zinc were present in concentrations at some locations that exceeded AWQS both upstream and downstream of the STP discharge. Aluminum and iron are detected throughout the Peconic and Carmans Rivers at concentrations that exceed the NYS AWQS in both the filtered and unfiltered fractions. Both are found in high concentrations in native Long Island soil and, for iron, at high levels in groundwater. The low $\mathrm{pH}$ of groundwater and precipitation contribute to the dissolution of these elements. Although most metals were detected in upstream samples (indicating a natural presence), the highest levels for copper and lead were detected in samples collected immediately downstream of the Laboratory's STP discharge (HM-N). The concentrations detected were consistent with the concentrations found in the STP discharge and, in most instances, were within the BNL SPDES permit limits. The NYS AWQS limits for copper and lead are very restrictive; consequently, the NYS-granted SPDES permit allows higher limits, provided toxicity testing shows no impact to aquatic organisms. Filtration of the samples reduced concentrations of most metals to below the NYS AWQS, indicating that most detections were due to sediment carryover. Silver was detected in a single sample collected downstream of the STP, at concentrations well below the SPDES permit limit. The highest concentrations of iron, aluminum, cadmium, and zinc were found at Station HY and are likely due to stormwater runoff from the William Floyd Parkway and contributions from groundwater. As with the recharge basins, cobalt is found in all filtered water samples and is probably a result of the filtration and not an indicator of water quality. Mercury was not detected in any samples in 2007 at a detection level of $0.2 \mathrm{ppb}$. Further discussion of mercury in the Peconic River sediment, water, and fish samples is found in Chapter 6.

\section{REFERENCES AND BIBLIOGRAPHY}

BNL. 1998. Operable Unit V: Remedial Investigation and Risk Assessment of the Eastern Area of the Laboratory. Brookhaven National Laboratory, Upton, NY.

BNL. 2001. Standards Based Management System Subject Area: Liquid Effluents. Brookhaven National Laboratory, Upton, NY. May 2001.

DOE Order 5400.5 1990. Radiation Protection of the Public and the Environment. U.S. Department of Energy, Washington, DC. Change 2: 1-7-93.

NYCRR Part 703.6. Title 6. 1999. Surface Water and Groundwater Quality Standards and Groundwater Effluent Limitations. New York State Department of Environmental Conservation. Albany, NY. Change 8-499.

Remien, J. 2007. Central Steam Facility Storm Water Outfall Remediation Closeout Report, Brookhaven National Laboratory, Upton, NY. February 21, 2007. 


\section{Natural and Cultural Resources}

The Brookhaven National Laboratory (BNL) Natural Resource Management Program is designed to protect and manage flora and fauna and the ecosystems in which they exist. The Laboratory's natural resource management strategy is based on understanding the site's resources and on maintaining compliance with applicable regulations. The goals of the program include protecting and monitoring the ecosystem, conducting research, and communicating with staff and the public on ecological issues. BNL focuses on protecting New York State threatened and endangered species on site, as well as continuing the Laboratory's leadership role within the greater Long Island Central Pine Barrens ecosystem.

Monitoring to determine whether current or historical activities are affecting natural resources is also part of this program. In 2007, deer and fish sampling results were consistent with previous years. Vegetables grown in the BNL garden plot located near the on-site apartment complex continue to support historical analyses that there are no Laboratory-generated radionuclides in produce.

The Foundation for Ecological Research in the Northeast began the development of Freshwater Wetland Monitoring Protocols for the Long Island Central Pine Barrens. This work is discussed in greater detail in this chapter.

The overriding goal of the Cultural Resource Management Program is to ensure that proper stewardship of BNL and DOE historic resources is established and maintained. Additional goals of the program include maintaining compliance with various historic preservation and archeological laws and regulations, and ensuring the availability of identified resources to on-site personnel and the public for research and interpretation. Additional details are discussed within this chapter.

\section{I NATURAL RESOURCE MANAGEMENT PROGRAM}

The purpose of the Natural Resource Management Program at BNL is to promote stewardship of the natural resources found at the Laboratory, as well as to integrate natural resource management and protection with BNL's scientific mission. To meet this purpose, the Laboratory prepared and issued a Natural Resource Management Plan (NRMP) (BNL 2003a). The NRMP describes the program strategy, elements, and planned activities for managing the various resources found on site.

\subsubsection{Identification and Mapping}

An understanding of an environmental baseline is the foundation of natural resource management planning. BNL uses digital global positioning systems (GPS) and geographic information systems (GIS) to clearly relate various "layers" of geographic information (e.g., vegetation types, soil condition, habitat, forest health, etc.). This is done to gain insight into interrelationships between the biotic systems and physical conditions at the Laboratory. In 2005, efforts were initiated to better understand the distribution of deer on site. A model of deer density was developed using the mapping and spatial analysis tools. The model enables resource managers to track changes in deer density over time, detect interactions between components of the ecosystem, and identify locations for management activities. 
Table 6-1. New York State Threatened, Endangered, Exploitably Vulnerable, and Species of Special Concern at BNL.

\begin{tabular}{|c|c|c|c|}
\hline Common Name & Scientific Name & $\begin{array}{l}\text { State } \\
\text { Status }\end{array}$ & $\begin{array}{l}\text { BNL } \\
\text { Status }\end{array}$ \\
\hline $\begin{array}{l}\text { Insects } \\
\text { Frosted elfin } \\
\text { Mottled duskywing } \\
\text { Persius duskywing } \\
\text { Pine Barrens bluet }\end{array}$ & $\begin{array}{l}\text { Callophrys iris } \\
\text { Erynnis martialis } \\
\text { Erynnis persius persius } \\
\text { Enallagma recurvatum }\end{array}$ & $\begin{array}{l}\mathrm{T} \\
\mathrm{SC} \\
\mathrm{E} \\
\mathrm{T}\end{array}$ & $\begin{array}{l}\text { Likely } \\
\text { Likely } \\
\text { Likely } \\
\text { Confirmed }\end{array}$ \\
\hline $\begin{array}{l}\text { Fish } \\
\text { Banded sunfish } \\
\text { Swamp darter }\end{array}$ & $\begin{array}{l}\text { Enniacanthus obesus } \\
\text { Etheostoma fusiforme }\end{array}$ & $\begin{array}{l}\mathrm{T} \\
\mathrm{T}\end{array}$ & $\begin{array}{l}\text { Confirmed } \\
\text { Confirmed }\end{array}$ \\
\hline $\begin{array}{l}\text { Amphibians } \\
\text { Eastern tiger salamander } \\
\text { Marbled salamander } \\
\text { Eastern spadefoot toad }\end{array}$ & $\begin{array}{l}\text { Ambystoma tigrinum tigrinum } \\
\text { Ambystoma opacum } \\
\text { Scaphiopus holbrookii }\end{array}$ & $\begin{array}{l}\mathrm{E} \\
\mathrm{SC} \\
\mathrm{SC}\end{array}$ & $\begin{array}{l}\text { Confirmed } \\
\text { Confirmed } \\
\text { Confirmed }\end{array}$ \\
\hline $\begin{array}{l}\text { Reptiles } \\
\text { Spotted turtle } \\
\text { Eastern hognose snake } \\
\text { Eastern box turtle } \\
\text { Eastern worm snake }\end{array}$ & $\begin{array}{l}\text { Clemmys guttata } \\
\text { Heterodon platyrhinos } \\
\text { Terrapene carolina } \\
\text { Carphophis amoenus }\end{array}$ & $\begin{array}{l}\mathrm{SC} \\
\mathrm{SC} \\
\mathrm{SC} \\
\mathrm{SC}\end{array}$ & $\begin{array}{l}\text { Confirmed } \\
\text { Confirmed } \\
\text { Confirmed } \\
\text { Confirmed }\end{array}$ \\
\hline $\begin{array}{l}\text { Birds (nesting, transient, } \\
\text { Horned lark } \\
\text { Whip-poor-will } \\
\text { Vesper sparrow } \\
\text { Grasshopper sparrow } \\
\text { Northern harrier } \\
\text { Cooper's hawk } \\
\text { Osprey } \\
\text { Sharp-shinned hawk }\end{array}$ & $\begin{array}{l}\text { or potentially present) } \\
\text { Eremophila alpestris } \\
\text { Caprimulgus vociferus } \\
\text { Pooecetes gramineus } \\
\text { Ammodramus savannarum } \\
\text { Circus cyaneus } \\
\text { Accipiter cooperii } \\
\text { Pandion haliaetus } \\
\text { Accipiter striatus }\end{array}$ & $\begin{array}{l}\text { SC } \\
\text { SC } \\
\text { SC } \\
\text { SC } \\
T \\
\text { SC } \\
\text { SC } \\
\text { SC }\end{array}$ & $\begin{array}{c}\text { Likely } \\
\text { Likely } \\
\text { Likely } \\
\text { Confirmed } \\
\text { Confirmed } \\
\text { Confirmed } \\
\text { Confirmed } \\
\text { Confirmed }\end{array}$ \\
\hline $\begin{array}{l}\text { Plants } \\
\text { Stargrass } \\
\text { Butterfly weed } \\
\text { Spotted wintergreen } \\
\text { Flowering dogwood } \\
\text { Pink lady's slipper } \\
\text { Winterberry } \\
\text { Sheep laurel } \\
\text { Narrow-leafed bush clover } \\
\text { Ground pine } \\
\text { Bayberry } \\
\text { Cinnamon fern } \\
\text { Clayton's fern } \\
\text { Royal fern } \\
\text { Crested fringed orchid } \\
\text { Swamp azalea } \\
\text { Long-beaked bald-rush } \\
\text { Stiff goldenrod } \\
\text { New York fern } \\
\text { Marsh fern } \\
\text { Virginia chain-fern }\end{array}$ & $\begin{array}{l}\text { Aletris farinosa } \\
\text { Asclepias tuberosa } \\
\text { Chimaphila maculata } \\
\text { Cornus florida } \\
\text { Cypripedium acaule } \\
\text { Ilex verticillata } \\
\text { Kalmia angustifolia } \\
\text { Lespedeza augustifolia } \\
\text { Lycopodium obscurum } \\
\text { Myrica pensylvanica } \\
\text { Osmunda cinnamomera } \\
\text { Osmunda claytoniana } \\
\text { Osmunda regalis } \\
\text { Plantathera cristata } \\
\text { Rhododendron viscosum } \\
\text { Rhynchospora scirpoides } \\
\text { Solidago rigida } \\
\text { Thelypteris novaboracensis } \\
\text { Thelypteris palustris } \\
\text { Woodwardia virginica }\end{array}$ & $\begin{array}{l}T \\
V \\
V \\
V \\
V \\
V \\
V \\
R \\
V \\
V \\
V \\
V \\
V \\
E \\
V \\
R \\
T \\
V \\
V \\
V\end{array}$ & $\begin{array}{l}\text { Confirmed } \\
\text { Confirmed } \\
\text { Confirmed } \\
\text { Confirmed } \\
\text { Confirmed } \\
\text { Confirmed } \\
\text { Confirmed } \\
\text { Confirmed } \\
\text { Confirmed } \\
\text { Confirmed } \\
\text { Confirmed } \\
\text { Confirmed } \\
\text { Confirmed } \\
\text { Likely } \\
\text { Confirmed } \\
\text { Confirmed } \\
\text { Confirmed } \\
\text { Confirmed } \\
\text { Confirmed } \\
\text { Confirmed }\end{array}$ \\
\hline \multicolumn{4}{|c|}{$\begin{array}{l}\text { Notes: } \\
\text { * Table information is based on } 6 \text { NYCRR Part 182, } 6 \text { NYCRR Part 193, and BNL survey data } \\
\text { No federally listed Threatened or Endangered Species are known to inhabit the BNL site. } \\
\text { E = Endangered } \\
R=\text { Rare } \\
\text { SC = Species of Special Concern } \\
T=\text { Threatened } \\
V=\text { Exploitably Vulnerable }\end{array}$} \\
\hline
\end{tabular}

A wide variety of vegetation, birds, reptiles, amphibians, and mammals inhabit the site. Through implementation of the NRMP, additional endangered, threatened, and species of special concern have been identified as having been resident at BNL during the past 30 years. The only New York State endangered species confirmed as now inhabiting Laboratory property is the eastern tiger salamander (Ambystoma t. tigrinum). Additionally, the New York State endangered Persius duskywing butterfly (Erynnis $p$. persius) and the crested fringed orchid (Plantathera cristata) have been identified on the site in the past. Five New York State threatened species have been positively identified on site and two other species are considered likely to be present. The banded sunfish (Enniacanthus obesus), the swamp darter fish (Etheostoma fusiforme), and the stiff goldenrod plant (Solidago rigida) have been previously reported (BNL 2000). The northern harrier (Circus cyaneus) was seen hunting over open fields in November 2003. In 2005, the Pine Barrens bluet (Enallagma recurvatum) damselfly was confirmed at one of the many coastal plain ponds located on site. The frosted elfin butterfly (Callophrys iris) has been identified as possibly being at BNL, based on historic documentation and the presence of its preferred habitat and host plant (wild lupine). In addition, stargrass (Aletris farinosa) was reconfirmed to exist at BNL. Several other species that inhabit the site, visit during migration, or have historically been identified, are listed as rare, species of special concern, or exploitably vulnerable by New York State (Table 6-1).

\subsubsection{Habitat Protection and Enhancement}

BNL has precautions in place to protect onsite habitats and natural resources. Activities to eliminate or minimize negative effects on sensitive or critical species are either incorporated into Laboratory procedures or into specific program or project plans. Environmental restoration projects remove pollutant sources that could contaminate habitats. Human access to critical habitats is limited. In some cases, habitats are enhanced to improve survival or increase populations. Even routine activities such as road maintenance are not performed until 
they have been duly evaluated and determined to be unlikely to affect habitat.

\subsubsection{Salamander Protection Efforts}

To safeguard eastern tiger salamander breeding areas, a map of these locations is reviewed when new projects are proposed. Distribution of the map is limited, to protect the salamander from exploitation by collectors and the pet trade. The map is routinely updated as new information concerning the salamanders is generated through research and monitoring. Other efforts to protect this state endangered species include determining when adult salamanders are migrating toward breeding locations, when metamorphosis has been completed, and when juveniles are migrating after metamorphosis. During these times, construction and maintenance activities near their habitats are postponed. BNL environmental protection staff must review any project planned near eastern tiger salamander habitats, and every effort is made to minimize impacts.

Water quality testing is conducted as part of the routine monitoring of recharge basins, as discussed in Chapter 5. In cooperation with the New York State Department of Environmental Conservation (NYSDEC), habitat surveys have been conducted annually since 1999. Biologists conducting egg mass and larval surveys have confirmed 26 on-site ponds that are used by eastern tiger salamanders. The study procedure calls for all ponds that had egg masses during the spring surveys to be surveyed again in June and July to check for the presence of larval salamanders. Egg mass surveys of 26 ponds plus additional flooded depressions at the Laboratory were conducted in 2007. A PhD candidate and students working through the intern programs offered by DOE and BNL's Office of Education conducted surveys of tiger salamander ponds, drift fence surveys, and radio telemetry tracking around four ponds. The results of these studies show the extent of egg mass production, the importance of precipitation as a trigger for metamorphic salamanders leaving ponds, and the extent of movements by both adults and metamorphic tiger salamanders. Work toward a comprehensive understanding of eastern tiger salamander movements and habitat requirements began in 2004, with funding provided to SUNY Binghamton by NYSDEC. Continued research adds to the understanding of the needs of this state endangered species. Information acquired from all research is entered into a database, and portions of the data are linked to a GIS. These data are used to visualize distributions, track reproductive success, and identify areas for focused management or study.

\subsubsection{Eastern Box Turtle}

A radio telemetry study of the eastern box turtle (Terrapene carolina) was initiated in 2006 and continued in 2007 to investigate the amount of territory overlap between individual turtles. The study was initiated after repeatedly finding turtles with ear infections and the discovery of three sick turtles simultaneously in 2005. Two of the three turtles died and were subsequently necropsied, with tissues sent to a laboratory for virus isolation. Results confirmed the presence of an iridovirus known to affect turtles and amphibians, which posed a great concern, given the endangered status of some amphibians. As the three turtles were found in a primary breeding pond for tiger salamanders, further study was warranted. The radiotelemetry study confirmed significant amounts of overlap within the territories of five turtles outfitted with transmitters over both years. This overlap provides an indication of the likelihood of disease transmission between turtles. Additionally, all five turtles spent some time near the pond and could have released the virus to the water, where it could infect amphibians.

Associated with the radiotelemetry study was a study to isolate and identify the iridovirus within eastern box turtles found at BNL. Routine transects of various areas of the Laboratory were established and traversed in order to capture eastern box turtles. When a turtle was found, it was given a unique identification mark, and samples from the mouth and cloaca were taken using cotton swabs. The samples were later tested for iridovirus. Unfortunately, due to difficulties at the contract analytical laboratory, iridovirus could not be isolated in 2006. The study was continued with revisions in 2007 in 
order to assess the potential for turtles to carry iridovirus and infect other reptiles or amphibians.Revisions included improved procedures for obtaining swab samples and alterations of lab procedures to improve the genetic analysis of samples. However, even with improved sampling, a single turtle in advanced stages of the disease only showed positive results on oral swabs and liver tissue analysis. Cloacal swabs of this animal and both oral and cloacal swabs of all other specimens had negative results, suggesting that swabbing may not be sufficient for early detection of infected animals (Snyder and Titus, 2007).

\subsubsection{Other Species}

As part of the eastern tiger salamander and herpetological surveys, information is being gathered on other species found on site. Including the tiger salamander (see Section 6.1.2.1), sightings of 26 species of reptiles and amphibians have been recorded over the past several years. The species include the northern red-back salamander (Plethodon c. cinereus), marbled salamander (Ambystoma opacum), four-toed salamander (Hemidactylium scutatum), red-spotted newt (Notophthalmus viridescens), spring peeper (Pseudacris crucifer), wood frog (Rana sylvatica), gray tree frog (Hyla versicolor), bullfrog (Rana catesbiana), green frog (Rana clamitans), pickerel frog (Rana palustris), Fowler's toad (Bufo woodhousei fowleri), eastern spadefoot toad (Scaphiopus holbrooki), snapping turtle (Chelydra serpentine), painted turtle (Chrysemys p. picta), musk turtle (Sternotherus odoratus), spotted turtle (Clemmys guttata), eastern box turtle (Terrapene c. carolina), northern black racer (Coluber constrictor), eastern ribbon snake (Thamnophis s. sauritus), eastern garter snake (Thamnophis s. sirtalis), northern water snake (Nerodia s. sipedon), northern ringnecked snake (Diadophis puctatus edwardsi), brown snake (Storeria d. dekayi), northern red-bellied snake (Storeria occiptiomaculata), and eastern worm snake (Carphophis amoenus). This list indicates that BNL has one of the most diverse herpetofaunal assemblages on Long Island.
Banded sunfish protection efforts include observing whether adequate flow in the Peconic River is maintained within areas currently identified as sunfish habitat, ensuring that existing vegetation in their habitat is not disturbed, and evaluating all activities taking place on the river for potential impacts on these habitats. A population estimate of reproductive success of the banded sunfish in a protected pond was conducted in summer 2007 and compared to values obtained in a similar survey in 2005 . Conservatively, approximately 3,000 fish remained in the pond after it nearly dried in 2005, based on overall estimates that summer. Hydrologic conditions were maintained throughout 2006 and into 2007. The population survey in 2007 resulted in an estimate of approximately 4,000 fish present. Differences in the two studies may have been responsible for the lower results in 2005. In addition, an increased number of brown bullhead (Ictalurus nebulosus) may have had a more significant negative impact on the sunfish population than previously expected.

A total of 216 species of birds have been identified at BNL since 1948; at least 85 species are known to nest on site. Some of these nesting birds have shown declines in their populations nationwide over the past 30 years. The Laboratory conducts routine monitoring of songbirds along six permanent bird survey routes in various habitats at BNL. In 2007, monthly surveys were conducted starting at the end of March and extending through the end of September. These surveys identified 69 songbird species, compared to 70 species in 2006 and 67 species during 2005. One of the species identified during the 2007 surveys had not been reported previously. A total of 111 songbird species have been identified during surveys in the past 8 years; 45 of these species were present each year. Variations in the number and species identified reflect the time of sampling, variations in weather patterns between years, or actual changes in the environment. The two most diverse transects pass near wetlands by the Biology Fields and the Peconic River. The four transects passing through the various forest types (white pine, moist pine barrens, and dry pine barrens) showed a less diverse bird 
community. Data are stored in an electronic database that is linked to the Laboratory's GIS.

Canada geese (Branta canadensis) are a protected species under the Migratory Bird Treaty Act. BNL has a resident, year-round (non migrating) flock of approximately 120 birds that occasionally create problems due to their droppings, choice of nesting areas, and assertive defense of nests and offspring. When questions regarding migratory birds arise, BNL consults NYSDEC, U.S. Fish \& Wildlife Services (FWS), and the United States Department of Agriculture Animal and Plant Health Inspection Service-Wildlife Services Division. Because Canada geese have protected status, they can only be managed under special FWS permits. In 2007, BNL began limited nest management through oiling or nest destruction. When nesting geese were identified as causing a safety problem due to defending of nests, the nests were destroyed. If nesting behavior was obvious, the eggs were oiled to prevent development. A total of 10 nests were either destroyed or oiled. Banding of geese in late June 2007 resulted in 37 newly banded birds. Surveys at the end of the summer prior to the arrival of migrant geese indicated a population of approximately 157 birds. Because of this significant increase in population, the Laboratory will likely take a more aggressive approach to goose management in the future.

The eastern bluebird (Sialia sialis) has been identified as one of the declining species of migratory birds in North America. This decline is due to loss of habitat and to nest site competition from European starlings (Sturnus vulgaris) and house sparrows (Passer domesticus). BNL's NRMP includes habitat enhancement for the eastern bluebird. Since 2000, the Laboratory has installed more than 56 nest boxes around open grassland areas on site to enhance the bluebird population. In 2007, the boxes were monitored approximately every 3 weeks during the breeding season to determine use and nesting success. Twenty-seven bluebird nests were observed; a sharp decline over past year's successes. Other birds using the houses included house wrens (Troglodytes aedon), black-capped chickadees (Poecile atricapilla), tufted titmouse (Baeolo- phus bicolor), and tree swallows (Tachycineta bicolor). House wrens were the only species that showed an increase in nesting success. Their success may explain, in part, the decline in bluebird nest success.

\subsubsection{Population Management}

The Laboratory also monitors and manages other populations, including species of interest, to ensure that they are sustained and to control invasive species.

\subsubsection{Wild Turkey}

The forested areas of BNL provide good nesting and foraging habitat for wild turkey (Meleagris gallapavo). The on-site population was estimated at 60 to 80 birds in 1999 and had grown to approximately 500 birds in 2004 . Since 2004, the population appears to have stabilized at approximately 300 birds. The population across Suffolk County, Long Island, is now sufficiently large for NYSDEC to consider establishing a hunting season to maintain the population at a reasonable number.

\subsubsection{White-Tailed Deer}

BNL consistently updates information on the resident population of white-tailed deer (Odocoileus virginianus). As there are no natural predators on site and hunting is not permitted at the Laboratory, there are no significant pressures on the population to migrate beyond their typical home range of approximately 1 square mile. Normally, a population density of 10 to 30 deer per square mile is considered an optimum sustainable level for a given area. This would equate to approximately 80 to 250 deer inhabiting the BNL property, under normal circumstances. This was the approximate density in 1966, when the Laboratory reported an estimate of 267 deer on site (Dwyer 1966). BNL has been conducting population surveys of the white-tailed deer since 2000. In February and March 2004, an aerial infrared survey was conducted of three properties, including Wertheim National Wildlife Refuge (south of BNL), Brookhaven National Laboratory, and Rocky Point Wildlife Area (northwest of BNL). The results indicated a population of 412 deer 
on site and immediately off site. When a correction for survey accuracy was applied, the on-site population was estimated at 446 animals. This value was much lower than a ground-based estimate of 1,302, made at the same time using the existing methodology. Because there was a large discrepancy between methods, a review of the ground-based methodology was conducted and the method of estimating was refined. The new method uses the Laboratory's vegetation map and estimates the deer population based on the habitat in which deer are sighted during surveys. The result of this revised method indicated that the deer population was approximately 497 , which is considered to be reasonably comparable to the aerial survey results. The next step taken was to apply the new population model to historic survey data. Most of the data resulted in a much lower estimate, with ranges from approximately 1,000 deer in 2001 to approximately 400 deer in 2005 . The current population estimate is 392 deer, based on surveys conducted in November and December 2007. Note that the current estimate is still higher than the optimal range of 80 to 250 deer on an area the size of BNL.

Deer overpopulation can affect animal and human health (e.g., animal starvation, Lyme disease from deer ticks, collision injuries - both human and animal), species diversity (songbird species reduction due to selective grazing and destruction of habitat by deer), and property values (damage to autos and browsing damage to ornamental plantings). In 2007, three deer-related collisions occurred on site, compared to 10 accidents in 2006 and 25 accidents documented in 2004. This downward trend in accidents is attributed to a major effort by BNL Safeguards and Security personnel to enforce the $30-\mathrm{mph}$ speed limit on site. Additional emphasis on vehicle-deer safety is also thought to have helped reduce this type of accident. Deer health continues to be affected due to lack of food. Deer damage to vegetation around buildings continues to be a problem, but varies depending on the severity of the winter and the availability of browse in the lawns.

Because the high deer population is a regional problem, the Laboratory is working on the is- sue with other local jurisdictions. As part of this regional approach, an issue and decision paper was prepared for Laboratory management consideration late in 2007. Options for deer management are limited, and most are controversial. While a single regional approach would benefit the community, land managers, and the health of the deer population, individual land managing organizations like the Laboratory must implement a regional approach.

\subsubsection{Compliance Assurance and Potential Impact Assessment}

The National Environmental Policy Act (NEPA) review process at BNL is key to ensuring that environmental impacts of a proposed action or activity are adequately evaluated and addressed. The Laboratory will continue to use NEPA (or NEPA-like) processes under the Comprehensive Environmental Response, Compensation and Liability Act (CERCLA) Environmental Restoration Program when identifying potential environmental impacts associated with site activities - especially with physical alterations. As appropriate, stakeholders such as EPA, NYSDEC, Suffolk County Department of Health Services (SCDHS), BNL's Community Advisory Council, and the Brookhaven Roundtable are involved in reviewing major projects that have the potential for significant environmental impacts. Formal NEPA reviews are coordinated with the State of New York.

\subsection{UPTON ECOLOGICAL AND RESEARCH RESERVE}

On November 9, 2000, then-Secretary of Energy Bill Richardson and Susan MacMahon, Acting Regional Director of Region 5 FWS, dedicated 530 acres of Laboratory property as an ecological research reserve. The property was designated by DOE as the Upton Ecological and Research Reserve (Upton Reserve) and was managed by FWS under an Interagency Agreement (DOE-FWS 2000). The Upton Reserve, on the eastern boundary of BNL, is home to a wide variety of flora and fauna. It contains wetlands and is largely within the core preservation area of the Long Island Central Pine Bar- 
rens. Based on information from a 1994-1995 biological survey of the Laboratory, experts believe the reserve is home to more than 200 plant species and at least 162 species of mammals, birds, fish, reptiles, and amphibians (LMS 1995). A transition from FWS management of the Upton Reserve to management by BNL and the Foundation for Ecological Research in the Northeast (FERN) occurred in 2005. During that year, FERN initiated its first forest-wide monitoring program to assess the health of the various forest types within the Pine Barrens, followed by a continuation of the effort in 2006. FERN established 91 permanent plots over the 2-year period of the monitoring program and is currently analyzing the data. One significant finding from the monitoring is the lack of forest regeneration. In virtually every forest type, there is a lack of survival of trees from seedlings through to saplings. This is likely a result of either deer over-abundance or lack of sunlight penetrating to the understory. Further information on the forest health initiative, as well as other activities of FERN, is available on the FERN website at www.fernli.org. In 2007, FERN developed draft protocols for monitoring wetland health throughout the Pine Barrens. These protocols will likely be completed in 2008 and implemented sometime thereafter.

The Interagency Agreement that established the Upton Reserve specified the formation of a Technical Advisory Group (TAG), which includes a supervisory biologist for FWS and representatives from NYSDEC, Suffolk County Parks Department, the Central Pine Barrens Joint Policy and Planning Commission, DOE, BNL's Community Advisory Council, Brookhaven Executive Roundtable, Brookhaven Science Associates, and The Nature Conservancy. The TAG's primary responsibility was to develop a comprehensive NRMP for BNL. The TAG also developed criteria for soliciting and reviewing proposals and awarding funds for research that is conducted within the Upton Reserve. While most of the TAG's responsibilities have been met, the Laboratory intends to periodically ask for assistance in reviewing annual reports required under the
NRMP, and to support the 5-year update of the plan, which is scheduled to begin late in 2008 .

Research on oak tree defoliators that was initiated by FWS and the Upton Reserve is continuing at the Laboratory. Much of the oak forest on site and immediately east of BNL has been subject to repeated defoliation by gypsy moth and orange-striped oak moth. This double defoliation, if it occurs year after year, can kill large sections of oak forest. Beginning in 2003, death of tree oaks was documented. Due to continued defoliation, oak mortality is now estimated at greater than 25 percent in many areas in the northeast quadrant of the Laboratory. The amount of defoliation appeared to decrease in 2007, which was likely due to the decreased number of surviving oaks in the affected area.

Research supported by FERN in 2007 included an investigation into the microbial world of soils located within a number of the Forest Health Plots. Microbial research carried out by a scientist at Dowling College identified several new species of fungus and bacteria that had not previously been known. Future work in the area of microbial diversity is expected to identify additional new species across the Pine Barrens. Additionally, a faculty and student team and The Nature Conservancy surveyed approximately 30 ponds throughout eastern Long Island for variations in water quality in ponds near roads versus ponds far from roads. This work is discussed in more detail under Section 6.5, below.

\subsection{MONITORING FLORA AND FAUNA}

The Laboratory routinely monitors flora and fauna to determine the effects of past and present Laboratory activities. Because soil contaminated with cesium-137 (Cs-137), a radioactive isotope of cesium, was used in some BNL landscaping projects in the past, traces have now been found in deer and in other animals and plants. Most radionuclide tables in this chapter list data for both potassium-40 (K-40), a naturally occurring radioisotope of potassium, and Cs-137. Because K-40 occurs naturally in the environment, it is not uncommon in flora and fauna. It is presented as a comparison to Cs-137 because Cs-137 competes with potassium at a cellular level. General trends indicate that 
Cs-137 will out-compete potassium when potassium salts are limited in the environment, which is the typical case on Long Island. In general, $\mathrm{K}-40$ values do not receive significant discussion in the scientific literature due to this relationship and the fact that K-40 occurs naturally. The results of the annual sampling conducted under the flora and fauna monitoring program follow.

\subsubsection{Deer Sampling}

White-tailed deer in New York State typically are large, with males weighing, on average, about 150 pounds; females typically weigh one-third less, approximately 100 pounds.

However, white-tailed deer on Long Island tend to be much smaller, weighing an average of 80 pounds. The available meat on local deer ranges from 20 to 40 pounds per deer. This fact has implications for calculating the potential radiation dose to consumers of deer meat containing Cs-137, because smaller deer do not provide sufficient amounts of venison to support the necessary calculations.

In 2007, as in recent years, an off-site deersampling program was conducted with the NYSDEC Wildlife Branch and FWS. While most off-site samples are from road-killed deer near the Laboratory, NYSDEC provides a few samples from hunters beyond BNL boundaries, yielding control data on deer living 1 mile or more from BNL. In addition, FWS occasionally informs Laboratory staff of deer that have died in or near the Wertheim National Wildlife Refuge and other FWS properties on Long Island. In all, three deer were obtained on site and eight were from off-site locations, ranging from adjacent to BNL along the William Floyd Parkway, to approximately 6.75 miles away (East Patchogue, New York).

BNL sampling technicians collect the samples and process them for analysis. Samples of meat, liver, and bone are taken from each deer, when possible. The meat and liver are analyzed for Cs-137, and the bone is analyzed for strontium-90 (Sr-90).

\subsubsection{Cs-137 in White-Tailed Deer \\ White-tailed deer sampled at the Laboratory contain higher concentrations of Cs-137 than}

deer from greater than 1 mile off site (BNL 2000), probably because they graze on vegetation growing in soil where elevated Cs-137 levels are known to exist. Cs-137 in soil can be transferred to aboveground plant matter via root uptake, where it then becomes available to browsing animals.

Removal of contaminated soil areas at BNL has occurred under the Laboratory's Environmental Restoration (ER) Program. All major areas of contaminated soil were remediated by September 2005. In addition, all buildings at the former Hazardous Waste Management Facility (HWMF) were removed in 2003, and the cleanup of the remainder of the facility was completed by fall 2005. Subsequent to the completion of cleanup at the former HWMF, additional minor contamination outside that facility was found and has been characterized.

The number of deer obtained for sampling steadily increased between 1996 and 2004. However, the numbers of deer obtained between 2005 and 2007 are significantly lower. As mentioned above, the number of deer killed on site and available for sampling has decreased, most likely due to increased safety awareness, better enforcement of speed restrictions, and a smaller deer population. In 1998, a statistical analysis based on existing data suggested that 40 deer from off site and 25 deer from on site were needed to achieve a statistically sound data set. Since that analysis was completed, BNL has attempted to obtain the required number of deer. The number obtained each year has varied due to the sampling method, which depends on vehicle and deer accidents and people reporting dead deer. The number of deer hit by vehicles varies widely from year to year, depending on the population of deer present near major roadways and the traffic density. Figure 6-1 shows the location of all deer samples taken within a 5-mile radius of the Laboratory since 2003. Most of the off-site samples are concentrated along the William Floyd Parkway on the west boundary of BNL, whereas the concentration on site is near the front gate area and the constructed portions of the Laboratory. This distribution is most likely due to the fact that people on their way to work see and report dead deer. Vehicle 


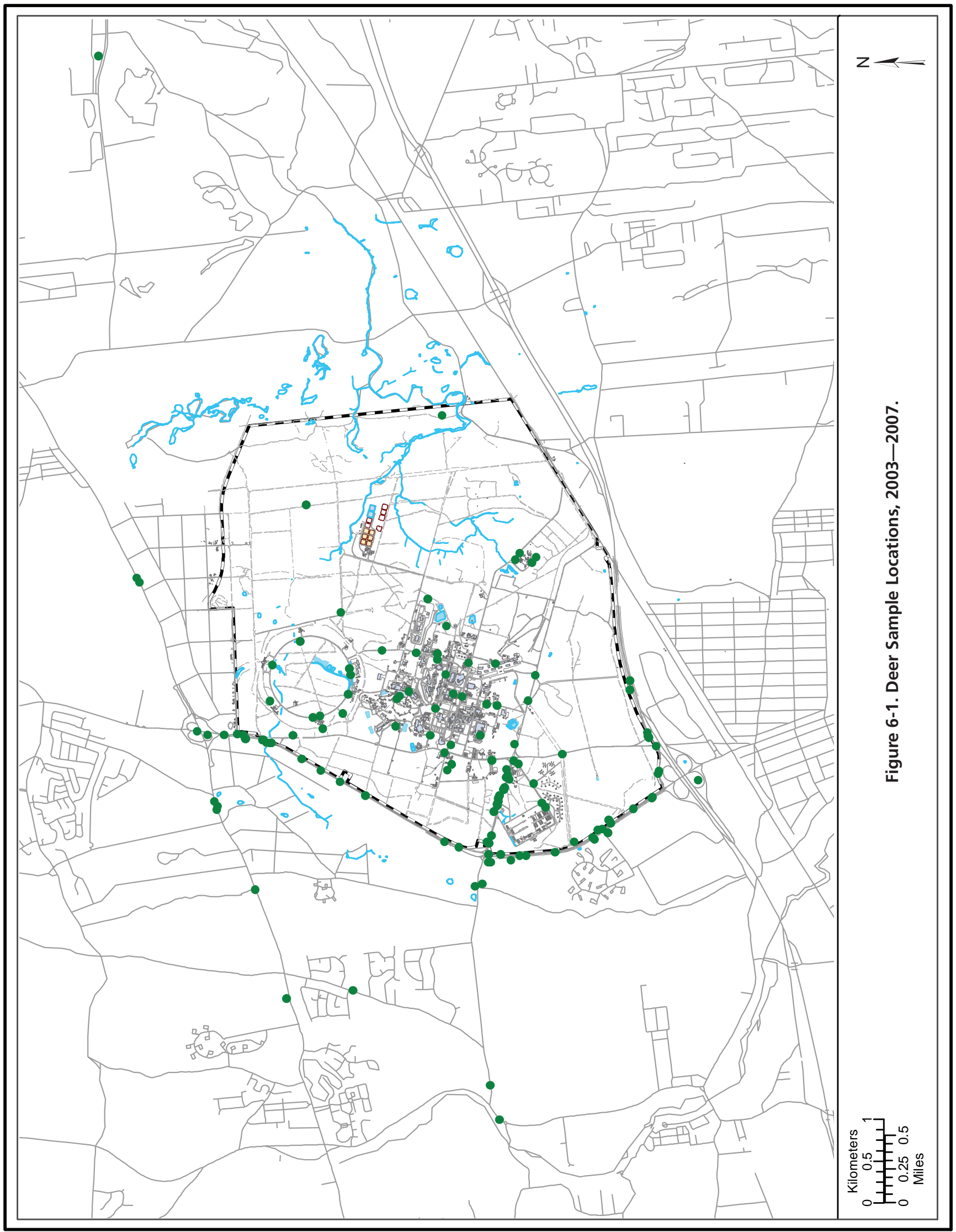


collisions with deer on site occur primarily early or late in the day, when deer are more active.

In 2007, Cs-137 concentrations in deer muscle ("meat") samples taken at BNL ranged from 0.01 to $0.25 \mathrm{pCi} / \mathrm{g}$ wet weight. The wet weight concentration is before a sample is dried for analysis, and is the form most likely to be consumed. Dry weight concentrations are typically higher than wet weight values. The maximum 2007 on-site concentration $(0.25 \mathrm{pCi} / \mathrm{g}$ wet weight) was seventeen times lower than the highest level reported in 2006 (4.27 pCi/g wet weight), and is much lower than the highest level ever reported (11.74 pCi/g wet weight, in 1996). The arithmetic average concentration in on-site meat samples was $0.17 \mathrm{pCi} / \mathrm{g}$, wet weight (see Table 6-2).

Cs-137 concentrations in off-site deer meat samples were separated into two groups: samples taken within 1 mile of BNL (four samples) and samples taken farther away (four samples) (see Table 6-2). Concentrations in meat samples taken within 1 mile ranged from 0.26 to 2.08 $\mathrm{pCi} / \mathrm{g}$ wet weight, with an average of $0.81 \mathrm{pCi} / \mathrm{g}$ wet weight; concentrations in meat taken from greater than 1 mile ranged from 0.27 to 1.19 $\mathrm{pCi} / \mathrm{g}$ wet weight, with an average of $0.61 \mathrm{pCi} / \mathrm{g}$ wet weight. Because deer on site may routinely travel up to 1 mile off site, the average for deer taken on site and within 1 mile of the Labora-

Table 6-2 Radiological Analyses of Deer Tissue (Flesh, Liver, Bone).

\begin{tabular}{|c|c|c|c|c|c|}
\hline Sample Location & $\begin{array}{l}\text { Collection } \\
\text { Date }\end{array}$ & $\begin{array}{l}\text { Tissue } \\
\text { Type }\end{array}$ & $\begin{array}{c}\text { K-40 } \\
\text { pCi/g (Wet Weight) }\end{array}$ & $\begin{array}{c}\text { Cs-137 } \\
\mathrm{pCi} / \mathrm{g} \text { (Wet Weight) }\end{array}$ & $\begin{array}{c}\text { Sr-90 } \\
\text { pCi/g (Dry Weight) }\end{array}$ \\
\hline \multicolumn{6}{|l|}{ BNL, On Site } \\
\hline \multirow{3}{*}{$\begin{array}{l}\text { Along gamma forest fence, just east of } \\
\text { stump dump }\end{array}$} & $02 / 13 / 07$ & Flesh & $3.80 \pm 0.31$ & $0.25 \pm 0.02$ & \\
\hline & & Liver & $2.07 \pm 0.18$ & $0.06 \pm 0.01$ & \\
\hline & & Bone & & & $2.18 \pm 0.30$ \\
\hline \multirow[t]{3}{*}{ Railroad Ave. } & 03/05/07 & Flesh & $3.20 \pm 0.24$ & $0.01 \pm 0.01$ & \\
\hline & & Liver* $^{*}$ & $2.82 \pm 0.20$ & $0.01 \pm 0.00$ & \\
\hline & & Bone & & & $1.11 \pm 0.22$ \\
\hline \multirow[t]{3}{*}{ BIdg 938, by BLIP } & $04 / 11 / 07$ & Flesh & $3.63 \pm 0.30$ & $0.25 \pm 0.02$ & \\
\hline & & Liver & $2.22 \pm 0.20$ & $0.04 \pm 0.01$ & \\
\hline & & Bone & & & $2.81 \pm 0.35$ \\
\hline \multicolumn{6}{|l|}{ Offsite $<1$ mile } \\
\hline \multirow{3}{*}{$\begin{array}{l}\text { William Floyd Pkwy., across from north } \\
\text { gate }\end{array}$} & $01 / 23 / 07$ & Flesh & $3.66 \pm 0.25$ & $0.26 \pm 0.02$ & \\
\hline & & Liver & $2.69 \pm 0.19$ & $0.06 \pm 0.01$ & \\
\hline & & Bone & & & $1.52 \pm 0.28$ \\
\hline \multirow{2}{*}{$\begin{array}{l}\text { William Floyd Pkwy., } 1 / 4 \text { mile south of } \\
\text { main gate }\end{array}$} & 08/07/07 & Flesh & $3.92 \pm 0.51$ & $0.50 \pm 0.06$ & \\
\hline & & Bone & & & $2.50 \pm 0.33$ \\
\hline \multirow{2}{*}{$\begin{array}{l}\text { William Floyd Pkwy., } 1 / 2 \text { mile north of } \\
\text { main Gate }\end{array}$} & 10/16/07 & Flesh & $3.50 \pm 0.47$ & $0.41 \pm 0.05$ & \\
\hline & & Bone $^{* *}$ & & & $0.66 \pm 0.24$ \\
\hline \multirow{3}{*}{$\begin{array}{l}\text { Rte. } 25,1.5 \text { miles east of William Floyd } \\
\text { Pkwy. }\end{array}$} & $10 / 25 / 07$ & Flesh & $3.42 \pm 0.43$ & $2.08 \pm 0.19$ & \\
\hline & & Liver & $2.63 \pm 0.40$ & $0.51 \pm 0.05$ & \\
\hline & & Bone & & & $5.04 \pm 1.00$ \\
\hline
\end{tabular}


Table 6-2 Radiological Analyses of Deer Tissue (Flesh, Liver, Bone) (concluded).

\begin{tabular}{|c|c|c|c|c|c|}
\hline Sample Location & $\begin{array}{l}\text { Collection } \\
\text { Date }\end{array}$ & $\begin{array}{c}\text { Tissue } \\
\text { Type }\end{array}$ & $\begin{array}{c}\text { K-40 } \\
\text { pCi/g (Wet Weight) }\end{array}$ & $\begin{array}{c}\text { Cs-137 } \\
\mathrm{pCi} / \mathrm{g} \text { (Wet Weight) }\end{array}$ & $\begin{array}{c}\text { Sr-90 } \\
\text { pCi/g (Dry Weight) }\end{array}$ \\
\hline \multicolumn{6}{|l|}{ Offsite $>1$ mile } \\
\hline \multirow{3}{*}{ Sunrise Hwy., near Hospital Rd. } & 01/04/07 & Flesh & $3.69 \pm 0.25$ & $1.19 \pm 0.10$ & \\
\hline & & Liver & $2.79 \pm 0.24$ & $0.20 \pm 0.02$ & \\
\hline & & Bone & & & $1.94 \pm 0.30$ \\
\hline \multirow[t]{3}{*}{ Wading Hollow Rd., Ridge } & 02/01/07 & Flesh & $3.54 \pm 0.28$ & $0.27 \pm 0.03$ & \\
\hline & & Liver & $2.63 \pm 0.18$ & $0.06 \pm 0.01$ & \\
\hline & & Bone & & & $1.19 \pm 0.23$ \\
\hline \multirow[t]{3}{*}{ Yaphank-Middle Island Rd. } & 02/16/07 & Flesh & $3.50 \pm 0.26$ & $0.43 \pm 0.04$ & \\
\hline & & Liver & $2.57 \pm 0.21$ & $0.11 \pm 0.01$ & \\
\hline & & Bone & & & $1.89 \pm 0.29$ \\
\hline \multirow[t]{3}{*}{ 1/2 mile west of Longwood High School } & 04/04/07 & Flesh & $3.56 \pm 0.26$ & $0.55 \pm 0.05$ & \\
\hline & & Liver & $3.06 \pm 0.22$ & $0.17 \pm 0.02$ & \\
\hline & & Bone & & & $2.96 \pm 0.34$ \\
\hline \multicolumn{6}{|l|}{ Averages by Tissue } \\
\hline \multicolumn{6}{|l|}{ Flesh } \\
\hline Avg. for all samples (11) & & & $3.58 \pm 1.12$ & $0.56 \pm 0.24$ & \\
\hline BNL on-site average (3) & & & $3.54 \pm 0.49$ & $0.17 \pm 0.03$ & \\
\hline BNL on- and off-site < 1 mile avg. (7) & & & $3.59 \pm 0.99$ & $0.54 \pm 0.21$ & \\
\hline Off site average (8 samples) & & & $3.60 \pm 1.00$ & $0.71 \pm 0.24$ & \\
\hline Off-site $<1$ mile average (4 samples) & & & $3.63 \pm 0.85$ & $0.81 \pm 0.20$ & \\
\hline Off-site > 1 mile average (4 samples) & & & $3.57 \pm 0.53$ & $0.61 \pm 0.12$ & \\
\hline \multicolumn{6}{|l|}{ Liver } \\
\hline Avg. for all samples (9) & & & $2.61 \pm 0.70$ & $0.14 \pm 0.06$ & \\
\hline BNL on-site average (3) & & & $2.37 \pm 0.34$ & $0.04 \pm 0.01$ & \\
\hline BNL on- and off-site < 1 mile avg. (5) & & & $2.49 \pm 0.55$ & $0.14 \pm 0.05$ & \\
\hline Off-site average (6) & & & $2.73 \pm 0.61$ & $0.18 \pm 0.06$ & \\
\hline Off-site < 1 mile average (2) & & & $2.66 \pm 0.44$ & $0.28 \pm 0.05$ & \\
\hline Off-site > 1 mile average (4) & & & $2.76 \pm 0.43$ & $0.13 \pm 0.03$ & \\
\hline \multicolumn{6}{|l|}{ Bone } \\
\hline Avg. for all samples (11) & & & & & $2.16 \pm 1.36$ \\
\hline BNL on-site average (3) & & & & & $2.03 \pm 0.51$ \\
\hline BNL on- and off-site < 1 mile avg. (7) & & & & & $2.26 \pm 1.22$ \\
\hline Off-site average (8) & & & & & $2.21 \pm 1.26$ \\
\hline Off-site < 1 mile average (4) & & & & & $2.43 \pm 1.11$ \\
\hline Off-site > 1 mile average $(4)$ & & & & & $2.00 \pm 0.59$ \\
\hline \multicolumn{6}{|c|}{$\begin{array}{l}\text { Notes: } \\
\text { All values are shown with a } 95 \% \text { confidence interval. } \\
\text { K-40 occurs naturally in the environment and is presented as a } \\
\text { comparison to Cs- } 137 \text {. } \\
\text { All averages are the arithmetic average and utilize estimated values } \\
\text { for ND. } \\
\text { Confidence limits are } 2 \sigma \text { sigma (95\%) propogated error. } \\
\text { BLIP = Brookhaven Linac Isotope Producer }\end{array}$} \\
\hline
\end{tabular}


tory is also calculated; for 2007 , this was 0.54 pCi/g wet weight.

Figure 6-2 compares the average values of Cs-137 concentrations in meat samples collected in 2007 from four different location groupings. Although the figure does not show this, 73 percent of all samples taken both on and off site are below $1 \mathrm{pCi} / \mathrm{g}$ wet weight (see Table 6-2).

Figure 6-3 presents the 10-year trend of onsite and near off-site Cs-137 averages in deer meat. While composed of a similar number of samples as in 1998, sampling in 2007 indicates a much narrower range of error and continues to indicate the effectiveness of cleanup actions across the Laboratory. In 2003, a seasonal pattern in Cs-137 concentrations in deer meat was noticed. This seasonality was present in earlier years and occurred again in 2006 (see Table 6-2). During the summer of 2004, a student in the Community College Intern Program re-

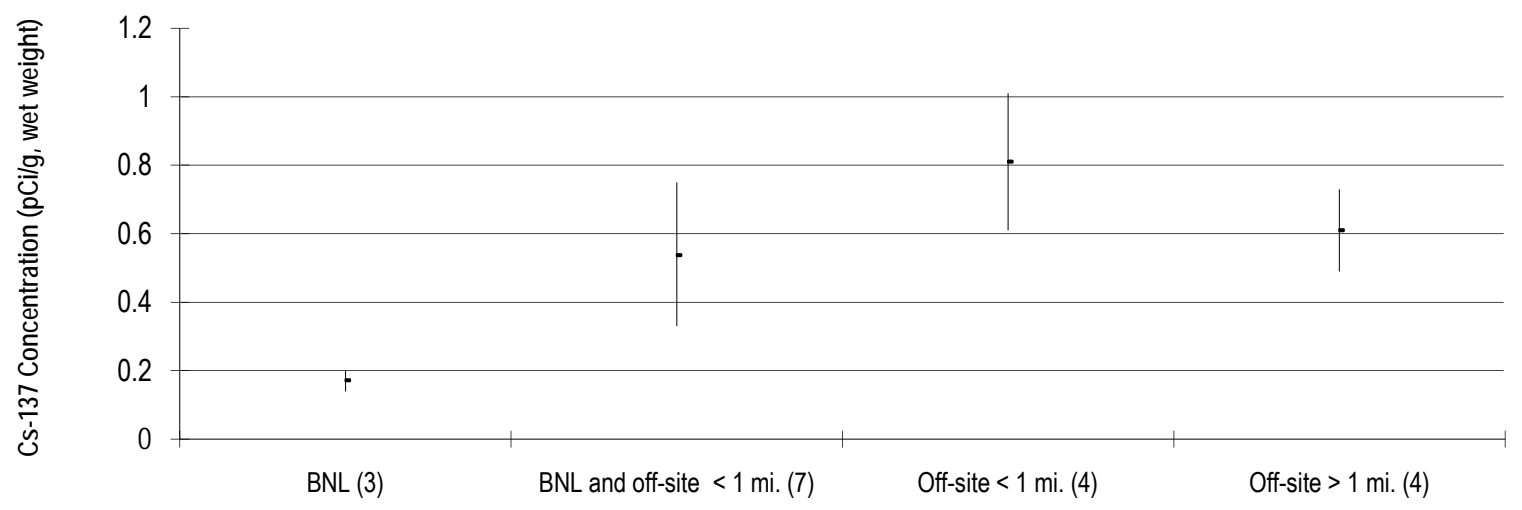

Notes: Averages are shown for samples collected at BNL, on site and off site within 1 mile, off site but within 1 mile of the boundary, and off site greater than 1 mile from the boundary.

Numbers in parentheses indicate the number of samples in that data set.

All values are presented with a $95 \%$ confidence interval.

Cs-137 = cesium -137

Figure 6-2. Comparison of Cs-137 Average Concentrations in Deer, 2007.

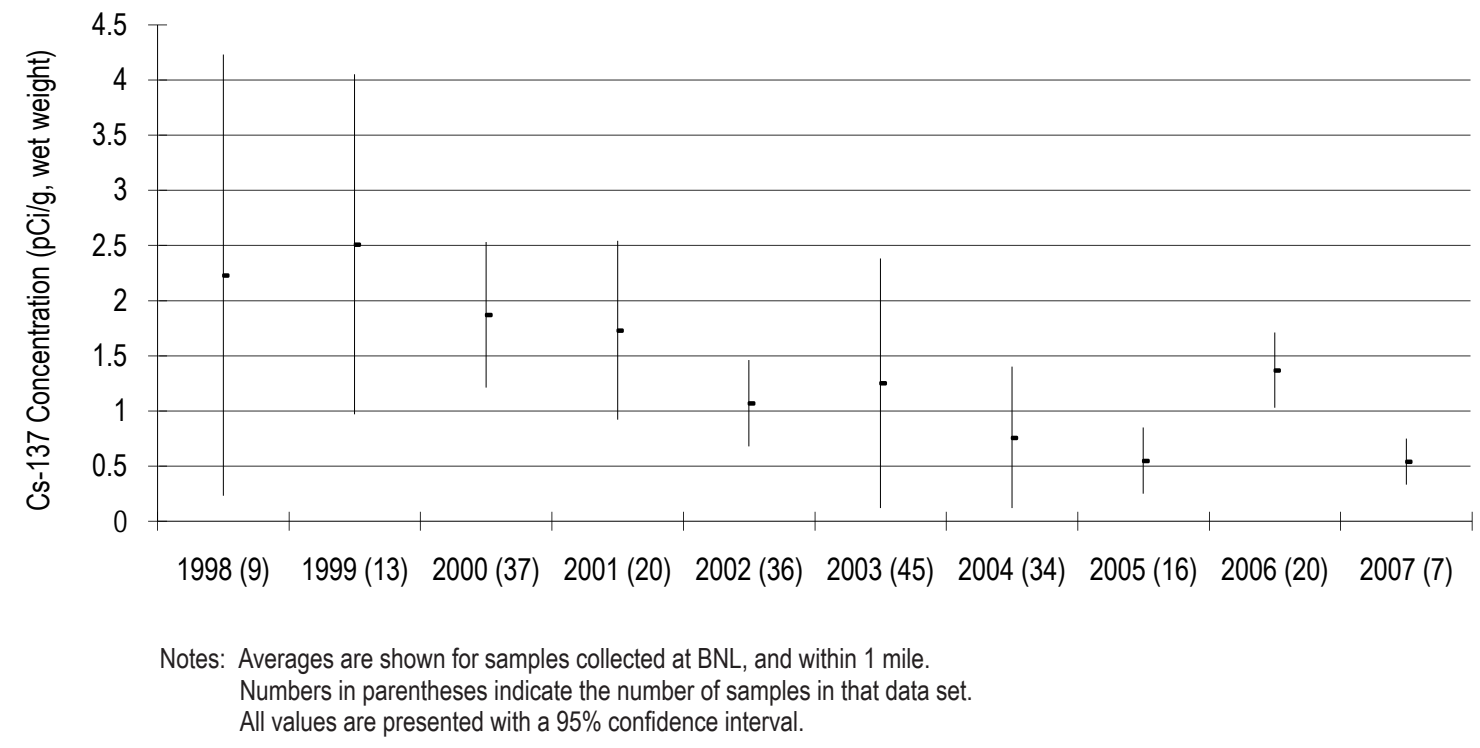

Figure 6-3. Trend of Cs-137 Concentrations in Deer Meat at BNL and Within 1 Mile of BNL, $1998-2007$. 
viewed all data from 2000-2003, analyzed it statistically, and determined that there was a statistical seasonal variation in values for deer both on site as well as far off site (Florendo 2004). This seasonality is likely due to diet and the biological processing of Cs-137. From January through May, deer have a limited food supply - mostly dry vegetation from the previous year's growth (with a fixed concentration of Cs-137 because plants are dormant). In the summer and fall, deer eat more and the vegetation is constantly growing, taking up nutrients and contaminants from the soil. In summer and fall, deer feeding on vegetation growing in soil containing Cs-137 are more likely to obtain a continuous supply, which is incorporated into their tissues. This increased concentration of Cs-137 in tissues is evidenced by the three highest values seen in deer in 2006 (3.06, 4.00, and $9.51 \mathrm{pCi} / \mathrm{g}$ wet weight) from samples taken in October and November. By January or February, the Cs-137 in their tissues has been eliminated through biological processes. The levels of Cs-137 in deer tissue during June through early August are not well known, as there are few vehicle-deer accidents at this time of year.

When possible, liver samples are taken concurrently with meat samples. Liver generally accumulates Cs-137 at a lower rate than muscle tissue. The typically lower values in liver allow the results to be used as a validity check for meat values (i.e., if liver values are higher than meat values, results can be considered questionable and should be confirmed). In liver samples collected on site in 2007, Cs-137 concentrations ranged from 0.01 to $0.06 \mathrm{pCi} / \mathrm{g}$ wet weight, with an average of $0.04 \mathrm{pCi} / \mathrm{g}$ wet weight. The off-site Cs-137 concentration in liver ranged from 0.06 to $0.51 \mathrm{pCi} / \mathrm{g}$ wet weight, with an average for all off-site liver samples of $0.18 \mathrm{pCi} / \mathrm{g}$ wet weight.

The potential radiological dose resulting from deer meat consumption is discussed in Chapter 8. The New York State Department of Health (NYSDOH) has formally considered the potential public health risk associated with elevated Cs-137 levels in on-site deer and determined that neither hunting restrictions nor formal health advisories are warranted (NYSDOH 1999).

With respect to the health of on-site deer based on their exposure to radionuclides, the International Atomic Energy Agency (IAEA) has concluded that chronic dose rates of 100 millirad per day to even the most radiosensitive species in terrestrial ecosystems are unlikely to cause detrimental effects in animal populations (IAEA 1992). A deer containing a uniform distribution of Cs-137 within muscle tissue at the highest levels observed to date (11.74 pCi/g wet weight, reported in 1996) would carry a total amount of about $0.2 \mu \mathrm{Ci}$. That animal would receive an absorbed dose of approximately 3 millirad per day, which is only 3 percent of the threshold evaluated by IAEA. The deer observed and sampled on site appear to have no health effects from the level of Cs137 found in their tissues.

\subsubsection{Strontium-90 in Deer Bone}

BNL began testing deer bones for Sr-90 content in 2000. In 2007, Sr-90 content ranged from 1.11 to $2.81 \mathrm{pCi} / \mathrm{g}$ dry weight in on-site samples. Sr-90 in off-site samples ranged from 0.66 to $5.04 \mathrm{pCi} / \mathrm{g}$ dry weight in samples taken within 1 mile of BNL, and 1.19 to $2.96 \mathrm{pCi} / \mathrm{g}$ dry weight in samples taken more than a mile from BNL. This overlap in values between all samples suggests that $\mathrm{Sr}-90$ is present in the environment at background levels, probably as a result of worldwide fallout from nuclear weapons testing. Sr-90 is present at very low levels in the environment, is readily incorporated into bone tissue, and may concentrate over time. BNL will continue to test for Sr-90 in bone to develop baseline information on this radionuclide and its presence in white-tailed deer.

\subsubsection{Small Mammal Sampling}

BNL discontinued small mammal sampling in 2007. The original goal of this sampling was to determine the suitability of small mammals, primarily squirrels, as a surrogate for deer sampling. This sampling was discontinued due to the difficulty of trapping squirrels, as well as difficulties in obtaining representative samples. 


\subsubsection{Other Animals Sampled}

When other animals, such as wild turkey or Canada geese, are found dead along the roads of the Laboratory and the immediate vicinity due to road mortality, they are tested. In 2007 , one goose and one turkey were sampled. Muscle from both birds was analyzed for Cs137 content. Muscle from the goose indicated a Cs-137 value less than the minimum detection level (MDL) established by the analytical laboratory, and the muscle from the turkey had a value of $0.03 \mathrm{pCi} / \mathrm{g}$ wet weight. Bone from both birds was analyzed for Sr-90 with values of less than the MDL for the goose and $0.37 \mathrm{pCi} / \mathrm{g}$ dry weight for the turkey. These data continue to indicate that both species do not readily uptake these radionuclides from their diet.

\subsubsection{Fish Sampling}

In collaboration with the NYSDEC Fisheries Division, BNL maintains an ongoing program for collecting and analyzing fish from the Peconic River and surrounding freshwater bodies. Routine annual on-site sampling of fish resumed in 2007. Large areas of open water on site resulting from the cleanup of the Peconic River have resulted in sufficient habitat to support larger fish. During sampling activities in 2007, numerous schools of fry of bass and sunfish were noticed. While low dissolved oxygen levels continue to be a problem for fish, the deeper pools provide areas of cooler, more highly oxygenated water for long-term survival. Fish were sampled earlier in the year to take advantage of periods when dissolved oxygen levels are higher, supporting the presence of fish.

As in the past, off-site fish sampling continued in 2007. All samples were analyzed for edible (fillet) content of each of the analytes reported. In 2007, various species of fish were collected off site from Swan Pond, Donahue's Pond, Forge Pond, Manor Road, and Lower Lake on the Carmans River (see Figure 5-8 for sampling stations). Swan Pond is a semicontrol location on the Peconic River system (a tributary of the Peconic not connected to the BNL branch), and Lower Lake on the Carmans River is the non-Peconic control site. Sampling is carried out in cooperation with NYSDEC and through a contract with the Cold Spring Harbor Fish Hatchery and Museum. One hundred and seventy-three samples were taken, representing eight species of fish.

\subsubsection{Radiological Analysis of Fish}

The species collected for radiological analysis in 2007 by the Laboratory and through contract labor included brown bullhead (Ictalurus nebulosus), chain pickerel (Esox niger), largemouth bass (Micropterus salmoides), bluegill (Lepomis macrochirus), pumpkinseed (Lepomis gibbosus), and black crappie (Pomoxis nigromaculatus). Gamma spectroscopy analysis was performed on all samples. When fish were not of sufficient mass to conduct all nonradiological and radiological analyses, samples of the same species were composited to gain sufficient volume for radiological analysis. Table 6-3 presents specific information on the sampling location, species collected, and analytical results. All sample results are presented as wet weight concentrations. Information on the natural radioisotope $\mathrm{K}-40$ is included as a comparison.

Cs-137 was detected at low levels in all samples from the Peconic River system, ranging from $0.04 \mathrm{pCi} / \mathrm{g}$ wet weight for pumpkinseed from Swan Pond to $0.24 \mathrm{pCi} / \mathrm{g}$ wet weight in a brown bullhead and chain pickerel from the Schultz Road area. In 2007, all fish taken from Lower Lake on the Carmans River (the nonPeconic control location) were too small for radiological analysis. Therefore, no data on this location are presented.

To account for the different feeding habits and weights of various species, it is important to compare species with similar feeding habits (i.e., bottom feeders such as brown bullhead should be compared to other bottom feeders). Cs-137 concentrations in brown bullhead collected at all locations along the Peconic River had values less than $0.24 \mathrm{pCi} / \mathrm{g}$ wet weight. Largemouth bass from the Peconic River showed Cs-137 levels of $0.16 \mathrm{pCi} / \mathrm{g}$ wet weight or less. Levels of Cs-137 in all fish species appear to be declining, compared with historic values.

Though it is clear from discharge records and sediment sampling that past BNL operations have contributed to anthropogenic (human- 
caused) radionuclide levels in the Peconic River system, most of these radionuclides were released between the late 1950s and early 1970s. Concentrations continue to decline over time through natural decay. Cs-137 has a half-life of 30 years. No Cs-137 was released from the BNL Sewage Treatment Plant (STP) to the Peconic River between 2003 and 2007 (see Figure 5-4 for a trend of Cs-137 discharges). Additionally, the cleanup of both on- and off-site portions of the Peconic River in 2004 and 2005 removed approximately 88 percent of Cs-137 in the sediment that was co-located with mercury. Removal of this contamination is expected to result in further decreases in Cs-137 levels in fish.

\subsubsection{Fish Population Assessment}

BNL suspended fish sampling on site in 2001 because prior fish sampling had depleted the population and limited the remaining fish to smaller sizes. Sampling resumed in 2007 when multiple schools of small fish were observed throughout the on-site portions of the river. The relative sizes of fish caught during annual sampling events will be tracked, and modifications to future sampling events will be made as necessary to ensure long-term health of the on-site fish populations.

\subsubsection{Nonradiological Analysis of Fish}

In 1997, under BNL's Environmental Restoration Program Operable Unit (OU) V Remediation Project, fish from the Peconic River on site were analyzed for metals, pesticides, and PCBs. Since 2002, analysis has been limited to off-site fish. The timing of sampling has varied from year to year, as well as the sample preparation (whole-body, tissue separation, composite sampling). In 1997, sampling was performed during April through May; in 1999, sampling was performed during September through December. Since 2000, sampling has been performed from July through August. Additionally, there has been a wide variation in fish size; therefore, samples have had to be composite whole-body to obtain significant mass for analysis. These variables make the comparisons from year to year difficult, as there can be significant seasonal variations in feeding, energy consump-
Table 6.3. Radiological Analyses of Fish from the Peconic River System.

\begin{tabular}{|c|c|c|}
\hline \multirow[b]{2}{*}{ Species/Location } & $\mathrm{K}-40$ & Cs-137 \\
\hline & \multicolumn{2}{|c|}{ pCi/g, wet weight } \\
\hline \multicolumn{3}{|l|}{ BNL, On Site } \\
\hline Brown bullhead 1a & $3.24 \pm 0.38$ & $0.19 \pm 0.03$ \\
\hline Brown bullhead 1c & $3.49 \pm 0.41$ & $0.14 \pm 0.02$ \\
\hline Brown bullhead 2c & $4.23 \pm 0.44$ & $0.15 \pm 0.03$ \\
\hline Brown bullhead 3c & $3.02 \pm 0.33$ & $0.09 \pm 0.02$ \\
\hline Brown bullhead 4c & $2.89 \pm 0.29$ & $0.13 \pm 0.01$ \\
\hline Brown bullhead 5c & $3.41 \pm 0.42$ & $0.10 \pm 0.03$ \\
\hline Brown bullhead 1d & $2.75 \pm 0.31$ & $0.12 \pm 0.02$ \\
\hline Brown bullhead 2d & $3.74 \pm 0.49$ & $0.15 \pm 0.03$ \\
\hline Brown bullhead 3d & $3.22 \pm 0.44$ & $0.14 \pm 0.02$ \\
\hline Brown bullhead 4d & $3.62 \pm 0.37$ & $0.13 \pm 0.02$ \\
\hline Brown bullhead 5d & $3.14 \pm 0.37$ & $0.10 \pm 0.02$ \\
\hline Brown bullhead 6d & $3.86 \pm 0.45$ & $0.21 \pm 0.03$ \\
\hline Chain pickerel 1a & $3.48 \pm 0.42$ & $0.16 \pm 0.02$ \\
\hline Largemouth bass 1c & $3.11 \pm 0.43$ & $0.16 \pm 0.03$ \\
\hline Pumpkinseed 1c & $3.03 \pm 0.57$ & $0.05 \pm 0.04$ \\
\hline Pumpkinseed 1d & $3.10 \pm 0.52$ & $0.11 \pm 0.04$ \\
\hline \multicolumn{3}{|l|}{ Schultz Road } \\
\hline Brown bullhead 2 & $3.54 \pm 0.39$ & $0.14 \pm 0.02$ \\
\hline Brown bullhead 5 & $3.97 \pm 0.45$ & $0.24 \pm 0.04$ \\
\hline Brown bullhead 6 & $3.88 \pm 0.44$ & $0.21 \pm 0.02$ \\
\hline Brown bullhead 7 & $4.96 \pm 0.68$ & $0.22 \pm 0.07$ \\
\hline Brown bullhead 8 & $3.42 \pm 0.50$ & $0.09 \pm 0.02$ \\
\hline Chain pickerel 1 & $3.94 \pm 0.48$ & $0.24 \pm 0.03$ \\
\hline Largemouth bass & $3.11 \pm 0.49$ & $0.13 \pm 0.02$ \\
\hline \multicolumn{3}{|l|}{ Donahue's Pond } \\
\hline Black crappie 1 & $2.91 \pm 0.68$ & $0.08 \pm 0.03$ \\
\hline Bluegill 1 & $2.71 \pm 0.79$ & $0.08 \pm 0.04$ \\
\hline Brown bullhead 1* & $2.97 \pm 0.76$ & $0.11 \pm 0.04$ \\
\hline Chain pickerel & $2.98 \pm 0.78$ & $0.19 \pm 0.06$ \\
\hline Largemouth bass & $3.11 \pm 0.91$ & $0.13 \pm 0.05$ \\
\hline Pumpkinseed 1 & $2.37 \pm 0.59$ & $0.08 \pm 0.03$ \\
\hline \multicolumn{3}{|c|}{ Swan Pond (Peconic River control location) } \\
\hline Pumpkinseed* & $2.27 \pm 0.23$ & $0.04 \pm 0.01$ \\
\hline \multicolumn{3}{|c|}{$\begin{array}{l}\text { All samples analyzed as edible portions (fillets) except pumpkinseeds } \\
\text { from Swan Pond,which were analyzed whole body composite. }\end{array}$} \\
\hline \multicolumn{3}{|c|}{$\begin{array}{l}\text { K- } 40 \text { occurs naturally in the environment and is presented as a } \\
\text { comparison to Cs- } 137 \text {. }\end{array}$} \\
\hline \multicolumn{3}{|l|}{ Cs-137 = cesium-137 } \\
\hline \multicolumn{3}{|l|}{$\mathrm{K}-40=$ potassium -40} \\
\hline${ }^{*}=$ estimated value for & based on ana & oratory qua \\
\hline
\end{tabular}


tion, and incorporation of nutrients into various tissues. Beginning in 2005, all fish of sufficient size were analyzed as edible portions (fillets). Smaller fish, such as golden shiners, were composited for whole-body analysis. In 2007, fish sampling was moved to the spring months to lessen the effect of low oxygen levels on fish distributions. Nearly all samples were obtained between April and mid-June.

Table 6-4 shows the 2007 concentration of metals in fish. According to NYSDEC, none of the metal concentrations were considered capable of affecting the health of consumers of such fish. Due to the fact that values for arsenic, beryllium, cadmium, cobalt, silver, thallium, selenium, and vanadium were near or less than the MDL for the analytical procedure, they were not included in Table 6-4. Other metals tested but not included in the table include aluminum, antimony, and nickel, as most values reported for these metals were less than the MDL. Values that were above the MDL are discussed below. Since fish taken on site were generally of smaller size, samples were analyzed for mercury only.

Table 6-4. Metals Analyses of Fish from the Peconic River System and Carmans River, Lower Lake.

\begin{tabular}{|c|c|c|c|c|c|c|c|c|}
\hline \multirow[b]{2}{*}{ Location/Species } & Barium & Chromium & Copper & Iron & Lead & Manganese & Mercury & Zinc \\
\hline & & & & \multicolumn{2}{|c|}{$\mathrm{mg} / \mathrm{kg}$} & & & \\
\hline \multicolumn{9}{|l|}{ BNL } \\
\hline Chain pickerel 1a & NT & NT & NT & NT & NT & NT & 0.859 & NT \\
\hline Chain pickerel/ Pumpkinseed & NT & NT & NT & NT & NT & NT & 0.919 & NT \\
\hline Chain pickerel 2a & NT & NT & NT & NT & NT & NT & 0.535 & NT \\
\hline Pumpkinseed 1a & NT & NT & NT & NT & NT & NT & 1.350 & NT \\
\hline Brown bullhead 1a & NT & NT & NT & NT & NT & NT & 0.362 & NT \\
\hline Brown bullhead 2a & NT & NT & NT & NT & NT & NT & 0.504 & NT \\
\hline Brown bullhead 3a & NT & NT & NT & NT & NT & NT & 0.435 & NT \\
\hline Brown bullhead 1c & NT & NT & NT & NT & NT & NT & 0.296 & NT \\
\hline Brown bullhead 2c & NT & NT & NT & NT & NT & NT & 0.261 & NT \\
\hline Brown bullhead 3c & NT & NT & NT & NT & NT & NT & 0.423 & NT \\
\hline Brown bullhead 4c & NT & NT & NT & NT & NT & NT & 0.389 & NT \\
\hline Brown bullhead $5 \mathrm{c}$ & NT & NT & NT & NT & NT & NT & 0.275 & NT \\
\hline Brown bullhead 6c & NT & NT & NT & NT & NT & NT & 0.283 & NT \\
\hline Brown bullhead 7c & NT & NT & NT & NT & NT & NT & 0.275 & NT \\
\hline Brown bullhead 8c & NT & NT & NT & NT & NT & NT & 0.394 & NT \\
\hline Brown bullhead 9c & NT & NT & NT & NT & NT & NT & 0.342 & NT \\
\hline Brown bullhead 10c & NT & NT & NT & NT & NT & NT & 0.275 & NT \\
\hline Largemouth bass $1 \mathrm{c}$ & NT & NT & NT & NT & NT & NT & 1.050 & NT \\
\hline Largemouth bass $2 \mathrm{c}$ & NT & NT & NT & NT & NT & NT & 0.489 & NT \\
\hline Pumpkinseed/Bluegill & NT & NT & NT & NT & NT & NT & 0.346 & NT \\
\hline Brown bullhead 1d & NT & NT & NT & NT & NT & NT & 0.205 & NT \\
\hline Brown bullhead 2d & NT & NT & NT & NT & NT & NT & 0.284 & NT \\
\hline Brown bullhead 3d & NT & NT & NT & NT & NT & NT & 0.219 & NT \\
\hline Brown bullhead 4d & NT & NT & NT & NT & NT & NT & 0.344 & NT \\
\hline Brown bullhead 5d & NT & NT & NT & NT & NT & NT & 0.420 & NT \\
\hline Brown bullhead $6 \mathrm{~d}$ & NT & NT & NT & NT & NT & NT & 0.217 & NT \\
\hline
\end{tabular}


CHAPTER 6: NATURAL AND CULTURAL RESOURCES

Table 6-4. Metals Analyses of Fish from the Peconic River System and Carmans River, Lower Lake(continued).

\begin{tabular}{|c|c|c|c|c|c|c|c|c|}
\hline \multirow[b]{2}{*}{ Location/Species } & Barium & Chromium & Copper & Iron & Lead & Manganese & Mercury & Zinc \\
\hline & \multicolumn{8}{|c|}{$-\mathrm{mg} / \mathrm{kg}$} \\
\hline Brown bullhead 7d & NT & NT & NT & NT & NT & NT & 0.172 & NT \\
\hline Brown bullhead 8d & NT & NT & NT & NT & NT & NT & 0.226 & NT \\
\hline Brown bullhead 9d & NT & NT & NT & NT & NT & NT & 0.346 & NT \\
\hline Brown bullhead 10d & NT & NT & NT & NT & NT & NT & 0.173 & NT \\
\hline Brown bullhead 11d & NT & NT & NT & NT & NT & NT & 0.238 & NT \\
\hline Brown bullhead 12d & NT & NT & NT & NT & NT & NT & 0.260 & NT \\
\hline Brown bullhead 13d & NT & NT & NT & NT & NT & NT & 0.132 & NT \\
\hline Brown bullhead 14d & NT & NT & NT & NT & NT & NT & 0.200 & NT \\
\hline Brown bullhead $15 d$ & NT & NT & NT & NT & NT & NT & 0.187 & NT \\
\hline Brown bullhead $16 \mathrm{~d}$ & NT & NT & NT & NT & NT & NT & 0.257 & NT \\
\hline Pumpkinseed 1d & NT & NT & NT & NT & NT & NT & 0.581 & NT \\
\hline Bluegill & NT & NT & NT & NT & NT & NT & 0.151 & NT \\
\hline \multicolumn{9}{|l|}{ Schultz Road } \\
\hline Black crappie & $<M D L$ & $<\mathrm{MDL}$ & $<M D L$ & $<M D L$ & $<M D L$ & $<\mathrm{MDL}$ & 0.339 & 6.25 \\
\hline Bluegill 1 & NT & NT & NT & NT & NT & NT & 0.152 & NT \\
\hline Bluegill 2 & NT & NT & NT & NT & NT & NT & 0.350 & NT \\
\hline Bluegill 3 & NT & NT & NT & NT & NT & NT & 0.222 & NT \\
\hline Brown bullhead 1 & NT & NT & NT & NT & NT & NT & 0.194 & NT \\
\hline Brown bullhead 2 & 0.282 & 0.102 & 0.451 & 6.84 & $<M D L$ & 0.304 & 0.343 & 7.12 \\
\hline Brown bullhead 3 & 0.195 & $<M D L$ & $<\mathrm{MDL}$ & 4.94 & $<\mathrm{MDL}$ & $<M D L$ & 0.338 & 5.46 \\
\hline Brown bullhead 4 & 0.103 & $<\mathrm{MDL}$ & $<\mathrm{MDL}$ & 3.17 & $<\mathrm{MDL}$ & $<M D L$ & 0.448 & 4.94 \\
\hline Brown bullhead 5 & 0.149 & 0.098 & $<M D L$ & 3.42 & $<M D L$ & $<M D L$ & 0.253 & 4.41 \\
\hline Brown bullhead 6 & 0.144 & $<M D L$ & $<\mathrm{MDL}$ & 4.03 & $<\mathrm{MDL}$ & $<\mathrm{MDL}$ & 0.294 & 5.02 \\
\hline Brown bullhead 7 & 0.132 & $<\mathrm{MDL}$ & 0.297 & 4.25 & $<M D L$ & $<\mathrm{MDL}$ & 0.378 & 4.95 \\
\hline Brown bullhead 8 & 0.195 & $<\mathrm{MDL}$ & $<\mathrm{MDL}$ & 2.67 & $<M D L$ & $<M D L$ & 0.138 & 4.44 \\
\hline Brown bullhead 9 & 0.477 & $<\mathrm{MDL}$ & $<\mathrm{MDL}$ & 2.92 & $<\mathrm{MDL}$ & 0.373 & 0.170 & 5.78 \\
\hline Chain pickerel 1 & 0.124 & $<M D L$ & $<\mathrm{MDL}$ & $<M D L$ & $<M D L$ & $<M D L$ & 0.250 & 6.35 \\
\hline Chain pickerel 2 & 0.366 & $<\mathrm{MDL}$ & $<\mathrm{MDL}$ & 4.37 & $<\mathrm{MDL}$ & 1.42 & 0.465 & 12.7 \\
\hline Largemouth bass & 0.107 & $<\mathrm{MDL}$ & $<\mathrm{MDL}$ & $<M D L$ & $<M D L$ & $<\mathrm{MDL}$ & 0.334 & 4.5 \\
\hline Pumpkinseed 2 & 0.155 & 0.112 & $<\mathrm{MDL}$ & 4.46 & $<\mathrm{MDL}$ & 0.235 & 0.261 & 5.87 \\
\hline \multicolumn{9}{|l|}{ Donahue's Pond } \\
\hline Black crappie 1 & $<\mathrm{MDL}$ & $<\mathrm{MDL}$ & 0.298 & 2.48 & 0.12 & $<\mathrm{MDL}$ & 0.088 & 3.62 \\
\hline Black crappie 2 & $<\mathrm{MDL}$ & $<\mathrm{MDL}$ & 0.343 & 2.42 & $<M D L$ & 0.207 & 0.064 & 4.57 \\
\hline Black crappie 3 & $<M D L$ & 0.104 & 0.286 & 2.39 & 0.099 & $<\mathrm{MDL}$ & 0.135 & 2.36 \\
\hline Black crappie 4 & $<M D L$ & $<\mathrm{MDL}$ & 0.296 & 2.47 & 0.11 & $<\mathrm{MDL}$ & 0.155 & 3.06 \\
\hline Bluegill 1 & $<\mathrm{MDL}$ & $<\mathrm{MDL}$ & 0.29 & 2.42 & 0.13 & 0.266 & 0.061 & 5.9 \\
\hline Bluegill 2 & $<M D L$ & $<\mathrm{MDL}$ & 0.287 & 2.39 & 0.13 & 0.203 & 0.048 & 5.98 \\
\hline Bluegill 3 & $<\mathrm{MDL}$ & $<M D L$ & 0.298 & 3.41 & 0.16 & 0.237 & 0.053 & 5.04 \\
\hline
\end{tabular}


Table 6-4. Metals Analyses of Fish from the Peconic River System and Carmans River, Lower Lake(continued).

\begin{tabular}{|c|c|c|c|c|c|c|c|c|}
\hline \multirow[b]{2}{*}{ Location/Species } & Barium & Chromium & Copper & Iron & Lead & Manganese & Mercury & Zinc \\
\hline & \multicolumn{8}{|c|}{$-\mathrm{mg} / \mathrm{kg}$} \\
\hline Bluegill 4 & 0.275 & $<\mathrm{MDL}$ & 0.287 & 2.39 & 0.14 & 1.01 & 0.105 & 6.17 \\
\hline Bluegill 5 & $<\mathrm{MDL}$ & $<M D L$ & 0.286 & 2.39 & $<M D L$ & $<M D L$ & 0.052 & 5.35 \\
\hline Bluegill 6 & $<M D L$ & $<\mathrm{MDL}$ & 0.3 & 2.5 & 0.1 & 0.238 & 0.055 & 3.28 \\
\hline Bluegill 7 & 0.294 & $<M D L$ & 0.3 & 2.77 & 0.13 & 1.42 & 0.088 & 6.82 \\
\hline Bluegill 8 & $<\mathrm{MDL}$ & $<M D L$ & 0.298 & 2.49 & 0.11 & $<M D L$ & 0.066 & 4.73 \\
\hline Bluegill 9 & $<\mathrm{MDL}$ & $<M D L$ & 0.286 & 2.38 & 0.13 & 0.33 & 0.065 & 3.71 \\
\hline Bluegill 10 & $<\mathrm{MDL}$ & $<\mathrm{MDL}$ & 0.298 & 2.49 & 0.12 & $<M D L$ & 0.082 & 3.78 \\
\hline Brown bullhead 1 & $<\mathrm{MDL}$ & $<M D L$ & 0.299 & 2.38 & 0.79 & $<M D L$ & $<M D L$ & 4.28 \\
\hline Brown bullhead 2 & 0.16 & $<M D L$ & 0.286 & 18.1 & $<M D L$ & 0.543 & 0.028 & 3.55 \\
\hline Brown bullhead 3 & 0.119 & 0.107 & 0.286 & 3.18 & 0.16 & 0.247 & 0.038 & 3.16 \\
\hline Brown bullhead 4 & $<M D L$ & 0.137 & 0.286 & 2.38 & 0.11 & $<M D L$ & 0.037 & 5.12 \\
\hline Brown bullhead 5 & $<M D L$ & $<M D L$ & 0.286 & 2.38 & 0.19 & $<\mathrm{MDL}$ & 0.139 & 2.65 \\
\hline Brown bullhead 6 & $<\mathrm{MDL}$ & $<M D L$ & 0.293 & 2.44 & 0.13 & $<M D L$ & 0.081 & 3.51 \\
\hline Chain pickerel & 0.122 & $<\mathrm{MDL}$ & 0.299 & 2.5 & 0.17 & 0.252 & 0.307 & 6.22 \\
\hline Largemouth bass & $<\mathrm{MDL}$ & $<M D L$ & 0.291 & 2.43 & 0.12 & $<M D L$ & 0.133 & 3 \\
\hline Pumpkinseed 1 & $<\mathrm{MDL}$ & $<M D L$ & 0.295 & 2.46 & 0.13 & 0.312 & NV & 6.55 \\
\hline Pumpkinseed 2 & 0.137 & 0.101 & 0.296 & 4.05 & $<M D L$ & 0.295 & NV & 6.33 \\
\hline Pumpkinseed 3 & $<\mathrm{MDL}$ & $<M D L$ & 0.294 & 2.45 & 0.16 & $<M D L$ & NV & 4.45 \\
\hline Pumpkinseed 4 & 0.266 & $<M D L$ & 0.299 & 3.81 & 0.14 & 0.419 & NV & 6 \\
\hline Pumpkinseed 5 & $<\mathrm{MDL}$ & $<M D L$ & 0.295 & 2.46 & 0.13 & $<M D L$ & NV & 5.77 \\
\hline Pumpkinseed 6 & $<\mathrm{MDL}$ & $<M D L$ & 0.365 & 2.5 & 0.14 & $<M D L$ & NV & 7.16 \\
\hline Pumpkinseed 7 & $<M D L$ & $<M D L$ & 0.297 & 2.48 & 0.31 & $<M D L$ & NV & 5.33 \\
\hline Pumpkinseed 8 & $<\mathrm{MDL}$ & $<M D L$ & 0.298 & 2.48 & 0.17 & $<M D L$ & NV & 5.87 \\
\hline Pumpkinseed 9 & $<\mathrm{MDL}$ & $<M D L$ & 0.297 & 2.48 & $<M D L$ & $<M D L$ & NV & 5.66 \\
\hline Pumpkinseed 10 & $<\mathrm{MDL}$ & $<\mathrm{MDL}$ & 0.287 & 2.39 & 0.12 & $<\mathrm{MDL}$ & NV & 4 \\
\hline \multicolumn{9}{|l|}{ Forge Pond } \\
\hline Black crappie 1 & $<\mathrm{MDL}$ & $<M D L$ & 0.516 & 3.41 & $<\mathrm{MDL}$ & $<M D L$ & 0.266 & 6.34 \\
\hline Black crappie 2 & $<\mathrm{MDL}$ & $<M D L$ & $<\mathrm{MDL}$ & $<M D L$ & $<M D L$ & $<M D L$ & 0.155 & 5.21 \\
\hline Black crappie 3 & 0.142 & $<M D L$ & $<M D L$ & 3.2 & $<M D L$ & $<M D L$ & 0.172 & 5.99 \\
\hline Black crappie 4 & $<\mathrm{MDL}$ & $<M D L$ & $<\mathrm{MDL}$ & 2.56 & $<M D L$ & $<M D L$ & 0.107 & 6.83 \\
\hline Brown bullhead 1 & 0.472 & 0.179 & $<\mathrm{MDL}$ & 16.1 & $<M D L$ & 0.792 & 0.044 & 6.6 \\
\hline Brown bullhead 2 & 0.295 & $<M D L$ & $<\mathrm{MDL}$ & 5.93 & $<M D L$ & 0.334 & 0.089 & 7.05 \\
\hline Brown bullhead 3 & 0.335 & $<M D L$ & 0.415 & 11.1 & 0.12 & 0.629 & 0.035 & 7.86 \\
\hline Brown bullhead 4 & 0.318 & 0.163 & 0.584 & 19.2 & $<M D L$ & 1.82 & 0.026 & 7.58 \\
\hline Brown bullhead 5 & 0.112 & $<M D L$ & 0.539 & 14 & $<\mathrm{MDL}$ & 0.369 & 0.041 & 8.18 \\
\hline Brown bullhead 6 & 0.199 & 0.099 & $<\mathrm{MDL}$ & 6.58 & $<M D L$ & 0.283 & 0.027 & 5.5 \\
\hline Chain pickerel 1 & 0.128 & 0.102 & $<\mathrm{MDL}$ & $<M D L$ & $<\mathrm{MDL}$ & 0.669 & 0.383 & 7.43 \\
\hline Chain pickerel 2 & $<\mathrm{MDL}$ & $<M D L$ & $<\mathrm{MDL}$ & 4.47 & $<M D L$ & $<\mathrm{MDL}$ & 0.346 & 13 \\
\hline Chain pickerel 3 & $<\mathrm{MDL}$ & $<\mathrm{MDL}$ & $<\mathrm{MDL}$ & 2.66 & $<\mathrm{MDL}$ & $<\mathrm{MDL}$ & 0.554 & 11.1 \\
\hline
\end{tabular}


CHAPTER 6: NATURAL AND CULTURAL RESOURCES

Table 6-4. Metals Analyses of Fish from the Peconic River System and Carmans River, Lower Lake(continued).

\begin{tabular}{|c|c|c|c|c|c|c|c|c|}
\hline \multirow[b]{2}{*}{ Location/Species } & Barium & Chromium & Copper & Iron & Lead & Manganese & Mercury & Zinc \\
\hline & \multicolumn{8}{|c|}{$-\mathrm{mg} / \mathrm{kg}-$} \\
\hline Chain pickerel 4 & $<\mathrm{MDL}$ & $<M D L$ & $<\mathrm{MDL}$ & 2.41 & $<\mathrm{MDL}$ & $<M D L$ & 0.532 & 5.39 \\
\hline Chain pickerel 5 & 0.11 & 0.106 & $<M D L$ & 3.34 & $<M D L$ & 0.294 & 0.225 & 10.8 \\
\hline Golden shiner 1 & 13.4 & 0.254 & 0.743 & 31.4 & $<\mathrm{MDL}$ & 21.3 & 0.054 & 30.8 \\
\hline Golden shiner 2 & 4.18 & 0.197 & 0.911 & 34.2 & $<M D L$ & 14.6 & 0.104 & 23.7 \\
\hline Golden shiner 3 & 9.16 & 0.276 & 0.397 & 28.4 & 0.11 & 17.3 & 0.061 & 27 \\
\hline Golden shiner 4 & 7.47 & 0.292 & 0.64 & 29.2 & $<M D L$ & 11.1 & 0.055 & 20.8 \\
\hline Golden shiner 5 & 8.16 & 0.254 & 0.399 & 10.5 & $<M D L$ & 8 & 0.040 & 18.9 \\
\hline Golden shiner 6 & 4.23 & 0.287 & 0.497 & 19.3 & $<M D L$ & 7.34 & 0.075 & 30.8 \\
\hline Largemouth bass 1 & 0.138 & 0.129 & $<\mathrm{MDL}$ & 4.12 & $<M D L$ & 0.222 & 1.040 & 5.28 \\
\hline Largemouth bass 2 & $<\mathrm{MDL}$ & 0.117 & $<\mathrm{MDL}$ & 2.6 & $<M D L$ & $<M D L$ & 0.580 & 4 \\
\hline Largemouth bass 3 & 0.208 & $<M D L$ & $<\mathrm{MDL}$ & 5.65 & $<M D L$ & 0.471 & 0.844 & 6.56 \\
\hline Largemouth bass 4 & $<\mathrm{MDL}$ & $<M D L$ & $<\mathrm{MDL}$ & $<M D L$ & $<M D L$ & $<M D L$ & 0.898 & 4.23 \\
\hline Largemouth bass 5 & $<\mathrm{MDL}$ & 0.102 & $<\mathrm{MDL}$ & $<M D L$ & $<M D L$ & $<M D L$ & 0.287 & 4.83 \\
\hline Pumpkinseed 1 & 0.127 & 0.1 & $<M D L$ & 6.55 & $<M D L$ & 0.445 & 0.198 & 6.57 \\
\hline Pumpkinseed 2 & 0.307 & $<M D L$ & 0.355 & 10.7 & $<\mathrm{MDL}$ & 0.652 & 0.334 & 13.4 \\
\hline Pumpkinseed 3 & 0.261 & $<M D L$ & $<\mathrm{MDL}$ & 3.73 & $<M D L$ & 0.286 & 0.293 & 8.99 \\
\hline Pumpkinseed 4 & 0.143 & $<M D L$ & $<\mathrm{MDL}$ & 7.05 & $<\mathrm{MDL}$ & $<M D L$ & 0.290 & 7.98 \\
\hline Pumpkinseed 5 & 0.297 & 0.129 & $<M D L$ & 5.92 & $<M D L$ & 0.314 & 0.204 & 12 \\
\hline Pumpkinseed 6 & $<\mathrm{MDL}$ & $<M D L$ & $<\mathrm{MDL}$ & $<M D L$ & $<M D L$ & $<M D L$ & 0.194 & 7.5 \\
\hline Yellow perch 1 & 0.151 & $<M D L$ & $<\mathrm{MDL}$ & $<M D L$ & $<M D L$ & 0.43 & 0.087 & 5.75 \\
\hline Yellow perch 2 & 0.166 & 0.100 & $<M D L$ & 3.22 & $<M D L$ & 0.449 & 0.094 & 7.68 \\
\hline Yellow perch 3 & 0.22 & 0.153 & 0.324 & 7.67 & $<\mathrm{MDL}$ & 0.904 & 0.255 & 7.75 \\
\hline Yellow perch 4 & 0.2 & $<M D L$ & $<M D L$ & 3.98 & $<\mathrm{MDL}$ & 1.26 & 0.066 & 8.11 \\
\hline Yellow perch 5 & $<\mathrm{MDL}$ & $<\mathrm{MDL}$ & $<\mathrm{MDL}$ & $<\mathrm{MDL}$ & $<\mathrm{MDL}$ & 0.219 & 0.088 & 4.84 \\
\hline \multicolumn{9}{|c|}{ Swan Pond (Peconic River control location) } \\
\hline Black crappie 1 & 0.172 & $<M D L$ & $<M D L$ & $<M D L$ & $<\mathrm{MDL}$ & 0.718 & 0.086 & 7.32 \\
\hline Black crappie 2 & 0.645 & 0.134 & 0.309 & 2.6 & $<M D L$ & 3.33 & 0.104 & 10.8 \\
\hline Black crappie 3 & 1.67 & 0.231 & $<M D L$ & $<M D L$ & $<M D L$ & 10.4 & 0.121 & 9.59 \\
\hline Black crappie 4 & $<\mathrm{MDL}$ & $<M D L$ & $<\mathrm{MDL}$ & $<M D L$ & $<M D L$ & $<M D L$ & 0.097 & 6.53 \\
\hline Black crappie 5 & $<M D L$ & $<M D L$ & $<M D L$ & $<M D L$ & $<M D L$ & $<M D L$ & 0.080 & 6.6 \\
\hline Brown bullhead 1 & 0.365 & $<M D L$ & 0.737 & 10.1 & $<M D L$ & 3.34 & 0.028 & 7.83 \\
\hline Brown bullhead 2 & 0.234 & $<M D L$ & 0.415 & 5.81 & $<M D L$ & 0.362 & 0.024 & 6.76 \\
\hline Brown bullhead 3 & 0.627 & $<\mathrm{MDL}$ & 0.591 & 7.4 & $<\mathrm{MDL}$ & 1.48 & 0.016 & 10.8 \\
\hline Brown bullhead 4 & 0.268 & 0.109 & 0.322 & 6.42 & $<M D L$ & 0.517 & 0.027 & 6.77 \\
\hline Brown bullhead 5 & 0.304 & $<\mathrm{MDL}$ & 0.413 & 10.8 & $<\mathrm{MDL}$ & 0.595 & 0.006 & 6.72 \\
\hline Chain pickerel 1 & $<M D L$ & 0.109 & 0.731 & 2.5 & $<M D L$ & 0.906 & 0.149 & 11.8 \\
\hline Chain pickerel 2 & $<\mathrm{MDL}$ & $<\mathrm{MDL}$ & 0.503 & 3.7 & $<\mathrm{MDL}$ & 1.79 & 0.133 & 9.45 \\
\hline Chain pickerel 3 & $<\mathrm{MDL}$ & 0.099 & 0.304 & 4.04 & $<\mathrm{MDL}$ & 1.24 & 0.101 & 13.8 \\
\hline Chain pickerel 4 & $<\mathrm{MDL}$ & 0.202 & 0.544 & 2.76 & $<\mathrm{MDL}$ & 0.485 & 0.163 & 16.9 \\
\hline Largemouth bass 1 & $<\mathrm{MDL}$ & $<M D L$ & 0.489 & 3.06 & $<\mathrm{MDL}$ & $<M D L$ & 0.414 & 6.54 \\
\hline
\end{tabular}


Table 6-4. Metals Analyses of Fish from the Peconic River System and Carmans River, Lower Lake (concluded).

\begin{tabular}{|c|c|c|c|c|c|c|c|c|}
\hline \multirow[b]{2}{*}{ Location/Species } & Barium & Chromium & Copper & Iron & Lead & Manganese & Mercury & Zinc \\
\hline & \multicolumn{8}{|c|}{$\mathrm{mg} / \mathrm{kg}$} \\
\hline Largemouth bass 2 & 0.118 & 0.165 & 0.438 & 3.02 & $<M D L$ & $<M D L$ & 0.218 & 6.71 \\
\hline Largemouth bass 3 & 0.154 & 0.111 & $<M D L$ & $<M D L$ & $<M D L$ & 0.54 & 0.196 & 7.38 \\
\hline Largemouth bass 4 & 0.151 & $<M D L$ & $<M D L$ & $<M D L$ & $<M D L$ & 0.59 & 0.171 & 7.61 \\
\hline Pumpkinseed 1 & 0.887 & 0.149 & 0.417 & 6.37 & $<\mathrm{MDL}$ & 4.96 & 0.059 & 16.3 \\
\hline Pumpkinseed 2 & 0.102 & $<M D L$ & $<M D L$ & $<M D L$ & $<M D L$ & $<M D L$ & 0.067 & 7.33 \\
\hline Pumpkinseed 3 & 0.215 & $<\mathrm{MDL}$ & $<M D L$ & 2.73 & $<\mathrm{MDL}$ & 0.687 & 0.071 & 14.7 \\
\hline Pumpkinseed 4 & 0.243 & $<M D L$ & $<M D L$ & $<M D L$ & $<M D L$ & 0.805 & 0.033 & 11.6 \\
\hline Pumpkinseed 5 & 0.164 & $<M D L$ & 0.388 & 3.01 & $<\mathrm{MDL}$ & 0.702 & 0.041 & 13.3 \\
\hline Yellow perch 1 & $<M D L$ & $<M D L$ & 0.438 & $<M D L$ & $<\mathrm{MDL}$ & 1.29 & 0.112 & 4.28 \\
\hline Yellow perch 2 & 0.114 & 0.163 & 0.511 & 2.74 & $<\mathrm{MDL}$ & 0.652 & 0.084 & 6.15 \\
\hline Yellow perch 3 & $<M D L$ & 0.131 & 0.502 & 4.41 & $<\mathrm{MDL}$ & 0.49 & 0.115 & 8.43 \\
\hline Yellow perch 4 & $<M D L$ & $<M D L$ & 0.442 & $<M D L$ & $<M D L$ & 0.658 & 0.115 & 6.19 \\
\hline Yellow perch 5 & 0.158 & 0.186 & 0.453 & $<M D L$ & $<\mathrm{MDL}$ & 1.4 & 0.074 & 7.18 \\
\hline Yellow perch 6 & 0.203 & 0.13 & 0.411 & $<M D L$ & $<\mathrm{MDL}$ & 0.278 & 0.098 & 6.79 \\
\hline \multicolumn{9}{|c|}{ Lower Lake, Carmans River (control location) } \\
\hline Bluegill 1 & NT & NT & NT & NT & NT & NT & 0.044 & NT \\
\hline Bluegill 2 & NT & NT & NT & NT & NT & NT & 0.042 & NT \\
\hline Bluegill 3 & NT & NT & NT & NT & NT & NT & 0.072 & NT \\
\hline Bluegill 4 & NT & NT & NT & NT & NT & NT & 0.041 & NT \\
\hline Bluegill 5 & NT & NT & NT & NT & NT & NT & 0.018 & NT \\
\hline Bluegill 6 & NT & NT & NT & NT & NT & NT & 0.030 & NT \\
\hline Bluegill 7 & NT & NT & NT & NT & NT & NT & 0.027 & NT \\
\hline Largemouth bass 1 & NT & NT & NT & NT & NT & NT & 0.161 & NT \\
\hline Largemouth bass 2 & NT & NT & NT & NT & NT & NT & 0.244 & NT \\
\hline Largemouth bass 3 & NT & NT & NT & NT & NT & NT & 0.073 & NT \\
\hline Largemouth bass 4 & NT & NT & NT & NT & NT & NT & 0.044 & NT \\
\hline Pumpkinseed 1 & NT & NT & NT & NT & NT & NT & 0.042 & NT \\
\hline Pumpkinseed 2 & NT & NT & NT & NT & NT & NT & 0.037 & NT \\
\hline Pumpkinseed 3 & NT & NT & NT & NT & NT & NT & 0.032 & NT \\
\hline Pumpkinseed 4 & NT & NT & NT & NT & NT & NT & 0.082 & NT \\
\hline Pumpkinseed 5 & NT & NT & NT & NT & NT & NT & 0.090 & NT \\
\hline Pumpkinseed 6 & NT & NT & NT & NT & NT & NT & 0.059 & NT \\
\hline Pumpkinseed 7 & NT & NT & NT & NT & NT & NT & 0.062 & NT \\
\hline Pumpkinseed 8 & NT & NT & NT & NT & NT & NT & 0.058 & NT \\
\hline Pumpkinseed 9 & NT & NT & NT & NT & NT & NT & 0.052 & NT \\
\hline \multicolumn{9}{|c|}{$\begin{array}{l}\text { Notes: } \\
\text { See Figure 5-8 for sampling locations. } \\
\text { All fish were analyzed as edible portions (fillets) except for golden shiners, which were analyzed as whole body-composite samples. } \\
\text { MDL = Minimum Detection Limit } \\
\text { NT = parameter not tested due to insufficient sample size. } \\
\text { Letters following sample numbers indicate specific on-site area designation associated with the Peconic River cleanup. }\end{array}$} \\
\hline
\end{tabular}


Due to its known health effects, mercury is the metal of highest concern. Mercury in onsite Peconic River samples ranged from 0.13 $\mathrm{mg} / \mathrm{kg}$ in a brown bullhead to $1.35 \mathrm{mg} / \mathrm{kg}$ in a pumpkinseed. This compares to a range of 0.46 to $0.62 \mathrm{mg} / \mathrm{kg}$ in fish taken in 2006 . The larger range in the 2007 on-site data is due to a larger sample size and larger range in fish size. Off-site Peconic River samples ranged from less than the MDL in a brown bullhead from Donahue's Pond to $1.04 \mathrm{mg} / \mathrm{kg}$ in a largemouth bass from Forge Pond. This range can be compared to $0.02 \mathrm{mg} / \mathrm{kg}$ in bluegill and golden shiner to $0.78 \mathrm{mg} / \mathrm{kg}$ in a brown bullhead taken from the Manor Road area in 2006. The highest 2007 mercury value in the control location on the Carmans River was $0.24 \mathrm{mg} / \mathrm{kg}$. All mercury values were less than the $1.0 \mathrm{mg} / \mathrm{kg}$ consumption standard set by the U.S. Food and Drug Administration, with the exception of the one largemouth bass from Forge Pond, mentioned above.

Values for metals not shown in Table 6-4 because they were at or near MDL were as follows: antimony was found in various species in levels between 0.30 and $1.26 \mathrm{mg} / \mathrm{kg}$ throughout the Peconic River; arsenic and cadmium were not detected in any sample taken from the Peconic River; nickel was recorded in Peconic River fish at levels between $0.10 \mathrm{mg} / \mathrm{kg}$ in a yellow perch from Swan Pond and $2.93 \mathrm{mg} / \mathrm{kg}$ in a brown bullhead taken at Schultz Rd; selenium was found in a yellow perch from Swan Pond at 0.59 $\mathrm{mg} / \mathrm{kg}$; and silver was found in a range from $0.10 \mathrm{mg} / \mathrm{kg}$ in largemouth bass, yellow perch, and golden shiners to $0.20 \mathrm{mg} / \mathrm{kg}$ in brown bullhead from Swan Pond. These reported values and those presented in Table 6-4 are not considered to pose any health risks to humans or animals that might consume the fish.

Table 6-5 shows the results of pesticide and PCB analyses in fish. Only samples and compounds with detectable results are presented. Concentrations of DDE and DDD, which are breakdown products of the pesticide DDT, were found in low levels in both on- and off-site fish sampled in 2007. DDT was found in seven fish from both the Peconic River and Carmans River. DDT ranged from $3.01 \mu \mathrm{g} / \mathrm{kg}$ in a yellow perch to $8.20 \mu \mathrm{g} / \mathrm{kg}$ in a largemouth bass, both from Forge Pond. The levels of pesticides detected did not exceed any established health standards for the consumers of such fish and thus are not considered harmful. DDT was commonly used on Long Island before 1970.

PCBs were found at levels above the MDL in four fish samples taken from the Peconic River system. On site, Aroclor-1254 was found in a single sample at $252 \mu \mathrm{g} / \mathrm{kg}$ in a brown bullhead; off site, at $5.5 \mu \mathrm{g} / \mathrm{kg}$ estimated in a chain pickerel from Swan Pond, $16.5 \mu \mathrm{g} / \mathrm{kg}$ in a brown bullhead from Schultz Rd, and $28 \mu \mathrm{g} / \mathrm{kg}$ in a yellow perch taken from Forge Pond. Aroclor-1242 was found in a concentration of $12.8 \mu \mathrm{g} / \mathrm{kg}$ in the same chain pickerel taken at Swan Pond that also contained Aroclor-1254. Aroclor-1248 was found in two fish at a concentration of $16.1 \mu \mathrm{g} /$ $\mathrm{kg}$ in a brown bullhead taken from Donahue's Pond and $0.01 \mu \mathrm{g} / \mathrm{kg}$ in the same yellow perch from Forge Pond that contained Aroclor- 1254. Historically, PCBs have been found in both fish and sediment at BNL and periodically at other locations in the Peconic River. The cleanup of the Peconic River that was completed in 2005 removed most $\mathrm{PCBs}$ within the sediments.

PCB and pesticide testing will be discontinued in fish samples in 2008 except for fish taken on site at BNL, which will continue to be tested for PCBs. This reduction in analysis is based on several years of data that show mostly the presence of DDT and its breakdown products in low levels. PCB monitoring will continue on site to document the effectiveness of the Peconic River cleanup. The Laboratory may periodically test for PCBs and pesticides in fish to verify the presence/absence in fish tissue.

\subsubsection{Aquatic Sampling}

\subsubsection{Radiological Analysis}

Annual sampling of sediment, vegetation, and freshwater in the Peconic River and a control location on the Carmans River was conducted in 2007. See Chapter 5 for a discussion on water quality and monitoring, and Figure 5-8 for the locations of sampling stations. Additionally refer to Section 6.3.6 for a discussion of sediment and water analysis related to monitoring postcleanup of the Peconic River. Because significant numbers of samples are now taken under 
Table 6-5. Pesticide and PCB Analyses of Fish from the Peconic River System and Carmans River, Lower Lake.

\begin{tabular}{|c|c|c|c|c|c|c|c|c|}
\hline \multirow[b]{2}{*}{ Location/Species } & 4,4"-DDD & 4,4"-DDE & 4,4"-DDT & Dieldrin & $\begin{array}{l}\text { Endrin } \\
\text { aldehyde }\end{array}$ & $\begin{array}{c}\text { Aroclor- } \\
1242\end{array}$ & $\begin{array}{c}\text { Aroclor- } \\
1248\end{array}$ & $\begin{array}{c}\text { Aroclor- } \\
1254\end{array}$ \\
\hline & \multicolumn{8}{|c|}{$\mathrm{mg} / \mathrm{kg}$} \\
\hline \multicolumn{9}{|l|}{ BNL, On Site } \\
\hline Brown bullhead & NT & NT & NT & NT & NT & $<\mathrm{MDL}$ & $<\mathrm{MDL}$ & 252 \\
\hline \multicolumn{9}{|l|}{ Schultz Road } \\
\hline Black crappie & $1.89^{*}$ & 0.00 & $<M D L$ & $<\mathrm{MDL}$ & $<M D L$ & $<M D L$ & $<M D L$ & $<M D L$ \\
\hline Brown bullhead 3 & 5.26 & 0.01 & $<M D L$ & $<M D L$ & $<M D L$ & $<\mathrm{MDL}$ & $<\mathrm{MDL}$ & $<M D L$ \\
\hline Brown bullhead 1 & $<M D L$ & $<M D L$ & $<\mathrm{MDL}$ & $<\mathrm{MDL}$ & $<\mathrm{MDL}$ & $<M D L$ & $<M D L$ & 16.5 \\
\hline Brown bullhead 4 & $3.36^{*}$ & 0.00 & $<\mathrm{MDL}$ & $<\mathrm{MDL}$ & $<\mathrm{MDL}$ & $<M D L$ & $<M D L$ & $<M D L$ \\
\hline Brown bullhead 5 & $<M D L$ & 0.00 & $<M D L$ & $<M D L$ & $<M D L$ & $<M D L$ & $<M D L$ & $<\mathrm{MDL}$ \\
\hline Brown bullhead 6 & $2.81^{*}$ & 0.00 & $<M D L$ & $<\mathrm{MDL}$ & $<\mathrm{MDL}$ & $<M D L$ & $<M D L$ & $<M D L$ \\
\hline Brown bullhead 7 & 10.70 & 0.02 & $<M D L$ & $<M D L$ & $<M D L$ & $<\mathrm{MDL}$ & $<M D L$ & $<\mathrm{MDL}$ \\
\hline Brown bullhead 8 & 4.08 & 0.01 & $<M D L$ & $<M D L$ & $<M D L$ & $<M D L$ & $<M D L$ & $<M D L$ \\
\hline Largemouth bass & 4.93 & 0.00 & $<\mathrm{MDL}$ & $<\mathrm{MDL}$ & $<\mathrm{MDL}$ & $<M D L$ & $<M D L$ & $<\mathrm{MDL}$ \\
\hline Pumpkinseed 2 & $1.54^{*}$ & 0.00 & $<M D L$ & $<M D L$ & $<M D L$ & $<\mathrm{MDL}$ & $<M D L$ & $<\mathrm{MDL}$ \\
\hline \multicolumn{9}{|c|}{ Swan Pond (Peconic River control location) } \\
\hline Black crappie 1 & $<M D L$ & 5.47 & $<M D L$ & $<\mathrm{MDL}$ & $<\mathrm{MDL}$ & $<M D L$ & $<M D L$ & $<\mathrm{MDL}$ \\
\hline Black crappie 2 & $<M D L$ & $1.84^{*}$ & $<M D L$ & $<M D L$ & $<M D L$ & $<M D L$ & $<M D L$ & $<M D L$ \\
\hline Black crappie 3 & 6.05 & 28.60 & $<\mathrm{MDL}$ & $<\mathrm{MDL}$ & $<\mathrm{MDL}$ & $<M D L$ & $<M D L$ & $<M D L$ \\
\hline Black crappie 4 & $<M D L$ & $3.76^{*}$ & $<M D L$ & $<M D L$ & $<M D L$ & $<M D L$ & $<M D L$ & $<M D L$ \\
\hline Black crappie 5 & $<M D L$ & 4.25 & $<M D L$ & $<M D L$ & $<M D L$ & $<M D L$ & $<M D L$ & $<M D L$ \\
\hline Brown bullhead 1 & $<M D L$ & 0.01 & $<\mathrm{MDL}$ & $<\mathrm{MDL}$ & $<\mathrm{MDL}$ & $<M D L$ & $<M D L$ & $<\mathrm{MDL}$ \\
\hline Brown bullhead 2 & 53.80 & 0.07 & 4.12 & $<M D L$ & $<M D L$ & $<M D L$ & $<\mathrm{MDL}$ & $<M D L$ \\
\hline Brown bullhead 3 & 4.62 & 10.10 & $<M D L$ & $<M D L$ & $<M D L$ & $<M D L$ & $<M D L$ & $<M D L$ \\
\hline Brown bullhead 4 & $3.13^{*}$ & 12.70 & $<\mathrm{MDL}$ & $<\mathrm{MDL}$ & $<\mathrm{MDL}$ & $<M D L$ & $<M D L$ & $<\mathrm{MDL}$ \\
\hline Brown bullhead 5 & $<M D L$ & $3.58^{*}$ & $<M D L$ & $<M D L$ & $<M D L$ & $<M D L$ & $<M D L$ & $<M D L$ \\
\hline Chain pickerel 2 & $<M D L$ & $<M D L$ & $<M D L$ & $<M D L$ & $<M D L$ & 12.8 & $<M D L$ & $5.5^{*}$ \\
\hline Chain pickerel 3 & $<M D L$ & $1.76^{*}$ & $<M D L$ & $<M D L$ & $<M D L$ & $<M D L$ & $<M D L$ & $<M D L$ \\
\hline Largemouth bass 1 & $<M D L$ & 9.66 & $<M D L$ & $<M D L$ & $<M D L$ & $<M D L$ & $<M D L$ & $<M D L$ \\
\hline Largemouth bass 2 & $<M D L$ & $1.56^{*}$ & $<\mathrm{MDL}$ & $<\mathrm{MDL}$ & $<M D L$ & $<\mathrm{MDL}$ & $<M D L$ & $<\mathrm{MDL}$ \\
\hline Pumpkinseed 2 & $<M D L$ & 0.00 & $<M D L$ & $<M D L$ & $<M D L$ & $<\mathrm{MDL}$ & $<\mathrm{MDL}$ & $<M D L$ \\
\hline Pumpkinseed 3 & $<M D L$ & 0.00 & $<\mathrm{MDL}$ & $<\mathrm{MDL}$ & $<\mathrm{MDL}$ & $<\mathrm{MDL}$ & $<M D L$ & $<\mathrm{MDL}$ \\
\hline Pumpkinseed 4 & $<\mathrm{MDL}$ & 0.00 & $<M D L$ & $<M D L$ & $<M D L$ & $<\mathrm{MDL}$ & $<\mathrm{MDL}$ & $<M D L$ \\
\hline Pumpkinseed 5 & $<\mathrm{MDL}$ & 0.00 & $<M D L$ & $<M D L$ & $<M D L$ & $<\mathrm{MDL}$ & $<\mathrm{MDL}$ & $<M D L$ \\
\hline Yellow perch 1 & $<M D L$ & $2.38^{*}$ & $<M D L$ & $<M D L$ & $<M D L$ & $<M D L$ & $<M D L$ & $<M D L$ \\
\hline Yellow perch 5 & $<\mathrm{MDL}$ & $1.03^{*}$ & $<M D L$ & $<M D L$ & $<\mathrm{MDL}$ & $<\mathrm{MDL}$ & $<\mathrm{MDL}$ & $<M D L$ \\
\hline Yellow perch 6 & $<\mathrm{MDL}$ & $3.83^{*}$ & $<\mathrm{MDL}$ & $<\mathrm{MDL}$ & $<\mathrm{MDL}$ & $<\mathrm{MDL}$ & $<\mathrm{MDL}$ & $<\mathrm{MDL}$ \\
\hline \multicolumn{9}{|l|}{ Donahue's Pond } \\
\hline Bluegill 6 & $<M D L$ & $3.27^{\star}$ & $<M D L$ & $<M D L$ & $<\mathrm{MDL}$ & $<M D L$ & $<M D L$ & $<M D L$ \\
\hline Brown bullhead 3 & $<M D L$ & $<M D L$ & $<\mathrm{MDL}$ & $<\mathrm{MDL}$ & $<\mathrm{MDL}$ & $<M D L$ & $16.1^{*}$ & $<\mathrm{MDL}$ \\
\hline Brown bullhead 5 & $<\mathrm{MDL}$ & $2.12^{*}$ & $<M D L$ & $<M D L$ & $<M D L$ & $<\mathrm{MDL}$ & $<\mathrm{MDL}$ & $<\mathrm{MDL}$ \\
\hline Pumpkinseed 1 & $3.72^{*}$ & $3.48^{*}$ & $<\mathrm{MDL}$ & $<\mathrm{MDL}$ & $<\mathrm{MDL}$ & $<M D L$ & $<\mathrm{MDL}$ & $<M D L$ \\
\hline
\end{tabular}


Table 6-5. Pesticide and PCB Analyses of Fish from the Peconic River System and Carmans River, Lower Lake(concluded).

\begin{tabular}{|c|c|c|c|c|c|c|c|c|}
\hline \multirow[b]{2}{*}{ Location/Species } & 4,4"-DDD & 4,4"-DDE & 4,4"-DDT & Dieldrin & $\begin{array}{l}\text { Endrin } \\
\text { aldehyde }\end{array}$ & $\begin{array}{c}\text { Aroclor- } \\
1242\end{array}$ & $\begin{array}{c}\text { Aroclor- } \\
1248\end{array}$ & $\begin{array}{c}\text { Aroclor- } \\
1254\end{array}$ \\
\hline & \multicolumn{8}{|c|}{$-\mathrm{mg} / \mathrm{kg}$} \\
\hline \multicolumn{9}{|l|}{ Forge Pond } \\
\hline Black crappie 1 & $2.54^{*}$ & 6.54 & $<M D L$ & $<M D L$ & $<M D L$ & $<\mathrm{MDL}$ & $<M D L$ & $<M D L$ \\
\hline Black crappie 2 & $1.38^{*}$ & $<M D L$ & $<\mathrm{MDL}$ & $<\mathrm{MDL}$ & $<M D L$ & $<\mathrm{MDL}$ & $<\mathrm{MDL}$ & $<\mathrm{MDL}$ \\
\hline Black crappie 3 & $1.91^{*}$ & $3.24^{*}$ & $<M D L$ & $<\mathrm{MDL}$ & $<M D L$ & $<M D L$ & $<M D L$ & $<M D L$ \\
\hline Brown bullhead 1 & 13.60 & 27.40 & $<M D L$ & $2.29^{*}$ & $<\mathrm{MDL}$ & $<M D L$ & $<M D L$ & $<M D L$ \\
\hline Brown bullhead 2 & $3.2^{*}$ & 6.21 & $<M D L$ & $<M D L$ & $<M D L$ & $<M D L$ & $<M D L$ & $<M D L$ \\
\hline Brown bullhead 3 & $3.8^{*}$ & 7.39 & $<\mathrm{MDL}$ & $<M D L$ & $<M D L$ & $<\mathrm{MDL}$ & $<\mathrm{MDL}$ & $<\mathrm{MDL}$ \\
\hline Brown bullhead 4 & $3.11^{*}$ & 5.31 & $<M D L$ & $<\mathrm{MDL}$ & $<M D L$ & $<\mathrm{MDL}$ & $<\mathrm{MDL}$ & $<\mathrm{MDL}$ \\
\hline Brown bullhead 5 & $2.63^{*}$ & 4.91 & $<\mathrm{MDL}$ & $<\mathrm{MDL}$ & $<M D L$ & $<\mathrm{MDL}$ & $<\mathrm{MDL}$ & $<\mathrm{MDL}$ \\
\hline Brown bullhead 6 & 15.80 & 30.80 & $<\mathrm{MDL}$ & $2.1^{*}$ & $<M D L$ & $<\mathrm{MDL}$ & $<M D L$ & $<\mathrm{MDL}$ \\
\hline Chain pickerel 2 & $<\mathrm{MDL}$ & $1.95^{*}$ & $<\mathrm{MDL}$ & $<\mathrm{MDL}$ & $<M D L$ & $<\mathrm{MDL}$ & $<\mathrm{MDL}$ & $<\mathrm{MDL}$ \\
\hline Chain pickerel 5 & $<M D L$ & 4.07 & $<M D L$ & $<\mathrm{MDL}$ & $<M D L$ & $<\mathrm{MDL}$ & $<M D L$ & $<\mathrm{MDL}$ \\
\hline Golden shiner 1 & 34.00 & 24.60 & $<\mathrm{MDL}$ & $1.88^{*}$ & $<M D L$ & $<\mathrm{MDL}$ & $<\mathrm{MDL}$ & $<\mathrm{MDL}$ \\
\hline Golden shiner 2 & 13.10 & 7.99 & $<\mathrm{MDL}$ & $<M D L$ & $<M D L$ & $<M D L$ & $<M D L$ & $<M D L$ \\
\hline Golden shiner 3 & 23.80 & 23.60 & $<\mathrm{MDL}$ & $<\mathrm{MDL}$ & $<\mathrm{MDL}$ & $<\mathrm{MDL}$ & $<\mathrm{MDL}$ & $<\mathrm{MDL}$ \\
\hline Golden shiner 4 & 31.30 & 26.20 & $<\mathrm{MDL}$ & $3.61^{*}$ & $<M D L$ & $<M D L$ & $<M D L$ & $<\mathrm{MDL}$ \\
\hline Golden shiner 5 & 32.70 & 21.10 & $<\mathrm{MDL}$ & 4.48 & $<M D L$ & $<\mathrm{MDL}$ & $<M D L$ & $<\mathrm{MDL}$ \\
\hline Golden shiner 6 & 23.10 & 21.90 & $<M D L$ & $<M D L$ & $<M D L$ & $<M D L$ & $<M D L$ & $<M D L$ \\
\hline Largemouth bass 1 & $1.46^{*}$ & $3.97^{*}$ & 8.20 & $<M D L$ & $<M D L$ & $<M D L$ & $<M D L$ & $<M D L$ \\
\hline Largemouth bass 5 & 0.00 & $3.47^{*}$ & 7.94 & $<M D L$ & $<\mathrm{MDL}$ & $<M D L$ & $<M D L$ & $<M D L$ \\
\hline Pumpkinseed 1 & $3.16^{*}$ & 10.00 & 7.84 & $<M D L$ & $<\mathrm{MDL}$ & $<M D L$ & $<M D L$ & $<M D L$ \\
\hline Pumpkinseed 2 & 4.48 & 6.86 & $<M D L$ & $<M D L$ & $<M D L$ & $<M D L$ & $<M D L$ & $<M D L$ \\
\hline Pumpkinseed 3 & $2.54^{*}$ & $3.33^{*}$ & $<M D L$ & $<M D L$ & $<M D L$ & $<M D L$ & $<\mathrm{MDL}$ & $<M D L$ \\
\hline Pumpkinseed 4 & $1.75^{*}$ & $2.59^{*}$ & $<M D L$ & $<M D L$ & $<M D L$ & $<M D L$ & $<M D L$ & $<M D L$ \\
\hline Pumpkinseed 6 & $<M D L$ & $2.1^{*}$ & $<M D L$ & $<M D L$ & $<\mathrm{MDL}$ & $<M D L$ & $<M D L$ & $<M D L$ \\
\hline Yellow perch 2 & $2.68^{*}$ & 5.56 & $<\mathrm{MDL}$ & $<M D L$ & $<M D L$ & $<M D L$ & $<M D L$ & $<\mathrm{MDL}$ \\
\hline Yellow perch 3 & 15.80 & 48.60 & $3.01^{*}$ & $2.73^{*}$ & $<M D L$ & $<M D L$ & $<M D L$ & $<M D L$ \\
\hline Yellow perch 4 & 11.00 & 25.90 & $<M D L$ & $1.56^{*}$ & $<M D L$ & $<\mathrm{MDL}$ & $<M D L$ & $<M D L$ \\
\hline Yellow perch 5 & 4.09 & 9.87 & $<\mathrm{MDL}$ & $<M D L$ & $<\mathrm{MDL}$ & $<\mathrm{MDL}$ & 0.01 & 28 \\
\hline \multicolumn{9}{|c|}{ Lower Lake, Carmans River (control location) } \\
\hline Bluegill 2 & $2.18^{*}$ & 4.47 & 5.37 & $<M D L$ & $1.69^{*}$ & $<M D L$ & $<M D L$ & $<M D L$ \\
\hline Bluegill 5 & $2.03^{*}$ & 4.88 & $<M D L$ & $<\mathrm{MDL}$ & $<M D L$ & $<\mathrm{MDL}$ & $<\mathrm{MDL}$ & $<\mathrm{MDL}$ \\
\hline Bluegill 7 & $<M D L$ & $2.04^{*}$ & $<M D L$ & $<M D L$ & $<M D L$ & $<M D L$ & $<M D L$ & $<M D L$ \\
\hline Largemouth bass 1 & $<M D L$ & $1.52^{*}$ & 4.92 & $<M D L$ & $<M D L$ & $<M D L$ & $<M D L$ & $<M D L$ \\
\hline Largemouth bass 4 & $<M D L$ & $2.47^{\star}$ & $<M D L$ & $<\mathrm{MDL}$ & $<M D L$ & $<M D L$ & $<M D L$ & $<\mathrm{MDL}$ \\
\hline Pumpkinseed 1 & $<\mathrm{MDL}$ & $1.49^{*}$ & $<\mathrm{MDL}$ & $<\mathrm{MDL}$ & $<M D L$ & $<\mathrm{MDL}$ & $<\mathrm{MDL}$ & $<\mathrm{MDL}$ \\
\hline Pumpkinseed 2 & $<M D L$ & $1.72^{*}$ & $<M D L$ & $<M D L$ & $<\mathrm{MDL}$ & $<M D L$ & $<M D L$ & $<M D L$ \\
\hline Pumpkinseed 6 & $<\mathrm{MDL}$ & $1.17^{*}$ & $<\mathrm{MDL}$ & $<M D L$ & $<\mathrm{MDL}$ & $<\mathrm{MDL}$ & $<\mathrm{MDL}$ & $<\mathrm{MDL}$ \\
\hline \multicolumn{9}{|c|}{$\begin{array}{l}\text { Notes: } \\
\text { Only samples showing detectable levels of pesticides and/or PCBs are } \\
\text { presented. } \\
\text { All fish analyzed as edible portions (fillets) except for golden shiner, } \\
\text { which were analyzed as whole body-composite samples. }\end{array}$} \\
\hline
\end{tabular}


Table 6-6. Radiological Analyses of Aquatic Vegetation and Sediment from the Peconic River and Carmans River System, Lower Lake.

\begin{tabular}{|c|c|c|}
\hline Location/Sample Type & \multicolumn{2}{|c|}{$-\mathrm{pCi} / \mathrm{g} \longrightarrow$} \\
\hline \multicolumn{3}{|l|}{ BNL, On Site } \\
\hline Aquatic vegetation & $40.9 \pm 3.72$ & ND \\
\hline Water & ND & ND \\
\hline \multicolumn{3}{|l|}{ Donahue's Pond } \\
\hline Aquatic vegetation & $0.35 \pm 0.09$ & $0.02 \pm 0.00$ \\
\hline Sediment & $0.53 \pm 0.36$ & $0.06 \pm 0.03$ \\
\hline Water & ND & ND \\
\hline \multicolumn{3}{|l|}{ Forge Pond } \\
\hline Aquatic vegetation & $1.93 \pm 0.21$ & $0.02 \pm 0.01$ \\
\hline Sediment & $2.78 \pm 0.45$ & $0.14 \pm 0.02$ \\
\hline \multicolumn{3}{|c|}{ Swan Pond (Peconic River control location) } \\
\hline Aquatic vegetation & $2.97 \pm 0.35$ & $0.03 \pm 0.01$ \\
\hline Sediment & $2.39 \pm 1.13$ & $1.04 \pm 0.15$ \\
\hline \multicolumn{3}{|c|}{ Lower Lake, Carmans River (control location) } \\
\hline Aquatic vegetation & NR & ND \\
\hline Sediment & NR & $0.77 \pm 0.20$ \\
\hline \multicolumn{3}{|c|}{$\begin{array}{l}\text { Notes: } \\
\text { Cs- } 137=\text { cesium- } 137 \\
\text { K- } 40=\text { potassium- } 40 \\
\text { ND = not detected } \\
\text { NR = not reported } \\
\text { Aquatic vegetation is reported as wet weight except for BNL sample } \\
\text { reported dry. } \\
\text { Sediment samples are reported on a dry weight basis. }\end{array}$} \\
\hline
\end{tabular}

this monitoring program, fewer samples are being taken through routine surveillance monitoring, to reduce duplication of effort.

Table 6-6 summarizes the radiological data. Low levels of Cs-137 were documented in sediments and vegetation at Donahue's Pond, Swan Pond, and Forge Ponds, while sediment samples taken at Lower Lake on the Carmans River only had low levels of Cs-137 detected.

\subsubsection{Metals in Aquatic Samples}

Metals analyses (Table 6-7) were conducted on aquatic vegetation and sediments from the Peconic River and Carmans River. Most of the data indicate metals at background levels. The standard used for comparison of sediments is the SCDHS soil cleanup objectives for heavy metals. Vegetation results are compared to soil cleanup standards, because metals in vegeta- tion may accumulate via uptake from sediment. In general, metals are seen in vegetation at levels lower than in associated sediment.

Other metals analyzed for, but not listed in Table 6-7 include antimony, arsenic, beryllium, cadmium, magnesium, potassium, selenium, sodium, and thalium. In general, levels of these metals are either below detection limits, below action levels or cleanup objectives, or, like sodium, are fairly common in the environment. Beryllium was detected in sediment from Donahue's Pond at $1.11 \mathrm{mg} / \mathrm{kg}$, which is just below the SCDHS cleanup objectives but well below action levels. Cadmium was found in sediments at Swan Pond at a concentration of $1.75 \mathrm{mg} / \mathrm{kg}$ which, like beryllium, is above cleanup objectives but well below SCDHS action levels. Lead was found to be above cleanup objectives at both control locations, but it was well below any action levels. Nickel was the only other metal to be found above cleanup objectives and was found at a concentration of $14.4 \mathrm{mg} / \mathrm{kg}$ in sediments from the Lower Lake control location.

\subsubsection{Pesticides and PCBs in Aquatic Samples}

Pesticides and PCBs analyses of aquatic samples continue to indicate the presence of DDT and its breakdown products in low levels in sediments of Swan Pond and Forge Pond. No pesticides or PCBs were detected in aquatic vegetation sampled at all locations. In general, DDT and its breakdown products appear to be slowly declining. Routine vegetation and sediment samples were not taken from on-site portions of the Peconic River, due to extensive post-cleanup monitoring associated with cleanup efforts.

\subsubsection{Peconic River Post-Cleanup Monitoring}

Sediment from the Peconic River was remediated in 2004 and 2005 to remove mercury and associated contaminants from the river. The cleanup of sections of the river on site focused on sediment in known depositional areas. The goal of the cleanup was to reduce the average mercury concentrations on site to less than $1 \mathrm{mg} / \mathrm{kg}$, with an overall goal to reduce mercury concentrations in the remediated areas, both on site and off site, to less than $2 \mathrm{mg} / \mathrm{kg}$. On-site remediation efforts resulted in a 96 per- 


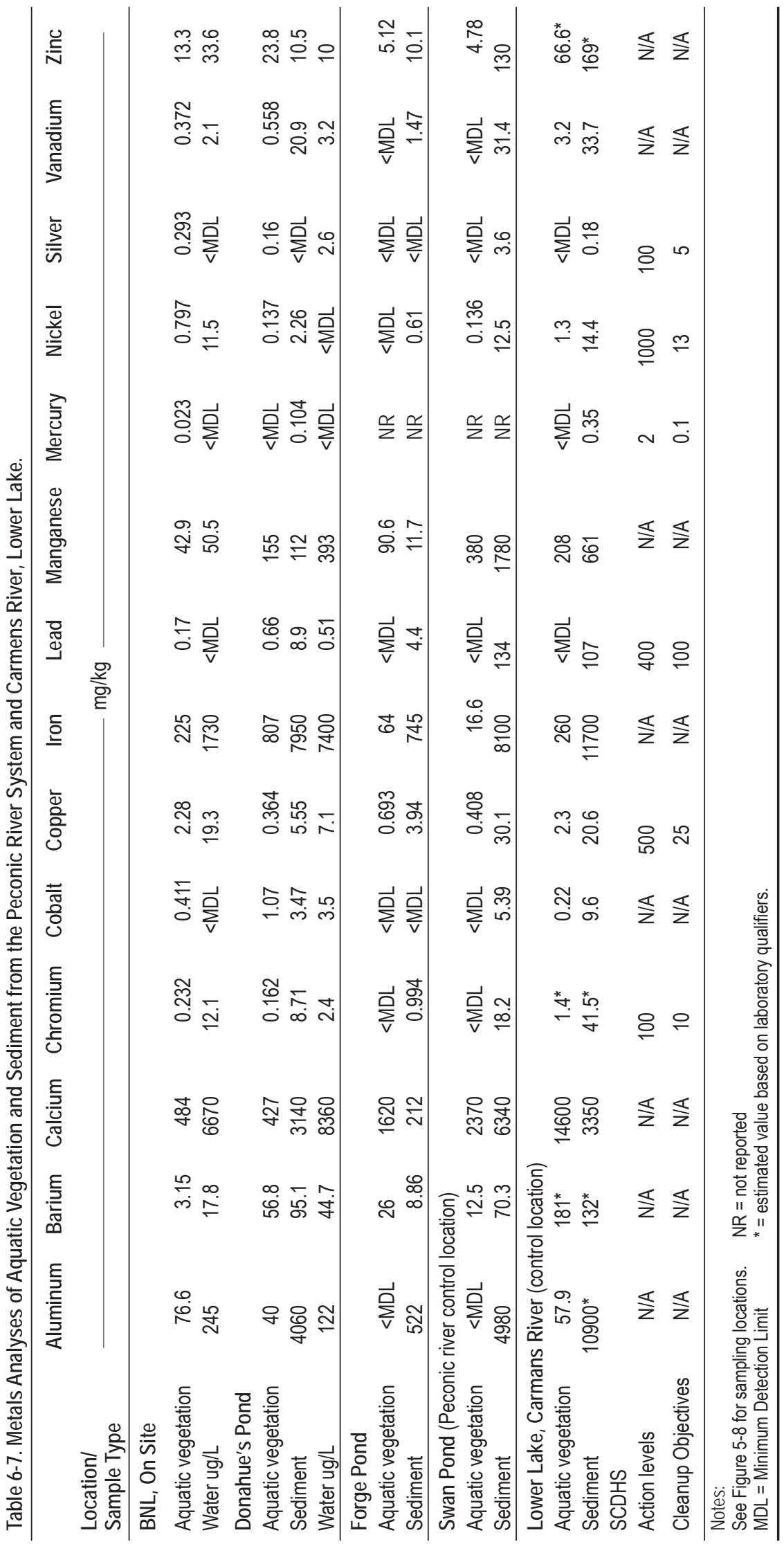

cent reduction in average mercury concentrations in river sediments, from approximately $4.6 \mathrm{mg} / \mathrm{kg}$ to $0.2 \mathrm{mg} / \mathrm{kg}$ (Envirocon, 2005).

Cleanup of off-site locations focused on a more stringent cleanup target that would allow the greatest flexibility for use as County parkland or for potential development. Sediment was removed from ponded areas where methylation leading to bioaccumulation is most likely to occur, as well as other areas containing higher concentrations of contamination east of the BNL property line to sections of the river upstream and downstream of Manor Road. The cleanup goal was to reduce average mercury concentrations within the sediment to less than $0.75 \mathrm{mg} / \mathrm{kg}$, with an overall mercury concentration goal of less than $2 \mathrm{mg} / \mathrm{kg}$ following the cleanup. Off-site remediation efforts resulted in a 95 percent reduction in average mercury concentrations in river sediments downstream of the BNL property line, from approximately $1.8 \mathrm{mg} / \mathrm{kg}$ to $0.09 \mathrm{mg} / \mathrm{kg}$, excluding the Manor Road area, which had an 83 percent reduction, from $1.08 \mathrm{mg} / \mathrm{kg}$ to $0.19 \mathrm{mg} / \mathrm{kg}$ (Envirocon, 2005).

The Laboratory and DOE are committed to a multi-year post-cleanup sampling of sediment, surface water, fish, and wetland restoration. Sampling results for 2007 are summarized below. Detailed information on 2007 sampling results can be found in the 2007 Peconic River Monitoring Report (BNL, 2008).

\subsubsection{Sediment Sampling}

Sediment was sampled in June 2007 at 16 Peconic River sampling stations on site and 14 sampling stations off site. Ninety-seven percent of the 30 annual sediment samples collected in 2007 met the mercury clean- 
up goal of $2.0 \mathrm{mg} / \mathrm{kg}$. One sample exceeded the $2.0 \mathrm{mg} / \mathrm{kg}$ goal. The sample results were shared with NYSDEC, EPA, and SCDHS. In August 2007, additional sediment samples were taken from transects upstream and downstream of two stations that had concentrations of mercury higher than $2.0 \mathrm{mg} / \mathrm{kg}$ during the 2006 annual sediment sampling. The August 2007 sample results indicated that mercury concentrations exceeded $2.0 \mathrm{mg} / \mathrm{kg}$ in two relatively small areas. Further evaluation of these areas will include additional sediment and surface water sampling in 2008.

\subsubsection{Water Column Sampling}

Surface water was analyzed for total mercury and methylmercury at 20 Peconic River sampling stations (see Figure 6-4) and one reference station on the Connetquot River. Samples were taken in both June and August. The 2007 June and August concentrations of total mercury were generally less than the respective 2003 pre-cleanup total mercury concentrations. Although the June 2007 methylmercury concentrations were generally higher than the June 2003 pre-cleanup methylmercury concentrations, the August 2007 methylmercury samples were generally lower than the August 2003 concentrations. Methylmercury samples collected from the STP effluent indicated that the STP is not a significant source of methylmercury to the Peconic River. However, total mercury samples collected from the Peconic River upstream and downstream of the STP and from the STP effluent indicated that the STP effluent does add mercury to the Peconic River at concentrations greater than the total mercury concentration upstream of the STP.

\subsubsection{Fish Sampling}

In 2007, fish were collected from Area A downstream of the STP, Area C, Area D near North Street, Schultz Road, the Manor Road area, and Donahue's Pond. The average mercury concentration among all fish was $0.32 \mathrm{mg} / \mathrm{kg}$. The EPA criterion for methyl mercury concentration in fish tissue is $0.3 \mathrm{mg} / \mathrm{kg}$. The average PCB concentration in fish in 2007 for all locations was below the detection limit. The 2007 average value for Cs-137 was also substantially lower than previous values.

\subsubsection{Wetland Sampling}

The annual wetland invasive plant survey and removal operations were conducted by Roux Associates, Inc. during July 2007. Twentyseven 42-gallon bags of Phragmites stalks and rhizomes were removed from the previously remediated sections of the Peconic River on BNL property, and 14 bags of Phragmites were removed from the off-site remediated sections of the river.

As of September 2006, the Laboratory met and exceeded the DEC Equivalency Permit requirements for "cover" growth in on-site marshy areas. A target percent cover of 65 percent in the low marsh was achieved, with an overall average for all 64 transects of 92 percent. No low marsh cleanup area had less than 79 percent cover, and percent cover of invasive species was less than the permit limit of 10 percent in any one wetland restoration. This was achieved with an average percent cover (for permit-specified invasive wetlands plants) of less than 1 percent across all cleanup areas.

In August, 2007, DEC toured the Peconic River wetlands and determined that the DEC Permit Equivalency conditions had been met. Monitoring of invasive species will continue until 2008, at which time BNL will evaluate all wetland restoration and invasive species surveys and control operations since completion of the cleanup in 2005. Based on the results of the evaluation, BNL may request EPA's approval that all Peconic River federal wetland restoration requirements have been met.

\subsubsection{Vegetation Sampling}

\subsubsection{Garden Vegetables}

On-site sampling of garden vegetables continued in 2007 (Table 6-8). Samples of zucchini, cucumber, tomato, pepper, and eggplant were analyzed for Cs-137 content. This radionuclide was not detected in any vegetable sample, but was detected in soils at very low levels $(0.26$ $\mathrm{pCi} / \mathrm{g})$. Sampling of off-site farm vegetation was discontinued in 2003 because historical data have consistently indicated the absence of BNL- 
related radionuclides in off-site vegetation. Confirmatory sampling (done approximately every 5 years) will be conducted off site to obtain data on farm vegetables in 2008 .

\subsubsection{Grassy Plants}

In 2003, grassy vegetation sampling was converted to a graded approach and was linked to other sampling programs. As an example of this approach, vegetation sampling would be conducted only if routine air sampling indicated that radionuclides had been released and deposited on soil and vegetation. Periodic confirmatory sampling of grassy vegetation was conducted in 2007. Results of this sampling are presented in Table 6-8.

Eleven samples of grassy vegetation from various lawn and cleanup areas across the Laboratory and one off-site sample for comparison were taken. None of the vegetation samples had detectable concentrations of Cs-137.

\subsection{OTHER MONITORING}

\subsubsection{Soil Sampling}

Soil sampling uses the same graded approach as that used for grassy vegetation sampling and was removed from the basic monitoring protocols in 2003. Confirmatory soil sampling was conducted along with the grassy vegetation sampling mentioned above. Soil samples from each location of a vegetation sample were taken and the results of the analysis are presented in Table 6-8. Soil concentrations of Cs-137 ranged from 0.04 to $4.47 \mathrm{pCi} / \mathrm{g}$ dry weight in various locations. This is compared to $0.26 \mathrm{pCi} / \mathrm{g}$ dry weight found at the NYSDEC game farm in Ridge. Most samples were considered to be at or below background levels, with the exception of the sample taken near Building 515. This location was one of the sites of landscape soil cleanup in 2000 and 2001. The elevated values are likely due to soil disturbance. A review of the data with the BNL Radiological Controls group indicated no concern for human activities on or adjacent to this location.

\subsubsection{Basin Sediments}

A 5-year testing cycle for basin sediment samples was established in 2003. There are 14
Table 6-8. Radiological Analyses of Garden Vegetables, Grassy Vegetation, and Associated Soils.

\begin{tabular}{|c|c|c|c|}
\hline Location & Matrix & $\begin{array}{l}\mathrm{K}-40 \\
\mathrm{pCi} / \mathrm{g}\end{array}$ & $\begin{array}{c}\text { Cs-137 } \\
\text { pCi/g }\end{array}$ \\
\hline \multicolumn{4}{|l|}{ Garden Vegetables } \\
\hline \multirow[t]{6}{*}{ BNL Garden } & Cucumber & $1.69 \pm 0.19$ & ND \\
\hline & Eggplant & $1.99 \pm 0.33$ & ND \\
\hline & Pepper & $1.71 \pm 0.21$ & ND \\
\hline & Tomato & $2.54 \pm 0.26$ & ND \\
\hline & Zuccini & $1.58 \pm 0.19$ & ND \\
\hline & Soil & $5.25 \pm 0.98$ & $0.26 \pm 0.06$ \\
\hline \multicolumn{4}{|l|}{ Grassy Vegetation } \\
\hline \multirow[t]{2}{*}{ Bldg. 490, back lawn } & Vegetation* & $14.1 \pm 4.1$ & \\
\hline & Soil & $6.55 \pm 0.59$ & $0.29 \pm 0.03$ \\
\hline \multirow[t]{2}{*}{ Bldg. 30, front lawn } & Vegetation* & $23.6 \pm 7.5$ & ND \\
\hline & Soil & $10.80 \pm 0.91$ & $0.04 \pm 0.01$ \\
\hline \multirow[t]{2}{*}{ Guest House, front lawn } & Vegetation* & $26.50 \pm 6.10$ & ND \\
\hline & Soil & $6.25 \pm 0.56$ & $0.30 \pm 0.03$ \\
\hline \multirow[t]{2}{*}{ NYSDEC Game Farm } & Vegetation* & $24.10 \pm 7.25$ & ND \\
\hline & Soil & $4.77 \pm 0.51$ & $0.26 \pm 0.03$ \\
\hline \multirow[t]{2}{*}{ Bldg. 515, front lawn } & Vegetation* & $14.90 \pm 6.15$ & ND \\
\hline & Soil & $9.43 \pm 0.72$ & $4.47 \pm 0.31$ \\
\hline \multirow[t]{2}{*}{ Bldg. 355, east lawn } & Vegetation* & $13.40 \pm 6.41$ & ND \\
\hline & Soil & $9.41 \pm 0.76$ & $0.53 \pm 0.04$ \\
\hline \multirow{2}{*}{$\begin{array}{l}\text { Cornell Ave. and } \\
\text { Upton Rd., } \\
\text { no-mow area }\end{array}$} & Vegetation* & $8.69 \pm 4.53$ & ND \\
\hline & Soil & $5.16 \pm 0.45$ & $0.21 \pm 0.02$ \\
\hline \multirow[t]{2}{*}{650 Sump } & Vegetation* & $7.54 \pm 4.08$ & ND \\
\hline & Soil & $5.74 \pm 0.50$ & $0.16 \pm 0.02$ \\
\hline \multirow[t]{2}{*}{ North of 5th Ave. } & Vegetation* & $4.51 \pm 3.03$ & ND \\
\hline & Soil & $6.42 \pm 0.50$ & $1.01 \pm 0.08$ \\
\hline \multirow[t]{2}{*}{ Biology Fields } & Vegetation* & $11.30 \pm 6.54$ & ND \\
\hline & Soil & $7.14 \pm 0.57$ & $0.09 \pm 0.02$ \\
\hline \multirow[t]{2}{*}{ Near basin HTW } & Vegetation* & $9.96 \pm 7.42$ & ND \\
\hline & Soil & $6.46 \pm 0.63$ & $0.18 \pm 0.02$ \\
\hline \multicolumn{4}{|c|}{$\begin{array}{l}\text { Notes: } \\
\text { Garden vegetables are reported as wet weight values. } \\
\text { Grassy vegetation is reported as dry weight values. } \\
\text { Cs- } 137=\text { cesium- } 137 \\
\text { K- } 40=\text { potassium- } 40 \\
{ }^{*}=\text { estimated value for K- } 40 .\end{array}$} \\
\hline
\end{tabular}

basins associated with outfalls that receive discharges permitted under the State Pollutant Discharge Elimination System (SPDES) permit (see Figure 5-6 for outfall locations). Basin sediments were sampled in 2007 and results are presented in Tables 6-9 and 6-10. Since there have not been radiological concerns with discharges to these basins, analysis of basin sediments was limited to PCBs, metals, and semi-volatile organic chemicals. 
CHAPTER 6: NATURAL AND CULTURAL RESOURCES

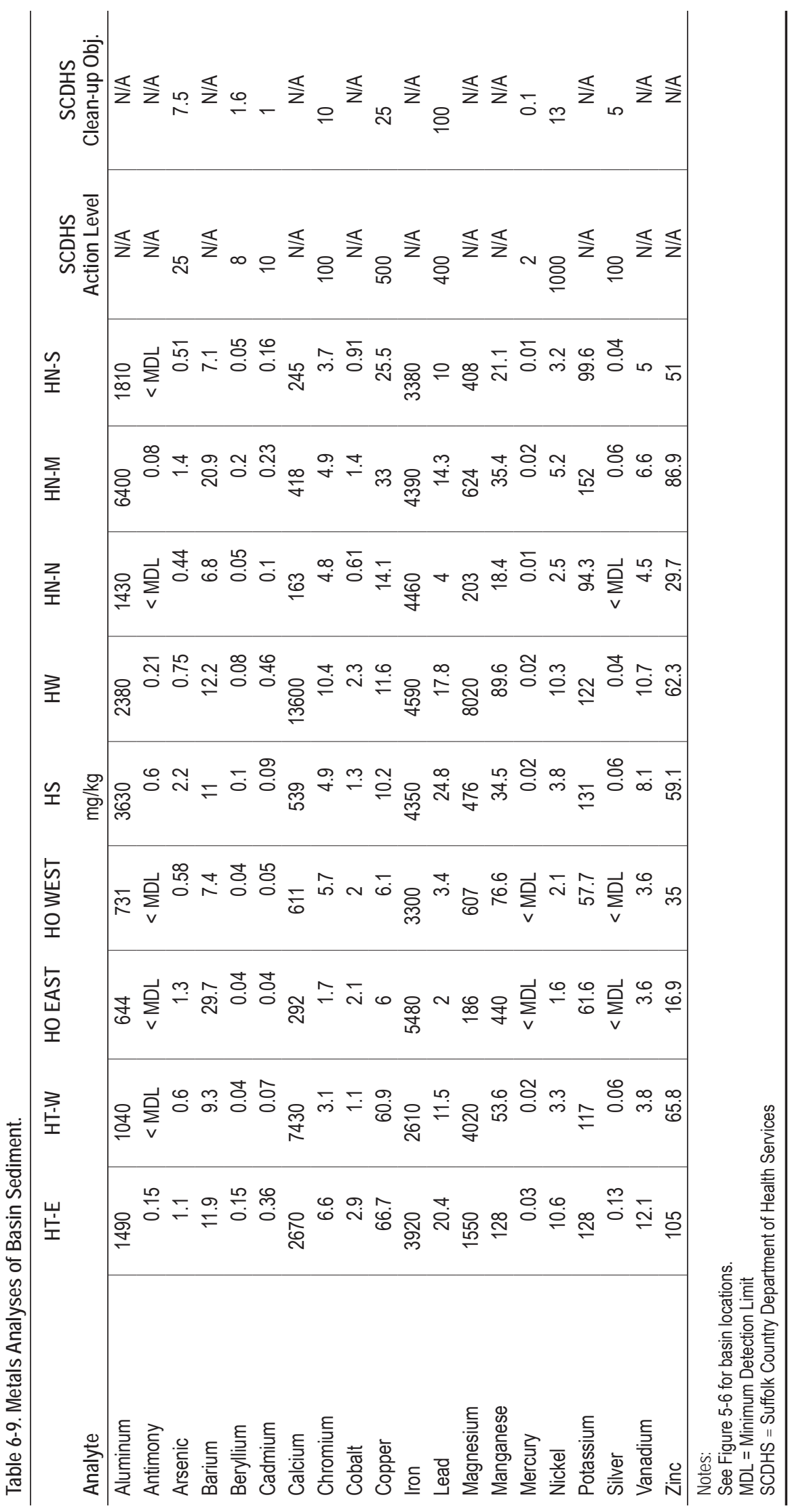

Analysis of basin sediments for PCBs indicated the continued presence of Aroclor-1254 and Aroclor-1260 at concentrations of 56 and $96 \mu \mathrm{g} / \mathrm{kg}$, respectively, in Basin HW (Weaver Road Basin). Aroclor-1254 was also present in basin HT-E at a concentration of $93 \mu \mathrm{g} / \mathrm{kg}$. These values are within the range of values previously detected in this basin.

Results of metals analysis of basin sediments are presented in Table 6-9. Of all metals having SCDHS cleanup objectives, only chromium was detected slightly above the target of $10 \mathrm{mg} / \mathrm{kg}$, with a value of $10.4 \mathrm{mg} / \mathrm{kg}$ in basin HW; this is well below the action level of $100 \mathrm{mg} / \mathrm{kg}$. While not a matter of concern, basin HW showed a marked increased in values of calcium and magnesium, compared to values obtained in 2002. Calcium increased from $1,630 \mathrm{mg} / \mathrm{kg}$ in 2002 to $13,600 \mathrm{mg} / \mathrm{kg}$ in 2007. Magnesium increased from $1,400 \mathrm{mg} / \mathrm{kg}$ to $8,020 \mathrm{mg} / \mathrm{kg}$ in the same period. The increase in these two metals is likely due to stormwater runoff from the former warehouse area. Many of the old World War II-era warehouses have been demolished over the past several years as new facilities have been installed. The removal of concrete foundations left dust that was likely carried by stormwater to basin HW.

Analysis of basin sediments for semi-volatile organic compounds resulted in positive results for a number of compounds associated with road runoff and the combustion of fossil fuels. Table 6-10 presents the results of analysis and only shows compounds that were found in one or more ba- 
sins. Several of the compounds listed were above SCDHS action levels in basins HO and HT-E. The sampling occurred late in the year and the basins could not be resampled before the end of the year. Therefore the basins were scheduled to be re-sampled early in 2008, in coordination with SCDHS.

\subsubsection{Chronic Toxicity Tests} Under the SPDES discharge permit, BNL conducted chronic toxicity testing of the STP effluents. Results of this testing are discussed in Chapter 3, Section 3.6.1.1. Testing will continue in 2008.

\subsubsection{Radiological and Mercury Monitoring of Precipitation}

As part of the BNL Environmental Monitoring Program, precipitation samples were collected quarterly at air monitoring Stations P4 and S5 (see Figure 4-3 for station locations), and were analyzed for radiological content and total mercury. Four samples were taken from each of these two stations in 2007. Gross alpha activity measurements were above the MDL at both $\mathrm{P} 4$ and S5 in January 2007. Values were estimated at 1.67 and $1.71 \mathrm{pCi} / \mathrm{L}$ from the two stations, respectively.

Gross beta activity was measured in samples in all four quarters from both stations. In general, radioactivity in precipitation comes from naturally occurring radionuclides in dust and from activation products that result from solar radiation. Location P4 had a maximum gross beta activity level of $4.8 \mathrm{pCi} / \mathrm{L}$, with an average of $3.84 \mathrm{pCi} / \mathrm{L}$. Location S5

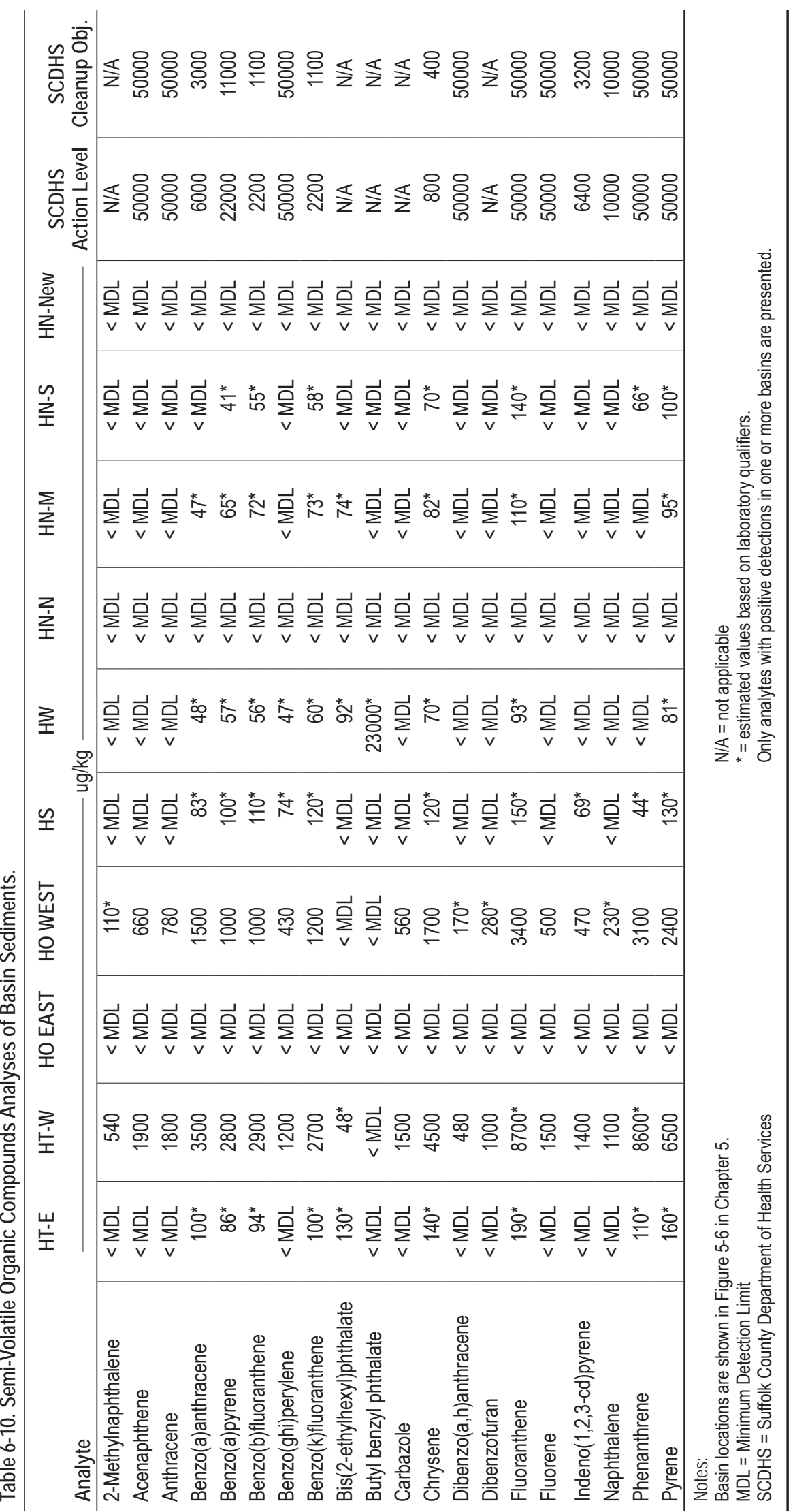


had a maximum gross beta activity level of 6.7 $\mathrm{pCi} / \mathrm{L}$, with an average of $4.53 \mathrm{pCi} / \mathrm{L}$. Gross beta activity values were within the range of values historically observed at these two locations. Beryllium-7 (Be-7) was the only radionuclide found above detection levels in precipitation samples. Be-7 was found during the second quarter sampling period at $39.4 \mathrm{pCi} / \mathrm{L}$ in rain from station $\mathrm{S} 5$, and at $49.6 \mathrm{pCi} / \mathrm{L}$ in rain from station $\mathrm{P} 4$. Be-7 is produced in the atmosphere by cosmic radiation and is periodically found in precipitation.

Beginning in 2006, BNL began testing precipitation for low level mercury in order to document the effect of atmospheric deposition of mercury on the Peconic River. Low level mercury analysis of precipitation indicated that atmospheric deposition of mercury ranged from non-detectable quantities in samples taken in January and May from Stations P4 and S5 to $13.5 \mathrm{ng} / \mathrm{L}$ and $13.2 \mathrm{ng} / \mathrm{L}$, respectively.

\subsection{WILDLIFE PROGRAMS}

BNL sponsors a variety of educational and outreach activities involving natural resources. These programs are designed to help participants understand the ecosystem and to foster interest in science. Wildlife programs are conducted at BNL in collaboration with DOE, local agencies, colleges, and high schools. Ecological research is also conducted on site to update the current natural resource inventory, gain a better understanding of the ecosystem, and guide management planning.

In 2007, the Environmental and Waste Management Services Division (EWMSD) and FERN hosted a total of 16 interns and one faculty member. Interns consisted of a high school intern, 11 undergraduate interns, and four school teachers during the summer. FERN also hosted two of the undergraduate interns for the development of Freshwater Wetland Health Monitoring Protocols. Two of the undergraduate interns worked with a faculty member from Southern University at New Orleans, as part of the Faculty and Student Teams Program. Interns worked on a variety of projects: surveying dragonflies and damselflies, radio tracking turtles, analyzing the water chemistry of coastal plain ponds, investigating turtle and amphibian diseases, inves- tigating the loss of the southern leopard frog on Long Island, genetics of resident gray and red fox at BNL, and population health of the banded sunfish. Teachers conducted mark-recapture and distribution studies on tiger beetles and burying beetles. Teachers also participated in a weeklong workshop in environmental monitoring under the Open Space Stewardship Program, which is managed by the BNL Office of Education Programs and partially funded by FERN. A limited discussion concerning each project is presented below.

An intern continued the long-term work on the identification and distribution of dragonflies and damselflies (Order Odonata) that was started in 2003, and expanded the project of using simple mark-recapture techniques for determining population estimates of dragonflies. These aquatic insects are common around the ponds and Peconic River on site. The distribution of aquatic insects is useful for monitoring the health of aquatic systems. In addition, results from the Odonate surveys will supplement the New York State Odonate Atlas. The number of species identified to date is 60 . The state atlas project will continue for another year, as will the Laboratory's surveys for Odonates.

In 2005, three eastern box turtles were found in one of BNL's many ponds. All three turtles had a fairly common infection of the ear. The turtles were taken to a wildlife rehabilitator for treatment and care. Two of the turtles subsequently died of their infections and their tissues were sent for analysis. In the analysis, an iridovirus implicated in amphibian declines was isolated. This resulted in a summer intern project started in 2006 and continued in 2007, with the help of a high school intern, in which samples from eastern box turtles were taken for virus identification and a radio telemetry study was conducted to look at range overlap. Range overlap is important to determine the potential for infected turtles to encounter non-infected turtles and transmit the virus. The study was conducted by an intern from Maine and provided indication of significant territorial overlap between individual turtles within a given area. This poses a potential problem if any of the turtles is carrying a virus. 
Another intern continued working with a $\mathrm{Ph}$.D. candidate from Rutgers University on the distribution of the southern leopard frog and chytrid fungus on Long Island. The southern leopard frog has had precipitous population declines, and the focus was to attempt to find existing populations of this frog and to document whether or not chytrid fungus is present in other frog species across Long Island. Unfortunately, the southern leopard frog still has not been found in any of the water bodies investigated. A second part of this work was to look at the potential effectiveness of reintroduction of the frog through cage rearing experiments which looked at the growth and survival of larvae in different wetlands.

Two interns revisited a project conducted in 2005 to look at the population health of the banded sunfish in an isolated pond on site. This effort is necessary to ensure the continued presence of this New York State threatened species and potentially use the protected population as a source for reintroductions in the future. This project is expected to be expanded with the help of the NYSDEC Inland Fisheries unit in 2008 to verify the distribution of this rare fish across eastern Long Island in preparation for establishing a recovery plan.

The Faculty and Student Team (FaST), along with an intern under the Science Undergraduate Laboratory Internship (SULI) program, conducted extensive tests of approximately 30 ponds across eastern Long Island looking at metals in sediments and at water quality parameters. The work facilitates the development of criteria for selecting ponds for wetland health monitoring based on their distance from disturbing factors like roads and development. This work is also important in assessing the longterm effects of acid rain.

Four teachers participating in the Academies Creating Teacher Scientists (ACTS) program worked on developing simple outdoor experiments that can be utilized with biology and environmental classes. The teachers established mark-recapture studies on several species of tiger beetles and with burying beetles. As mentioned above, the teachers also attended a week-long workshop under the Open Space
Stewardship Program (OSSP) called "Gaining Research Experience in the Environment (GREEN) Institute," where they shared their expertise with approximately 20 other teachers participating in OSSP so they could discuss the program within their home schools. The OSSP is expected to grow throughout Suffolk County to foster a sense of stewardship in students and to gather much-needed environmental data on numerous open space parcels throughout the county.

Another of the undergraduate students continued working on a project to isolate genetic material from fox droppings. This non-invasive genetic technique is being utilized to look at the inter-relatedness of numerous fox families living on site, and to try to distinguish between red and gray fox. The gray fox is known to live on site, but is rarely seen. Once thought to be extirpated from Long Island, a gray fox that had been struck by a car was found on site in 2004 . Using non-invasive genetics techniques may also allow researchers to estimate population size and distribution of these two species.

FERN hosted two summer students who assisted in the development and testing of monitoring protocols for determining the health of wetlands within the Long Island Central Pine Barrens. The students' work, along with the monitoring protocols, is available on the FERN website at www.fern-li.org.

Members of EWMSD and other BNL departments volunteered as speakers for schools and civic groups and provided on-site ecology tours. EWMSD also hosted several environmental events in association with Earth Day. In October, BNL hosted the Twelfth Annual Pine Barrens Research Forum for ecosystems researchers to share and discuss their results.

The Laboratory also hosted the annual Wildland Fire Academy, offered by NYSDEC and the Central Pine Barrens Commission. Using the Incident Command System of wildfire management, this academy trains fire fighters in the methods of wildland fire suppression, prescribed fire, and fire analysis. BNL has developed and is implementing a Wildland Fire Management Plan. While plans were prepared for conducting a prescribed fire during the Academy, the 
conditions did not meet the requirements of the prescription. Post-fire monitoring on previous fires that was conducted in 2007 indicates that prescribed fires have been somewhat effective at opening up the understory to allow forest regeneration. The Laboratory intends to continue the use of prescribed fire for fuel and forest management in the future, and is working with NYSDEC and The Nature Conservancy to prepare additional prescriptions for a larger portion of the northern and eastern sections of the BNL property.

\subsection{CULTURAL RESOURCE ACTIVITIES}

The BNL Cultural Resource Management (CRM) Program ensures that the Laboratory fully complies with the numerous cultural resource regulations. The Cultural Resource Management Plan for Brookhaven National Laboratory (BNL, 2005) guides the management of all of BNL's historical resources. Along with achieving compliance with applicable regulations, one of the major goals of the CRM program is to fully assess both known and potential cultural resources. The range of the Laboratory's cultural resources includes buildings and structures, World War I (WWI) earthwork features, the Camp Upton Historical Collection, scientific equipment, photo/audio/video archives, and institutional records. As various cultural resources are identified, plans for their long-term stewardship are being developed and implemented. Achieving these goals will ensure that the contributions BNL and the site have made to our history and culture are documented and available for interpretation. The Laboratory has three structures or sites that have been determined to be eligible for listing on the National Register of Historic Places: the Brookhaven Graphite Research Reactor complex, the High Flux Beam Reactor complex, and the WWI training trenches associated with Camp Upton. The BNL trenches are examples of the few surviving WWI earthworks in the United States.

Cultural resource management activities performed in 2007 include identifying additional equipment artifacts associated with the HFBR and BGRR, and electronically scanning the diary of a World War I soldier for website posting.
Outreach activities consisted of providing presentations on Laboratory cultural resources and tours of the WWI trenches to several small groups, and participating in local fairs.

\section{REFERENCES AND BIBLIOGRAPHY}

BNL. 1999. Record of Decision: Operable Unit I and Radiologically Contaminated Soils. BNL/OU1/12.1/1-57 05-OCT-99. Brookhaven National Laboratory, Upton, NY. BNL. 2000. 1999 Site Environmental Report. BNL-52553. Brookhaven National Laboratory, Upton, NY.

BNL. 2003a. Natural Resource Management Plan for Brookhaven National Laboratory. BNL-71870-2003. Brookhaven National Laboratory, Upton, NY.

BNL. 2003b. Wildland Fire Management Plan for Brookhaven National Laboratory. BNL-71629-2003. Brookhaven National Laboratory, Upton, NY.

BNL. 2005. Cultural Resource Management Plan for Brookhaven National Laboratory. BNL-73839-2005. Brookhaven National Laboratory, Upton, NY. March 2005.

BNL 2007. 2006 Peconic River Monitoring Report. Brookhaven National Laboratory.

DOE-FWS. 2000. Interagency Agreement Number AlO201CH1107 Between the U.S. Department of Interior, U.S. Fish \& Wildlife Service, Long Island National Wildlife Refuge Complex, and the U.S. Department of Energy Chicago Operations Office Brookhaven Group.

Dwyer, Norval. 1966. Brookhaven National Laboratory. Long Island Forum (reprint), West Islip, NY.

Florendo, Esperanza. 2004. "Seasonal food intake affecting Cs-137 levels in white-tailed deer at Brookhaven National Laboratory." CCI Paper. Brookhaven National Laboratory.

IAEA. 1992. Effects of lonizing Radiation on Plants and Animals at Levels Implied by Current Radiation Protection Standards. Technical Report Series No. 332. International Atomic Energy Agency, Vienna.

LMS. 1995. Phase /I Sitewide Biological Inventory Report, Final. Lawler, Matusky \& Skelly Engineers. Pearl River, NY.

Merwin, D, Manfra, A. 2007. A Stage I Archaeological Survey for the Proposed NSLS-II at Brookhaven National Laboratory. The Institute for Long Island Archaeology, Department of Anthropology, State University of New York at Stony Brook.

NYSDOH. 1996. Radioactive Contamination in the Peconic River. Bureau of Environmental Radiation Protection, New York State Department of Health, Albany, NY.

NYSDOH. 1999. Deer Meat Contaminated with Cesium137 at Brookhaven National Laboratory. Bureau of Environmental Radiation Protection, New York State Department of Health, Albany, NY.

QEA. 2004a. Peconic River 2003 Data Summary Report. Quantitative Environmental Analysis, LLC. Montvale, New Jersey. 
CHAPTER 6: NATURAL AND CULTURAL RESOURCES

QEA. 2004b. 2004 Methylmercury Sampling Program Results: Addendum to the Peconic River 2003 Data Summary Report. Quantitative Environmental Analysis, LLC. Montvale, New Jersey.

QEA. 2006. 2005 Peconic River Water Column Sampling Data Summary Report. Quantitative Environmental Analysis, LLC. Montvale, New Jersey.

Snyder, S. and V. Titus. 2007. "Spatial distribution of Iridovirus in the Eastern box turtle population at Brookhaven National Laboratory: Implications for transmittance based on home range size." SULI Poster, Brookhaven National Laboratory. 
Intentionally Left Blank 


\section{Groundwater Protection}

Brookhaven National Laboratory's (BNL) Groundwater Protection Management Program is made up of four elements: prevention, monitoring, restoration, and communication. The Laboratory has implemented aggressive pollution prevention measures to protect groundwater resources. An extensive groundwater monitoring well network is used to verify that prevention and restoration activities are effective. In 2007, BNL collected groundwater samples from 850 monitoring wells during 2,289 individual sampling events. Twelve groundwater remediation systems removed 198 pounds of volatile organic compounds and returned approximately 1.2 billion gallons of treated water to the Upper Glacial aquifer. Since the beginning of active groundwater remediation in December 1996, the Laboratory has removed 5,897 pounds of volatile organic compounds by treating 12.8 billion gallons of groundwater. During 2007, two groundwater treatment systems removed approximately 5.2 millicuries of strontium-90 while remediating 10 million gallons of groundwater. Since 2003, BNL has removed approximately 16.7 millicuries of strontium-90 from the groundwater while remediating 34.5 million gallons of groundwater.

\subsection{THE BNL GROUNDWATER PROTECTION MANAGEMENT PROGRAM}

The primary goal of BNL's Groundwater Protection Management Program is to ensure that plans for groundwater protection, management, monitoring, and restoration are fully defined, integrated, and managed in a manner that is consistent with federal, state, and local regulations. The program helps to fulfill the environmental monitoring requirements outlined in DOE Order 450.1, Environmental Protection Program. The program consists of four interconnecting elements: 1) preventing pollution of the groundwater, 2) monitoring the effectiveness of engineered and administrative controls at operating facilities and groundwater treatment systems, 3) restoring the environment by cleaning up contaminated soil and groundwater, and 4) communicating with stakeholders on groundwater protection issues. The Laboratory is committed to protecting groundwater resources from further chemical and radionuclide releases, and to remediating existing contaminated groundwater.

\subsubsection{Prevention}

As part of BNL's Environmental Management System, the Laboratory has implemented a number of pollution prevention activities that are designed to protect groundwater resources (see Chapter 2). BNL has established a work control program that requires the assessment of all experiments and industrial operations to determine their potential impact on the environment. The program enables the Laboratory to integrate pollution prevention and waste minimization, resource conservation, and compliance into planning and decision making. Efforts have been implemented to achieve or maintain compliance with regulatory requirements and to implement best management practices designed to protect groundwater (see Chapter 3). Examples include upgrading underground storage tanks, closing cesspools, and adding engineered controls (e.g., barriers to prevent rainwater infiltration that could move contaminants out of the soil and into groundwater), and administrative controls (e.g., reducing the toxicity and volume of chemicals in use or storage). BNL's comprehensive ground- 
water monitoring program is used to confirm that these controls are working.

\subsubsection{Monitoring}

The Laboratory's groundwater monitoring network is designed to evaluate the impacts of groundwater contamination from former and current operations and to track cleanup progress. Each year, BNL collects several thousand groundwater samples from an extensive network of on- and off-site monitoring wells (see Table 7-1). Results from groundwater monitoring are used to verify that protection and restoration efforts are working. Groundwater monitoring is focused on two general areas: 1) Environmental Surveillance (ES) monitoring, designed to satisfy DOE and New York State monitoring requirements for active research and support facilities, and 2) Long Term Response Actions (LTRA) monitoring related to the Laboratory's obligations under the Comprehensive Environmental Response, Compensation and Liability Act (CERCLA). These monitoring programs are coordinated to ensure completeness and to prevent duplication of effort in the installation, monitoring, and abandonment of wells. The monitoring program elements have been integrated and include data quality objectives; plans and procedures; sampling and analysis; quality assurance; data management; and the installation, maintenance, and abandonment of wells. These elements are integrated to create a cost-effective monitoring system and to ensure that water quality data are available for review and interpretation in a timely manner.

\subsubsection{Restoration}

BNL was added to the National Priorities List in 1989. To help manage the restoration effort, 30 separate Areas of Concern were grouped into six Operable Units (OUs). Remedial Investigation/Feasibility Studies have been conducted for each OU, and the focus is currently on operating cleanup systems. Contaminant sources (e.g., contaminated soil and underground storage tanks) are being removed or remediated to prevent further contamination of groundwater. All remediation work is carried out under an Interagency Agreement involving EPA, the New York
Table 7-1. Summary of BNL Groundwater Monitoring Program, 2007.

\begin{tabular}{lcc}
\hline & $\begin{array}{c}\text { Long Term } \\
\text { Response } \\
\text { Actions Program }\end{array}$ & $\begin{array}{c}\text { Environmental } \\
\text { Surveillance } \\
\text { Program }\end{array}$ \\
\hline $\begin{array}{l}\text { Number of wells } \\
\text { monitored }\end{array}$ & 725 & 125 \\
$\begin{array}{l}\text { Number of sampling } \\
\text { events }\end{array}$ & 2,049 & 240 \\
$\begin{array}{l}\text { Number of analyses } \\
\text { performed }\end{array}$ & 5,967 & 664 \\
$\begin{array}{l}\text { Number of results } \\
\text { Percent of nondetect- } \\
\text { able analyses }\end{array}$ & 78,815 & 7,678 \\
$\begin{array}{l}\text { Number of permanent } \\
\text { wells installed }\end{array}$ & 91 & 92 \\
$\begin{array}{l}\text { Number of temporary } \\
\text { wells installed }\end{array}$ & 52 & 5 \\
$\begin{array}{l}\text { Number of wells } \\
\text { abandoned }\end{array}$ & 36 & 19 \\
\hline
\end{tabular}

State Department of Environmental Conservation (NYSDEC), and DOE.

\subsubsection{Communication}

BNL's Community Education, Government and Public Affairs Office ensures that the Laboratory communicates with its stakeholders in a consistent, timely, and accurate manner. A number of communication mechanisms are in place, such as press releases, web pages, mailings, public meetings, briefings, and roundtable discussions. Specific examples include routine meetings with the Community Advisory Council and the Brookhaven Executive Roundtable (see Chapter 2, Section 2.4.2). Quarterly and annual technical reports that summarize data, evaluations, and program indices are prepared. In addition, BNL has developed a Groundwater Protection Contingency Plan (BNL 2003) that provides a formal process to promptly communicate off-normal or unusual monitoring results to Laboratory management, DOE, regulatory agencies, and other stakeholders, including the public and employees.

\subsection{GROUNDWATER PROTECTION PERFORMANCE}

BNL has made significant investments in environmental protection programs, and is mak- 
ing progress in achieving its goal of preventing new groundwater impacts. No new impacts to groundwater quality have been identified since 2001. A new impact is defined as the detection and confirmation of previously unidentified groundwater contamination. The Groundwater Protection Contingency Plan, mentioned earlier as a communications tool, also is designed to ensure that appropriate and timely actions are taken if unusual or off-normal results are observed. The contingency plan provides guidelines for verifying the data, evaluating the source of the problem, notifying stakeholders, and implementing appropriate corrective actions. The Laboratory will continue efforts to prevent new groundwater impacts, and is vigilant in measuring and communicating its performance.

\subsection{GROUNDWATER MONITORING}

Elements of the groundwater monitoring program include installing monitoring wells; planning and scheduling; developing and following quality assurance procedures; collecting and analyzing samples; verifying, validating, and interpreting data; and reporting. Monitoring wells are used to evaluate BNL's progress in restoring groundwater quality, to comply with regulatory permit requirements, to monitor active research and support facilities, and to assess the quality of groundwater that enters and exits the site.

The Laboratory monitors research and support facilities where there is a potential for environmental impact, as well as areas where past waste handling practices or accidental spills have already degraded groundwater quality. The groundwater beneath the site is classified by New York State as Class GA groundwater, which is defined as a source of potable water. Federal drinking water standards (DWS), New York State DWS, and New York State Ambient Water Quality Standards (NYS AWQS) for Class GA groundwater are used as goals for groundwater protection and remediation. BNL evaluates the potential impact of radiological and nonradiological contamination by comparing analytical results to the standards. Contaminant concentrations that are below the standards are also compared to background values to evaluate the potential effects of facility operations. The de- tection of low concentrations of facility-specific volatile organic compounds (VOCs) or radionuclides may provide important early indications of a contaminant release and allow for timely identification and remediation of the source.

Groundwater quality at BNL is routinely monitored through a network of approximately 850 on-site and off-site wells (see SER Volume II, Groundwater Status Report, for details). In addition to water quality assessments, water levels are routinely measured in more than 875 on- and off-site wells to assess variations in the direction and velocity of groundwater flow. Groundwater flow directions in the vicinity of the Laboratory are shown in Figure 7-1.

The following active facilities have groundwater monitoring programs: the Sewage Treatment Plant (STP) area, Waste Management Facility (WMF), Major Petroleum Facility (MPF), Alternating Gradient Synchrotron (AGS), Relativistic Heavy Ion Collider (RHIC), and several vehicle maintenance and petroleum storage facilities. Inactive facilities include the former Hazardous Waste Management Facility (HWMF), two former landfill areas, Waste Concentration Facility (WCF), Brookhaven Graphite Research Reactor (BGRR), High Flux Beam Reactor (HFBR), and Brookhaven Medical Research Reactor (BMRR). As a result of detailed groundwater investigations conducted over the past 15 years, six significant VOC plumes and eight radionuclide plumes have been identified (see Figures 7-2 and 7-3).

\subsection{SUPPLEMENTAL MONITORING OF WATER SUPPLY WELLS}

Most of BNL's water supply is obtained from a network of six large-capacity wells (wells 4, $6,7,10,11$, and 12). A seventh well, number 9, is a small-capacity well that supplies process water to a facility where biological research is conducted. This well is in limited operation and is not routinely monitored. The locations of the supply wells are shown in Figure 7-1. All of the Laboratory's supply wells are screened within the Upper Glacial aquifer.

As described in Chapter 3, the quality of the BNL potable water supply is monitored as required by the Safe Drinking Water Act 


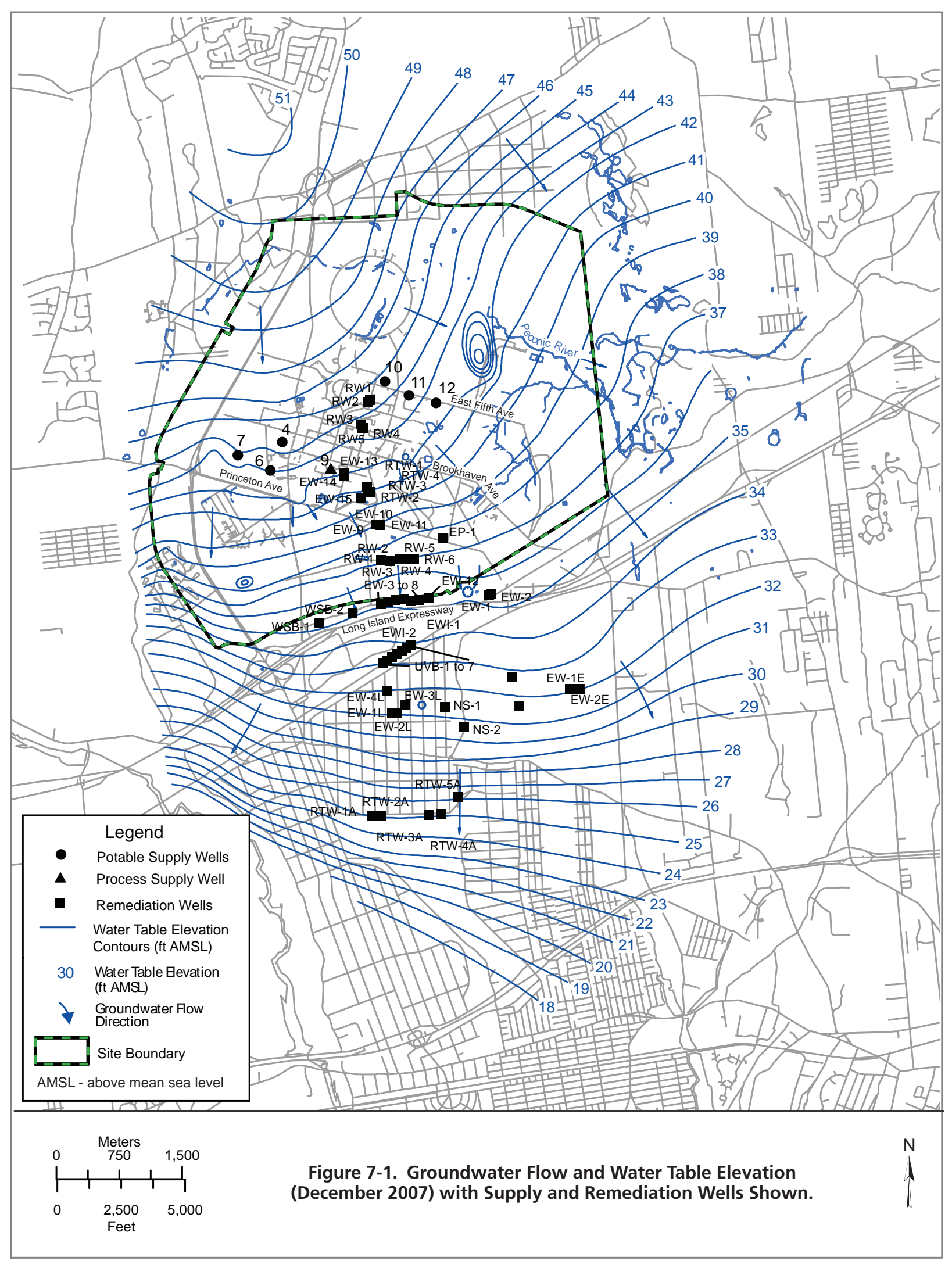




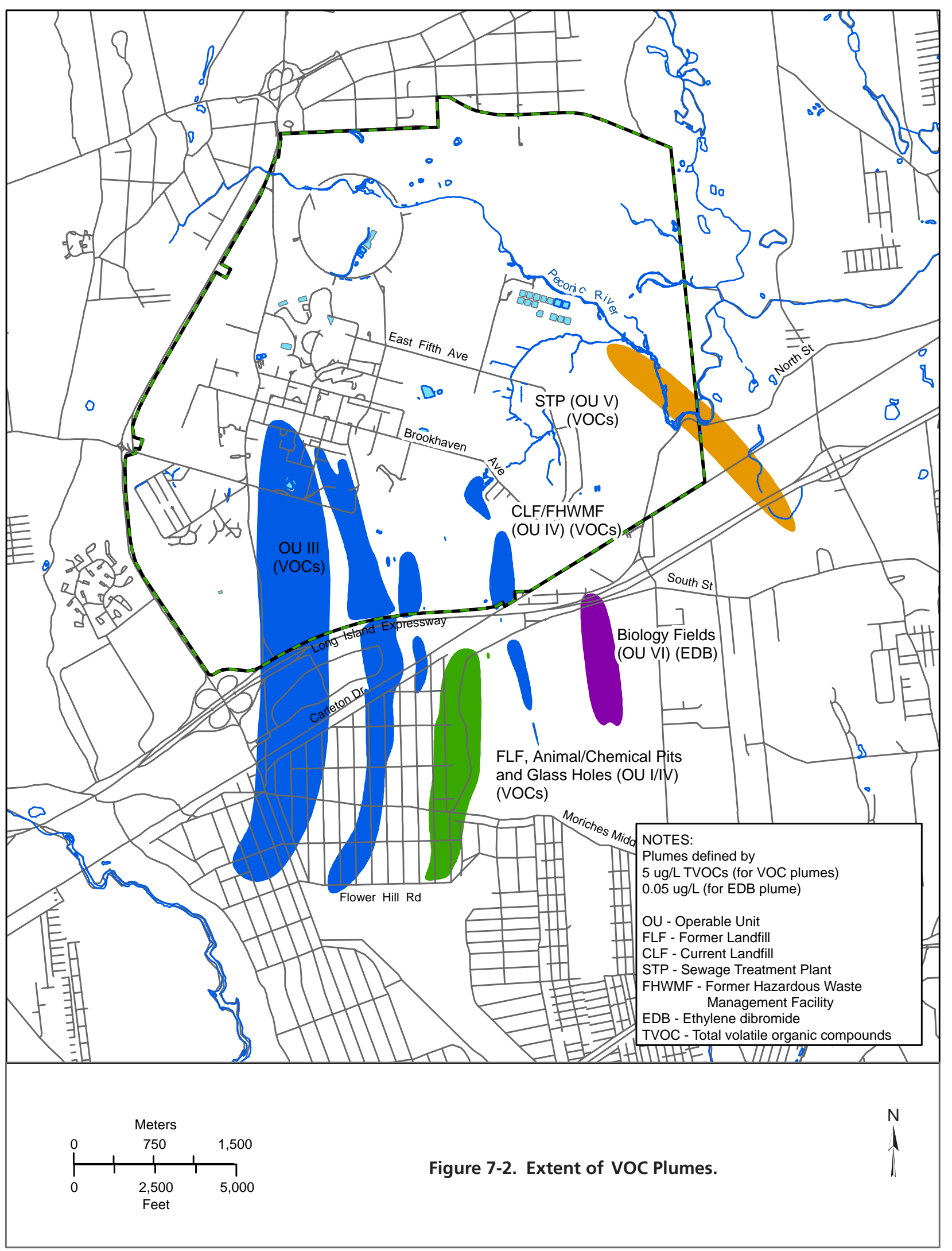




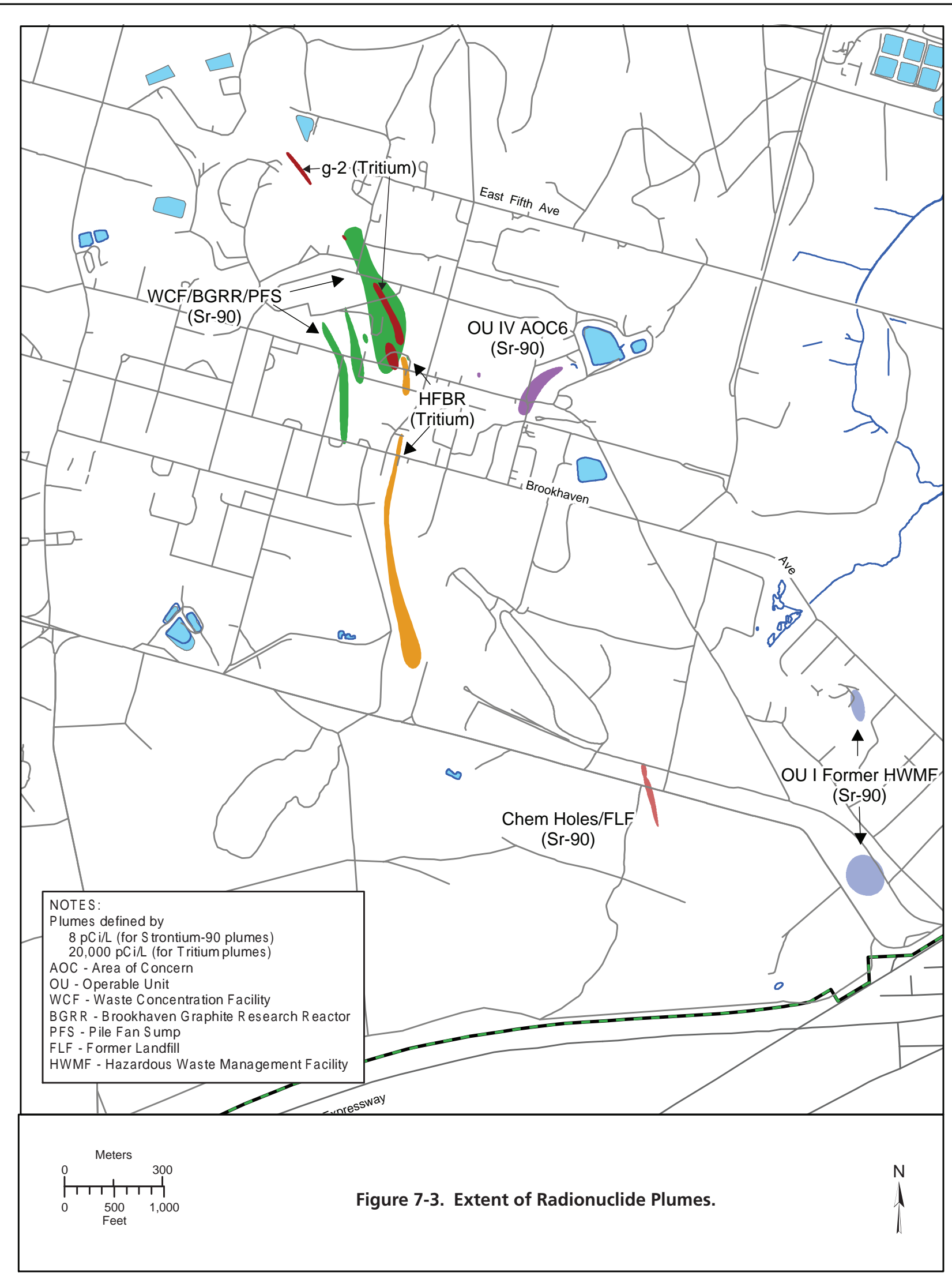


CHAPTER 7: GROUNDWATER PROTECTION

(SDWA), and the analytical results are reported to the Suffolk County Department of Health Services (SCHDS). During 2007, the BNL potable water system fully complied with all drinking water requirements. The Laboratory conducts supplemental sampling of the water supply that goes beyond the minimum SDWA required testing. This additional testing is conducted because some of the potable supply wells are near known or suspected groundwater contamination plumes and source areas. This program includes additional testing for VOCs, anions, metals, and strontium-90 (Sr-90) and tritium, which are known to have contaminated the groundwater in several areas of the site.

To better understand the geographical source of the Laboratory's drinking water and to identify potential sources of contamination within these geographical areas, BNL prepared a Source Water Assessment for Drinking Water Supply Wells (Bennett et al. 2000). In 2003, the New York State Department of Health (NYSDOH) prepared a source water assessment for all potable water supply wells on Long Island, including the BNL potable supply wells (NYSDOH 2003). The source water assessments are designed to serve as management tools in further protecting Long Island's sole source aquifer system.

\subsubsection{Radiological Results}

During 2007, samples collected from the six potable supply wells were analyzed for gross alpha and gross beta activity, tritium, and Sr-90 (see Table 7-2). Nuclide-specific gamma spectroscopy was also performed. All radioactivity levels in the potable water well samples were consistent with those of typical background water samples.

\subsubsection{Nonradiological Results}

In addition to the quarterly SDWA compliance samples described in Section 3.7 of Chapter 3, BNL collected supplemental VOC samples from active supply wells during the year. The samples were analyzed for VOCs following either EPA Standard Method 524 or 624 . As in past years, low levels of several VOCs (e.g., chloroform, 1,1,1-trichloroethane [TCA], bromodichloromethane, and dibromochloromethane) were
Table 7-2. Potable Well Radiological Analytical Results.

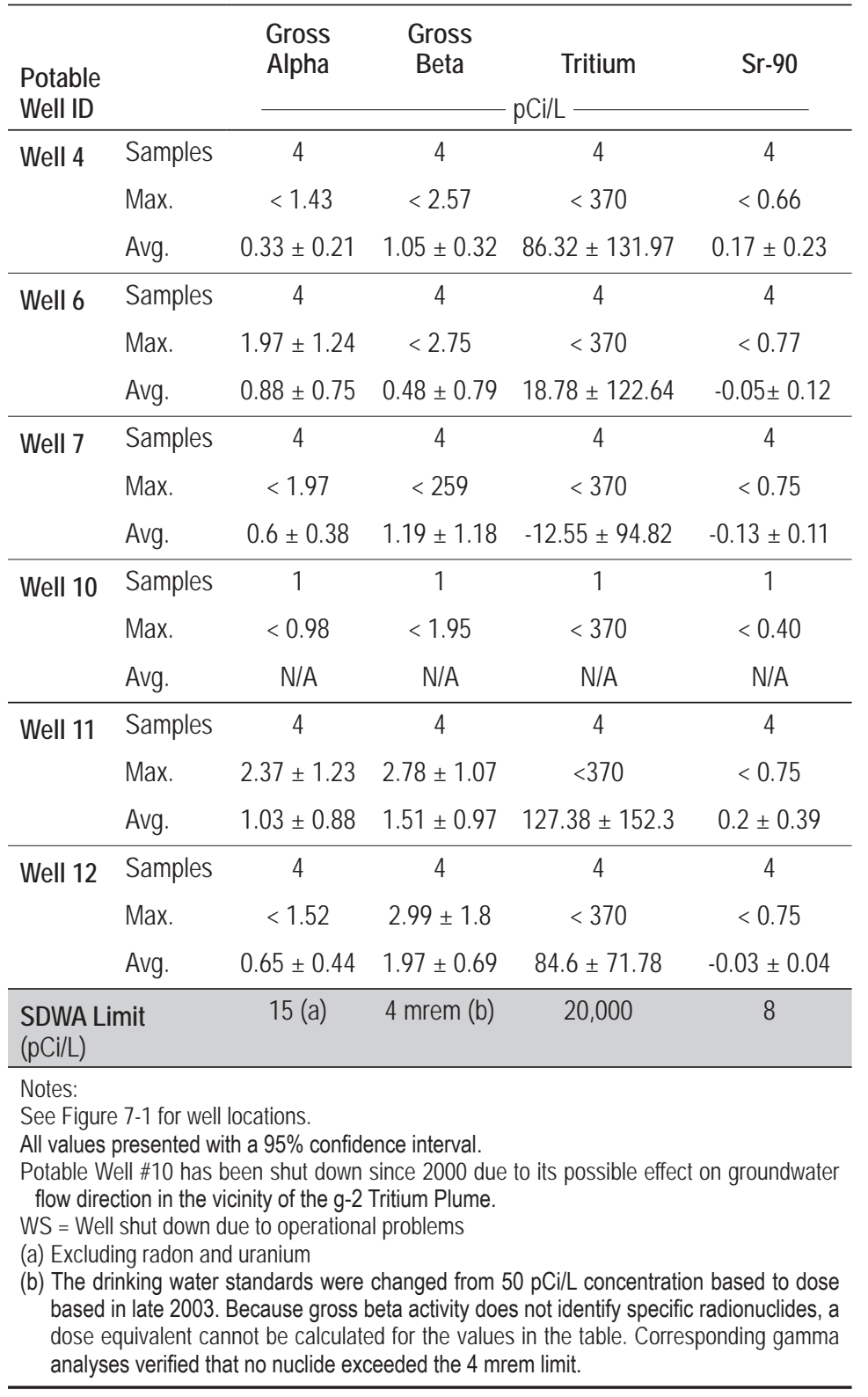

occasionally detected in the supply wells, but at concentrations well below the applicable drinking water standards (DWS). Samples were also analyzed for metals and anions one time during the year (see Tables 7-3 and 7-4). As in previous years, iron $(\mathrm{Fe})$ was the only parameter detected at concentrations greater than the DWS, which is $0.3 \mathrm{mg} / \mathrm{L}$. The iron levels in wells 4,6 , and 7 were $1.4 \mathrm{mg} / \mathrm{L}, 3.4 \mathrm{mg} / \mathrm{L}$, and $2.4 \mathrm{mg} / \mathrm{L}$, respectively. Because high levels of iron are naturally present in some portions of the Upper Glacial aquifer on the western side of the Laboratory 
Table 7-3. Potable Water Supply Wells Water Quality Data.

\begin{tabular}{|c|c|c|c|c|}
\hline \multicolumn{2}{|l|}{$\begin{array}{l}\text { Potable } \\
\text { Well ID }\end{array}$} & \multirow{2}{*}{$\begin{array}{c}\text { Chlorides } \\
1\end{array}$} & \multirow{2}{*}{$\begin{array}{c}\begin{array}{c}\text { Sulfates } \\
\mathrm{mg} / \mathrm{L}\end{array} \\
1\end{array}$} & \multirow{2}{*}{$\begin{array}{c}\begin{array}{c}\text { Nitrate and } \\
\text { Nitrite }\end{array} \\
1\end{array}$} \\
\hline Well 4 & $\mathrm{~N}$ & & & \\
\hline & Value & 22.5 & 8.6 & 0.3 \\
\hline \multirow[t]{2}{*}{ Well 6} & $\mathrm{~N}$ & 1 & 1 & 1 \\
\hline & Value & 18.8 & 8.6 & 0.17 \\
\hline \multirow[t]{2}{*}{ Well 7} & $\mathrm{~N}$ & 1 & 1 & 1 \\
\hline & Value & 25 & 10.2 & 0.29 \\
\hline \multirow[t]{2}{*}{ Well 11} & $\mathrm{~N}$ & 1 & 1 & 1 \\
\hline & Value & 25 & 10 & 0.6 \\
\hline \multirow[t]{2}{*}{ Well 12} & $\mathrm{~N}$ & 1 & 1 & 1 \\
\hline & Value & 27.3 & 9.8 & 0.47 \\
\hline NYS DWS & & 250 & 250 & 10 \\
\hline Typical MDL & & 4 & 4 & 1 \\
\hline \multicolumn{5}{|c|}{$\begin{array}{l}\text { Notes: } \\
\text { See Figure } 7-1 \text { for well locations. } \\
\text { Potable Well \#10 has been shut down since } 2000 \text { due to its possible } \\
\text { effect on groundwater flow direction in the vicinity of the g-2 Tritium } \\
\text { Plume. } \\
\text { N = Number of samples } \\
\text { NYS DWS = New York State Drinking Water Standard } \\
\text { MDL = Minimum Detection Limit }\end{array}$} \\
\hline
\end{tabular}

site, water obtained from wells 4,6 , and 7 is treated at the BNL Water Treatment Plant to reduce iron levels to below the $0.3 \mathrm{mg} / \mathrm{L}$ DWS before it is distributed.

\subsection{ENVIRONMENTAL SURVEILLANCE PROGRAM}

BNL's Environmental Surveillance (ES) program includes groundwater monitoring at 10 active research facilities (e.g., accelerator beam stop and target areas) and support facilities (e.g., fuel storage and waste management facilities). During 2007, groundwater samples were collected from 125 wells during 240 individual sampling events. Nineteen temporary wells were also installed to characterize the g-2 tritium plume, which resulted in the collection of 291 groundwater samples from multiple depth intervals. Detailed descriptions and maps related to the ES groundwater monitoring program can be found in SER Volume II, Groundwater Status Report.

Although no new impacts to groundwater quality have been discovered since 2001, groundwater quality continues to be impacted at two BNL facilities: continued periodic high levels of tritium at the g-2 tritium source area, and continued high levels of VOCs at the Upton service station. Highlights of the surveillance program are as follows:

- Tritium continues to be detected in the g-2 source area monitoring wells, at concentrations above the 20,000 pCi/L DWS. During 2007, the maximum tritium concentration in source area wells was $94,900 \mathrm{pCi} / \mathrm{L}$, in January. Tritium concentrations were less than $50,000 \mathrm{pCi} / \mathrm{L}$ during the second half of the year. Although the engineered stormwater controls are effectively protecting the activated soil shielding at the source area, monitoring data indicate that the continued release of tritium appears to be related to the flushing of residual tritium from the deep vadose zone following natural periodic fluctuations in the local water table. The amount of tritium remaining in the deep vadose zone is expected to decrease over time due to this flushing mechanism, and by natural radioactive decay.

- Monitoring of the downgradient areas of the g-2 tritium plume was accomplished using a combination of permanent and temporary wells. The highest tritium concentration was $198,000 \mathrm{pCi} / \mathrm{L}$, observed in temporary well GP-73 installed approximately 250 feet northwest of the HFBR. The plume was tracked to the area immediately south of the HFBR, where a tritium concentration of 83,000 $\mathrm{pCi} / \mathrm{L}$ was detected in temporary well GP-84. As a result of natural radioactive decay and dispersion in the aquifer, the tritium plume (as defined by concentrations $>20,000 \mathrm{pCi} / \mathrm{L}$ DWS) appears to be breaking up into discrete segments.

- Since April 2006, all tritium concentrations in the Brookhaven Linear Isotope Producer (BLIP) facility surveillance wells have been less than the 20,000 pCi/L DWS. The maximum tritium concentration during 2007 was $13,100 \mathrm{pCi} / \mathrm{L}$. These results indicate that the engineered stormwater controls are effectively protecting the activated soil shielding, and that the amount of residual tritium in the 
deep vadose zone is diminishing.

- At the Upton service station, VOCs associated with petroleum products and solvents continue to be detected in several monitoring wells directly downgradient of the station at concentrations that exceed the DWS. During 2007, high levels of VOCs were detected during the October sample round, with total xylenes detected at $140 \mu \mathrm{g} / \mathrm{L}$, ethylbenzene at 15 $\mu \mathrm{g} / \mathrm{L}, 1,2,4$-trimethylbenzene at $35 \mu \mathrm{g} / \mathrm{L}$, and the solvent PCE at a concentration of $14 \mu \mathrm{g} / \mathrm{L}$. Monitoring of the leak detection systems at the service station indicates that the gasoline storage tanks and associated distribution lines are not leaking. Furthermore, evaluation of current vehicle maintenance operations indicates that all waste oils and used solvents are being properly stored and recycled. Therefore, it is believed that the contaminants detected in groundwater originate from historical vehicle maintenance activities and are not related to current operations.

\subsection{LONG TERM RESPONSE ACTIONS GROUNDWATER MONITORING PROGRAM}

The LTRA groundwater monitoring program is used to track the progress that the groundwater treatment systems are making toward plume remediation (see Section 7.7, below). During 2007, the LTRA program monitored 725 monitoring wells during 2,049 individual groundwater sampling events. Also in 2007, 52 temporary wells were installed, which resulted in the collection of 542 groundwater samples from multiple depth intervals.

Maps showing the main VOC and radionuclide plumes are provided

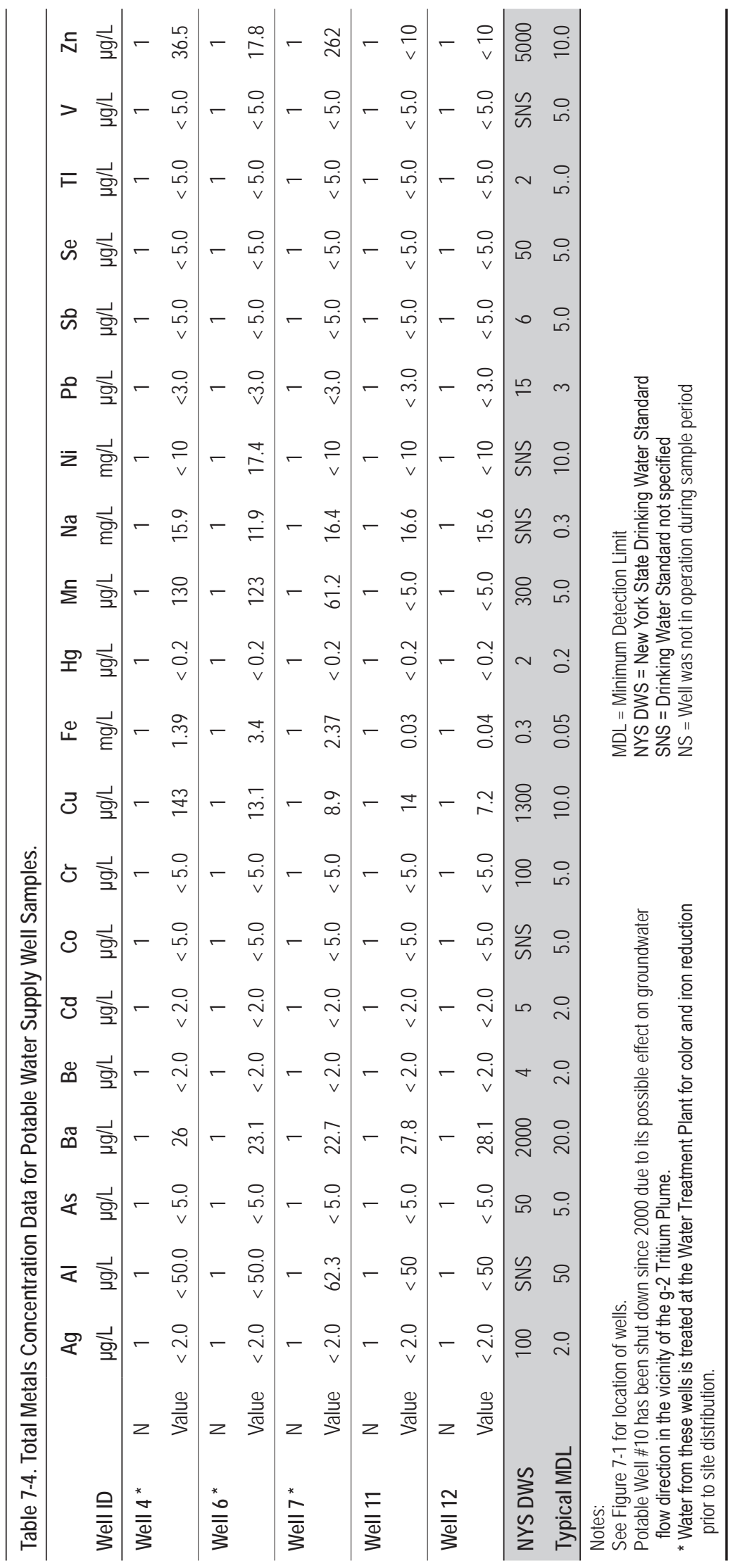


as Figures 7-2 and 7-3, respectively. Detailed descriptions and maps related to the LTRA groundwater monitoring program can be found in SER Volume II, Groundwater Status Report. Highlights of the program are described below.

- The HFBR Pump and Recharge system was re-started in December 2007 as per the OU III Record of Decision (ROD) contingency that was triggered in November, 2006. A new extraction well (EW-16) was constructed several hundred feet north of Princeton Avenue, and is being operated together with one of the existing extraction wells (EW-11) located near Princeton Avenue. The system is expected to be operated for several years.

- Building 96 source area extraction well RTW-2 (which was on standby during 2006) was placed back in service in October 2007 due to increasing PCE concentrations in the groundwater. An ion exchange system was added to the treatment system for extraction well RTW-1, because hexavalent chromium (VI) was detected in nearby monitoring wells at concentrations exceeding the DWS.

- Due to the persistently high levels of PCE observed in the groundwater at the Building 96 source area, in late 2007 BNL initiated an engineering evaluation to assess potential additional remedial alternatives. The evaluation is examining alternatives such as soil excavation, additional groundwater extraction wells, soil mixing with vapor extraction, electrical resistance heating, and injecting hydrogen release compounds. The evaluation will include additional geological characterization to better define the extent of a near-surface silt layer, which is believed to contain residual PCE contamination that is being slowly released to the groundwater.

- Two additional extraction wells were installed for the Chemical Holes Sr-90 system in 2007. The additional extraction wells were necessary to meet the cleanup goal of reducing Sr-90 levels to below DWS by 2040.

- An additional extraction well (RTW-6A) was installed at the Airport System, and began operating in November 2007. The additional extraction well was necessary to capture and treat the western portion of the VOC plume in this area.

- Groundwater samples that were collected during the g-2 tritium plume characterization effort described earlier identified higher than expected Sr-90 concentrations in the vicinity of the HFBR. This contamination represents the downgradient portion of the WCF Sr-90 plume. Based on preliminary groundwater modeling results, it is likely that several additional extraction wells will be necessary in order to achieve the OU III Environmental Services Division goal of reducing Sr-90 levels to below the $8 \mathrm{pCi} / \mathrm{L}$ DWS by 2070 . Additional characterization work will be performed in this area in 2008 .

\subsection{GROUNDWATER TREATMENT SYSTEMS}

The primary mission of the LTRA program is to operate and maintain groundwater treatment systems and prevent additional groundwater contamination from migrating off site. The cleanup objectives will be met by a combination of active treatment and natural attenuation. The specific cleanup goals are as follows:

- Achieve maximum contaminant levels (MCLs) for VOCs in the Upper Glacial aquifer by 2030

- Achieve MCLs for VOCs in the Magothy aquifer by 2065

- Achieve MCLs for Sr-90 at the BGRR in the Upper Glacial aquifer by 2070

- Achieve MCLs for Sr-90 at the Chemical Holes in the Upper Glacial aquifer by 2040 During 2007, BNL continued to make significant progress in restoring groundwater quality. Figure 7-4 shows the locations of 14 groundwater treatment systems in operation. Table 7-5 provides a summary of the amount of VOCs and Sr-90 removed from the aquifer since the start of active remediation in December 1996. During 2007, 198 pounds of VOCs and approximately $5.2 \mathrm{mCi}$ of Sr-90 were removed from the groundwater, and more than 1.2 billion gallons of treated groundwater were returned to the aquifer. To date, 5,897 pounds of VOCs have been removed from the aquifer, and noticeable improvements in groundwater quality 

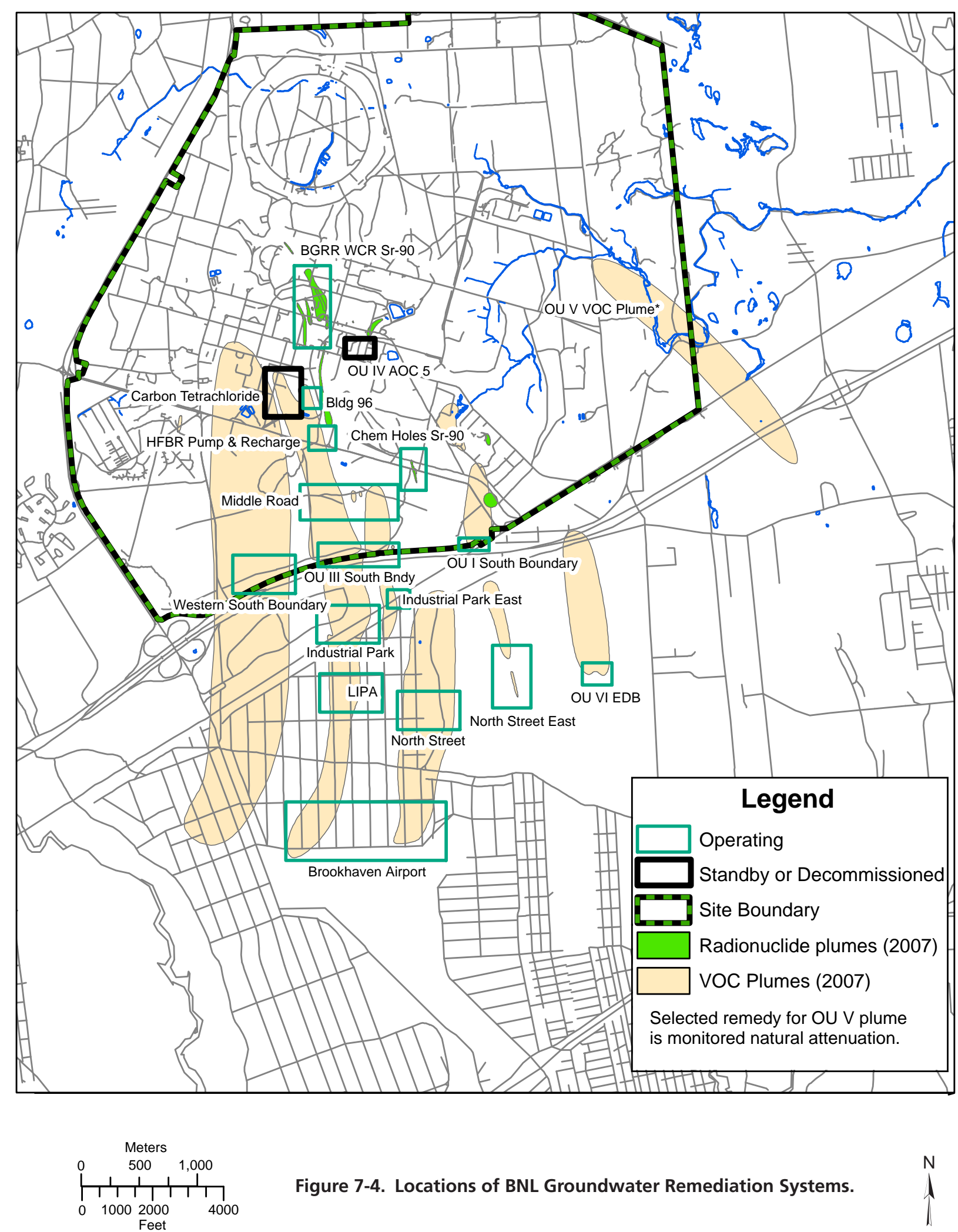

Figure 7-4. Locations of BNL Groundwater Remediation Systems. 
Table 7-5. BNL Groundwater Remediation Systems Treatment Summary for 1997 through 2007.

\begin{tabular}{|c|c|c|c|c|c|}
\hline \multirow[b]{2}{*}{ Remediation System } & \multirow[b]{2}{*}{$\begin{array}{l}\text { Start } \\
\text { Date }\end{array}$} & \multicolumn{2}{|c|}{$1997-2006$} & \multicolumn{2}{|c|}{2007} \\
\hline & & $\begin{array}{l}\text { Water Treated } \\
\text { (Gallons) }\end{array}$ & $\begin{array}{c}\text { VOCs } \\
\text { Removed } \\
\text { (Pounds) (e) }\end{array}$ & $\begin{array}{l}\text { Water Treated } \\
\text { (Gallons) }\end{array}$ & $\begin{array}{c}\text { VOCs Removed } \\
\text { (Pounds) (e) }\end{array}$ \\
\hline OU I South Boundary & 12/1996 & $3,047,314,000$ & 331 & $137,000,000$ & 6 \\
\hline OU III HFBR Tritium Plume (a) & 05/1997 & $241,528,000$ & 180 & $7,450,000$ & 0 \\
\hline OU III Carbon Tetrachloride (d) & 10/1999 & $153,538,075$ & 349 & Not in Service & 0 \\
\hline OU III Building 96 & $01 / 2001$ & $135,497,416$ & 71 & $2,800,000$ & $<1$ \\
\hline OU III Middle Road & $10 / 2001$ & $1,139,411,550$ & 707 & $128,000,000$ & 34 \\
\hline OU III South Boundary & 06/1997 & $3,048,952,850$ & 2,537 & $136,000,000$ & 32 \\
\hline $\begin{array}{l}\text { OU III Western South } \\
\text { Boundary }\end{array}$ & 09/2002 & $531,647,000$ & 45 & $71,000,000$ & 4 \\
\hline OU III Industrial Park & 09/1999 & $1,234,478,330$ & 967 & $130,000,000$ & 43 \\
\hline OU III Industrial Park East & 06/2004 & $226,172,000$ & 29 & $61,000,000$ & 4 \\
\hline OU III North Street & 06/2004 & $503,122,000$ & 232 & $186,000,000$ & 36 \\
\hline OU III North Street East & $06 / 2004$ & $357,976,000$ & 16 & $71,000,000$ & 4 \\
\hline OU III LIPA/Airport & 08/2004 & $675,887,000$ & 200 & $171,000,000$ & 35 \\
\hline OU IV AS/SVE (b) & 11/1997 & (c) & 35 & Decommissioned & 0 \\
\hline OU VI EDB & $10 / 2004$ & $333,711,000$ & (f) & $138,000,000$ & (f) \\
\hline \multicolumn{2}{|l|}{ Total } & \multicolumn{2}{|l|}{$11,616,851,220$} & $1,239,250,000$ & 198 \\
\hline \multirow[b]{2}{*}{ Remediation System } & \multirow[b]{2}{*}{$\begin{array}{l}\text { Start } \\
\text { Date }\end{array}$} & \multicolumn{2}{|c|}{ 2003-2006 } & \multicolumn{2}{|c|}{2007} \\
\hline & & $\begin{array}{l}\text { Water Treated } \\
\text { (Gallons) }\end{array}$ & $\begin{array}{l}\text { Sr-90 Removed } \\
(\mathrm{mCi})\end{array}$ & $\begin{array}{l}\text { Water Treated } \\
\text { (Gallons) }\end{array}$ & $\begin{array}{c}\text { Sr-90 Removed } \\
(\mathrm{mCi})\end{array}$ \\
\hline OU III Chemical Holes Sr-90 & 02/2003 & $10,004,826$ & 2.32 & $2,400,000$ & 0.27 \\
\hline OU III BGRR/WCF Sr-90 & 06/2005 & $14,551,000$ & 9.25 & $7,600,000$ & 4.9 \\
\hline Total & & $24,555,826$ & 11.57 & $10,000,000$ & 5.17 \\
\hline \multicolumn{3}{|c|}{$\begin{array}{l}\text { Notes: } \\
\text { (a) System was reactivated in late } 2007 \text { as a contingency action. } \\
\text { (b) System was shut down on January 10, } 2001 \text { and decommissioned } \\
\text { in } 2003 \text {. } \\
\text { (c) Air Sparging/Soil Vapor Extraction (AS/SVE) system performance was } \\
\text { measured by pounds of VOCs removed per cubic feet of air treated. } \\
\text { (d) System was shut down and placed in standby mode in August } 2004 \text {. } \\
\text { (e) Values are rounded to the nearest whole number. } \\
\text { (f) Because EDB has only been detected at trace levels in the treatment } \\
\text { system influent, no removal of VOCs is reported. }\end{array}$} & $\begin{array}{l}\text { BGRR = Brookhave } \\
\text { EDB = ethylene dibr } \\
\text { HFBR = High Flux B } \\
\text { LIPA = Long Island } \\
\text { WCF = Waste Conc } \\
\text { VOCs = volitile orga }\end{array}$ & $\begin{array}{l}\text { aphite Research React } \\
\text { Reactor } \\
\text { Ruthority } \\
\text { tion Facility } \\
\text { ompounds }\end{array}$ & \\
\hline
\end{tabular}

are evident in the OU I South Boundary, OU III South Boundary, OU III Industrial Park, OU III Industrial Park East, OU III North Street, OU IV, Building 96, and Carbon Tetrachloride areas. Also to date, the Chemical Holes Strontium-90 System has removed $2.6 \mathrm{mCi}$ of Sr-90, and the BGRR/Waste Concentration Facility Strontium90 System has removed $14.2 \mathrm{mCi}$ of Sr-90. Detailed information on the groundwater treat- ment systems can be found in SER Volume II, Groundwater Status Report.

\section{REFERENCES AND BIBLIOGRAPHY}

Bennett, D., D. Paquette, K. Klaus, and W. Dorsch. 2000. Brookhaven National Laboratory, Source Water Assessment for Drinking Water Supply Wells. BNL52608. Brookhaven National Laboratory, Upton, NY. December 27, 2000 
BNL 2003. Groundwater Protection Contingency Plan. Brookhaven National Laboratory, Upton, NY. Standards Based Management System Subject Area. September 2003.

DOE 2003. DOE Order 450.1, Environmental Protection Program. U.S. Department of Energy, Washington, DC.

NYSDOH. 2003. Long Island Source Water Assessment Summary Report. New York Sate Department of Health, June 23, 2003. 
Intentionally Left Blank 


\section{Radiological Dose Assessment}

Brookhaven National Laboratory (BNL) performs periodic reviews of site operations and research projects to ensure that the overall radiological dose impact to members of the public, workers, visitors, and the environment is "As Low As Reasonably Achievable," referred to as ALARA. All scientific experiments, new projects, and operational processes are evaluated for safety and health, dose risk, and environmental impacts. The potential radiological dose to the public is calculated at the site boundary as the "maximum" dose that could be received by a hypothetical individual defined as the maximally exposed individual (MEI). The doses are calculated for the direct and indirect dose pathways to an individual via air immersion, inhalation of particulates and gases, and ingestion of deer meat and fish. The 2007 total Effective Dose Equivalent (EDE) from all Laboratory activities was well below the EPA and DOE regulatory dose limits for the public, workers, and the environment.

The average annual on-site external dose from ambient sources was $70 \pm 12 \mathrm{mrem}(700 \pm 120$ $\mu \mathrm{Sv})$ and $64 \pm 10 \mathrm{mrem}(640 \pm 100 \mu \mathrm{Sv})$ at off-site locations. Both on-and off-site dose measurements include the contribution from natural terrestrial and cosmic background radiation. A statistical comparison of the average doses measured using thermoluminescent dosimeters (TLDS) at 49 on-site and 15 off-site locations showed that there was no external dose contribution from BNL operations above the natural background radiation level. An additional nine TLDs were used to measure onsite areas known to have slightly elevated radiation dose above natural background. The results of these measurements are described in Section 8.1.2.

The EDE from air emissions was calculated as 5.96E-02 mrem (0.60 $\mathrm{SSv})$ to the MEI. The dose from the ingestion pathway was estimated as $3.02 \mathrm{mrem}(30 \mu \mathrm{Sv})$ from the consumption of deer meat, and $0.08 \mathrm{mrem}(0.8 \mu \mathrm{Sv})$ from the consumption of fish caught in the vicinity of the Laboratory. The total annual dose to the MEI from all the pathways was estimated as $3.16 \mathrm{mrem}(32 \mu \mathrm{Sv})$. The $B N L$ dose from the air inhalation pathway was less than 1 percent of EPA's annual regulatory dose limit of 10 mrem $(100 \mu \mathrm{Sv})$, and the total dose was less than 4 percent of DOE's annual dose limit of 100 mrem $(1,000 \mu \mathrm{Sv})$ from all pathways.

Doses to aquatic and terrestrial biota were also evaluated and found to be well below DOE regulatory limits. Other short-term projects, such as remediation work and waste management disposal activities conducted in 2007, were assessed for radiological emissions and their potential dose impacts. There was no radiological risk to the public, BNL employees, or the environment from these projects and activities. In summary, the overall dose impact from all Laboratory activities in 2007 was insignificant above the natural background radiation levels. 


\subsection{DIRECT RADIATION MONITORING}

Direct, penetrating beta and gamma radiation is measured using TLDs. The principle of TLD operation is that when certain crystals are exposed to radiation, impurities in the crystals' low-temperature trapping sites are excited to higher energy states. These electrons remain in a high-energy state at normal ambient temperature. When the TLDs are heated (annealed), the electrons return to the lower energy state, emitting photon energy (light), which is measured with a photomultiplier tube; the light intensity is directly proportional to the absorbed radiation dose. The environmental TLDs used at the Laboratory are composed of calcium fluoride and lithium fluoride crystals. Accuracy is verified by exposing the TLD to a known and character- ized radiation source. BNL participates in the inter-comparison proficiency testing programs sponsored by DOE, as a check of its ability to measure radiation doses accurately.

A direct radiation-monitoring program is used to measure the external dose contribution to members of the public and workers from radiation sources at the Laboratory. This is achieved by measuring direct penetrating radiation exposures both on and off site. The direct measurements taken at the off-site locations are with the premise that off-site exposures are true natural background radiation (contribution from cosmic and terrestrial) exposures and represent no contribution from BNL operations. On- and off-site external dose measurements were averaged, and then compared with each other using the statistical t-test to measure any variations in the averages and thus the contribution, if any,

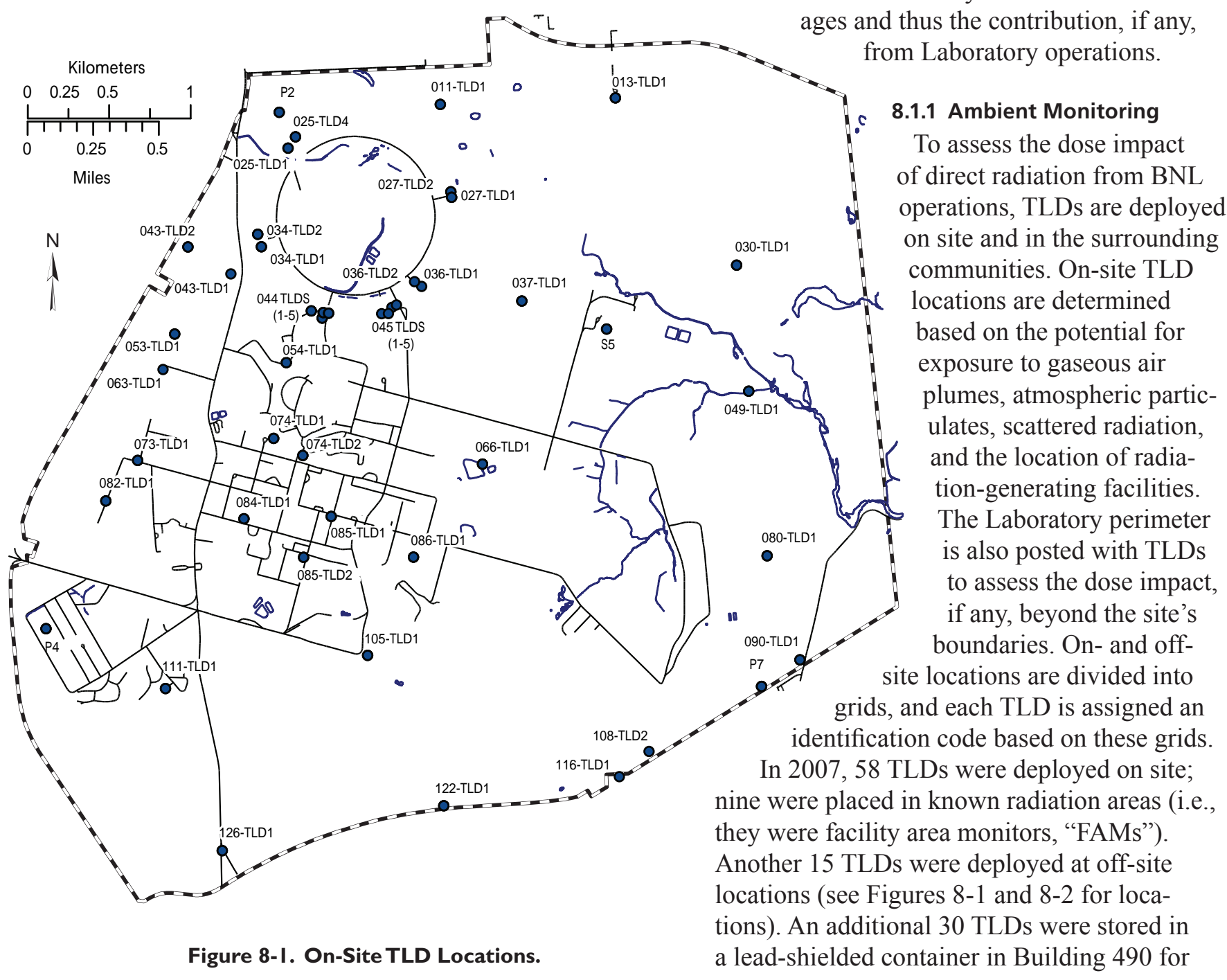




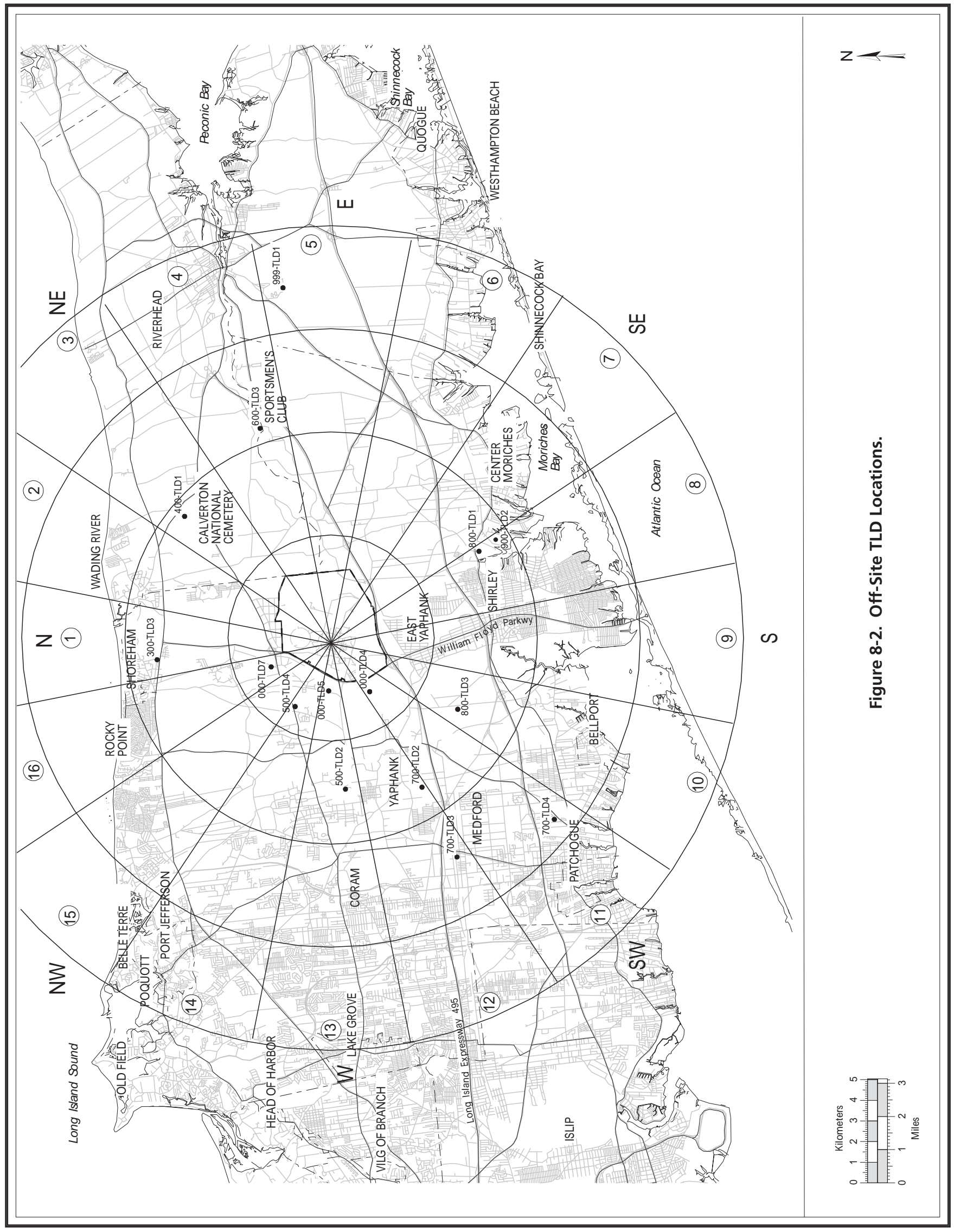


use as reference and control TLDs for comparison purposes. The average of the control TLD values was reported as "075-TLD4" in Tables 8-1 and 8-2. Note that a small "residual" dose was reported for the control TLDs when they were annealed, because it is not possible to completely shield TLDs from all natural background and cosmic radiation sources. The on- and off-site TLDs were collected and read quarterly to determine the external radiation dose measured.

Table 8 - 1 shows the quarterly and yearly onsite radiation dose measurements for 2007. The on-site average external doses for the first, second, third, and fourth quarters were $19.1 \pm 3.1$, $16.7 \pm 3.5,15.9 \pm 3.4$, and $18.4 \pm 3.6 \mathrm{mrem}$, respectively. The on-site average annual external dose from all potential environmental sources, including cosmic and terrestrial radiation sources, was $70 \pm 12$ mrem $(700 \pm 120 \mu \mathrm{Sv})$.

Table 8-2 shows the quarterly and yearly offsite radiation dose measurements. The off-site average external doses for the first, second, third, and fourth quarters were $16.9 \pm 4.1,15.2$ $\pm 2.7,15.2 \pm 3.7$, and $15.9 \pm 2.7 \mathrm{mrem}$, respectively. The off-site average annual ambient dose from all potential environmental sources, including cosmic and terrestrial radiation sources, was $64 \pm 10$ mrem $(640 \pm 100 \mu \mathrm{Sv})$.

To determine the BNL contribution to the external direct radiation dose, a statistical t-test between the measured on- and off-site external dose averages was conducted. The t-test showed no significant difference between the off-site dose (64 $\pm 10 \mathrm{mrem})$ and on-site dose $(70 \pm 12 \mathrm{mrem})$ at the 95 percent confidence level. From the measured TLD doses, it can be safely concluded that there was no measurable external dose contribution to on- and off-site locations from Laboratory operations in 2007.

\subsubsection{Facility Area Monitoring}

Nine on-site TLDs were designated as facility area monitors because they were posted in known radiation areas. Table 8-3 shows the external doses measured with the FAM-TLDs. The environmental TLDs 088-TLD1 through 088-TLD4 are posted at the S-6 blockhouse location and on the fence of the former Hazardous Waste Management Facility (HWMF). These TLDs measured slightly higher external doses than the normal natural background

\begin{tabular}{|c|c|c|c|c|c|c|c|}
\hline \multirow[b]{2}{*}{ TLD\# } & \multirow[b]{2}{*}{ Location } & $\begin{array}{c}\text { 1st } \\
\text { Quarter }\end{array}$ & $\begin{array}{l}\text { 2nd } \\
\text { Quarter }\end{array}$ & $\begin{array}{c}\text { 3rd } \\
\text { Quarter }\end{array}$ & $\begin{array}{c}\text { 4th } \\
\text { Quarter }\end{array}$ & $\begin{array}{c}\text { Avg./Qtr. } \\
\pm 2 \sigma(95 \%)\end{array}$ & $\begin{array}{l}\text { Annual Dose } \\
\pm 2 \sigma(95 \%)\end{array}$ \\
\hline & & \multicolumn{6}{|c|}{ (mrem) } \\
\hline 011-TLD1 & North firebreak & 17.7 & 12.5 & 12.6 & 14.4 & $14 \pm 5$ & $57 \pm 19$ \\
\hline 013-TLD1 & North firebreak & 16.8 & 14.7 & 15.0 & 17.8 & $16 \pm 3$ & $64 \pm 12$ \\
\hline 025-TLD1 & Bldg. 1010 beam stop 1 & 18.2 & 16.4 & 14.1 & 16.9 & $16 \pm 3$ & $66 \pm 13$ \\
\hline 025-TLD4 & Bldg. 1010 beam stop 4 & 18.8 & 18.0 & 16.1 & 17.5 & $18 \pm 2$ & $70 \pm 9$ \\
\hline 027-TLD1 & Bldg. 1002A South & 16.2 & 14.7 & 12.9 & 16.7 & $15 \pm 3$ & $61 \pm 13$ \\
\hline 027-TLD2 & Bldg. 1002D East & 16.1 & 14.2 & 13.8 & 15.8 & $15 \pm 2$ & $60 \pm 9$ \\
\hline 030-TLD1 & NE Firebreak & 19.8 & 15.3 & 15.0 & 17.0 & $17 \pm 4$ & $67 \pm 17$ \\
\hline 034-TLD1 & Bldg. 1008 collimator 2 & 17.5 & 16.3 & 15.8 & 18.5 & $17 \pm 2$ & $68 \pm 10$ \\
\hline 034-TLD2 & Bldg. 1008 collimator 4 & 18.0 & 18.9 & 15.4 & 18.8 & $18 \pm 3$ & $71 \pm 13$ \\
\hline 036-TLD1 & Bldg. 1004B East & 17.3 & 15.5 & 13.2 & 19.5 & $16 \pm 5$ & $66 \pm 21$ \\
\hline 036-TLD2 & Bldg. 1004 East & 20.3 & 21.2 & 16.2 & 18.8 & $19 \pm 4$ & $77 \pm 17$ \\
\hline 037-TLD1 & $\mathrm{S}-13$ & 17.1 & 15.4 & 14.8 & 16.8 & $16 \pm 2$ & $64 \pm 9$ \\
\hline 043-TLD1 & North access road & 20.5 & 16.8 & 16.7 & 18.1 & $18 \pm 3$ & $72 \pm 14$ \\
\hline 043-TLD2 & North of Meteorology Tower & 18.5 & 17.3 & 17.3 & 18.6 & $18 \pm 1$ & $72 \pm 6$ \\
\hline 044-TLD1 & Bldg. 1006 & 18.1 & 15.8 & 16.7 & 17.8 & $17 \pm 2$ & $68 \pm 8$ \\
\hline
\end{tabular}


Table 8-1. On-Site Direct Ambient Radiation Measurements (concluded).

\begin{tabular}{|c|c|c|c|c|c|c|c|}
\hline \multirow[b]{2}{*}{ TLD\# } & \multirow[b]{2}{*}{ Location } & $\begin{array}{c}\text { 1st } \\
\text { Quarter }\end{array}$ & $\begin{array}{l}\text { 2nd } \\
\text { Quarter }\end{array}$ & $\begin{array}{c}\text { 3rd } \\
\text { Quarter }\end{array}$ & $\begin{array}{c}\text { 4th } \\
\text { Quarter }\end{array}$ & $\begin{array}{c}\text { Avg./Qtr. } \\
\pm 2 \sigma(95 \%)\end{array}$ & $\begin{array}{c}\text { Annual Dose } \\
\pm 2 \sigma(95 \%)\end{array}$ \\
\hline & & \multicolumn{6}{|c|}{$-(\mathrm{mrem})-$} \\
\hline 044-TLD2 & South of Bldg. 1000E & 18.4 & 16.6 & 15.7 & 17.5 & $17 \pm 2$ & $68 \pm 9$ \\
\hline 044-TLD3 & South of Bldg. 1000P & 18.4 & 15.2 & 14.4 & 17.2 & $16 \pm 4$ & $65 \pm 14$ \\
\hline 044-TLD4 & North-east of Bldg. 1000P & 19.6 & 16.5 & 15.1 & 20.5 & $18 \pm 5$ & $72 \pm 20$ \\
\hline 044-TLD5 & North of Bldg. 1000P & 18.7 & 18.1 & 15.3 & 17.2 & $17 \pm 3$ & $69 \pm 12$ \\
\hline 045-TLD1 & Bldg. 1005S & 21.1 & 16.7 & 16.4 & 16.9 & $18 \pm 4$ & $71 \pm 17$ \\
\hline 045-TLD2 & East of Bldg. 1005S & 20.2 & 17.6 & 16.8 & 19.8 & $19 \pm 3$ & $74 \pm 13$ \\
\hline 045-TLD3 & South-east of Bldg. $1005 \mathrm{~S}$ & 18.6 & 15.6 & 15.5 & 19.2 & $17 \pm 4$ & $69 \pm 15$ \\
\hline 045-TLD4 & South-west of Bldg. $1005 \mathrm{~S}$ & 20.9 & 17.2 & 15.8 & 19.1 & $18 \pm 4$ & $73 \pm 17$ \\
\hline 045-TLD5 & West south west of Bldg. 1005 S & 19.5 & 13.9 & 14.2 & 16.3 & $16 \pm 5$ & $64 \pm 20$ \\
\hline 049-TLD1 & East firebreak & 20.1 & 16.3 & 14.6 & 17.9 & $17 \pm 5$ & $69 \pm 18$ \\
\hline 053-TLD1 & West firebreak & 24.2 & 19.1 & 17.8 & 19.4 & $20 \pm 5$ & $81 \pm 22$ \\
\hline 054- TLD1 & Bldg. 914 & 18.9 & 18.8 & 12.3 & 19.5 & $17 \pm 7$ & $70 \pm 27$ \\
\hline 063-TLD1 & West firebreak & 19.1 & 17.9 & 18.2 & 21.8 & $19 \pm 3$ & $77 \pm 14$ \\
\hline 066-TLD1 & Waste Management Facility & 17.0 & 13.9 & 14.0 & 15.5 & $15 \pm 3$ & $60 \pm 11$ \\
\hline 073-TLD1 & Meteorology Tower/Bldg. 51 & 20.4 & 17.3 & 17.4 & 18.9 & $19 \pm 3$ & $74 \pm 11$ \\
\hline 074-TLD1 & Bldg. 560 & 20.7 & 17.9 & 18.2 & 19.7 & $19 \pm 3$ & $77 \pm 10$ \\
\hline 074-TLD2 & Bldg. 907 & 20.5 & 16.0 & 14.3 & 19.2 & $18 \pm 6$ & $70 \pm 22$ \\
\hline 080-TDL1 & East firebreak & 20.1 & 18.4 & 18.6 & 19.7 & $19 \pm 2$ & $77 \pm 6$ \\
\hline 082-TLD1 & West firebreak & 21.8 & 18.1 & 20.0 & 21.1 & $20 \pm 3$ & $81 \pm 13$ \\
\hline 084-TLD1 & Tennis courts & 19.5 & 15.9 & 15.5 & 18.0 & $17 \pm 4$ & $69 \pm 15$ \\
\hline 085-TDL2 & Upton gas station & 18.2 & 17.9 & 17.1 & 19.7 & $18 \pm 2$ & $73 \pm 9$ \\
\hline 085-TLD1 & Diversity Office & 19.8 & NP & 16.7 & 19.9 & $19 \pm 4$ & $75 \pm 14$ \\
\hline 086-TLD1 & Baseball fields & 20.6 & 19.3 & 19.0 & 20.5 & $20 \pm 2$ & $79 \pm 6$ \\
\hline 090-TLD1 & North St. Gate & $\mathrm{L}$ & 15.7 & 16.3 & 16.6 & $16 \pm 1$ & $65 \pm 4$ \\
\hline 105-TLD1 & South firebreak & 20.0 & 19.2 & 17.9 & 21.6 & $20 \pm 3$ & $79 \pm 12$ \\
\hline 108-TLD1 & Water tower & 17.8 & 16.8 & 15.7 & 17.4 & $17 \pm 2$ & $68 \pm 7$ \\
\hline 108-TLD2 & Tritium Pole & L & 20.5 & 19.0 & 24.3 & $21 \pm 5$ & $85 \pm 21$ \\
\hline 111-TLD1 & Trailer park & 20.0 & 17.8 & 16.2 & 18.8 & $18 \pm 3$ & $73 \pm 13$ \\
\hline 122-TLD1 & South firebreak & 18.5 & 16.2 & 16.0 & 17.1 & $17 \pm 2$ & $68 \pm 9$ \\
\hline 126-TLD1 & South gate & 20.1 & 16.9 & 17.5 & 18.8 & $18 \pm 3$ & $73 \pm 11$ \\
\hline P2 & & 18.3 & 13.8 & 13.9 & 15.1 & $15 \pm 4$ & $61 \pm 16$ \\
\hline P4 & & 17.5 & 15.6 & 15.7 & 17.4 & $17 \pm 2$ & $66 \pm 8$ \\
\hline P7 & & 19.2 & 15.8 & 15.2 & 17.3 & $17 \pm 3$ & $68 \pm 14$ \\
\hline S5 & & 17.1 & 16.7 & 14.8 & 17.7 & $17 \pm 2$ & $66 \pm 10$ \\
\hline On-site average & & 19.1 & 16.7 & 15.9 & 18.4 & $18 \pm 3$ & $70 \pm 12$ \\
\hline Std. dev. $(2 \sigma)$ & & 3.1 & 3.5 & 3.4 & 3.6 & & \\
\hline 075-TLD4 & Control TLD average & 9.0 & 8.6 & 9.3 & 8.9 & $8.9 \pm 1$ & $36 \pm 02$ \\
\hline $\begin{array}{l}\text { Notes: } \\
\text { See Figure 8-1 for TLL } \\
L=\text { TLD lost } \\
\text { NP = TLD not posted }\end{array}$ & cations. & & & & & & \\
\hline
\end{tabular}


Table 8-2. Off-Site Direct Radiation Measurements.

\begin{tabular}{|c|c|c|c|c|c|c|c|}
\hline & & $\begin{array}{c}\text { 1st } \\
\text { Quarter }\end{array}$ & $\begin{array}{c}\text { 2nd } \\
\text { Quarter }\end{array}$ & $\begin{array}{c}\text { 3rd } \\
\text { Quarter }\end{array}$ & $\begin{array}{c}\text { 4th } \\
\text { Quarter }\end{array}$ & $\begin{array}{l}\text { Avg./Qtr. } \\
\pm 2 \sigma(95 \%)\end{array}$ & $\begin{array}{c}\text { Annual Dose } \\
\pm 2 \sigma(95 \%)\end{array}$ \\
\hline TLD\# & Location & & & & (mrem) - & & \\
\hline 000-TLD4 & Private property & 13.7 & 15.1 & 13.7 & 15.8 & $15 \pm 2$ & $58 \pm 8$ \\
\hline 000-TLD5 & Longwood Estate & 15.6 & 14.8 & 14.7 & 15.3 & $15 \pm 1$ & $60 \pm 3$ \\
\hline 000-TLD7 & Mid-Island Game Farm & 17.7 & 15.9 & 15.2 & 15.8 & $16 \pm 2$ & $65+8$ \\
\hline 300-TLD3 & Private property & 16.6 & NP & NP & NP & $17 \pm 0$ & $66 \pm 0$ \\
\hline 400-TLD1 & Calverton Nat. Cemetary & 21.2 & 18.0 & 19.5 & 17.9 & $19 \pm 3$ & $77 \pm 12$ \\
\hline 500-TLD2 & Private property & 16.3 & 13.0 & 14.4 & 15.2 & $15 \pm 3$ & $59 \pm 11$ \\
\hline 500-TLD4 & Private property & NP & NP & NP & 16.5 & $17 \pm 0$ & $66+0$ \\
\hline 600-TLD3 & Sportsmen's Club & 18.3 & 15.4 & 15.6 & 16.6 & $16+3$ & $66 \pm 10$ \\
\hline 700-TLD2 & Private property & 15.5 & 14.5 & 14.5 & 15.9 & $15 \pm 0$ & $60 \pm 0$ \\
\hline 700-TLD3 & Private property & 17.6 & 14.3 & 13.3 & 17.0 & $16 \pm 4$ & $62 \pm 16$ \\
\hline 700-TLD4 & Private property & 19.7 & 15.1 & 16.9 & 17.2 & $17 \pm 4$ & $69 \pm 15$ \\
\hline 800-TLD1 & Private property & 18.4 & 15.3 & 16.3 & 12.3 & $16 \pm 5$ & $62+20$ \\
\hline 800-TLD3 & Suffolk County CD & 16.4 & 17.7 & 16.0 & 16.3 & $17 \pm 1$ & $66 \pm 6$ \\
\hline 900-TLD2 & Private property & 14.0 & 14.2 & 12.3 & 14.8 & $14 \pm 0$ & $55 \pm 0$ \\
\hline 999-TLD1 & Private property & 15.6 & 14.4 & NP & NP & $15 \pm 2$ & $60 \pm 7$ \\
\hline Off-site average & & 16.9 & 15.2 & 15.2 & 15.9 & $16 \pm 3$ & $64 \pm 10$ \\
\hline Std. dev. $(2 \sigma)$ & & 4.1 & 2.7 & 3.7 & 2.7 & & \\
\hline 075-TLD4 & Control TLD average & 9.4 & 8.7 & 8.7 & 9.2 & $9.0+1$ & $36 \pm 3$ \\
\hline \multicolumn{8}{|c|}{$\begin{array}{l}\text { Notes: } \\
\text { See Figure 8-2 for TLD locations. } \\
C D=\text { Correctional Department } \\
\text { NP = TLD not posted for the quarter }\end{array}$} \\
\hline
\end{tabular}

radiation doses measured in other areas of BNL. The elevated external dose measured at the former HWMF can be attributed to the presence of small amounts of soil contamination. However, a comparison of the 2007 dose rates to doses from previous years show that the dose rates have declined significantly since the removal of most of the radioactive soil. As Table 8-3 shows, the dose is currently just slightly above natural background levels. The former HWMF is fenced, access is controlled, and only qualified staff members are allowed inside the facility.

Two TLDs (075-TLD3 and 075-TLD5) near Building 356 showed higher than normal quarterly averages: $29 \pm 1$ mrem $(290 \pm 10 \mu \mathrm{Sv})$ and $30 \pm 6 \mathrm{mrem}(300 \pm 60 \mu \mathrm{Sv})$, respectively. The yearly doses were measured at $114 \pm 5$ mrem $(1140 \pm 50 \mu \mathrm{Sv})$ for 075 -TLD3, and 118 $\pm 25 \mathrm{mrem}(1180 \pm 250 \mu \mathrm{Sv})$ for 075-TLD5.
The direct doses are higher than the on-site annual average because Building 356 houses a cobalt-60 (Co-60) source, which is used to irradiate materials, parts, and electronic circuit boards. The elevated dose from Building 356 is attributed to the "sky-shine" phenomenon. Although it is conceivable that individuals who use the parking lot adjacent to Building 356 could receive a dose from this source, the dose would be minimal due to the limited time an individual spends in the parking lot.

In previous years, two FAM-TLDs placed on the fence northeast and northwest of Building 913-B (the Alternating Gradient Synchrotron tunnel access) showed higher than normal ambient external dose. The second-quarter dose was measured at $48.1 \mathrm{mrem}$ for 054-TLD2. For the three remaining quarters, both TLDs showed dose slightly above normal background radiation. 
Table 8-3. Facility Area Monitoring.

\begin{tabular}{|c|c|c|c|c|c|c|c|}
\hline \multirow[b]{2}{*}{ TLD\# } & \multirow[b]{2}{*}{ Location } & $\begin{array}{c}\text { 1st } \\
\text { Quarter }\end{array}$ & $\begin{array}{c}\text { 2nd } \\
\text { Quarter }\end{array}$ & $\begin{array}{c}\text { 3rd } \\
\text { Quarter }\end{array}$ & $\begin{array}{c}\text { 4th } \\
\text { Quarter }\end{array}$ & $\begin{array}{c}\text { Avg./Qtr. } \\
\pm 2 \sigma(95 \%)\end{array}$ & $\begin{array}{c}\text { Annual } \\
\text { Dose } \\
\pm 2 \sigma(95 \%)\end{array}$ \\
\hline & & \multicolumn{6}{|c|}{ - (mrem) } \\
\hline 054-TLD2 & N/E of Bldg. 913-B & 22.7 & 48.1 & 15.0 & 25.1 & $28 \pm 28$ & $111 \pm 112$ \\
\hline 054-TLD3 & N/W of Bldg. 913-B & 29.2 & 25.3 & 13.9 & 21.5 & $22 \pm 13$ & $90 \pm 51$ \\
\hline S6 & & 21.0 & 17.6 & 17.1 & 21.6 & $19 \pm 5$ & $77 \pm 18$ \\
\hline 088-TLD1 & FWMF-50' East of S-6 & 19.6 & 18.3 & 17.4 & 19.2 & $19 \pm 2$ & $75 \pm 8$ \\
\hline 088-TLD2 & FWMF-50' West of S-6 & 21.5 & 20.5 & 19.6 & 22.2 & $21 \pm 2$ & $84 \pm 9$ \\
\hline 088-TLD3 & FWMF-100' West of S-6 & 22.0 & 19.5 & 19.3 & 22.8 & $21 \pm 3$ & $84 \pm 9$ \\
\hline 088-TLD4 & FWMF-150' West of S-6 & 19.7 & 17.9 & 19.8 & 18.5 & $19 \pm 2$ & $76 \pm 7$ \\
\hline 075-TLD3 & Bldg. 356 & 29.1 & 27.6 & 29.0 & 28.4 & $29 \pm 1$ & $114 \pm 5$ \\
\hline 075-TLD5 & North Corner of Bldg. 356 & 26.8 & 30.0 & 27.6 & 33.8 & $30 \pm 6$ & $118 \pm 25$ \\
\hline $\begin{array}{l}\text { Notes: } \\
\text { See Figure } 8 \\
\text { FWMF = For }\end{array}$ & $\begin{array}{l}\text { TLD locations. } \\
\text { laste Management Facility }\end{array}$ & & & & & & \\
\hline
\end{tabular}

\subsection{DOSE MODELING}

EPA regulates radiological emissions from DOE facilities under the requirements set forth in 40 CFR 61, Subpart H, National Emission Standards for Hazardous Air Pollutants (NESHAPs). This regulation specifies the compliance and monitoring requirements for reporting radiation doses received by members of the public from airborne radionuclides. The regulation mandates that no member of the public shall receive a dose from DOE operations that is greater than $10 \mathrm{mrem}(100 \mu \mathrm{Sv})$ in a year. The emission monitoring requirements are set forth in Subpart H, Section 61.93(b) and include the use of a reference method for continuous monitoring at major release points (defined as those with a potential to exceed 1 percent of the $10 \mathrm{mrem}$ standard), and a periodic confirmatory measurement for all other release points. The regulations also require DOE facilities to submit an annual NESHAPs report to EPA that describes the major and minor emission sources and dose to the MEI. The dose estimates from various facilities are given in Table 8-4, and the emissions are discussed in detail in Chapter 4.

As a part of the NESHAPs review process at $\mathrm{BNL}$, any source that has the potential to emit radioactive materials is evaluated for regulatory compliance. Although the activities conducted under the Environmental Restoration (ER)
Program are exempt under the Comprehensive Environmental Response, Compensation and Liability Act (CERCLA), these activities are monitored and assessed for any potential to release radioactive materials, and to determine their dose contribution, if any, to the environment. Any new processes or activities are evaluated for compliance with NESHAPs regulations using EPA's approved dose modeling software (see Section 8.2.1 for details). Because this model was designed to treat all radioactive emission sources as continuous over the course of a year, it is not well suited for estimating short-term or acute releases. Consequently, it overestimates potential dose contributions from short-term projects and area sources. For that reason, the results are considered to be "conservative"that is, erring on the side of caution.

\subsubsection{Dose Modeling Program}

Compliance with NESHAPs regulations is demonstrated through the use of EPA dose modeling software and the Clean Air Act Assessment Package-1988 (CAP88-PC), Versions 2.1 and 3.0. This computer program uses a Gaussian plume model to estimate the average dispersion of radionuclides released from elevated stacks or diffuse sources. It calculates a final value of the projected dose at the specified distance from the release point by computing dispersed radio- 
Table 8-4. MEI Effective Dose Equivalent From Facilities or Routine Processes.

\begin{tabular}{|c|c|c|c|c|}
\hline Building No. & Facility or Process & Construction Permit No. & $\begin{array}{l}\text { MEI Dose } \\
(\text { mrem) (a) }\end{array}$ & Notes \\
\hline 348 & Radiation Protection & None & ND & (b) \\
\hline 463 & Biology Facility & None & ND & (b) \\
\hline 490 & Medical Research & BNL-489-01 & $6.01 \mathrm{E}-12$ & (b) \\
\hline $490 \mathrm{~A}$ & Energy and Environment National Security & None & ND & (b) \\
\hline 491 & Brookhaven Medical Research Reactor & None & ND & (e) \\
\hline 510 & Calorimeter Enclosure & BNL-689-01 & ND & $(f)$ \\
\hline $510 \mathrm{~A}$ & Physics & None & ND & (b) \\
\hline 535 & Instrumentation & None & ND & (b) \\
\hline 555 & Chemistry Facility & None & ND & (b) \\
\hline 725 & National Synchrotron Light Source & None & ND & (b) \\
\hline 750 & High Flux Beam Reactor & None & $6.68 \mathrm{E}-6$ & (c) \\
\hline 801 & Target Processing Lab & None & $1.14 \mathrm{E}-8$ & (b), (c) \\
\hline $802 B$ & Evaporator Facility & BNL-288-01 & NO & (e) \\
\hline 820 & Accelerator Test Facility & BNL-589-01 & ND & (d) \\
\hline 830 & Environmental Science Department & None & ND & (d) \\
\hline 865 & Reclamation Building & None & ND & (c) \\
\hline 906 & Medical-Chemistry & None & ND & \\
\hline 925 & Accelerator Department & None & ND & (b) \\
\hline 931 & Brookhaven Linac Isotope Producer & None & $5.96 \mathrm{E}-2$ & (c) \\
\hline 938 & REF/NBTF & BNL-789-01 & ND & (g) \\
\hline 942 & Alternate Gradient Syncrotron Booster & BNL-188-01 & ND & (h) \\
\hline-- & Relativistic Heavy Ion Collider & BNL-389-01 & ND & (d) \\
\hline \multicolumn{2}{|c|}{ Total Potential Dose from BNL Operations } & \multicolumn{3}{|c|}{$5.96 \mathrm{E}-2$} \\
\hline EPA Limit & & \multicolumn{3}{|c|}{10.0 mrem } \\
\hline \multicolumn{2}{|c|}{$\begin{array}{l}\text { Notes: } \\
\text { Diffuse, Fugitive, and Other sources are not included in this table since } \\
\text { they are short-term emissions. } \\
\text { MEI = Maximally Exposed Individual } \\
\text { NBTF = Neutron Beam Test Facility } \\
\text { REF = Radiation Effects Facility } \\
\text { (a) "Dose" in this table means effective dose equivalent to MEI. } \\
\text { (b) Dose is based on emissions calculated using } 40 \text { CFR } 61 \text {, Appendix D } \\
\text { methodology. } \\
\text { (c) Emissions are monitored at the facility. }\end{array}$} & \multicolumn{3}{|c|}{$\begin{array}{l}\text { (d) ND = No dose from emissions source in } 2007 . \\
\text { (e) NO = Not operational in } 2007 \text {. } \\
\text { (f) This has become a zero-release facility since original permit } \\
\text { application. } \\
\text { (g) This facility is no longer in use; it produces no radioactive } \\
\text { emissions. } \\
\text { (h) Booster ventilation system prevents air release through } \\
\text { continuous air recirculation. }\end{array}$} \\
\hline
\end{tabular}

nuclide concentrations in air, rate of deposition on ground surfaces, and intake via the food pathway (where applicable). CAP88-PC calculates both the EDE to the MEI and the collective population dose within a 50-mile radius of the emission source. In most cases, the CAP88-PC model provides conservative doses. For the purpose of modeling the dose to the MEI, all emission points are located at the center of the developed portion of the BNL site. The dose cal- culations are based on very low concentrations of the environmental releases and on chronic, continuous intakes in a year. The input parameters used in the model include radionuclide type, emission rate in curies (Ci) per year, stack parameters such as height and diameter, and emission exhaust velocity. Site-specific weather and population data are factored into the dose assessment. Weather data are supplied by measurements from the Laboratory's meteorological 
tower. These measurements include wind speed, direction, frequency, and air temperature (see Chapter 1 for details). Population data used in the model are based on the Long Island Power Authority population survey (LIPA 2000). Because visiting researchers and their families may reside at the BNL on-site apartment area for extended periods, these residents are included in the population file used for dose assessment.

\subsubsection{Dose Calculation Methods and Pathways 8.2.2.1 Maximally Exposed Individual}

The MEI is defined as a hypothetical person who resides at the site boundary and has a lifestyle such that no other member of the public could receive a higher dose. This person is assumed to reside 24 hours a day, 365 days a year at the BNL site boundary in the downwind direction, and to consume significant amounts of fish and deer containing radioactivity attributable to Laboratory operations based on projections from the New York State Department of Health (NYS$\mathrm{DOH})$. In reality, it is highly unlikely that such a combination of "maximized dose" to any single individual would occur, but the concept is useful for evaluating maximum potential risk and dose.

\subsubsection{Effective Dose Equivalent}

The EDE to the MEI for low levels of radioactive materials dispersed into the environment was calculated using the CAP88-PC dose modeling program, Versions 2.1 and 3.0. Site meteorology data were used to calculate annual dispersions for the midpoint of a given wind sector and distance. Facility-specific radionuclide release rates $(\mathrm{Ci} / \mathrm{yr})$ were used for continuously monitored facilities. For small sources, the emissions were calculated using the method set forth in 40 CFR 61, Appendix D. The Gaussian dispersion model calculated the EDE at the site boundary and the collective population dose values from immersion, inhalation, and ingestion pathways. These dose and risk calculations to the MEI are based on low emissions and chronic intakes.

\subsubsection{Dose Calculation: Fish Ingestion}

To calculate the EDE from the fish consumption pathway, the intake is estimated. Intake is the average amount of fish consumed by a person engaged in recreational fishing in the Peconic River. Based on a NYSDOH study, the consumption rate is estimated at 15 pounds (7 kg) per year (NYSDOH 1996). For each radionuclide of concern for fish samples, the dry weight activity concentration was converted to picocuries per gram ( $\mathrm{pCi} / \mathrm{g}$ ) wet weight, since "wet weight" is the form in which fish are caught and consumed. A dose conversion factor was used for each radionuclide to convert the activity concentration into the EDE. For example, the committed dose equivalent factor for cesium-137 (Cs-137) is 5.0E-02 rem/ $\mu \mathrm{Ci}$, as set forth in DOE/EH-0071. The dose was calculated as: dose $(\mathrm{rem} / \mathrm{yr})=$ intake $(\mathrm{kg} / \mathrm{yr}) \times$ activity in flesh $(\mu \mathrm{Ci} / \mathrm{kg}) \times$ dose factor $(\mathrm{rem} / \mu \mathrm{Ci})$.

\subsubsection{Dose Calculation: Deer Meat Ingestion}

The dose calculation for the deer meat ingestion pathway is similar to that for fish consumption. The Cs-137 radionuclide dose conversion factor was used to estimate dose, based on the U.S. Environmental Protection Agency Exposure Factors Handbook (EPA 1996). The total quantity of deer meat ingested during the course of a year was estimated as 64 pounds $(29 \mathrm{~kg})$ (NYSDOH 1999).

\subsection{SOURCES: DIFFUSE, FUGITIVE, "OTHER"}

Diffuse sources are described as releases of radioactive contaminants to the atmosphere that do not have a well-defined emission point such as a stack or vent. Such sources are also known as nonpoint or area sources. Fugitive sources include releases to the air not through an actively ventilated air stream (i.e., leaks from vents are fugitive sources). As a part of the NESHAPs review process, in addition to stack emissions, any fugitive or diffuse emission source that could potentially emit radioactive materials to the environment is evaluated. Although CERCLA-prompted actions, such as remediation projects, are exempt from the procedural requirements to obtain federal, state, or local permits, any BNL activity or process with the potential to emit radioactive material must be evaluated and assessed for dose impact to members of the public. The following radiologi- 
cal sources were evaluated in 2007 for potential contribution to the overall site dose.

\subsubsection{Medical Department}

In the Medical Department (Building 490), Room 9-830 was used for bio-assay, lysis of cells, immuno-precipitation, separation of recoverable radioactive proteins by electrophoresis, and the incorporation of radio-labeled tracers by injection into experimental animals to investigate certain scientific principles and perform research. Very small quantities of radioactive tracers were used in the research project with low levels of radioactivity; between 2 to 20 millicurie quantities. A single or combination of the following radiotracers were used in the process: carbon-14 (half-life: 5730 years), fluorine-18 (half-life: 109.74 minutes), carbon-11 (half-life: 20.48 minutes), and phosphorus-32 (half life: 14.29 days). The research experiments can be repeated from 10 to 200 times over the course of a year. Room 9-830 is equipped with a fume hood with a HEPA filtration system to control the particulate emissions. The work was performed in accordance with a radiological work permit and the health and safety protection procedures of the facility.

The radioactive source term was based on the maximum quantity of radioactive materials used with the number of injections in a given year. In 2007, iodine-131 (half-life: 8.0917 days) was used 20 times, with a maximum activity of 20 microcuries (mCi); iodine-125 (half-life: 60.14 days) was used 20 times, with a maximum activity of less than $10 \mathrm{mCi}$; tritium and tritiated compounds were estimated to be used approximately 200 times, with a maximum activity of $20 \mathrm{mCi}$; carbon-14 was used approximately 100 times, also with a maximum activity of $20 \mathrm{mCi}$; and fluorine-18, carbon-11, and phosphorus-32 were used approximately 10 times, with a maximum activity of $100 \mathrm{mCi}$ each. The estimated source quantities were corrected for the emission factor because of their low probability for becoming airborne and because they were tagged tracers.

The effective dose equivalent to the MEI resulting from research operations in Room 9830 was estimated to be $2.08 \mathrm{E}-05 \mathrm{mrem} /$ year at BNL's southeast MEI location. The EDE was well below the $10 \mathrm{mrem} / \mathrm{year}$ annual limit specified in 40 CFR 61, Subpart H.

\subsubsection{Waste Loading Area}

The former Hazardous Waste Management Facility was a Resource Conservation and Recovery Act (RCRA)-permitted facility used for processing and storage of RCRA waste, radioactive waste, and mixed wastes generated at BNL. Currently, the former HWMF is fenced and categorized as a radiological facility under a surveillance and maintenance program of the Environmental and Waste Management Services Division. It is located south of Brookhaven Avenue in the southeast wind sector of the Laboratory. The project requirements were to excavate the remaining contaminated soil that was left at the waste loading area (WLA) during the 2005 remediation action plan for the former HWMF. The residual contamination was left in a 122 by 84 meter surface area that was designated to be used as the loading dock for other remedial activities at a later date. However, a decision was made in 2007 to proceed with the remediation of the WLA area. Therefore, a NESHAPs evaluation was performed to evaluate the dose risks to the members of the public during the remediation activities.

An excavator was used to scrape the top layers of soil and a front-end loader was used to load the contaminated soil into rail cars for off-site disposal. To minimize airborne dust particles and the resuspension of particulates, workers used suppression control techniques such as water mist spray and laying a tarp cover over the soil. Water mist was also sprayed over dirt roadways and the excavated work areas before the contaminated soil was loaded into rail cars. Excavation and soil loading activities were suspended during conditions of sustained high wind ( $>20 \mathrm{mph}$ ). An air particulate filter sample collection system was set up in the upwind direction (as a control sampler) and in the downwind direction to monitor particulates released from the excavation and loading activities.

The potential source term was defined as the amount of radioactive material, in grams or curies, based on the material-at-risk (MAR) that could get released into the environment. The 
MAR was defined as the maximum amount of radionuclides available to be acted upon by a given physical stress (in this case, decontamination and decommissioning activities), with some probability of release. The MAR values represented the maximum quantities of radionuclides present in the soil samples during the characterization activities. The following radionuclides were used in the NESHAP evaluation: tritium (0.2 pCi/g), cobalt-60 (0.4 pCi/g), strontium-90 (33.1 pCi/g), cesium-137 (395 pCi/g), uranium235 (7.4 pCi/g), uranium-238 (0.73 pCi/g), plutonium-238 (0.06 pCi/g), plutonium-239/240 (3.4 pCi/g), and americium-241 (4.6 pCi/g).

The radiological dose and risk to the MEI were assessed using the Clean Air Act Code CAP88-PC, version 3.0 modeling program, to show compliance with 40CFR 61.93 (a) of the CAA regulations. The total annual dose to the MEI resulting from the remediation project in the WLA was estimated to be 5.90E-2 mrem, well below the $10 \mathrm{mrem} /$ year annual limit specified in 40 CFR 61, Subpart H.

\subsection{DOSE FROM POINT SOURCES}

\subsubsection{Brookhaven Linac Isotope Producer}

Source term descriptions for point sources are given in Chapter 4. The Brookhaven Linac Isotope Producer (BLIP) facility is the only emission source with any potential to contribute dose to members of the public greater than 1 percent of the EPA limit (i.e., $0.1 \mathrm{mrem}$, or $1.0 \mu \mathrm{Sv}$ ). The BLIP facility uses the excess beam capacity of the Linear Accelerator (Linac) to produce short-lived radioisotopes for medical diagnostic procedures, medical imaging, and scientific research. During the irradiation process, the targets are cooled continuously by recirculating water in a 16-inch-diameter shaft. The principal gaseous radionuclides produced as a result of activation of the cooling water are $\mathrm{O}-15, \mathrm{~N}-13$, and C-11. Because the BLIP facility has the potential to exceed 1 percent of the EPA emission limit, the facility emissions are directly measured using a low-resolution gamma spectrometer with an in-line sampling system connected to the air exhaust, to measure the short-lived gaseous products that cannot be sampled and analyzed by conventional analytical methods.
Particulates and radioiodine are monitored with paper and granular activated charcoal filters, which are exchanged weekly for analysis by a contract analytical laboratory. A tritium sampler also operates continuously, with weekly sample collection and analyses frequency.

In 2007, the BLIP facility operated over a period of 20 weeks. During the year, $837 \mathrm{Ci}$ of C-11 and $1698 \mathrm{Ci}$ of O-15 were released from the BLIP facility. A small quantity of tritiated water vapor from activation of the targets' cooling water was also released: 4.92E-02 $\mathrm{Ci}$. The EDE to the MEI was calculated to be $5.96 \mathrm{E}-02 \mathrm{mrem}(0.60 \mu \mathrm{Sv})$ in a year from BLIP operations.

Anticipating an increase in operating hours for the BLIP facility in 2008 because of greater demand for medical diagnostic isotopes and reduced production at the Los Alamos National Laboratory production facility, an application for a NESHAPs permit was prepared. That application will be submitted to EPA in early 2008 .

\subsubsection{High Flux Beam Reactor}

In 2007, the HFBR facility was in a "cold" shutdown mode and was downgraded from a nuclear facility to a radiological facility. Tritium samples were taken monthly and the dose contribution was determined to be $6.68 \mathrm{E}-6 \mathrm{mrem}$ $(7 \mathrm{nSv})$ in a year.

\subsubsection{Brookhaven Medical Research Reactor}

In 2007, the Brookhaven Medical Research Reactor (BMRR) facility was in a "cold" shutdown mode. Tritium sampling and analyses were completed inside the building to quantify the tritium contents in the humid enclosed air. The tritium concentrations in the building were found to be very low-insignificant from a dose risk point of view and there was no dose contribution from the BMRR.

\subsubsection{Unplanned Releases}

There were no unplanned releases in 2007.

\subsection{DOSE FROM INGESTION}

Because deer and fish bioaccumulate radionuclides in their tissues, bones, and organs, tissue samples were analyzed to evaluate the dose contribution to humans from the ingestion pathway. 
As discussed in Chapter 6, deer meat samples collected off site and less than 1 mile from the BNL boundary were used to assess the potential dose impact to the MEI. Four samples of deer meat (flesh) were used to calculate the "off site and less than 1 mile" average at $0.81 \pm 0.20$ $\mathrm{pCi} / \mathrm{g}$; however, the maximum concentration of $2.1 \mathrm{pCi} / \mathrm{g}$ was used for the purpose of MEI dose calculations. Potassium-40 (K-40) and Cs-137 were the two radionuclides detected in the tissue samples. K-40 is a naturally occurring radionuclide and is not related to BNL operations. In 2007, the average $\mathrm{K}-40$ concentrations in tissue samples (off site $<1$ mile) were $3.7 \pm 0.9 \mathrm{pCi} / \mathrm{g}$ (wet weight) in the flesh and $2.7 \pm 0.4 \mathrm{pCi} / \mathrm{g}$ (wet weight) in the liver. The maximum Cs-137 concentrations were $2.1 \pm 0.2 \mathrm{pCi} / \mathrm{g}$ (wet weight) in the flesh and $0.5 \pm 0.1 \mathrm{pCi} / \mathrm{g}$ (wet weight) in the liver (see Table 6-2). The potential dose from consuming deer meat with the average Cs-137 concentration was estimated as 3.02 mrem ( 30 $\mu \mathrm{Sv}$ ) in a year. This is less than 30 percent of the health advisory limit of $10 \mathrm{mrem}(100 \mu \mathrm{Sv})$ established by NYSDOH.

In collaboration with the New York State Department of Environmental Conservation (NYSDEC) Fisheries Division, BNL maintains an ongoing program of collecting and analyzing fish from the Peconic River and surrounding freshwater bodies. In 2007, chain pickerel samples collected in the Peconic River at the Schultz Road site had the highest concentration of Cs-137, at $0.24 \pm 0.03 \mathrm{pCi} / \mathrm{g}$; this was used to estimate the EDE to the MEI. The potential dose from consuming 15 pounds of brown bullhead annually was calculated to be 0.08 mrem ( 0.8 $\mu \mathrm{Sv}$ ) — well below the NYSDOH health advisory limit of 10 mrem.

\subsection{DOSE TO AQUATIC AND TERRESTRIAL BIOTA}

DOE-STD-1153-2002, A Graded Approach for Evaluating Radiation Doses to Aquatic and Terrestrial Biota, provides the guidelines for screening methods to estimate radiological doses to aquatic animals, terrestrial plants, and terrestrial animals, using site-specific environmental surveillance data. The RESRAD-BIOTA 1.0 biota dose level 2 program was used to evaluate compliance with the requirements for pro- tection of biota specified in DOE Order 5400.5 (1990), Radiation Protection of the Public and the Environment, and DOE Order 450.1, General Environmental Protection Program.

In 2007, the terrestrial animal and plant doses were evaluated based on $4.47 \mathrm{pCi} / \mathrm{g}$ of Cs-137 found in the surface soils on the lawn of Building 515. The dose to terrestrial animals was calculated to be $0.22 \mathrm{mGy} / \mathrm{day}$, and to plants, 0.02 $\mathrm{mGy} /$ day. The doses to terrestrial animals and plants were well below the biota dose limit of 1 $\mathrm{mGy} /$ day.

For calculating dose to aquatic animals, radionuclide concentration values from Swan Pond were used for both the surface water and sediment samples from the same location. The Cs-137 sediment concentration was 1.04 $\mathrm{pCi} / \mathrm{g}$, and the $\mathrm{Sr}-90$ concentration in surface water was $1.0 \mathrm{pCi} / \mathrm{L}$. The aquatic animal dose was calculated to be $3.96 \mathrm{E}-07 \mathrm{~Gy} /$ day and the calculated dose to riparian animals was 3.92E$06 \mathrm{~Gy} /$ day. Therefore, the dose to aquatic and riparian animals was also well below the 10 $\mathrm{mGy} /$ day limit specified by the regulations.

\subsection{CUMULATIVE DOSE}

Table 8-5 summarizes the potential cumulative dose from the BNL site in 2007. The total dose to the MEI from air and ingestion pathways was estimated to be 3.16 mrem ( $32 \mu \mathrm{Sv})$. In comparison, the EPA regulatory limit for the air pathway is $10 \mathrm{mrem}(100 \mu \mathrm{Sv})$ and the DOE limit from all pathways is $100 \mathrm{mrem}(1,000 \mu \mathrm{Sv})$. The cumulative population dose would be 0.19 personrem ( 2 person-mSv) in a year. The effective dose was well below the DOE and EPA regulatory limits, and the ambient TLD dose was within normal background levels seen at the Laboratory site. The potential dose from drinking water was not estimated, because most of the residents adjacent to the BNL site get their drinking water from the Suffolk County Water Authority rather than private wells.

To put the potential dose impact into perspective, a comparison was made with other sources of radiation. The annual dose from all natural background sources and radon is approximately 300 mrem (3.0E-3 $\mu \mathrm{Sv})$. A diagnostic chest $\mathrm{x}-$ ray would result in 5 to $20 \mathrm{mrem}(50-200 \mu \mathrm{Sv})$ 
Table 8-5. BNL Site Dose Summary.

\begin{tabular}{l|c|c|c}
\hline \multicolumn{1}{l}{ Pathway } & $\begin{array}{c}\text { Dose to Maximally } \\
\text { Exposed Individual }\end{array}$ & $\begin{array}{c}\text { Percent of DOE } \\
100 \text { mrem/year Limit }\end{array}$ & \multicolumn{1}{c}{$\begin{array}{c}\text { Estimated } \\
\text { Population Dose per year }\end{array}$} \\
\hline Inhalation & & & \\
\hline Air & $0.06 \mathrm{mrem}(0.60 \mu \mathrm{Sv})$ & $<1 \%$ & 0.19 person-rem \\
\hline Ingestion & None & None & None \\
\hline Drinking water & $0.08 \mathrm{mrem}(0.8 \mu \mathrm{Sv})$ & $<1 \%$ & Not tracked \\
\hline Fish & $3.02 \mathrm{mrem}(30 \mu \mathrm{Sv})$ & $<4 \%$ & Not tracked \\
\hline Deer Meat & $3.16 \mathrm{mrem}(32 \mu \mathrm{Sv})$ & $<4 \%$ & 0.19 person-rem \\
\hline All Pathways &
\end{tabular}

per exposure. Using natural gas in homes yields approximately 9 mrem $(90 \mu \mathrm{Sv})$ per year, cosmic radiation yields $26 \mathrm{mrem}(260 \mu \mathrm{Sv})$, and natural potassium in the body yields approximately 39 mrem $(390 \mu \mathrm{Sv})$ of internal dose. Even with worst-case estimates of dose from the air pathway and ingestion of local deer meat and fish, the cumulative dose from BNL operations was well below the dose that could be received from a single chest $\mathrm{x}$-ray.

\section{REFERENCES AND BIBLIOGRAPHY}

40 CFR 61, Subpart H. National Emissions Standard for Hazardous Air Pollutants. U.S. Environmental Protection Agency, Washington, DC. 1989.

66 FR 25380. May 14, 2001. U.S. Department of Energy. 10 CFR 834, Radiation Protection of the Public and the Environment. Federal Register.

ANSI/HPS. 1999. Sampling and Monitoring Releases of Airborne Radioactive Substances from the Stacks and Ducts of Nuclear Facilities. N13.1-1999.

DOE. 2002. A Graded Approach for Evaluation of Radiation Doses to Aquatic and Terrestrial Biota. DOE-STD-1153-2002. U.S. Department of Energy, Washington, DC. July 2002.

DOE Order 5400.5. 1990. Radiation Protection of the Public and the Environment. U.S. Department of Energy, Washington, DC. Change 2: 1-7-93.
DOE Order 450.1. 2003. General Environmental Protection Program. U.S. Department of Energy, Washington, DC. Jan.15, 2003.

DOE/EH-0071. Internal Dose Conversion Factors for Calculations of Dose to the Public. July 1988.

EPA. 1992. User's Guide for CAP88-PC, Version 2.1.1. EPA 402B92001. U.S. Environmental Protection Agency, Washington, DC.

EPA. 1996. Food Ingestion Factors, Exposure Factors Handbook-Volume II. EPA600P95002FB. U.S. Environmental Protection Agency, Washington, DC.

LIPA. 2000. Population Survey 1999: Current Population Estimates for Nassau and Suffolk Counties and the Rockaway Peninsula. Long Island Power Authority, Uniondale, NY. October 1999.

NCRP. 1987. Exposure of the Population of the United States and Canada from Natural Background Radiation. NCRP Report No. 94. National Council on Radiation Protection and Measurements, Bethesda, MD.

NYSDOH. 1993. Environmental Radiation in New York State. Bureau of Environmental Radiation Protection, New York State Department of Health, Albany, NY.

NYSDOH. 1996. Radioactive Contamination in the Peconic River. Bureau of Environmental Radiation Protection, New York State Department of Health, Albany, NY.

NYSDOH. 1999. Deer Meat Contaminated With Cs137 at Brookhaven National Laboratory. Bureau of Environmental Radiation Protection, New York State Department of Health, Albany, NY. 
Intentionally Left Blank 


\section{Quality Assurance}

Quality assurance is an integral part of every activity at Brookhaven National Laboratory (BNL). A comprehensive Quality Assurance/Quality Control (QA/QC) Program is in place to ensure that all environmental monitoring samples are representative and that data are reliable and defensible. QC in the contract analytical laboratories is maintained through daily instrument calibration, efficiency and background checks, and testing for precision and accuracy. Data are verified and validated as required by project-specific quality objectives before being used to support decision making. The multilayered components of QA monitored at BNL ensure that all analytical data reported for the 2007 Site Environmental Report are reliable and of high quality.

\subsection{QUALITY PROGRAM ELEMENTS}

As required by DOE Order 450.1, Environmental Protection Program, BNL has established a QA/QC Program to ensure that the accuracy, precision, and reliability of environmental monitoring data are consistent with the requirements of Title 10 of the Code of Federal Regulations, Part 830 (10 CFR 830), Subpart A, Quality Assurance Requirements (2000) and DOE Order 414.1A, Quality Assurance. The responsibility for quality at BNL starts with the Laboratory director, who approves the policies and standards of performance governing work, and extends throughout the entire organization. The purpose of the BNL Quality Management (QM) System is to implement QM methodology throughout the various Laboratory management systems and associated processes, in order to:

- Plan and perform BNL operations in a reliable and effective manner to minimize any impact on the health and safety of the public, employees, and the environment

- Standardize processes and support continual improvement in all aspects of Laboratory operations

- Enable the delivery of products and services that meet customers' requirements and expectations

For environmental monitoring, QA is deployed as an integrated system of management activities. These activities involve planning, implementation, control, reporting, assessment, and continual improvement. QC activities measure each process or service against the QA standards. QA/QC practices and procedures are documented in manuals, plans, and a comprehensive set of standard operating procedures (SOPs) for environmental monitoring (EMSOPs). Staff members who must follow these procedures are required to document that they have reviewed and understand them.

The ultimate goal of the environmental monitoring and analysis QA/QC program is to ensure that results are representative and defensible, and that data are of the type and quality needed to verify protection of the public, employees, and the environment. Figure 9-1 depicts the flow of the QA/QC elements of BNL's Environmental Monitoring Program and indicates the sections of this chapter that discuss each element in more detail.

Laboratory environmental personnel determine sampling requirements using the EPA Data Quality Objective (DQO) process (EPA 2000) or its equivalent. During this process, the project manager for each environmental program determines the type, amount, and quality of data needed to support decision making, the legal requirements, and stakeholder concerns. An environmental monitoring plan or project-specific sampling plan is then prepared, specifying the location, frequency, type of sample, analytical 


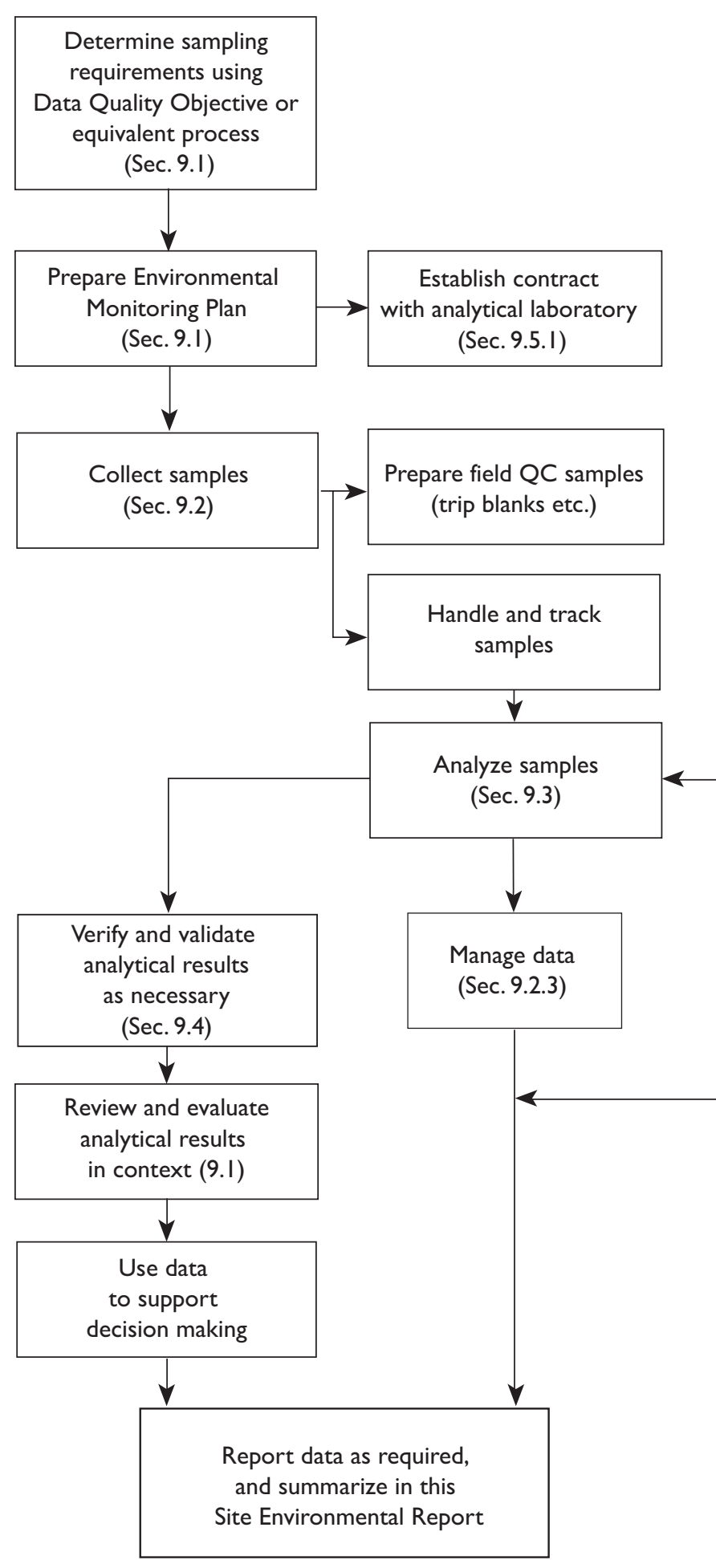

Figure 9-1. Flow of Environmental Monitoring QA/QC Program Elements. methods to be used, and a sampling schedule. These plans and the EM-SOPs also specify data acceptance criteria. Contracts with off-site analytical laboratories are established for sampling analysis. The EM-SOPs direct sampling technicians on proper sample collection, preservation, and handling requirements. Field QC samples are prepared as necessary. Samples are analyzed in the field or at certified contract analytical laboratories in accordance with EM-SOPs. The results are then validated or verified in accordance with published procedures. Finally, data are reviewed and evaluated by environmental professionals and management in the context of expected results, related monitoring results, historical data, and applicable regulatory requirements (e.g., drinking water standards, permit limits, etc.). Data are then used to support decision making. Data are also reported as required and summarized in this annual report.

\subsection{SAMPLE COLLECTION AND HANDLING}

In 2007, environmental monitoring samples were collected as specified by EM-SOPs, the BNL Environmental Monitoring Plan Update (BNL 2007), and project-specific work Test Laboratory Proficiency (Sec. 9.6) and Audit (Sec. 9.7)

plans, as applicable. For example, the BNL Groundwater Monitoring Program Quality Assurance Project Plan (QAPP) (BNL 1999) describes the QA program and QC requirements that must be followed for groundwater monitoring. This plan documents organizational structure, documentation requirements, sampling requirements, field QA/QC sample collection, acceptance criteria, sample custody requirements, data validation procedures, and general data handling and database procedures.

BNL has sampling SOPs for all environmental media, including groundwater, surface water, soil, sediment, air, flora, and fauna. These procedures contain detailed information on how to prepare for sample collection; what type of field equipment to use and how to calibrate it; how to 
properly collect, handle, and preserve samples; and how to manage any wastes generated during sampling. The procedures ensure consistency between samples collected by BNL sampling personnel and outside contractors in support of the environmental restoration, compliance, and surveillance programs.

QC checks of sampling processes include the collection of field duplicates, matrix spike samples, field blanks, trip blanks, and equipment blanks. For example, field readings of water quality parameters are taken until all parameters are within acceptable limits. Also, specific sampling methodologies include QC checks. An example of this is the low-flow groundwater sampling technique, which includes checks to ensure that monitoring wells are properly purged before readings are taken.

All wastes generated during sampling (contaminated equipment, purge water from wells, etc.) are managed in accordance with applicable requirements. A factor considered during sample collection is minimizing the amount of waste generated, consistent with the Pollution Prevention Program described in Chapter 2.

\subsubsection{Field Sample Handling}

To ensure the integrity of samples, chain-ofcustody (COC) was maintained and documented for all samples collected in 2007. A sample is considered to be in the custody of a person if any of the following rules of custody are met: 1) the person has physical possession of the sample, 2) the sample remains in view of the person after being in possession, 3) the sample is placed in a secure location by the custody holder, or 4) the sample is in a designated secure area. These procedures are outlined in EM-SOP 109, "Chain-of-Custody, Storage, Packaging, and Shipment of Samples” (BNL 2008). All environmental monitoring samples in 2007 maintained a valid COC from the time of sample collection through sample disposal by the contract analytical laboratories.

\subsubsection{Custody and Documentation}

Field sampling technicians are responsible for the care and custody of samples until they are transferred to a receiving group or contract ana- lytical laboratory. Samples requiring refrigeration are placed immediately into a refrigerator or a cooler with cooling media, and kept under custody rules. The technician signs the COC form when relinquishing custody, and contract analytical laboratory personnel sign the COC form when accepting custody.

As required by EM-SOP-201, "Documentation of Field Activities" (BNL 2007a), the field sampling technician is also required to maintain a bound, weatherproof field logbook, which is used to record sample ID number, collection time, description, collection method, and COC number. Daily weather conditions, field measurements, and other appropriate site-specific observations also are recorded in the logbook.

\subsubsection{Preservation and Shipment}

Before sample collection, the field sampling technicians prepare all bottle labels and affix them to the appropriate containers, as defined in the QA program plan or applicable EM-SOPs. Appropriate preservatives are added to the containers before or immediately after collection; in appropriate cases, samples are refrigerated. For example, samples collected for methylmercury are cooled immediately and shipped to the contract analytical laboratory on the day of collection. After samples arrive at the laboratory, they are preserved with hydrochloric acid.

Sample preservation is maintained as required throughout shipping. If samples are sent via commercial carrier, a bill-of-lading is used. COC seals are placed on the shipping containers; their intact status upon receipt indicates that custody was maintained during shipment. These procedures are outlined in EM-SOP 109.

\subsubsection{Field Quality Control Samples}

Field QC samples collected for the environmental monitoring program include equipment blanks, trip blanks, field blanks, field duplicate samples, and matrix spike/matrix spike duplicate samples. The rationale for selecting specific field QC samples, and minimum requirements for their use in the environmental monitoring program, are provided in the BNL EM-SOP 200 series. Equipment blanks and trip blanks (see below) were collected for all appropriate media in 2007. 
An equipment blank is a volume of solution (in this case, laboratory-grade water) that is used to rinse a sampling tool after decontamination. The rinse water is collected and tested to verify that the sampling tool is not contaminated. Equipment blank samples are collected, as needed, to verify the effectiveness of the decontamination procedures on nondedicated or reusable sampling equipment.

A trip blank is provided with each shipping container of samples to be analyzed for volatile organic compounds (VOCs). Analysis of trip blanks shows whether a sample bottle was contaminated during shipment from the manufacturer, while in bottle storage, in shipment to a contract analytical laboratory, or during analysis at a lab. Trip blanks consist of an aliquot of laboratory-grade water sealed in a sample bottle, usually prepared by the contract analytical laboratory prior to shipping the sample bottles to BNL. If trip blanks were not provided by the lab, then field sampling technicians prepare trip blanks before they collect the samples. Trip blanks were included with all shipments of aqueous samples for VOC analysis in 2007.

Field blanks are collected to check for crosscontamination that may occur during sample collection. For the Groundwater Monitoring Program, one field blank is collected for every 20 samples, or one per sampling round, whichever is more frequent. Field blanks are analyzed for the same parameters as groundwater samples. For other programs, the frequency of field blank collection is based on their specific DQOs.

In 2007 (as in other years), the most common contaminants detected in the trip, field, and equipment blanks included methylene chloride, toluene, and chloroform. These compounds are commonly detected in blanks and do not pose significant problems with the reliability of the analytical results. Several other compounds were also detected, such as acetone and strontium-90 (Sr-90), at low levels. When these contaminants are detected, validation or verification procedures are used, where applicable, to qualify the associated data as "nondetects," (see Section 9.4). The results from blank samples collected during 2007 did not indicate any significant impact on the quality of the results.
Field duplicate samples are analyzed to check the reproducibility of sampling and analytical results, based on EPA Region II guidelines (EPA 2006). For example, in the Groundwater Monitoring Program, duplicates are collected for 5 percent of the total number of samples collected for a project per sampling round. During 2007, 180 duplicate samples were collected for nonradiological analyses, and 553 duplicate samples were collected for radiological analyses. All duplicate samples were acceptable for input into BNL's Environmental Information Management System (EIMS) database, which is used to manage the Laboratory's environmental data. Duplicates were analyzed only for the parameters relevant to the program they monitored. Of the 9,597 nonradiological parameters analyzed in 2007, 98 percent of the analyses met QA criteria. Of the 2,901 radiological parameters monitored, 95.8 percent met QA criteria. While these results indicate consistency between the contract analytical laboratory and field sampling technicians, there is an apparent pattern to many of the "out-of-control" duplicate results. Analysis of samples by Test America (TA) in areas where no tritium is expected has shown low levels of tritium (below 4,000 pCi/L). However, reanalyses of the same samples cannot confirm these detections. To minimize the reporting of false positives, TA has instituted a policy of reanalyzing tritium detections for projects where active or passive tritium remediation is not being monitored. This includes all projects except the sitewide HFBR groundwater monitoring program and the g-2 groundwater monitoring program. If the tritium results cannot be verified, the reanalyses are reported.

Matrix spike and matrix spike duplicates are performed to determine whether the sample matrix (e.g., water, soil, air, vegetation, bone, or oil) adversely affected the sample analysis. A spike is a known amount of analyte added to a sample. Matrix spikes are performed at a rate specified by each environmental program's DQOs. The rate is typically one per 20 samples collected per project. No significant matrix effects were observed in 2007 for routine matrices such as water and soil. Nonroutine matrices, such as oil, exhibited the expected matrix issues. 


\subsubsection{Tracking and Data Management}

Most environmental monitoring samples and analytical results were tracked in the EIMS. The small number of environmental samples that were not tracked in the EIMS were from Chemtex Lab, which cannot produce the electronic data deliverables needed to enter the data into BNL's EIMS. Tracking was initiated when a sample was recorded on a COC form. Copies of the COC form and supplemental forms were provided to the project manager or the sample coordinator and forwarded to the data coordinator to be entered into the EIMS. Each contract analytical laboratory also maintained its own internal sample tracking system.

Following sample analysis, the contract analytical laboratory provides the results to the project manager or designee and, when applicable, to the validation subcontractor, in accordance with their contract. Once results of the analyses are entered into the EIMS, reports can be generated by project personnel and DOE Brookhaven Site Office staff using a web-based data query tool.

\subsection{SAMPLE ANALYSIS}

In 2007, environmental samples were analyzed by one of five contract laboratories, whose selection is discussed in Section 9.3.1. All samples were analyzed according to EPA-approved methods, where such methods exist, and by standard industry methods where there are no EPA methods. In addition, field sampling technicians performed field monitoring for parameters such as conductivity, dissolved oxygen, $\mathrm{pH}$, temperature, and turbidity.

\subsubsection{Qualifications}

BNL used the following contract analytical laboratories for analysis of environmental samples in 2007:

- General Engineering Lab (GEL) in Charleston, South Carolina, for radiological and nonradiological analytes

- H2M Lab in Melville, New York, for nonradiological analytes

- Test America (TA), formerly Severn-Trent Lab, based in St. Louis, Missouri, for radiological and nonradiological analytes
- Chemtex Lab in Port Arthur, Texas, for select nonradiological analytes

- Brooks Rand in Seattle, Washington, for mercury and methylmercury analyses

The process of selecting off-site contract analytical laboratories involves a number of factors: 1 ) their record on performance evaluation (PE) tests, 2) their contract with the DOE Integrated Contract Procurement Team, 3) pre-selection bidding, and 4) their adherence to their own QA/QC programs, which must be documented and provided to BNL. Routine QC procedures that laboratories must follow, as discussed in Section 9.5, include daily instrument calibrations, efficiency and background checks, and standard tests for precision and accuracy. All the laboratories contracted by BNL in 2007 were certified by the New York State Department of Health (NYSDOH) for the relevant analytes, where such certification existed. The laboratories also were subject to $\mathrm{PE}$ testing and DOEsponsored audits (see Section 9.7).

\subsection{VERIFICATION AND VALIDATION OF ANALYTICAL RESULTS}

Environmental monitoring data are subject to data verification and, in certain cases, data validation, when the data quality objectives of the project require this step. For example, groundwater samples collected for the Long Term Remedial Action (LTRA) group undergo data verification, whereas specific data collected for specific waste streams undergo full validation.

The data verification process involves checking for common errors associated with analytical data. The following criteria can cause data to be rejected during the data verification process:

- Holding time missed - The analysis is not initiated or the sample is not extracted within the time frame required by EPA or by the contract.

- Incorrect test method - The analysis is not performed according to a method required by the contract.

- Poor recovery - The compounds or radioisotopes added to the sample before laboratory processing are not recovered at the recovery ratio required by the contract.

- Insufficient $Q A / Q C$ data - Supporting data 
received from the contract analytical laboratory are insufficient to allow validation of results.

- Incorrect minimum detection limit (MDL)

- The contract analytical laboratory reports extremely low levels of analytes as "less than minimum detectable," but the contractually required limit is not used.

- Invalid chain-of-custody - There is a failure to maintain proper custody of samples, as documented on COC forms.

- Instrument failure - The instrument does not perform correctly.

- Preservation requirements not met - The requirements identified by the specific analytical method are not met or properly documented.

- Contamination of samples from outside sources - These possible sources include sampling equipment, personnel, and the contract analytical laboratory.

- Matrix interference - Analysis is affected by dissolved inorganic/organic materials in the matrix.

Data validation involves a more extensive process than data verification. Validation includes all the verification checks as well as checks for less common errors, including instrument calibration that was not conducted as required, internal analyte standard errors, transcription errors, and calculation errors. The amount of data checked varies, depending on the environmental media and on the DQOs for each project. Data for some projects, such as long-term groundwater monitoring, may require only verification. Data from some waste streams receive the more rigorous validation testing, performed on 20 to 100 percent of the analytical results. The results of the verification or validation process are entered into the EIMS.

\subsubsection{Checking Results}

Nonradiological data analyzed in 2007 were verified and/or validated, when project DQOs required, using BNL EM-SOPs in the 200 Series and EPA contract laboratory program guidelines (EPA 1992, 2006). Radiological packages were verified and validated using BNL and DOE guidance documents (BNL 2002, DOE 1994).
During 2007, the verifications were conducted using a combination of manually checking the hard copy data packages and the use of a computer program developed at BNL to verify the information reported electronically and is stored in the EIMS.

\subsection{CONTRACT ANALYTICAL LABORATORY QA/QC}

In 2007, procedures for calibrating instruments, analyzing samples, and assessing QC were consistent with EPA methodology. QC checks performed included: analyzing blanks and instrument background; using Amersham Radiopharmaceutical Company or National Institute for Standards and Technology (NIST) traceable standards; and analyzing reference standards, spiked samples, and duplicate samples. Analytical laboratory contracts specify analytes, methods, required detection limits, and deliverables - which include standard batch QA/QC performance checks. As part of the laboratory selection process, candidate laboratories are required to provide BNL with copies of their QA/QC manuals and QA program plans.

When discrepancies were found in field sampling designs, documented procedures, COC forms, data analyses, data processing systems, and QA software, or when failures in PE testing occurred, nonconformance reports were generated. Following investigation into the root causes, corrective actions were taken and tracked to closure.

\subsection{PERFORMANCE OR PROFICIENCY EVALUATIONS}

Four of the contract analytical laboratories (GEL, TA, H2M, and Brooks Rand) participated in several national and state PE testing programs in 2007. The fifth contractor, Chemtex Laboratory, did not participate in PE testing because there is no testing program for the specific analytes Chemtex analyzed: tolytriazole, polypropylene glycol monobutyl ether, and 1,1hydroxyethylidene diphosphonic acid. Each of the participating laboratories took part in at least one testing program, and several laboratories participated in multiple programs. Results of the tests provide information on the quality of a lab- 
oratory's analytical capabilities. The testing was conducted by Environmental Resource Associates (ERA), the National Voluntary Laboratory Accreditation Program (NVLAP), the voluntary Mixed Analyte Performance Evaluation Program (MAPEP), and NYSDOH Environmental Laboratory Accreditation Program (ELAP). The results from these tests are summarized in Section 9.6.1. Because Brooks Rand only analyzed samples for mercury and methylmercury, their PE results are not summarized. Brooks Rand maintained the required certification when performing analyses for BNL in 2007.

\subsubsection{Summary of Test Results}

In Figures 9-2 and 9-3, results are plotted as percentage scores that were "Acceptable," "Warning (But Acceptable)," or "Not Acceptable." A Warning (But Acceptable) is considered by the testing organization to be "satisfactory." An "average overall satisfactory" score is the sum of results rated as Acceptable and those rated as Warning (But Acceptable), divided by the total number of results reported. A Not Acceptable rating reflects a result that is greater than three standard deviations from the known value - a criterion set by the independent testing organizations.

Figure 9-2 summarizes radiological performance scores in the ERA and MAPEP programs. During 2007, the New York State ELAP did not provide radiological samples for PE testing, so there were no ELAP scores as there have been in past years. GEL and TA had average overall satisfactory scores of 99 and 93 percent, respectively. More details about the radiological assessments are in Section 9.6.1.1.

Figure 9-3 summarizes the nonradiological performance results of the three participating laboratories (GEL, H2M, and TA) in the ERA, MAPEP, and ELAP tests. For nonradiological tests, the average overall satisfactory results ranged from 95.3 to 100 percent. Additional details on nonradiological evaluations are in Section 9.6.1.2.

\subsubsection{Radiological Assessments}

In 2007, TA and GEL participated in the ERA and MAPEP programs. The NYSDOH Envi- ronmental Laboratory Accreditation Program provided no samples for radiological testing in 2007.

Both GEL and TA participated in the ERA radiological PE studies. For GEL's tests on radiological samples, 98.4 percent were in the acceptable range; 90 percent of TA's tests were acceptable. GEL and TA participated in the MAPEP evaluations: 95 percent of GEL's tests on radiological samples were in the acceptable range, and 5 percent were in the warning (but acceptable) range. For TA's MAPEP tests on radiological samples, 95.4 percent were in the acceptable range and 1.5 percent were in the warning (but acceptable) range.

\subsubsection{Nonradiological Assessments}

During 2007, H2M and GEL participated in the NYSDOH ELAP evaluations of performance on tests of nonpotable water, potable water, and solid wastes. NYSDOH found 100 percent of H2M's nonradiological tests to be in the acceptable range and 95.4 percent of GEL's nonradiological tests to be in the acceptable range. TA, which is certified through the National Environmental Laboratory Accreditation Conference (NELAC), was not required to participate in ELAP evaluations.

H2M, TA, and GEL voluntarily participated in the ERA water supply and water pollution studies, although this evaluation is not required for New York State certification. ERA found that 100 percent of H2M's tests were in the acceptable range and 96 percent of TA's tests were in the acceptable range, as were 97 percent of GEL's tests.

TA and GEL also voluntarily participated in MAPEP evaluations. These evaluations showed that 98.0 percent of TA's nonradiological tests were in the acceptable range and 99.4 percent of GEL's nonradiological tests were in the acceptable range.

H2M also voluntarily participated in NISTNVLAP evaluations. These evaluations showed that 100 percent of H2M's nonradiological tests were in the acceptable range.

\subsection{AUDITS}

As part of DOE's Integrated Contract Pro- 


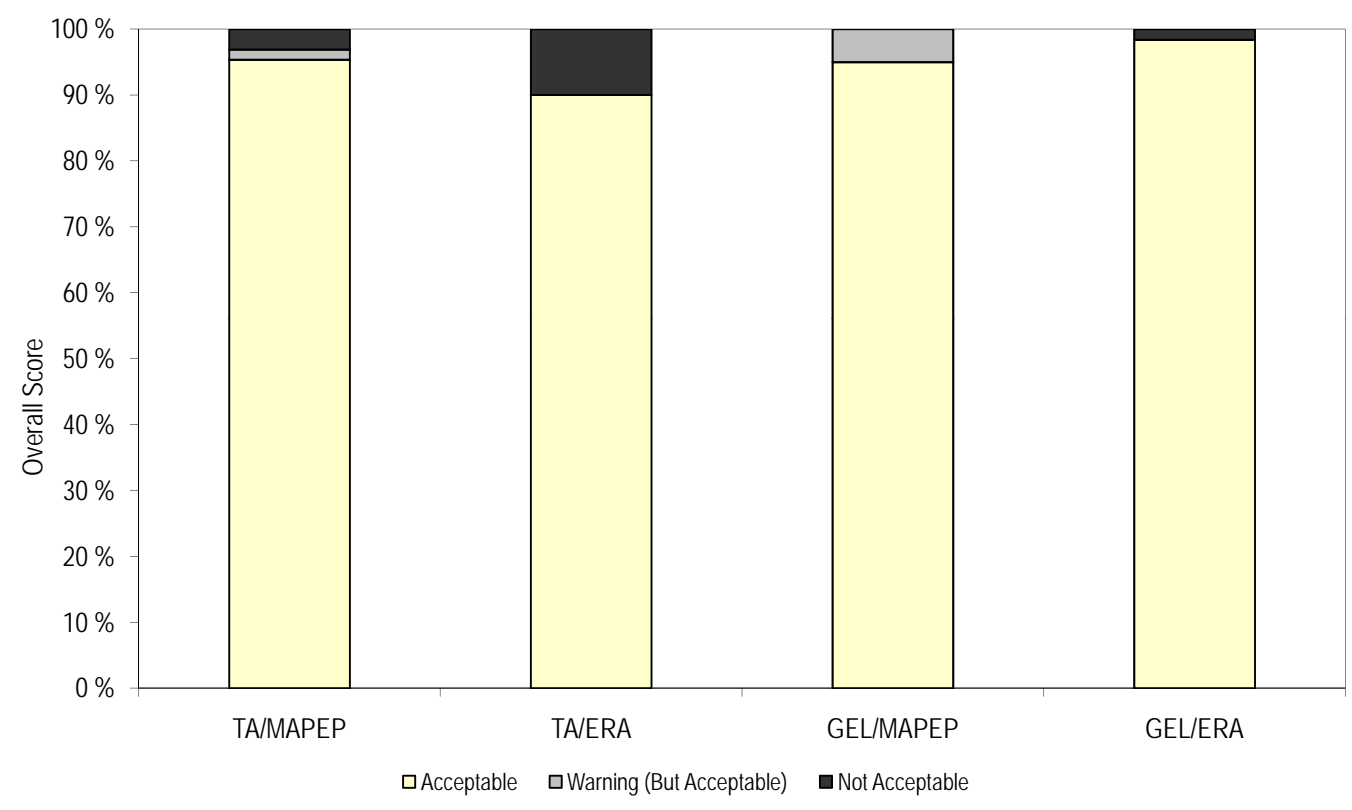

Note that the Acceptable scores and the Warning (But Acceptable) scores combined constitute the "overall satisfactory" category referred to in the text of this chapter.

Figure 9-2. Summary of Scores in the Radiological Proficiency Evaluation Programs.

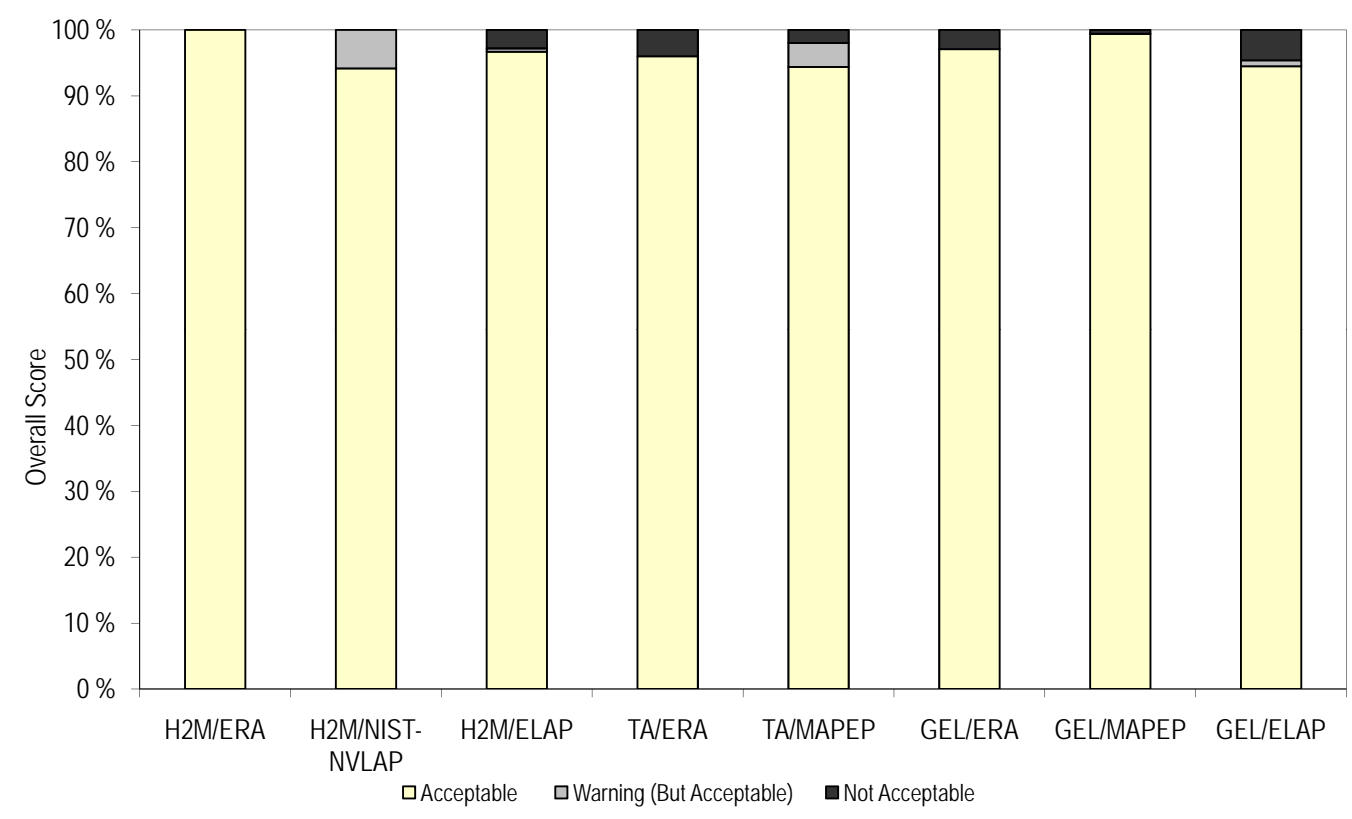

Note that the Acceptable scores and the Warning (But Acceptable) scores combined constitute the "overall satisfactory" category referred to in the text of this chapter.

Figure 9-3. Summary of Scores in the Nonradiological Proficiency Evaluation Programs.

curement Team Program, TA and GEL were audited during 2007 (DOE 2007a, b). During the audits, errors are categorized into Priority I and Priority II findings. Priority I status indicates a problem that can result in unusable data or a finding that the contract analytical laboratory cannot adequately perform services for DOE. Priority II status indicates problems that do not 
result in unusable data and do not indicate that the contract analytical laboratory cannot adequately perform services for DOE (DOE 2002). There were no Priority I findings for GEL. TA had two Priority I findings.

The results of the STL audit included two Priority I findings (one radiological and one waste management) and 18 Priority II findings: 11 radiological findings, two QA management system findings, one waste management finding, three inorganic findings, and one Laboratory Information Management System (LIMS) finding. The two Priority I findings against their radiological analysis and waste management departments indicated that the Technical Director of the radiochemistry department did not have the appropriate education/and or technical background and that the implementation of the radiation protection program had systematic failures and a lack of accountability of the radiological inventory. Based on these findings, it was necessary to suspend sending samples for radiological analyses until the TA facility successfully closed these issues with DOE. On July 11, 2007, DOE issued a letter stating that a re-audit of the facility resulted in the closing of the Priority I findings. Therefore, on July 26, 2007 authorization with given to ship BNL samples to TA. The results of the GEL audit included 13 Priority II findings: two QA management system findings, three organic findings, three inorganic findings, four radiological findings, and one waste management finding. Corrective action plans were submitted to DOE by both contract analytical laboratories to document that procedures were put in place to correct these findings. Based on the audits, the analytical data met DOE's criteria for acceptable status.

\subsection{CONCLUSION}

Based on the data validations, data verifications, and results of the independent Performance Evaluation assessments, the chemical and radiological results reported in this 2007 Site Environmental Report are of acceptable quality.

\section{REFERENCES AND BIBLIOGRAPHY}

10 CFR 830 Subpart A. U.S. Department of Energy. Quality Assurance Requirements. U.S. Code of Federal Regulations. 2000.

BNL. 1999. BNL Groundwater Monitoring Program Quality Assurance Project Plan (QAPP). Brookhaven National Laboratory. Upton, NY. August 31, 1999.

BNL. 2006. EM-SOP 209. "Radiochemical Data Validation." Brookhaven National Laboratory, Upton, NY.

BNL 2007a. EM-SOP-201 "Documentation of Field Activities." Brookhaven National Laboratory, Upton, NY.

BNL. 2007. Brookhaven National Laboratory Environmental Monitoring Plan Update January 2007. BNL-52676-2006. Brookhaven National Laboratory, Upton, NY.

BNL. 2008. EM-SOP 109. "Chain-of-Custody, Storage, Packaging, and Shipment of Samples." Brookhaven National Laboratory. Upton, NY.

DOE. 1994. RD-4 Guidance for Radiochemical Data Validation. Draft. Report EM-73. U.S. Department of Energy, Washington, DC.

DOE. 2007a. Continuing Qualification Audit of Severn Trent Laboratories, Inc. Earth City, Mo. May 24, 2007.

DOE. 2007b. Continuing Qualification Audit of General Engineering Laboratories, Inc. Charleston, South Carolina. May 25, 2007.

DOE. Order 414.1A. 2001. Quality Assurance. U.S. Department of Energy. Washington, DC. November 24, 1998.

DOE. Order 450.1. 2003. Environmental Protection Program. U.S. Department of Energy. Washington, DC. 1-15-03.

DOE. 2002. Environmental Management Consolidated Audit Program EMCAP Procedure Number 1.0 Revision 2. October 1, 2002.

EPA. 1992. Evaluation of Metals Data for the Contract Laboratory Program. EPA Region-II SOP HW-2. U.S. Environmental Protection Agency, Washington, DC.

EPA. 1998. EPA Requirements for Quality Assurance Project Plans for Environmental Data Operations. Report QA/R-5. U.S. Environmental Protection Agency, Washington, DC. EPA. 2000. "Guidance for the Data Quality Objectives Process (QA/G-4)." U.S. Environmental Protection Agency, Washington, DC.

EPA. 2006. CLP Organic Data Review and Preliminary Review. EPA Region-II SOP HW-6. U.S. Environmental Protection Agency, Washington, DC. Revision 14September 2006. 
Intentionally Left Blank 


\section{Acronyms and Abbreviations}

These acronyms and abbreviations reflect the typical manner in which terms are used for this specific document and may not apply to all situations. Items with an asterisk $\left(^{*}\right)$ are described in the glossary of technical terms, which follows this list.

\begin{tabular}{|c|c|c|c|}
\hline $\mathrm{AEC}$ & Atomic Energy Commission & CRM & Cultural Resource Management \\
\hline AGS & Alternating Gradient Synchrotron & CRMP & Cultural Resource Management Plan \\
\hline ALARA* & "As Low As Reasonably Achievable" & Cs & cesium \\
\hline AMSL & above mean sea level & CSF & Central Steam Facility \\
\hline $\mathrm{AOC}^{*}$ & area of concern & CTN & Center for Transitional Neuroimaging \\
\hline APG & Analytical Products Group & $\mathrm{CWA}^{*}$ & Clean Water Act \\
\hline ARARs & Applicable, Relevant, and & CY & calendar year \\
\hline & Appropriate Requirements & $\mathrm{D}_{2} \mathrm{O}^{*}$ & heavy water \\
\hline ARPA* $^{*}$ & Archeological Resource Protection Act & DAC & Derived Air Concentration \\
\hline AS/SVE* & air sparging/soil vapor extraction & DCA & 1,1-dichloroethane \\
\hline AST & aboveground storage tank & DCE & 1,1-dichloroethylene \\
\hline AWQS & Ambient Water Quality Standards & DCG * & derived concentration guide \\
\hline BAF & Booster Applications Facility & $D \& D$ & decontamination and decommissioning \\
\hline BGD & belowground duct & DDD & dichlorodiphenyldichloroethane \\
\hline BGRR & Brookhaven Graphite Research Reactor & $\mathrm{DDE}$ & dichlorodiphenyldichloroethylene \\
\hline BHSO & DOE Brookhaven Site Office & DDT & dichlorodiphenyltrichloroethane \\
\hline BLIP & Brookhaven Linac Isotope Producer & DMR & Discharge Monitoring Report \\
\hline BMRR & Brookhaven Medical Research Reactor & $\mathrm{DOE}^{*}$ & U.S. Department of Energy \\
\hline BNL & Brookhaven National Laboratory & DOE CH & DOE Chicago Operations Office \\
\hline BOD* & biochemical oxygen demand & DQO & Data Quality Objective \\
\hline $\mathrm{Bq}^{*}$ & becquerel & DSA & Documented Safety Analysis \\
\hline $\mathrm{Bq} / \mathrm{g}$ & becquerel per gram & DSB & Duct Service Building \\
\hline $\mathrm{Bq} / \mathrm{L}$ & becquerel per liter & DUV - FEL & Deep UltraViolet - Free Electron Laser \\
\hline BRAHMS & Broad Range Hadron Magnetic Spectrometer & DWS & Drinking Water Standards \\
\hline BSA & Brookhaven Science Associates & $E A^{*}$ & Environmental Assessment \\
\hline Btu & British thermal units & $\mathrm{EDB}^{*}$ & ethylene dibromide \\
\hline $\mathrm{CAA}^{*}$ & Clean Air Act & $\mathrm{EDE}^{*}$ & Effective Dose Equivalent \\
\hline CAAA* $^{*}$ & CAA Amendments (1990) & EDTA & ethylenediaminetetraacetic acid \\
\hline CAC & Community Advisory Council & $\mathrm{EE} / \mathrm{CA}$ & Engineering Evaluation/Cost Analysis \\
\hline CAP & Clean Air Act Assessment Package & EIMS* & Environmental Information Management System \\
\hline CBS & chemical bulk storage & ELAP & Environmental Laboratory Approval Program \\
\hline CCR & Consumer Confidence Report & EML & Environmental Measurements Laboratory \\
\hline CEGPA & $\begin{array}{l}\text { Community, Education, Government } \\
\text { and Public Affairs }\end{array}$ & $\begin{array}{l}\text { EMP } \\
\text { EMS* }\end{array}$ & $\begin{array}{l}\text { Environmental Monitoring Plan } \\
\text { Environmental Management System }\end{array}$ \\
\hline CERCLA* & $\begin{array}{l}\text { Comprehensive Environmental Response, } \\
\text { Compensation and Liability Act }\end{array}$ & $\mathrm{EPA}^{*}$ & U.S. Environmental Protection Agency \\
\hline CFC-11 & an ozone-depleting refrigerant & $\mathrm{EPCRA}^{*}$ & $\begin{array}{l}\text { Emergency Planning and } \\
\text { Community Right-to-Know Act }\end{array}$ \\
\hline $\begin{array}{l}\text { ctm, cts } \\
\text { CFN }\end{array}$ & cubic teet per minute, per second & ER & environmental restoration \\
\hline CFR & U.S. Code of Federal Regulations & ERA & Environmental Resource Associates \\
\hline $\mathrm{Ci}^{*}$ & curie & ERD & Environmental Restoration Division \\
\hline $\mathrm{CO}$ & certificate to operate & $\mathrm{ES}^{*}$ & environmental surveillance \\
\hline $\mathrm{COC}^{*}$ & chain-of-custody & $\begin{array}{l}\text { ESR } \\
\text { ES\&H }\end{array}$ & $\begin{array}{l}\text { Experimental Safety Review } \\
\text { Environment, Safety, and Health }\end{array}$ \\
\hline
\end{tabular}




\begin{tabular}{|c|c|c|c|}
\hline$E S A^{*}$ & Endangered Species Act & LTRA & Long Term Remedial Action \\
\hline \multirow[t]{2}{*}{ ESH\&Q } & \multirow{2}{*}{$\begin{array}{l}\text { Environment, Safety, Health, and } \\
\text { Quality Directorate }\end{array}$} & MACT & Maximum Available Control Technology \\
\hline & & MAPEP & Mixed Analyte Performance Evaluation Program \\
\hline ESPC & Energy Savings Performance Contract & MAR & Materials-at-risk \\
\hline ESSH & Environmental Safety, Security and Health & MCL & maximum contaminant level \\
\hline \multirow[t]{2}{*}{ EWMSD } & \multirow{2}{*}{$\begin{array}{l}\text { Environmental and Waste } \\
\text { Management Services Division }\end{array}$} & $\mathrm{MDL}^{*}$ & minimum detection limit \\
\hline & & $\mathrm{MEI}^{*}$ & maximally exposed individual \\
\hline FAMS & Facility area monitors & $\mathrm{MeV}$ & million electron volts \\
\hline FFCA ${ }^{*}$ & Federal Facilities Compliance Act & MGD & million gallons per day \\
\hline FIFRA* & $\begin{array}{l}\text { Federal Insecticide, Fungicide, and } \\
\text { Rodenticide Act }\end{array}$ & $\mathrm{mg} / \mathrm{L}$ & milligrams per liter \\
\hline FRP & Facility Response Plan & MMBtu & million British thermal units \\
\hline FWS* & U.S. Fish \& Wildlife Service & MOA & Memorandum of Agreement \\
\hline FY & fiscal year & MPF & Major Petroleum Facility \\
\hline $\mathrm{GBq}$ & giga (billion or $\mathrm{E}+09$ ) becquerel & MPN & most probable number \\
\hline GAB & gross alpha and beta & mrem & milli (thousandth of a) rem \\
\hline GC/ECD & gas chromatography/electron capture detector & MRI & Magnetic Resonance Imaging \\
\hline GC/MS & gas chromatography/mass spectrometry & MRC & Medical Research Center \\
\hline GDS & Groundwater Discharge Standard & $M S L^{*}$ & mean sea level \\
\hline GEL & General Engineering Laboratory, LLC & $\mathrm{mSv}$ & millisievert \\
\hline GeV & giga (billion) electron volts & MTBE & methyl tertiary butyl ether \\
\hline gge & gas gallon equivalent & MW & megawatt \\
\hline GIS & Geographical Information System & $\mu g / L$ & micrograms per liter \\
\hline GWh & gigawatt hour & NA & not analyzed \\
\hline $\mathrm{H} 2 \mathrm{M}$ & H2M Labs, Inc. & NCRP & $\begin{array}{l}\text { National Council on Radiation } \\
\text { Protection and Measurements }\end{array}$ \\
\hline HEPA & high efficiency particulate air & ND & not detected \\
\hline HFBR & High Flux Beam Reactor & NEAR & Neighbors Expecting Accountability \\
\hline HSS & Health, Safety and Security & & and Remediation \\
\hline HTO & tritiated water (liquid or vapor) & NELAC & National Environmental Laboratory \\
\hline HVAC & heating/ventilation/air conditioning & & Accreditation Conference \\
\hline HWMF & Hazardous Waste Management Facility & NELAP & National Environmental Laboratory \\
\hline & lodine & & \\
\hline IAEA & International Atomic Energy Agency & NEPA* & National Environmental Policy Act \\
\hline IAG & Interagency Agreement & NESHAPs* & $\begin{array}{l}\text { National Emission Standards for } \\
\text { Hazardous Air Pollutants }\end{array}$ \\
\hline IC & ion chromatography & & nano (one-billionth) aram per Joule \\
\hline ICP/MS & inductively coupled plasma/mass spectrometry & $\mathrm{ng} / \mathrm{J}$ & nano (one-billionth) gram per Joule \\
\hline ISMS & Integrated Safety Management System & $\mathrm{NHPA}^{*}$ & National Historic Preservation Act \\
\hline ISO* & International Organization for Standardization & NIST & National Institute for Standards and Technology \\
\hline & potassium & $\mathrm{NO}_{2}$ & nitrogen dioxide \\
\hline $\mathrm{kBq}$ & kilobecquerels (1,000 Bq) & NOV & Notice of Violation \\
\hline $\mathrm{KeV}$ & kilo (thousand) electron volts & $\mathrm{NO}_{x}^{*}$ & nitrogen oxides \\
\hline $\mathrm{Kr}$ & kryptonite & NOEC & no observable effect concentration \\
\hline kwH & kilowatt hours & NPDES & National Pollutant Discharge Elimination System \\
\hline LDR & Land Disposal Restriction & NR & not required \\
\hline LED & light emitting diode & NRMP & Natural Resource Management Plan \\
\hline LEED & Leadership in Energy and Environmental Design & NS & not sampled \\
\hline LIE & Long Island Expressway & NSF-ISR & NSF-International Strategic Registrations, Ltd. \\
\hline LIMS & Laboratory Information Management System & NSLS & National Synchrotron Light Source \\
\hline Linac & Linear Accelerator & NSRC & Nanoscale Science Research Centers \\
\hline LIPA & Long Island Power Authority & NSRL & NASA Space Radiation Laboratory \\
\hline LSTPD & Laboratory Science Teacher & NT & not tested \\
\hline & Professional Development & NYCRR* & New York Codes, Rules, and Regulations \\
\hline
\end{tabular}




\begin{tabular}{|c|c|c|c|}
\hline NYISO & New York Independent System Operator & SCSC & Suffolk County Sanitary Code \\
\hline NYPA & New York Power Authority & SDL & Source Development Laboratory \\
\hline NYS & New York State & SDWA* & Safe Drinking Water Act \\
\hline NYSDEC & NYS Department of Environmental Conservation & SER & Site Environmental Report \\
\hline NYSDOH & NYS Department of Health & $\mathrm{SI}$ & International System (measurement units) \\
\hline NYSHPO & NYS Historic Preservation Office & SNS & standard not specified \\
\hline $\mathrm{O}_{3}{ }^{*}$ & ozone & $\mathrm{SO}_{2}$ & sulfur dioxide \\
\hline O\&M & Operation and Maintenance & SOP & standard operating procedure \\
\hline ODS & ozone-depleting substances & SPCC & Spill Prevention Control and Countermeasures \\
\hline OHSAS & $\begin{array}{l}\text { Occupational Health and Safety } \\
\text { Assessment Series }\end{array}$ & $\begin{array}{l}\text { SPDES* } \\
\mathrm{Sr}\end{array}$ & $\begin{array}{l}\text { State Pollutant Discharge Elimination System } \\
\text { strontium }\end{array}$ \\
\hline OMC & Occupational Medical Clinic & STAR & Solenoid Tracker at RHIC \\
\hline ORC & oxygen-releasing compound & STEM & Scanning Transmission Electron Microscope \\
\hline ORPS* & Occurrence Reporting and Processing System & STL & Severn Trent Laboratories, Inc. \\
\hline OSHA & Occupational Health and Safety Administration & STP & Sewage Treatment Plant \\
\hline $\mathrm{OU}^{*}$ & operable unit & SU & standard unit \\
\hline$P 2 *$ & pollution prevention & SUNY & State University of New York \\
\hline PAAA* $^{*}$ & Price-Anderson Act Amendment & $\mathrm{Sv}^{*}$ & sievert; unit for assessing radiation dose risk \\
\hline PAF & Process Assessment Form & SVE $^{*}$ & soil vapor extraction \\
\hline $\mathrm{Pb}$ & lead & SVOC* & semivolatile organic compound \\
\hline PBT & persistent, bioaccumulative, and toxic & $\mathrm{t}_{1 / 2}{ }^{*}$ & half-life \\
\hline PCBs* & polychlorinated biphenyls & TAG & Technical Advisory Group \\
\hline PCE & tetrachloroethylene (or perchloroethylene) & $\mathrm{TBq}$ & tera (trillion, or $\mathrm{E}+12$ ) becquerel \\
\hline $\mathrm{pCi} / \mathrm{g}$ & picocuries per gram & TCA & 1,1,1-trichloroethane \\
\hline PE & performance evaluation & TCAP & Transportation Safety and Operations \\
\hline PET & positron emission tomography & & Compliance Assurance Process \\
\hline $\mathrm{ppb}$ & parts per billion & $\mathrm{TCE}^{*}$ & trichloroethylene \\
\hline ppm & parts per million & TCLP & toxicity characteristic leaching procedure \\
\hline PRAP & Proposed Remedial Action Plan & TEAM & Transformational Energy Action Management \\
\hline $\mathrm{QA}^{*}$ & quality assurance & TKN & Total Kjeldahl nitrogen \\
\hline QAPP & Quality Assurance Program Plan & TLD* & thermoluminescent dosimeter \\
\hline $\mathrm{QC}^{*}$ & quality control & TPL & Target Processing Laboratory \\
\hline QM & Quality Management & TRE & Toxic Reduction Evaluation \\
\hline R-11 (etc.) & ozone-depleting refrigerant & TRI & Toxic Release Inventory \\
\hline $\mathrm{RA}^{*}$ & removal action & TSCA $^{*}$ & Toxic Substances Control Act \\
\hline RACT & Reasonably Available Control Technology & TVDG & Tandem Van de Graaff \\
\hline RATA & Relatiivistic accuracy test & TVOC* $^{*}$ & total volatile organic compounds \\
\hline RCRA* & Resource Conservation and Recovery Act & $\mathrm{UIC}^{*}$ & underground injection control \\
\hline $\mathrm{RD} / \mathrm{RA}$ & Remedial Design/Remedial Action & UST* $^{*}$ & underground storage tank \\
\hline RF & resuspension factor & VOC* & volatile organic compound \\
\hline RHIC & Relativistic Heavy Ion Collider & VUV* & very ultraviolet \\
\hline ROD* & Record of Decision & WAC & waste acceptance criteria \\
\hline RPD & relative percent difference & WBS & Work Breakdown Structure \\
\hline RSB & Research Support Building & WCPP & Waste Certification Program Plan \\
\hline RWMB & Radioactive Waste Management Basis & WCF & Waste Concentration Facility \\
\hline RWP & Radiological Work Permit & WET & Whole Effluent Toxicity \\
\hline SARA* & Superfund Amendments and Reauthorization Act & WLA & Waste Loading Area \\
\hline SBMS* & Standards Based Management System & WM & Waste Management \\
\hline SCDHS & Suffolk County Department of Health Services & WMF & Waste Management Facility \\
\hline SCR & Special Case Resource & WTP & Water Treatment Plant \\
\hline
\end{tabular}




\section{Technical Terms}

These definitions reflect the typical manner in which the terms are used for this specific document and may not apply to all situations. Bold-face words in the descriptions are defined in separate entries.

\section{A}

AA (atomic absorption) - A spectroscopy method used to determine the elemental composition of a sample. In this method, the sample is vaporized and the amount of light it absorbs is measured.

accuracy - The degree of agreement of a measurement with an accepted reference or true value. It can be expressed as the difference between two values, as a percentage of the reference or true value, or as a ratio of the measured value and the reference or true value.

activation - The process of making a material radioactive by bombardment with neutrons, protons, or other high energy particles.

activation product - A material that has become radioactive by bombardment with neutrons, protons, or other high energy particles.

activity - Synonym for radioactivity.

Administrative Record - A collection of documents established in compliance with CERCLA. Consists of information the CERCLA lead agency uses in its decision on the selection of response actions. The Administrative Record file should be established at or near the facility and made available to the public. An Administrative Record can also be the record for any enforcement case.

aerobic - An aerobic organism is one that lives, acts, or occurs only in the presence of oxygen.

aerosol - A gaseous suspension of very small particles of liquid or solid.

ALARA (As Low As Reasonably Achievable) - A phrase that describes an approach to minimize exposures to individuals and minimize releases of radioactive or other harmful material to the environment to levels as low as social, technical, economic, practical, and public policy considerations will permit. ALARA is not a dose limit, but a process with a goal to keep dose levels as far below applicable limits as is practicable.

alpha radiation - The emission of alpha particles during radioactive decay. Alpha particles are identical in makeup to the nucleus of a helium atom and have a positive charge. Alpha radiation is easily stopped by materials as thin as a sheet of paper and has a range in air of only an inch or so. Despite its low penetration ability, alpha radiation is densely ionizing and therefore very damaging when ingested or inhaled. Naturally occurring radioactive sources such as radon emit alpha radiation. air stripping - A process for removing VOCs from contaminated water by forcing a stream of air through the water in a vessel. The contaminants evaporate into the air stream. The air may be further treated before it is released into the atmosphere.

ambient air - The surrounding atmosphere, usually the outside air, as it exists around people, animals, plants, and structures. It does not include the air immediately adjacent to emission sources.

analyte - A constituent that is being analyzed.

anneal - To heat a material and then cool it. In the case of thermoluminescent dosimeters (TLDs), this is done to reveal the amount of radiation the material had absorbed.

anion - A negatively charged ion, often written as a superscript negative sign after an element symbol, such as $\mathrm{Cl}^{-}$.

anthropogenic - Resulting from human activity; anthropogenic radiation is human-made, not naturally occurring.

AOC (area of concern) - Under CERCLA, this term refers to an area where releases of hazardous substances may have occurred or a location where there has been a release or threat of a release of a hazardous substance, pollutant, or contaminant (including radionuclides). AOCs may include, but need not be limited to, former spill areas, landfills, surface impoundments, waste piles, land treatment units, transfer stations, wastewater treatment units, incinerators, container storage areas, scrap yards, cesspools, tanks, and associated piping that are known to have caused a release into the environment or whose integrity has not been verified.

aquifer - A water-saturated layer of rock or soil below the ground surface that can supply usable quantities of groundwater to wells and springs. Aquifers can be a source of water for domestic, agricultural, and industrial uses.

ARPA (Archaeological Resources Protection Act) This law, passed in 1979, has been amended four times. It protects any material remains of past human life or activities that are of archaeological interest. Known and potential sites of interest are protected from uncontrolled excavations and pillage, and artifacts found on public and Indian lands are banned from commercial exchange.

AS/SVE (air sparging/soil vapor extraction) - A method of extracting volatile organic compounds from the groundwater, in place, using compressed air. (In contrast, air stripping occurs in a vessel.) The vapors are typically collected using a soil vapor extraction system. 


\section{$\mathrm{B}$}

background - A sample or location used as reference or control to compare BNL analytical results to those in areas that could not have been impacted by BNL operations.

background radiation - Radiation present in the environment as a result of naturally occurring radioactive materials in the Earth, cosmic radiation, or human-made radiation sources, including fallout.

beta radiation - Beta radiation is composed of charged particles emitted from a nucleus during radioactive decay. A negatively charged beta particle is identical to an electron. A positively charged beta particle is called a positron. Beta radiation is more penetrating than alpha radiation, but it may be stopped by materials such as aluminum or Lucite ${ }^{\mathrm{TM}}$ panels. Naturally occurring radioactive elements such as potassium-40 emit beta radiation.

blank - A sample (usually reagent-grade water) used for quality control of field sampling methods, to demonstrate that cross contamination has not occurred.

blowdown - Water discharged from either a boiler or cooling tower in order to prevent the build-up of inorganic matter within the boiler or tower and to prevent scale formation (i.e., corrosion).

BOD (biochemical oxygen demand) - A measure of the amount of oxygen in biological processes that breaks down organic matter in water; a measure of the organic pollutant load. It is used as an indicator of water quality.

Bq (becquerel) - A quantitative measure of radioactivity. This alternate measure of activity is used internationally and with increasing frequency in the United States. One Bq of activity is equal to one nuclear decay per second.

bremsstrahlung - Translates as "fast braking" and refers to electromagnetic radiation produced by the sudden retardation of a charged particle in an intense electric field.

\section{C}

CAA (Clean Air Act), CAA Amendments (CAAA) - The original Clean Air Act was passed in 1963, but the U.S. air pollution control program is based on the 1970 version of the law. The 1990 Clean Air Act Amendments (CAAA) are the most far-reaching revisions of the 1970 law. In common usage, references to the CAA typically mean to the 1990 amendments. (source: EPA's "Plain English Guide to the Clean Air Act" glossary, accessed 3-7-05)

caisson - A watertight container used in construction work under water or as a foundation.

cap - A layer of natural or synthetic material, such as clay or gunite, used to prevent rainwater from penetrating and spreading contamination. The surface of the cap is generally mounded or sloped so water will drain off.

carbon adsorption/carbon treatment - A treatment system in which contaminants are removed from groundwater, surface water, and air by forcing water or air through tanks containing activated carbon (a specially treated material that attracts and holds or retains contaminants). carbon tetrachloride - A poisonous, nonflammable, colorless liquid, $\mathrm{CCl}_{4}$.

CERCLA (Comprehensive Environmental Response, Compensation and Liability Act) - Pronounced "sir-klah" and commonly known as Superfund, this law was enacted by Congress on December 11, 1980. It created a tax on the chemical and petroleum industries and provided broad federal authority to respond directly to releases or threatened releases of hazardous substances that may endanger public health or the environment. CERCLA established prohibitions and requirements concerning closed and abandoned hazardous waste sites; provided for liability of persons responsible for releases of hazardous waste at these sites; and established a trust fund to provide for cleanup when no responsible party could be identified

The law authorizes two kinds of response actions: shortterm removals, where actions may be taken to address releases or threatened releases requiring prompt response, and long-term remedial response actions that permanently and significantly reduce the dangers associated with releases or threats of releases of hazardous substances that are serious, but not immediately life threatening. These actions can be conducted only at sites listed on EPA's National Priorities List (NPL). CERCLA was amended by the Superfund Amendments and Reauthorization Act (SARA) on October 17, 1986, accessed 03-7-05)

CFR (Code of Federal Regulations) - A codification of all regulations developed and finalized by federal agencies in the Federal Register. The CFR is arranged by "title," with Title 10 covering energy- and radiation-related issues, and Title 40 covering protection of the environment. Subparts within the titles are included in citations, as in "40 CFR Subpart H."

characterization - Facility or site sampling, monitoring, and analysis activities to determine the extent and nature of contamination. Characterization provides the basis of necessary technical information to select an appropriate cleanup alternative.

Ci (curie) - A quantitative measure of radioactivity. One $\mathrm{Ci}$ of activity is equal to $3.7 \mathrm{E}+10$ decays per second. One curie has the approximate activity of 1 gram of radium. It is named after Marie and Pierre Curie, who discovered radium in 1898 .

Class GA groundwater - New York State Department of Environmental Conservation classification for high quality groundwater, where the best intended use is as a source of drinking water supply.

closure - Under RCRA regulations, this term refers to a hazardous or solid waste management unit that is no longer operating and where potential hazards that it posed have been addressed (through clean up, immobilization, capping, etc.) to the satisfaction of the regulatory agency.

COC (chain-of-custody) - A method for documenting the history and possession of a sample from the time of collection, through analysis and data reporting, to its final disposition. 
cocktail - a mixture of chemicals used for scintillation counting.

collective Effective Dose Equivalent - A measure of health risk to a population exposed to radiation. It is the sum of the EDEs of all individuals within an exposed population, frequently considered to be within 50 miles ( 80 kilometers) of an environmental release point. It is expressed in personrem or person-sievert.

Committed Effective Dose Equivalent - The total EDE received over a 50-year period following the internal deposition of a radionuclide. It is expressed in rems or sieverts.

composite sample - A sample of an environmental medium containing a certain number of sample portions collected over a period of time, possibly from different locations. The constituent samples may or may not be collected at equal time intervals over a predefined period of time, such as 24 hours.

confidence interval - A numerical range within which the true value of a measurement or calculated value lies. In the SER, radiological values are shown with a 95 percent confidence interval: there is a 95 percent probability that the true value of a measurement or calculated value lies within the specified range. See also "Uncertainty" discussion in Appendix B.

conservative - Estimates that err on the side of caution because all possibly deleterious components are included at generous or high values.

contamination - Unwanted radioactive and/or hazardous material that is dispersed on or in equipment, structures, objects, air, soil, or water.

control - See background.

cooling water - Water used to cool machinery and equipment. Contact cooling water is any wastewater that contacts machinery or equipment to remove heat from the metal; noncontact cooling water has no direct contact with any process material or final product. Process wastewater cooling water is water used for cooling that may have become contaminated through contact with process raw materials or final products.

cover boards - Sheets of plywood placed on the ground near ponds to serve as attractive habitat for salamanders, as part of a population study.

curie - See Ci.

CWA (Clean Water Act) - Growing public awareness and concern for controlling water pollution led to enactment of the Federal Water Pollution Control Act Amendments of 1972. As amended in 1977, this law became commonly known as the Clean Water Act. It established the basic structure for regulating discharges of pollutants into the waters of the United States, giving EPA the authority to implement pollution control programs such as setting wastewater standards for industry. The CWA also continued requirements to set water quality standards for all contaminants in surface waters and made it unlawful for any person to discharge any pollutant from a point source into navigable waters unless a permit was obtained. The CWA also funded the construction of sewage treatment plants and recognized the need for planning to address the critical problems posed by nonpoint source pollution.

Revisions in 1981 streamlined the municipal construction grants process. Changes in 1987 phased out the construction grants program. Title I of the Great Lakes Critical Programs Act of 1990 put into place parts of the Great Lakes Water Quality Agreement of 1978, signed by the U.S. and Canada; the two nations agreed to reduce certain toxic pollutants in the Great Lakes. Over the years many other laws have changed parts of the CWA, accessed 03-7-05)

\section{$\mathrm{D}$}

\section{$\mathbf{D}_{2} \mathbf{O}$ - See heavy water.}

daughter, progeny - A given nuclide produced by radioactive decay from another nuclide (the "parent"). See also radioactive series.

DCG (derived concentration guide) - The concentration of a radionuclide in air or water that, under conditions of continuous exposure for one year by a single pathway (e.g., air inhalation, absorption, or ingestion), would result in an effective dose equivalent of $100 \mathrm{mrem}(1 \mathrm{mSv})$. The values were established in DOE Order 5400.5.

decay product - A nuclide resulting from the radioactive disintegration of a radionuclide, being formed either directly or as a result of successive transformations in a radioactive series. A decay product may be either radioactive or stable.

decontamination - The removal or reduction of radioactive or hazardous contamination from facilities, equipment, or soils by washing, heating, chemical or electrochemical action, mechanical cleaning, or other techniques to achieve a stated objective or end condition.

disposal - Final placement or destruction of waste.

DOE (Department of Energy) - The federal agency that promotes scientific and technical innovation to support the national, economic, and energy security of the United States. DOE has responsibility for 10 national laboratories and for the science and research conducted at these laboratories, including Brookhaven National Laboratory.

DOE Order 231.1A - This order, Environment, Safety, and Health Reporting, is dated 8/19/03. It replaces the 1995 version, Order 231.1, as well as the "ORPS" order, DOE Order 232.1A, Occurrence Reporting and Processing of Operations Information, dated 7/21/97, and Order 210.1, Performance Indicator..., dated 9/27/95.

DOE Order 450.1 - This order, Environmental Protection Program, is dated 1/15/03. It replaces DOE Order 5400.1, General Environmental Protection Program, dated 11/9/88.

DOE Order 5400.5 - This order, Radiation Protection of the Public and the Environment, was first published by DOE in 1990 and was modified in 1993. It established 
the standards and requirements for operations of DOE and DOE contractors with respect to protecting the public and the environment against undue risk from radiation.

dose - See EDE.

dosimeter - A portable detection device for measuring exposure to ionizing radiation. See Chapter 8 for details.

downgradient - In the direction of groundwater flow from a designated area; analogous to "downstream."

DQO (Data Quality Objective) -The Data Quality Objective (DQO) process was developed by EPA for facilities to use when describing their environmental monitoring matrices, sampling methods, locations, frequencies, and measured parameters, as well as methods and procedures for data collection, analysis, maintenance, reporting, and archiving. The DQO process also addresses data that monitor quality assurance and quality control.

drift fence - A stretch of temporary fencing to prevent an animal population from leaving the area, used at BNL as part of a population study.

dry weight - The dry weight concentration of a substance is after a sample is dried for analysis. Dry weight concentrations are typically higher than wet weight values.

D-waste - Liquid waste containing radioactivity.

\section{E}

EA (Environmental Assessment) - A report that identifies potentially significant effects from any federally approved or funded project that might change the physical environment. If an EA identifies a "significant" potential impact (as defined by NEPA), an Environmental Impact Statement (EIS) must be researched and prepared.

EDB (ethylene dibromide) - A colorless, nonflammable, heavy liquid with a sweet odor; slightly soluble in water. Although the U.S. Department of Health and Human Services has determined that ethylene dibromide may reasonably be anticipated to be a carcinogen, it is still used to treat felled logs for bark beetles; to control wax moths in beehives; as a chemical intermediary for dyes, resins, waxes, and gums; to spot-treat milling machinery; and to control Japanese beetles in ornamental plants.

EDE (Effective Dose Equivalent) - A value used to express the health risk from radiation exposure to tissue in terms of an equivalent whole body exposure. It is a "normalized" value that allows the risk from radiation exposure received by a specific organ or part of the body to be compared with the risk due to whole-body exposure. The EDE equals the sum of the doses to different organs of the body multiplied by their respective weighting factors. It includes the sum of the EDE due to radiation from sources external to the body and the committed effective dose equivalent due to the internal deposition of radionuclides. EDE is expressed in rems or sieverts.

effluent - Any liquid discharged to the environment, including stormwater runoff at a site or facility.
EIMS (Environmental Information Management System) - A database system used to store, manage, verify, protect, retrieve, and archive BNL's environmental data.

EM (environmental monitoring) - Sampling for contaminants in air, water, sediment, soil, food stuffs, plants, and animals, either by directly measuring or by collecting and analyzing samples.

emissions - Any gaseous or particulate matter discharged to the atmosphere.

EMS (Environmental Management System) - The BNL EMS meets the requirements of the ISO 14001 EMS standard, with emphasis on compliance assurance, pollution prevention, and community outreach. An extensive environmental monitoring program is one component of BNL's EMS.

environment - Surroundings (including air, water, land, natural resources, flora, fauna, and humans) in which an organization operates, and the interrelation of the organization and its surroundings.

environmental aspect - Elements of an organization's activities, products, or services that can interact with the surrounding air, water, land, natural resources, flora, fauna, and humans.

environmental impact - Any change to the surrounding air, water, land, natural resources, flora, and fauna, whether adverse or beneficial, wholly or partially resulting from an organization's activities, products, or services.

environmental media - Includes air, groundwater, surface water, soil, flora, and fauna.

environmental monitoring or surveillance - See EM.

EPA (U. S. Environmental Protection Agency) - The federal agency responsible for developing and enforcing environmental laws. Although state or local regulatory agencies may be authorized to administer environmental regulatory programs, EPA generally retains oversight authority.

EPCRA (Emergency Planning and Community Right-toKnow Act) - Also known as Title III of SARA, EPCRA was enacted by Congress as the national legislation on community safety, to help local groups protect public health, safety, and the environment from chemical hazards. To implement EPCRA, Congress required each state to appoint a State Emergency Response Commission (SERC). The SERCs were required to divide their states into Emergency Planning Districts and to name a Local Emergency Planning Committee for each district

Broad representation by fire fighters, health officials, government and media representatives, community groups, industrial facilities, and emergency managers ensures that all necessary elements of the planning process are represented.

ES (environmental surveillance) - Sampling for contaminants in air, water, sediment, soil, food stuffs, plants, and animals, either by directly measuring or by collecting and analyzing samples. 
ESA (Endangered Species Act) - This provides a program for conserving threatened and endangered plants and animals and their habitats. The FWS maintains the list of 632 endangered species (326 are plants) and 190 threatened species (78 are plants). Species include birds, insects, fish, reptiles, mammals, crustaceans, flowers, grasses, and trees. Anyone can petition FWS to include a species on this list. The law prohibits any action, administrative or real, that results in a "taking" of a listed species or adversely affects habitat. Likewise, import, export, interstate, and foreign commerce of listed species are all prohibited. EPA's decision to register pesticides is based in part on the risk of adverse effects on endangered species as well as environmental fate (how a pesticide will affect habitat). Under FIFRA, EPA can issue emergency suspensions of certain pesticides to cancel or restrict their use if an endangered species will be adversely affected.

evapotranspiration - A process by which water is transferred from the soil to the air by plants that take the water up through their roots and release it through their leaves and other aboveground tissue.

exposure - A measure of the amount of ionization produced by $\mathbf{x}$-rays or gamma rays as they travel through air. The unit of radiation exposure is the roentgen $(\mathbf{R})$.

\section{F}

fallout - Radioactive material, made airborne as a result of aboveground nuclear weapons testing, that has been deposited on the Earth's surface.

FFCA (Federal Facility Compliance Act) - Formerly, the federal government maintained that it was not subject to fines and penalties under solid and hazardous waste law because of the doctrine of "sovereign immunity." The State of Ohio challenged this in Ohio v. the Department of Energy (1990). The U.S. Circuit Court of Appeals found in favor of the State (June 11, 1990), writing that the federal government's sovereign immunity is waived under both the CWA sovereign immunity provision and RCRA's citizen suit provision. The Circuit Court decision was overturned by the Supreme Court on April 21, 1992, in DOE v. Ohio, which held that the waiver of sovereign immunity in RCRA and CWA is not clear enough to allow states to impose civil penalties directly. After the high court's ruling, the consensus among lawmakers was that a double standard existed: the same government that developed laws to protect human health and the environment and required compliance in the private sector, was itself not assuming the burden of compliance. As a result, Congress enacted the FFCA (October 6, 1992, Pub. Law 102-386), which effectively overturned the Supreme Court's ruling. In the legislation Congress specifically waived sovereign immunity with respect to RCRA for federal facilities.

Under section 102, FFCA amends section 6001 of RCRA to specify that federal facilities are subject to "all civil and administrative penalties and fines, regardless of whether such penalties or fines are punitive or coercive in nature." These penalties and fines can be levied by EPA or by authorized states. In addition, FFCA states that "the United States hereby expressly waives any immunity otherwise applicable to the United States." Although federal agents, employees, and officers are not liable for civil penalties, they are subject to criminal sanctions. No departments, agencies, or instrumentalities are subject to criminal sanctions. Section 104 (1) and (2) require EPA to conduct annual RCRA inspections of all federal facilities.

FIFRA (Federal Insecticide, Fungicide, and Rodenticide Act) - The primary focus of this law was to provide federal control of pesticide distribution, sale, and use. EPA was given authority under FIFRA not only to study the consequences of pesticide usage but also to require users (farmers, utility companies, and others) to register when purchasing pesticides. Through later amendments to the law, users also must take exams for certification as applicators of pesticides. All pesticides used in the U.S. must be registered (licensed) by EPA. Registration assures that pesticides will be properly labeled and that if used in accordance with specifications, will not cause unreasonable harm to the environment.

FS (feasibility study) - A process for developing and evaluating remedial actions using data gathered during the remedial investigation. The FS defines the objectives of the remedial program for the site and broadly develops remedial action alternatives, performs an initial screening of these alternatives, and performs a detailed analysis of a limited number of alternatives that remain after the initial screening stage.

FWS (U.S. Fish \& Wildlife Service) - The U.S. Fish and Wildlife Service is the principal federal agency responsible for conserving, protecting, and enhancing fish, wildlife, plants, and their habitats for the continuing benefit of the people of the United States. FWS manages the 95-million-acre National Wildlife Refuge System, which encompasses 544 national wildlife refuges, thousands of small wetlands, and other special management areas. It also operates 69 national fish hatcheries, 64 fishery resources offices, and 81 ecological services field stations. The agency enforces federal wildlife laws, administers the Endangered Species Act, manages migratory bird populations, restores nationally significant fisheries, conserves and restores wildlife habitat such as wetlands, and helps foreign and Native American tribal governments with their conservation efforts. It also oversees the Federal Assistance Program, which distributes hundreds of millions of dollars in excise taxes on fishing and hunting equipment to state fish and wildlife agencies.

fugitive source - Unanticipated sources of volatile hazardous air pollutants due to leaks from valves, pumps, compressors, relief valves, connectors, flanges, and various other pieces of equipment. 


\section{G}

gamma radiation - Gamma radiation is a form of electromagnetic radiation, like radio waves or visible light, but with a much shorter wavelength. It is more penetrating than alpha or beta radiation, capable of passing through dense materials such as concrete.

gamma spectroscopy - This analysis technique identifies specific radionuclides. It measures the particular energy of a radionuclide's gamma radiation emissions. The energy of these emissions is unique for each nuclide, acting as a "fingerprint."

geotextile - A product used as a soil reinforcement agent and as a filter medium. It is made of synthetic fibers manufactured in a woven or loose manner to form a blanket-like product.

grab sample - A single sample collected at one time and place.

Green Building - Construction that adheres to guidelines established by the Green Building Council, a coalition of leaders from across the building industry working to promote structures that are environmentally responsible, profitable, and healthy places to live and work.

groundwater - Water found beneath the surface of the ground (subsurface water). Groundwater usually refers to a zone of complete water saturation containing no air.

gunite - A mixture of cement, sand, and water sprayed over a mold to form a solid, impermeable surface. Formerly a trademarked name, now in general usage.

\section{$\mathrm{H}$}

half-life $\left(\mathbf{t}_{1 / 2}\right)$ - The time required for one-half of the atoms of any given amount of a radioactive substance to disintegrate; the time required for the activity of a radioactive sample to be reduced by one half.

halon - An ozone-depleting fire suppressant; suffixes $(-1301$, etc.) indicate variants.

hazardous waste - Toxic, corrosive, reactive, or ignitable materials that can injure human health or damage the environment. It can be liquid, solid, or sludge, and include heavy metals, organic solvents, reactive compounds, and corrosive materials. It is defined and regulated by RCRA, Subtitle C.

heat input - The heat derived from combustion of fuel in a steam generating unit. It does not include the heat from preheated combustion air, recirculated flue gases, or the exhaust from other sources.

heavy water $\left(\mathbf{D}_{2} \mathbf{O}\right)$ - A form of water containing deuterium, a nonradioactive isotope of hydrogen.

herpetofaunal - Relating to the study of reptiles.

hot cell - Shielded and air-controlled facility for the remote handling of radioactive material.

hydrology - The science dealing with the properties, distribution, and circulation of natural water systems.
I

inert - Lacking chemical or biological action.

influent - Liquid (such as stormwater runoff or wastewater) flowing into a reservoir, basin, or treatment plant.

intermittent river - A stream that dries up on occasion, usually as a result of seasonal factors or decreased contribution from a source such as a wastewater treatment plant.

ionizing radiation - Any radiation capable of displacing electrons from atoms or molecules, thereby producing ions. High doses of ionizing radiation may produce severe skin or tissue damage. See also alpha, beta, gamma radiation; $\mathrm{x}$-rays.

ISO 14001 EMS standard - The International Organization for Standardization (ISO) sets standards for a wide range of products and management operations. Following the success of the ISO 9000 Standards for quality management, ISO introduced the 14000 series for environmental management. BNL was the first DOE Office of Science laboratory to obtain third-party registration to this globally recognized environmental standard.

isotope - Two or more forms of a chemical element having the same number of protons in the nucleus (the same atomic number), but having different numbers of neutrons in the nucleus (different atomic weights). Isotopes of a single element possess almost identical chemical properties.

L

leaching - The process by which soluble chemical components are dissolved and carried through soil by water or some other percolating liquid.

light water - As used in this document, tap water, possibly filtered.

liquid scintillation counter - An analytical instrument used to quantify tritium, carbon-14, and other beta-emitting radionuclides. See also scintillation.

\section{$\mathrm{M}$}

matrix, matrices - The natural context (e.g., air, vegetation, soil, water) from which an environmental sample is collected.

MDL (minimum detection limit) - The lowest level to which an analytical parameter can be measured with certainty by the analytical laboratory performing the measurement. While results below the MDL are sometimes measurable, they represent values that have a reduced statistical confidence associated with them (less than 95 percent confidence).

MEI (maximally exposed individual) - The hypothetical individual whose location and habits tend to maximize his/ her radiation dose, resulting in a dose higher than that received by other individuals in the general population.

metamorphic - In the state of changing from larval to mature forms. 
mixed waste - Waste that contains both a hazardous waste component (regulated under Subtitle C of RCRA) and a radioactive component.

monitoring - The collection and analysis of samples or measurements of effluents and emissions for the purpose of characterizing and quantifying contaminants, and demonstrating compliance with applicable standards.

monitoring well - A well that collects groundwater for the purposes of evaluating water quality, establishing groundwater flow and elevation, determining the effectiveness of treatment systems, and determining whether administrative or engineered controls designed to protect groundwater are working as intended.

MSL (mean sea level) - The average height of the sea for all stages of the tide. Used as a benchmark for establishing groundwater and other elevations.

\section{$\mathrm{N}$}

NEPA (National Environmental Policy Act) - Assures that all branches of government give proper consideration to the environment before any land purchase or any construction projects, including airports, buildings, military complexes, and highways. Project planners must assess the likely impacts of the project by completing an Environmental Assessment (EA) and, if necessary, an Environmental Impact Statement (EIS).

NESHAPs (National Emissions Standards for Hazardous Air Pollutants) - Standards that limit emissions from specific sources of air pollutants linked to serious health hazards. NESHAPs are developed by EPA under the CAA. Hazardous air pollutants can be chemical or radioactive. Their sources may be human-made, such as vehicles, power plants, and industrial or research processes, or natural, such as radioactive gas in soils.

neutrino - A small, neutral particle created as a result of particle decay. Neutrinos were believed to be massless, but recent studies have indicated that they have small, but finite, mass. Neutrinos interact very weakly.

NHPA (National Historic Preservation Act) - With passage of the National Historic Preservation Act in 1966, Congress made the federal government a full partner and a leader in historic preservation. The role of the federal government is fulfilled through the National Park Service. State participation is through State Historic Preservation Offices. "Before 1966, historic preservation was mainly understood in one-dimensional terms: the proverbial historic shrine or Indian burial mound secured by lock and key-usually in a national park- set aside from modern life as an icon for study and appreciation. NHPA largely changed that approach, signaling a much broader sweep that has led to the breadth and scope of the vastly more complex historic preservation mosaic we know today."

nonpoint source pollution - Nonpoint source pollution occurs when rainfall, snowmelt, or irrigation water runs over land or through the ground, picks up pollutants, and depos- its them into rivers, lakes, and coastal waters or introduces them into groundwater. Nonpoint source pollution also includes adverse changes to the hydrology of water bodies and their associated aquatic habitats. After Congress passed the Clean Water Act in 1972, the nation's water quality community emphasized point source pollution (coming from a discrete conveyance or location, such as industrial and municipal waste discharge pipes). Point sources were the primary contributors to the degradation of water quality then, and the significance of nonpoint source pollution was poorly understood. Today, nonpoint source pollution remains the largest source of water quality problems. It is the main reason that approximately 40 percent of surveyed rivers, lakes, and estuaries are not clean enough to meet basic uses such as fishing or swimming.

$\mathbf{N O}_{\mathrm{x}}$ - Nitrogen oxides are gases consisting of one molecule of nitrogen and varying numbers of oxygen molecules. Nitrogen oxides are produced, for example, by the combustion of fossil fuels in vehicles and electric power plants. In the atmosphere, $\mathrm{NO}_{\mathrm{X}}$ can contribute to the formation of smog, impair visibility, and have health consequences. $\mathrm{NO}_{\mathrm{x}}$ are considered "criteria air pollutants" under the CAA.

nuclide - A species of atom characterized by the number of protons and neutrons in the nucleus.

NYCRR (New York Codes, Rules, and Regulations) The NYCRR primarily contains state agency rules and regulations adopted under the State Administrative Procedure Act. There are 22 Titles: one for each state department, one for miscellaneous agencies and one for the Judiciary. Title 6 addresses environmental conservation, so many references in the SER are to "6 NYCRR."

\section{$\mathrm{O}$}

$\mathbf{O}_{3}$ - See ozone.

on site - The area within the boundaries of a site that is controlled with respect to access by the general public.

opacity - Under the Clean Air Act (CAA), a measurement of the degree to which smoke (emissions other than water vapor) reduces the transmission of light and obscures the view of an object in the background.

ORPS (Occurrence Reporting and Processing System) A system for identifying, categorizing, notifying, investigating, analyzing, and reporting to DOE events or conditions discovered at the BNL site. It was originally established by DOE Order 232.1, which has been replaced by DOE Order 231.1A.

OU (operable unit) - Division of a contaminated site into separate areas based on the complexity of the problems associated with it. Operable units may address geographical portions of a site, specific site problems, or initial phases of an action. They may also consist of any set of actions performed over time, or actions that are concurrent, but located in different parts of a site. An OU can receive specific investigation and a particular remedy may be proposed. A Record of Decision (ROD) is prepared for each OU. 
outfall - The place where wastewater is discharged.

oxides of nitrogen $\left(\mathrm{NO}_{\mathrm{x}}\right)$ - See $\mathrm{NO}_{\mathrm{x}}$.

ozone $\left(\mathbf{O}_{3}\right)$ - A very reactive type of oxygen formed naturally in the upper atmosphere which provides a shield for the earth from the sun's ultraviolet rays. At ground level or in the lower atmosphere, it is pollution that forms when oxides of nitrogen and hydrocarbons react with oxygen in the presence of strong sunlight. Ozone at ground level can lead to health effects and cause damage to trees and crops.

\section{$P$}

P2 (pollution prevention) - Preventing or reducing the generation of pollutants, contaminants, hazardous substances, or wastes at the source, or reducing the amount for treatment, storage, and disposal through recycling. Pollution prevention can be achieved through reduction of waste at the source, segregation, recycle/reuse, and the efficient use of resources and material substitution. The potential benefits of pollution prevention include the reduction of adverse environmental impacts, improved efficiency, and reduced costs.

PAAA (Price-Anderson Act Amendments) - The PriceAnderson Act (PAA) was passed in 1957 to provide for prompt compensation in the case of a nuclear accident. The PAA provided broad financial coverage for damage, injury, and costs, and required DOE to indemnify contractors. The amended act of 1988 (PAAA) extended indemnification for 15 years and required DOE to establish and enforce nuclear safety rules. The PAAA Reauthorization, passed in December of 2002, extended current indemnification levels through 2004. 10 CFR 820 and its Appendix A provide DOE enforcement procedure and policy.

Parshall flume - An engineered channel used to measure the flow rate of water. It was named after the inventor, who worked for the U.S. government as an irrigation research engineer.

PCBs (polychlorinated biphenyls) - A family of organic compounds used from 1926 to 1979 (when they were banned by EPA) in electrical transformers, lubricants, carbonless copy paper, adhesives, and caulking compounds. PCBs are extremely persistent in the environment because they do not break down into different and less harmful chemicals. PCBs are stored in the fatty tissues of humans and animals through the bioaccumulation process.

percent recovery - For analytical results, the ratio of the measured amount, divided by the known (spiked) amount, multiplied by 100 .

permit - An authorization issued by a federal, state, or local regulatory agency. Permits are issued under a number of environmental regulatory programs, including CAA, CWA, RCRA, and TSCA. Permits grant permission to operate, to discharge, to construct, and so on. Permit provisions may include emission/effluent limits and other requirements such as the use of pollution control devices, monitoring, record keeping and reporting. Also called a "license" or "certificate" under some regulatory programs.
pH - A measure of hydrogen ion concentration in an aqueous solution. Acidic solutions have a $\mathrm{pH}$ less than 7, neutral solutions have a $\mathrm{pH}$ of 7 , and basic solutions have a $\mathrm{pH}$ greater than 7 and up to 14 .

plume - A body of contaminated groundwater or polluted air flowing from a specific source. The movement of a groundwater plume is influenced by such factors as local groundwater flow patterns, the character of the aquifer in which groundwater is contained, and the density of contaminants. The movement of an air contaminant plume is influenced by the ambient air motion, the temperatures of the ambient air and of the plume, and the density of the contaminants.

point source - Any confined and discrete conveyance (e.g., pipe, ditch, well, or stack) of a discharge.

pollutant - Any hazardous or radioactive material naturally occurring or added to an environmental medium, such as air, soil, water, or vegetation.

potable water - Water of sufficient quality for use as drinking water without endangering the health of people, plants, or animals.

precision - A statistical term describing the dispersion of data around a central value, usually represented as a variance, standard deviation, standard error, or confidence interval.

putrescible waste - Garbage that contains food and other organic biodegradable materials. There are special management requirements for this waste in 6 NYCRR Part 360.

\section{Q}

QA(quality assurance) - In environmental monitoring, any action to ensure the reliability of monitoring and measurement data. Aspects of QA include procedures, inter-laboratory comparison studies, evaluations, and documentation.

QC (quality control) - In environmental monitoring, the routine application of procedures to obtain the required standards of performance in monitoring and measurement processes. QC procedures include calibration of instruments, control charts, and analysis of replicate and duplicate samples.

qualifier - A letter or series of letter codes in a graph or chart indicating that the associated value did not meet analytical requirements or was estimated.

quenching - Anything that interferes with the conversion of decay energy to electronic signal in the photomultiplier tubes of detection equipment, usually resulting in a reduction in counting efficiency.

\section{$\mathrm{R}$}

R (roentgen) - A unit of exposure to ionizing radiation. It is the amount of gamma or $\mathrm{x}$-rays required to produce ions carrying one electrostatic unit of electrical charge in one cubic centimeter of dry air under standard conditions. It is named after the German scientist Wilhelm Roentgen, who discovered x-rays. 
RA (removal actions, "removals") - Interim actions that are undertaken to prevent, minimize, or mitigate damage to the public health or environment that may otherwise result from a release or threatened release of hazardous substances, pollutants, or contaminants pursuant to CERCLA, and that are not inconsistent with the final remedial action. Under CERCLA, EPA may respond to releases or threats of releases of hazardous substances by starting an RA to stabilize or clean up an incident or site that immediately threatens public health or welfare. Removal actions are less comprehensive than remedial actions. However, removal actions must contribute to the efficiency of future remedial actions.

radiation - Some atoms possess excess energy, causing them to be physically unstable. Such atoms become stable when the excess energy is released in the form of charged particles or electromagnetic waves, known as radiation.

radiation event $-\mathrm{A}$ single detection of a charged particle or electromagnetic wave.

radioactive series - A succession of nuclides, each of which transforms by radioactive disintegration into the next until a stable nuclide results. The first member of the series is called the parent and the intermediate members are called daughters or progeny.

radioactivity - The spontaneous transition of an atomic nucleus from a higher energy to a lower energy state. This transition is accompanied by the release of a charged particle or electromagnetic waves from the atom. Also known as "activity."

radionuclide $-\mathrm{A}$ radioactive element characterized by the number of protons and neutrons in the nucleus. There are several hundred known radionuclides, both artificially produced and naturally occurring.

RCRA (Resource Conservation and Recovery Act) Pronounced "rick-rah," this act of Congress gave EPA the authority to control the generation, transportation, treatment, storage, and disposal of hazardous waste. RCRA also set forth a framework for the management of nonhazardous wastes. The 1986 amendments to RCRA enabled EPA to address environmental problems that could result from underground tanks storing petroleum and other hazardous substances. RCRA focuses only on active and future facilities and does not address abandoned or historical sites (see CERCLA). In 1984, amendments to RCRA called the Hazardous and Solid Waste Amendments (HSWA, pronounced "hiss-wa") required phasing out the land disposal of hazardous waste. Some other mandates of this strict law include increased enforcement authority for EPA, more stringent hazardous waste management standards, and a comprehensive underground storage tank (UST) program.

recharge - The process by which water is added to a zone of saturation (aquifer) from surface infiltration, typically when rainwater soaks through the earth to reach an aquifer.

recharge basin - A basin (natural or artificial) that collects water. The water will infiltrate to the aquifer. release - Spilling, leaking, pumping, pouring, emitting, emptying, discharging, injecting, escaping, leaching, dumping, or disposing of a hazardous substance, pollutant, or contaminant into the environment. The National Contingency Plan also defines the term to include a threat of release.

rem - Stands for "roentgen equivalent man," a unit by which human radiation dose is assessed (see also Sv). The rem is a risk-based value used to estimate the potential health effects to an exposed individual or population. 100 rem $=1$ sievert.

remedial (or remediation) alternatives - Options considered under CERCLA for decontaminating a site such as an operable unit (OU) or area of concern (AOC). Remedial actions are long-term activities that prevent the possible release, or stop or substantially reduce the actual release, of substances that are hazardous but not immediately lifethreatening. See also feasibility study (FS) and Record of Decision (ROD).

residual fuel - Crude oil, Nos. 1 and 2 fuel oil that have a nitrogen content greater than 0.05 weight percent, and all fuel oil Nos. 4, 5, and 6, as defined by the American Society of Testing and Materials in ASTM D396-78, Standard Specifications for Fuel Oils, (c. 2001).

riparian - An organism living on the bank of a river, lake, or tidewater.

ROD (Record of Decision) - A document that records a regulatory agency's decision for the selected remedial action. The ROD also includes a responsiveness summary and a bibliography of documents that were used to reach the remedial decision. When the ROD is finalized, remedial design and implementation can begin.

roentgen - See $\mathrm{R}$.

RPD (relative percent difference) - A measure of precision, expressed by the formula: $\mathrm{RPD}=[(\mathrm{A}-\mathrm{B}) /(\mathrm{A}+\mathrm{B})] \mathrm{x}$ 200 , where A equals the concentration of the first analysis and $\mathrm{B}$ equals the concentration of the second analysis.

runoff - The movement of water over land. Runoff can carry pollutants from the land into surface waters or uncontaminated land.

\section{S}

sampling - The extraction of a prescribed portion of an effluent stream or environmental media for purposes of inspection or analysis.

SARA (Superfund Amendments and Reauthorization Act) - This Act of Congress in 1986 reauthorized CERCLA to continue cleanup activities around the country. Several site-specific amendments, definitions clarifications, and technical requirements were added to the legislation, including additional enforcement authorities. Title III of SARA also authorized EPCRA.

SBMS (Standards-Based Management System) - A document management tool used to develop and integrate 
systems, and to demonstrate BNL's conformance to requirements to perform work safely and efficiently.

scintillation - Flashes of light produced in a phosphor by a radioactive material.

SDWA (Safe Drinking Water Act) - The Safe Drinking Water Act was established to protect the quality of drinking water in the United States. It focuses on all waters actually or potentially designed for drinking use, whether from above ground or underground sources. The SDWA authorized EPA to establish safe standards of purity and required all owners or operators of public water systems to comply with health-related standards. State governments assume regulatory power from EPA.

sediment - The layer of soil and minerals at the bottom of surface waters, such as streams, lakes, and rivers.

sensitivity - The minimum amount of an analyte that can be repeatedly detected by an instrument.

sievert - See Sv.

skyshine - Radiation emitted upward from an open-topped, shielded enclosure and reflected downward, resulting in the possibility that flora and fauna (including humans) outside the shielded enclosure can be exposed to radiation.

sludge - Semisolid residue from industrial or water treatment processes.

sole source aquifer - An area defined by EPA as being the primary source of drinking water for a particular region. Includes the surface area above the sole source aquifer and its recharge area.

SPDES (State Pollutant Discharge Elimination System) This permit program is delegated to the states, but the effluent limitations and other requirements are set by the federal government. 6 NYCRR Section 750-1.11(a) concerns the provisions of SPDES permits and lists the citations for the various effluent limitations from the Federal Register and the CFR.

stable - Nonradioactive.

stakeholder - People or organizations with vested interests in BNL and its environment and operations. Stakeholders include federal, state, and local regulators; the public; DOE; and BNL staff.

stripping - A process used to remove volatile contaminants from a substance (see also air stripping).

sump - A pit or tank that catches liquid runoff for drainage or disposal.

Sv (sievert) - A unit for assessing the risk of human radiation dose, used internationally and with increasing frequency in the United States. One sievert is equal to 100 rem.

SVE (soil vapor extraction) - An in situ (in-place) method of extracting VOCs from soil by applying a vacuum to the soil and collecting the air, which can be further treated to remove the VOCs, or discharged to the atmosphere.

SVOC - A general term for volatile organic compounds that vaporize relatively slowly at standard temperature and pressure. See also VOC.

synoptic - Relating to or displaying conditions as they occur over a broad area.

\section{$\mathrm{T}$}

$\mathbf{t}_{1 / 2}$ (half-life) - The time required for one-half of the atoms of any given amount of a radioactive substance to disintegrate; the time required for the activity of a radioactive sample to be reduced by one half.

TCE (trichloroethylene, also known as trichloroethene) A stable, colorless liquid with a low boiling point. TCE has many industrial applications, including use as a solvent and as a metal degreasing agent. TCE may be toxic when inhaled or ingested, or through skin contact, and can damage vital organs, especially the liver. See also VOC.

Tier III reports - Reports, required by SARA, that are prepared to document annual emissions of toxic materials to the environment. These are also known as TRI Section 313 reports.

TLD (thermoluminescent dosimeter) - A device used to measure radiation dose to occupational workers or radiation levels in the environment.

tritium - The heaviest and only radioactive nuclide of hydrogen, with a half-life of 12.3 years and a very-low-energy radioactive decay (tritium is a beta emitter).

TSCA (Toxic Substances Control Act) - Enacted by Congress in1976, TSCA empowers EPA to track the 75,000 industrial chemicals produced or imported into the United States. EPA repeatedly screens these chemicals and can require reporting or testing of any that may pose an environmental or human health hazard. EPA can ban the manufacture or import of chemicals that pose an unreasonable risk.

TVOC (total volatile organic compounds) - A sum of all individual VOC concentrations detected in a given sample.

\section{$\mathrm{U}$}

UIC (underground injection control) - A hole with vertical dimensions greater than its largest horizontal dimensions; used for disposal of wastewater.

UST (underground storage tank) - A stationary device, constructed primarily of nonearthen material, designed to contain petroleum products or hazardous materials. In a UST, 10 percent or more of the volume of the tank system is below the surface of the ground.

upgradient/upslope - A location of higher groundwater elevation; analogous to "upstream."

\section{$\mathrm{V}$}

vadose - Relating to water in the ground that is above the permanent groundwater level.

vernal pool - A small, isolated, and contained basin that holds water on a temporary basis, most commonly during winter and spring. It has no aboveground outlet for water and is extremely important to the life cycle of many am- 
phibians (such as the tiger salamander), as it is too shallow to support fish, a major predator of amphibian larvae.

VOC (volatile organic compound) -A general term for organic compounds capable of a high degree of vaporization at standard temperature and pressure. Because VOCs readily evaporate into the air, the potential for human exposure is greatly increased. Due to widespread industrial use, VOCs are commonly found in soil and groundwater.

VUV - Stands for "very ultraviolet" and refers to a beamline at the NSLS with wavelengths at the far ultraviolet end of the spectrum.

\section{$\mathrm{W}$}

waste minimization - Action that avoids or reduces the generation of waste, consistent with the general goal of minimizing current and future threats to human health, safety, and the environment. Waste minimization activities include recycling, improving energy usage, reducing waste at the source, and reducing the toxicity of hazardous waste. This action is associated with pollution prevention, but is more likely to occur after waste has been generated.

water table - The water-level surface below the ground where the unsaturated zone ends and the saturated zone begins. It is the level to which a well that is screened in the unconfined aquifer will fill with water.

watershed - The region draining into a river, a river system, or a body of water. weighting factor - A factor which, when multiplied by the dose equivalent delivered to a body organ or tissue, yields the equivalent risk due to a uniform radiation exposure of the whole body. See also EDE.

wet weight - The wet weight concentration of a substance is before a sample is dried for analysis (in other words, in its "natural" state), and is the form most likely to be consumed. Wet weight concentrations are typically lower than dry weight values.

wind rose - A diagram that shows the frequency of wind from different directions at a specific location.

\section{$\mathrm{X}$}

x-rays - A form of electromagnetic radiation with short wavelength, generated when high-energy electrons strike matter or when lower-energy beta radiation is absorbed in matter. Gamma radiation and x-rays are identical, except for the source.

\section{Z}

zeolite - A naturally occurring group of more than 100 minerals, formed of silicates and aluminum, with unique and diverse crystal properties. Zeolites can perform ion exchange, filtering, odor removal, and chemical sieve and gas absorption tasks. Synthetic zeolites are now used for most applications. 


\section{Understanding Radiation}

This section introduces the general reader to some basic concepts of radioactivity and an understanding of the radiation emitted as radioactive materials decay to a stable state. To better comprehend the radiological information in the Site Environmental Report (SER) it, is important to remember that not all radiations are the same and that different kinds of radiation affect living beings differently.

This appendix includes discussions on the common sources of radioactivity in the environment, types of radiation, the analyses used to quantify radioactive material, and how radiation sources contribute to radiation dose. Some general statistical concepts are also presented, along with a discussion of radionuclides that are of environmental interest at BNL. The discussion begins with some definitions and background information on scientific notation and numerical prefixes used when measuring dose and radioactivity. The definitions of commonly used radiological terms are found in the Technical Topics section of the glossary, Appendix A, and are indicated in boldface type here only when the definition in the glossary provides additional details.

\section{RADIOACTIVITY AND RADIATION}

All substances are composed of atoms that are made of subatomic particles: protons, neutrons, and electrons. The protons and neutrons are tightly bound together in the positively charged nucleus (plural: nuclei) at the center of the atom. The nucleus is surrounded by a cloud of negatively charged electrons. Most nuclei are stable because the forces holding the protons and neutrons together are strong enough to overcome the electrical energy that tries to push them apart. When the number of neutrons in the nucleus exceeds a threshold, then the nucleus becomes unstable and will spontaneously "decay,” or emit excess energy ("nuclear” energy) in the form of charged particles or electromagnetic waves. Radiation is the excess energy released by unstable atoms. Radioactivity and radioactive refer to the unstable nuclear property of a substance (e.g., radioactive uranium). When a charged particle or electromagnetic wave is detected by radiation-sensing equipment, this is referred to as a radiation event.

Radiation that has enough energy to remove electrons from atoms within material (a process called ionization) is classified as ionizing radiation. Radiation that does not have enough energy to remove electrons is called nonionizing radiation. Examples of nonionizing radiation include most visible light, infrared light, microwaves, and radio waves. All radiation, whether ionizing or not, may pose health risks. In the SER, radiation refers to ionizing radiation.

Radioactive elements (or radionuclides) are referred to by name followed by a number, such as cesium-137. The number indicates the mass of that element and the total number of neutrons and protons contained in the nucleus of the atom. Another way to specify cesium-137 is Cs-137, where Cs is the chemical symbol for cesium in the Periodic Table of the Elements. This type of abbreviation is used in the SER.

\section{SCIENTIFIC NOTATION}

Most numbers used for measurement and quantification in the SER are either very large or very small, and many zeroes would be required to express their value. To avoid this, scientific notation is used, with numbers represented in multiples of 10. For example, the number two million five hundred thousand (two and a half million, or 2,500,000) is written in scientific notation as $2.5 \times 10^{6}$, which represents " 2.5 multiplied by (10 raised to the power of 6)." Since even " $2.5 \times 10^{6}$ " can be cumbersome, the capital letter $E$ is substituted for the phrase " 10 raised to the power of ...." Using this format, $2,500,000$ is represented as $2.5 \mathrm{E}+06$. The " +06 " refers to the number of places the decimal point was moved to the left to create the shorter version. Scientific notation is also used to represent numbers smaller than zero, in which case a 


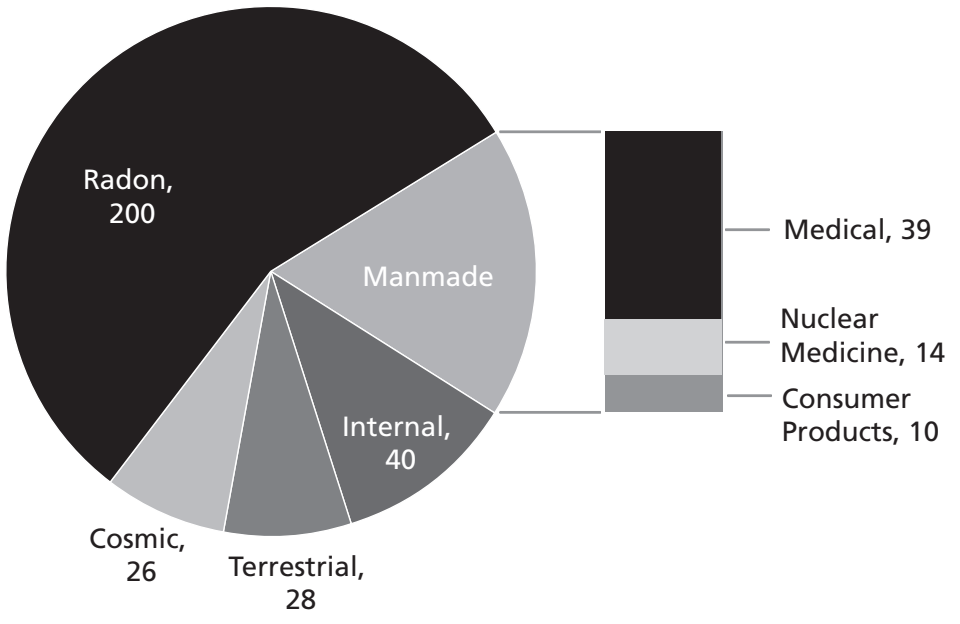

Figure B-1. Typical Annual Radiation Doses from Natural and ManMade Sources (mrem). Source: NCRP Report No. 93 (NCRP 1987)

minus sign follows the $\mathrm{E}$ rather than a plus. For example, 0.00025 can be written as $2.5 \times 10^{-4}$ or 2.5E-04. Here, “-04" indicates the number of places the decimal point was moved to the right.

\section{NUMERICAL PREFIXES}

Another method of representing very large or small numbers without using many zeroes is to use prefixes to represent multiples of ten. For example, the prefix milli (abbreviated $\mathrm{m}$ ) means that the value being represented is one-thousandth of a whole unit; $3 \mathrm{mg}$ (milligrams) is 3 thousandths of a gram or E-03. See Appendix $\mathrm{C}$ for additional common prefixes, including pico (p), which means trillionth or E-12, giga (G), which means billion or E+09, and tera (T), which means trillion, $\mathrm{E}+12$.

\section{SOURCES OF IONIZING RADIATION}

Radiation is energy that has both natural and manmade sources. Some radiation is essential to life, such as heat and light from the sun. Exposure to high-energy (ionizing) radiation has to be managed, as it can pose serious health risks at large doses. Living things are exposed to radiation from natural background sources: the atmosphere, soil, water, food, and even our own bodies. Humans are exposed to ionizing radiation from a variety of common sources, the most significant of which follow.

Background Radiation - Radiation that occurs naturally in the environment is also called background activity. Background radiation consists of cosmic radiation from outer space, radiation from radioactive elements in soil and rocks, and radiation from radon and its decay products in air. Some people use the term background when referring to all non-occupational sources commonly present. Other people use natural to refer only to cosmic and terrestrial sources, and background to refer to common man-made sources such as medical procedures, consumer products, and radioactivity present in the atmosphere from former nuclear testing. In the SER, the term natural background is used to refer to radiation from cosmic and terrestrial radiation.

Cosmic - Cosmic radiation primarily consists of charged particles that originate in space, beyond the earth's atmosphere. This includes ionizing radiation from the sun, and secondary radiation generated by the entry of charged particles into the earth's atmosphere at high speeds and energies. Radioactive elements such as hydrogen-3 (tritium), beryllium-7, carbon-14, and sodium-22 are produced in the atmosphere by cosmic radiation. Exposure to cosmic radiation increases with altitude, because at higher elevations the atmosphere and the earth's magnetic field provide less shielding. Therefore, people who live in the mountains are exposed to more cosmic radiation than people who live at sea level. The average dose from cosmic radiation to a person living in the United States is approximately 26 mrem per year. (For an explanation of dose, see effective dose equivalent in Appendix A. The units rem and sieverts also are explained in Appendix A.)

Terrestrial - Terrestrial radiation is released by radioactive elements that have been present in the soil since the formation of the earth. Common radioactive elements that contribute to terrestrial exposure include isotopes of potassium, thorium, actinium, and uranium. The average dose from terrestrial radiation to a person living in the United States is approximately 28 mrem per year, but may vary considerably depending on the local geology.

Internal - Internal exposure occurs when radionuclides are ingested, inhaled, or absorbed through the skin. Radioactive material may be incorporated into food through the uptake of terrestrial radionuclides by plant roots. People can 
ingest radionuclides when they eat contaminated plant matter or meat from animals that have consumed contaminated plants. The average dose from food for a person living in the United States is about 40 mrem per year. A larger exposure, for most people, comes from breathing the decay products of naturally occurring radon gas. The average dose from breathing air with radon byproducts is about 200 mrem per year, but that amount varies depending on geographical location. An EPA map shows that BNL is located in one of the regions with the lowest potential radon risk.

Medical - Every year in the United States, millions of people undergo medical procedures that use ionizing radiation. Such procedures include chest and dental x-rays, mammography, thallium heart stress tests, and tumor irradiation therapies. The average doses from nuclear medicine and x-ray examination procedures are about 14 and 39 mrem per year, respectively. Anthropogenic - Sources of anthropogenic (manmade) radiation include consumer products such as static eliminators (containing polonium-210), smoke detectors (containing americium-241), cardiac pacemakers (containing plutonium-238), fertilizers (containing isotopes from uranium and thorium decay series), and tobacco products (containing polonium-210 and lead-210). The average dose from consumer products to a person living in the United States is 10 mrem per year (excluding tobacco contributions).

\section{COMMON TYPES OF IONIZING RADIATION}

The three most common types of ionizing radiation are described below.

Alpha Radiation - An alpha particle is identical in makeup to the nucleus of a helium atom, consisting of two neutrons and two protons. Alpha particles have a positive charge and have little or no penetrating power in matter. They are easily stopped by materials such as paper and have a range in air of only an inch or so. However, if alpha-emitting material is ingested, alpha particles can pose a health risk inside the body. Naturally occurring radioactive elements such as uranium emit alpha radiation.

Beta Radiation - Beta radiation is composed of particles that are identical to electrons.
Therefore, beta particles have a negative charge. Beta radiation is slightly more penetrating than alpha radiation, but most beta radiation can be stopped by materials such as aluminum foil and plexiglass panels. Beta radiation has a range in air of several feet. Naturally occurring radioactive elements such as potassium- 40 emit beta radiation. Some beta particles present a hazard to the skin and eyes.

Gamma Radiation - Gamma radiation is a form of electromagnetic radiation, like radio waves or visible light, but with a much shorter wavelength. Gamma rays are emitted from a radioactive nucleus along with alpha or beta particles. Gamma radiation is more penetrating than alpha or beta radiation, capable of passing through dense materials such as concrete. Gamma radiation is identical to $\mathrm{x}$-rays except that $\mathrm{x}$-rays are more energetic. Only a fraction of the total gamma rays a person is exposed to will interact with the human body.

\section{TYPES OF RADIOLOGICAL ANALYSES}

The amount of radioactive material in a sample of air, water, soil, or other material can be assessed using several analyses, the most common of which are described below.

Gross alpha - Alpha particles are emitted from radioactive material in a range of different energies. An analysis that measures all alpha particles simultaneously, without regard to their particular energy, is known as a gross alpha activity measurement. This type of measurement is valuable as a screening tool to indicate the total amount but not the type of alpha-emitting radionuclides that may be present in a sample.

Gross beta - This is the same concept as that for gross alpha analysis, except that it applies to the measurement of gross beta particle activity.

Tritium - Tritium radiation consists of low-energy beta particles. It is detected and quantified by liquid scintillation counting. More information on tritium is presented in the section Radionuclides of Environmental Interest, later in this appendix.

Strontium-90 - Due to the properties of the radiation emitted by strontium-90 (Sr-90), a special analysis is required. Samples are chemically processed to separate and collect any 
strontium atoms that may be present. The collected atoms are then analyzed separately. More information on Sr-90 is presented in the section Radionuclides of Environmental Interest.

Gamma - This analysis technique identifies specific radionuclides. It measures the particular energy of a radionuclide's gamma radiation emission. The energy of these emissions is unique for each radionuclide, acting as a "fingerprint” to identify it.

\section{STATISTICS}

Two important statistical aspects of measuring radioactivity are uncertainty in results, and negative values.

Uncertainty - Because the emission of radiation from an atom is a random process, a sample counted several times usually yields a slightly different result each time; therefore, a single measurement is not definitive. To account for this variability, the concept of uncertainty is applied to radiological data. In the SER, analysis results are presented in an $\mathrm{x} \pm \mathrm{y}$ format, where " $x$ " is the analysis result and " $\pm y$ " is the 95 percent "confidence interval" of that result. That means there is a 95 percent probability that the true value of $\mathrm{x}$ lies between $(\mathrm{x}+\mathrm{y})$ and $(\mathrm{x}-\mathrm{y})$.

Negative values - There is always a small amount of natural background radiation. The laboratory instruments used to measure radioactivity in samples are sensitive enough to measure the background radiation along with any contaminant radiation in the sample. To obtain a true measure of the contaminant level in a sample, the background radiation level must be subtracted from the total amount of radioactivity measured. Due to the randomness of radioactive emissions and the very low concentrations of some contaminants, it is possible to obtain a background measurement that is larger than the actual contaminant measurement. When the larger background measurement is subtracted from the smaller contaminant measurement, a negative result is generated. The negative results are reported, even though doing so may seem illogical, because they are essential when conducting statistical evaluations of data.

Radiation events occur randomly; if a radioactive sample is counted multiple times, a spread, or distribution, of results will be obtained. This spread, known as a Poisson distribution, is centered about a mean (average) value. Similarly, if background activity (the number of radiation events observed when no sample is present) is counted multiple times, it also will have a Poisson distribution. The goal of a radiological analysis is to determine whether a sample contains activity greater than the background reading detected by the instrument. Because the sample activity and the background activity readings are both Poisson distributed, subtraction of background activity from the measured sample activity may result in values that vary slightly from one analysis to the next. Therefore, the concept of a minimum detection limit (MDL) was established to determine the statistical likelihood that a sample's activity is greater than the background reading recorded by the instrument.

Identifying a sample as containing activity greater than background, when it actually does not have activity present, is known as a Type I error. Most laboratories set their acceptance of a Type I error at 5 percent when calculating the MDL for a given analysis. That is, for any value that is greater than or equal to the MDL, there is 95 percent confidence that it represents the detection of true activity. Values that are less than the MDL may be valid, but they have a reduced confidence associated with them. Therefore, all radiological data are reported, regardless of whether they are positive or negative

At very low sample activity levels that are close to the instrument's background reading, it is possible to obtain a sample result that is less than zero. This occurs when the background activity is subtracted from the sample activity to obtain a net value, and a negative value results. Due to this situation, a single radiation event observed during a counting period could have a significant effect on the mean (average) value result. Subsequent analysis may produce a sample result that is positive. When the annual data for the SER are compiled, results may be averaged; therefore, all negative values are retained for reporting as well. This data handling practice is consistent with the guidance provided in the Handbook of 
Radioactivity Measurements Procedures (NCRP 1985) and the Environmental Regulatory Guide for Radiological Effluent Monitoring and Environmental Surveillance (DOE 1991). Average values are calculated using actual analytical results, regardless of whether they are above or below the MDL, or even equal to zero. The uncertainty of the mean, or the 95 percent confidence interval, is determined by multiplying the population standard deviation of the mean by the $\mathrm{t}_{(0.05)}$ statistic.

\section{RADIONUCLIDES OF ENVIRONMENTAL INTEREST}

Several types of radionuclides are found in the environment at BNL due to historical operations.

Cesium-137 - Cs-137 is a fission-produced radionuclide with a half-life of 30 years (after 30 years, only one half of the original activity level remains). It is found in the worldwide environment as a result of past aboveground nuclear weapons testing and can be observed in near-surface soils at very low concentrations, usually less than 1 pCi/g (0.004 Bq/g). Cs-137 is a beta-emitting radionuclide, but it can be detected by gamma spectroscopy because its decay product, barium-137m, emits gamma radiation.

Cs-137 is found in the environment at BNL mainly as a soil contaminant, from two main sources. The first source is the worldwide deposition from nuclear accidents and fallout from weapons testing programs. The second source is deposition from spills or releases from BNL operations. Nuclear reactor operations produce Cs-137 as a byproduct. In the past, wastewater containing small amounts of Cs-137 generated at the reactor facilities was routinely discharged to the Sewage Treatment Plant (STP), resulting in low-level contamination of the STP and the Peconic River. In 2002/2003, under the Environmental Restoration Program, sand and its debris containing low levels of Cs-137, Sr-90, and heavy metals were removed, assuring that future discharges from the STP are free of these contaminants. Soil contaminated with Cs-137 is associated with the following areas that have been, or are being, addressed as part of the Environmental Remediation Program: former Hazardous Waste Management Facility, Waste Concentration Facility, Building 650 Reclamation Facility and Sump Outfall Area, and the Brookhaven Graphite Research Reactor (BGRR).

Strontium-90 - Sr-90 is a beta-emitting radionuclide with a half-life of 28 years. Sr-90 is found in the environment principally as a result of fallout from aboveground nuclear weapons testing. Sr-90 released by weapons testing in the 1950s and early 1960s is still present in the environment today. Additionally, nations that were not signatories of the Nuclear Test Ban Treaty of 1963 have contributed to the global inventory of fission products (Sr-90 and Cs-137). This radionuclide was also released as a result of the 1986 Chernobyl accident in the former Soviet Union.

Sr-90 is present at BNL in the soil and groundwater. As in the case of Cs-137, some Sr-90 at BNL results from worldwide nuclear testing; the remaining contamination is a byproduct of reactor operations. The following areas with Sr-90 contamination have been or are being addressed as part of the Environmental Remediation Program: former Hazardous Waste Management Facility, Waste Concentration Facility, Building 650 Reclamation Facility and Sump Outfall Area, the BGRR, Former and Interim Landfills, Chemical and Glass Holes Area, and the STP.

The information in SER tables is arranged by method of analysis. Because Sr-90 requires a unique method of analysis, it is reported as a separate entry. Methods for detecting Sr-90 using state-of-the-art equipment are quite sensitive (detecting concentrations less than $1 \mathrm{pCi} / \mathrm{L}$ ), which makes it possible to detect background levels of Sr-90.

Tritium - Among the radioactive materials that are used or produced at BNL, tritium has received the most public attention. Approximately 4 million $\mathrm{Ci}(1.5 \mathrm{E}+5 \mathrm{TBq})$ per year are produced in the atmosphere naturally (NCRP 1979). As a result aboveground weapons testing in the 1950s and early 1960s in the United States, the global atmospheric tritium inventory was increased by a factor of about 200. Other human activities such as consumer product manufacturing and nuclear power reactor opera- 
tions have also released tritium into the environment. Commercially, tritium is used in products such as self-illuminating wristwatches and exit signs (the signs may each contain as much as $25 \mathrm{Ci}$ [925 GBq] of tritium). Tritium also has many uses in medical and biological research as a labeling agent in chemical compounds, and is frequently used in universities and other research settings such as BNL and the other national laboratories.

Of the sources mentioned above, the most significant contributor to tritium in the environment has been aboveground nuclear weapons testing. In the early 1960s, the average tritium concentration in surface streams in the United States reached a value of 4,000 pCi/L (148 Bq/ L; NCRP 1979). Approximately the same concentration was measured in precipitation. Today, the level of tritium in surface waters in New York State is less than one-twentieth of that amount, below 200 pCi/L (7.4 Bq/L; NYSDOH 1993). This is less than the detection limit of most analytical laboratories.

Tritium has a half-life of 12.3 years. When an atom of tritium decays, it releases a beta particle, causing transformation of the tritium atom into stable (nonradioactive) helium. The beta radiation that tritium releases has a very low energy, compared to the emissions of most other radioactive elements. In humans, the outer layer of dead skin cells easily stops the beta radiation from tritium; therefore, only when tritium is taken into the body can it cause an exposure. Tritium may be taken into the body by inhalation, ingestion, or absorption of tritiated water through the skin. Because of its low energy radiation and short residence time in the body, the health threat posed by tritium is very small for most exposures.

Environmental tritium is found in two forms: gaseous elemental tritium, and tritiated water or water vapor, in which at least one of the hydrogen atoms in the $\mathrm{H}_{2} \mathrm{O}$ water molecule has been replaced by a tritium atom (hence, its shorthand notation, HTO). Most of the tritium released from BNL sources is in the form of
HTO, none as elemental tritium. Sources of tritium at BNL include the reactor facilities (all now non-operational), where residual water (either heavy or light) is converted to tritium via neutron bombardment; the accelerator facilities, where tritium is produced by secondary radiation interactions with soil and water; and facilities like the Brookhaven Linac Isotope Producer (BLIP), where tritium is formed from secondary radiation interaction with cooling water. Tritium has been found in the environment at BNL as a groundwater contaminant from operations in the following areas: Current Landfill, BLIP, Alternating Gradient Synchrotron, and the High Flux Beam Reactor. Although small quantities of tritium are still being released to the environment through BNL emissions and effluents, the concentrations and total quantity have been drastically reduced, compared with historical operational releases as discussed in Chapters 4 and 5.

\section{REFERENCES AND BIBLIOGRAPHY}

DOE Order 5400.5. 1993. Radiation Protection of the Public and the Environment. U.S. Department of Energy, Washington, DC. Change 2: 1-7-93.

DOE. 1991. Environmental Regulatory Guide for Radiological Effluent Monitoring and Environmental Surveillance. DOE/EH-0173T. U.S. Department of Energy, Washington, DC.

NCRP. 1979. Tritium in the Environment. NCRP Report No. 62. National Council on Radiation Protection and Measurements. Bethesda, MD.

NCRP. 1985. Handbook of Radioactivity Measurements Procedures, NCRP Report No. 58. National Council on Radiation Protection and Measurements, Bethesda, MD.

NCRP. 1987. Ionizing Radiation Exposure of the Population of the United States. NCRP Report No. 93. National Council on Radiation Protection and Measurements. Bethesda, MD.

NYSDOH. 1996. Radioactive Contamination in the Peconic River. Bureau of Environmental Radiation Protection, New York State Department of Health, Albany, NY.

NYSDOH. 1993. Environmental Radiation in New York State. Bureau of Environmental Radiation Protection, New York State Department of Health, Albany, NY.

Radiochemistry Society Online. www.radiochemistry. org/nomenclature/index/html, accessed 3-25-04. 
APPENDIX C

\section{Units of Measure and Half-Life Periods}

UNITS OF RADIATION MEASUREMENT AND CONVERSIONS

\begin{tabular}{|l|c|c|}
\hline U.S. System & International System & Conversion \\
\hline curie $(\mathrm{Ci})$ & becquerel $(\mathrm{Bq})$ & $1 \mathrm{Ci}=3.7 \times 10^{10} \mathrm{~Bq}$ \\
\hline rad & gray $(\mathrm{Gy})$ & $1 \mathrm{rad}=0.01 \mathrm{~Gy}$ \\
\hline rem & sievert $(\mathrm{Sv})$ & $1 \mathrm{rem}=0.01 \mathrm{~Sv}$ \\
\hline
\end{tabular}

APPROXIMATE METRIC CONVERSIONS

\begin{tabular}{|c|c|c|c|c|c|}
\hline When you know & multiply by & to obtain & When you know & multiply by & to obtain \\
\hline centimeters $(\mathrm{cm})$ & 0.39 & inches (in.) & in. & 2.54 & $\mathrm{~cm}$ \\
\hline meters (m) & 3.28 & feet $(\mathrm{ft})$ & $\mathrm{ft}$ & 0.305 & $\mathrm{~m}$ \\
\hline kilometers (km) & 0.62 & miles (mi) & $\mathrm{mi}$ & 1.61 & $\mathrm{~km}$ \\
\hline kilograms (kg) & 2.20 & pounds (lb) & $\mathrm{lb}$ & 0.45 & $\mathrm{~kg}$ \\
\hline liters (L) & 0.264 & gallons (gal) & gal & 3.785 & L \\
\hline cubic meters $\left(m^{3}\right)$ & 35.32 & cubic feet $\left(\mathrm{ft}^{3}\right)$ & $\mathrm{ft}^{3}$ & 0.03 & $\mathrm{~m}^{3}$ \\
\hline hectares (ha) & 2.47 & acres & acres & 0.40 & ha \\
\hline square kilometers $\left(\mathrm{km}^{2}\right)$ & 0.39 & square miles $\left(\mathrm{mi}^{2}\right)$ & $\mathrm{mi}^{2}$ & 2.59 & $\mathrm{~km}^{2}$ \\
\hline degrees Celcius $\left({ }^{\circ} \mathrm{C}\right)$ & $1.8\left({ }^{\circ} \mathrm{C}\right)+32$ & degrees Fahrenheit $\left({ }^{\circ} \mathrm{F}\right)$ & ${ }^{\circ} \mathrm{F}$ & $\left({ }^{\circ} \mathrm{F}-32\right) / 1.8$ & ${ }^{\circ} \mathrm{C}$ \\
\hline
\end{tabular}

SCIENTIFIC NOTATION USED FOR MEASUREMENTS

\begin{tabular}{|l|c|c|c|c|}
\hline Multiple & Decimal Equivalent & Notation & Prefix & Symbol \\
\hline $1 \times 10^{12}$ & $1,000,000,000,000$ & $\mathrm{E}+12$ & Tera- & $\mathrm{T}$ \\
\hline $1 \times 10^{9}$ & $1,000,000,000$ & $\mathrm{E}+9$ & giga- & $\mathrm{k}$ \\
\hline $1 \times 10^{3}$ & 1,000 & $\mathrm{E}+03$ & kilo- & $\mathrm{C}$ \\
\hline $1 \times 10^{-2}$ & 0.01 & $\mathrm{E}-02$ & $\mathrm{centi}$ & $\mathrm{m}$ \\
\hline $1 \times 10^{-3}$ & 0.001 & $\mathrm{E}-03$ & milli- & $\mu$ \\
\hline $1 \times 10^{-6}$ & 0.000001 & $\mathrm{E}-06$ & micro- & $\mathrm{n}$ \\
\hline $1 \times 10^{-9}$ & 0.000000001 & $\mathrm{E}-09$ & nano- & $\mathrm{p}$ \\
\hline $1 \times 10^{-12}$ & 0.00000000000 & $\mathrm{E}-12$ & pico- & \\
\hline
\end{tabular}

\section{CONCENTRATION CONVERSIONS}

$\begin{array}{|lll|}1 \mathrm{ppm}=1,000 \mathrm{ppb} & \\ 1 \mathrm{ppb}=0.001 \mathrm{ppm}=1 \mu \mathrm{g} / \mathrm{L}^{*} \\ 1 \mathrm{ppm}=1 \mathrm{mg} / \mathrm{L}=1000 \mu \mathrm{g} / \mathrm{L}^{*}\end{array}$

\footnotetext{
* For aqueous fractions only.
} 


\begin{tabular}{|l|c|}
\hline \multicolumn{2}{|c|}{ HALF-LIFE PERIODS } \\
\hline Am-241 & $432.7 \mathrm{yrs}$ \\
\hline C-11 & $\sim 20 \mathrm{~min}$ \\
\hline Co-60 & $5.3 \mathrm{yrs}$ \\
\hline Cs-137 & $30.2 \mathrm{yrs}$ \\
\hline N-13 & $\sim 10 \mathrm{~min}$ \\
\hline $\mathrm{N}-22$ & $2.6 \mathrm{yrs}$ \\
\hline 0-15 & $\sim 2 \mathrm{~min}$ \\
\hline PU-238 & $87.7 \mathrm{yrs}$ \\
\hline Pu-239 & $24,100.0 \mathrm{yrs}$ \\
\hline Pu-240 & $6,560.0 \mathrm{yrs}$ \\
\hline Sr-90 & $29.1 \mathrm{yrs}$ \\
\hline tritium & $12.3 \mathrm{yrs}$ \\
\hline U-234 & $247,000.0 \mathrm{yrs}$ \\
\hline U-235 & $\sim 700$ million yrs \\
& $(7.0004 \mathrm{E} 8)$ \\
\hline U-238 & $87.7 \mathrm{yrs}$ \\
\hline
\end{tabular}


APPENDIX D

\title{
Federal, State, and Local Laws and Regulations Pertinent to BNL
}

\author{
DOE DIRECTIVES, REGULATIONS, AND STANDARDS \\ DOE O 231.1-A Order: Environment, Safety and Health Reporting 08/19/03 \\ DOE O 414.1 Order: Management Assessment and Independent Assessor's Guide 05/31/2001 \\ DOE O 435.1 Order, Change 1: Radioactive Waste Management 08/28/2001 \\ DOE O 450.1 Order: Environmental Protection Program 01/15/2003 \\ DOE P 450.5 Policy: Line Environment, Safety, and Health Oversight 06/26/1997 \\ DOE O 5400.5 Order: Change 2, Radiological Protection of the Public and the Environment 01/07/1993
}

\section{FEDERAL LAWS AND REGULATIONS}

Executive Order

13148 Greening of the Government Through Leadership in Environmental Management

10 CFR 1021 National Environmental Protection Act, Implementing and Procedures

10 CFR 1022 Compliance with Floodplain/Wetlands Environmental Review Requirements

10 CFR 830 Subpart A: Quality Assurance Requirements

10 CFR 834 Radiation Protection of the Public and the Environment

16 USC $470 \quad$ National Historic Preservation Act

36 CFR $60 \quad$ National Register of Historic Places

36 CFR 63 Determination of Eligibility for Inclusion in the National Register of Historic Places

36 CFR 79 Curation of Federally Owned and Administered Archaeological Collections

36 CFR $800 \quad$ Protection of Historic Properties

40 CFR 50-0 National Primary and Secondary Ambient Air Quality Standards

40 CFR 82 Protection of Stratospheric Ozone

40 CFR 109 Criteria for State, Local and Regional Oil Removal Contingency Plans

40 CFR 110 Discharge of Oil

40 CFR 112 Oil Pollution Prevention Act

40 CFR 113 Liability Limits for Small Onshore Storage Facilities

40 CFR 116 Designation of Hazardous Substances

40 CFR 117 Determination of Reportable Quantities for Hazardous Substances

40 CFR 121 State Certification of Activities Requiring a Federal License or Permit 
APPENDIX D: FEDERAL, STATE, AND LOCAL LAWS

AND REGULATIONS PERTINENT TO BNL

40 CFR $122 \quad$ National Pollution Discharge Elimination System (NPDES)

40 CFR 123 State Program Requirements

40 CFR $124 \quad$ Procedures for Decision-making

40 CFR 125 Criteria and Standards for the National Pollutant Discharge Elimination System

40 CFR 129 Toxic Pollutant Effluent Standards

40 CFR $130 \quad$ Water Quality Planning and Management

40 CFR $131 \quad$ Water Quality Standards

40 CFR $132 \quad$ Water Quality Guidance for the Great Lakes System

40 CFR 133 Secondary Treatment Regulation

40 CFR $135 \quad$ Prior Notice of Citizen Suits

40 CFR $136 \quad$ Guidelines Establishing Test Procedures for the Analysis of Pollutants

40 CFR $141 \quad$ National Primary Drinking Water Regulations

40 CFR $142 \quad$ National Primary Drinking Water Regulations Implementation

40 CFR $143 \quad$ National Secondary Drinking Water Regulations

40 CFR $144 \quad$ Underground Injection Control (UIC) Program

40 CFR $146 \quad$ Underground Injection Control (UIC) Program: Criteria and Standards

40 CFR 148 Hazardous Waste Injection Restrictions

40 CFR 149 Sole Source Aquifers

40 CFR 167 Submissions of Pesticide Reports

40 CFR 168 Statements of Enforcement Policies and Interpretations

40 CFR 169 Books and Records of Pesticide Production and Distribution

40 CFR $170 \quad$ Worker Protection Standard

40 CFR $171 \quad$ Certification of Pesticide Applicators

40 CFR 260 Hazardous Waste Management Systems: General

40 CFR 261 Identification and Listing of Hazardous Waste

40 CFR 262 Standards Applicable to Generators of Hazardous Waste

40 CFR 263 Standards Applicable to Transporters of Hazardous Waste

40 CFR 264 Standards for Owners and Operators of Hazardous Waste Treatment, Storage, and Disposal Facilities

40 CFR 265 Interim Status Standards for Owners and Operators of Hazardous Waste Treatment, Storage, and Disposal Facilities

40 CFR 266 Standards for the Management of Special Hazardous Wastes and Specific Types of Hazardous Waste Management Facilities

40 CFR $268 \quad$ Land Disposal Restrictions 
40 CFR 270

40 CFR 271

40 CFR 272

40 CFR 273

40 CFR 279

40 CFR 280

40 CFR 300

40 CFR 302

40 CFR 355

40 CFR 370

40 CFR 372

40 CFR 700

40 CFR 702

40 CFR 704

40 CFR 707

40 CFR 710

40 CFR 712

40 CFR 716

40 CFR 717

40 CFR 720

40 CFR 721

40 CFR 723

40 CFR 725

40 CFR 745

40 CFR 747

40 CFR 749

40 CFR 750

40 CFR 761

40 CFR 763

40 CFR 1500

40 CFR 1501
EPA Administered Permit Program: The Hazardous Waste Permit Program

Requirements for Authorization of State Hazardous Waste Mgmt Programs

Approved State Hazardous Waste Management Programs

Standards for Universal Waste Management

Standards for the Management of Used Oil

Technical Standards and Corrective Action Requirements for Owners and Operators of Underground Storage Tanks (USTs)

National Oil and Hazardous Substances Pollution Contingency Plan

Designation, Reportable Quantities, and Notification

Emergency Planning and Notification

Hazardous Chemical Report: Community Right-to-Know

Toxic Chemical Release Report: Community Right-to-Know

Toxic Substances Control Act [TSCA]

Toxic Substances Control Act: General Practices and Procedures

Toxic Substances Control Act: Reporting and Recordkeeping Requirements

Chemical Imports and Exports

Inventory Reporting Regulations

Chemical Information Rules

Health and Safety Data Reporting

Records and Reports of Allegations that Chemical Substances Cause Significant Adverse Reactions to Health or the Environment

Premanufacture Notification

Significant New Users of Chemical Substances

Premanufacture Notification Exemptions

Reporting Requirements and Review Processes for Microorganisms

Lead-Based Paint Poisoning Prevention in Certain Residential Structures

Metalworking Fluids

Water Treatment Chemicals

Procedures for Rulemaking Under Section 6 of TSCA

PCBs Manufacturing, Processing, Distribution in Commerce, and Use Prohibitions

Asbestos

Council on Environmental Quality: Purpose, Policy, and Mandate

NEPA and Agency Planning 


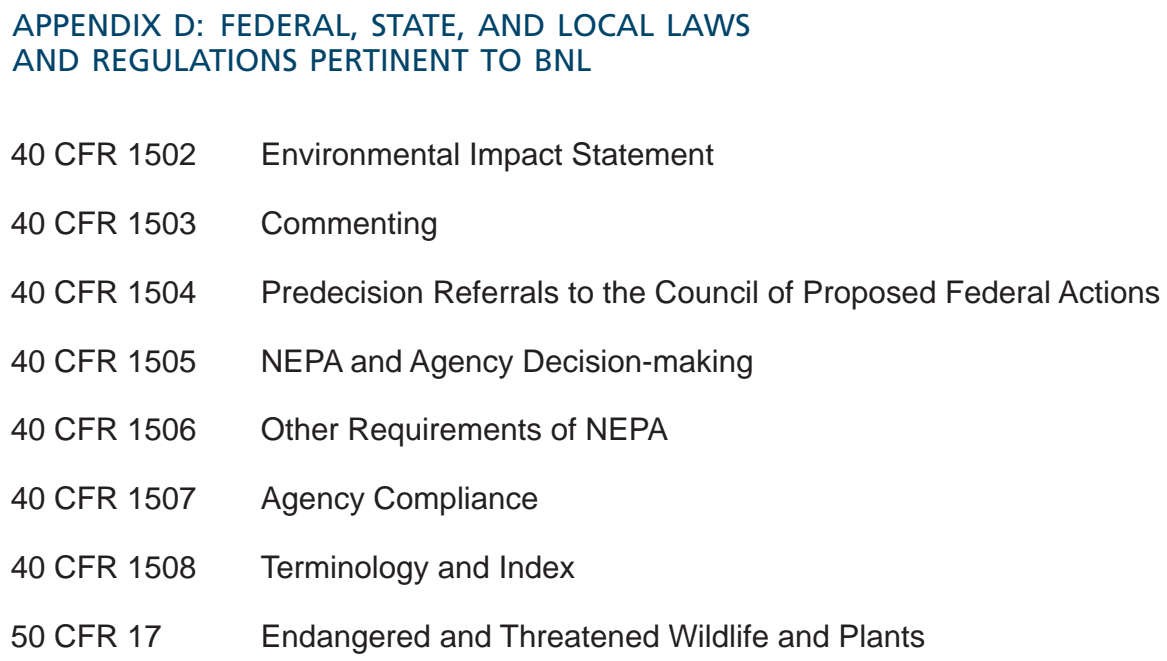

6 NYCRR 182 Endangered and Threatened Species of Fish and Wildlife, Species of Special Concern

6 NYCRR 200 Environmental Conservation Law

6 NYCRR 201 Subpart 201-1: General Provisions

6 NYCRR 202 Subpart 202: Emissions Verification

6 NYCRR 203 Indirect Sources of Air Contamination

6 NYCRR $204 \quad \mathrm{NO}_{x}$ Budget Training Program

6 NYCRR 205 Architectural and Maintenance (AIM) Coatings

6 NYCRR 207 Control Measures for an Air Pollution Episide

6 NYCRR 208 Landfill Gas Collection and Control System for Certain Municipal Solid Waste Landfills

6 NYCRR 211 General Prohibitions

6 NYCRR 212 General Process Emission Sources

6 NYCRR 215 Open Fires

6 NYCRR 217 Environmental Conservation Rules and Regulations [Exhaust and Emission Standards]

6 NYCRR 218 Subpart 218-1 [More on Vehicle Exhaust]

6 NYCRR 221 Asbestos-Containing Surface Coating Material

6 NYCRR 225 Subpart 225-1: Fuel Composition and Use - Sulfur Limitations

6 NYCRR 227 Solvent Metal Cleaning Processes

6 NYCRR 228 Surface Coating Processes

6 NYCRR 229 Petroleum and Volatile Organic Liquid Storage and Transfer

6 NYCRR 230 Gasoline Dispensing Sites and Transport Vehicles

6 NYCRR 231 New Source Review in Nonattainment Areas and Ozone Transport Regions

6 NYCRR 234 Graphic Arts

6 NYCRR 237 Acid Deposition Reduction NO Budget Training Program 
6 NYCRR 238 Acid Deposition Reduction $\mathrm{SO}_{2}$ Budget Training Program

6 NYCRR 239 Portable Fuel Container Spillage Control

6 NYCRR 240 Conformity to State or Federal Implementation Plans

6 NYCRR 250 Miscellaneous Orders

6 NYCRR 256 Air Quality Classification System

6 NYCRR 257 Air Quality Standards

6 NYCRR 307 [Air Quality in] Suffolk County

6 NYCRR 320 Pesticides - General

6 NYCRR 325 Application of Pesticides

6 NYCRR 326 Registration and Certification of Pesticides

6 NYCRR 327 Use of Chemicals for the Control or Elimination of Aquatic Vegetation

6 NYCRR 328 Use of Chemicals for the Extermination of Undesirable Fish

6 NYCRR 329 Use of Chemicals for the Control or Elimination of Aquatic Insects

6 NYCRR 360-1 General Provisions: Solid Waste Management Facilities

6 NYCRR 361 Siting of Industrial Hazardous Waste Facilities

6 NYCRR 364 Waste Transporter Permits

6 NYCRR 370 Hazardous Waste Management Regulations

6 NYCRR 371 Identification and Listing of Hazardous Waste

6 NYCRR 372 Hazardous Waste Manifest System and Related Standards for Generators, Transporters and Facilities

6 NYCRR 373 Hazardous Waste Management Facilities

6 NYCRR 374 Standards for the Management of Specific Hazardous Wastes

6 NYCRR $376 \quad$ Land Disposal Restrictions

6 NYCRR 595 Release of Hazardous Substances

6 NYCRR 596 Hazardous Substance Bulk Storage Regulations

6 NYCRR 597 List of Hazardous Substances

6 NYCRR 611 Environmental Priorities and Procedures in Petroleum Cleanup and Removal

6 NYCRR 612 Registration of Petroleum Storage Facilities

6 NYCRR 613 Handling and Storage of Petroleum

6 NYCRR 663 Freshwater Wetlands Permit Requirements

6 NYCRR 666 Regulation for Administration and Management of the Wild, Scenic, and Recreational Rivers System in New York State Excepting Private Land in the Adirondack Park

6 NYCRR 700 Part 700 Water Quality Regulations 
APPENDIX D: FEDERAL, STATE, AND LOCAL LAWS

AND REGULATIONS PERTINENT TO BNL

6 NYCRR 701 Classification - Surface Waters and Groundwaters

6 NYCRR 702 Derivation and Use of Standards and Guidance Values

6 NYCRR 703 Surface Water and Groundwater Quality Standards and Groundwater Effluent Limitations

6 NYCRR 750 Obtaining a SPDES Permit

10 NYCRR 5 State Sanitary Code - Part 5

SUFFOLK COUNTY RULES, REGULATIONS, AND STANDARDS

SCSC Art. 12 Toxic and Hazardous Material Storage, Handling and Control 


\section{Site Environmental Report Reader Response Form}

The 2007 Site Environmental Report (SER) was written to inform outside regulators, the public, and BNL employees of the Laboratory's environmental performance for the calendar year. The report summarizes BNL's on-site environmental data; environmental management performance; compliance with applicable regulations; and environmental, restoration, and surveillance monitoring programs.

BNL welcomes your comments, suggestions for improvements, or any questions you may have. Please fill in the information below, and mail your response form to:

Brookhaven National Laboratory

Environmental and Waste Management Services Division

Attention: SER Project Coordinator

Building 120

P.O. Box 5000

Upton, NY 11973-5000

Name

Address

Phone-

Email

Comments, Suggestions, or Questions

I would like to be added to your Environmental Issues mailing list. 


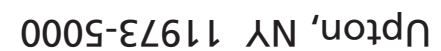
000S xog Od

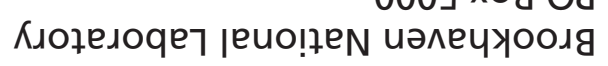
ozı 6u!p!ng

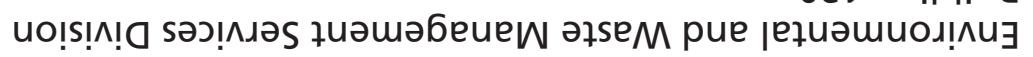

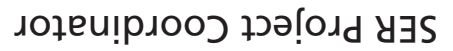


BROOKHAVEN NATIONAL LABORATORY

\section{SITE ENVIRONMENTAL REPORT}

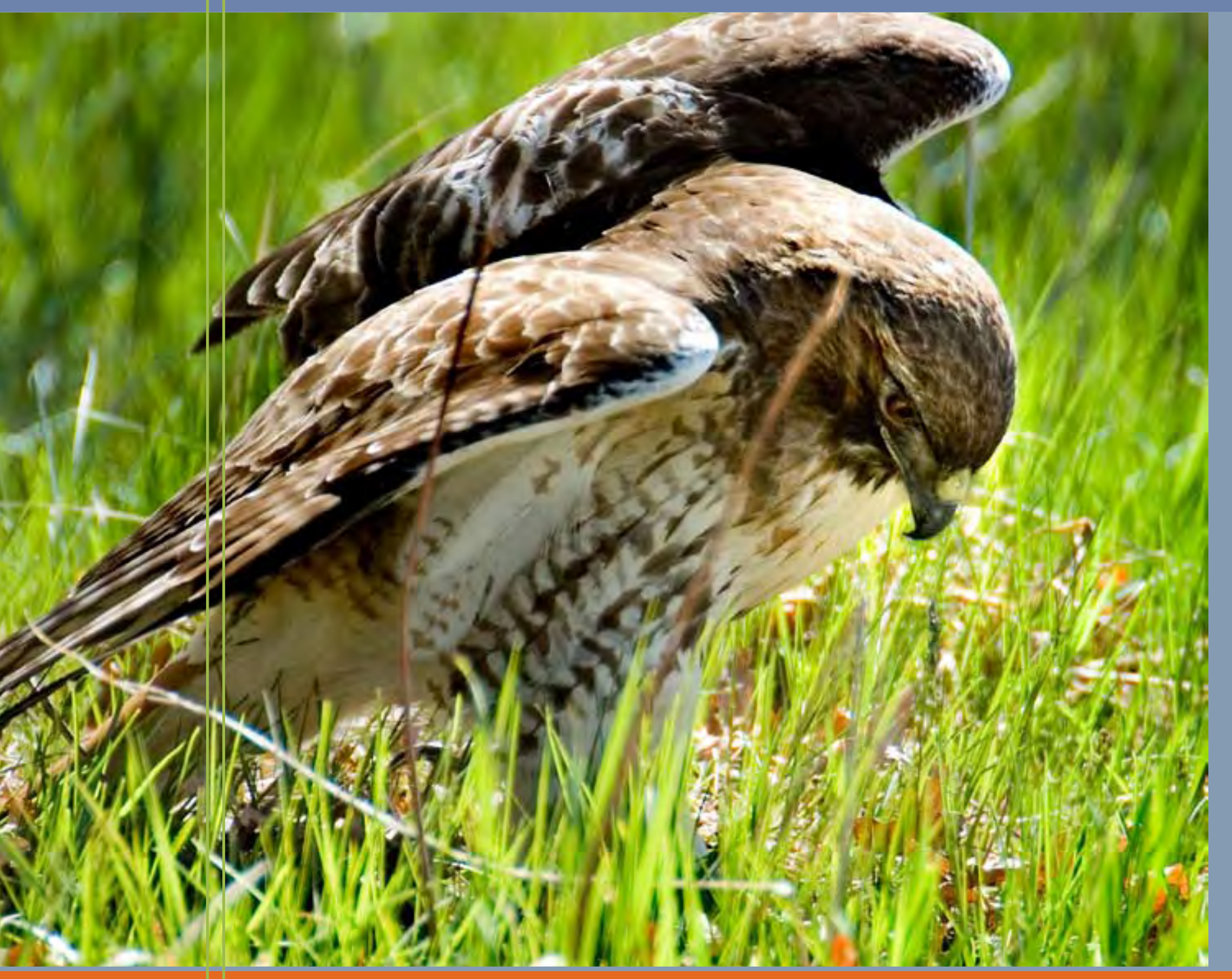

Volume II

GROUNDWATER STATUS REPORT 


\title{
2007 \\ SITE ENVIRONMENTAL REPORT \\ VOLUME II \\ GROUNDWATER STATUS REPORT
}

June 13, 2008

Revised - September 8, 2008

Environmental and Waste Management Services Division

Long Term Response Actions Group

\author{
Brookhaven National Laboratory \\ Operated by \\ Brookhaven Science Associates \\ Upton, NY 11973
}




\section{REPORT CONTRIBUTORS}

From the initial collection of samples, to the final reproduction, the 2007 BNL Groundwater Status Report required the expertise and cooperation of many people and organizations to complete. The contributions of the following individuals are gratefully acknowledged:

Environmental and Waste Management Services

John Burke William Dorsch

Brian Foley

George Goode

Robert Howe

Richard Lagattolla

Chris Ogeka

Doug Paquette

Kathleen Robinson

Andrew Rohkohl

Vincent Racaniello

Susan Young

Frank Tramontano

\section{Environmental Restoration Projects}

Les Hill

\section{Plant Engineering Division}

Eric Kramer

J.R. Holzmacher P.E., LLC

Yuping Shen

Patricia Zalak

Tony Zalak

R\&C Formations, LTD.

Robert Casson

Robert Heiss Jr.

Philip Hoffken Jr.

Melissa Carpentieri

\section{P.E. Consulting Engineer}

Drew Bennett 
This page intentionally left blank. 


\section{Contents}

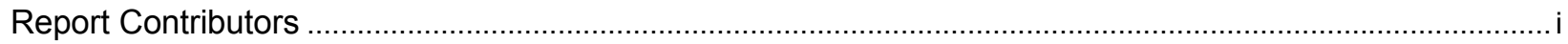

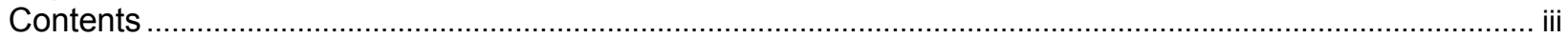

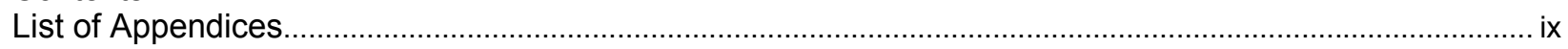

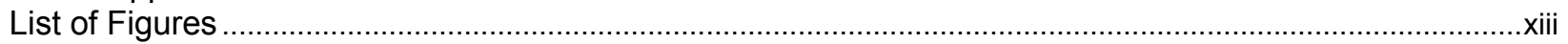

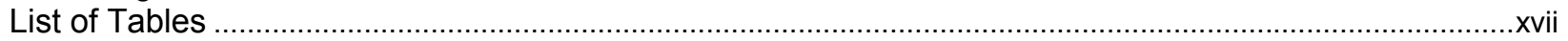

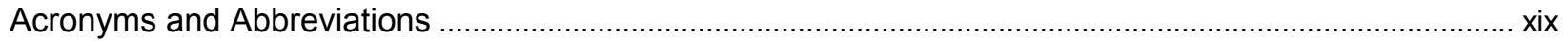

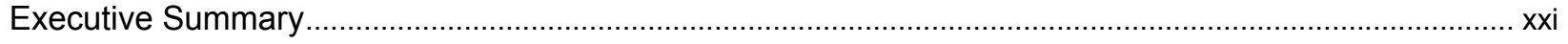

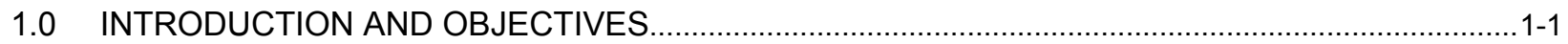

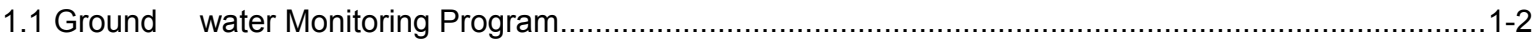

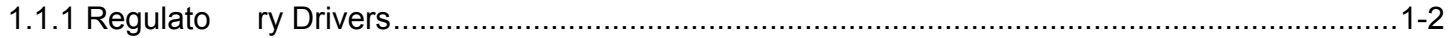

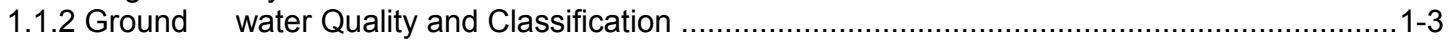

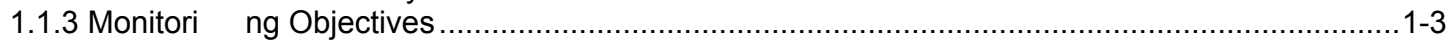

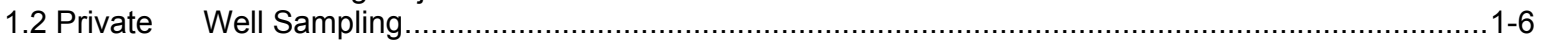

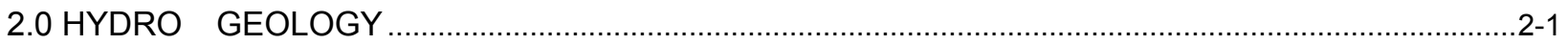

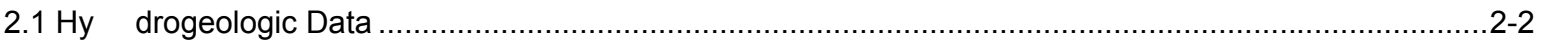

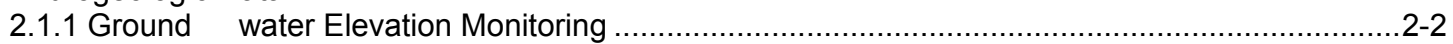

2.1.2 Pumpage of On-Site Water Supply and Remediation Wells ............................................2-3

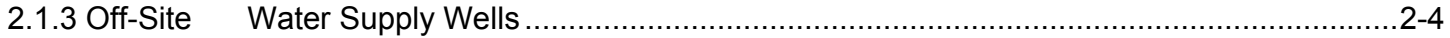

2.1.4 Summary of Onsite Recharge and Precipitation Data ............................................... $2-4$

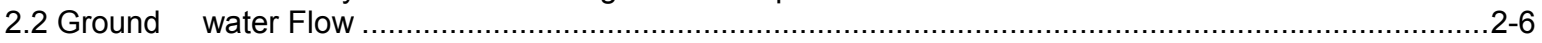

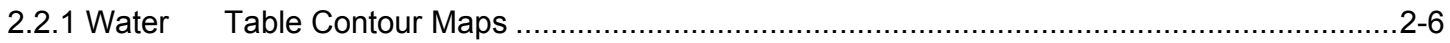

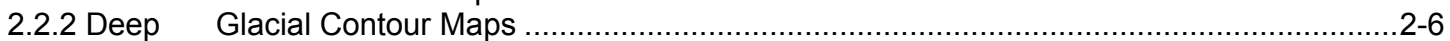

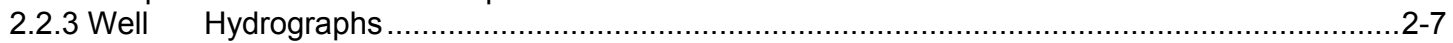

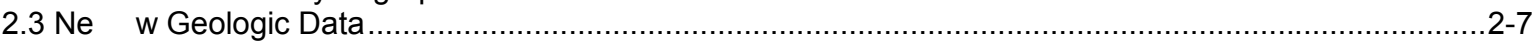

3.0 ENVIRONMENTAL RESTORATION GROUNDWATER MONITORING AND REMEDIATION .......3-1

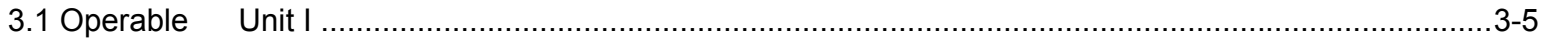

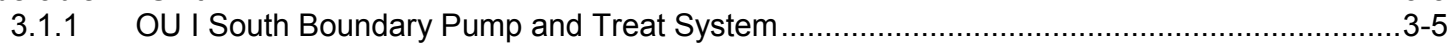

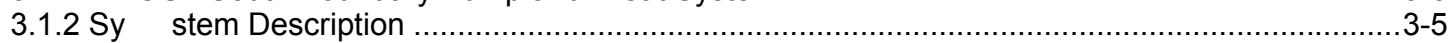

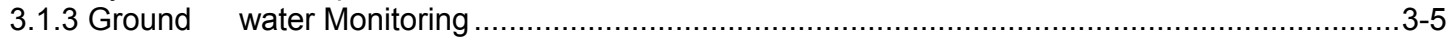

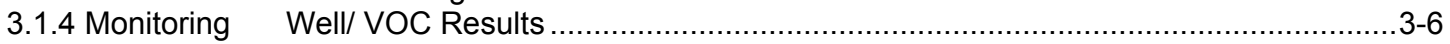

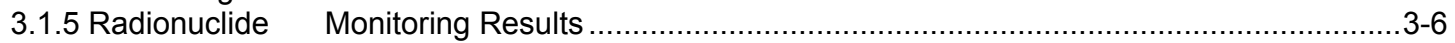

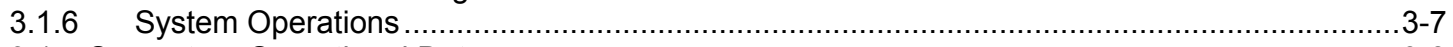

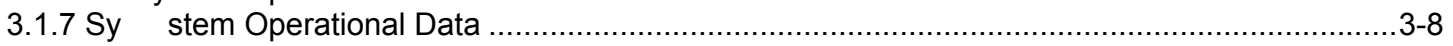

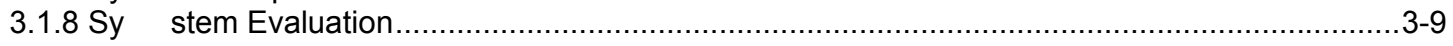

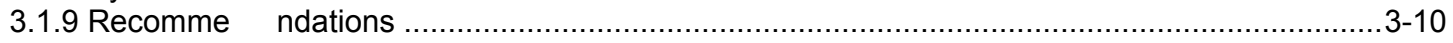

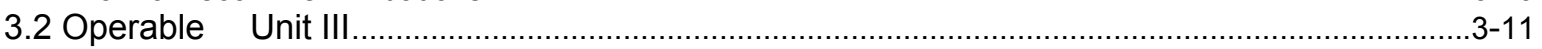

3.2.1 Carbon Tetrachloride Pump and Treat System ...................................................... $3-13$

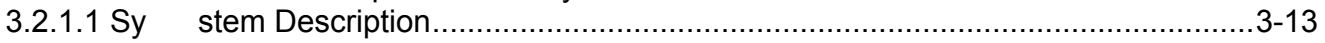

3.2.1.2 Ground $\quad$ water Monitoring ........................................................................ $3-13$

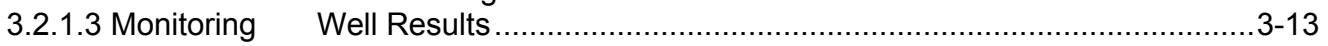

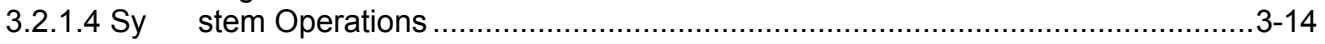

3.2.1.5 Sy stem Operational Data .................................................................. $3-14$

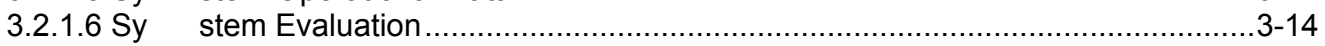

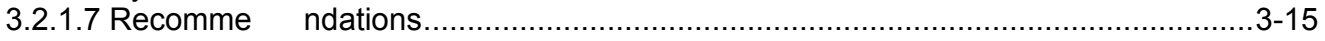

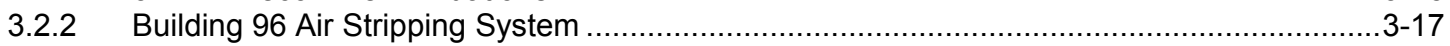

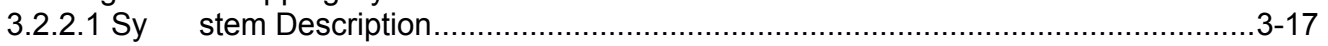

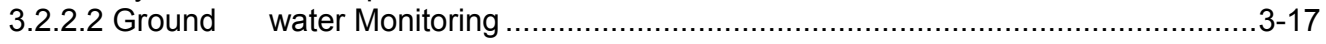

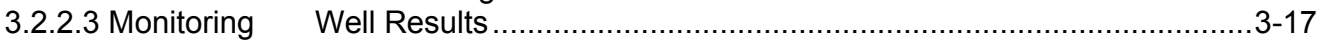

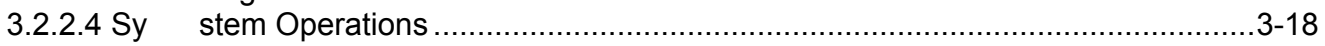

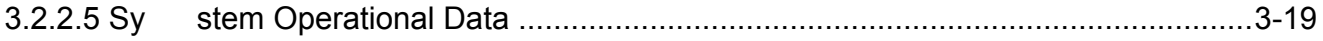

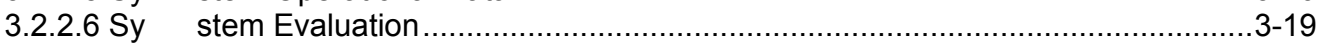

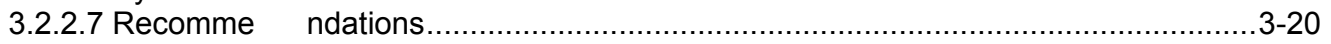

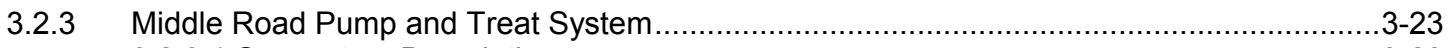

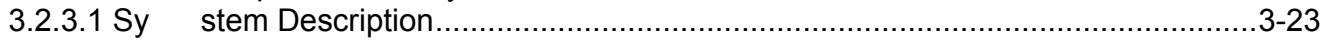

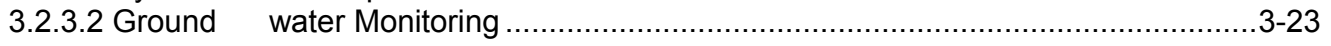




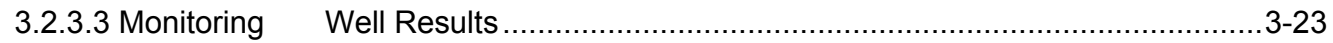

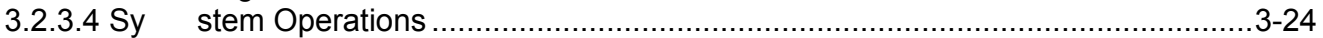

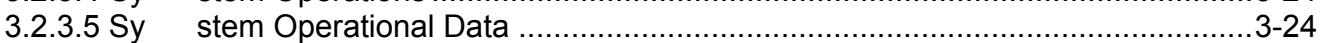

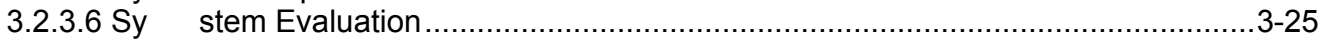

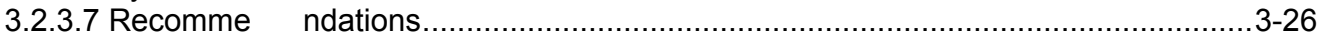

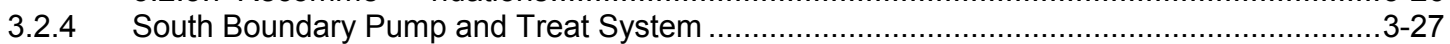

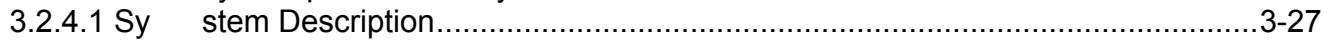

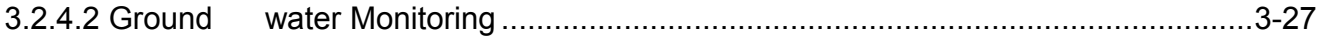

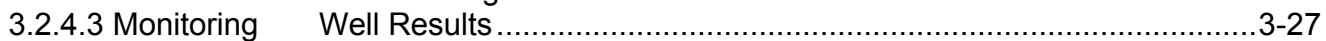

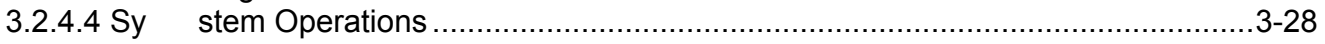

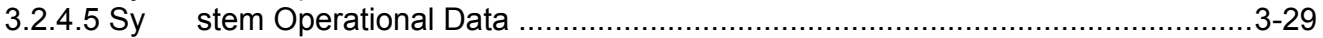

3.2.4.6 Sy stem Evaluation ........................................................................... $3-29$

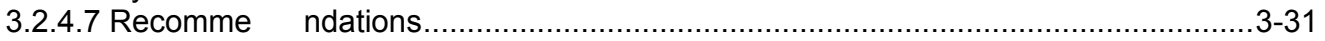

3.2.5 Western South Boundary Pump and Treat System ................................................. $3-33$

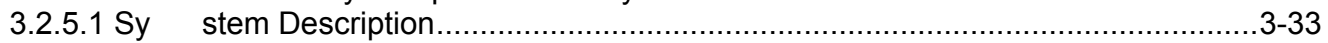

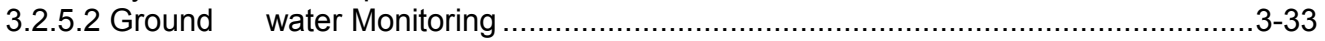

3.2.5.3 Monitoring Well Results ........................................................................... 3

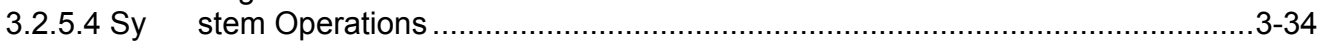

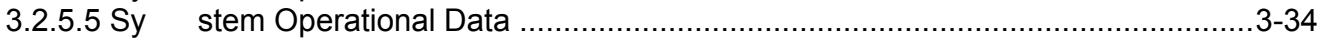

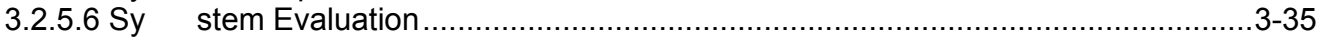

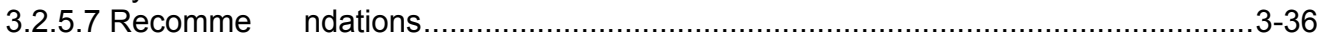

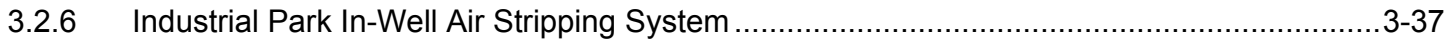

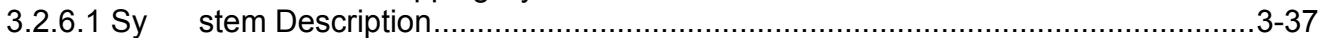

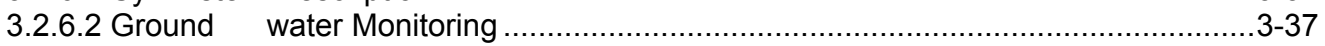

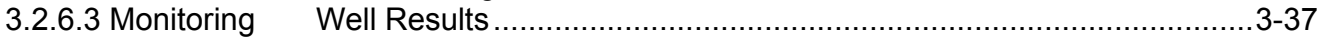

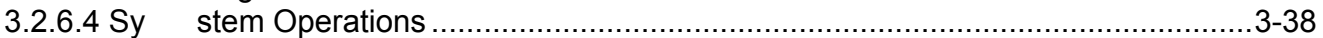

3.2.6.5 Sy stem Operational Data .................................................................. 39

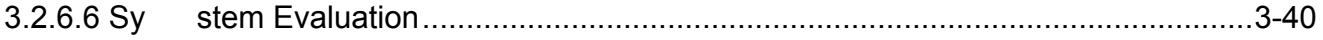

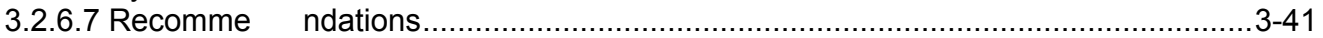

3.2.7 Industrial Park East Pump and Treat System ........................................................... $3-43$

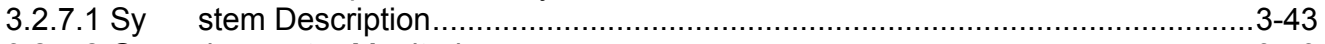

3.2.7.2 Ground $\quad$ water Monitoring ........................................................................ $3-43$

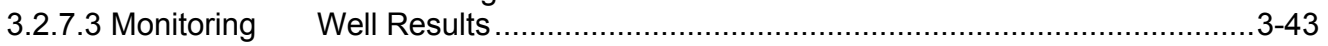

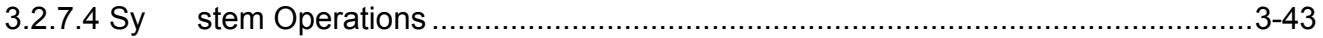

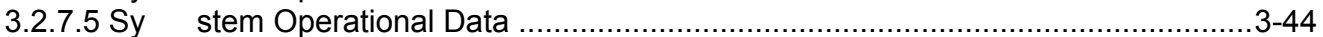

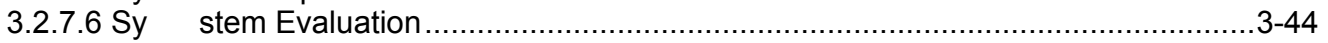

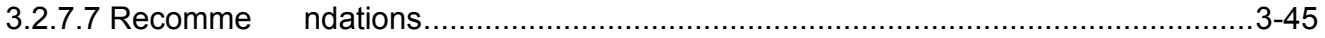

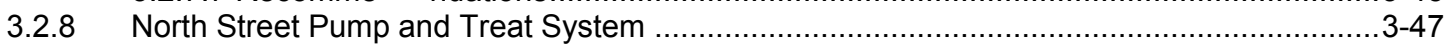

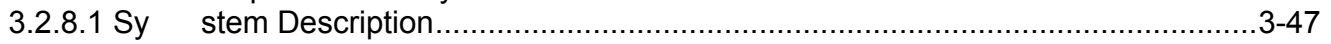

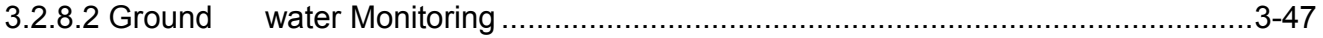

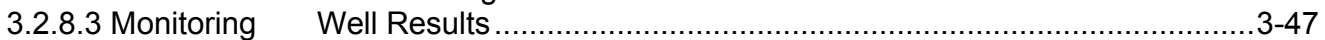

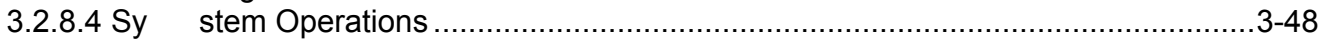

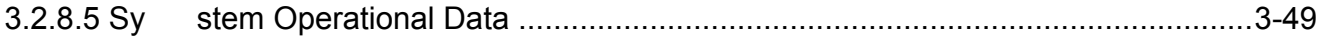

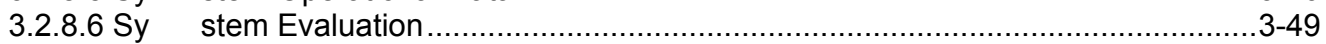

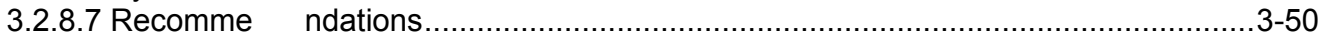

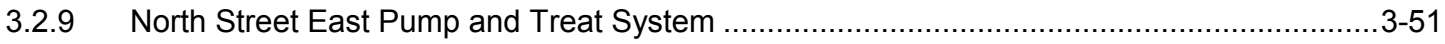

3.2.9.1 Sy stem Description............................................................................. 31

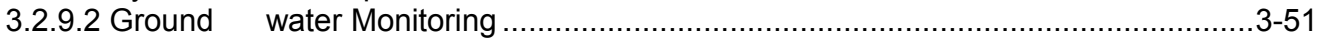

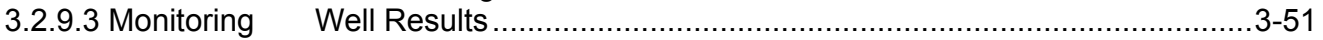

3.2.9.4 Sy stem Operations ......................................................................... $3-52$

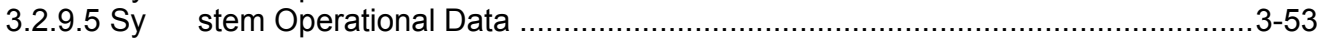

3.2.9.6 Sy stem Evaluation ................................................................................. $3-53$

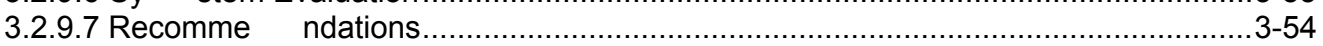

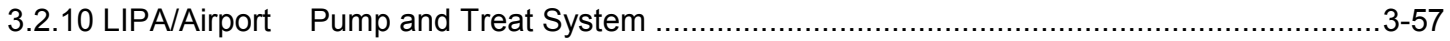

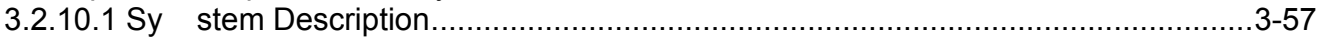

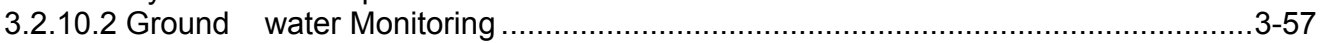

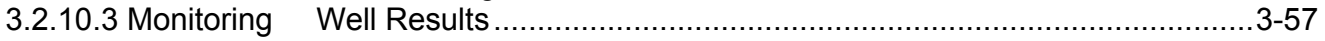

3.2.10.4 Sy stem Operations .................................................................................

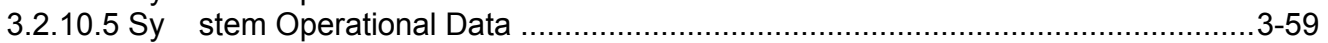

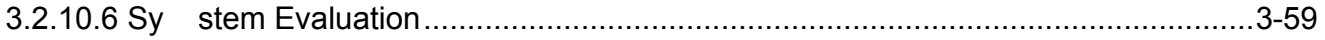

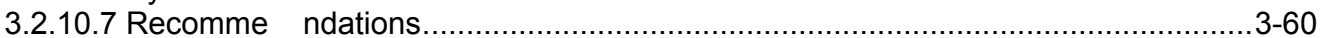

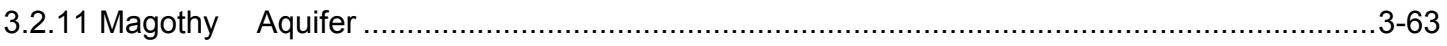

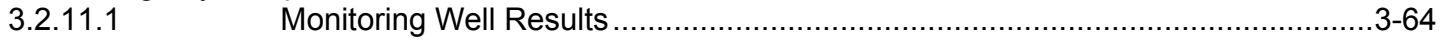




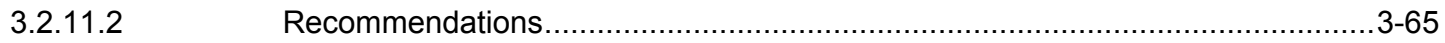

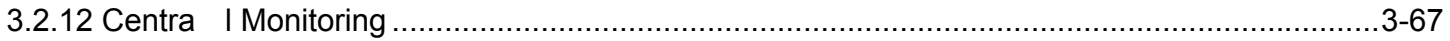

3.2.12.1 Ground water Monitoring .......................................................................

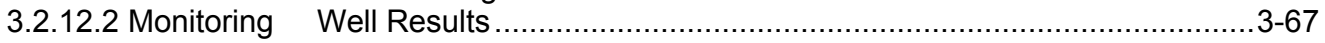

3.2.12.3 Ground water Monitoring Program Evaluation .............................................

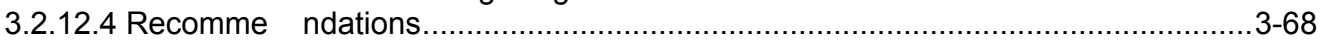

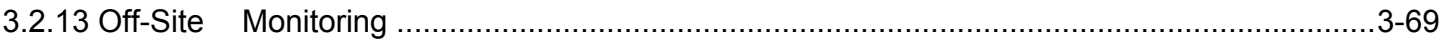

3.2.13.1 Ground water Monitoring ........................................................................

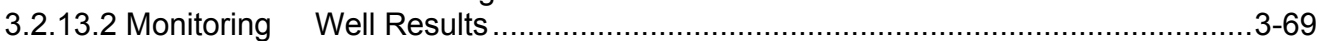

3.2.13.3 Ground water Monitoring Program Evaluation .............................................. $3-69$

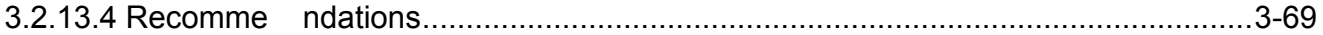

3.2.14 South Boundary Radionuclide Monitoring Program........................................................ $3-71$

3.2.14.1 Ground water Monitoring ......................................................................

3.2.14.2 Monitoring Well Results ...........................................................................

3.2.14.3 Ground water Monitoring Program Evaluation...............................................

3.2.14.4 Recomme ndations.............................................................................

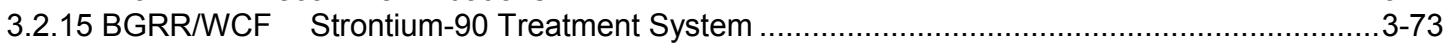

3.2.15.1 Sy stem Description...............................................................................

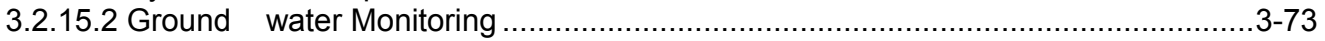

3.2.15.3 Monitoring Well/Temporary Well Data ......................................................... $3-74$

3.2.15.4 Sy stem Operations ............................................................................

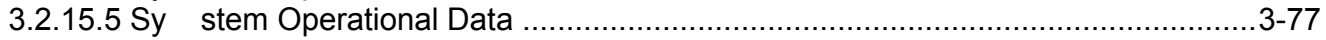

3.2.15.6 Ground water Monitoring Program Evaluation................................................

3.2.15.7 Recomme ndations.........................................................................

3.2.16 Chemical/Animal Holes Strontium-90 Treatment System .............................................. $3-81$

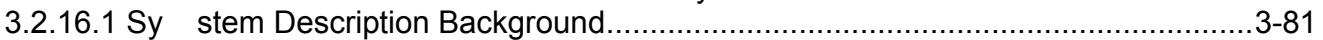

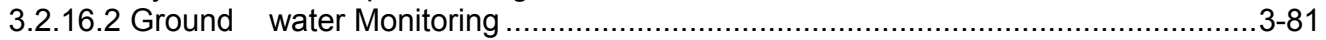

3.2.16.3 Monitoring Well Results …….....................................................................

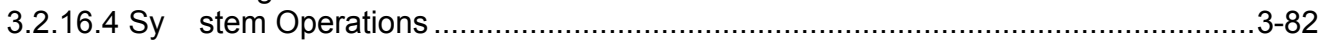

3.2.16.5 Sy stem Operational Data ……………................................................ $3-83$

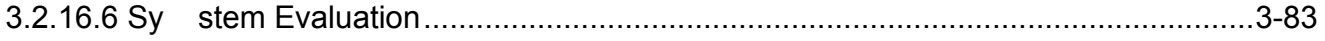

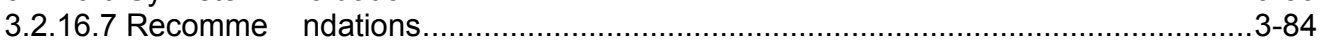

3.2.17 HFBR Pump and Recharge System ................................................................

3.2.17.1 HFBR Pump and Recharge System ...................................................... $3-85$

3.2.17.2 Sy stem Description.............................................................................

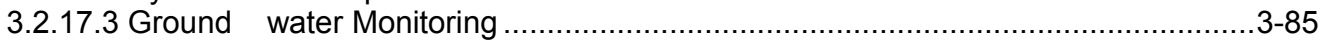

3.2.17.4 Monitoring Well Data .............................................................................

3.2.17.5 Ground water Monitoring Program Evaluation ...............................................

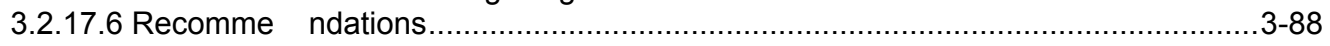

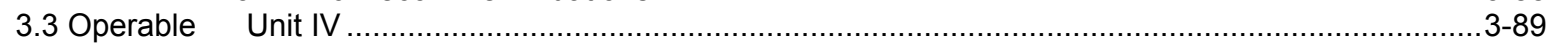

3.3.1 Post Closure Monitoring (Former OU IV AS/SVE System) ……..............................................

3.3.1.1 Ground ～water Monitoring ........................................................................ $3-89$

3.3.1.2 Monitoring Well Results ....................................................................

3.3.1.3 Post Closure Monitoring Evaluation................................................................

3.3.1.4 Recomme ndations.............................................................................

3.3.2 Building 650 Strontium-90 Monitoring Program ..............................................................

3.3.2.1 Ground ～water Monitoring ........................................................................

3.3.2.2 Monitoring Well Results .........................................................................

3.3.2.3 Ground water Monitoring Program Evaluation.................................................

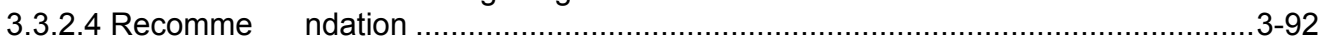

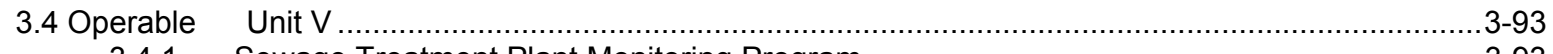

3.4.1 Sewage Treatment Plant Monitoring Program ...................................................... $3-93$

3.4.2 Ground water Monitoring ...................................................................................

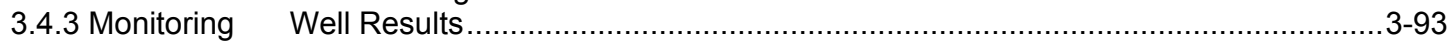

3.4.4 Ground water Monitoring Program Evaluation........................................................... $3-94$

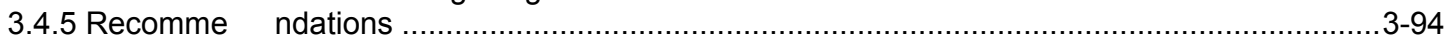

3.5 Operable Unit VI EDB Pump and Treat System ......................................................................

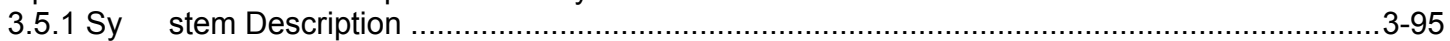

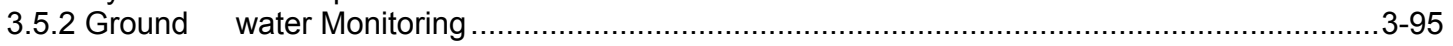

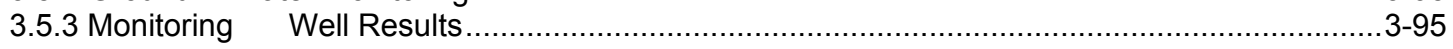

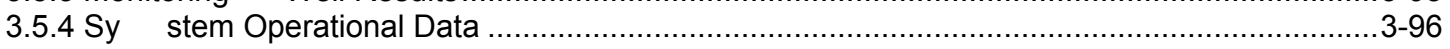

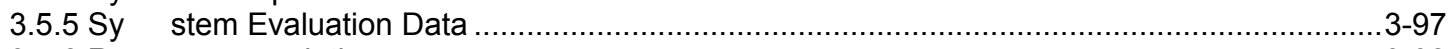

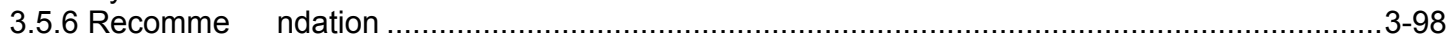




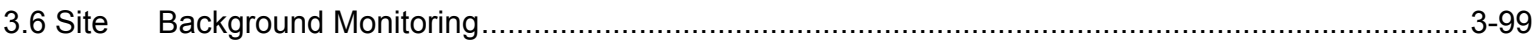

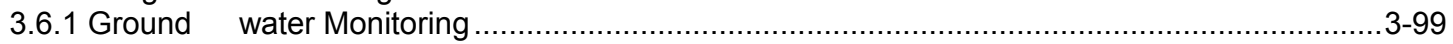

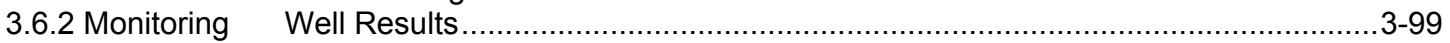

3.6.3 Monitoring Program Evaluation ...............................................................................

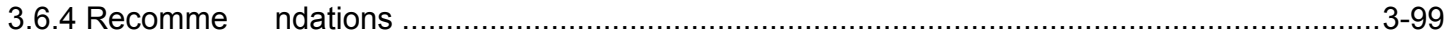

3.7 Current and Former Landfill Groundwater Monitoring.....................................................................

3.7.1 Current Landfill Summary ....................................................................................

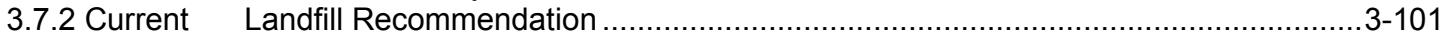

3.7.3 Former Landfill Summary ….....................................................................................

3.7.4 Former Landfill Recommendation ……….................................................................

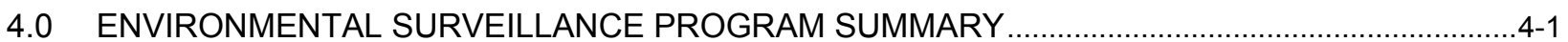

$4.1 \quad$ Alternating Gradient Synchrotron (AGS) Complex …....................................................................

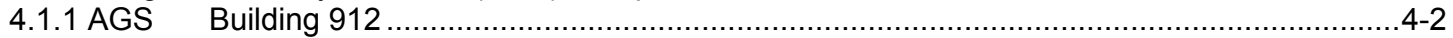

4.1.1.1 AGS Building 912 Groundwater Monitoring …................................................4-2

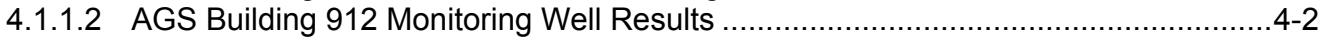

4.1.1.3 AGS Building 912 Groundwater Monitoring Program Evaluation ............................4-2

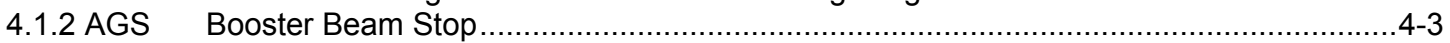

4.1.2.1 AGS Booster Groundwater Monitoring ...........................................................4-3

4.1.2.2 AGS Booster Monitoring Well Results...........................................................4-3

4.1.2.3 AGS Booster Groundwater Monitoring Program Evaluation ..................................4-3

4.1.3 NASA Space Radiation Laboratory Facility ……......................................................

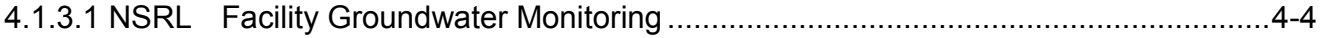

4.1.3.2 NSRL Facility Monitoring Well Results ................................................................4-4

4.1.3.3 NSRL Groundwater Monitoring Program Evaluation ...........................................4-4

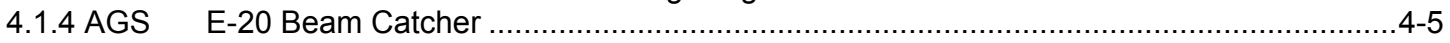

4.1.4.1 AGS E-20 Catcher Groundwater Monitoring ....................................................4-5

4.1.4.2 AGS E-20 Catcher Monitoring Well Results ......................................................4-5

4.1.4.3 AGS E-20 Catcher Groundwater Monitoring Program Evaluation ............................4-5

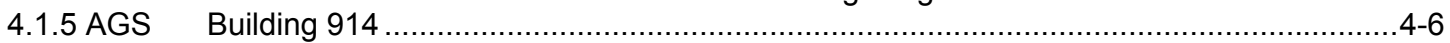

4.1.5.1 AGS Building 914 Groundwater Monitoring …….............................................4-6

4.1.5.2 AGS Building 914 Monitoring Well Results ......................................................4-6

4.1.5.3 AGS Building 914 Groundwater Monitoring Program Evaluation .............................4-6

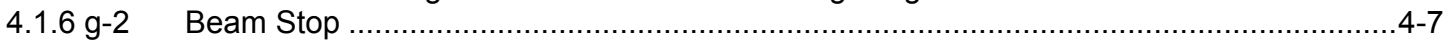

4.1.6.1 g-2 Beam Stop Groundwater Monitoring .......................................................... 4-7

4.1.6.2 g-2 Beam Stop Monitoring Well Results.........................................................4-7

4.1.6.3 g-2 Beam Stop Groundwater Monitoring Program Evaluation ...............................4-7

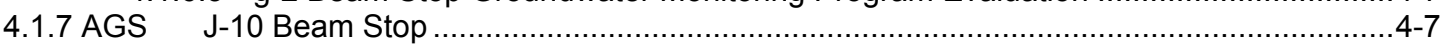

4.1.7.1 AGS J-10 Beam Stop Groundwater Monitoring …...........................................4-8

4.1.7.2 AGS J-10 Beam Stop Monitoring Well Results ................................................4-8

4.1.7.3 AGS J-10 Beam Stop Groundwater Monitoring Program Evaluation .........................4-8

4.1.8 Former AGS U-Line Beam Target and Stop Areas ……................................................ 4

4.1.8.1 Former AGS U-Line Groundwater Monitoring ….................................................4-9

4.1.8.2 Former AGS U-Line Monitoring Well Results ...................................................4-9

4.1.8.3 Former AGS U-Line Groundwater Monitoring Program Evaluation...........................4-9

4.2 g-2 Tritium Source Area and Groundwater Plume ..................................................................... 4-10

4.2.1 g-2 Tritium Source Area and Plume Groundwater Monitoring …..................................... 4-11

4.2.2 g-2 Tritium Source Area and Plume Monitoring Well Results.............................................4-11

4.2.3 g-2 Tritium Source Area and Plume Groundwater Monitoring Program Evaluation................4-13

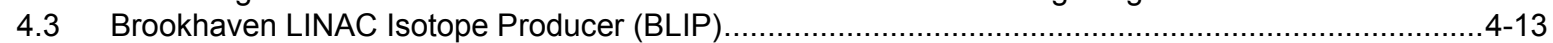

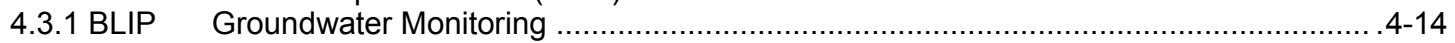

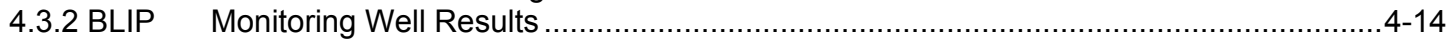

4.3.3 BLIP Groundwater Monitoring Program Evaluation .......................................................... $4-16$

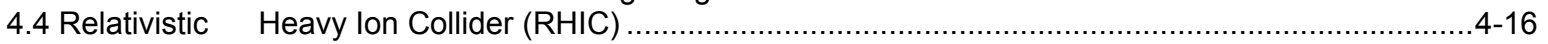

4.4.1 RHIC Groundwater Monitoring …….................................................................... $4-16$

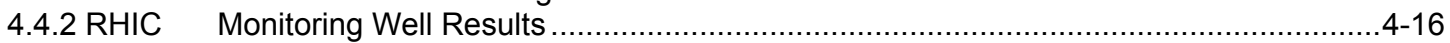

4.4.3 RHIC Groundwater Monitoring Program Evaluation ..................................................... $4-17$

$4.5 \quad$ Brookhaven Medical Research Reactor (BMRR) …........................................................... 4

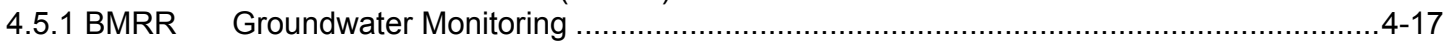

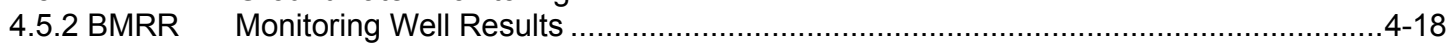

4.5.3 BMRR Groundwater Monitoring Program Evaluation ................................................... $4-18$

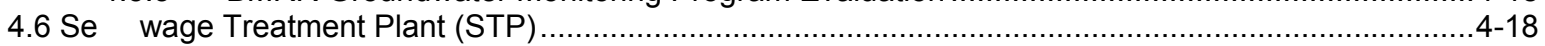

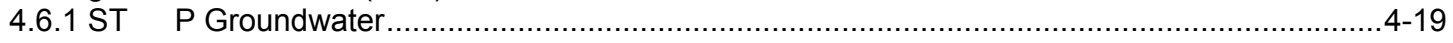




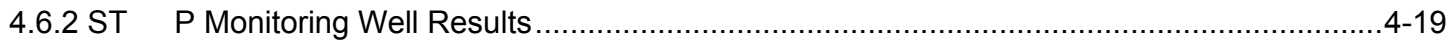

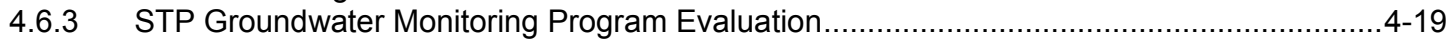

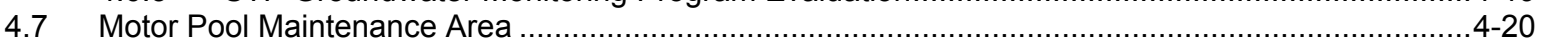

4.7.1 Motor Pool Maintenance Area Groundwater Monitoring ............................................. 4-20

4.7.2 Motor Pool Monitoring Well Results .................................................................. $4-20$

4.7.3 Motor Pool Monitoring Program Evaluation ............................................................. $4-23$

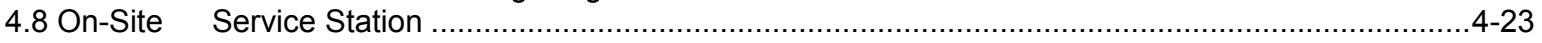

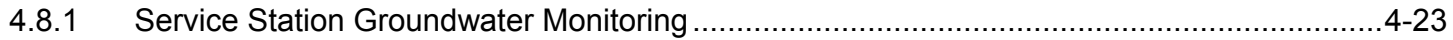

4.8.2 Service Station Monitoring Well Results ........................................................... $4-23$

4.8.3 Service Station Groundwater Monitoring Program Evaluation......................................... $4-24$

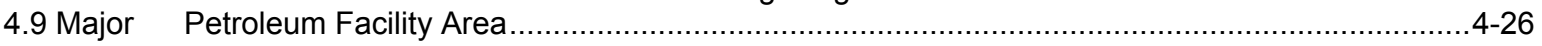

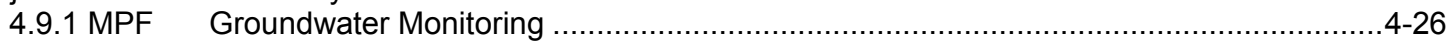

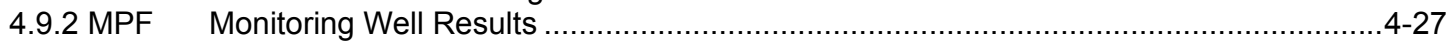

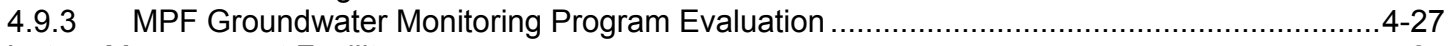

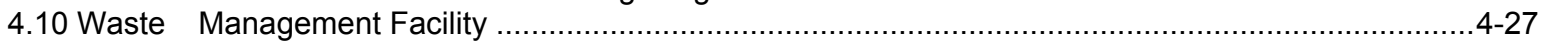

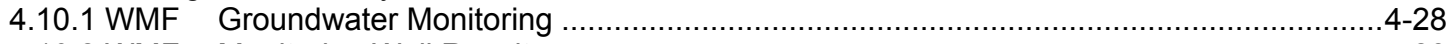

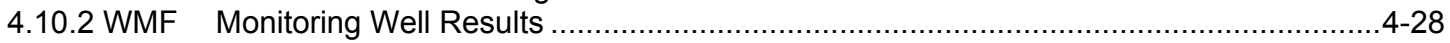

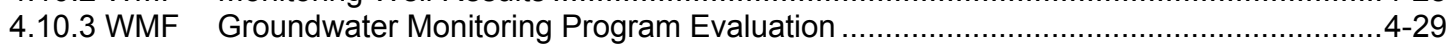

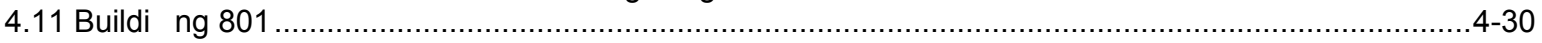

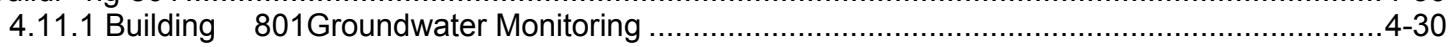

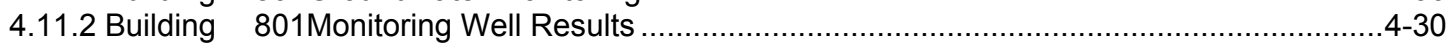

4.11.3 Building 801 Groundwater Monitoring Program Evaluation .......................................4-30

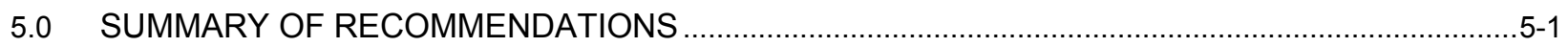

5.1 OU I South Boundary Pump and Treatment System ............................................................ $5-1$

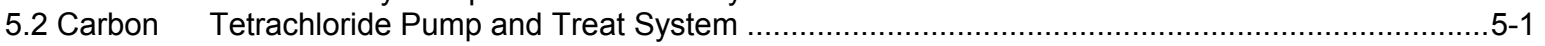

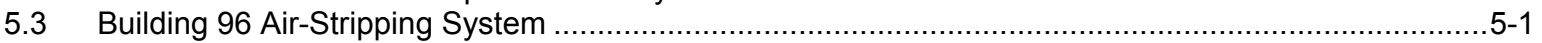

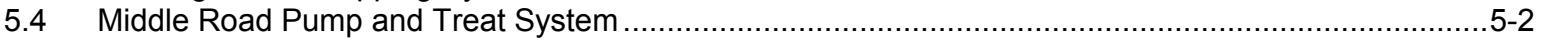

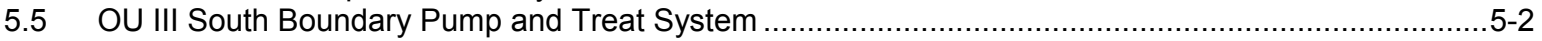

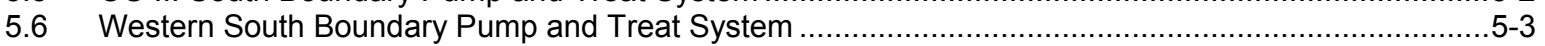

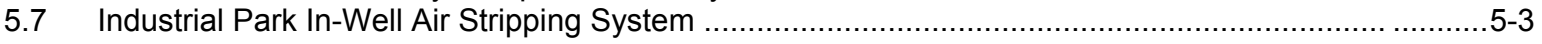

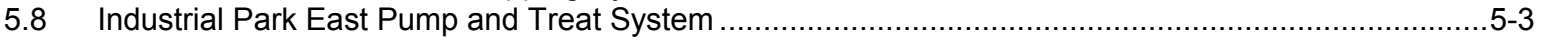

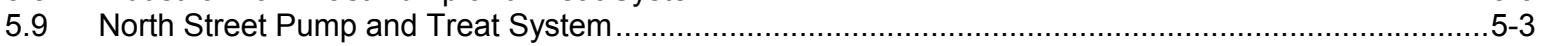

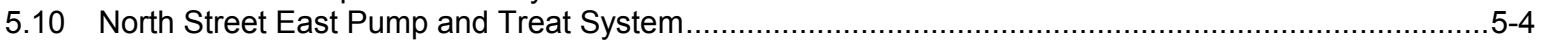

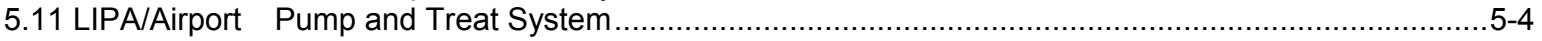

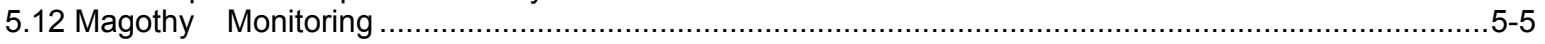

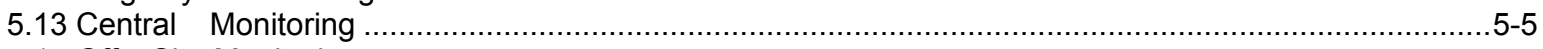

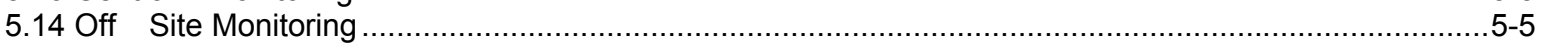

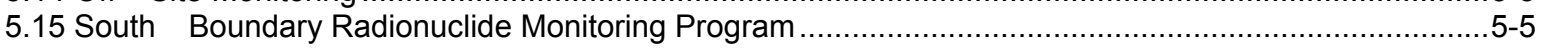

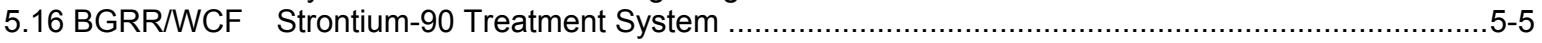

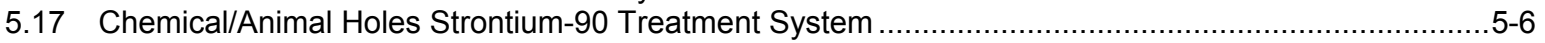

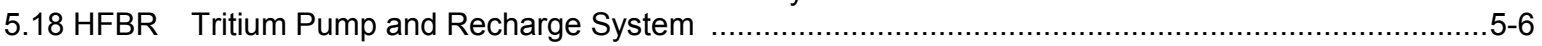

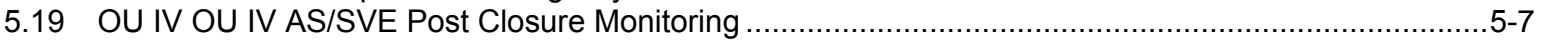

5.20 Building 650 (Sump Outfall) Strontium-90 Monitoring ............................................................. $5-7$

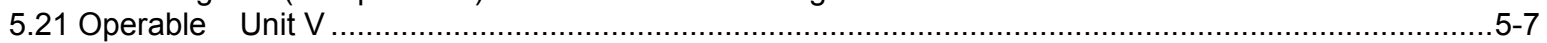

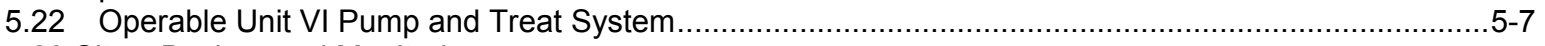

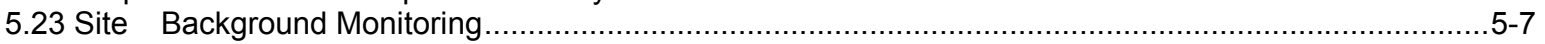

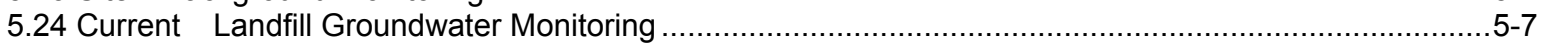

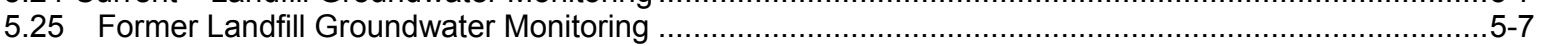

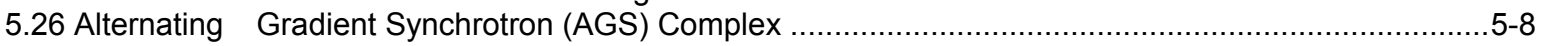

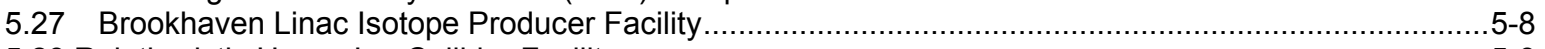

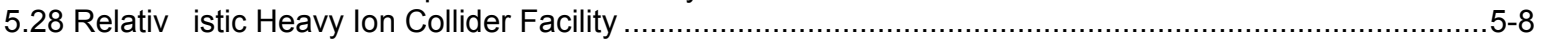

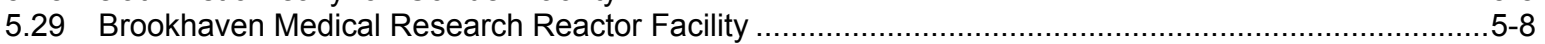

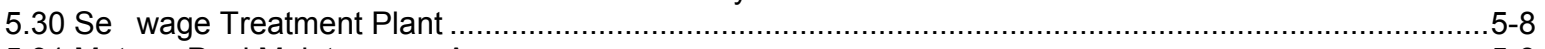

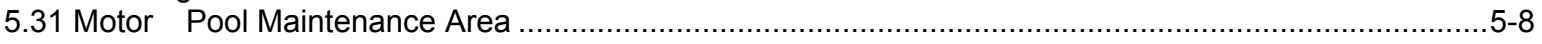

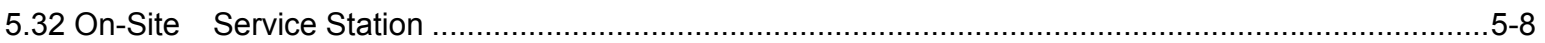

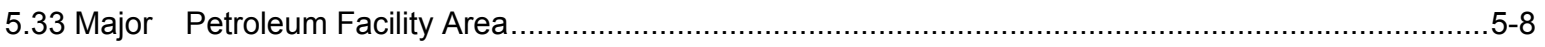

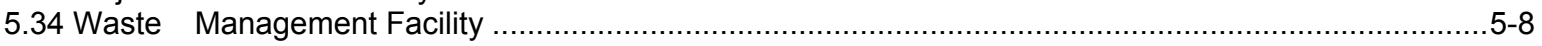

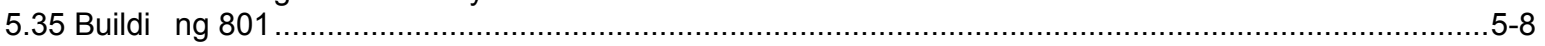

Reference List 
SER VOLUME II: GROUNDWATER STATUS REPORT

This page intentionally left blank. 


\section{List of Appendices}

A. Sitewide Groundwater Elevation Measurements and Vertical Gradient Calculations 2007

B. Long-term and Short-term Well Hydrographs

C. $\quad 2007$ Long Term Response Actions Groundwater Results

OU I (South Boundary)

OU III (Carbon Tetrachloride)

OU III (Bldg. 96)

OU III (Middle Road)

OU III (South Boundary)

OU III (Western South Boundary)

OU III (Industrial Park)

OU III (Industrial Park East)

OU III North Street

OU III (North Street East)

OU III (LIPA/Airport)

Magothy

OU III (Central)

OU III (Off-Site)

OU III (BGRR/WCF Sr-90)

Chemical/Animal Holes Sr-90

OU III (AOC 29/HFBR Tritium)

OU IV (AOC 5 AS/SVE)

OU IV (AOC 6 Sr-90)

OU $\mathrm{V}$

OU VI EDB

Site Background

Current Landfill

Former Landfill

D. 2007 Environmental Surveillance Groundwater Results

AGS Research Areas

Building 801

BLIP Facility

RHIC Facility

Major Petroleum Facility

Motor Pool Area

Service Station

Sewage Treatment Plant and Peconic River

New Waste Management Facility 
E. Sample Collection, Tracking, and QA/QC Results

1.0 Ground water Sampling

1.1 Sampl e Collection

1.1.1 Decontamination

1.2 Sample Tracking System

1.2.1 Sample Identification

1.2.2 Sample Tracking

1.2.3 Sample Packaging and Shipping

1.2.4 Sample Documentation

1.3 Anal ytical Methods

1.3.1 Chemical Analytical Methods

1.3.2 Radiological Analytical Methods

1.4 Qualit y Assurance and Quality Control

1.4.1 Calibration and Preventive Maintenance of Field Instruments

1.4.2 QA/QC Sample Collection

1.4.2.1 Equipment Blanks

1.4.2.2 Field Blanks

1.4.2.3 Duplicate Samples

1.4.3 Data Verification

1.4.4 Data Usability

1.4.5 Data Qualification

1.4.6 Data Qualification

F. Remediation System Data Tables

OU I South Boundary System

F-1 Extraction Wells Tritium and VOC Data

F-2 Air Stripper Influent Tritium and VOC Data

F-3 Air Stripper Effluent VOC Data

F-4 Air Stripper Effluent Rad Data

F-5 Cumulative Mass Removal

\section{OU III Carbon Tetrachloride System}

F-6 Extraction Wells VOC Data 
OU III Building 96 System

F-7 Influent and Effluent VOC concentrations

F-8 Air Sampling Results

F-9 Pumpage and Mass Removal

\section{OU III Middle Road System}

F-10 Extraction Wells VOC Data

F-11 Air Stripper Influent VOC Data

F-12 Air Stripper Effluent VOC Data

F-13 Cumulative Mass Removal

\section{OU III South Boundary System}

F-14 Extraction Wells Data

F-15 Air Stripper Influent Data

F-16 Air Stripper Effluent Data

F-17 Cumulative Mass Removal

\section{OU III Western South Boundary System}

F-18 Extraction Wells VOC Data

F-19 Air Stripper Influent Data

F-20 Air Stripper Effluent Data

F-21 Cumulative Mass Removal

\section{OU III Industrial Park System}

F-22 TVOC Influent, Effluent and Efficiency Performance

F-23 Cumulative Mass Removal

F-24 Air Flow Rates

\section{OU III Industrial Park East System}

F-25 Extraction Wells VOC Data

F-26 Cumulative Mass Removal

F-27 Influent Wells VOC Data

F-28 Effluent VOC Data

\section{OU III North Street System}

F-29 Cumulative Mass Removal

F-30 Extraction Wells VOC and Tritium Data

F-31 Carbon Influent VOC Data

F-32 Carbon Effluent VOC Data 


\section{OU III North Street East System \\ F-33 Extraction Wells VOC Data \\ F-34 Carbon Influent VOC Data \\ F-35 Carbon Effluent VOC Data \\ F-36 Cumulative Mass Removal}

\section{OU III LIPA/Airport System \\ F-37 Cumulative Mass Removal \\ F-38 Extraction Wells VOC Data \\ F-39 Carbon Influent VOC Data \\ F-40 Carbon Effluent VOC Data}

\section{BGRR/WCF Sr-90 System}

F-41 Extraction Well Data

F-42 System Influent Data

F-43 System Effluent Data

F-44 Cumulative Mass Removal

OU III Chemical/Animal Holes Sr-90 System

F-45 System Influent Data

F-46 System Effluent Data

F-47 Cumulative Mass Removal

\section{OU III HFBR Tritium System}

F-48 Extraction Wells Data

OU VI EDB Pump and Treat System

F-49 Extraction Well Data

F-50 Influent VOC Data

F-51 Carbon Effluent VOC Data

\section{G. Data Usability Reports}

H. 2007 Environmental Monitoring Report Current and Former Landfill Areas 


\section{List of Figures}

E-1 2007 Extents of Primary BNL VOC Plumes

E-2 2007 Extents of Primary BNL Radionuclide Plumes

1-1 Key Site Features

1-2 Monitoring Well Locations

2-1 Generalized Geologic Cross Section in the Vicinity of Brookhaven National Laboratory

2-2 Water Table Contours of the Shallow Glacial Zone December 3-6, 2007

Potentiometric Surface Contours of the Deep Glacial Zone December 3-6, 2007

Summary of BNL Supply Well Pumpage 1992 Through 2007

2-5 Suffolk County Water Authority Pumping Near BNL

3.0-1 Operating and Planned Groundwater Remediation Systems

3.0-2 Summary of Laboratory Analyses Performed for the Environmental Management Program in 2007

3.1-1 OU I South Boundary / North Street East TVOC Plume Distribution

3.1-2 OU I South Boundary / North Street East TVOC Hydrogeologic Cross Section (A-A')

3.1-3 OU I Current Landfill / South Boundary / North Street East Historical VOC Trends

3.1-4 OU I South Boundary / North Street East Historical Tritium Trends

3.1-5 OU I South Boundary / North Street East Sr-90 Results

3.1-6 OU I South Boundary / North Street East Historical Sr-90 Trends

3.1-7 Historic Total Volatile Organic Compound Trends in Extraction Wells, OU I South Boundary Groundwater Remediation System

3.1-8 Actual vs. Model Predicted VOC Mass Removal, OU I South Boundary Groundwater Remediation System

3.1-9 Average Core Monitoring Well TVOC Concentration, OU I South Boundary Groundwater Remediation System

3.1-10 OU I South Boundary / North Street East TVOC Plume Comparison 1997-2007

3.2-1 OU III / OU IV / North Street TVOC Plume Distributions

3.2-2 OU III TVOC Hydrogeologic Cross Section (B-B')

3.2-3 OU III / OU IV / North Street TVOC Plume Comparison 1997-2007

3.2.1-1 OU III Carbon Tetrachloride Plume Distribution

3.2.1-2 OU III Carbon Tetrachloride Historical Trends

3.2.2-1 OU III Building 96 Area TVOC Plume Distribution

3.2.2-2 OU III Building 96 Area Historical VOC Trends

3.2.2-3 OU III Building 96 Area Hydrogeologic Cross Section (D-D')

3.2.2-4 OU III Building 96 Area TVOC Plume Comparison 2000-2007

3.2.2-5 OU III Building 96 Area Hexavalent Chromium Results

3.2.3-1 OU III and OU IV Plume(s) Historical VOC Trends

3.2.3-2 OU III Middle Road TVOC Hydrogeologic Cross Section (E-E')

3.2.3-3 Cumulative Mass Removed, OU III Middle Road Groundwater Remediation System

3.2.3-4 Total Volatile Organic Compounds in Recovery Wells, OU III Middle Road Groundwater Remediation System

3.2.3-5 Average Core Monitoring Well TVOC Concentration, OU III Middle Road Groundwater Remediation System

3.2.4-1

3.2.4-2

OU III and OU IV TVOC Plume Distribution in South Boundary / Industrial Park Areas

OU III South Boundary TVOC Hydrogeologic Cross Section (F-F')

3.2.4-3 Total Volatile Organic Compounds in Extraction Wells, OU III South Boundary Groundwater Remediation System

3.2.4-4 Actual vs. Model Predicted VOC Mass Removal, OU III South Boundary Groundwater Remediation System

3.2.4-5 Average Monitoring Well TVOC Concentration, OU III South Boundary Groundwater Remediation System

3.2.5-1 OU III Western South Boundary Historic VOC Trends

3.2.5-2 VOC Mass Removal, OU III Western South Boundary Remediation System 
3.2.6-1

3.2.6-2

3.2.6-3

3.2.6-4

3.2.6-5

$3.2 .6-6$

3.2.7-1

3.2.7-2

3.2.8-1

3.2.8-2

3.2.8-3

3.2.8-4

3.2.8-5

3.2.9-1

3.2.10-1

3.2.10-2

3.2.10-3

3.2.10-4

thy Well Locations and TVOC Results

3.2.11-2 Magoth y Historical VOC Trends

3.2.14-1 OU III South Boundary Radionuclide Monitoring Well Locations

3.2.15-1

3.2.15-2

3.2.15-3

3.2.15-4

3.2.15-5

3.2.15-6

3.2.16-1

3.2.16-2

3.2.16-3

3.2.17-1

3.2.17-2

3.2.17-3

3.2.17-4 T

3.2.17-5

3.2.17-6

3.3.2-1

3.3.2-2

3.4-1

3.4-2

3.4-3

3.5-1

$3.5-2$

3.5-3

$3.5-4$ OU III Industrial Park Historical VOC Trends Remediation System System Cross Section $\left(\mathrm{H}-\mathrm{H}^{\prime}\right)$ 1997-2007

OU III Airport/LIPA TVOC Plume Distribution

OU III Airport West TVOC Hydrogeologic Cross Section (N-N')

OU III BGRR/WCF Sr-90 Plume Distribution

OU III BGRR/WCF Sr-90 Cross Section (I-I')

OU III BGRR/WCF Sr-90 Cross Section (J-J')

OU III BGRR/WCF Sr-90 Cross Section (K-K')

OU III BGRR/WCF Historical Sr-90 Trends

Strontium 90 BGRR Cumulative MilliCuries Removed

OU III Chemical/Animal Holes Sr-90 Plume Distribution

OU III Chemical/Animal Holes Historical Sr-90 Trends

OU III HFBR AOC 29 Tritium Plume Distribution

OU III HFBR AOC 29 Tritium Hydrogeologic Cross Section (L-L')

OU III HFBR AOC 29 Historical Tritium Trends

ritium Concentration Highs - HFBR Upper Lawn, OU III HFBR AOC 29

OU III HFBR AOC 29 Tritium Plume Comparison 1997-2007

OU IV AOC 6 Sr-90 Plume Distribution

OU IV AOC 6 Historical Sr-90 Trends

OU V Sewage Treatment Plant TVOC Plume Distribution

OU V Sewage Treatment Plant Historical VOC Trends

OU V Sewage Treatment Plant TVOC Plume Comparison 1997-2007

OU VI EDB Plume Distribution

OU VI EDB Hydrogeologic Cross Section (M-M')

OU VI Historical EDB Trends

OU VI EDB Plume Comparison 1999-2007

OU III Industrial Park and Industrial Park East TVOC Hydrogeologic Cross Section (G-G')

TVOC Influent Concentration, OU III Industrial Park Groundwater Remediation System TVOC Effluent Concentration, OU III Industrial Park Groundwater Remediation System Actual vs. Updated Model Predicted VOC Mass Removal, OU III Industrial Park Groundwater

Average Core Monitoring Well TVOC Concentration, OU III Industrial Park Groundwater Remediation

Eastern Middle Road / Industrial Park East TVOC Hydrogeologic Cross Section (C-C')

VOC Mass Removal, OU III Industrial Park East Groundwater Remediation System

North Street (OU I / IV Former Landfill, Animal/Chemical Pits and Glass Holes) TVOC Hydrogeologic

North Street (OU I / IV Former Landfill, Animal/Chemical Pits and Glass Holes) Historical VOC Trends Cumulative Mass Removed, OU III North Street Groundwater Remediation System

North Street (OU I / IV Former Landfill, Animal/Chemical Pits and Glass Holes) TVOC Plume Comparison

North Street (OU I / IV Former Landfill, Animal/Chemical Pits and Glass Holes) TVOC Plume Distribution

Cumulative Mass Removed, OU III North Street East Groundwater Remediation System

TVOC Influent Concentrations, OU III LIPA / Airport Groundwater Remediation System

Cumulative Mass Removed, OU III LIPA / Airport Groundwater Remediation System

Chemical / Animal Holes Strontium 90 Cumulative MilliCuries Removed, OU III Chemical/Animal Holes

HFBR Peak Tritium Concentrations in Groundwater - HFBR to Cornell Avenue, OU III HFBR AOC 29 
4-1 Environmental Surveillance Monitoring Well Locations AGS and BLIP Facility Area Maximum Tritium Concentrations Downgradient of AGS Booster Beam Stop (Wells 064-51 and 064-52)

4-3 Maximum Tritium and Sodium-22 Concentrations in Temporary and Permanent Monitoring Wells Downgradient of the Former E-20 Catcher Maximum Tritium Concentrations Downgradient of the 914 Transfer Tunnel (Wells 064-03, -53 and -54) Maximum Tritium Concentrations in Wells 054-63 and 054-64, Downgradient of the J-10 Beam Stop Maximum Tritium Concentrations in Well 054-129, Downgradient of the Former U-Line Target

4-7 Maximum Tritium Concentrations in Temporary and Permanent Wells, Downgradient of U-Line Beam Stop

4-8 Environmental Surveillance AOC 16T g-2 Tritium Plume First Quarter 2008

4-9 Environmental Surveillance AOC 16T g-2 Tritium Plume Cross Section (O-O')

4-10 Maximum Tritium Concentrations Downgradient of the g-2 Tritium Source Area

4-11 Maximum Tritium Concentrations in Wells $\sim 40$ Feet Downgradient of the BLIP Target Vessel Tritium Concentrations vs. Water Table Position, 40 feet Downgradient of the BLIP Target Vessel Environmental Surveillance Monitoring Well Locations Relativistic Heavy Ion Collider Environmental Surveillance Monitoring Well Locations Brookhaven Medical Research Reactor Tritium Concentrations Downgradient of the BMRR from 1997-2007 Environmental Surveillance Monitoring Well Locations Sewage Treatment Plant and Live Fire Range Environmental Surveillance Monitoring Well Locations Motor Pool VOC Concentration Trends Downgradient of the Gasoline UST Area

Environmental Surveillance Monitoring Well Locations Service Station Carbon Tetrachloride Concentration Trends in Service Station Monitoring Wells Downgradient Well 085-17: Trend of Service Station-Related VOCs Downgradient Well 085-236: Trend of Service Station-Related VOCs Downgradient Well 085-237: Trend of Service Station-Related VOCs Environmental Surveillance Monitoring Well Locations Major Petroleum Facility VOC Concentrations Downgradient of the Major Petroleum Facility, in Well 076-380 Environmental Surveillance Monitoring Well Locations Waste Management Facility Tritium Concentration Trends in Well 056-23, Downgradient of Waste Management Facility Sr-90 Concentration Trends in Downgradient Wells 065-37 and 065-325 at Building 801 
SER VOLUME II: GROUNDWATER STATUS REPORT

This page intentionally left blank. 


\section{List of Tables}

E-1 BNL Groundwater Remediation System Treatment Summary for 1997-2007

E-2 Groundwater Restoration Progress

1-1. Groundwater Standards for Inorganic Compounds

1-2. Groundwater Standards for Pesticides and PCBs

1-3. Groundwater Standards for Organic Compounds

1-4. Groundwater Standards for Radiological Compounds

1-5. Summary of LTRA Groundwater Samples and Analytical Methods

1-6. Summary of Environmental Surveillance Samples and Analytical Methods

1-7. $\quad$ Summary of Monitoring Wells and Piezometers

1-8. $\quad$ LTRA Groundwater Monitoring Program - Well Sampling Frequency

2-1. $\quad 2007$ Water Pumpage Report for Potable Supply Wells

2-2. $\quad 2007$ Water Pumpage Report for Process Supply Wells

2-3. $\quad 2007$ Remediation Well Pumpage Report

2-4. $\quad 2007$ Recharge Basin Flow Report

2-5. BNL Monthly Precipitation Summary (1949-2007)

3.0-1 Summar y of Groundwater Remediation Systems at BNL

3.1-1 OU I South Boundary Pump and Treat System 2007 SPDES Equivalency Permit Levels

3.1-2 OU I South Boundary System 2007 Air Stripper VOC Emissions Data

3.2.2-1 OU III Building 96 VOC Emission Rates, 2007 Average

3.2.3-1 Middle Road Air Stripping Tower 2007 SPDES Equivalency Permit Levels

3.2.3-2 OU III Middle Road Air Stripper VOC Emission Rates 2007 Average

3.2.4-1 OU III South Boundary Air Stripping Tower 2007 SPDES Equivalency Permit Levels

3.2.4-2 OU III South Boundary Air Stripper VOC Emission Rates, 2007 Average

3.2.5-1 Western South Boundary Pump \& Treat System 2007 SPDES Equivalency Permit Levels

3.2.5-2 Western South Boundary 2007 Air Stripper VOC Emissions Data

3.2.7-1 Industrial Park East Pump \& Treat System 2007 SPDES Equivalency Permit Levels

3.2.8-1 OU III North Street 2007 SPDES Equivalency Permit Levels

3.2.9-1 OU III North Street East 2007 SPDES Equivalency Permit Levels

3.2.10-1 OU III LIPA/Airport Pump \& Treat System 2007 SPDES Equivalency Permit Levels

3.2.11-1 Magothy Aquifer Contamination (Historical and 2007)

3.2.11-2 Magoth y Remedy

3.2.15-1 Sr-90 BGRR Treatment System 2007 SPDES Equivalency Permit Levels

3.2.15-2 W CF Strontium-90 Plume Characterization

3.2.16-1 Sr-90 Chemical Holes Treatment System 2007 SPDES Equivalency Permit Levels

3.2.17-1 Summary of Tritium Results From Vertical Profile Wells, July 2007 through March 2008 HFBR

3.5-1 OU VI EDB Pump \& Treat System 2007 SPDES Equivalency Permit Levels

3.6-1 Radiological Background Monitoring, 1996-2001

4-1.1 g-2 Tritium Plume Characterization, Transect "A" Analytical Data (pCi/L), August 23 - September 14, 2007

4-1.2 g-2 Tritium Plume Characterization, Transect "B" Analytical Data (pCi/L), June 25 - July 3, 2007

4-1.3 g-2 Tritium Plume Characterization, Transect "C" Analytical Data (pCi/L), October 23 - March 12, 2008

4-1.4 g-2 Tritium Plume Characterization, Transect “D” Analytical Data (pCi/L), February 5- March 7, 2008 
SER VOLUME II: GROUNDWATER STATUS REPORT

This page intentionally left blank. 


\section{Acronyms and Abbreviations}

These acronyms and abbreviations reflect the typical manner in which terms are used in Volume II of this document, and may not apply to all situations.

$\begin{array}{ll}\text { AGS } & \text { Alternating Gradient Synchrotron } \\ \text { AOC } & \text { Area of Concern } \\ \text { AS/SVE } & \text { Air Sparge/Soil Vapor Extraction } \\ \text { ASL } & \text { Analytical Services Laboratory } \\ \text { ASTM } & \text { American Society for Testing and Materials } \\ \text { AWQS } & \text { Ambient Water Quality Standards } \\ \text { BERA } & \text { Brookhaven Employees Recreation } \\ & \text { Association } \\ \text { BGRR } & \text { Brookhaven Graphite Research Reactor } \\ \text { BLIP } & \text { Brookhaven LINAC Isotope Producer } \\ \text { BLS } & \text { below land surface } \\ \text { BMRR } & \text { Brookhaven Medical Research Reactor } \\ \text { BNL } & \text { Brookhaven National Laboratory } \\ \text { CERCLA } & \text { Comprehensive Environmental Response } \\ & \text { Compensation and Liability Act } \\ \text { CFR } & \text { Code of Federal Regulations } \\ \text { COC } & \text { Chain of Custody } \\ \text { CR } & \text { chromium } \\ \text { CRDL } & \text { Contract Required Detection Limit } \\ \text { CSF } & \text { Central Steam Facility } \\ \text { CY } & \text { calendar year } \\ \text { DCA } & \text { 1,1-dichloroethane } \\ \text { DCE } & \text { 1,1-dichloroethene } \\ \text { DCG } & \text { Derived Concentration Guide } \\ \text { DMR } & \text { Discharge Monitoring Report } \\ \text { DOE } & \text { U.S. Department of Energy } \\ \text { DQO } & \text { Data Quality Objective } \\ \text { DTW } & \text { Depth to Water } \\ \text { DWS } & \text { Drinking Water Standard } \\ \text { EDB } & \text { ethylene dibromide } \\ \text { EDD } & \text { Electronic Data Deliverable } \\ \text { EE/CA } & \text { Engineering Evaluation/Cost Analysis } \\ \text { EIMS } & \text { Environmental Information Management } \\ & \text { System } \\ \text { EM } & \text { Environmental Management } \\ \text { EMS } & \text { Environmental Management System } \\ \text { EPA } & \text { United States Environmental Protection } \\ & \text { Agency } \\ \text { ER } & \text { Environmental Restoration } \\ \text { ERP } & \text { Emissions Rate Potential } \\ & \end{array}$

$\begin{array}{ll}\text { ES } & \text { Environmental Surveillance } \\ \text { ESD } & \text { Explanation of Significant Differences } \\ \text { EW } & \text { extraction well } \\ \text { EWMSD } & \text { Environmental and Waste Management } \\ & \text { Services Division } \\ \text { FFA } & \text { Federal Facility Agreement } \\ \text { FRP } & \text { Facility Response Plan } \\ \text { FFS } & \text { Focused Feasibility Study } \\ \text { FS } & \text { Feasibility Study } \\ \text { ft msl } & \text { feet above mean sea level } \\ \text { GAC } & \text { granular activated carbon } \\ \text { gal/hr } & \text { gallons per hour } \\ \text { GeV } & \text { giga electron volt } \\ \text { GPM } & \text { gallons per minute } \\ \text { HFBR } & \text { High Flux Beam Reactor } \\ \text { HWMF } & \text { Hazardous Waste Management Facility } \\ \text { IAG } & \text { Inter Agency Agreement } \\ \text { ID } & \text { identification } \\ \text { K gal } & \text { thousand gallons } \\ \text { Ib/gal } & \text { pounds per gallon } \\ \text { IbS } & \text { pounds } \\ \text { LEL } & \text { Lower Explosive Limit } \\ \text { LIE } & \text { Long Island Expressway } \\ \text { LINAC } & \text { Linear Accelerator } \\ \text { LIPA } & \text { Long Island Power Authority } \\ \text { LOAEL } & \text { Lowest Observed Adverse Effects Level } \\ \text { LTRA } & \text { Long Term Response Actions } \\ \text { MCL } & \text { Maximum Contaminant Level } \\ \text { MDL } & \text { Minimum Detection Limit } \\ \text { mg/L } & \text { milligrams per liter } \\ \text { MGD } & \text { millions of gallons per day } \\ \text { MNA } & \text { Monitored Natural Attenuation } \\ \text { MPF } & \text { Major Petroleum Facility } \\ \text { MS/MSD } & \text { Matrix Spike/Matrix Spike Duplicate } \\ \text { msI } & \text { mean sea level } \\ \text { MTBE } & \text { methyl tertiary butyl ether } \\ \text { NCP } & \text { National Oil and Hazardous Substances } \\ \text { NPL } & \text { Pollution Contingency Plan } \\ & \text { National Priorities List } \\ & \end{array}$




$\begin{array}{ll}\text { NSRL } & \text { NASA Space Radiation Laboratory } \\ \text { NYCRR } & \text { New York Code of Rules and Regulations } \\ \text { NYS } & \text { New York State } \\ \text { NYSDEC } & \text { New York State Department of } \\ & \text { Environmental Conservation } \\ \text { NYSDOH } & \text { New York State Department of Health } \\ \text { O\&M } & \text { Operation and Maintenance } \\ \text { OU } & \text { Operable Unit } \\ \text { PCBs } & \text { polychlorinated biphenyls } \\ \text { PCE } & \text { tetrachloroethylene } \\ \text { pCi/L } & \text { pico Curies per liter } \\ \text { PE } & \text { Plant Engineering } \\ \text { PLC } & \text { programmable logic controller } \\ \text { ppb } & \text { parts per billion } \\ \text { QA/QC } & \text { Quality Assurance and Quality Control } \\ \text { RA V } & \text { Removal Action V } \\ \text { RCRA } & \text { Resource Conservation and Recovery Act } \\ \text { RHIC } & \text { Relativistic Heavy lon Collider } \\ \text { RI } & \text { Remedial Investigation } \\ \text { RI/FS } & \text { Remedial Investigation/Feasibility Study } \\ \text { ROD } & \text { Record of Decision } \\ \text { RPD } & \text { Relative Percent Difference } \\ \text { RTW } & \text { Recirculating Treatment Well } \\ \text { RW } & \text { remediation well } \\ & \end{array}$

$\begin{array}{ll}\text { SBMS } & \text { Standards Based Management System } \\ \text { SCDHS } & \begin{array}{l}\text { Suffolk County Department of Health } \\ \text { Services }\end{array} \\ \text { SCGs } & \text { Standards, Criteria and Guidances } \\ \text { SCWA } & \text { Suffolk County Water Authority } \\ \text { SDG } & \text { Sample Delivery Group } \\ \text { SDWA } & \text { Safe Drinking Water Act } \\ \text { SOP } & \text { Standard Operating Procedure } \\ \text { SPCC } & \text { Spill Prevention Control and } \\ & \text { Countermeasures } \\ \text { SPDES } & \text { State Pollutant Discharge Elimination } \\ & \text { System } \\ \text { Sr-90 } & \text { Strontium-90 } \\ \text { STP } & \text { Sewage Treatment Plant } \\ \text { SU } & \text { standard unit } \\ \text { SVOC } & \text { semi-volatile organic compound } \\ \text { TVOC } & \text { total volatile organic compound } \\ \text { USGS } & \text { United States Geological Survey } \\ \text { UST } & \text { underground storage tank } \\ \text { VOC } & \text { volatile organic compound } \\ \text { Hg/L } & \text { micrograms per liter } \\ \text { WCF } & \text { Waste Concentration Facility } \\ \text { WMF } & \text { Waste Management Facility } \\ & \end{array}$

SBMS Standards Based Management System

Services

SCGs Standards, Criteria and Guidances

SCWA Suffolk County Water Authority

SDG Sample Delivery Group

SDWA Safe Drinking Water Act

SOP Standard Operating Procedure

SPCC Spill Prevention Control and Countermeasures System

Sr-90 strontium-90

STP Sewage Treatment Plant

SVOC semi-volatile organic compound

TVOC total volatile organic compound

USGS United States Geological Survey

UST underground storage tank

VOC volatile organic compound

$\mu \mathrm{g} / \mathrm{L}-\mathrm{micr}$

WMF Waste Management Facility 


\section{BROOKHAVEN NATIONAL LABORATORY GROUNDWATER STATUS REPORT}

\section{Executive Summary}

The mission of the Laboratory's Groundwater Protection Program is to protect and restore the aquifer system at Brookhaven National Laboratory (BNL). Four key elements make up the program:

- Pollution prevention - preventing the potential pollution of groundwater at the source

- Monitoring - monitoring the effectiveness of pollution-prevention efforts, as well as progress in restoring contaminated groundwater

- Restoration - restoring groundwater quality that BNL has impacted

- Communication - communicating the findings and the results of the program to regulators and other stakeholders

The 2007 BNL Groundwater Status Report is a comprehensive summary of data collected during the calendar year, and an evaluation of Groundwater Protection Program performance. This is the twelfth annual groundwater status report issued by BNL. This document examines the performance of the program on a project-by-project basis, as well as comprehensively in a "watershed-like" analysis.

How to Use This Document.This detailed technical document includes summaries of laboratory data, as well as data interpretations. It is intended for internal BNL users, regulators, and other technically oriented stakeholders. Less technical summaries of this information are presented as Chapter 7 of this Site Environmental Report. Environmental Restoration (ER) refers to work being performed under the Comprehensive Environmental Response, Compensation and Liability Act (CERCLA) by the Long Term Response Actions (LTRA) Group, including measuring and monitoring of groundwater remediation performance, and efforts in achieving cleanup goals. Environmental Surveillance (ES) refers to the monitoring of groundwater quality at active research and support facilities, primarily in response to Department of Energy (DOE) Order 450.1, Environmental Protection. Data are presented in five key areas:

- Improvements to the understanding of the hydrogeologic environment beneath BNL and surrounding areas

- Identification of any new impacts on groundwater quality due to BNL's active operations

- Progress in cleaning up the groundwater contamination

- Performance of individual groundwater remediation systems

- Recommended changes to the groundwater protection program

This document satisfies BNL's requirement to report groundwater data under the Interagency Agreement (IAG) and partially fulfills the commitment of BNL's Groundwater Protection Program to communicate the findings and progress of the program to regulators and stakeholders.

Section 1 summarizes the regulatory drivers of the data collection work in 2007, the site's groundwater classification, and the objectives of the groundwater monitoring efforts. Section 2 discusses improvements to our understanding of the hydrogeologic environment at BNL and its surrounding area. It also summarizes the dynamics of the groundwater flow system in 2007. Section 3 summarizes the groundwater cleanup data, progress towards achieving the site's cleanup goal, and recommended modifications to the remediation systems or monitoring programs. Section 4 summarizes the groundwater 
surveillance data used to verify that operational and engineering controls are preventing further contamination from the site's active experimental and support facilities. The recommended changes to the Groundwater Protection Program are summarized in Section 5.

\section{HYDROGEOLOGIC DATA}

The following were important hydrogeologic findings in 2007:

- The desired flow conditions continued to be maintained in the central portion of the site during 2007 with 90 percent of the total site wide potable and process water pumpage being derived from the western supply well field. No shifting of contaminant plumes outside of the established monitoring networks was observed on-site in 2007.

- The implementation of effective water conservation measures has resulted in a significant reduction in the amount of process and supply water pumped from the aquifer since 1999.

- Total annual precipitation in 2007 was 45.3 inches, which is below the yearly average of 48 inches. Seven of the past 10 years have featured above normal average precipitation at BNL.

\section{GROUNDWATER RESTORATION PROGRESS AND ISSUES (CERCLA)}

Table E-1 summarizes the status and progress of groundwater cleanup at BNL under the provisions of CERCLA. During 2007, twelve VOC groundwater remediation systems were in operation, along with two Sr-90 treatment systems. In 2007, 198 pounds of volatile organic compounds (VOCs) were removed from the aquifers by the treatment systems. To date, 5,897 pounds of VOCs in the aquifer have been removed. The Operable Unit (OU) III Chemical Holes Strontium-90 System removed $0.27 \mathrm{mCi}$ of strontium-90 (Sr90) from the Upper Glacial aquifer in 2007, for a total to date of $2.59 \mathrm{mCi}$. The OU III BGRR Sr-90 system removed $4.9 \mathrm{mCi}$ of $\mathrm{Sr}-90$ during the year, for a total of $14.15 \mathrm{mCi}$ since operations began in 2005.

Groundwater remediation is expected to be a long-term process for most of the plumes. Noticeable improvements in groundwater quality are evident in the OU I South Boundary, OU III Carbon Tetrachloride, OU III North Street, OU III Industrial Park, OU III LIPA, and OU III South Boundary areas. One system (OU IV AS/SVE) has been decommissioned in 2003, one system remained in standby since 2004 (OU III Carbon Tetrachloride) and a number of individual system extraction wells have been placed on standby. The HFBR Pump and Recharge system was restarted in response to the triggering of the OU III ROD contingency. Groundwater remediation activities are expected to continue until the cleanup objectives for the plumes have been met. The specific goals are as follows:

- Achieve maximum contaminant levels (MCLs) for VOCs in the Upper Glacial aquifer by 2030

- Achieve MCLs for VOCs in the Magothy aquifer by 2065

- Achieve MCL of 8 pCi/L for Sr-90 at the BGRR in Upper Glacial aquifer by 2070

- Achieve MCL of 8 pCi/L for Sr-90 at the Chemical Holes in the Upper Glacial aquifer by 2040

The cleanup objectives will be met by a combination of active treatment and natural attenuation. The comprehensive groundwater monitoring program will measure the remediation progress.

The locations and extent of the primary VOC and radionuclide plumes at BNL as of December 2007 are summarized in Figures E-1 and E-2, respectively. Significant items of interest during 2007 were the following: 
- 725 monitoring wells were sampled as part of the LTRA Groundwater Monitoring Program in 2007 , comprising a total of 2,049 groundwater sampling events. Approximately 52 temporary wells were also installed in 2007, for approximately 542 samples. BNL continued to make significant progress in characterizing and restoring groundwater quality at the site.

- During 2007, 1.4 billion gallons of groundwater were treated. (Table E-1).

Table E-1.

BNL Groundwater Remediation System Treatment Summary for 1997 - 2007.

\begin{tabular}{|c|c|c|c|c|}
\hline \multirow[b]{2}{*}{ VOCs Remediation (start date) } & \multicolumn{2}{|c|}{$1997-2006$} & \multicolumn{2}{|c|}{2007} \\
\hline & $\begin{array}{l}\text { Water } \\
\text { Treated } \\
\text { (gallons) }\end{array}$ & $\begin{array}{c}\text { VOCs } \\
\text { Removed } \\
\text { (pounds)(c) }\end{array}$ & $\begin{array}{l}\text { Water } \\
\text { Treated } \\
\text { (gallons) }\end{array}$ & $\begin{array}{c}\text { VOCs } \\
\text { Removed } \\
\text { (pounds)(c) }\end{array}$ \\
\hline OU III South Boundary (June 1997) & $3,048,952,850$ & 2,537 & $136,000,000$ & 32 \\
\hline OU III Industrial Park (Sept. 1999) & $1,234,478,330$ & 967 & $130,000,000$ & 43 \\
\hline OU III W. South Boundary (Sept. 2002) & $531,647,000$ & 45 & $71,000,000$ & 4 \\
\hline OU III Carbon Tetrachloride (Oct. 1999) & $153,538,075$ & 349 & Standby & 0 \\
\hline OU I South Boundary (Dec. 1996) & $3,047,314,000$ & 331 & $137,000,000$ & 6 \\
\hline OU III HFBR Tritium Plume (May 1997) (a) & $241,528,000$ & 180 & $7,450,000$ & 0 \\
\hline OU IV AS/SVE (Nov. 1997) (b) & 0 & 35 & Decommissioned & 0 \\
\hline OU III Building 96 (Feb. 2001) & $135,497,416$ & 71 & $2,800,000$ & $<1$ \\
\hline OU III Middle Road (Oct. 2001) & $1,139,411,550$ & 707 & $128,000,000$ & 34 \\
\hline OU III Industrial Park East (May 2004) & $226,172,000$ & 29 & $61,000,000$ & 4 \\
\hline OU III North Street (June 2004) & $503,122,000$ & 232 & $186,000,000$ & 36 \\
\hline OU III North Street East (June 2004) & $357,976,000$ & 16 & $71,000,000$ & 4 \\
\hline OU III LIPA/Airport (June 2004) & $675,887,000$ & 200 & $171,000,000$ & 35 \\
\hline OU VI EDB (August 2004) & $333,711,000$ & $N A(d)$ & $138,000,000$ & $N A(d)$ \\
\hline \multirow[t]{3}{*}{ Totals } & $11,616,851,220$ & 5,699 & $1,239,250,000$ & 198 \\
\hline & \multicolumn{2}{|c|}{$2003-2006$} & \multicolumn{2}{|c|}{2007} \\
\hline & $\begin{array}{l}\text { Water } \\
\text { Treated } \\
\text { (gallons) }\end{array}$ & $\begin{array}{l}\text { Sr-90 } \\
\text { Removed } \\
(\mathrm{mCl})\end{array}$ & $\begin{array}{l}\text { Water } \\
\text { Treated } \\
\text { (gallons) }\end{array}$ & $\begin{array}{l}\text { Sr-90 } \\
\text { Removed } \\
(\mathrm{mCl})\end{array}$ \\
\hline OU III Chemical Holes (Feb 2003) & $10,004,826$ & 2.32 & $2,400,000$ & 0.27 \\
\hline OU III BGRR (June 2005) & $14,551,000$ & 9.25 & $7,600,000$ & 4.9 \\
\hline Totals & $24,555,826$ & 11.57 & $10,000,000$ & 5.17 \\
\hline
\end{tabular}

Notes:

(a) System was placed in standby mode on Sept. 29, 2000, but restarted 12/07.

(b) Air Sparging/Soil Vapor Extraction system performance measured by pounds of VOC removed. System was dismantled in December 2003.

(c) Values rounded to the nearest whole number.

(d) EDB has been detected at trace levels in the system influent since operations began and well below the standard. Therefore, no removal of VOCs are reported. 
- The HFBR Pump and Recharge system was re-started in December 2007 as per the OU III ROD contingency that was triggered in November, 2006. New extraction well EW-16 was constructed several hundred feet north of Princeton Avenue and is operated in conjunction with EW-11. The system is expected to remain on several years until the high concentration tritium slug detected in 2006 has been completely addressed.

- An engineering evaluation for the persistent Building 96 source area PCE looked at various alternatives such as soil excavation, an additional extraction well, soil mixing with vapor extraction, electrical resistance heating, and injection by hydrogen release compounds. Additional characterization to better define the extent of the silt layers and the continuing PCE source associated with these silt layers will be needed prior to the selection of an alternative. Extraction well RTW-2 (which was on standby) was placed back in service in October 2007 due to increasing PCE concentrations in nearby monitoring wells. A design modification along with a SPDES Discharge application was submitted to NYSDEC in February 2008 for converting extraction well RTW-1 to a pumping well discharging to the nearby storm water drainage culvert. Sampling of RTW-1 for as part of the SPDES application detected chromium (VI) concentrations exceeding the DWS. The operation of RTW-1 maintains hydraulic control of the source area. Ion-exchange treatment has been added to this well.

- Two additional extraction wells and five monitoring wells were installed and added to the Chemical Holes Sr-90 system in 2007. The additional extraction wells were necessary to meet the cleanup goal of reducing Sr-90 to below DWS in this plume by 2040.

- Airport System extraction well RTW-6A was installed and placed in operation in November 2007 to address the increasing concentrations in western perimeter monitoring well 800-96 during 2006. This extraction well was necessary to capture and treat the western portion of the plume in this area.

- Sr-90 samples obtained during the 2007 g-2 tritium plume characterization effort identified higher than expected Sr-90 in the vicinity of the HFBR. This is the downgradient portion of the Waste Concentration Facility Sr-90 plume. Based on preliminary groundwater modeling, using the updated plume concentrations, it was determined that several additional extraction wells will be necessary in order to achieve the OU III ESD cleanup goal of $8 \mathrm{pCi} / \mathrm{L}$ of Sr-90 by 2070.

Other progress highlights include:

- The OU I South Boundary system resumed full-time operations following a period of pulse pumping, which began in September 2005. This is in anticipation of a higher concentration slug of VOCs in the vicinity of monitoring well 107-40, approaching the south boundary.

- The OU III Carbon Tetrachloride system remained on standby as per the petition for shutdown. There has been no rebound observed in monitoring well carbon tetrachloride concentrations.

- OU III Middle Road extraction wells RW-4, RW-5, and RW-6 remained on standby due to low VOC concentrations.

- OU III South Boundary extraction wells EW-6, EW-7, EW-8, and EW-12 were all on standby due to low VOC concentrations. The highest concentrations at the OU III South Boundary are now limited to the western portion of the system.

- The OU III Western South Boundary system continued pulse pumping operations, which began in September 2005, due to low VOC concentrations.

- OU III Industrial Park extraction well UVB-4 was placed on standby mode in 2007. The system continued to effectively remove VOCs from the Upper Glacial aquifer. 
Progress of the groundwater restoration program is summarized in Table E-2.

\section{INSTITUTIONAL CONTROLS}

Institutional controls are in place at BNL to ensure effectiveness of all groundwater remedies. During 2007 , the institutional controls continue to be effective in protecting human health and the environment. In accordance with the BNL Land Use Controls Management Plan, Revision 2 dated July 25, 2007, the following institutional controls continued to be implemented for the groundwater remediation program.

- Groundwater monitoring, including BNL potable supply systems and Suffolk County Department of Health Services (SCDHS) monitoring of Suffolk County Water Authority (SCWA) well fields closest to BNL

- 5-year reviews, as required by CERCLA, until cleanup goals are met and to determine the effectiveness of the groundwater monitoring program

- Controls on the installation of new supply wells and recharge basins on BNL property

- Public water service in plume areas south and east of BNL

- Prohibitions on the installation of new potable water supply wells where public water service exists (Suffolk County Sanitary Code Article 4)

- Property access agreements for treatment systems off the BNL property.

An annual update on Institutional Controls summarizes noteworthy issues, changes, breaches etc. was submitted to the regulatory agencies in December 2007.

\section{ENVIRONMENTAL SURVEILLANCE (FACILITY) MONITORING RESULTS}

During 2007, the Environmental Surveillance (ES) Program monitored groundwater quality at 10 active research and support facilities. Groundwater samples were collected from 125 wells during 240 individual sampling events. Although no new impacts to groundwater quality were discovered during 2007, groundwater quality continues to be impacted at two facilities: continued periodic high levels of tritium at the g-2 tritium source area, and continued VOCs at the Upton Service Station. At the Brookhaven Linac Isotope Producer (BLIP), tritium levels were less than the 20,000 pCi/L DWS during all of 2007.

Following the concurrence from the NYSDEC, a Record of Decision (ROD) was signed by the U.S. DOE and U.S. EPA in early 2007 (BNL 2007b). This ROD requires continued routine inspection and maintenance of the impermeable caps at the $\mathrm{g}-2$ and BLIP source areas, and groundwater monitoring of the source areas to verify the continued effectiveness of the storm water controls. Furthermore, the ROD requires monitoring the g- 2 tritium plume until it attenuates to less than the $20,000 \mathrm{pCi} / \mathrm{L} \mathrm{DWS}$. Contingency actions have been developed if tritium levels exceeding $1,000,000 \mathrm{pCi} / \mathrm{L}$ are detected within the g-2 plume, or if the g-2 tritium plume does not attenuate as predicted by the groundwater model.

Highlights for the surveillance monitoring program are as follows:

- Tritium continues to be detected in the g-2 source area monitoring wells, at concentrations above the $20,000 \mathrm{pCi} / \mathrm{L}$ DWS. During 2007 the maximum tritium concentration in source area wells was $94,900 \mathrm{pCi} / \mathrm{L}$ in January. Tritium concentrations were less than $50,000 \mathrm{pCi} / \mathrm{L}$ during the second half of the year. A short-term spike in tritium levels was observed in January 2008, with a tritium concentration of $186,000 \mathrm{pCi} / \mathrm{L}$ detected in source area well 054-07. Tritium levels in this well dropped to $21,800 \mathrm{pCi} / \mathrm{L}$ by February 2008. Although the engineered stormwater controls are effectively protecting the activated soil shielding at the source area, monitoring data indicates that 
the continued release of tritium appears to be related to the flushing of residual tritium from the vadose zone following significant natural periodic fluctuations in the local water table.

- During mid 2007 through early 2008, monitoring of the downgradient areas of the g-2 tritium plume was accomplished using a combination of permanent and temporary wells. The highest tritium concentration was $198,000 \mathrm{pCi} / \mathrm{L}$, observed in temporary well GP-73 located approximately 250 feet northwest of the HFBR. The plume was tracked to the area immediately south of the HFBR, with a maximum tritium concentration of $83,000 \mathrm{pCi} / \mathrm{L}$ in temporary well GP-84. As a result of natural radioactive decay and dispersion in the aquifer, the tritium plume (as defined by concentrations $>20,000 \mathrm{pCi} / \mathrm{L} \mathrm{MCL}$ ) appears to be breaking up into discrete segments.

- Since April 2006, all tritium concentrations in the BLIP facility surveillance wells have been less than the $20,000 \mathrm{pCi} / \mathrm{L}$ DWS. The maximum tritium concentration during 2007 was $13,100 \mathrm{pCi} / \mathrm{L}$. During the first half of 2008 , tritium concentrations were less than $2,000 \mathrm{pCi} / \mathrm{L}$. These results indicate that the engineered stormwater controls are effectively protecting the activated soil shielding, and that the amount of residual tritium in the deep vadose zone is diminishing.

- At the Service Station, VOCs associated with petroleum products and solvents continue to be detected in several monitoring wells directly downgradient of the station at concentrations that exceed the DWS. During 2007, high levels of VOCs were detected during the October sample round, with total xylenes detected at $140 \mu \mathrm{g} / \mathrm{L}$, ethylbenzene at $15 \mu \mathrm{g} / \mathrm{L}, 1,2,4$-trimethylbenzene at $35 \mu \mathrm{g} / \mathrm{L}$, and the solvent PCE at a concentration of $14 \mu \mathrm{g} / \mathrm{L}$. No floating petroleum was detected in the monitoring wells. Monitoring of the leak detection systems at the Service Station indicates that the gasoline storage tanks and associated distribution lines are not leaking. Furthermore, evaluation of current vehicle maintenance operations indicates that all waste oils and used solvents are being properly stored and recycled. Therefore, it is believed that the contaminants detected in groundwater originates from historical vehicle maintenance activities and are not related to current operations.

\section{PROPOSED CHANGES TO THE GROUNDWATER PROTECTION PROGRAM}

The data summarized in this report are the basis for several significant operational and groundwater monitoring changes to the groundwater protection and cleanup programs. A summary of those significant changes follows (specific details of which are provided in Chapter 5):

- OU I South Boundary System - Install a temporary well approximately 500 feet north of well 107-40 to characterize the VOC concentrations along the plume center line in this area. Follow up with a permanent monitoring well based on temporary well results. Reduce Sr-90 and tritium sampling frequency for select wells.

- Carbon Tetrachloride System - Install several temporary wells along the plume center line upgradient of EW-15. Update the groundwater model and evaluate if the current carbon tetrachloride levels would naturally attenuate to cleanup objectives. Petition for project closure if warranted.

- Building 96-Begin operation of the modified RTW-1 as a pumping well with chromium treatment and discharge to the surface water drainage culvert. Install additional soil borings and collect samples as necessary to precisely define the extent of silt layers and PCE soil contamination in the source area. This delineation will assist in the selection of the appropriate remedial alternative for the source area. 
- Middle Road System - Install a temporary well to confirm the western edge of the plume. Install a temporary well several hundred feet upgradient of RW-1 and locate a permanent well to monitor the plume core.

- OU III Western South Boundary-Place extraction well WSB-1 back in full-time operation due to increasing concentrations in plume core monitoring well 126-11.

- Industrial Park System - Place extraction well UVB-4 back in operation to address VOCs currently being observed in plume core monitoring well 000-262.

- Industrial Park East - Continue pulse pumping for one year, and if no VOC concentration rebound is observed in either the monitoring or extraction wells petition for shutdown of this system.

- North Street East-Continue pulse pumping for one year, and if no VOC concentration rebound is observed in either the monitoring or extraction wells petition for shutdown of this system.

- LIPA/Airport System - Return extraction well RTW-3A to full-time operations to intercept VOCs migrating from upgradient plume core monitoring wells. Install a temporary well to the west of RTW-3A to locate a perimeter monitoring well in this area.

- BGRR/Waste Concentration Facility Sr-90 - Utilize temporary wells to characterize the high concentration Sr-90 slug in the vicinity of the HFBR during the fourth quarter of 2008. Coordinate with g-2 plume tritium characterization to identify the higher tritium concentrations in this area. This data will be used to locate additional extraction wells.

- Chemical Holes Sr-90 - Implement pulse pumping of EW-1 to evaluate Sr-90 rebounding in this well. Install temporary wells upgradient of plume core well 106-16 to identify the source of increasing Sr-90 detections in this monitoring well.

- Operable Unit VI System-Add a plume bypass well east of 000-508 to verify the capture zone of EW-2E.

- Waste Management Facility- The five new downgradient groundwater monitoring wells installed at the WMF in late 2007 will be incorporated into the monitoring program starting in February 2008 . 
Table E-2.

Groundwater Restoration Progress.

\begin{tabular}{|c|c|c|c|c|c|c|}
\hline Project & Target & Mode & $\begin{array}{l}\text { Treatment } \\
\text { Type }\end{array}$ & $\begin{array}{l}\text { Treatment } \\
\text { Progress }\end{array}$ & $\begin{array}{l}\text { Years of } \\
\text { Operation }\end{array}$ & Highlights \\
\hline \multicolumn{7}{|l|}{ OUI } \\
\hline $\begin{array}{l}\text { OU I South } \\
\text { Boundary } \\
\text { (RA V) }\end{array}$ & VOCs & $\begin{array}{l}\text { Operational } \\
\text { (pulse) }\end{array}$ & P\&T with AS & $\begin{array}{l}337 \mathrm{lb} \text { of VOCs } \\
\text { treated to date }\end{array}$ & 10 of 14 & $\begin{array}{l}\text { Hot spot migrating toward the } \\
\text { extraction wells based on } \\
\text { monitoring well data. }\end{array}$ \\
\hline Current Landfill & $\begin{array}{l}\text { VOCs } \\
\text { tritium }\end{array}$ & $\begin{array}{l}\text { Long Term } \\
\text { Monitoring \& } \\
\text { Maintenance }\end{array}$ & $\begin{array}{l}\text { Landfill } \\
\text { capping }\end{array}$ & $\begin{array}{l}\text { Cap is } \\
\text { maintained and } \\
\text { stable }\end{array}$ & 12 of 30 & $\begin{array}{l}\text { Groundwater quality slowly } \\
\text { improving. VOCs and tritium } \\
\text { stable or slightly decreasing. }\end{array}$ \\
\hline Former Landfill & $\begin{array}{l}\text { VOCs } \\
\text { Sr-90 } \\
\text { tritium }\end{array}$ & $\begin{array}{l}\text { Long Term } \\
\text { Monitoring \& } \\
\text { Maintenance }\end{array}$ & $\begin{array}{l}\text { Landfill } \\
\text { capping }\end{array}$ & $\begin{array}{l}\text { Cap is } \\
\text { maintained and } \\
\text { stable. }\end{array}$ & 11 of 30 & $\begin{array}{l}\text { Continued decline in Sr-90. } \\
\text { VOCs have been below NYS } \\
\text { AWQS since } 1998 \text {. }\end{array}$ \\
\hline Former HWMF & Sr-90 & $\begin{array}{l}\text { Long Term } \\
\text { Response } \\
\text { Action }\end{array}$ & Monitoring & NA & NA & $\begin{array}{l}\text { Sr-90 detected at } 13 \mathrm{pCi} / \mathrm{L} \text { in } \\
\text { well } 088-26 \text { in } 2007 \text {, down from } \\
21.6 \text { in } 2003 .\end{array}$ \\
\hline \multicolumn{7}{|l|}{ OU III } \\
\hline $\begin{array}{l}\text { Chemical/Animal } \\
\text { Holes }\end{array}$ & Sr-90 & Operational & $\begin{array}{l}\text { P\&T with ion } \\
\text { exchange (IE) }\end{array}$ & $\begin{array}{l}2.6 \mathrm{mCi} \mathrm{Sr}-90 \\
\text { removed to date }\end{array}$ & 5 of 10 & $\begin{array}{l}\text { Installed two new extraction } \\
\text { wells in } 2007 \text { to meet cleanup } \\
\text { goals. }\end{array}$ \\
\hline $\begin{array}{l}\text { Carbon } \\
\text { Tetrachloride } \\
\text { source control }\end{array}$ & $\begin{array}{l}\text { VOCs } \\
\text { (carbon } \\
\text { tetra- } \\
\text { chloride) }\end{array}$ & Standby & $\begin{array}{l}\text { P\&T with } \\
\text { carbon }\end{array}$ & $\begin{array}{l}349 \mathrm{lb} \text { of VOCs } \\
\text { treated to date }\end{array}$ & Complete & $\begin{array}{l}\text { No rebound of VOCs observed } \\
\text { in monitoring wells during } \\
2007 .\end{array}$ \\
\hline $\begin{array}{l}\text { Building } 96 \\
\text { source control }\end{array}$ & VOCs & $\begin{array}{l}\text { RTW-1,3,4 } \\
\text { in standby }\end{array}$ & $\begin{array}{l}\text { Recirculation } \\
\text { wells with AS }\end{array}$ & $\begin{array}{l}71 \mathrm{lbs} \text { of VOCs } \\
\text { treated to date }\end{array}$ & 5 & $\begin{array}{l}\text { Treatment well RTW-2 } \\
\text { restarted October } 2007 \text { due to } \\
\text { rebounding VOC } \\
\text { concentrations. Evaluating } \\
\text { alternative remedies to address } \\
\text { persistent PCE in source area. } \\
\text { Cr(VI) detections in RTW-1 } \\
\text { will be treated with ion- } \\
\text { exchange. }\end{array}$ \\
\hline South Boundary & VOCs & $\begin{array}{l}\text { Operational } \\
\text { (EW-6, EW- } \\
7, \text { EW-8 and } \\
\text { EW-12 on } \\
\text { standby) }\end{array}$ & P\&T with AS & $\begin{array}{l}2,569 \mathrm{lbs} \text { of } \\
\text { VOCs treated to } \\
\text { date }\end{array}$ & 10 of 13 & $\begin{array}{l}\text { Continued decline in } \\
\text { monitoring well VOC } \\
\text { concentrations at the site } \\
\text { boundary with the exception of } \\
\text { several wells in the vicinity of } \\
\text { EW- } 4 \text { and EW-5. Determined } \\
\text { that VOCs are not migrating } \\
\text { below the gray-brown Magothy } \\
\text { clay in between the Middle } \\
\text { Road and South Boundary. }\end{array}$ \\
\hline Middle Road & VOCs & $\begin{array}{l}\text { Operational } \\
\text { (RW-4, RW- } \\
\text { 5, and RW-6 } \\
\text { on standby) }\end{array}$ & P\&T with AS & $\begin{array}{l}784 \mathrm{lbs} \text { of VOCs } \\
\text { treated to date }\end{array}$ & 6 of 25 & $\begin{array}{l}\text { Extraction wells RW-1 and -2 } \\
\text { continue to show moderate } \\
\text { VOC levels. Eastern extraction } \\
\text { wells showing low VOC } \\
\text { concentrations. }\end{array}$ \\
\hline
\end{tabular}


Table E-2 (continued).

Groundwater Restoration Progress.

\begin{tabular}{|c|c|c|c|c|c|c|}
\hline Project & Target & Mode & $\begin{array}{l}\text { Treatment } \\
\text { Type }\end{array}$ & $\begin{array}{l}\text { Treatment } \\
\text { Progress }\end{array}$ & $\begin{array}{l}\text { Years of } \\
\text { Operation }\end{array}$ & $\begin{array}{l}\text { Groundwater Quality } \\
\text { Highlights }\end{array}$ \\
\hline \multicolumn{7}{|l|}{ OU III (cont.) } \\
\hline $\begin{array}{l}\text { Western South } \\
\text { Boundary }\end{array}$ & VOCs & $\begin{array}{l}\text { Operational } \\
\text { (Pulse) }\end{array}$ & P\&T with AS & $\begin{array}{l}49 \mathrm{lbs} \text { of VOCs } \\
\text { treated to date }\end{array}$ & 5 of 11 & $\begin{array}{l}\text { System continued in pulse } \\
\text { pumping mode due to low } \\
\text { VOC concentrations. } \\
\text { Maximum TVOCs in } \\
\text { monitoring well during } 2007 \\
\text { was } 45 \mu \mathrm{g} / \mathrm{L} \text {. }\end{array}$ \\
\hline Industrial Park & VOCs & $\begin{array}{l}\text { Operational } \\
\text { (UVB-1 on } \\
\text { standby) }\end{array}$ & $\begin{array}{l}\text { In-well } \\
\text { stripping }\end{array}$ & $\begin{array}{l}1,010 \mathrm{lbs} . \text { of } \\
\text { VOCs treated to } \\
\text { date. }\end{array}$ & 8 of 12 & $\begin{array}{l}\text { Marked increase in VOC levels } \\
\text { in the vicinity of UVB-4. }\end{array}$ \\
\hline $\begin{array}{l}\text { Industrial Park } \\
\text { East }\end{array}$ & VOCs & Operational & $\begin{array}{l}\text { P\&T with } \\
\text { carbon t }\end{array}$ & $\begin{array}{l}33 \mathrm{lbs} \text {. of VOCs } \\
\text { treated to date. }\end{array}$ & 3.5 of 5 & $\begin{array}{l}\text { Continued decrease in VOC } \\
\text { concentrations. All wells } \\
\text { currently below the capture } \\
\text { goal of } 50 \mu \mathrm{g} / \mathrm{L} \text {. Began pulse } \\
\text { pumping in } 2007 \text {. Installed new } \\
\text { injection well in } 2007 \text {. }\end{array}$ \\
\hline North Street & VOCs & Operational & $\begin{array}{l}\text { P\&T with } \\
\text { carbon }\end{array}$ & $\begin{array}{l}268 \mathrm{lbs} \text {. of VOCs } \\
\text { treated to date. }\end{array}$ & 3.5 of 8 & $\begin{array}{l}\text { High concentration segment of } \\
\text { plume continues to be located } \\
\text { in the capture zone of NS-1 } \\
\text { and NS-2. Leading edge of } \\
\text { plume beyond the capture } \\
\text { zone prior to system start-up, } \\
\text { migrating towards the Airport } \\
\text { system. }\end{array}$ \\
\hline $\begin{array}{l}\text { North Street } \\
\text { East }\end{array}$ & VOCs & Operational & $\begin{array}{l}\text { P\&T with } \\
\text { carbon }\end{array}$ & $\begin{array}{l}20 \mathrm{lbs} \text {. of VOCs } \\
\text { treated to date. }\end{array}$ & 3.5 of 10 & $\begin{array}{l}\text { Concentrations in plume core } \\
\text { wells at very low levels in } \\
2007 .\end{array}$ \\
\hline $\begin{array}{l}\text { Long Island } \\
\text { Power Authority } \\
\text { (LIPA) } \\
\text { Right of Wayl } \\
\text { Airport }\end{array}$ & VOCs & Operational & $\begin{array}{l}\text { P\&T and } \\
\text { recirculation } \\
\text { wells with } \\
\text { carbon }\end{array}$ & $\begin{array}{l}235 \mathrm{lbs} \text {. of VOCs } \\
\text { treated to date. }\end{array}$ & 3.5 of 10 & $\begin{array}{l}\text { Airport wells continued pulse } \\
\text { pumping in } 2007 \text {. Installed new } \\
\text { extraction well in } 2007 \text { to } \\
\text { address increasing VOCs in } \\
\text { perimeter well } 800-96 \text { during } \\
2006 \text {. }\end{array}$ \\
\hline HFBR Tritium & Tritium & Operational & $\begin{array}{l}\text { Pump and } \\
\text { recharge }\end{array}$ & $\begin{array}{l}0.2 \text { Ci removed } \\
\text { for off-site } \\
\text { disposal.* } \\
180 \mathrm{lb} \text { of VOCs } \\
\text { also removed } \\
\text { from aquifer \& } \\
\text { treated. }\end{array}$ & 3.5 & $\begin{array}{l}\text { Installed additional pump and } \\
\text { extraction well. Restarted } \\
\text { system in December } 2007 \\
\text { response to triggering of OU III } \\
\text { ROD contingency at Weaver } \\
\text { Drive. }\end{array}$ \\
\hline $\begin{array}{l}\text { BGRR/Waste } \\
\text { Concentration } \\
\text { Facility (WCF) }\end{array}$ & Sr-90 & Operational & P\&T with IE & $\begin{array}{l}14.15 \mathrm{mCi} \text { to } \\
\text { date }\end{array}$ & 2.5 of 10 & $\begin{array}{l}\text { Identified area of higher than } \\
\text { expected Sr-90 concentrations } \\
\text { in downgradient portion of } \\
\text { plume that will require system } \\
\text { modification to achieve } \\
\text { cleanup goal. }\end{array}$ \\
\hline
\end{tabular}

Continued 
Table E-2 (continued).

Groundwater Restoration Progress.

\begin{tabular}{|c|c|c|c|c|c|c|}
\hline Project & Target & Mode & $\begin{array}{l}\text { Treatment } \\
\text { Type }\end{array}$ & $\begin{array}{l}\text { Treatment } \\
\text { Progress }\end{array}$ & $\begin{array}{l}\text { Years of } \\
\text { Operation }\end{array}$ & $\begin{array}{l}\text { Groundwater Quality } \\
\text { Highlights }\end{array}$ \\
\hline $\begin{array}{l}\text { OU IV AS/SVE } \\
\text { system }\end{array}$ & VOCs & $\begin{array}{l}\text { Decommis- } \\
\text { sioned }\end{array}$ & $\begin{array}{l}\text { Air sparging/ } \\
\text { soil vapor } \\
\text { extraction }\end{array}$ & $\begin{array}{l}35 \mathrm{lb} \text { of VOCs } \\
\text { removed. }\end{array}$ & Complete & $\begin{array}{l}\text { VOC concentrations in } \\
\text { monitoring wells remain low. } \\
\text { System decommissioned in } \\
\text { Dec. } 2003 .\end{array}$ \\
\hline \multicolumn{7}{|l|}{ OU V } \\
\hline $\begin{array}{l}\text { AOC } 6 / 650 \text { sump } \\
\text { outfall }\end{array}$ & Sr-90 & $\begin{array}{l}\text { Long Term } \\
\text { Response } \\
\text { Action }\end{array}$ & $\begin{array}{l}\text { Monitored } \\
\text { Natural } \\
\text { Attenuation } \\
\text { (MNA) }\end{array}$ & $\begin{array}{l}\text { Plume slowly } \\
\text { migrating south } \\
\text { within } \\
\text { monitoring- well } \\
\text { network. }\end{array}$ & NA & $\begin{array}{l}\text { Sr-90 plume still migrating } \\
\text { slowly southwest from Bldg. } \\
650 \text { sump outfall and } \\
\text { attenuating. }\end{array}$ \\
\hline \multicolumn{7}{|l|}{ OU V } \\
\hline STP & $\begin{array}{l}\text { VOCs, } \\
\text { tritium }\end{array}$ & $\begin{array}{l}\text { Long Term } \\
\text { Response } \\
\text { Action }\end{array}$ & MNA & NA & NA & $\begin{array}{l}\text { Low-level VOC plume } \\
\text { concentrations continued to } \\
\text { slowly decline during } 2007 \text {. } \\
\text { Tritium continued to be } \\
\text { detected in monitoring wells } \\
\text { just above detection limits. }\end{array}$ \\
\hline \multicolumn{7}{|l|}{ OU VI } \\
\hline $\begin{array}{l}\text { Ethylene } \\
\text { Dibromide } \\
\text { (EDB) }\end{array}$ & EDB & Operational & $\begin{array}{l}\text { P\&T with } \\
\text { carbon }\end{array}$ & $\begin{array}{l}\text { NA (due to } \\
\text { minimal EDB in } \\
\text { influent, no VOC } \\
\text { removal is } \\
\text { reported). }\end{array}$ & 3.5 of 10 & $\begin{array}{l}\text { The highest EDB } \\
\text { concentration in a monitoring } \\
\text { well in } 2007 \text { was } 2.3 \mu \mathrm{g} / \mathrm{L} \text {, } \\
\text { which continues a slow and } \\
\text { steadily decreasing trend. } \\
\text { Detections of EDB were } \\
\text { observed in the extraction } \\
\text { wells. }\end{array}$ \\
\hline $\begin{array}{l}\text { Notes: } \\
\text { AS = Air Stripping } \\
\text { AS/SVE = Air Spa } \\
\text { HWMF = Hazardo } \\
\text { IE = Ion Exchange } \\
\text { MNA = Monitored } \\
\text { NA = Not Applicab } \\
\text { NYS AWQS = Nev } \\
\text { P\&T = Pump and } \\
\text { RA = Removal Act } \\
\text { STP = Sewage Tr }\end{array}$ & $\begin{array}{l}\text { ing/Soil } \\
\text { Waste } \\
\text { atural Att } \\
\text { York Stat } \\
\text { eat } \\
\text { in } \\
\text { tment Pla }\end{array}$ & $\begin{array}{l}\text { or Extraction } \\
\text { agement Faci } \\
\text { Iation } \\
\text { mbient Water }\end{array}$ & uality Standard & & & \\
\hline * Off site remova & ritium n & nducted d & ow-flow pul & the & 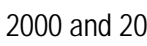 & \\
\hline
\end{tabular}




\section{$1.0 \quad$ INTRODUCTION AND OBJECTIVES}

The mission of Brookhaven National Laboratory's Groundwater Protection Program is to protect and restore the aquifer system at BNL. The program is summarized in the BNL Groundwater Protection Management Program Description (Paquette et al. 2002). The program is built on four key elements:

- Pollution prevention-preventing the potential pollution of groundwater at the source

- Restoration-restoring groundwater that BNL operations have impacted

- Monitoring-monitoring the effectiveness of pollution-prevention efforts, as well as progress in restoring the quality of affected groundwater

- Communication-communicating the findings and results of the program to regulators and stakeholders

The BNL 2007 Groundwater Status Report is a comprehensive summary of groundwater data collected in calendar year 2007 that provides an interpretation of information on the performance of the Groundwater Protection Program. This is the twelfth annual groundwater status report issued by the Laboratory. This document is unique in that it examines performance of the program on a projectby-project (facility-by-facility) basis, as well as comprehensively in a "watershed-like" analysis.

How To Use This Document. This document is a detailed technical report that includes analytical laboratory data, as well as data interpretations conducted by BNL's Long Term Response Actions (LTRA) Group. This technical document is intended for internal users, regulators, and other technically oriented stakeholders. This document can also be obtained through BNL's website. Data are presented in four key subject areas:

- Improvements to the understanding of the hydrogeologic environment and surrounding areas

- Identification of any new impacts to groundwater quality due to BNL's active operations

- Progress in cleaning contaminated groundwater

- Proposed changes to the groundwater protection program

This document satisfies BNL's requirement to report groundwater data under the Interagency Agreement and partially fulfills the commitment of the Groundwater Protection Program to communicate the program's findings and progress to regulators and stakeholders.

Section 1 discusses the drivers of the data collection work in 2007, the site's groundwater classification, and the objectives of groundwater monitoring. Section 2 discusses improvements to our understanding of the hydrogeologic environment at BNL and its surrounding area. It also summarizes the dynamics of the groundwater flow system in 2007. In Section 3, the groundwater cleanup data and progress towards achieving the site's cleanup goal are described. Section 4 outlines the groundwater surveillance data used to verify that operational and engineered controls are preventing further contamination from BNL's active experimental and support facilities. Section $\mathbf{5}$ is a summary of the proposed recommendations to the Groundwater Protection Program identified in Sections 3 and 4.

Appendices A and B include hydrogeologic data that support the discussions in Section 2 . Appendix C contains the analytical results for each sample obtained under the LTRA monitoring program. Appendix D contains analytical results for each sample obtained under the Environmental Surveillance program. Due to the volume of these data, all of the report appendices are included on a CD ROM, which significantly reduces the size of this report in printed format. The CD ROM has a contents table with active links; by selecting the specific project and analytical suite, the user will be 
directed to the associated table of results. The results also can be printed from the CD ROM. The groundwater results are arranged by specific monitoring project and analytical group: Volatile organic compounds (VOCs), semivolatile organic compounds (SVOCs), metals, general chemistry, pesticides/PCBs, and radionuclides. The data are organized further by well identification (ID) and the date of sample collection. Chemical/radionuclide concentrations, detection limits, and uncertainties are reported, along with a data verification, validation, and/or usability qualifier (if assigned), and/or a laboratory data qualifier. If a data verification/validation qualifier was not assigned, the laboratory data qualifier is shown. Results exceeding the corresponding groundwater standard or guidance criteria (see Section 1.1.2) are identified by bold text. Including the complete results enables the reader to analyze the data in detail. Appendix E contains information on sample collection, analysis, and Quality Assurance/Quality Control. Appendix F consists of data supporting the remediation system discussions in Section 3, and Appendix G is a compilation of data usability report forms. Appendix H contains the 2007 Environmental Monitoring Report for the Current and Former Landfill areas.

\subsection{Groundwater Monitoring Program \\ 1.1.1 Regulatory Drivers}

Activities at BNL are driven by federal and state regulations as well as DOE orders.

Comprehensive Environmental Response, Compensation and Liability Act

On December 21, 1989, BNL was included as a Superfund Site on the National Priorities List of contaminated sites identified for priority cleanup. DOE, EPA, and NYSDEC created a comprehensive Federal Facilities Agreement that integrated DOE's response obligations under CERCLA, RCRA (the Resource Conservation and Recovery Act), and New York State hazardous waste regulations. The interagency agreement that was finalized and signed by these parties in May 1992 includes a requirement for groundwater monitoring (USEPA 1992).

\section{New York State Regulations, Permits, and Licenses}

The monitoring programs for the Current Landfill and Former Landfill are designed in accordance with post-closure Operation and Maintenance requirements specified in 6 NYCRR (New York Code of Rules and Regulations) Part 360, Solid Waste Management Facilities.

BNL's Major Petroleum Facility (MPF) is operated under NYSDEC Bulk Petroleum Storage License No. 01-1700. This license requires BNL to routinely monitor the groundwater. Together with approved engineering controls, the groundwater-monitoring program verifies that storage operations for bulk fuel have not degraded the quality of the groundwater. The engineering controls and monitoring program for the MPF are described in the BNL Spill Prevention, Control and Countermeasures Plan (BNL 2001a).

BNL's Waste Management Facility (WMF) is a hazardous waste storage facility operated under NYSDEC Permit No. 1-422-00032/00102-0. The permit requires groundwater monitoring as a secondary means of verifying the effectiveness of the facility's administrative and engineered controls.

\section{DOE Orders}

DOE Order 450.1, Section 5-D-14, Responsibilities, states that DOE facilities are required to "Conduct environmental monitoring, as appropriate, to support the site's ISMS [Integrated Safety Management System], to detect, characterize, and respond to releases from DOE activities; assess impacts; estimate dispersal patterns in the environment; characterize the pathways of exposure to members of the public; characterize the exposures and doses to individuals, to the population; and to evaluate the potential impacts to the biota in the vicinity of the DOE activity" (DOE 2003). 


\subsubsection{Groundwater Quality and Classification}

In Suffolk County, drinking water supplies are obtained exclusively from groundwater aquifers (e.g., the Upper Glacial aquifer, the Magothy aquifer, and, to a limited extent, the Lloyd aquifer). EPA designated the Long Island aquifer system as a sole source aquifer in 1978, pursuant to Section 1424(e) of the Safe Drinking Water Act (SDWA). Groundwater in the sole source aquifers underlying the BNL site is classified as "Class GA Fresh Groundwater" by the State of New York (6 NYCRR Parts 700-705); the best usage of Class GA groundwater is as a source of potable water. Accordingly, in establishing the goals for protecting and remediating groundwater, BNL followed federal Drinking Water Standards (DWS), NYS DWS, and NYS Ambient Water Quality Standards (AWQS) for Class GA groundwater.

For drinking water supplies, the applicable federal maximum concentration levels (MCLs) are set forth in 40 CFR (Code of Federal Regulations) 141 (for primary MCLs) and 40 CFR 143 (for secondary MCLs). In New York State, the SDWA requirements relating to the distribution and monitoring of public water supplies are promulgated under the NYS Sanitary Code (10 NYCRR Part 5), enforced by SCDHS as an agent for the New York State Department of Health (NYSDOH). These regulations apply to any water supply that has at least five service connections or that regularly serves at least 25 individuals. BNL supplies water to approximately 3,500 employees and visitors and therefore must comply with these regulations. In addition, DOE Order 5400.5, Radiation Protection of the Public and Environment (DOE 1993), establishes Derived Concentration Guides (DCGs) for radionuclides not covered by existing federal or state regulations.

BNL evaluates the potential impact of radiological and nonradiological levels of contamination by comparing analytical results to NYS and DOE reference levels. Nonradiological data from groundwater samples collected from surveillance wells usually are compared to NYS AWQS (6 NYCRR Part 703.5). Radiological data are compared to the NYS AWQS for tritium, Sr-90, and gross beta; the NYS AWQS for gross alpha, radium-226, and radium-228; and the 40 CFR 141/DOE DCGs for determining the $4 \mathrm{mrem} / \mathrm{yr}$ dose for other beta- or gamma-emitting radionuclides.

Tables 1-1, 1-2, 1-3, and 1-4 show the regulatory and DOE "standards, criteria, and guidance" used for comparisons to BNL's groundwater data.

\subsubsection{Monitoring Objectives}

Groundwater monitoring is driven by regulatory requirements, DOE Orders, best management practice, and BNL's commitment to environmental stewardship. The Laboratory monitors its groundwater resources for the following reasons:

\section{Groundwater Resource Management}

- To support initiatives in protecting, managing, and remediating groundwater by refining the conceptual hydrogeologic model of the site and maintaining a current assessment of the dynamic patterns of groundwater flow and water table fluctuations.

- To determine the natural background concentrations for comparative purposes. The site's background wells provide information on the chemical composition of groundwater that has not been affected by BNL's activities. These data are a valuable reference for comparison with the data on groundwater quality from affected areas. The network of wells also can warn of any contaminants originating from potential sources that may be located upgradient of the BNL site.

- To ensure that potable water supplies meet all regulatory requirements.

\section{Groundwater Surveillance}

- To verify that operational and engineered controls effectively prevent groundwater contamination.

- To trigger early action and communication, should the unexpected happen (e.g., control failure). 
- To determine the efficacy of the operational and engineered control measures designed to protect the groundwater.

- To demonstrate compliance with applicable requirements for protecting and remediating groundwater.

\section{Groundwater Restoration}

- To track a dynamic groundwater cleanup problem when designing, constructing, and operating treatment systems.

- To measure the performance of the groundwater remediation efforts in achieving cleanup goals.

- To protect public health and the environment during the cleanup period.

- To define the extent and degree of groundwater contamination.

- To provide early warning of the arrival of a leading edge of a plume, thereby triggering contingency remedies to protect public health and the environment.

The details of the monitoring are described in the BNL Environmental Monitoring Plan (BNL 2007a). This plan includes a description of the source area, description of groundwater quality, criteria for selecting locations for groundwater monitoring, and the frequency of sampling and analysis. Figure 1-1 highlights BNL's OU locations designated as part of the CERCLA program, and key site features. Details on the sampling parameters, frequency, and analysis by well are listed in Tables 1-5 and 1-6. Screen zone, total depth, and ground surface elevations have been summarized for all monitoring wells in Table 1-7. Figure 1-2 shows the locations of wells monitored as part of the Laboratory's groundwater protection program. Detailed groundwater monitoring rationale can be found in BNL's Environmental Monitoring Plan. BNLs LTRA groundwater monitoring has been streamlined into five general phases of monitoring (Table 1-8):

\section{$\underline{\text { Start-up }}$}

A quarterly sampling frequency is implemented on all wells for a period of two years. This increased sampling frequency provides sufficient data while the system operation is in its early stages.

\section{Operations and Maintenance (O\&M)}

This is a period of reduced monitoring during the time when the system is in a routine operational state and varies for each system. This phase is also utilized for several plume monitoring programs not requiring active remediation.

\section{Shutdown Monitoring}

This is a two year period of monitoring implemented just prior to petitioning for system shut down. The increased sampling frequency provides the necessary data to support the shutdown petition.

\section{Standby Monitoring}

This is a period of reduced monitoring over a five year duration to identify any rebounding of contaminant concentrations. If concentrations remain below MCLs the petition for closure and decommissioning of the system is recommend.

\section{Post Closure Monitoring}

This is a monitoring period of varying length for $20 \%$ of the key wells in a given project following system closure and continues until the ROD goal of meeting MCLs in the Upper Glacial aquifer by 2030 is reached. This phase is considerably longer for the Magothy and Sr-90 cleanups due to greater length of the time to reach MCLs required for those projects. 
Since 2001, BNL has been using a structured Data Quality Objective (DQO) process to review and refine the groundwater monitoring and remediation projects. The results of the DQO reviews are documented annually in updates to the BNL Environmental Monitoring Plan.

Table 1-8. LTRA Groundwater Monitoring Program - Well Sampling Frequency.

\begin{tabular}{|c|c|c|c|}
\hline Project Activity Phase & Well Type & Phase Duration (yrs.) & Sampling Freq. (events/yr.) ${ }^{\star * \star *}$ \\
\hline \multirow[t]{3}{*}{ Start-up Monitoring } & Plume Core & 2 & $4 x$ \\
\hline & Plume Perimeter & 2 & $4 x$ \\
\hline & Sentinel/Bypass & 2 & $4 x$ \\
\hline \multicolumn{4}{|l|}{ Operations \& Maintenance } \\
\hline \multirow[t]{3}{*}{ (O\&M) Monitoring } & Plume Core & End Start-up to Shutdown* & $2 x$ \\
\hline & Plume Perimeter & End Start-up to Shutdown* & $2 x$ \\
\hline & Sentinel/Bypass & End Start-up to Shutdown* & $4 x$ \\
\hline \multirow[t]{3}{*}{ Shutdown Monitoring } & Plume Core & 2 & $4 x$ \\
\hline & Plume Perimeter & 2 & $4 x$ \\
\hline & Sentinel/Bypass & 2 & $4 x$ \\
\hline \multirow[t]{3}{*}{ System Standby Monitoring } & Key Plume Core & 5 & $2 x$ \\
\hline & Plume Perimeter & 5 & $1 x$ \\
\hline & Sentinel/Bypass & 5 & $2 x$ \\
\hline Post Closure Monitoring *** & $20 \%$ of key wells & To $2030^{* *}$ & $1 x$ \\
\hline
\end{tabular}

The groundwater monitoring well networks for each program are organized into background, core, perimeter, and bypass wells. The wells are designated as follows:

- Background -water quality results will be used to determine upgradient water quality

- Plume Core - utilized to monitor the high concentration or core area of the plume

- Perimeter - used to define the outer edge of the plume both horizontally and vertically

- Bypass Detection - used to determine whether plume capture performance is being met

- Sentinel - An early warning well to detect the leading edge of a plume. 


\subsection{Private Well Sampling}

During 2007, there were eight known homeowners in the residential area overlying the plume who continue to use their private wells for drinking water purposes. In accordance with the OU III and VI RODs, annually DOE formally offers those homeowners free testing of their private drinking water wells. SCDHS coordinates and performs the sampling and analysis. The response rate to the annual letters sent to the homeowners over the several years has been low. Between one to two homeowners accept DOEs offer for annual sampling. During 2007, of the eight homeowners who were offered the free testing, only one requested the sampling. The results from SCDHS indicate that there were no VOCs detected. 


\subsection{HYDROGEOLOGY}

This section briefly describes the improvements to our understanding of the hydrogeologic environment at BNL and the surrounding area. It also summarizes the dynamics of the groundwater flow system in 2007, along with on-site pumping rates and rainfall recharge.

Detailed descriptions, including the lithology and the geometry of the aquifer underlying BNL and its surrounding areas, are found in the U.S. Geologic Survey (USGS) report by Scorca and others (1999), Stratigraphy and Hydrologic Conditions at the Brookhaven National Laboratory and Vicinity, Suffolk County, New York, 1994-97, and the USGS report by Wallace deLaguna (1963), Geology of Brookhaven National Laboratory and Vicinity, Suffolk County New York. The stratigraphy below BNL consists of approximately 1,300 feet of unconsolidated deposits overlying bedrock (Figure 2-1). Among these unconsolidated deposits, the current groundwater monitoring program focuses on groundwater quality within the Upper Pleistocene deposits, and the upper portions of the Matawan Group-Magothy Formation.

Figure 2-1.

Generalized Geologic Cross Section in the Vicinity of Brookhaven National Laboratory.

(North)

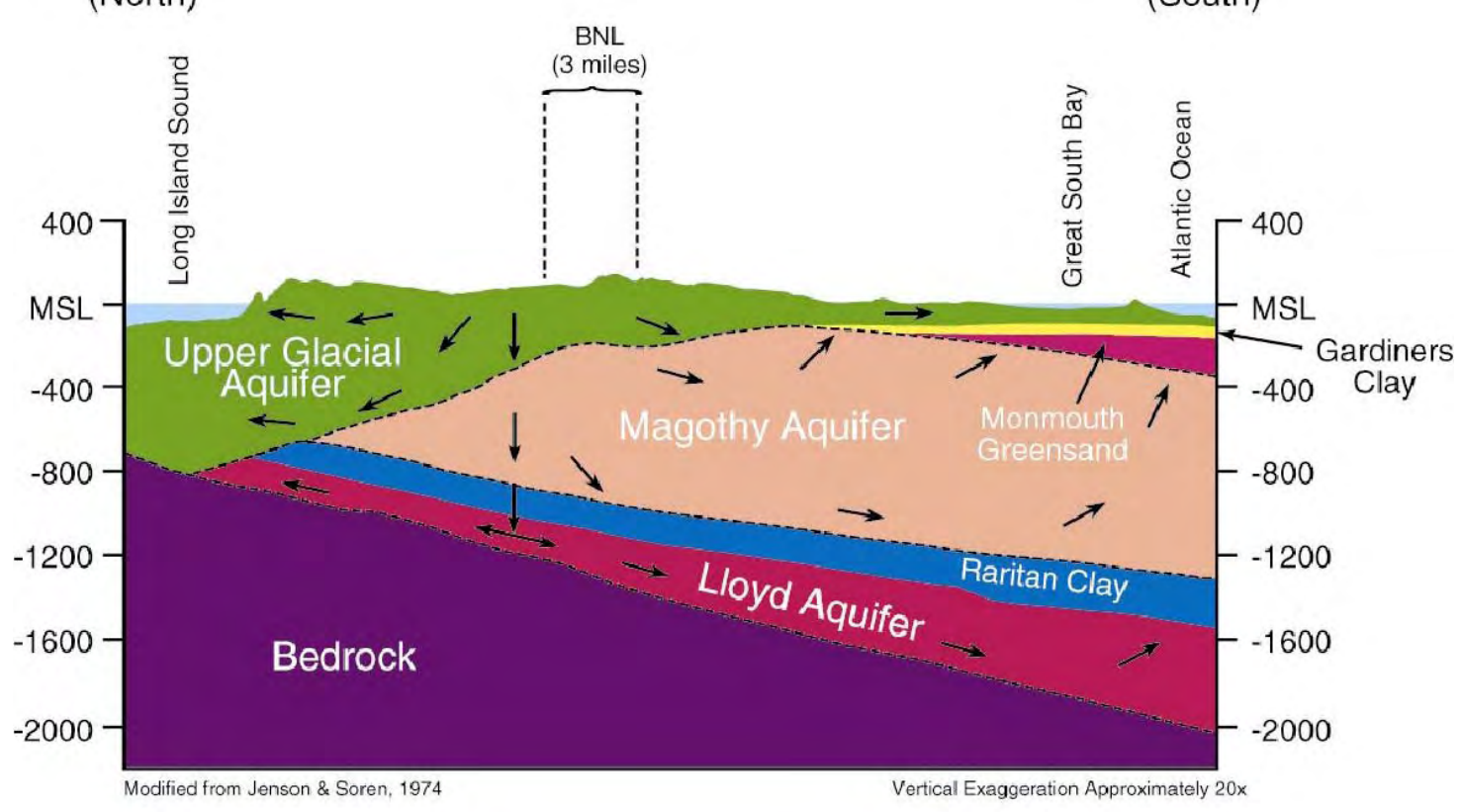

Explanation:

- Geologic Contact Dashed Were Inferred

MSL Mean Sea Level

$\longleftarrow$ Direction of Groundwater Flow
Schematic Not To Scale

The Pleistocene deposits are about 100-200 feet thick and are divided into two primary hydrogeologic units: undifferentiated sand and gravel outwash and moraine deposits, and the finer-grained, more poorly sorted stratigraphic Upton Unit. The Upton Unit makes up the lower portion of the Upper Glacial aquifer beneath several areas of the site. It generally consists of fine- to medium-white to greenish sand with interstitial clay. In addition to these two major hydrogeologic units, there are several other distinct hydrogeologic units within the Upper Glacial aquifer. They include localized, near-surface clay layers in the vicinity of the Peconic River (including the STP area), and reworked Magothy deposits that characterize the base of the aquifer in several areas. The Gardiners Clay is a regionally defined geologic unit that is discontinuous beneath BNL and areas to the south. Typically, it is characterized by variable amounts of green silty clay, sandy, and gravelly green clay, and clayey silt. Where it exists, the Gardiners 
Clay acts as a confining or semi-confining unit that impedes the vertical flow and migration of contaminants between the Upper Glacial aquifer and the underlying Magothy aquifer.

The Magothy aquifer is composed of the continental deltaic deposits of the Cretaceous Age that unconformably underlie the Pleistocene deposits. The Magothy aquifer at BNL is approximately 800 feet thick, and because it is composed of fine sand interbedded with silt and clay, it is generally less permeable than the Upper Glacial aquifer. The Magothy aquifer is highly stratified. Of particular importance at BNL is that the upper portion of the Magothy contains extensive, locally continuous layers of grey-brown clay (referred to herein as the Magothy Brown Clay). Regionally, the Magothy Brown Clay is not interpreted as being continuous; however, beneath BNL and adjacent off-site areas, it acts as a confining unit (where it exists), impeding the vertical groundwater flow and movement of contaminants between the Upper Glacial and Magothy aquifers.

Regional patterns of groundwater flow near BNL are influenced by natural and artificial factors. Figures 2-2 and 2-3 show the locations of pumping wells and recharge basins. Under natural conditions, recharge to the regional aquifer system is derived solely from precipitation. A regional groundwater divide exists immediately north of BNL near Route 25 . It is oriented roughly east-west, and appears to coincide with the centerline of a regional recharge area. Groundwater north of this divide flows northward, ultimately discharging to the Long Island Sound (Figure 2-1). Shallow groundwater in the BNL area generally flows to the south and east. During high water table conditions that groundwater can discharge into local surface water bodies such as the Peconic River and adjacent ponds. The BNL site is within a regional deep-water recharge area, where downward flow helps to replenish the deep sections of the Upper Glacial aquifer, the Magothy aquifer, and the Lloyd aquifer. South of BNL, groundwater flow becomes more horizontal and ultimately flows upward as it moves toward regional discharge areas such as Carmans River and Great South Bay. Superimposed on the natural regional field of groundwater flow are the artificial influences due to pumping and recharge operations.

\subsection{Hydrogeologic Data}

Various hydrogeologic data collection and summary activities were undertaken as part of the 2007 Groundwater Protection Program to evaluate groundwater flow patterns and conditions. This work is described in the following sections and includes the results of groundwater elevation monitoring, information on pumping and recharging activities on and off site, and precipitation data.

\subsubsection{Groundwater Elevation Monitoring}

Synoptic water levels are obtained quarterly from a network of on-site and off-site wells screened at various depths within the Upper Glacial aquifer and upper portions of the Magothy aquifer. These data are used to characterize the groundwater flow-field (direction and rate) and to evaluate seasonal and artificial variations in its flow patterns. Additional water level data from off-site wells are obtained from the USGS.

The quarterly synoptic water level measurement events comprising the complete network of on-site and off-site wells were reduced to a semi-annual event starting in 2006. This reduction was based on the fact that the Laboratory has compiled nearly 15 years of quarterly water level data, all planned groundwater remediation systems have been operational for at least 3 years and there has been little change to largescale groundwater flow directions. The synoptic water level measurement rounds using the on-site and off-site monitoring well network were conducted from June 11 to 14, 2007 and December 3 to 6, 2007 with data collected from 771 and 774 wells, respectively. Reduced synoptic measurement efforts using wells located in the central part of the BNL site are also conducted semiannually. These data are important for monitoring any small scale changes to groundwater flow in the vicinity of known or potential contaminant source areas, and to collect data necessary for maintaining hydrographs for key wells. The BNL central area synoptic measurements were conducted on March 22, 2007 and September 24, 2007 with data collected from approximately 100 shallow glacial wells during these events. Water 
levels were measured with electronic water level indicators following the BNL Environmental Monitoring Standard Operating Procedure (EM-SOP-300). Appendix A has the depth-to-water (DTW) measurements and the calculated groundwater elevations for these measurements. Monitoring results for long-term and short-term hydrographs for select wells are discussed in Section 2.2.

\subsubsection{Pumpage of On-Site Water Supply and Remediation Wells}

BNL operates six water supply wells to provide potable and process cooling water and 61 treatment wells. All six water supply wells are screened entirely within the Upper Glacial aquifer. Fourteen of the 61 treatment wells are in standby mode. Figures 2-2 and 2-3 show the locations of the water supply and remediation wells. The effects the groundwater withdrawals have on the aquifer system are discussed in Section 2.2.

Table 2-1 provides the monthly and total water usage for 2007 for the six on-site potable supply wells $(4,6,7,10,11$, and 12). It includes information on each well's screened interval and pumping capacity. These wells primarily withdraw groundwater from the middle section of the Upper Glacial aquifer. The variation in monthly pumpage primarily reflects changes in water demand, and maintenance schedules for the water supply system. The western potable well field includes wells 4, 6, and 7; the eastern field contains wells 10,11 , and 12 . The water supply operating protocols, which have been established by the BNL Water and Sanitary Planning Committee, currently require that the western well field be used as the primary source of water, with a goal of obtaining 75 percent or more of the sitewide water supply from that well field. Using the western well field minimizes the groundwater flow direction effects of supply well pumping on several segments of the groundwater contaminant plumes located in the center of the BNL site. Figure 2-4 below summarizes monthly pumpage for the eastern and western well fields.

Figure 2-4.

Summary of BNL Supply Well Pumpage 1992 through 2007.

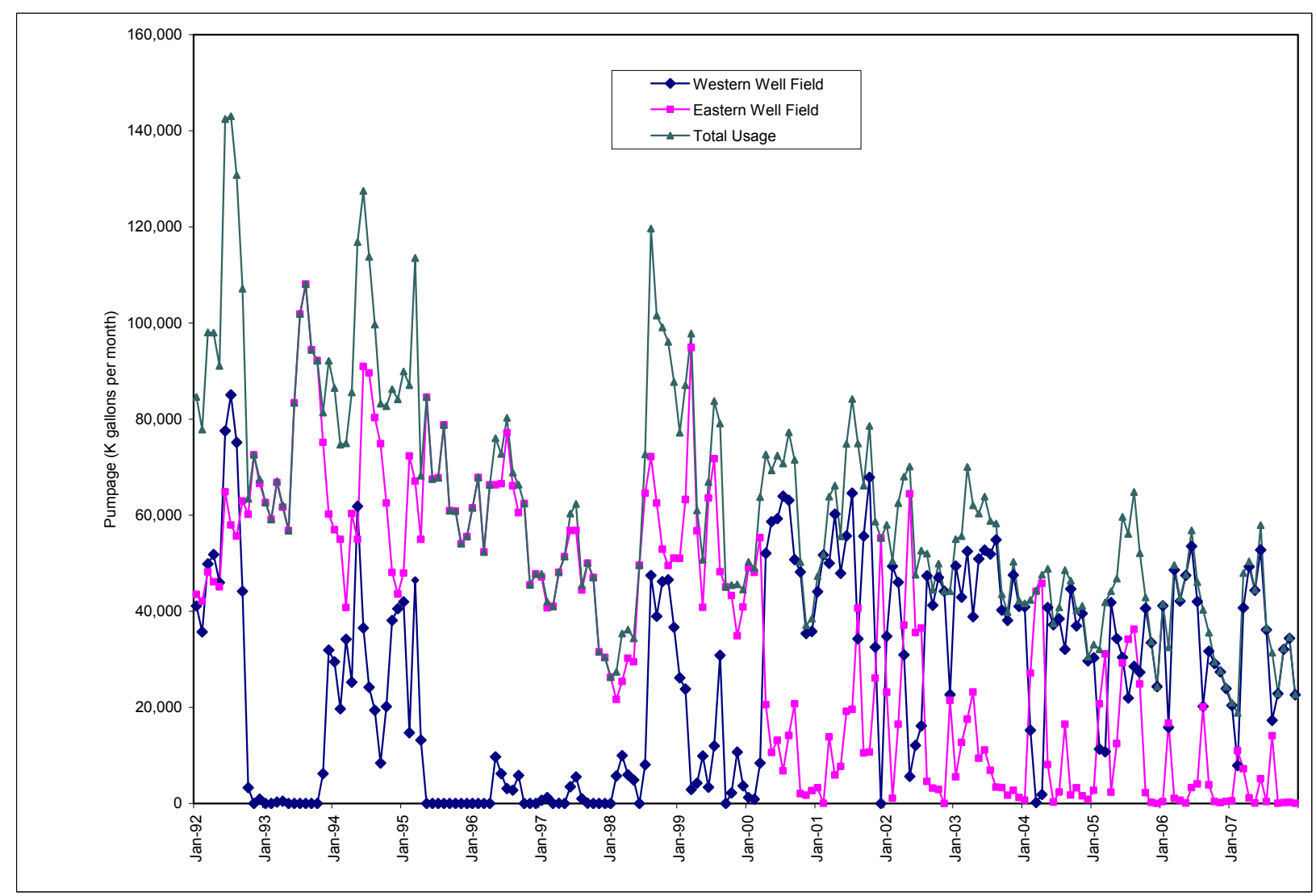


Since 1999, the implementation of effective water conservation measures has resulted in a significant reduction in the amount of water pumped from the aquifer. During 2007, a total of 421 million gallons of water were withdrawn from the aquifer, and the Laboratory met its goal of obtaining more than 75 percent of its total water supply from the western well field. The western well field provided approximately 90 percent of the water supply, with most of the pumpage obtained from wells 6 and 7. Supply well 10 has been maintained in standby mode since 2000 due to the impacts it might have on contaminant plume flow directions in the central portion of the site (especially on the g-2 tritium plume and the Waste Concentration Facility Sr-90 plume). Table 2-2 summarizes the 2007 BNL process water usage. Table 23 summarizes the 2007 monthly water pumpage for the groundwater remediation systems. Additional details on groundwater remediation system pumping are provided in Section $\mathbf{3}$ of this report.

\subsubsection{Off-Site Water Supply Wells}

Several SCWA well fields are located near BNL. The two closest SCWA well fields are the William Floyd (Parr Village) Well Field and the Country Club Drive Well Field (see Figures 2-2 and 2-3 for locations of the SCWA well fields). Other SCWA well fields (e.g., Lambert Avenue) are sited south of Sunrise Highway.

The William Floyd Well Field is west/southwest of BNL (Figures 2-2 and 2-3), and consists of three water supply wells that withdraw groundwater from the mid Upper Glacial aquifer and the upper portion of the Magothy aquifer. Country Club Drive Well Field is south/southeast of BNL, and consists of three water supply wells that withdraw groundwater from the mid section of the Upper Glacial aquifer. Pumpage information for 1989 through 2007 is provided as Figure 2-5. In 2007, the William Floyd (Parr Village) and Country Club Drive Well Fields produced 469 and 471 million gallons for the year, respectively. Lambert Avenue produced 510 million gallons for the year.

\subsubsection{Summary of On-Site Recharge and Precipitation Data}

This section summarizes artificial (i.e., on-site recharge basins) and natural recharge from precipitation. Table 2-4 summarizes the monthly and total flow of water through 10 on-site recharge basins during 2007. Their locations are shown on Figures 2-2 and 2-3. Section 2.2 (Groundwater Flow) provides a discussion on the effects associated with recharge. Seven of the basins (HN, HO, HS, HT-W, HT-E, HX, and HZ) receive stormwater runoff and cooling water discharges. Flow into these basins is monitored monthly per the SPDES permit requirements. Generally, the amount of water recharging to the groundwater system to these basins reflects supply well pumpage. Annual water supply flow diagrams show the general relationships between recharge basins and the supply wells, and are published in Volume I of the annual Site Environmental Report.

The remaining three basins (Removal Action V [RA V], OU III, and Western South Boundary) were constructed to recharge water processed through several of the groundwater remediation systems. Until September 2001, treated groundwater from the OU III South Boundary Pump and Treat System was discharged solely to the OU III basin, adjacent to former recharge basin HP along Princeton Avenue. After September 2001, groundwater from that system and the OU III Middle Road Pump and Treat System was discharged equally to the OU III and RA V basins. Treated groundwater from the OU I South Boundary is discharged to the RA V basin. Table 2-4 gives estimates of flow to these basins. The discharge to these basins for 2007 (14 and 9 million gallons per month, average, for the OU III and RA V basins, respectively) is significantly greater than that from other individual on-site basins. Pulse pumping and the placement of several groundwater remediation extraction wells on standby resulted in an overall decrease of discharge totals.

Other important sources of artificial recharge, not included in Table 2-4, include a stormwater retention basin referred to as HW (on Weaver Drive), and the sand filter beds at the STP. Basin HW causes localized mounding of the water table. At the sand filter beds, approximately 10 to 15 percent of the treated effluent (approximately 15 million gallons annually) seeps directly to the underlying water table via leaks in the underlying tile-drain collection system. The remaining treated effluent (approximately 130 million gallons annually) is discharged to the Peconic River. Most of the water released to the Peconic 
River recharges to the aquifer before it reaches the BNL site boundary, except during times of seasonally high water levels.

Figure 2-5.

Suffolk County Water Authority Pumping Near BNL.
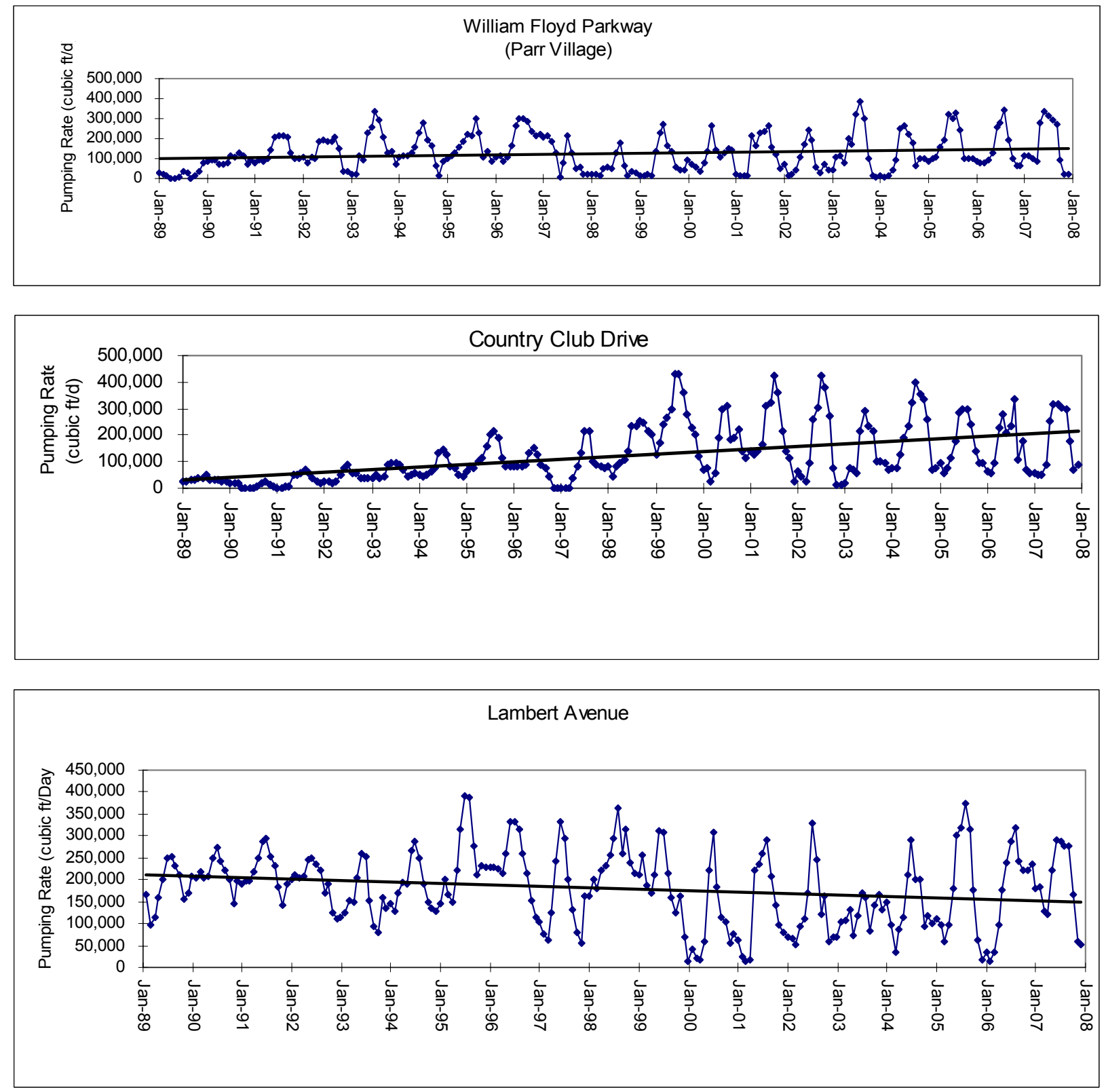

Precipitation provides the primary recharge of water to the aquifer system at BNL. In an average year, approximately 24 inches of rainfall recharges the Upper Glacial aquifer. Under long-term conditions in undeveloped areas of Long Island, about 50 percent of precipitation is lost through evapotranspiration and direct runoff to streams; the other 50 percent infiltrates the soil and recharges the groundwater system (Aronson and Seaburn 1974; Franke and McClymonds 1972). In 2007, it is estimated that the recharge at BNL was approximately 23 inches. Table 2-5 summarizes monthly and annual precipitation results from 
1949 to 2007 collected on site by BNL Meteorology Services. Variations in the water table generally can be correlated with seasonal precipitation patterns. As depicted in Table 2-5, total annual precipitation in 2007 was 45.3 inches, and is below the yearly average of 48.72 inches. Seven of the past 10 years have featured above-normal annual average precipitation at BNL.

\subsection{Groundwater Flow}

BNL routinely monitors horizontal and vertical groundwater flow directions and magnitudes within the Upper Glacial aquifer and uppermost Magothy aquifer by using water level data collected from a large network of on-site and off-site monitoring wells. Short-term and long-term seasonal fluctuations of water levels are also evaluated using hydrographs for select wells, and trends in precipitation.

\subsubsection{Water Table Contour Maps}

Figure 2-2 is a groundwater elevation contour map representing the configuration of the water table for December 2007. The contours were generated from the water level data from shallow Upper Glacial aquifer wells, assisted by a contouring package (Quick SURF). Localized hydrogeologic influences on groundwater flow were considered, including on-site and off-site pumping wells, and on-site recharge basins (summarized in Section 2.1).

Groundwater flow in the shallow Upper Glacial aquifer is generally characterized by a southeasterly component of flow in the northern portion of the site, with a gradual transition to a more southerly direction at the southern boundary and beyond. Flow directions in the eastern portion of BNL are predominately to the east and southeast (Figure 2-2). The general groundwater flow pattern for 2007 was consistent with historical flow patterns observed by SCDHS, USGS, and BNL. As described in Section 2.1.2, above, the water supply operating protocols established by BNL in late 2005 requires that the western well field be used as the primary source of water, with a goal of obtaining 75 percent or more of the water supply from these wells. This protocol resulted in a more stable south-southeast groundwater flow direction in the central portion of the site during all of 2006 and 2007.

Localized man-made disturbances to groundwater flow patterns are evident on the groundwater contour maps. They result primarily from active on-site and off-site well pumpage, and the discharge of water to on-site recharge basins. Influences from the pumping wells can be seen as cones of depressions, most notably near potable supply wells 4 and 7 and near the groundwater treatment wells along the southern boundary (Figure 2-2).

Influences from water recharge activities can be observed as localized mounding of the water table, particularly around recharge basin OU III and the RA V basin (in the center of the site), and the STP. The degree of mounding is generally consistent with the monthly flows to recharge basins summarized in Section 2.1. However, the extent of some of the mounding also reflects the ability of the underlying deposits to transmit water, which varies across the site. For example, the volume of recharged water at the STP sand filter beds typically is not as great as that at recharge basin OU III or the RA V basin. However, the presence of near-surface clay layers underlying portions of the STP sand filter beds results in an extensive groundwater mound.

Other noteworthy features are the influence that surface water bodies have on groundwater flow directions. Figure 2-2 shows groundwater flowing towards the Carmans River in areas south/southwest of BNL. This pattern is consistent with the fact that the Carmans River is a significant discharge boundary.

\subsubsection{Deep Glacial Contour Maps}

Figure 2-3 shows the potentiometric surface contour maps of the deep zone of the Upper Glacial aquifer for December 2007. The contours were generated in the same manner as the water table contours, but using water level data from wells screened only within the deep sections of the Upper Glacial aquifer.

The patterns for groundwater flow in the deep Upper Glacial for 2007 are similar to those in the shallow (or water table) zone. They are characterized by a southeasterly component in the northern portion of the site, with a gradual transition to a more southerly flow at the southern site boundary and beyond. In areas 
south/southwest of BNL, the deep glacial contour maps also indicate flow toward the Carmans River. The localized influences of pumping on the potentiometric surface configurations are evident as cones of depression. As with the water table configurations, variations in these localized hydrogeologic effects are attributed to the monthly variations in pumpage.

Although the localized influences of recharging on the potentiometric surface configurations are evident for the deep Upper Glacial aquifer, they are not as pronounced as those observed at the water table. Such hydrogeologic effects generally decrease with depth in the aquifer. Furthermore, mounding is not present beneath the STP sand filter beds because mounding is controlled by shallow, near-surface clay layers. Finally, the surface water/groundwater interactions that take place along the Peconic River in the vicinity of BNL do not influence the deep glacial zone.

\subsubsection{Well Hydrographs}

Groundwater hydrographs are useful in estimating recharge rates and the location of the water table relative to contaminant sources. Long-term (typically 1950-2007) and short-term (1997-2007) well hydrographs were constructed from water level data that were obtained for select USGS and BNL wells, respectively. These hydrographs track fluctuations in water level over time. Precipitation data also were compared to natural fluctuations in water levels. Appendix B contains the well hydrographs, together with a map depicting the locations of these wells. In 2006, the USGS installed a real time continuous water level recorder in BNL well ID 093-03 (USGS Site Number 405149072532201 - S5517.1), located adjacent to the southeast corner of BNL's Brookhaven Center building. Data from this monitoring station can be accessed on the world wide web at:

http://groundwaterwatch.usgs.gov/AWLSites.asp?S=405149072532201\&ncd=rtn.

Six long-term hydrographs were constructed from historical water level data from wells installed and maintained by the USGS and BNL. These wells provide reasonable areal coverage for historical trends in areas both on site and surrounding BNL (just south of the southern boundary). The water level elevation data indicate water table fluctuations of 8 to 14 feet. The maximum observed variation of 14 feet reflects the regional drought that occurred in the 1960s. The minimum observed variation of 8 feet is more indicative of water level elevations fluctuations that have occurred since the late 1970s.

Quarterly data on water levels collected during 2007 were used to construct nine short-term hydrographs from three well clusters (well cluster 75-39/-40/-41, 105-05/-07/-24, and 122-01/-04/-05). Generally, the highest groundwater elevations can be observed during the March time period. Based on data from both long- and short-term hydrographs, water table elevations in the BNL vicinity in 2007 showed a steady decline through the year. This is in contrast to 2006 when water levels were the highest observed since 1997 and just below some of the highest recorded water elevations observed since record keeping began in the late 1940s (Table 2-5).

\subsection{New Geologic Data}

No new geologic data were collected during 2007. However, several temporary wells were drilled in early 2008 to augment the geologic information in the area of Building 96. Several more are planned for this area in mid 2008. 
SER VOLUME II: GROUNDWATER STATUS REPORT

This page intentionally left blank. 


\subsection{ENVIRONMENTAL RESTORATION GROUNDWATER MONITORING AND REMEDIATION}

Chapter 3 gives an overview of groundwater monitoring and remediation efforts at BNL during calendar year 2007. The chapter is organized first by Operable Unit, and then by the specific groundwater remediation system and/or monitoring program. Figure 1-2 shows the locations of monitoring wells throughout the site and by project. Monitoring well location maps specific to particular monitoring programs are included throughout Chapter 3.

\section{Report and Data on CD}

Appendices $\mathrm{C}$ and $\mathrm{D}$ contain the analytical results for each sample. Due to the large volume of data, these appendices are included on a CD ROM; this significantly reduces the size of the hardcopy of this report. The CD ROM has a table of contents with active links, such that, by selecting the specific project and analytical suite, the user will be directed to the associated table of results. Users can print a hardcopy of the results from the CD ROM. The groundwater results are arranged by specific monitoring project and then by analytical group (VOCs, SVOCs, metals, chemistry, pesticides/PCBs, and radionuclides). The data are organized further by well ID and the date of collection of the sample. Chemical/radionuclide concentrations, detection limits, and uncertainties are reported, along with a data verification, validation, and/or usability qualifier (if assigned), and/or a laboratory data qualifier. If a data verification/validation qualifier was not assigned, the laboratory data qualifier is presented. Results that exceed the corresponding groundwater standard or guidance criteria (see Section 1.1.1 [Regulatory Drivers]) are in bold text. Inclusion of the complete results allows the reader to analyze them in detail. In addition, this entire report is included on the CD-ROM with active links to tables and figures.

\section{About the Plume Maps}

Maps are provided that depict the areal extent and magnitude of the contaminant plumes. In most cases, the volatile organic compound (VOC) plumes were simplified by using the total VOC (TVOC) values for drawing the contours, except for those plumes that consist almost exclusively of one chemical, such as the OU III Carbon Tetrachloride plume and the OU VI Ethylene Dibromide (EDB) plume. TVOC concentrations are a summation of all the individual VOCs analyzed by EPA Method 524.2.

The extent of plumes containing VOC contamination was contoured to represent concentrations that were greater than the typical NYS AWQS of 5 micrograms per liter $(\mu \mathrm{g} / \mathrm{L})$ for most compounds. Radionuclide plumes were contoured to their appropriate drinking water standard (DWS). Figure 3.0-1 shows the VOC and radionuclide plumes as well as the locations and groundwater capture zones for each of the treatment systems.

Following the capping of the landfill areas and the beginning of active groundwater remediation systems in 1997, there have been significant changes in the size and concentrations of several of the VOC plumes. These changes can be attributed to the following:

- The beneficial effects of active remediation systems

- Source control and removal actions

- The impacts of BNL pumping and recharge on the groundwater flow system

- Radioactive decay, biological degradation, and natural attenuation 
Additionally, BNL's ability to accurately depict these plumes has been enhanced over the years by the:

- addition of permanent monitoring wells to the existing well networks

- installation of temporary wells during groundwater characterization efforts that helped to fill in data gaps

During 2007, the contaminant plumes were tracked by collecting 2,049 groundwater samples obtained from 725 on-site and off-site monitoring wells. Figure 3.0-2 below provides a summary of the number of analyses performed, arranged by analytical method. Unless otherwise noted, the extent of contamination for a given plume is depicted by primarily using 2007 data from permanent monitoring wells. In several cases, data from the first three months of 2008 were utilized. Contaminant plumes associated with HFBR Tritium, BGRR/WCF Sr-90, and Bldg. 96 projects were further defined in 2007 using temporary wells (i.e., direct push Geoprobes or vertical profiles).

A single representative round of monitoring data was chosen for each plume, typically from the last quarter of the year because it includes the most comprehensive sampling round for the year. This report also serves as the fourth quarter report for the remediation systems. Contaminant concentration trend plots for key monitoring wells in each plume are provided to identify significant changes. Data from monitoring wells sampled under BNL's Environmental Surveillance Monitoring Program are also evaluated in Section 4.0.

Figure 3.0-2.

Summary of Laboratory Analyses Performed for the Environmental Management Program in 2007.

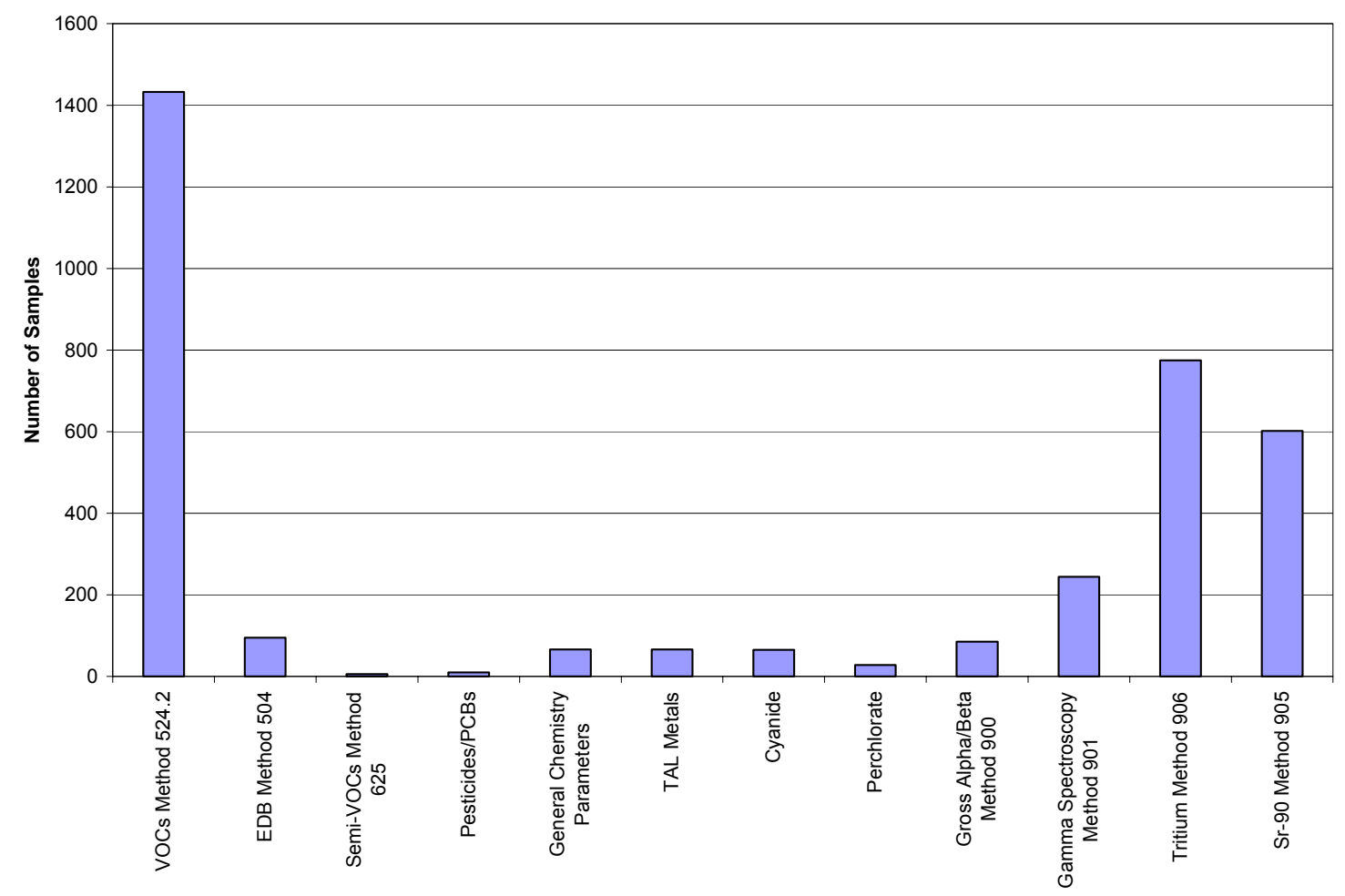




\section{History and Status of Groundwater Remediation at BNL}

Groundwater remediation systems have operated at BNL since 1997, beginning with the OU I South Boundary Pump and Treat System. The goal of groundwater remediation, as defined by the OU III Record of Decision, is, within 30 years or less (by 2030), to prevent or minimize plume growth and not to exceed MCLs in the Upper Glacial aquifer. Based on additional information obtained during the Strontium-90 Pilot Study, the OU III Explanation of Significant Differences (BNL 2005a) identified changes to the cleanup goal timeframes for the Sr-90 plumes. For the BGRR/WCF and Chemical Holes Sr-90 plumes, MCLs must be reached within 70 years (by 2070) and 40 years (by 2040), respectively. In addition, cleanup of the Magothy aquifer VOC contamination must meet MCLs within 65 years (by 2065).

There are currently 14 groundwater remediation systems in operation. The last treatment system, for the on-site BGRR/WCF Sr-90 plume, began operations in 2005. One system remains in standby mode (the Carbon Tetrachloride Pump and Treat System). Another system has met its cleanup goals and has been decommissioned: the OU IV, Area of Concern (AOC) 5, Air Sparge/Soil Vapor Extraction System [OU IV AS/SVE]. Figure 3.0-1 shows the locations and groundwater capture zones for each of the treatment systems. In addition to the groundwater treatment systems, two landfill areas (Current and Former) were capped, which minimizes the potential for groundwater contamination.

BNL's Plant Engineering personnel perform routine maintenance checks on the treatment systems daily, in addition to their routine and non-routine maintenance. BNL's Environmental and Waste Management Services Division (EWMSD) collects the treatment system performance samples (influent, midpoint, effluent). Full details of the maintenance checks are recorded in the system's operation and maintenance daily inspection logs. The daily logs are available at the treatment facility, or in the project files.

In general, BNL uses two types of groundwater remediation systems to treat VOC contamination: pump and treat with air stripping or carbon treatment, or recirculation wells with air stripping or carbon treatment. Pump and treat remediation consists of pumping groundwater from the plume up to the surface and piping it to a treatment system, where the contaminants are removed by either air stripping or granular activated carbon. Treated water is then introduced back into the aquifer via recharge basins, injection wells, or dry wells.

Table 3.0-1 summarizes the operating remediation systems. Groundwater remediation at BNL is proceeding as predicted. 
Table 3.0-1. 2007 Summary of Groundwater Remediation Systems at BNL.

\begin{tabular}{|c|c|c|c|c|c|c|}
\hline $\begin{array}{l}\text { Operable Unit } \\
\text { System }\end{array}$ & Type & $\begin{array}{c}\text { Target } \\
\text { Contaminant }\end{array}$ & $\begin{array}{l}\text { No. of } \\
\text { Wells }\end{array}$ & $\begin{array}{l}\text { Years in } \\
\text { Operation }\end{array}$ & $\begin{array}{l}\text { Recharge } \\
\text { Method }\end{array}$ & $\begin{array}{c}\text { Pounds VOCs } \\
\text { Removed } \\
\text { (Year/Cum) }\end{array}$ \\
\hline \multicolumn{7}{|l|}{ Operable Unit I } \\
\hline $\begin{array}{l}\text { South } \\
\text { Boundary }\end{array}$ & P\&T, AS & VOC & 2 & 10 & Basin & $6 / 337$ \\
\hline \multicolumn{7}{|c|}{ Operable Unit III } \\
\hline $\begin{array}{l}\text { South } \\
\text { Boundary }\end{array}$ & P\&T, (AS) & VOC & 7 & 10 & Basin & $32 / 2569$ \\
\hline $\begin{array}{l}\text { HFBR Pump } \\
\text { and Recharge }\end{array}$ & $\begin{array}{l}\text { Pump and } \\
\text { Recirculate }\end{array}$ & Tritium & 4 & $\begin{array}{l}\text { Operate: } 3.5 \\
\text { Standby: } 6.5\end{array}$ & Basin & $0 / 180$ \\
\hline Industrial Park & $\begin{array}{l}\text { Recirculation/ } \\
\text { In-Well } \\
\text { (AS/Carbon) }\end{array}$ & VOC & 7 & 8 & $\begin{array}{c}\text { Recirculation } \\
\text { Well }\end{array}$ & $43 / 1010$ \\
\hline${ }^{*}$ Carbon Tet & P\&T (Carbon) & VOC & 3 & $\begin{array}{l}\text { Operate: } 5 \\
\text { Standby: } 3\end{array}$ & Basin & $N A / 349$ \\
\hline Building 96 & $\begin{array}{l}\text { Recirculation Well } \\
\text { (AS/Carbon) }\end{array}$ & VOC & 4 & $\begin{array}{l}\text { Operate: } 4 \\
\text { Standby: } 3\end{array}$ & $\begin{array}{l}\text { Recirculation } \\
\text { Well }\end{array}$ & $<1 / 71$ \\
\hline Middle Road & P\&T (AS) & VOC & 6 & 6 & Basin & $34 / 741$ \\
\hline $\begin{array}{l}\text { Western South } \\
\text { Boundary }\end{array}$ & P\&T (AS) & VOC & 2 & 5 & Basin & $4 / 49$ \\
\hline $\begin{array}{l}\text { Chemical } \\
\text { Holes }\end{array}$ & P\&T (IE) & Sr-90 & 3 & 5 & Dry Well & $0.27^{\star \star / 2.60}$ \\
\hline North Street & P\&T (Carbon) & VOC & 2 & 3.5 & Wells & $36 / 268$ \\
\hline $\begin{array}{l}\text { North Street } \\
\text { East }\end{array}$ & P\&T (Carbon) & VOC & 2 & 3.5 & Wells & $4 / 19$ \\
\hline LIPA/Airport & $\begin{array}{l}\text { P\&T and Recirc. } \\
\text { Wells (Carbon) }\end{array}$ & VOC & 10 & 3.5 & $\begin{array}{c}\text { Wells and } \\
\text { Recirculation } \\
\text { Well }\end{array}$ & $35 / 237$ \\
\hline $\begin{array}{l}\text { Industrial Park } \\
\text { East }\end{array}$ & P\&T (Carbon) & VOC & 2 & 3.5 & Wells & $4 / 32$ \\
\hline BGRR/WCF & P\&T (IE) & Sr-90 & 5 & 2.5 & Dry Wells & $4.9 * \star / 14.2$ \\
\hline \multicolumn{7}{|c|}{ Operable Unit VI } \\
\hline EDB & P\&T (Carbon) & EDB & 2 & 3.5 & Wells & $N A^{\star \star \star}$ \\
\hline $\begin{array}{l}\text { Notes: } \\
\text { AS = Air Stripping } \\
\text { AS/SVE = Air Sparg } \\
\text { EDB = ethylene dibr } \\
\text { IE = Ion Exchange } \\
\text { LIPA = Long Island } \\
\text { P\&T = Pump and Tr } \\
\text { Recirculation = Douk } \\
\text { In-Well = The air stri }\end{array}$ & $\begin{array}{l}\text { /Soil Vapor Extraction } \\
\text { hide } \\
\text { wer Authority } \\
\text { screened well with disc } \\
\text { er in these wells is loca }\end{array}$ & $\begin{array}{l}\text { ge of treated wa } \\
\text { in the well vault. }\end{array}$ & \multicolumn{4}{|c|}{$\begin{array}{l}\text { NA = Not Applicable } \\
{ }^{*} \text { This system was shut down August 1, } 2004 \\
{ }^{* *} \text { Sr-90 removal is expressed in mCi. } \\
{ }^{* *} \text { DB was only detected in the system influen } \\
\text { standard. Therefore, no removal of VOCs } \\
\text { o the same well in a shallow recharge screen }\end{array}$} \\
\hline
\end{tabular}




\subsection{OPERABLE UNIT I}

The two sources of groundwater contamination contained within the OU I project are the former Hazardous Waste Management Facility (HWMF) and the Current Landfill. The former HWMF was BNL's central RCRA Receiving Facility for processing, neutralizing, and storing hazardous and radioactive wastes for off-site disposal until 1997, when a new Waste Management Facility was constructed along East Fifth Avenue. Several hazardous materials spills were documented at the former HWMF. A soil remediation program was completed for this facility in September of 2005.

The plumes from the Current Landfill and former HWMF become commingled south of the former HWMF. The commingling was partially caused by the pumping and recharge effects of the Spray Aeration System, which operated from 1985 to 1990. This system was designed to treat VOCcontaminated groundwater originating from the former HWMF. The TVOC plume is depicted in Figure 3.1-1. A segment of the plume extends off site, approximately 3,400 feet south of the site property boundary.

The on-site segment of the Current Landfill/former HWMF plume is being remediated by a groundwater pump and treat system consisting of two wells screened in the deep portion of the Upper Glacial aquifer at the site property boundary (OU I South Boundary Treatment System). The extracted groundwater is treated for VOCs by air stripping, and is recharged to the ground at the RA V basin, located northwest of the Current Landfill (Figure 3.1-1). A second system (North Street East System) was built to treat the off-site portion of the plume. The off-site groundwater remediation system began operations in June 2004 and was included under the Operable Unit III Record of Decision (see Section 3.2.9).

Tritium was detected in several on-site monitoring wells at concentrations below the $20,000 \mathrm{pCi} / \mathrm{L}$ DWS in 2007. Sr-90 is detected in on-site wells, one of which exceeded the $8 \mathrm{pCi} / \mathrm{L}$ DWS in 2007, as discussed in Section 3.1.5.

\subsubsection{OU I South Boundary Pump and Treat System}

This section summarizes the operational and monitoring well data for 2007 from the OU I South Boundary Groundwater Pump and Treat System, and presents conclusions and recommendations for its future operation. This system began operating in December 1996.

Three quarterly reports were prepared with the operational data from January 1, 2007 through September 30, 2007. This Report also serves as a summary of the fourth quarter operational data. Discharge Monitoring Reports for treated effluent water from the air-stripping tower were submitted to EPA and NYSDEC each month.

\subsubsection{System Description}

For a complete description of the OU I South Boundary Treatment System, see the Operations and Maintenance Manual for the RA V Treatment Facility (BNL 2005b).

\subsubsection{Groundwater Monitoring}

Well Network

The OU I South Boundary monitoring program uses a network of 44 monitoring wells (Figure 1-2). A discussion of monitoring well data specific to the Current Landfill source area is provided in Appendix H.

Sampling Frequency and Analysis

The wells are monitored as per the schedule provided in Table 1-5. 


\subsubsection{Monitoring Well VOC Results}

Figure 3.1-1 shows the areal extent of TVOC contamination from the Current Landfill/former HWMF area based on the full round of samples collected in the third and fourth quarters of 2007. The primary VOCs detected in the on-site segment of this plume include chloroethane and DCA, which originated from the Current Landfill. TCA, DCE, TCE, and chloroethane are prevalent in the off-site segment of the plume (North Street East). TVOC concentrations less than $40 \mu \mathrm{g} / \mathrm{L}$ are currently detected in monitoring wells immediately downgradient of the Current Landfill. The landfill was capped in November 1995 and the leading edge of the TVOC plume appears to be attenuating to levels below $5 \mu \mathrm{g} / \mathrm{L}$ approximately 1,000 feet southeast of the landfill footprint.

The OU I South Boundary/North Street East plume (defined by TVOC concentrations greater than $5 \mu \mathrm{g} / \mathrm{L}$ ) extends from south of the former HWMF and monitoring well 098-59 to the site boundary (a distance of approximately 2,260 feet), where it has been hydraulically cut off from the off-site segment of the plume by extraction wells EW-1 and EW-2. Its maximum width is about 750 feet at the southern site boundary. The plume segments with higher TVOC concentrations (greater than 50 $\mu \mathrm{g} / \mathrm{L})$ are approximately 300 feet wide. The areas of the plume displaying the highest TVOC concentrations (greater than $100 \mu \mathrm{g} / \mathrm{L}$ ) were approximately 1,200 to 2,400 feet downgradient of the former HWMF. Contaminant concentrations near well 098-59 have declined significantly, indicating that the trailing edge of the high concentration segment is continuing to migrate away from this area and toward the site boundary. The off-site portion of the plume is discussed in Section 3.2.9, the North Street East Pump and Treat System.

Figure 3.1-2 shows the vertical distribution of VOCs. The transect line for cross-section $A-A^{\prime}$ is shown on Figure 3.1-1. DCA and chloroethane are primarily detected in the shallow zone of the Upper Glacial aquifer near the source areas, and in the deep Upper Glacial at the site boundary and off site. TCA, DCE, TCE, chloroethane, and chloroform are found in the mid to deep Upper Glacial aquifer off site, south of North Street.

The plume remains bounded by the current network of wells. Figure 3.1-3 gives the historical trends in VOC concentrations for key plume core and bypass wells that monitor the plume. Appendix C has a complete set of 2007 analytical results for the 44 wells. Significant findings for 2007 include:

- The trailing edge of the OU I South Boundary plume appears to have migrated south of plume core well 098-59 (Figure 3.1-3) based on the last several years of data. This well began to show a steadily decreasing trend in TVOC concentrations during 2002 after peaking at $371 \mu \mathrm{g} / \mathrm{L}$ in 1997 , as a high-concentration slug of contaminants continues to migrate southward. The third-quarter 2007 TVOC concentration in this well was $2 \mu \mathrm{g} / \mathrm{L}$ and the concentration has remained below 7 $\mu \mathrm{g} / \mathrm{L}$ since the third quarter of 2005 . This well is screened in the Upton Unit immediately above the Gardiners Clay.

- Monitoring well 107-40 was installed to assist in defining the VOC hot spot migration south of well 098-59 and was sampled for the first time in 2006. The initial TVOC concentration of 108 $\mu \mathrm{g} / \mathrm{L}$ in this well has slowly increased to $135 \mu \mathrm{g} / \mathrm{L}$ in the fourth quarter of 2008 . The levels of VOCs detected in this well are indicative of the plume hot spot continuing to move through this area and toward the extraction wells.

- There were no detections of VOCs above NYS AWQS in perimeter wells.

- VOC concentrations in bypass wells 115-42 and 000-138 remained at levels just above detection limits in 2007. TVOCs in well 115-41 increased slightly to $7 \mu \mathrm{g} / \mathrm{L}$ during the fourth quarter of 2007. VOCs greater than DWS continue to be hydraulically contained at the site boundary.

\subsubsection{Radionuclide Monitoring Results}

The monitoring wells were analyzed for tritium and Sr-90 semiannually, and gamma spectroscopy annually. The complete results for these wells are provided in Appendix C. 
The tritium concentration in all wells continues to be well below the $20,000 \mathrm{pCi} / \mathrm{L}$ DWS. Tritium concentration in well 098-30 (immediately south of former HWMF) continued the slight increasing trend begun in 2006 with a detection of $9,210 \mathrm{pCi} / \mathrm{L}$ in the fourth quarter. Concentrations in well 10812 (located along the South Firebreak Road) which slightly increased in 2006 from nondetectable levels up to $6,210 \mathrm{pCi} / \mathrm{L}$ declined to barely detectable levels in 2007 . The tritium in these wells most likely represent the attenuated remnants of tritium concentrations originating from the former HWMF.

Tritium has historically been detected in wells 115-14, 115-29, and 108-12, located near the site boundary, at concentrations well below the DWS. The maximum concentrations in wells 115-14 and $115-29$ during 2007 were $1,820 \mathrm{pCi} / \mathrm{L}$ and $1,710 \mathrm{pCi} / \mathrm{L}$, respectively. These concentrations reflect the continued steady decline over the past several years. Concentrations have also declined in well 108-12 (maximum of $840 \mathrm{pCi} / \mathrm{L}$ in 2007), following a brief spike in 2006. A plot of historical tritium results for select OU I South Boundary program wells is shown on Figure 3.1-4.

There are 10 wells (including six that are also part of the OU I South Boundary Monitoring Program) used to monitor Sr-90 contamination from the former HWMF (Table 1-5). The extent of Sr-90 concentrations is shown on Figure 3.1-5. Sr-90 has historically been detected in three wells located within and downgradient of the former HWMF (088-26, 098-21, and 098-30) at concentrations above the $8 \mathrm{pCi} / \mathrm{L}$ DWS. Well $088-26$ was the only one of the three to show Sr-90 concentrations above the DWS, with a maximum concentration of $13 \mathrm{pCi} / \mathrm{L}$ in August 2007. Sentinel monitoring wells were installed in 2002, downgradient of the leading edge of the plume. Sr90 was detected in well 107-35 for the first time during the second half of 2004 at a maximum concentration of $2.6 \mathrm{pCi} / \mathrm{L}$. Concentrations have slowly increased to $6 \mathrm{pCi} / \mathrm{L}$ in December 2007, which indicates that a slug of Sr-90 originating from the former HWMF is in the vicinity of this well This sentinel well is approximately 1,000 feet from the site boundary, equivalent to 25-30 years of travel time in the aquifer. Sr-90 concentration trends for key monitoring wells are provided in Figure 3.1-6.

\subsubsection{System Operations}

The extraction wells are currently sampled quarterly. The influent and effluent of the airstripper tower are sampled monthly for VOCs and weekly for $\mathrm{pH}$. Table 3.1-1 provides the effluent limitations for meeting the requirements of the State Pollutant Discharge Elimination System (SPDES) equivalency permit. The system resumed full time operation in July 2007 following a period of pulse pumping that was initiated in September 2005.

Table 3.1-1.

OU I South Boundary Pump and Treat System 2007 SPDES Equivalency Permit Levels

\begin{tabular}{lcc}
\hline Parameters & $\begin{array}{c}\text { Permit } \\
\text { Level }\end{array}$ & $\begin{array}{c}\text { Max. } \\
\text { Measured } \\
\text { Value }\end{array}$ \\
\hline $\mathrm{pH}$ & $6.0-9.0 \mathrm{SU}$ & $6.9-7.9 \mathrm{SU}$ \\
Benzene & $0.8 \mu \mathrm{g} / \mathrm{L}$ & $<0.50 \mu \mathrm{g} / \mathrm{L}$ \\
Chloroform & $7.0 \mu \mathrm{g} / \mathrm{L}$ & $<0.50 \mu \mathrm{g} / \mathrm{L}$ \\
Chloroethane & $5.0 \mu \mathrm{g} / \mathrm{L}$ & $<0.50 \mu \mathrm{g} / \mathrm{L}$ \\
1,2-Dichloroethane & $5.0 \mu \mathrm{g} / \mathrm{L}$ & $<0.50 \mu \mathrm{g} / \mathrm{L}$ \\
1,1-Dichloroethene & $5.0 \mu \mathrm{g} / \mathrm{L}$ & $<0.50 \mu \mathrm{g} / \mathrm{L}$ \\
1,1,1-Trichloroethane & $5.0 \mu \mathrm{g} / \mathrm{L}$ & $<0.50 \mu \mathrm{g} / \mathrm{L}$ \\
Carbon tetrachloride & $5.0 \mu \mathrm{g} / \mathrm{L}$ & $<0.50 \mu \mathrm{g} / \mathrm{L}$ \\
1,2-Dichloropropane & $5.0 \mu \mathrm{g} / \mathrm{L}$ & $<0.50 \mu \mathrm{g} / \mathrm{L}$ \\
Methylene chloride & $5.0 \mu \mathrm{g} / \mathrm{L}$ & $<0.50 \mu \mathrm{g} / \mathrm{L}$ \\
Trichloroethylene & $5.0 \mu \mathrm{g} / \mathrm{L}$ & $<0.50 \mu \mathrm{g} / \mathrm{L}$ \\
Vinyl chloride & $2.0 \mu \mathrm{g} / \mathrm{L}$ & $<0.50 \mu \mathrm{g} / \mathrm{L}$ \\
1,2-Xylene & $5.0 \mu \mathrm{g} / \mathrm{L}$ & $<0.50 \mu \mathrm{g} / \mathrm{L}$ \\
Sum of 1,3- \& 1,4-Xylene & $10.0 \mu \mathrm{g} / \mathrm{L}$ & $<0.50 \mu \mathrm{g} / \mathrm{L}$ \\
\hline Notes: & & \\
SU Standard Units & & \\
Required sampling frequency is monthly for VoCs and weekly for pH. \\
\hline
\end{tabular}

The following is a summary of the OU operations for 2007:

January-September 2007

The system operated normally during the first three quarters. The system was in a pulse pumping mode one month on and one month off until July 2007 when full time operations resumed. In August 
the system experienced problems in EW-2 which led to the system being shut off in late September for well maintenance and repair.

October-December 2007

The system was off in October and part of November while well repairs and maintenance were being conducted. The system operated normally for all of December.

\subsubsection{System Operational Data}

\section{Extraction Wells}

During 2007, 137 million gallons of groundwater were pumped and treated by the OU I system, with an average flow rate of 260 gpm for the year. Typical flows while operating are 550-600 gpm. Table 2-3 contains the monthly pumping data for the two extraction wells. VOC and tritium concentrations in samples from EW-1 (115-27) and EW-2 (115-43) are provided in Table F-1 in Appendix F . TVOC levels in both wells continued to show a slight decreasing trend with time (Figure 3.1-7). Year-end tritium levels were below detection limits in both wells.

\section{System Influent and Effluent}

VOC concentrations in 2007 for the air-stripper influent and effluent are summarized in Tables F-2 and F-3 in Appendix F. Tritium data for influent and effluent samples are shown in Table F-4. The influent concentrations of TCA and DCA generally have displayed an overall decrease over the 10 years of OU I South Boundary System operation.

The air-stripper system effectively removed all contaminants from the influent groundwater. All effluent data were below the analytical method detection limit and below the regulatory limit specified in the equivalency permit conditions.

\section{Cumulative Mass Removal}

The mass of VOCs removed from the aquifer by the OU I treatment system was calculated. Average flow rates for each monthly monitoring period were used, in combination with the TVOC concentration in the air-stripper's influent, to calculate the rate of contaminants removed. The cumulative mass of VOCs removed by the treatment system vs. time was then plotted (Figure 3.1-8).

Table 3.1-2

OU I South Boundary System

2007 Air Stripper VOC Emissions Data

\begin{tabular}{lcc}
\hline Parameter & $\begin{array}{c}\text { Allowable } \\
\text { ERP* }^{*}(\mathrm{~b} / \mathrm{hr})\end{array}$ & $\begin{array}{c}\text { Actual** ERP* } \\
(\mathrm{lb} / \mathrm{hr})\end{array}$ \\
\hline Carbon tetrachloride & 0.016 & $<0.0002$ \\
Chloroform & 0.0086 & $<0.0002$ \\
1,1-Dichloroethane & $10^{\star *}$ & 0.00035 \\
1,2-Dichloroethane & 0.011 & $<0.0002$ \\
1,1-Dichloroethene & 0.194 & $<0.0002$ \\
Chloroethane & $10^{\star *}$ & 0.0004 \\
1,1,1-Trichloroethane & $10^{\star *}$ & $<0.0002$ \\
Trichloroethene & 0.119 & $<0.0002$ \\
\hline
\end{tabular}

ERP = Emissions Rate Potential, stated in lb/hr. * ERP is based on NYSDEC Air Guide 1 Regulations. ${ }^{*}$ Actual rate reported is the average for the year.

*** 6 NYCRR Part 212 restricts emissions of VOCs to a maximum of $10 \mathrm{lb} / \mathrm{hr}$ without controls.
During 2007, 6.4 pounds of VOCs were removed. Cumulatively, 337 pounds have been removed since 1997. Groundwater modeling estimated that the system would remove between 300 to 350 pounds by 2006-2007. Cumulative mass removal data for this system are summarized in Table F-5.

\section{Air Discharge}

Table 3.1-2 presents the VOC air emissions data for the year 2007 and compares the values to levels stipulated in NYSDEC Air Guide 1 regulations. Emission rates are calculated through mass balance for water treated during operations. The concentration of each constituent of the airstripper's influent was averaged for the year. That value was converted from $\mu \mathrm{g} / \mathrm{L}$ to pounds per gallon (lb/gal), which was multiplied by the average pumping rate ( $\mathrm{gal} / \mathrm{hr}$ ) to compare with the regulatory value. All VOC air emissions were well below allowable levels.

\section{Recharge Basin}


There are nine sentinel monitoring wells in the immediate area surrounding the RA V recharge basin (Figure 1-2). These wells are used to monitor water quality and water levels to assess the impact of the recharge basin on the aquifer. Appendix $\mathbf{C}$ contains the data for these monitoring wells. The highest detection of tritium during 2007 was $550 \mathrm{pCi} / \mathrm{L}$ in well $076-172$, which is slightly above the detection limit. Beginning November 1, 2001, the RA V recharge basin began receiving treated groundwater from the OU III South Boundary and Middle Road treatment systems. The OU III South Boundary SPDES equivalency permit was modified to include the Middle Road Treatment System and their outfalls at the OU III and RA V recharge basins. This basin resumed receiving water from the HFBR Tritium Pump and Recharge Wells in 2007.

\subsubsection{System Evaluation}

The pump and treat system continued to maintain hydraulic control of contaminants originating from the Current Landfill and former HWMF, and to prevent further contaminant migration across the site's southern boundary. No SPDES or air equivalency permit limits have been exceeded, and no operating difficulties were experienced beyond normal maintenance. There have been no problems and no observed interference with other BNL operations, such as the recharge to Basin $\mathrm{HO}$ or the OU III South Boundary Pump and Treat System. Pulse pumping (1 month on, 1 month off) of the system was implemented beginning in September 2005, per recommendations in the 2004 Groundwater Status Report. Pulse pumping was discontinued in July 2007 per the recommendations in the 2006 Groundwater Status Report.

The OU I South Boundary Pump and Treat system performance can be evaluated based on the five major decisions identified by applying the DQO process.

\section{Was the BNL Groundwater Contingency Plan triggered?}

No. There were no unusual or unexpected concentrations of contaminants observed in monitoring or extraction wells associated with the OU I South Boundary Pump and Treat System during 2007.

\section{Has the plume been controlled?}

Yes. An analysis of the plume perimeter and bypass wells reveals no significant increases in VOC concentrations in perimeter and bypass monitoring wells during 2007; thus, the plume has not grown and continues to be controlled. Figure 3.1-1 illustrates that the plume has been effectively cut off at the south boundary and there is separation with the off-site segment of the plume.

The groundwater contour maps are used to evaluate the capture zones of the OU I South Boundary Pump and Treat System (Figures 2-2 and 2-3). The capture zone for the OU I South Boundary Pump and Treat System is indicated in Figure 3.0-1. The capture zone depicted includes the $50 \mu \mathrm{g} / \mathrm{L}$ isocontour that is the capture goal of this system.

\section{Is the system operating as planned? Specifically, is the aquifer being restored at the planned rate} for this treatment system?

Yes. The hydraulic capture performance of the system is operating as previously modeled and the system continues to be effective in capturing and removing VOCs from the deep Upper Glacial aquifer. In 2003, the beginning of a steady decline in VOC concentrations in well 098-59 was observed. This decline continued in 2007 and it appears that the trailing edge of this high concentration segment has migrated south of this area. Monitoring well 107-40 was installed in 2006 and is used to track this high concentration segment as it migrates to the south boundary. The system resumed full-time operation in 2007 based on increasing VOC concentrations in well 107-40. VOC concentrations in EW-1 and EW-2 were observed to remain stable; however, it is anticipated that there will be some increase in concentrations in the near future as the hot spot arrives at the site boundary. Based on monitoring well results and mass removal of contaminants, the system is operating as planned. 
4. Can the groundwater treatment system be shut down?

No, the system has not met all shutdown requirements (see below).

4a. Have asymptotic TVOC concentrations been reached in core wells?

Asymptotic conditions are demonstrated by analyzing the average trends in TVOC concentrations in the plume core wells. Asymptotic conditions have not yet been achieved. Aquifer cleanup continues to be demonstrated based on the continued decreasing slope to the trend of average TVOC concentrations in plume core wells, as shown in Figure 3.1.9. Changes in the distribution of the plume are shown in Figure 3.1-10, which compares the TVOC plume from 1997 to 2007.

4 b. Is the mean TVOC concentration in core wells less than $50 \mu \mathrm{g} / \mathrm{L}$ ?

Yes, the mean TVOC concentration is currently less than $50 \mu \mathrm{g} / \mathrm{L}$ (Figure 3.1-9).

4c. How many individual plume core wells are above $50 \mu \mathrm{g} / \mathrm{L}$ ?

Monitoring well 107-40, which was installed in 2006, is the only plume core well to have TVOC concentrations exceeding $50 \mu \mathrm{g} / \mathrm{L}$. TVOC concentrations are currently increasing in this well.

4d. During pulsed operation of the system, is there significant concentration rebound in core wells? No. Pulsing of the OU I South Boundary System that began in September 2005 was suspended in July to allow the plume hot spot detected in well 107-40 to migrate south to the extraction wells. The arrival of the hot spot should result in some increase in VOC concentrations in EW-1 and -2.

5. Have the groundwater cleanup goals been met? Specifically, have MCLs been achieved (expected by 2030)?

No. MCLs have not been achieved for individual VOCs in plume core wells. However, MCLs are expected to be achieved by 2030 .

\subsubsection{Recommendations}

The following are recommendations for the OU I South Boundary Pump and Treat System and groundwater monitoring program:

- Based on TVOC concentration increases in upgradient plume core well 107-40 the leading edge of the high concentration segment of the VOC plume is approaching the south boundary and should arrive in the near future. As a result, full-time operation of extraction wells EW-1 and EW2 will continue until further notice.

- Install vertical profile well approximately 500 feet north of well 107-40 along the Princeton Avenue Firebreak Road to locate the centerline of the VOC high concentration slug. Install a monitoring well if TVOCs are greater than $50 \mu \mathrm{g} / \mathrm{L}$.

- The routine operation and maintenance monitoring frequency implemented in the fourth quarter of 2004 should be continued. Plume core and perimeter wells are monitored on a semiannual frequency. Sentinel and bypass wells are sampled at a quarterly frequency. Maintain a quarterly sampling frequency for well 107-40 to monitor the hot spot.

- Reduce frequency of Sr-90 sampling for wells 107-34, 107-35, 108-43, 108-44, 115-41, and 11542 from quarterly to semi-annually, due to the absence of Sr-90 in these wells. Drop Sr-90 analysis for all other off-site wells due to absence of Sr-90. Reduce tritium sampling in bypass wells $115-41$ and 115-42 from quarterly to semi-annually. 


\subsection{OPERABLE UNIT III}

There were several VOC, Sr-90, and tritiu m plumes addressed under the OU III Rem edial Investigation/Feasibility Study (RI/FS). The VOC plumes originated from several sources, including Building 96, the Warehouse area, various small sourc es in the north central developed portio $\mathrm{n}$ of the site, the For mer Landfill, OU IV, and the form er carbon tetrachloride underground stor age tank (UST). Figure 3.2-1 is a si mplified representation of the plum es using TVOC concentrations. The eastern portion of Figure 3.2-1 also includes the OU IV plu me and the North Street (OU I/IV) plumes. Figure 3.2-2 is cross-section B-B', which is drawn through the north-south center-line of the primary OU III VOC plumes, as shown in Figure 3.2-1.

The primary chem ical co ntaminants found i n OU III groundwater are T CA, PCE, and carbon tetrachloride. These three chemicals are the primary VOCs detected in the OU III on-site monitoring wells. Off site, carbon tetrachloride and PCE are the main contaminants detected.

Figure 3.2-3 presents a comparison of the OU III plumes between 1997 and 2007. Several changes in the plumes can be observed in this comparison:

- The extent of the higher concentration seg ments of the plumes both on and off site has decreased over the 10- year period. This is due primarily to the groundw ater re mediation that has been implemented, along with the affects of natural attenuation.

- Hydraulic control of the plumes by the OU III South Boundary Treatment Sy stem at the si te boundary is evidenced by the break in the plume in this area.

- The attenuation of the on-site potion of the North Street VOC plume.

- The migration of the off-site higher VOC concentration slug from the vicin ity of Moric hesMiddle Island Road in 1997 to the Airport Treatment System extraction wells in 2007.

Three radiological plumes were addressed under Operable Unit III. The HFBR tritiu m plume extends several thousand feet south from the HFBR spent fu el pool. Sr-90 plum es ar e present downgradient of the form er Waste Concentration Facility (WCF) and several sources related to the Brookhaven Graphite Research Reactor (BGRR). A S r-90 plume is also present downgradie nt of the Chemical/Glass Holes and Animal Pits area.

Sections 3.2.1 throug $\mathrm{h}$ 3.2.17 summarize and evaluate the groundwater monitoring and system operations data for the OU III VOC and radiological plumes, including both operational groundwater treatment systems and the monitoring-only programs. 
SER VOLUME II: GROUNDWATER STATUS REPORT

This page intentionally left blank. 


\subsubsection{Carbon Tetrachloride Pump and Treat System}

This section summarizes the data from the OU III Carbon Tetrachloride Pump and Treat System and offers conclusions and recommendations for monitoring. This system began operating on October 6, 1999 and was formally shut down and placed in standby mode on August 1, 2004 after receiving regulatory approval of the petition for shutdown. This summary is prepared annually and discusses the monitoring data from January 1, 2007 through December 31, 2007.

\subsubsection{System Description}

A complete description of the pump and treat system is contained in the Carbon Tetrachloride Groundwater Removal Action Operations and Maintenance Manual (BNL 2000a).

\subsubsection{Groundwater Monitoring}

Well Network

A network of 32 wells was designed to monitor the extent of the plume and the effectiveness of remediation. As was recommended in the petition to shut down the carbon tetrachloride system, two monitoring wells (095-300 and 095-301) were installed in the vicinity of extraction well EW-15 in 2004. Well 095-300 was installed to monitor the western edge of the plume in the vicinity of well EW-15, and well 095-301 was installed upgradient of well EW-15.

\section{Sampling Frequency and Analysis}

The wells are sampled quarterly (shutdown phase), and samples are analyzed for VOCs (see Table 1-5).

\subsubsection{Monitoring Well Results}

Carbon tetrachloride is the primary contaminant in this plume. However, there are also low levels of chloroform (a breakdown compound of carbon tetrachloride). The plume extends from the former UST southeast to the vicinity of the Weaver Drive recharge basin, a distance of approximately 1,300 feet (Figure 3.2.1-1). The width of the plume, as defined by the $50 \mu \mathrm{g} / \mathrm{L}$ carbon tetrachloride isocontour, is approximately 100 feet. The complete 2007 analytical results from the monitoring of wells in the carbon tetrachloride program are provided in Appendix C. A summary of key monitoring well data for 2007 follows:

- Plume core well 085-98, just south of the former UST, had carbon tetrachloride concentrations greater than $150,000 \mu \mathrm{g} / \mathrm{L}$ in 1999 . A dramatic reduction in concentrations has been observed in this well, beginning in 1999 with the start of groundwater pump and treat. The concentration of carbon tetrachloride was $11 \mu \mathrm{g} / \mathrm{L}$ in October 2007 (Figure 3.2.1-2).

- Plume core well 085-17 is sited next to the BNL service station on Rochester Avenue and downgradient of the source area. It has continued to show declining carbon tetrachloride trends from a peak of more than $4,000 \mu \mathrm{g} / \mathrm{L}$ in 2000 to a concentration of $41 \mu \mathrm{g} / \mathrm{L}$ in October 2007 (Figure 3.2.1-2). Of note on this well is that other compounds related to petroleum products are also detected in this well and this is due to the service station located in this area (see Section 4.8).

- Plume core well 85-161 is approximately 120 feet downgradient of the source area. Concentrations in this well have remained low throughout 2007, with a concentration of 2.8 $\mu \mathrm{g} / \mathrm{L}$ in October 2007.

- Plume core well 095-183 is approximately 450 feet downgradient of the source area. Carbon tetrachloride concentrations in this well have decreased from greater than $2,000 \mu \mathrm{g} / \mathrm{L}$ in 2000 , to $<0.5 \mu \mathrm{g} / \mathrm{L}$ in October 2007 (Figure 3.2.1-2). 
- Plume perimeter wells 095-300 and core well 095-301 were installed in 2004, as recommended in the Petition to Shutdown the Carbon Tetrachloride System (BNL 2004j). Well 095-300 was installed west of EW-15 to confirm the western edge of the carbon tetrachloride plume. The analytical results for this well show a carbon tetrachloride concentration of $.65 \mu \mathrm{g} / \mathrm{L}$ in October 2007, thus confirming the western edge of the plume. Well 095-301 was installed to monitor concentrations of the plume immediately upgradient of well EW-15. Concentrations of carbon tetrachloride varied from $37 \mu \mathrm{g} / 1$ in January to $1.1 \mu \mathrm{g} / \mathrm{L}$ in October 2007.

\subsubsection{System Operations}

\section{Operating Parameters}

In 2007, the extraction wells were sampled quarterly. All samples are analyzed for VOCs. The extraction well data is located in Table F-6. The parameters for sampling $\mathrm{pH}$ and VOCs adhere to the requirements of the SPDES equivalency permit. However, the system was in standby in 2007. The system operations are summarized below.

\section{January - December 2007}

The system was in standby mode during this period. Sampling for the SPDES equivalency permit was stopped and will be resumed if the system is restarted.

\subsubsection{System Operational Data}

The system was shut down for the entire year so no data are available

\subsubsection{System Evaluation}

The system was placed in a standby mode in August 2004 after approval of the petition for shutdown. The system ran for approximately one month in 2005 . The system remained in standby mode for all of 2006 and 2007. The groundwater extraction wells will remain on a quarterly sampling schedule to monitor for any significant rebound in concentrations of carbon tetrachloride.

The Carbon Tetrachloride Pump and Treat System performance can be evaluated based on the five major decision rules identified by applying the DQO process.

\section{Was the BNL Groundwater Contingency Plan triggered?}

No. There were no detections of either carbon tetrachloride or any other contaminants in wells associated with this monitoring network during 2007 that would have triggered the BNL Groundwater Contingency Plan.

\section{Were the cleanup goals met?}

Yes. The groundwater cleanup goals for the system have been met. The system was shut down in August 2004.

\section{Has the plume been controlled?}

Yes. The plume has been controlled, and the system is in standby mode.

\section{Is the system operating as planned?}

The system is currently shut down and being maintained in standby mode. Shutdown of the system at these concentrations is consistent with meeting the OU III ROD cleanup objectives of meeting MCLs by 2030 . 
5. Is an engineering evaluation needed to modify the Middle Road treatment system to ensure the capture and remediation of the carbon tetrachloride plume?

Based on data from bypass and Middle Road tracking wells, no engineering study is required at this time. The Middle Road system will capture any higher levels of carbon tetrachloride not captured by this system.

\subsubsection{Recommendations}

The following are recommendations for the OU III Carbon Tetrachloride Groundwater Remediation System and monitoring program:

- Maintain the system in standby mode. If significant concentrations of carbon tetrachloride are detected in monitoring or extraction wells, the system will be turned on.

- Move monitoring well 095-92 to the Middle Road Pump and Treat System well network.

- Perform two to four temporary wells in the center of the plume north of extraction well EW-15 and south of well 85-17. These data will be used to help perform the recommended modeling evaluation below.

- Perform groundwater modeling to evaluate if the remaining levels of contaminants in this area can meet the cleanup objectives through natural attenuation. If it can be demonstrated by the model that the current levels will achieve these objectives, then a petition for closure of this system will be submitted to the regulators. 
SER VOLUME II: GROUNDWATER STATUS REPORT

This page intentionally left blank. 


\subsubsection{Building 96 Air Stripping System}

This section summarizes the 2007 operational data from the OU III Building 96 Treatment System, which consists of recirculation wells with air stripping and vapor phase carbon treatment. It also presents conclusions and recommendations for future operation of the system. The system began operation in February 2001. Three of the four recirculation wells (RTW-2, RTW-3, and RTW-4) were placed in standby mode in July 2004 and the fourth recirculation well (RTW-1) was initially placed in standby mode on June 1, 2005 and remained in standby until it was restarted October 17, 2005 due to a rebound in VOC concentrations. As noted in Section 3.2.2.4, well RTW-1 was placed back in standby mode in June 2006, and downgradient well RTW-2 was re-started on October 15, 2007 due to a rebound in VOC concentrations.

Characterization results identified a shallow low permeability zone, referred to as the "silt zone." Monitoring data indicate that high concentrations of VOCs are present in this zone and provide a continuing source of VOCs to groundwater. Due to the continuing source of VOC contamination in the silt zone, three injections of the oxidizer potassium permanganate $\left(\mathrm{KMnO}_{4}\right)$ were conducted from December 2004 through January 2006. Based on the monitoring well data since then, these injections were not successful in reducing the high VOC concentrations in the silt zone

\subsubsection{System Description}

Contaminated groundwater is drawn from the aquifer via a submersible well pump in a lower well screen, 48 to 58 feet below land surface (bls), near the base of the contaminant plume. The groundwater then is pumped into a stripping tray adjacent to each of the four wells, and after treatment is recharged back to the shallow portion of the plume, 25 to 35 feet bls, through the upper screen. The contaminated air stream is then carried to a treatment and control building, where it is passed through two vapor phase granular activated carbon units in series to remove the VOCs. Treated air is then discharged to the atmosphere. A complete description of the system is included in the Building 96 Groundwater Source Control Treatment System Operations and Maintenance Manual (BNL 2002a). A modification to this manual was prepared and is titled, Operations and Maintenance Manual Modification, Building 96 (BNL 2004c).

\subsubsection{Groundwater Monitoring}

The monitoring network of 33 wells is used to monitor the VOC plume and the effectiveness of the groundwater remediation system (Figure 1-2). The wells are sampled and analyzed for VOCs on a quarterly frequency, in accordance with Table 1-5.

\subsubsection{Monitoring Well Results}

Complete VOC results are provided in Appendix C. Since sufficient data has been collected following the $\mathrm{KMnO}_{4}$ injections, the monitoring well sampling frequency was changed from monthly to quarterly, effective the third quarter of 2006. The fourth-quarter 2007 plume is shown on Figure 3.2.2-1. A summary of key monitoring well data for 2007 follows:

- The highest TVOC concentration seen in 2007 was 3,543 $\mu \mathrm{g} / \mathrm{L}$, from well $085-347$, during the third quarter sampling round. Although this is significantly high, it is approximately half of the maximum concentration seen in 2005 and 2006 of $7,173 \mu \mathrm{g} / \mathrm{L}$ and 8,754 $\mu \mathrm{g} / \mathrm{L}$, respectively, in well 085-353. Historically, the highest concentration seen in this area was $18,000 \mu \mathrm{g} / \mathrm{L}$ TVOCs, in well 095-84 in October 1998. As shown in trend Figure 3.2.2-2, plume core monitoring wells 085-347, 085-353, and 095-84 continue to show significant rebounding of contaminant levels over the last few years. Based on this data, the $\mathrm{KMnO}_{4}$ injections have not been effective in the silt zone.

- TVOC concentrations in plume core well 085-352 (screened in the silt zone) began rebounding in 2007 to $1,330 \mu \mathrm{g} / \mathrm{L}$ after two years of $285 \mu \mathrm{g} / \mathrm{L}$ or less in 2005 and 2006 . The same can be said 
for well $085-349$, which rose to $1,718 \mu \mathrm{g} / \mathrm{L}$ in 2007 . This helps demonstrate continued leaching of PCE from the silt zone.

- Plume core wells 095-162 and 095-172 (located between recirculation wells RTW-1 and downgradient wells RTW-2 through RTW-4) began increasing in 2006 and 2007 after several years of less than $50 \mu \mathrm{g} / \mathrm{L}$ TVOCs. This is due to the plume passing by RTW-1 while it remains in standby mode. Maximum TVOC concentrations in these well in 2007 were $136 \mu \mathrm{g} / \mathrm{L}$ and 196 $\mu \mathrm{g} / \mathrm{L}$, respectively. This contamination will be captured by the downgradient recirculation treatment wells.

- Plume perimeter well 095-295, located on the west side of the plume, maintained low TVOC concentrations throughout 2006 and 2007. The highest 2006 and 2007 TVOC concentrations in well $095-295$ were $9.8 \mu \mathrm{g} / \mathrm{L}$ and $5.9 \mu \mathrm{g} / \mathrm{L}$, respectively. The bypass monitoring wells immediately downgradient of extraction wells RTW-2, RTW-3, and RTW-4 detected TVOC concentrations in 2007 up to $119 \mu \mathrm{g} / \mathrm{L}$ in the western portion of the plume, $122 \mu \mathrm{g} / \mathrm{L}$ in the center portion, and 142 $\mu \mathrm{g} / \mathrm{L}$ in the eastern portion of the plume. As a result of increasing contamination in this portion of the plume, downgradient well RTW-2 was placed back in service in October 2007, and RTW-3 and RTW-4 were placed back in service in February 2008.

- Data from three temporary wells (Geoprobes) installed in February 2008 along Weaver Drive identified TVOC concentrations up to $91 \mu \mathrm{g} / \mathrm{L}$ in GP-01. See Section 3.2.2.4 below for discussion on the purpose of the Geoprobes.

\subsubsection{System Operations}

\section{Operating Parameters}

Three of the four downgradient recirculation wells (RTW-1, RTW-3, and RTW-4) remained in standby mode in 2007. Due to a rebound in VOC concentrations in the downgradient portion of the plume, recirculation well RTW-2 was put back on in October of 2007, and RTW-3 and RTW-4 were placed back in service in February 2008. As noted in the 2006 Groundwater Status Report, the continued operation of RTW-1 as a recirculation well may be causing adverse impacts on the plume. As a result, RTW-1 has remained in standby mode since June 2006.

\section{January-September 2007}

The system was in standby mode for this entire period.

\section{October-December 2007}

Extraction well RTW-2 was placed back on-line in October and pumped approximately 2.8 million gallons for the quarter.

As recommended in the 2006 Groundwater Status Report, to maintain hydraulic containment of the source area, in the fall of 2007 BNL began preparing design drawings to modify recirculation well RTW-1 to discharge the treated effluent to the nearby surface drainage culvert. This involves running a discharge line to the culvert about 300 feet away and requires a SPDES equivalency permit.

During metals sampling in late November 2007 to support the submittal of an equivalency permit application, total chromium (Cr) was detected up to $185 \mu \mathrm{g} / \mathrm{L}$ in a $\mathrm{RTW}-1$ effluent sample. The groundwater standard is $50 \mu \mathrm{g} / \mathrm{L}$ and the SPDES limit is $100 \mu \mathrm{g} / \mathrm{L}$.

On December 12, 2007, RTW-1 effluent resample results from two different labs indicated hexavalent chromium $\mathrm{Cr}(\mathrm{VI})$ at $124 \mu \mathrm{g} / \mathrm{L}$ and $131 \mu \mathrm{g} / \mathrm{L}$. In accordance with the BNL Groundwater Contingency Plan, on the December 20, 2007 IAG teleconference, the regulators were informed of the sampling results and next steps. Subsequent actions performed over the next couple of months included:

- Resampling RTW-1 as well as the remaining three recirculation wells for total $\mathrm{Cr}$ and $\mathrm{Cr}(\mathrm{VI})$.

- Comprehensive sampling of all the Bldg. 96 monitoring wells for $\mathrm{Cr}(\mathrm{VI})$. 
- Installation of three temporary wells (Geoprobes) along Weaver Drive to determine the downgradient extent of the $\mathrm{Cr}(\mathrm{VI})$ contamination.

- Evaluate the source of the $\mathrm{Cr}(\mathrm{VI})$ in the Bldg. 96 area.

- Evaluate technologies to treat $\mathrm{Cr}(\mathrm{VI})$ prior to discharge to the culvert.

The data suggest that the most likely cause of the elevated $\mathrm{Cr}(\mathrm{VI})$ levels was the treatment of soils with $\mathrm{KMnO}_{4}$. One of the byproducts of the reaction is manganese oxide, which oxidizes trivalent chromium to $\mathrm{Cr}(\mathrm{VI})$. It is expected that over time, the $\mathrm{Cr}(\mathrm{VI})$ will revert back to trivalent chromium (the less toxic form). In January and March 2008 the regulators were briefed on the results of the follow-up actions. The results from the monitoring well and Geoprobe sampling indicated that the detections of $\mathrm{Cr}(\mathrm{VI})$ is not widespread, but rather is localized as a result of the previous $\mathrm{KMnO} 4$ injections. The highest Cr(VI) detection in a Bldg. 96 monitoring well was $389 \mu \mathrm{g} / \mathrm{L}$, in well 095-169. The three Geoprobes installed along Weaver Drive did not detect any $\mathrm{Cr}(\mathrm{VI})$. The monitoring well data from January 2008 and the February 2008 Geoprobe data are posted on Figure 3.2.2-5.

As a result, in February 2008 the design modification for RTW-1 was submitted to the regulators, along with the SPDES equivalency permit application. In addition to VOC treatment using air stripping, ion exchange resin will be used to treat the $\mathrm{Cr}(\mathrm{VI})$ prior to discharge. NYSDEC approved the SPDES permit in March 2008.

As recommended in the 2006 Groundwater Status Report, an evaluation of alternatives to remediate the continuing source of VOCs in the silt zone was initiated. This evaluation looked at various alternatives such as soil excavation, an additional extraction well, soil mixing with vapor extraction, electrical resistance heating, and injection by hydrogen release compounds.

\subsubsection{System Operational Data}

\section{Recirculation Well Influent and Effluent}

Three of the four recirculation wells (RTW-1, RTW-3, and RTW-4) remained in standby mode in 2007. Recirculation well RTW-2 was placed back into operation in October 2007. Table F-7 lists the quarterly influent and effluent VOC concentrations for all of the recirculation wells. The highest TVOC concentration from the influent of these wells was $174 \mu \mathrm{g} / \mathrm{L}$ in RTW-1 in the fourth quarter. The maximum TVOC in the influent of the downgradient wells was $28 \mu \mathrm{g} / \mathrm{L}$ in RTW-3. Note that RTW-4, which was placed back on-line in February 2008, detected influent TVOCs up to $121 \mu \mathrm{g} / \mathrm{L}$ in March 2008. The highest effluent TVOC concentration was from RTW-2, at $2 \mu \mathrm{g} / \mathrm{L}$, from December 2007.

\section{Cumulative Mass Removal}

RTW-2 was the only recirculation well running during 2007. Since it ran for just three months, mass removal was not calculated. The pumping and mass removal data are summarized in Table F-9 in Appendix F. Since February 2001, the system has removed approximately 71 pounds of VOCs.

\section{Air Treatment System}

Air sampling was performed in December of 2007 and the analytical data are available in Appendix F, Table F-8. Since RTW-2 ran for only three months, the emissions rate was not calculated (Table 3.2.2-1).

\subsubsection{System Evaluation}

A review of the Building 96 treatment well influent and monitoring well data indicated that the remedial effectiveness of RTW-1 had reached a plateau without significant impact on the high concentrations of a continuing source of VOCs located in the silt zone of the aquifer upgradient of RTW-1. Therefore, in an attempt to reduce the high concentrations of VOCs, primarily PCE, in the silt zone area upgradient of RTW-1, the injection of $\mathrm{KMnO}_{4}$ was conducted (BNL 2004d). Three 
rounds of $\mathrm{KMnO}_{4}$ injections were conducted in the silt zone area upgradient of extraction well RTW-1 in December 2004, April 2005, and January 2006.

The locations for the three rounds of $\mathrm{KMnO}_{4}$ injections are shown on Figure 3.2.2-2. Also, a cross section that includes this area is shown on Figure 3.2.2-3.

After three rounds of $\mathrm{KMnO}_{4}$ injections followed by a full year of continued monitoring in 2007, elevated VOC concentrations (primarily PCE) are still present in the northern part of the silt zone upgradient of RTW-1 near wells 085-347 and 085353. The highest TVOC concentration in this area in 2007 was 3,543 $\mu \mathrm{g} / \mathrm{L}$ in well 085-347.

As described in the 2006 Groundwater Status Report, the $\mathrm{KMnO}_{4}$ injections did not effectively address the continuing source of VOCs in the silt zone. A comparison of the plume from 2000 to 2007 is shown in Figure 3.2.2-4.

The OU III Building 96 Treatment System performance can be evaluated based on the two major decisions identified by applying the DQO process.

1. Was the BNL Groundwater Contingency Plan triggered?

Yes. As noted above, during the Nov/Dec 2007 sampling of RTW-1 influent, Cr(VI) was identified above the groundwater standard, triggering the Groundwater Contingency Plan. This was significant, since $\mathrm{Cr}(\mathrm{VI})$ was not previously detected as a contaminant of concern in this area and cannot be treated with the existing system. Following communication with the regulators, additional monitoring well and temporary well sampling was performed. Based on the data, ion-exchange resin treatment will be included for RTW-1.

\section{Have the source control objectives been met?}

No. Based on the goals established in the Building 96 Groundwater Source Control Operations and Maintenance Manual (BNL 2002a), as updated by the Operations and Maintenance Manual Modification Building 96 (BNL 2004c), the source control goals for this system have not been met. Based on monitoring data, the $\mathrm{KMnO}_{4}$ injections have not been effective in remediating the PCE concentrations in the shallow silt zone. As a result, a continuing source of high VOC contamination still exists in this area.

\subsubsection{Recommendations}

The following are recommendations for the OU III Building 96 groundwater remediation system and monitoring program:
OU III Building 96

VOC Emission Rates, 2007 Average

\begin{tabular}{|c|c|c|}
\hline Parameter & $\begin{array}{c}\text { Allowable } \\
\text { ERP* }\end{array}$ & $\begin{array}{c}\text { Actual** } \\
\text { ER }\end{array}$ \\
\hline dichlorodifluoromethane & 0.0000187 & 3.4 \\
\hline acetone & 0.000674 & ND \\
\hline methylene chloride & 0.000749 & 1.1 \\
\hline 2-butanone & 0.000187 & ND \\
\hline benzene & 0.000112 & 3.8 \\
\hline tetrachloroethene & 0.000165 & ND \\
\hline m,p-xylene & 0.0000116 & ND \\
\hline isopropylbenzene & 0.000243 & ND \\
\hline n-propylbenzene & 0.0000599 & ND \\
\hline 1,3,5-trimethylbenzene & 0.000375 & 1.1 \\
\hline 1,2,4-trimethylbenzene & 0.000225 & 2.6 \\
\hline 4-isopropyltoluene & 0.00000749 & ND \\
\hline naphthalene & 0.0000225 & ND \\
\hline carbon disulfide & 0.0000487 & ND \\
\hline styrene & 0.00000637 & ND \\
\hline trans-1,3-dichloropropane & 0.0000157 & ND \\
\hline \multicolumn{3}{|l|}{$\mathrm{ER}=$ Emissions Rate } \\
\hline \multicolumn{3}{|c|}{$\begin{array}{l}\text { ERP = Emissions Rate Potential, stated in lb/hr. } \\
{ }^{*} \text { ERP is based on NYSDEC Air Guide } 1 \text { Regulations. } \\
{ }^{\star} \text { Actual rate reported is the average for the year. } \\
\mathrm{ND}=\text { Analyte not detected }\end{array}$} \\
\hline NS = Not sampled & & \\
\hline
\end{tabular}


- In the spring of 2008 implement the modification to recirculation well RTW-1 to work as a pumping well with $\mathrm{Cr}(\mathrm{VI})$ treatment, and discharge to the nearby surface drainage culvert. In addition to the existing air stripping treatment for VOCs, this will involve the installation of ionexchange treatment vessels for $\mathrm{Cr}(\mathrm{VI})$, and running a discharge line to the culvert about 300 feet away. Effluent sampling frequency will be performed as per the approved SPDES equivalency permit. Once $\mathrm{Cr}(\mathrm{VI})$ concentrations drop below allowable discharge levels and all monitoring wells in the vicinity of the pumping well are below these levels, treatment for chromium will be eliminated.

- Continue monitoring well sampling at the current quarterly frequency, and add total $\mathrm{Cr}$ and $\mathrm{Cr}(\mathrm{VI})$ to the analysis.

- Maintain operation of downgradient recirculation wells RTW-2, RTW-3, and RTW-4. Continue operation until TVOC concentrations $<50 \mu \mathrm{g} / \mathrm{L}$ are seen in the recirculation wells' influent and adjacent monitoring wells. Maintain a monthly sampling frequency of the influent and effluent for each well when they are operating. When in standby mode reduce the sampling to quarterly.

- In the spring of 2008, perform soil borings at the location of the highest VOC contamination and analyze the silt zone soil cores for VOCs. Geophysical logs and soil cores will be obtained to determine detailed lithology. These data will aid in precisely defining the nature and extent of the source area, which is critical to determine the most cost-effective remedial alternative for this area. In addition, one well will be installed to help evaluate the effectiveness of using soil vapor extraction technology in this area.

- Following the collection of the source area analytical and geological data, complete an evaluation of alternative methods for remediating the contamination in the silt zone upgradient of extraction well RTW-1. This evaluation will include excavation of the source area, adding an additional extraction well in the source area, and evaluating other remedial technologies. The evaluation will be prepared in 2008 .

- Following the determination of the remedial action to address the VOCs in the silt zone, update the project DQOs.

- Add a core monitoring well west of well 095-172 to determine VOC concentrations just upgradient of RTW-2. 
SER VOLUME II: GROUNDWATER STATUS REPORT

This page intentionally left blank. 


\subsubsection{Middle Road Pump and Treat System}

The Middle Road Groundwater Pump and Treat System began operating on October 23, 2001. This section summarizes the operational data from the Middle Road system for 2007, and presents conclusions and recommendations for future operation. The analytical data from the monitoring wells are also evaluated in detail.

\subsubsection{System Description}

The Middle Road system was designed with six extraction wells and air-stripping technology to remove VOCs from the groundwater. On September 30, 2003, extraction wells RW-4 and RW-5 were placed in standby mode due to low concentrations of VOCs. In September 2006, well RW-6 was also placed in standby mode due to low VOC concentrations. The system is currently operating at a pumping rate of approximately $300 \mathrm{gpm}$. A complete description of the system is included in the Operation and Maintenance Manual for the OU III Middle Road and South Boundary Groundwater Treatment Systems, Revision 1 (BNL 2003a).

\subsubsection{Groundwater Monitoring}

The Middle Road Monitoring Program consists of a network of 23 monitoring wells located between the Princeton Avenue firebreak road and the OU III South Boundary Pump and Treat System (Figure 1-2).

The 23 Middle Road wells are sampled and analyzed for VOCs. Nine of the wells are sampled quarterly, and the others are sampled semiannually. Several wells are also utilized in the OU III HFBR Tritium Monitoring Program (Table 1-5).

\subsubsection{Monitoring Well Results}

The complete VOC results are shown in Appendix C. The highest plume concentrations are found between extraction wells RW-1 and RW-3, based on influent data for these wells and available monitoring well data (Figure 3.2-1). TVOC concentrations in monitoring wells east of RW-3 are generally below $10 \mu \mathrm{g} / \mathrm{L}$. VOC concentrations have generally continued to decline in 2007 . Results for key monitoring wells are as follows.

- The highest TVOC concentration detected was in bypass detection well 113-11, at $424 \mu \mathrm{g} / \mathrm{L}$ in October 2007. The VOCs in this bypass well were present prior to the operation of the pump and treat system, and are expected to be captured by the OU III South Boundary system.

- Bypass well 113-17 has shown a significant decrease in TVOCs since 2005 with concentrations dropping from $1,347 \mu \mathrm{g} / \mathrm{L}$ to $179 \mu \mathrm{g} / \mathrm{L}$.

- Plume core well 105-23 is approximately 2,000 feet upgradient of RW-1, near Princeton Avenue. TVOC concentrations have decreased from $1,794 \mu \mathrm{g} / \mathrm{L}$ during 2001 , to $42 \mu \mathrm{g} / \mathrm{L}$ in the fourth quarter of 2007 (Figure 3.2.3-1).

- TVOC concentrations in plume core wells to the east of well 105-23, along Princeton Avenue, were generally below $100 \mu \mathrm{g} / \mathrm{L}$ in 2007 . TVOC concentrations decreased in well 105-44, from $423 \mu \mathrm{g} / \mathrm{L}$ in 2001 to $9 \mu \mathrm{g} / \mathrm{L}$ in the fourth quarter of 2007 (Figure 3.2.3-1).

Figure 3.2.3-2 shows the vertical distribution of contamination running along an east-west line through the extraction wells; the location of this cross section (E-E') is given in Figure 3.2-1. VOC contamination in the western portion of the remediation area (RW-1 through RW-3) extends into the Upper Magothy aquifer, as does the screen on well RW-3. This figure shows that the area of TVOCs exceeding the capture goal of $50 \mu \mathrm{g} / \mathrm{L}$ is limited to the western portion of the treatment system in the vicinity of RW-1, RW-2 and RW-3. 


\subsubsection{System Operations}

The effluent sampling parameters for $\mathrm{pH}$ and VOCs follow the requirements for monthly sampling, as per the SPDES equivalency permit. In addition, system influent samples are analyzed for tritium during each system-sampling event. Tritium remains below detection limits in all samples. All effluent concentrations from the treatment system during this period of operation were below equivalency permit levels except for pH (Table 3.2.3-1).

Approximately 128 million gallons of water were pumped and treated in 2007 by the OU III Middle Road System. The following paragraphs summarize the Middle Road System operations for 2007.

January-September 2007

The system was off in August and September due to electrical repairs and numerous electrical storms that knocked out electric and communications to the system. Approximately 84 million gallons of water were treated.

October - December 2007

The system operated normally and pumped and treated approximately 43 million gallons of water during this quarter. The system was down in December due to communication problems between the extraction wells and stripping tower.
Table 3.2.3-1.

Middle Road Air Stripping Tower 2007 SPDES Equivalency Permit Levels

\begin{tabular}{lcc}
\hline Parameters & Permit Limit & $\begin{array}{c}\text { Max. } \\
\text { Observed } \\
\text { Value }\end{array}$ \\
\hline pH range (SU) & $6.5-8.5$ & $6.75-7.44$ \\
carbon tetrachloride & $5 \mu \mathrm{g} / \mathrm{L}$ & $\mathrm{ND}$ \\
chloroform & $7 \mu \mathrm{g} / \mathrm{L}$ & $\mathrm{ND}$ \\
dichlorodifluoromethane & $5 \mu \mathrm{g} / \mathrm{L}$ & $\mathrm{ND}$ \\
1,1-dichloroethane & $5 \mu \mathrm{g} / \mathrm{L}$ & $\mathrm{ND}$ \\
1,1-dichloroethylene & $5 \mu \mathrm{g} / \mathrm{L}$ & $\mathrm{ND}$ \\
methyl chloride & $5 \mu \mathrm{g} / \mathrm{L}$ & $\mathrm{ND}$ \\
tetrachloroethylene & $5 \mu \mathrm{g} / \mathrm{L}$ & $\mathrm{ND}$ \\
toluene & $5 \mu \mathrm{g} / \mathrm{L}$ & $\mathrm{ND}$ \\
1,1,1-trichloroethane & $5 \mu \mathrm{g} / \mathrm{L}$ & $\mathrm{ND}$ \\
1,1,2 trichloroethane & $5 \mu \mathrm{g} / \mathrm{L}$ & $\mathrm{ND}$ \\
trichloroethylene & $10 \mu \mathrm{g} / \mathrm{L}$ & $\mathrm{ND}$ \\
\hline Notes: & \\
ND = Not detected above method detection limit of $0.50 \mu \mathrm{g} / \mathrm{L}$. & \\
SU = Standard Units \\
Required sampling frequency is monthly for $\mathrm{VOCs}$ and $\mathrm{pH}$.
\end{tabular}

\subsubsection{System Operational Data}

System Influent and Effluent

All parameters in the SPDES equivalency permit limits were within the specified ranges during 2007. Figure 3.2.3-4 plots the concentrations of TVOCs in the extraction wells versus time.

Results from samples collected from the extraction wells are found on Table F-10 (Appendix F). The influent VOC concentrations remained constant over the reporting period. The average TVOC concentration in the influent during 2007 was $46 \mu \mathrm{g} / \mathrm{L}$ (see Table F-11). The results from sampling the influent and effluent are summarized in Tables F-11 and F-12, respectively. 


\section{Cumulative Mass Removal}

Mass balance was calculated for the period of operation to determine the mass removed from the aquifer by the pumping wells. Average flow rates for each monthly monitoring period were used, in combination with the TVOC concentration in the airstripper influent, to determine the pounds removed. Flow averaged 248 gpm during 2007 (Table 2-3, and Table F-13), and approximately 34 pounds of VOCs were removed. Approximately 741 pounds of VOCs have been removed since the system began startup testing on October 23, 2001. The cumulative total of VOCs removed vs. time is plotted in Figure 3.2.3-3.

\section{Air Discharge}

Table 3.2.3- 2 shows the air emissions data from the system for the OU III Middle Road tower during 2007, and compares the values to levels stipulated in NYSDEC Air Guide 1 regulations. Emission rates are obtained through mass-balance calculations for all water treated during that time (Table F-10). The concentration of each constituent was averaged for 2007, and those values were used in determining the emissions rate. All air emissions were below permitted limits.
Table 3.2.3-2. Middle Road Air Stripper VOC Emission Rates, 2007 Average

\begin{tabular}{|c|c|c|}
\hline Parameter & $\begin{array}{l}\text { Allowable } \\
\text { ERP* (lb/hr) }\end{array}$ & $\begin{array}{l}\text { Actual }\left.\right|^{* *} \\
(\mathrm{lb} / \mathrm{hr})\end{array}$ \\
\hline carbon tetrachloride & 0.022 & 0.0002 \\
\hline chloroform & 0.0031 & 0.0001 \\
\hline 1,1-dichloroethane & $10^{\star \star \star}$ & 0.000026 \\
\hline 1,2-dichloroethane & 0.008 & 0.000002 \\
\hline 1,1-dichloroethylene & 0.034 & 0.0001 \\
\hline cis-1,2-dichloroethylene & $10^{* \star *}$ & 0.0001 \\
\hline trans-1,2-dichloroethene & $10^{\star \star \star}$ & 0 \\
\hline tetrachloroethylene & 0.387 & 0.0041 \\
\hline 1,1,1-trichloroethane & $10^{\star \star \star}$ & 0.0005 \\
\hline trichloroethylene & 0.143 & 0.0002 \\
\hline \multicolumn{3}{|l|}{ Notes: } \\
\hline \multicolumn{3}{|c|}{$\begin{array}{l}\text { ERP = Emission Rate Potential. Reported in lb/hr. } \\
{ }^{*} \text { ERP based on NYSDEC Air Guide } 1 \text { Regulations. } \\
{ }^{*} \text { Rate reported is the average rate for the year. } \\
{ }^{* \star} 6 \text { NYCRR Part } 212 \text { restricts emissions of VOCs to a } \\
\text { maximum of } 10 \mathrm{lb} / \mathrm{hr} \text { without controls. }\end{array}$} \\
\hline
\end{tabular}

\section{Extraction Wells}

Extraction wells RW-4 and RW-5 were shut down on September 30, 2003 and placed on standby due to low concentrations of VOCs. The extraction wells, including wells RW-4 and RW-5, are sampled quarterly. RW-6 was shut down in September 2006 due to low VOC concentrations in this well. Quarterly sampling of the wells will continue. The influent VOC concentrations remained constant over the reporting period for the operational wells.

\subsubsection{System Evaluation}

The system has been operating since October 23, 2001. Groundwater mapping indicates that hydraulic control has been achieved.

The OU III Middle Road Pump and Treat System performance can be evaluated based on the five major decisions identified for this system from the groundwater DQO process.

\section{Was the BNL Contingency Plan triggered?}

No. There were no unusual or unexpected VOC concentrations observed in the monitoring wells and extraction wells associated with the OU III Middle Road Pump and Treat System during 2007.

\section{Has the plume been controlled?}

Yes. VOC concentrations in plume perimeter wells remained stable at low concentrations during 2007, indicating that the plume is being controlled. High VOC concentrations in bypass wells were present before the system was operational and are not within the capture zone of the extraction wells. It will take several additional years before the contaminants migrate to the South Boundary System. Semiannual groundwater elevation data were obtained from many of the OU III Middle Road 
monitoring program wells, in addition to wells located throughout the BNL on-site and off-site monitoring areas. Groundwater contour maps are generated using these data (Figures 2-2 and 2-3).

The capture zone for the OU III Middle Road system is depicted in Figure 3.0-1. The capture zone includes the $50 \mu \mathrm{g} / \mathrm{L}$ isocontour, which is the capture goal of this system.

3. Is the system operating as planned? Specifically, is the aquifer being restored at the planned rate for this treatment system?

Yes. The system is operating as planned based on the mass removal of VOCs. Monitoring wells continue to show generally decreasing concentration trends during 2007.

\section{Can the groundwater treatment system be shut down?}

No, the system has not met all shutdown requirements (see 4a through 4d).

4a. Have asymptotic VOC concentrations been reached in core wells?

No. Monitoring and extraction wells have shown generally decreasing concentration trends since 2002 and these trends have continued.

4b. Is the mean TVOC concentration in core wells less than $50 \mu \mathrm{g} / \mathrm{L}$ (expected by 2025)?

Yes, the average TVOC concentration for the plume core wells was $47 \mu \mathrm{g} / \mathrm{L}$ (Figure 3.2.3-5).

4c. How many individual plume core wells are above $50 \mu \mathrm{g} / \mathrm{L}$ ?

Three of the 14 plume core wells contain TVOC concentrations greater than $50 \mu \mathrm{g} / \mathrm{L}$.

$4 d$. During pulsed operation of the system, is there significant concentration rebound in the core wells?

The OU III Middle Road System has not been pulsed, to date.

5. Have the groundwater cleanup goals been met? Have MCLs been achieved (expected by 2030)? No. MCLs have not been achieved for individual VOCs in all plume core wells. However, MCLs are expected to be achieved by 2030 .

\subsubsection{Recommendations}

The following recommendations are made for the OU III Middle Road Pump and Treat System and groundwater monitoring program:

- Maintain the routine operation and maintenance monitoring frequency that began in 2003.

- Maintain extraction wells RW-4, RW-5, and RW-6 in standby mode during 2008. Restart the wells if extraction or monitoring well data indicate that TVOC concentrations exceed the $50 \mu \mathrm{g} / \mathrm{L}$ capture goal.

- Install a temporary well about 100 feet to the west of well 113-09 to confirm the western edge of the OU III plume in this area. Based on the results of this temporary well, additional sampling or another permanent monitoring well may be required.

- Install a temporary well several hundred feet upgradient of RW-1 to locate a permanent well(s) in this area to provide for monitoring of VOCs migrating toward RW-1. 


\subsubsection{South Boundary Pump and Treat System}

This section summarizes the operational data from the OU III South Boundary Groundwater Pump and Treat System for 2007, and gives conclusions and recommendations for future operation. Also included within this section is an evaluation of the system and extraction well monitoring and sampling data.

\subsubsection{System Description}

This system began operation on June 17, 1997. It utilizes air-stripping technology for treatment of groundwater contaminated with chlorinated solvents. The water is pumped from seven extraction wells. The system is currently operating at a pumping rate of approximately $500 \mathrm{gpm}$, utilizing five extraction wells. Extraction well EW-12 was placed on standby during October 2003, and EW-8 in October 2006 due to low VOC concentrations. Wells EW-6 and EW-7 were placed in standby mode in November and December 2007 as per recommendations in the 2006 report. A complete description of the system is included in the Operation and Maintenance Manual for the OU III Middle Road and South Boundary Groundwater Treatment Systems, Revision 1 (BNL 2003a).

\subsubsection{Groundwater Monitoring}

The monitoring well network consists of 38 wells and was designed to monitor the VOC plume(s) in this area of the southern site boundary, as well as the efficiency of the groundwater remediation system (Figure 3.2.4-1). The South Boundary wells are sampled and analyzed for VOCs at frequencies detailed in Table 1-5. A number of OU III South Boundary wells are also analyzed for radionuclides as detailed in Section 3.2.14.

\subsubsection{Monitoring Well Results}

The south boundary segment of the OU III VOC plume continued to be bounded by the existing monitoring well network. Individual VOC concentrations in the plume perimeter wells were less than $5 \mu \mathrm{g} / \mathrm{L}$ except for well 121-08, which had a concentration of TCA at $7.1 \mu \mathrm{g} / \mathrm{L}$ in October 2007 (TVOC at $24 \mu \mathrm{g} / \mathrm{L}$ ) (Figure 3.2.4-1). This is still well below the capture goal of the system of 50 $\mu \mathrm{g} / \mathrm{L}$ TVOC. VOCs were detected in the deep Upper Glacial aquifer in the vicinity of the site boundary, as depicted in Figures 3.2-2, 3.2. 4-1, and 3.2.4-2. Appendix $\mathbf{C}$ has the complete groundwater monitoring results for 2007.

The plume core wells continued to show the same trend of decreasing VOC concentrations that were observed following the startup of the pump and treat system in 1997, with several exceptions. The bulk of the VOC contamination in this area is currently located between EW-3 and EW-5, as can be seen in Figure 3.2.4-2, which is a cross section ( $\left.F-F^{\prime}\right)$ drawn along the south boundary and incorporating the extraction wells. The VOC concentration trends for specific key wells are shown in Figure 3.2.3-1. Results for key monitoring wells are as follows:

- Plume core well 114-07 is immediately upgradient of EW-12. Increasing VOC concentrations in this well during 1998 prompted the addition of EW-12, which began pumping in December 1999. TVOC concentrations in 2007 remained below the NYS AWQS, with no VOCs exceeding NYS AWQS since 2001. EW-12 was placed on standby in October 2003.

- Plume core well 122-22 is immediately east of EW-8. A sharp drop in TVOC concentrations was observed during 1997 and 1998 from its pre startup concentration of 1,617 $\mu \mathrm{g} / \mathrm{L}$. VOC concentrations have remained very low, with no VOC exceedances of NYS AWQS since 2002.

- Plume core well 122-19 is directly downgradient of EW-8. TVOC concentrations were as high as $367 \mu \mathrm{g} / \mathrm{L}$ in 1997; VOCs have not been detected above standards since 2002. 
- Plume core well 122-04 is located between EW-7 and EW-8. VOC concentrations remained low during 2007 with the highest concentration being a detection of PCE at $6.2 \mu \mathrm{g} / \mathrm{L}$ in April 2007. Concentrations dropped to $3.9 \mu \mathrm{g} / \mathrm{L}$ in October 2007.

- Plume core well 121-23 is immediately downgradient of EW-5. During 2007, the TVOC concentrations ranged between 53 and $85 \mu \mathrm{g} / \mathrm{L}$. The primary contaminant observed is PCE. This is consistent with the contaminants in EW-4 and EW-5.

- Plume core well 121-13 is immediately upgradient of, and between, EW-4 and EW-5. TVOC concentrations in this well have fluctuated somewhat since 1997, peaking at 1,098 $\mu \mathrm{g} / \mathrm{L}$ in 1999 . The recent PCE concentration in this well ranged from $780 \mu \mathrm{g} / \mathrm{L}$ in June 2005 to $3.1 \mu \mathrm{g} / \mathrm{L}$ in October 2007. PCE is the primary compound in wells 121-13, 121-23, EW-4, and EW-5. This rapid rise and then fall in concentrations of PCE represents a slug of contamination migrating into this area.

- A new monitoring well (OU III SBMW-01-2006) was installed in 2006 to monitor the higher VOC concentrations seen at well 113-17 and 113-11. The well is located between the Middle Road and South Boundary systems. The 2007 results showed TVOC concentrations as high as $474 \mu \mathrm{g} /$ Lin July 2007 (see Figure 3.2-2).

- Plume core well 121-11 is upgradient of EW-3. TVOC concentrations ranged from $6 \mu \mathrm{g} / \mathrm{L}$ in April 2007 to approximately $23 \mu \mathrm{g} / \mathrm{L}$ in October 2007.

- Bypass detection wells 122-34 and 122-35, south of EW-8, were below NYS AWQS for VOCs from 2003 through 2007.

- Plume core well 122-05 is a Magothy monitoring well west of EW-8. TVOC concentrations have been showing a declining trend with concentrations at $25 \mu \mathrm{g} / \mathrm{L}$ in October 2007.

Table 3.2.4-1.

OU III South Boundary Air Stripping Tower 2007 SPDES Equivalency Permit Levels

\begin{tabular}{lcc}
\hline Parameters & $\begin{array}{c}\text { Permit } \\
\text { Limit* }\end{array}$ & $\begin{array}{c}\text { Max. } \\
\text { Observed } \\
\text { Value }\end{array}$ \\
\hline pH range(SU) & $6.5-8.5$ & $6.9-7.6$ \\
carbon tetrachloride & $5 \mu \mathrm{g} / \mathrm{L}$ & $\mathrm{ND}$ \\
chloroform & $7 \mu \mathrm{g} / \mathrm{L}$ & $\mathrm{ND}$ \\
dichlorodifluoromethane & $5 \mu \mathrm{g} / \mathrm{L}$ & $\mathrm{ND}$ \\
1,1-dichloroethane & $5 \mu \mathrm{g} / \mathrm{L}$ & $\mathrm{ND}$ \\
1,1-dichloroethylene & $5 \mu \mathrm{g} / \mathrm{L}$ & $\mathrm{ND}$ \\
methyl chloride & $5 \mu \mathrm{g} / \mathrm{L}$ & $\mathrm{ND}$ \\
tetrachloroethylene & $5 \mu \mathrm{g} / \mathrm{L}$ & $\mathrm{ND}$ \\
toluene & $5 \mu \mathrm{g} / \mathrm{L}$ & $\mathrm{ND}$ \\
1,1,1-trichloroethane & $5 \mu \mathrm{g} / \mathrm{L}$ & $\mathrm{ND}$ \\
1,1,2 trichloroethane & $5 \mu \mathrm{g} / \mathrm{L}$ & $\mathrm{ND}$ \\
trichloroethylene & $10 \mu \mathrm{g} / \mathrm{L}$ & $\mathrm{ND}$ \\
\hline *Maximum allowed by requirements equivalent to a SPDES permit. \\
ND = Not detected above method detection limit of $0.50 \mu \mathrm{g} / \mathrm{L}$. \\
Required sampling frequency is monthly for VOCs and pH. \\
\hline
\end{tabular}

\subsubsection{System Operations}

The individual extraction wells are sampled quarterly, and all samples are analyzed for VOCs. The effluent sampling parameters of $\mathrm{pH}$ and VOCs are done monthly, in accordance with SPDES permit equivalency requirements (Table 3.2. 4-1). In addition, samples are analyzed for tritium with each system-sampling event. In all samples, tritium continues to remain below analytical reporting limits. All effluent VOC concentrations from the treatment system during this period of operation were below permit equivalency requirements.

\section{System Operations}

Approximately 136 million gallons of water were pumped and treated in 2007 by the OU III South Boundary System. Well EW-8 was put in standby mode in October 2006, and EW-12 has remained in standby since 2003. Wells EW-6 and EW-7 were put on standby near the end of 2007.

January-September 2007

Approximately 95 million gallons of water 
were pumped and treated. There were communications and electrical problems during this period, which resulted in the system being off for the month of September.

October 2007-December 2007

The OU III South Boundary System pumped and treated approximately 42 million gallons of water. There were electrical problems with EW-4 during this quarter, which resulted in well maintenance and repair. In addition, well EW-6 was put on standby in November and EW-7 in December, due to low VOC concentrations.

\subsubsection{System Operational Data}

\section{System Influent and Effluent}

Figure 3.2.4-3 plots the concentrations of TVOCs in the extraction wells versus time. The overall influent water quality and the individual extraction wells show a general declining trend of concentrations. The system was also sampled monthly for tritium, which was not detected above the reporting limit in any sample during 2007. System influent and effluent sampling results are summarized in Tables F-15 and F-16, respectively.

Cumulative Mass Removal

Average flow rates for each monthly monitoring period were used, in combination with the TVOC concentration in the air-stripper influent, to calculate the mass removed (see Table F-17). The cumulative total of TVOCs removed by the treatment system versus time is plotted in Figure 3.2.4-4. The 2007

Table 3.2.4-2. OU III South Boundary Air Stripper VOC Emission Rates, 2007 Average

\begin{tabular}{|c|c|c|}
\hline Parameter & $\begin{array}{c}\text { Allowable } \\
\text { ERP* }\end{array}$ & $\begin{array}{c}\text { Actual }^{* *} \\
\text { ER }\end{array}$ \\
\hline carbon tetrachloride & 0.022 & 0.0005 \\
\hline chloroform & 0.0031 & 0.0001 \\
\hline 1,1-dichloroethane & $10^{\star \star *}$ & $<0.0002$ \\
\hline 1,2-dichloroethane & 0.008 & $<0.0002$ \\
\hline 1,1-dichloroethylene & 0.034 & 0.0002 \\
\hline cis-1,2-dichloroethylene & $10^{\star \star *}$ & 0.0001 \\
\hline trans-1,2-dichloroethylene & $10^{\star \star *}$ & 0 \\
\hline tetrachloroethylene & 0.387 & 0.0032 \\
\hline 1,1,1-trichloroethane & $10^{\star \star *}$ & 0.0005 \\
\hline trichloroethylene & 0.143 & 0.0001 \\
\hline \multicolumn{3}{|c|}{$\begin{array}{l}\text { ERP = Emissions Rate Potential, stated in lb/hr. } \\
{ }^{*} \text { ERP is based on NYSDEC Air Guide } 1 \text { Regulations. } \\
{ }^{* \star} \text { Actual rate reported is the average for the year. } \\
{ }^{* \star} 6 \text { NYCRR Part } 212 \text { restricts emissions of VOCs to a maximum of } \\
10 \mathrm{lb} / \mathrm{hr} \text { without controls. }\end{array}$} \\
\hline
\end{tabular}
total was approximately 32 pounds. Cumulatively, the system has removed approximately 2,569 pounds since it was started on June 17, 1997.

\section{Air Discharge}

Table 3.2.4-2 shows the air emissions data from the OU III South Boundary for 2007, and compares the values to levels stipulated in NYSDEC Air Guide 1 regulations. Emission rates are obtained through mass-balance calculations for all water treated during that time (Table F-15 ). The concentration of each constituent was averaged for the year, and that value was used in the calculation. All air emissions were below allowable levels.

\section{Extraction Wells}

In general, the extraction wells continued to show slowly decreasing VOC concentrations during 2007 (Figure 3.2.4-3). Table F-14 in Appendix F summarizes the data for the extraction wells.

\subsubsection{System Evaluation}

The pump and treat system continues to maintain hydraulic control and continues to prevent further plume migration across the southern site boundary. Plume core and bypass wells continued to show stable or decreasing VOC concentrations. The system operated at an average of 252 gpm during 2007. There was some significant downtime due to electrical problems and scheduled maintenance. No permit equivalency standards were exceeded and some operating difficulties were experienced due to electrical problems. There have been no air emission exceedances. 
The OU III South Boundary Pump and Treat System performance can be evaluated based on the five major decisions identified for this system resulting from the groundwater DQO process.

\section{Was the BNL Groundwater Contingency Plan triggered?}

No. There were no unusual or unexpected VOC concentrations observed in the monitoring and extraction wells associated with the OU III South Boundary Pump and Treat System during 2007.

\section{Has the plume been controlled?}

Yes. The capture zone for the OU III South Boundary Pump and Treat System is depicted in Figure 3.0-1. The capture zone depicted includes the $50 \mu \mathrm{g} / \mathrm{L}$ isocontour, which is the capture goal of this system.

3. Is the system operating as planned? Specifically, is the aquifer being restored at the planned rate for this treatment system?

Yes. The OU III South Boundary System continues to be effective in removing VOCs from the deep portions of the Upper Glacial aquifer. The overall reduction in the high-concentration areas of the plume near the south boundary is evident.

The OU III South Boundary System is planned to operate for 15 years; at the end of 2007 it had operated for approximately 10.5 years. The system is removing contamination at the expected rate and hydraulic control of the plume was demonstrated; hence, it is operating as planned. The duration of operation for the OU III South Boundary System is dependent on the effectiveness of the Middle Road Groundwater Treatment System, and the travel time from the Middle Road to the South Boundary. The Middle Road System started operation approximately 4.5 years after the OU III South Boundary System. The contaminant travel time from Middle Road to the OU III South Boundary system is approximately five to 10 years. Therefore, the high concentrations observed in the vicinity of well 113-17 (located just south of the Middle Road System) will likely determine the operating period of this system (Figures 3.2-1 and 3.2-2). This well has shown a significant decrease from over $1,300 \mu \mathrm{g} / \mathrm{L}$.

The trend in the mean of the TVOC concentrations in the core groundwater monitoring wells is declining (Figure 3.2.4-5).

4. Can the groundwater treatment system be shut down?

No, the system has not met all shutdown requirements (see below).

4a. Have asymptotic TVOC concentrations been reached in core wells?

No. The average TVOC concentrations of the OU III South Boundary wells continued a decreasing trend in 2007 (Figure 3.2.4-5).

$4 \mathrm{~b}$. Is the mean TVOC concentration in core wells less than $50 \mu \mathrm{g} / \mathrm{L}$ ?

Yes. Starting in late 2005 and continuing through 2007 (Figure 3.2.4-5).

4c. How many individual plume core wells are above $50 \mu \mathrm{g} / \mathrm{L}$ ?

Two core wells, 121-23 and SBMW-01, have TVOC concentrations above $50 \mu \mathrm{g} / \mathrm{L}$. Extraction well EW-4 also has concentrations above $50 \mu \mathrm{g} / \mathrm{L}$.

$\underline{4 d . \text { During pulsed operation of the system, is there significant concentration rebound in the core }}$ wells?

The OU III South Boundary System has not been pulsed to date. 
5. Have the groundwater cleanup goals been met? Specifically, have MCLs been achieved (expected by 2030)?

No. MCLs have not been achieved for individual VOCs in plume core wells. Based on modeling results, MCLs are expected to be achieved by 2030, as required by the OU III ROD.

\subsubsection{Recommendations}

The following are recommendations for the OU III South Boundary Pump and Treat System and groundwater monitoring program:

- Maintain the routine operations and maintenance monitoring frequency that began in 2003.

- Extraction well EW-12 was placed in standby mode in 2003 and EW-8 in 2006. Wells EW-6 and EW-7 were placed on standby at the end of 2007. These wells will continue in standby mode during 2008. The wells will be restarted if extraction or monitoring well data indicate TVOC concentrations exceed the $50 \mu \mathrm{g} / \mathrm{L}$ capture goal.

- Maintain wells EW-6, EW-7, EW-8 and EW-12 in standby mode. All extraction wells will continue to be sampled on a quarterly basis. 
SER VOLUME II: GROUNDWATER STATUS REPORT

This page intentionally left blank. 


\subsubsection{Western South Boundary Pump and Treat System}

The Western South Boundary Pump and Treat System was designed to capture VOCs exceeding 20 $\mu \mathrm{g} / \mathrm{L}$ TVOC in the Upper Glacial aquifer along a western portion of the BNL south boundary. The system reduces additional off-site migration of the contamination, and potential impacts of the VOC plume to the Carmans River. The system began operating in September 2002.

\subsubsection{System Description}

A complete description of the Western South Boundary Treatment System is contained in the Operations and Maintenance Manual for the Western South Boundary Treatment System (BNL 2002b).

\subsubsection{Groundwater Monitoring}

A network of 17 wells is used to monitor this portion of the plume. Their locations are shown in Figure 1-2. The wells are sampled at the O\&M phase frequency; see Table 1-5 for details.

\subsubsection{Monitoring Well Results}

The primary VOCs associated with this portion of the plume are dichlorodifluoromethane (freon), TCA, TCE, and chloroform. VOC contamination is located in the mid to deep Upper Glacial aquifer. Groundwater monitoring for this system was initiated in 2002. Figure 3.2-1 presents fourth-quarter 2007 monitoring well concentrations. A summary of key monitoring well data for 2007 follows:

- Plume core wells 121-42, 126-13, 127-04, and 127-06 have been generally decreasing in concentrations since the treatment system was started in 2002. TVOCs in wells 121-42 and 12706 , located upgradient of extraction well WSB-2, have remained around $20 \mu \mathrm{g} / \mathrm{L}$ since 2005 . TVOC concentrations in core well 126-15, located midway between the two extraction wells, has remained consistently low, below $5 \mu \mathrm{g} / \mathrm{L}$ from 2002 through most of 2006. In late 2006 and 2007, the concentrations began increasing but still remained below $20 \mu \mathrm{g} / \mathrm{L}$ TVOC.

- TVOC concentrations in plume core well 126-14, located upgradient of WSB-1, have decreased slightly since system start-up, but have remained elevated above $20 \mu \mathrm{g} / \mathrm{L}$. TVOC concentrations in plume core well 126-11, located adjacent to WSB-1, dropped off significantly since system start-up; however, it began increasing since 2006 and reached $27 \mu \mathrm{g} / \mathrm{L}$ in the fourth quarter 2007 (see Figure 3.2.5-1). The highest TVOC detection of the seven plume core wells was $31 \mu \mathrm{g} / \mathrm{L}$ in well 126-14 in April 2007.

- Maximum TVOC concentrations during 2007 were found in bypass detection well 130-08, located south of extraction well WSB-1, at $45 \mu \mathrm{g} / \mathrm{L}$ during the third quarter. The highest VOC detected was dichlorodifluoromethane, at $25 \mu \mathrm{g} / \mathrm{L}$.

- TVOC concentrations in bypass detection well 126-16 dropped-off to its lowest level in four years: $19 \mu \mathrm{g} / \mathrm{L}$ in the first quarter of 2007 but it increased slightly over the year. Plume bypass well 127-07, located downgradient of WSB-2, has been steadily declining in TVOC concentrations since 2005. In the third and fourth quarter of 2007, TVOCs dropped to less than $10 \mu \mathrm{g} / \mathrm{L}$. If any of the three bypass detection wells starts showing increasing trends, the need to take further action will be evaluated.

- Plume perimeter well 130-03, located west of extraction well WSB-1, detected a maximum TVOC concentration in 2007 of $29 \mu \mathrm{g} / \mathrm{L}$ in April. This is a decreasing trend from the historical high of $58 \mu \mathrm{g} / \mathrm{L}$ TVOC in December 2004. The capture zones of the Western South Boundary extraction wells were not intended to include this area. 
- Plume perimeter wells 119-03 and 125-01 monitor the groundwater quality in the vicinity of the OU III Western South Boundary recharge basin. There have been no detections of VOCs exceeding NYS AWQS for these wells since they were installed in 2002.

\subsubsection{System Operations}

During 2007, the extraction wells were sampled quarterly. The influent and effluent of the airstripper tower were sampled twice per month in May, but due to a scheduling error, the system was only sampled once per month when the system was running in February, July, and November. The system was placed in standby mode for pulse pumping the remainder of the time. All samples were analyzed for VOCs. In addition, the effluent sample was analyzed for $\mathrm{pH}$ and tritium twice a month. No tritium was detected in 2007. Table 3.2.5-1 provides the effluent limitations for meeting the requirements of the SPDES equivalency permit. All effluent discharges met the SPDES equivalency permit requirements. The system operations are summarized as follows:

January-September 2007

The treatment system operated normally from January to September. The system has been in a pulse pumping schedule since 2005 . The schedule is one month on and two months off.

October-December 2007

The system was off in October and December as part of the pulse pumping schedule. Normal system operations were conducted in November and the system operated without interruption.

\subsubsection{System Operational Data}

Extraction Wells

During 2007, approximately 71 million gallons of groundwater were pumped and treated by the OU III Western South Boundary System, with an average flow rate of approximately $259 \mathrm{gpm}$ while in operation. Table 2-3 gives monthly pumping data for the two extraction wells. VOC and tritium concentrations for extraction wells WSB-1 (126-12) and WSB-2 (127-05) are provided in Table F-18 in Appendix F (on the CD-ROM). VOC levels in both wells continued to show a slight decreasing trend since system start-up in 2002, through 2006. Since 2006 through mid 2007 there has been a slight increasing trend; however, in May 2007 the TVOC concentrations began dropping off. TVOC extraction well concentrations typically ranged between 8 to $19 \mu \mathrm{g} / \mathrm{L}$ for 2007 (see Figure 3.2.5-3 for a graph of extraction wells trends over time). Most of the individual VOC compounds were either below or slightly above the NYS AWQS .

System Influent and Effluent

All influent TVOC concentrations were less than $18 \mu \mathrm{g} / \mathrm{L}$, and individual VOC concentrations were less than the NYS AWQS, except for May 2007 data that detected TCA at $5.5 \mu \mathrm{g} / \mathrm{L}$. These levels are consistent with the historical influent concentrations. The influent consists primarily of freon, TCA, TCE, and chloroform (Tables F-19 and F-20, Appendix F). 
The air-stripper system effectively removed all elevated contaminants from the influent groundwater. All effluent data were below the analytical method detection limit and below the regulatory limit specified in the equivalency permit conditions.

\section{Cumulative Mass Removal}

The mass of VOCs removed from the aquifer by the treatment system was calculated. Average flow rates for each monthly monitoring period were used, in combination with the TVOC concentration in the air-stripper's influent, to calculate the pounds removed per month (Table F-21, Appendix F ). The cumulative mass of VOCs removed by the treatment system is provided in Figure 3.2.5-2. During 2007, four pounds of TVOCs were removed; a total of 49 pounds have been removed since the startup of the system in 2002.

\section{Air Discharge}

Table 3.2.5-2 presents the VOC air emission data for the year 2007 and compares the values to levels stipulated in NYSDEC Air Guide 1 regulations. Emission rates are calculated through mass balance for all water treated during operation. The concentration of each constituent of the air-stripper's influent was averaged for the year. That value was converted from $\mu \mathrm{g} / \mathrm{L}$ to $\mathrm{lb} / \mathrm{gal}$, which was multiplied by the average pumping rate $(\mathrm{gal} / \mathrm{hr}$ ) to compare with the regulatory value. All VOC air emissions were well below allowable levels.

\subsubsection{System Evaluation}

The system has been fully operational since September 2002, and pulse pumping was initiated in late 2005. The Western South Boundary Pump and Treat System performance can be evaluated based on the five major decisions identified for this system from the groundwater DQO process.

\section{Was the BNL Contingency Plan triggered?}

No. There were no unusual or unexpected VOC concentrations observed in the monitoring wells associated with the Western South Boundary Treatment System during 2007.

\section{Has the plume been controlled?}

Yes. VOC concentrations in all of the plume perimeter wells except 130-03 remained stable at or less than the drinking water standard during 2007, indicating that the plume is being controlled. Perimeter well 130-03 has been slowly decreasing since late 2004 to a low of $27 \mu \mathrm{g} / \mathrm{L}$ in the fourth quarter 2007 . The capture zone of WSB-1was not intended to include this area. As noted above, low VOC concentrations in the bypass wells were present before the system was operational and not within the capture zone of the extraction wells. The capture zone for the treatment system is depicted in Figure 3.0-1.

3. Is the system operating as planned? Specifically, is the aquifer being restored at the planned rate? Yes. The system is operating as planned based on meeting the capture goal of $20 \mu \mathrm{g} / \mathrm{L}$ TVOCs. Plume core monitoring wells began showing decreasing concentration trends since 2002 except for well 12611 in 2006 and 2007. Increasing VOCs in monitoring wells immediately upgradient of WSB-1 (i.e., 126-11 and 126-14) will be captured by the system. 
4. Can the groundwater treatment system be shut down?

No, the system has not met all shutdown requirements. However, the extraction wells began pulsepumping in late 2005 based on low TVOC concentrations in core monitoring wells and the extraction wells (see 4a through 4b).

4a. Have asymptotic VOC concentrations been reached in core wells?

No. As noted in Section 3.2.5.3 above, all core monitoring wells have been steadily decreasing since the system became operational in mid 2002, except for well 126-11. This well, immediately upgradient of WSB-1, has been steadily increasing since 2006. Extraction wells WSB-1 and WSB-2 have shown generally steady and low concentration trends since 2002 between approximately 10 $\mu \mathrm{g} / \mathrm{L}$ and $25 \mu \mathrm{g} / \mathrm{L}$ TVOCs, respectively. However, there was a slight increase in TVOC concentrations in both extraction wells starting in late 2005 through mid 2007. Most of the extraction well and influent individual VOC data have been below the NYS AWQS.

4b. Is the mean TVOC concentration in core wells less than $20 \mu \mathrm{g} / \mathrm{L}$ ?

No, although five out of seven core wells have been below $20 \mu \mathrm{g} / \mathrm{L}$ TVOCs for the past 18 months.

4c. How many individual plume core wells are above $20 \mu \mathrm{g} / \mathrm{L}$ TVOCs?

TVOC concentrations in two of seven core wells were above $20 \mu \mathrm{g} / \mathrm{L}$. Wells 126-11 and 126-14, just upgradient of extraction well WSB-1, showed TVOCs up to $27 \mu \mathrm{g} / \mathrm{L}$ and $31 \mu \mathrm{g} / \mathrm{L}$, respectively, in 2007 .

4 d. During pulsed operation of the system, is there significant concentration rebound in core wells? Yes. As noted above, plume core well 126-11 has been steadily increasing since 2006, shortly after pulse pumping began. The highest TVOC concentration in 2007 was $27 \mu \mathrm{g} / \mathrm{L}$. TVOC concentrations in the extraction wells increased slightly since 2006; however, they remained below $20 \mu \mathrm{g} / \mathrm{L}$ in 2007.

5. Have the groundwater cleanup goals been met? Are MCLs expected to be been achieved by 2030?

No. MCLs have not been achieved for individual VOCs in all plume core wells. However, MCLs are expected to be achieved by 2030 .

\subsubsection{Recommendations}

The following are recommendations for the OU III Western South Boundary Treatment System and groundwater monitoring program:

- Based on increasing TVOC concentrations (i.e., $>20 \mu \mathrm{g} / \mathrm{L}$ ) in core well 126-11 in 2007, return extraction well WSB-1 to on full-time operation. Continue pulse pumping WSB-2 at the schedule of one month on and two months off. This process will continue and any changes to the VOC concentrations in the influent and the monitoring wells will be evaluated.

- If any of the three bypass detection wells starts showing increasing trends, the need to take further action will be evaluated.

- As there have been no detections of VOCs exceeding NYS AWQS for plume perimeter wells 119-03 and 125-01 since they were installed in 2002, VOC analysis will be discontinued. These wells monitor the groundwater quality in the vicinity of the OU III Western South Boundary recharge basin. Also, since background well 124-02 has not had any detections of VOC above the NYS AWQS, this parameter will be dropped.

- Maintain the routine O\&M monitoring frequency that began in 2005. 


\subsubsection{Industrial Park In-Well Air Stripping System}

This section summarizes the operational data from the OU III Industrial Park In-Well Air Stripping System for 2007 and presents conclusions and recommendations for its future operation. The system began operation on September 27, 1999. The OU III Industrial Park system was designed to contain and remediate the portion of OU III plume existing between BNL's southern boundary and the southern boundary of the Parr Industrial Park. Figure 3.2.4-1 illustrates the extent of the OU III contaminant plume in the vicinity of the Industrial Park.

\subsubsection{System Description}

The OU III Industrial Park system consists of a line of seven in-well air stripping treatment wells. Each treatment well is constructed with two well screens separated by an inflatable packer. Contaminated groundwater is withdrawn from the aquifer via submersible pump through a lower screen (extraction screen) set at the base of the treatment well. The groundwater is pumped to a stripping tray located in a below ground vault over the wellhead. After passing through the stripping tray, treated groundwater flows back down the well and is recharged to a shallower portion of the aquifer through an upper screen (recharge screen). Some of the treated groundwater that is recharged through the upper screen recirculates through the cell and is drawn back into the extraction screen for further treatment, while the balance flows in the direction of regional groundwater flow.

A closed-loop air system through a single blower keeps the vault under a partial vacuum. This vacuum draws air from below the stripping tray as contaminated groundwater is discharged on top. VOCs are transferred from the liquid phase to the vapor phase as contaminated groundwater passes through the stripping tray. The contaminated air stream is carried from the vault to a treatment and control building, where it is passed through two granular activated carbon (GAC) units in series to remove the VOCs. Treated air is then recirculated back to the wellhead. The carbon units, system blower, and system control panel are all housed in a one-story masonry treatment building. A complete description of the system is included in the Operation and Maintenance Manual for the OU III Off-Site Removal Action (BNL 2000b).

\subsubsection{Groundwater Monitoring}

Well Network

The monitoring well network consists of 40 wells and is designed to monitor the VOC plumes in the vicinity of the industrial park south of the site, and also the effectiveness of the in-well air stripping groundwater treatment system on this part of the high-concentration OU III VOC plumes. The wells are located throughout the industrial park, and on Carleton Drive, shown in Figure 3.2.4-1. Screen depths are set to capture water levels at multiple depths and to obtain water quality data as follows: 1) above the treatment well effluent depth, 2) at the effluent depth, and 3) at the treatment well influent depth.

Sampling Frequency and Analysis

Plume core and perimeter wells are sampled either annually or semiannually and analyzed for VOCs. Bypass detection and Magothy wells are sampled quarterly and analyzed for VOCs (Table 1-5).

\subsubsection{Monitoring Well Results}

The complete results are included in Appendix C. VOC concentrations in the plume perimeter wells that monitor the width of the plume (000-245 and 000-272) remained below NYS AWQS during 2007. Based on these data, the plume is effectively bounded by the current well network. Figure 3.2.4-1 shows the plume distribution based on fourth-quarter 2007 data. The vertical extent of contamination is shown in Figure 3.2.6-1. The location of this cross section $\left(\mathrm{G}-\mathrm{G}^{\prime}\right)$ is illustrated in Figure 3.2-1 and 3.2.4-1. 2007 Results for key monitoring wells are as follows. 


\section{Plume Core Wells}

- Wells 000-253 (just east of UVB-1) and 000-256 (between UVB-1 and UVB-2), which had both shown concentrations in 2001 well over $1000 \mu \mathrm{g} / \mathrm{L}$ TVOC, have continued to show concentrations at or below NYS AWQS. Since 2003, UVB-1 has remained in standby.

- Well 000-259, which was sampled in May and November 2007 (between UVB-2 and UVB-3), had elevated concentrations of $297 \mu \mathrm{g} / \mathrm{L}$ and $193 \mu \mathrm{g} / \mathrm{L}$ TVOCs, respectively. This is consistent with data observed in extraction wells UVB-2 and UVB-3.

- A steady decline in TVOC concentrations was observed in well 000-112 (immediately upgradient of UVB-1 and UVB-2) since 1999, when concentrations were near 2,000 $\mu \mathrm{g} / \mathrm{L}$. TVOC concentrations were at $4 \mu \mathrm{g} / \mathrm{L}$ in November 2007 (Figure 3.2.6-2).

- Well 000-262 (between UVB-4 and UVB-5) began showing decreasing TVOC concentrations in 2002 (Figure 3.2.6-2 ). TVOC concentrations in this well peaked at 2,175 $\mu \mathrm{g} / \mathrm{L}$ in 2001 and dropped to $211 \mu \mathrm{g} / \mathrm{L}$ in November 2006; however, in 2007 this well showed a marked increase to $408 \mu \mathrm{g} / \mathrm{L}$ in May and $695 \mu \mathrm{g} / \mathrm{L}$ in November.

- The TVOC concentration in well 000-268 (between UVB-6 and UVB-7) was $78 \mu \mathrm{g} / \mathrm{L}$ in November 2007 (Figure 3.2.6-2). These data are consistent with data observed in UVB wells 6 and 7.

\section{Plume Bypass Wells}

- TVOC concentrations in most of the wells located near Carleton Drive were stable or decreasing during 2007. Wells 000-431 and 000-432 serve as bypass monitoring points downgradient of UVB-2. Well 000-432 has shown TVOC concentrations between $4 \mu \mathrm{g} / \mathrm{L}$ and $10 \mu \mathrm{g} / \mathrm{L}$ during 2007. TVOC concentrations in 000-431 were below NYS AWQS during 2007. The low TVOC concentrations in these wells indicate that the system is effective in hydraulically controlling the plume.

- TVOC concentrations in wells $000-275,-276,-277$, and -278 are all below the capture goal of 50 $\mu \mathrm{g} / \mathrm{L}$, indicating that the system is effective in capturing the plume. The highest concentration observed was $14.5 \mu \mathrm{g} / \mathrm{L}$ (January 2007), in well 000-277.

- Wells 000-273 and -274 have shown an increasing concentration trend. Well 000-273 went from $15 \mu \mathrm{g} / \mathrm{L}$ in March 2006 to $375 \mu \mathrm{g} / \mathrm{L}$ TVOC in November 2006, and as expected down to $54 \mu \mathrm{g} / \mathrm{L}$ in November 2007. Well 000-274 increased from $20 \mu \mathrm{g} / \mathrm{L}$ in March 2006 to $143 \mu \mathrm{g} / \mathrm{L}$ in November 2006. This well declined to $21 \mu \mathrm{g} /$ in July 2007 and then back up to $187 \mu \mathrm{g} / \mathrm{L}$ in November. However, data from January 2008 showed concentrations back down to $65 \mu \mathrm{g} / \mathrm{L}$. These wells are located immediately downgradient of well UVB-1, which was shut down in October 2005. These TVOC concentrations being observed in the monitoring wells are from contamination that was in the "stagnation zone" downgradient of UVB-1 while it was operating. Now that it has been shut down, the contaminants have migrated downgradient of the extraction well. These contaminants could not be captured by the extraction well because they were too far downgradient but were held up by the pumping. As these higher concentration slugs of contaminants are passing by the monitoring wells, the concentrations increase and then decline. These contaminants will be captured by the LIPA extraction wells.

\section{Perimeter Wells}

VOC concentrations for individual constituents remained below NYS AWQS $(5 \mu \mathrm{g} / \mathrm{L})$ in each of the shallow wells screened to monitor above the adjacent UVB effluent well screens.

\subsubsection{System Operations}

In 2007, approximately 130 million gallons of groundwater were pumped and treated. 


\section{Operating Parameters}

Water samples are obtained monthly from each of the seven extraction wells before air stripping in each UVB tray and after treatment. All samples are analyzed for VOCs. These samples determine the wells' removal efficiency and performance. Based on these results, operational adjustments are made to optimize the system's performance.

\section{System Operations}

The following summarizes the system operations for 2007 :

Well UVB-1 remained in standby mode throughout the year.

January - September 2007

The system was off from March 26 to April 5 for electrical repairs, and again from August 1 to August 8 for repairs to the blower. For the rest of this period the system operated although several wells were off for brief periods for repairs and/or routine maintenance.

October - December 2007

Well UVB-5 was off from October 1 to October 19, with electrical problems. The rest of the system operated normally for the remainder of the period. Well UVB-4 was put in standby in January 2007 as per last year's annual report recommendations.

\subsubsection{System Operational Data}

Recirculation Well Influent and Effluent

During 2007, influent TVOC concentrations in all treatment system wells remained stable, except for a significant drop in the concentrations in UVB-2 in the fourth quarter (Figure 3.2.6-3). The corresponding effluent well concentrations (Figure 3.2.6-4) showed decreasing or stable TVOC concentrations for the year. UVB-1 remained in standby mode for 2007. There was significant downtime for the system in 2007 due to electrical problems and routine maintenance and cleaning of the wells.

Overall for 2007, the average removal efficiency was 85 percent (Table F-22, Appendix F). Well UVB-1 was not used in this calculation because it was off, and well UVB-4 was not utilized because all of the influent concentrations were very low.

\section{Cumulative Mass Removal}

Calculations were performed to determine the VOC mass removed from the aquifer by the remediation wells during the year. The average estimated flow rates for each monthly monitoring period were used, in combination with the influent and effluent TVOC concentrations. Table F-23 summarizes these data and they are included in Appendix F. Flow averaged approximately $41 \mathrm{gpm}$ for the six operating wells during 2007. Figure 3.2.6-5 plots the total pounds of TVOCs removed by the treatment system vs. time. During 2007, 43 pounds were removed from the aquifer, with a total of 1,010 pounds removed since 1999 .

\section{Air Treatment System}

Air samples were collected quarterly from the GAC vessels prior to treatment, between the two vessels, and after the second vessel (effluent). The samples were used to determine when a GAC changeout was needed. In addition, airflow rates were recorded to optimize the efficiency of individual recirculation wells.

Airflow rates are measured for each in-well air-stripping unit inside the treatment building. These rates averaged $564 \mathrm{cfm}$ for the seven wells during 2007 (Table F-24, Appendix F). 


\subsubsection{System Evaluation}

The OU III Industrial Park In-Well Air Stripping System performance can be evaluated based on the five major decisions identified for this system resulting from the groundwater DQO process.

\section{Was the BNL Groundwater Contingency Plan triggered?}

No. There were no unusual or unexpected VOC concentrations observed in the monitoring wells or extraction wells associated with the OU III Industrial Park System during 2007.

\section{Has the plume been controlled?}

Yes. An analysis of the plume perimeter and bypass well data reveals that there were no significant VOC concentration increases in these wells during 2007, except for higher concentrations in wells 000-273 and -274, which is expected, as explained in Section 3.2.6.3. Therefore, it is concluded that there has been no plume growth and the plume continues to be controlled.

The capture zone for the OU III Industrial Park System is depicted in Figure 3.0-1. The capture zone depicted includes the TVOC $50 \mu \mathrm{g} / \mathrm{L}$ isocontour, which is the capture goal of this system.

3. Is the system operating as planned? Specifically, is the aquifer being restored at the planned rate for this treatment system?

Yes. The treatment system is effectively removing contamination. The current estimate for treatment system operations is approximately 12 years (2011). The OU III Industrial Park System continues to effectively remove VOCs from the deep Upper Glacial aquifer. Figure 3.2-3 compares the OU III plume from 1997 to 2007. The overall reduction in the high-concentration areas of the plume near the south boundary is evident. This is an indication that concentrations of VOCs approaching the Industrial Park System will decrease over time.

The overall trend in the mean of the TVOC concentrations in the core groundwater monitoring wells is declining (Figure 3.2.6-6). The system is removing contamination at the expected rate and hydraulic control of the plume is demonstrated; hence, it is operating as planned.

\section{Can the groundwater treatment system be shut down?}

No, the system has not met all shutdown requirements (see below).

4a. Have asymptotic TVOC concentrations been reached in core wells?

No. concentrations show an overall slightly decreasing trend.

4b. Is the mean TVOC concentration in core wells less than $50 \mu \mathrm{g} / \mathrm{L}$ ?

No, the mean TVOC concentration in the plume core wells was $\sim 100 \mu \mathrm{g} / \mathrm{L}$.

4c. How many individual plume core wells are above $50 \mu \mathrm{g} / \mathrm{L}$ TVOC?

Three (000-259, -262, and -268) of the nine plume core wells have TVOC concentrations exceeding $50 \mu \mathrm{g} / \mathrm{L}$, as of the fourth quarter 2007.

$\underline{4 d .}$ During pulsed operation of the system, is there significant concentration rebound in the core wells?

No. The OU III Industrial Park In-Well Air Stripping System has not been pulsed to date.

5. Have the groundwater cleanup goals been met? Have MCLs been achieved (expected by 2030)?

No. MCLs have not been achieved for individual VOCs in plume core wells. Based on model predictions, MCLs are expected to be achieved by 2030, as required by the OU III ROD. 


\subsubsection{Recommendations}

The following are recommendations for the Industrial Park In-Well Air Stripping System and groundwater monitoring program:

- The current routine operations and maintenance monitoring frequency will be maintained during 2008 .

- The system will continue operations at 60 gpm per well except for well UVB-1, which is to remain in a standby mode. It is recommended that well UVB-4 be placed back in operation to address VOCs being observed in monitoring well 000-262, which is located between UVB-4 and UVB-5. Monthly recovery well sampling will continue, and if TVOC concentrations greater than $50 \mu \mathrm{g} / \mathrm{L}$ are observed, well UVB-1 will be restarted. 
SER VOLUME II: GROUNDWATER STATUS REPORT

This page intentionally left blank. 


\subsubsection{Industrial Park East Pump and Treat System}

This section summarizes the 2007 operational and monitoring well data for the OU III Industrial Park East (IPE) Groundwater Pump and Treat System, and presents conclusions and recommendations for its future operation. The system began full operation in June 2004 to provide capture and control for a downgradient portion of the OU III VOC plume, which has migrated beyond the BNL site boundary.

\subsubsection{System Description}

The treatment facility (Building OS-2) is located at the Industrial Park immediately east of Building OS-1, the Industrial Park Groundwater Treatment System. This system includes two extraction wells and two recharge wells. Extraction well EW I-1 is screened in the Upper Glacial Aquifer and EW I-2 is screened in the upper portion of the Magothy aquifer (see Figure 3.2.6-1 and 3.2.3 ). Extraction well EW I- 1 is designed to operate at a maximum rate of approximately $120 \mathrm{gpm}$; extraction well EW I-2 is designed for approximately $100 \mathrm{gpm}$. In 2007, a new injection well was added to this system.

The treated water is recharged to the Upper Glacial aquifer through two recharge wells near the extraction wells, designated as DW I-1 and DW I-2. A complete description of the system is contained in the Operations and Maintenance Manual for the Industrial Park East Offsite Groundwater Remediation System (BNL 2004i).

\subsubsection{Groundwater Monitoring}

The monitoring network consists of 12 wells (Figure 1-2) that are sampled quarterly and analyzed for VOCs. These wells monitor the VOC plume south of the LIE to Astor Drive in the East Yaphank residential area, as well as the effectiveness of the groundwater treatment system.

\subsubsection{Monitoring Well Results}

The primary VOCs associated with this portion of the OU III plume are TCA, trichloroethylene, and 1,1-dichloroethylene. Groundwater monitoring for this system was initiated in 2004; however, three of the wells have been monitoring the plume since 1999. Fourth-quarter well data is posted on Figures 3.2.4-1, 3.2.6-1, and 3.2.7.1 . The complete results are in Appendix C. Results for key monitoring wells are as follows:

- Maximum TVOC concentrations during 2007 were found in downgradient well 000-495, at 16 $\mu \mathrm{g} / \mathrm{L}$ during the fourth quarter, with TCA as the highest VOC, at $8.6 \mu \mathrm{g} / \mathrm{L}$.

- In plume core well 000-514, about 100 feet west of the extraction wells, VOC concentrations were less then MCLs during 2007.

- VOCs in plume bypass wells 000-493, -494 , have remained below the MCL since they were installed in June 2004. Concentrations in well 000-494 have shown VOCs below MCLs in 2007.

- Upgradient wells 122-24 and 122-25, which had shown concentrations as high as $570 \mu \mathrm{g} / \mathrm{L}$ in 2002, have been below $50 \mu \mathrm{g} / \mathrm{L}$ since August 2004. This correlates well with what has been observed in the area of the extraction wells, which is about 2 years' travel time from these wells.

\subsubsection{System Operations}

\section{Operating Parameters}

The influent, midpoint, and effluent of the carbon vessels are sampled once a month and analyzed for $\mathrm{pH}$ and VOCs. The extraction wells are sampled monthly. All samples are analyzed for VOCs. In addition; the $\mathrm{pH}$ of the influent and effluent samples is measured monthly. Sampling for $\mathrm{pH}$ and VOCs adheres to the requirements of the SPDES equivalency permit. All effluent samples during this period of operation were within the permit levels (Table 3.2.7-1). 
Table 3.2.7-1. Industrial Park East Pump \& Treat System 2007 SPDES Equivalency Permit Levels

\begin{tabular}{lcc}
\hline Parameters & $\begin{array}{c}\text { Permit } \\
\text { Limit } \\
(\mu \mathrm{g} / \mathrm{L})\end{array}$ & $\begin{array}{c}\text { Max. } \\
\text { Measured } \\
\text { Value }(\mu \mathrm{g} / \mathrm{L})\end{array}$ \\
\hline $\mathrm{pH}$ (range) & $5.5-8.5 \mathrm{SU}$ & $5.6-6.6 \mathrm{SU}$ \\
bromoform & 50 & $<0.50$ \\
carbon tetrachloride & 5 & $<0.50$ \\
chloroform & 5 & 0.68 \\
methylene chloride & 5 & 0.79 \\
tetrachloroethylene & 5 & $<0.50$ \\
toluene & 5 & $<0.50$ \\
trichloroethylene & 10 & $<0.50$ \\
1,2-dichloroethane & 5 & $<0.50$ \\
1,1 dichloroethane & 5 & $<0.50$ \\
1,1-dichloroethylene & 5 & $<0.50$ \\
1,1,1-trichloroethane & 5 & 1.1 \\
\hline Required sampling frequency is monthly for VOCs and pH. \\
\hline
\end{tabular}

\section{System Operations}

The following information summarizes the system operations for 2007.

\section{January-September 2007}

The system was off from February to the first half of April to install a new diffusion well. The system operated normally for the rest of this period. Forty-four million gallons were pumped and treated during the first three quarters of 2007.

\section{October-December 2007}

The system began pulse pumping of one month on and one month off in October. It was off for the month of November due to the system being pulse pumped. The system pumped and treated 17 million gallons of groundwater this quarter.

\section{Extraction Wells Operational Data}

During 2007, approximately 61 million gallons were pumped and treated by the IPE system, with an average flow rate of $120 \mathrm{gpm}$. The system began pulse pumping operations in November with a one month on and one month off. Table F-

25 shows the monthly pumping data for the system. VOC concentrations for the IPE extractions wells are provided in Table F-27. TVOC concentrations in EW I-1 ranged from $1.53 \mu \mathrm{g} / \mathrm{L}$ to $4.99 \mu \mathrm{g} / \mathrm{L}$ throughout 2007 and $6.6 \mu \mathrm{g} / \mathrm{L}$ to $22.08 \mu \mathrm{g} / \mathrm{L}$ in EW I-2.

\subsubsection{System Operational Data}

\section{System Influent and Effluent}

The overall TVOC influent concentrations to the carbon vessels were similar to levels that were recorded in 2006. Tables F-27 and F-28 in Appendix F present the influent and effluent data.

\section{Cumulative Mass Removal}

The mass of VOCs removed from the aquifer was calculated using average flow rates for each monthly monitoring period and influent concentrations to the carbon treatment system.

Table F-25 lists monthly pumpage rates for 2007 and gives total pounds of VOCs removed by the treatment system. Figure 3.2.7-2 plots mass removal versus time. Approximately 4 pounds of VOCs were removed from the aquifer during 2007, and 32 pounds since system startup in 2004.

\subsubsection{System Evaluation}

This system is designed to achieve the overall OU III ROD objectives of minimizing plume growth and meeting MCLs in the Upper Glacial aquifer in 30 years (i.e., 2030) or less. According to the $O U$ III Explanation of Significant Differences (BNL 2005b), MCLs within the Magothy aquifer must be met within 65 years (i.e., 2065) or less. The system will address the highest VOC concentration portion of the plume (above $50 \mu \mathrm{g} / \mathrm{L}$ ).

The Industrial Park East Pump and Treat System performance during 2007 can be evaluated based on the five major decisions identified for this system from the groundwater DQO process: 


\section{Was the BNL Groundwater Contingency Plan triggered?}

No. There were no unusual or unexpected VOC concentrations observed in the monitoring wells or extraction wells associated with the Industrial Park East Groundwater Pump and Treat System during 2007.

\section{Has the plume been controlled?}

Yes. The downgradient monitoring shows all concentrations below the capture goal of $50 \mu \mathrm{g} / \mathrm{L}$ of TVOCs. Contamination which has been detected in downgradient well 000-429 was present before the system began operations and this system was not designed to capture this.

\section{Is the System operating as planned?}

Yes. The system is operating as planned.

4. Can the groundwater treatment system be shut down?

Yes, the system has met all shutdown requirements.

4a. Have asymptotic VOC concentrations been reached in core wells?

All monitoring wells are below the capture goal of $50 \mu \mathrm{g} / \mathrm{L}$ for the treatment system.

4b. Is the mean TVOC concentration in core wells less than $50 \mu \mathrm{g} / \mathrm{L}$ (expected by 2025)?

Yes.

4c. How many individual plume core wells are above $50 \mu \mathrm{g} / \mathrm{L}$ ?

None.

$\underline{4 d .}$ During pulsed operation of the system, is there significant concentration rebound in the core wells?

The Industrial Park East System just started pulse pumping and no rebound has been observed to date.

5. Have the groundwater cleanup goals been met? Specifically, have MCLs been achieved in the Upper Glacial aquifer (expected by 2030) and the Magothy aquifer (expected by 2065)?

No. MCLs have not been achieved for individual VOCs in all plume core wells. However, concentrations are very close to this level, with the highest concentration being 5.1 of TCA in well 122-24. MCLs are expected to be achieved by 2030 and 2065 for the Upper Glacial and Magothy aquifers, respectively, as required by the OU III ROD and ESD.

\subsubsection{Recommendations}

The following is recommended for the Industrial Park East Pump and Treat System and groundwater monitoring program.

- Continue pulse pumping for one year and if in November 2008 no rebound is seen (i.e., TVOC concentrations exceeding $50 \mu \mathrm{g} / \mathrm{L}$ ) in extraction or monitoring wells, then petition for shutdown of this system. 
SER VOLUME II: GROUNDWATER STATUS REPORT

This page intentionally left blank. 


\subsubsection{North Street Pump and Treat System}

The North Street Pump and Treat System addresses a VOC plume that originated at the Former Landfill/Chemical Holes area. The VOC plume is presently located south of the site boundary, with the leading edge extending south to the vicinity of the Brookhaven Airport. The groundwater pump and treat system began operating in May 2004 (Figure 3.2-1).

Groundwater treatment consists of two extraction wells operating at a combined pumping rate of approximately $450 \mathrm{gpm}$. This pumping captures the higher concentration portion of the VOC plume (i.e., TVOC concentrations greater than $50 \mu \mathrm{g} / \mathrm{L}$ ) in the Upper Glacial aquifer, and will minimize the potential for VOC migration into the Magothy aquifer.

The North Street plume has been divided into two segments for remediation purposes. The area to the north of extraction well NS-2 is being addressed by the remediation system on North Street, whereas the Airport System handles the area to the south (Figure 3.0-1). The Airport System was constructed to address the leading edge of this plume and satisfy the cleanup objectives defined in the OU III ROD (i.e., minimize plume growth and meet MCLs in the Upper Glacial aquifer by 2030).

\subsubsection{System Description}

The North Street system consists of two extraction wells. Extracted groundwater is piped through two 20,000-pound GAC units and discharged to four injection wells. Both the North Street and North Street East systems share the four injection wells. Extraction well NS-1 is designed to operate at a rate of approximately $200 \mathrm{gpm}$, and extraction well NS-2 is designed for $250 \mathrm{gpm}$. A complete description of the system is contained in the Operations and Maintenance Manual for the North Street/North Street East Offsite Groundwater Treatment Systems (BNL 2004f).

\subsubsection{Groundwater Monitoring}

Well Network

A network of 27 wells monitors the North Street VOC plume (Figure 1-2). The monitoring program also addresses radiological contaminants that may have been introduced to groundwater in the OU IV portion of the site (particularly the Building 650 and 650 sump outfall areas), as well as the Former Landfill/Chemical/Animal Holes. Wells sampled under the OU III South Boundary and Industrial Park Programs are also utilized for mapping this plume.

\section{Sampling Frequency and Analysis}

The 27 wells are sampled and analyzed for VOCs according to the schedule in Table 1-5. Twentyfour wells are sampled and analyzed annually for gross alpha/beta, gamma spectroscopy, and Sr-90. All wells are sampled and analyzed annually for tritium.

\subsubsection{Monitoring Well Results}

The primary VOCs associated with this plume are carbon tetrachloride, PCE, TCA, and chloroform. Figure 3.2-1 and Figure 3.2. 8-5 depict the TVOC plume distribution and include data from the monitoring wells. The complete groundwater monitoring well data for 2007 are included in Appendix C. A north-south hydrogeologic cross section $\left(\mathrm{H}-\mathrm{H}^{\prime}\right)$ of the plume is provided in Figure 3.2.8-1. The location for the cross section is shown in Figure 3.2-1. Monitoring well 000-154 had historically shown the highest VOC concentrations (primarily carbon tetrachloride) in the North Street area. TVOC concentrations greater than $1,000 \mu \mathrm{g} / \mathrm{L}$ were observed in 1997 and 1998, but have steadily declined since then to less than $6 \mu \mathrm{g} / \mathrm{L}$ in 2007. The trailing edge of the higher concentration segment of this plume has migrated south of this location. Plots of the VOC concentration trends in this area are shown in Figure 3.2.8-2.

VOC concentrations in wells 000-463 and 000-464, located about 200 feet north of NS-1, are still elevated (peak TVOC of $74 \mu \mathrm{g} / \mathrm{L}$ in 000-463 during 2007), but have been steadily declining, as shown in Figure 3.2.8-2. Well 000-472, adjacent to NS-2, has also steadily declined in the past 2 years, with 
a TVOC concentration ranging from $308 \mu \mathrm{g} / \mathrm{L}$ to $67 \mu \mathrm{g} / \mathrm{L}$, observed in the second-quarter 2007 sample.

Several monitoring wells (800-63, 800-92, 800-59, and 800-106) located south of the North Street extraction wells have displayed increasing TVOC concentrations over the past several years. This suggests that the leading edge of the higher concentration segment, which had migrated beyond the North Street extraction well locations prior to that system start-up, has reached this location. This contamination will be captured by the Airport System.

Historically, tritium has been detected in localized off-site areas approximately within the area covered by the North Street VOC plume. Potential sources for this tritium are located in the Former Landfill/Chemical/Animal Holes and OU IV Building 650 areas of the site. Tritium has been detected in the deep Upper Glacial aquifer at concentrations well below the DWS of $20,000 \mathrm{pCi} / \mathrm{L}$.

Historically, the highest tritium concentration was detected in 2001 in temporary well 000-337, at $9,130 \mathrm{pCi} / \mathrm{L}$. This location is approximately 300 feet north of well $000-153$. Tritium has been detected historically in well $000-153$, but concentrations have decreased from $2,560 \mathrm{pCi} / \mathrm{L}$ in 2001 to $<\mathrm{MDA}$ in 2007. In 2007, tritium was not detected in any of the North Street monitoring program wells. This is consistent with the steady decline in tritium concentrations observed over the past several years. Radiological monitoring of North Street wells will continue in 2008.

\subsubsection{System Operations}

Bi-weekly laboratory analyses are performed on influent, midpoint, and effluent samples from the GAC units. All samples are analyzed for VOCs, and the influent and effluent samples are also analyzed for $\mathrm{pH}$. In addition, the system effluent is analyzed for tritium. Table 3.2.8-1 provides the effluent limitations for meeting the requirements of the SPDES equivalency permit. The extraction wells are sampled quarterly.

\section{January-September 2007}

Routine operations continued from January through September, with approximately 139 million gallons pumped and treated during the first three quarters. The system was off periodically to allow for scheduled carbon filter changeouts. In addition, the system was off for the month of June to clean and replace float switches in the injection wells. Various power surges due to lightning strikes were experienced during the first three quarters, all of which required system restarts and repair.

\section{October-December}

Table 3.2.8-1

\section{OU III North Street}

2007 SPDES Equivalency Permit Levels

\begin{tabular}{lcc}
\hline Parameters & $\begin{array}{c}\text { Permit Limit } \\
(\mu \mathrm{g} / \mathrm{L})\end{array}$ & $\begin{array}{c}\text { Max. Observed } \\
\text { Value }(\mu \mathrm{g} / \mathrm{L})\end{array}$ \\
\hline $\mathrm{pH}$ (range) & $5.5-8.5 \mathrm{SU}$ & $5.9-7.5 \mathrm{SU}$ \\
carbon tetrachloride & 5 & $\mathrm{ND}$ \\
chloroform & 5 & $\mathrm{ND}$ \\
1,1-dichloroethane & 5 & $\mathrm{ND}$ \\
1,2-dichloroethane & 5 & $\mathrm{ND}$ \\
1,1-dichloroethylene & 5 & $\mathrm{ND}$ \\
tetrachloroethylene & 5 & $\mathrm{ND}$ \\
toluene & 5 & $\mathrm{ND}$ \\
1,1,1-trichloroethane & 5 & $\mathrm{ND}$ \\
trichloroethylene & 10 & $\mathrm{ND}$ \\
\hline ND = Not detected above method detection limit of $0.50 \mu \mathrm{g} / \mathrm{L}$. \\
$\begin{array}{l}\text { Required effluent sampling frequency is monthly for VOCs and } \\
\text { HH. }\end{array}$
\end{tabular}

Routine operations continued from October through December. The system was off periodically to allow for scheduled carbon changeouts. Approximately 47 million gallons were pumped and treated during this quarter. 


\subsubsection{System Operational Data}

The system was operational from January to December 2007, with only minor shutdowns due to electrical outages, programmable logic controller (PLC) issues, scheduled maintenance, and GAC changeouts.

\section{Extraction Wells}

Table F-29 contains the monthly pumping data and mass removal data for the system. VOC concentrations for the extraction wells are provided in Table F-30. TVOC values in well NS-1 declined from 36 to $26 \mu \mathrm{g} / \mathrm{L}$ over the year, and well NS-2 remained unchanged, with TVOC values ranging from 16 to $20 \mu \mathrm{g} / \mathrm{L}$. The decline in NS-1 TVOCs correlates to the concentrations in monitoring wells 000-463 and 000-464, located 200 feet upgradient of NS-1. There were no radionuclides detected in the extraction wells or in system influent in 2007.

\section{System Influent and Effluent}

VOC concentrations in 2007 for the NS carbon influent and effluent are summarized in Tables F31 and F-32. The combined influent TVOC concentration declined from $75 \mu \mathrm{g} / \mathrm{L}$ in December 2004 to $15 \mu \mathrm{g} / \mathrm{L}$ in December 2007.

The carbon vessels for the system effectively removed all contaminants from the influent groundwater. All effluent data were below the analytical method's detection limit.

\section{Cumulative Mass Removal}

The mass of VOCs removed from the aquifer by the OU III North Street Pump and Treat System was calculated using the average flow rates for each monthly monitoring period, in combination with the TVOC concentration in the carbon unit's influent, to calculate the pounds removed per month. The cumulative mass of VOCs removed by the treatment system vs. time is plotted on Figure 3.2.8-3. During 2007, approximately 139 million gallons of groundwater were pumped and treated by the North Street system, and approximately 36 pounds of VOCs were removed. Since May 2004, the system has removed 268 pounds of VOCs. The mass removal data are summarized in Table F-29.

\subsubsection{System Evaluation}

Figure 3.2.8-4 compares the TVOC plume from 1997 to 2007. The following significant changes were observed in the plume over this period:

- The trailing edge of the plume has migrated south of the BNL site.

- TVOC concentrations in monitoring wells 200 feet upgradient of NS-1 are showing a steady decline.

- TVOCs in wells downgradient of NS-1 and NS-2 are increasing, as this plume segment that was south of the North Street system prior to start-up migrates toward the Airport.

The OU III North Street Monitoring Program can be evaluated from the five decision rules identified in the groundwater DQO process.

\section{Was the BNL Groundwater Contingency Plan triggered?}

No. There were no unusual or unexpected VOC or radionuclide concentrations in the monitoring wells or extraction wells associated with the North Street Pump and Treat System during 2007.

\section{Has the plume been controlled?}

Yes. The cleanup goals have not been met; however, it must be verified that the plume is not growing. An analysis of the plume perimeter and bypass wells shows that there have been no significant increases in VOC concentrations in 2007; thus, it can be concluded that that plume has not grown and 
continues to be controlled. It should be noted that a segment of the plume now located between Crestwood Drive north to Waldorf Drive was beyond the capture zone of the North Street extraction wells at the time of system start-up. This portion of the plume will be addressed by the Airport extraction wells directly downgradient.

The leading edge of the plume was defined at Flower Hill Drive at concentrations below the NYS AWQS for individual VOCs. The Airport Pump and Treat System is designed to capture any contaminants migrating south of Flower Hill Drive.

3. Is the system operating as planned? Specifically, is the aquifer being restored at the planned rate? The hydraulic capture performance of the system is operating as modeled in the system design, and the system has been removing VOCs from the deep Upper Glacial aquifer. After 3 years of operation, the system influent VOC concentrations have been slightly higher than originally projected in the final design. The pre-design modeling predicted that the system will need to operate until 2012. Based on current data this prediction appears to remain valid.

\section{Are there off-site radionuclides that would trigger additional actions?}

No. During 2007 there were no detections of radionuclides in the monitoring wells.

\section{Can the groundwater treatment system be shut down?}

No, the system has not met all shutdown requirements.

\section{5a. Have asymptotic TVOC concentrations been reached in core wells?}

No. Asymptotic conditions have not yet been achieved.

\section{5b. Are there individual plume core wells above $50 \mu \mathrm{g} / \mathrm{L}$ TVOC?}

Currently five of 12 plume core wells are showing concentrations greater than $50 \mu \mathrm{g} / \mathrm{L}$ TVOC.

5c. During pulsed operation of the system, is there significant concentration rebound in the core wells?

The North Street System has not been pulsed to date.

5d. Have the groundwater cleanup goals been met? Will MCLs be achieved by 2030?

MCLs have not been achieved for individual VOCs in plume core wells. Based on the groundwater modeling and current system performance, MCLs are expected to be achieved by 2030 .

\subsubsection{Recommendations}

The following are recommended for the North Street Pump and Treat System and groundwater monitoring program:

- Maintain the operations and maintenance sampling frequency for monitoring wells initiated in 2006.

- Eliminate the Sr-90, gamma spectroscopy, and gross alpha/beta analysis for monitoring well samples due to the absence of any detections for radionuclides over the past several years. 


\subsubsection{North Street East Pump and Treat System}

This section summarizes the 2007 operational and monitoring well data for the OU III North Street East (NSE) Groundwater Pump and Treat System, and presents conclusions and recommendations for its future operation. The system began operation in June 2004 to provide capture and control of the downgradient portion of the OU I VOC plume, which has migrated beyond the BNL site boundary.

\subsubsection{System Description}

The North Street East Treatment System consists of two extraction wells pumped through two 20,000-gallon GAC units and discharged to injection wells. Both the North Street and North Street East systems are located in the same building and discharge the treated water to four injection wells located on North Street. Extraction well NSE-1 is designed to operate at a rate of approximately 200 gpm; extraction well NSE-2 is designed for $100 \mathrm{gpm}$. A complete description of the system is contained in the Operations and Maintenance Manual for the North Street/North Street East Offsite Groundwater Treatment Systems (BNL 2004f).

\subsubsection{Groundwater Monitoring}

The monitoring network consists of 15 wells. The monitoring program was designed to monitor the VOC plume off site, south of the OU I South Boundary System, as well as the efficiency of the NSE groundwater remediation system (Figure 1-2). During 2007, the wells were sampled at the O\&M phase frequency (core and perimeter wells sampled semi-annually, and sentinel wells sampled quarterly). However, as recommended in the 2006 Groundwater Status Report, plume core wells 000$482,000-483$, and 000-484 maintained the quarterly sampling frequency since they are immediately upgradient of extraction well NSE-2. Well 000-481 should have also been changed to the quarterly frequency. This change will take place in 2008. The wells are also sampled at least annually for tritium, Sr-90, and gamma spectroscopy. Eleven of the 15 wells are also sampled annually for gross alpha/beta. See Table 1-5 for details.

\subsubsection{Monitoring Well Results}

Figure 3.1-1 shows the extent of the VOC plume. The plume originated from the Current Landfill and former HWMF (sources in OU I). The on-site segment of the plume is being treated by the OU I South Boundary Remediation System. The off-site segment of the plume, located south of BNL, is being addressed by the NSE Remediation System. This segment of the plume extends from the vicinity of North Street to south of the LIPA right of way, a distance of approximately 3,400 feet. The maximum width of this segment of the plume is approximately 450 feet. The higher concentration segments of the plume (the $10 \mu \mathrm{g} / \mathrm{L}$ TVOC contour) are just north of the LIPA right of way and extraction well NSE-1, and just north of NSE-2.

Figure 3.1-2 depicts the vertical distribution of VOCs (primarily TCA, DCE, TCE, chloroform, and choroethane) within the deep Upper Glacial aquifer. The transect line for cross-section A-A' is shown in Figure 3.1-1. Figure 3.1-3 gives the historical trends in VOC concentrations for key core and bypass wells along the Current Landfill/former HWMF/NSE plume. Appendix $\mathbf{C}$ contains a complete set of 2007 analytical results for the 15 NSE program wells. A summary of key monitoring well data for 2007 follows:

- The plume continues to be bounded by the current network of wells.

- All monitoring wells in the plume have remained below the treatment system capture goal of 50 $\mu \mathrm{g} / \mathrm{L}$ TVOCs in 2005,2006 , and 2007 , except for one detection in well $000-478$ of $58 \mu \mathrm{g} / \mathrm{L}$, in March 2005. 
- The maximum plume TVOC concentration observed in 2007 was $36 \mu \mathrm{g} / \mathrm{L}$ in plume core well $000-478$. The primary compound identified in the sample was chloroform, at $26 \mu \mathrm{g} / \mathrm{L}$. This well is located in the center-line of the plume just upgradient of NSE-1. The 2007 VOCs in this well are consistent with the last two years of data. When the well was installed in 2004, TVOCs were as high as $205 \mu \mathrm{g} / \mathrm{L}$. Plume core well, 000-477, located slightly west of 000-478, has remained consistent over the past 2 years, with TVOC concentrations less than $20 \mu \mathrm{g} / \mathrm{L}$.

- TVOC concentrations in core wells 000-479 and 000-480 were as high as $77 \mu \mathrm{g} / \mathrm{L}$ in 2004, but have dropped to less than $5 \mu \mathrm{g} / \mathrm{L}$ since mid 2005. These wells are upgradient of NSE-1.

- TVOC concentrations in plume perimeter well 000-137 remained very low, with detections since 2002 of below $5 \mu \mathrm{g} / \mathrm{L}$. This signifies that the trailing edge of the shallower lobe of this plume has migrated south of North Street (Figure 3.1-2). Concentrations in core well 000-138 have dropped from $253 \mu \mathrm{g} / \mathrm{L}$ in 1999 to less than $50 \mu \mathrm{g} / \mathrm{L}$ since 2000. In 2007, the TVOCs dropped further to less than $5 \mu \mathrm{g} / \mathrm{L}$.

- The maximum TVOC concentration in plume core well 000-124 was less than $5 \mu \mathrm{g} / \mathrm{L}$ in 2007 , down from a high of $489 \mu \mathrm{g} / \mathrm{L}$ in 1998 .

- Following an increase in TVOC concentrations in 2005 and 2006, plume core well 000-481, located between NSE-1 and NSE-2, has dropped back to less than $5 \mu \mathrm{g} / \mathrm{L}$ in 2007. In addition, nearby core wells $000-482,000-483,000-484$, and $000-485$ have remained less than $5 \mu \mathrm{g} / \mathrm{L}$ since 2005 .

- The highest tritium concentration in the plume in 2007 was detected at $520 \mathrm{pCi} / \mathrm{L}$ in well 000 215. There have been no detections of tritium greater than $1,000 \mathrm{pCi} / \mathrm{L}$ in any of the wells since 2005. In addition, historically there have not been any detections of Sr-90 in any of the monitoring wells.

\subsubsection{System Operations}

Influent, midpoint, and effluent samples from the GAC units are sampled monthly, per SPDES Equivalency Permit requirements. The extraction wells were also sampled monthly, except for July and December 2007. All samples are analyzed for VOCs. In addition, the influent and effluent samples are analyzed monthly for $\mathrm{pH}$. The system effluent is also analyzed for tritium. Table 3.2.9-1 provides the effluent limitations for meeting the requirements of the SPDES equivalency permit. 
Table 3.2.9-1.

OU III North Street East

2007 SPDES Equivalency Permit Levels

\begin{tabular}{|c|c|c|}
\hline Parameters & $\begin{array}{l}\text { Permit Limit } \\
\qquad(\mu \mathrm{g} / \mathrm{L})\end{array}$ & $\begin{array}{c}\text { Max. } \\
\text { Observed } \\
\text { Value }(\mu \mathrm{g} / \mathrm{L})\end{array}$ \\
\hline $\mathrm{pH}$ range & 5.5-8.5 SU & $5.6-6.4 \mathrm{SU}$ \\
\hline carbon tetrachloride & 5 & ND \\
\hline chloroform & 5 & 1.9 \\
\hline 1,1-dichloroethane & 5 & ND \\
\hline 1,2-dichloroethane & 5 & ND \\
\hline 1,1-dichloroethylene & 5 & ND \\
\hline tetrachloroethylene & 5 & ND \\
\hline toluene & 5 & ND \\
\hline 1,1,1-trichloroethane & 5 & ND \\
\hline trichloroethylene & 10 & ND \\
\hline $\begin{array}{l}\mathrm{ND}=\text { Not Detected above } \\
\text { Required effluent sam }\end{array}$ & $\begin{array}{l}\text { ction limit of } 0.50 \\
\text { monthly for VC }\end{array}$ & $\begin{array}{l}\mu \mathrm{g} / \mathrm{L} . \\
\mathrm{Cs} \text { and } \mathrm{pH} .\end{array}$ \\
\hline
\end{tabular}

\subsubsection{System Operational Data}

The NSE system operated from January through December 2007. The system was operational throughout the year with only minor shutdowns due to electrical outages, programmable logic controller (PLC) issues, and scheduled maintenance. During 2007, approximately 4 pounds of VOCs were removed. Since October 2006 the system was pulse pumped with the system on one month and off the next.

\section{January through September}

The system was down for two months in June and July due to electrical surges and injection well maintenance. The system pumped and treated approximately 58 million gallons of water.

October through December

The system operated normally for the last quarter of 2007. The system was on in October and November and off in December per the pulse pumping schedule. In this quarter, the system pumped and treated approximately 13 million gallons of water.

Extraction Wells

During 2007, 71 million gallons were pumped and treated by the NSE system; Table 2-3 contains the monthly pumping data for the two extraction wells. VOC concentrations for NSE-1 (000-487) and NSE-2 (000-483) are provided in Table F-33 in Appendix F. Declining TVOC trends are noted for both wells during 2007, with concentrations below $10 \mu \mathrm{g} / \mathrm{L}$ reported in both wells during the entire year.

\section{System Influent and Effluent}

VOC concentrations for 2007 for the carbon treatment influent and effluent are summarized in Tables F-34 and F-35. Influent TVOC concentrations have been at or below $10 \mu \mathrm{g} / \mathrm{L}$ since 2005. The carbon treatment system effectively removed VOCs from the influent groundwater. All effluent concentrations were below the regulatory limit specified in the equivalency permit. No tritium has been detected in the system effluent above $600 \mathrm{pCi} / \mathrm{L}$ since the system began operating in 2004 .

\section{Cumulative Mass Removal}

The mass of VOCs removed from the aquifer by the NSE Treatment System was calculated. Average flow rates for each monthly monitoring period were used, in combination with the VOC concentration in the system influent, to calculate the rate of contaminant removal (Table F-36). The cumulative mass of VOCs removed by the treatment system versus time was then plotted (Figure 3.2.9-1). It shows that 4 pounds of VOCs were removed during 2007, with a cumulative total of 19 pounds of VOCs removed since system startup in April 2004.

\subsubsection{System Evaluation}

The system began operations in June 2004 and was planned to run for approximately 10 years. The system is operating as designed. No operating difficulties were experienced beyond normal maintenance, and system effluent concentrations did not exceed SPDES equivalency permit requirements. 
The North Street East Pump and Treat System performance can be evaluated based on the four major decisions identified for this system from the groundwater DQO process.

\section{Was the BNL Groundwater Contingency Plan triggered?}

No. There were no unusual or unexpected concentrations of contaminants observed in monitoring or extraction wells associated with the NSE Treatment System.

\section{Has the plume been controlled?}

Yes. The system has been in operation for three years, and an analysis of the plume perimeter and bypass wells shows that there have been no significant increases in VOC concentrations in 2007, thus we conclude that plume has not grown and is controlled.

3. Is the system operating as planned? Specifically, is the aquifer being restored at the planned rate? The system is operating as modeled in the system design, and the system has been removing VOCs from the deep Upper Glacial aquifer. However, system influent VOC concentrations have been less than originally projected. In addition, the monitoring wells have shown low concentrations following initial startup of the system. Indications are that the system may not need to operate as long as originally planned.

\section{Can the groundwater treatment system be shut down?}

No. Even though shutdown criteria of reaching less than $50 \mu \mathrm{g} / \mathrm{L}$ TVOCs for at least four consecutive sampling rounds has been met in the core monitoring and extraction wells, one well, 000-478, is under the $50 \mu \mathrm{g} / \mathrm{L}$ criteria and should be captured by the system.

\section{4a. Have asymptotic TVOC concentrations been reached in core wells?}

No. Since the system has only been operating for just over three years, sufficient time has not yet been realized to reach an asymptotic condition. These conditions may be achieved in the next couple of years.

4b. Are there individual plume core wells above $50 \mu \mathrm{g} / \mathrm{L}$ TVOC?

No. All core wells were below $50 \mu \mathrm{g} / \mathrm{L}$ TVOCs.

4c. During pulsed operation of the system, is there significant concentration rebound in core wells? Since the system was first shut down for pulse pumping starting October 2006, all core wells have remained low and no rebounding has been identified.

4 d. Have the groundwater cleanup goals been met? Have MCLs been achieved (expected by 2030)? No. MCLs have not been achieved for individual VOCs in plume core wells. Wells 000-477 and 000-478 identified TCA and chloroform above MCLs. However, MCLs are expected to be achieved by 2030 .

\subsubsection{Recommendations}

The following recommendations are made for the NSE Pump and Treat System and groundwater monitoring program:

- Maintain the routine operations and maintenance monitoring frequency for the monitoring wells that began in third quarter 2006. However, plume core wells 000-481, 000-482, 000-483, and 000-484 should be maintained at the quarterly sampling frequency since they are immediately upgradient of extraction well NSE-2. 
- Delete Sr-90, gross alpha/beta, and gamma spectroscopy from the analyte, list since there have been no detections above the standards.

- Continue pulse pumping of both extraction wells, since the system influent concentrations have remained very low over the past two years and all of the monitoring wells are already below the capture goal of $50 \mu \mathrm{g} / \mathrm{L}$ TVOC. The pulse pumping consists of having the system on for one month, then off in standby mode for the next month. The extraction well sampling frequency will change from a monthly schedule to only sample during the months the system is in operation (every other month) If concentrations above the capture goal of $50 \mu \mathrm{g} / \mathrm{L} \mathrm{TVOCs}$ are observed in either the core monitoring wells or the extraction wells, the well(s) will be put back into full-time operation. If no rebound is observed in 2008 , then petition for shutdown of the system.

- As of the first quarter 2008, lower the pump location four feet in monitor wells 000-482, 000-483, and 000-484 to obtain data from a slightly deeper portion of the aquifer. 
SER VOLUME II: GROUNDWATER STATUS REPORT

This page intentionally left blank. 


\subsubsection{LIPA/Airport Pump and Treat System}

\subsubsection{System Description}

The three components of the LIPA/Airport Pump and Treat System are as follows.

1. The Magothy extraction well (EW-4L) on Stratler Drive (see Figure 3.2.10-1) addresses highlevel VOCs identified in the Magothy aquifer immediately upgradient of this well on Carleton Drive. The capture goal for this well is $50 \mu \mathrm{g} / \mathrm{L}$ TVOC.

2. The three LIPA extraction wells (EW-1L, -2L, and -3L) were installed to address high concentrations of VOCs in the Upper Glacial aquifer that had migrated past the Industrial Park System before that system became operational in 1999. The capture goal for these extraction wells is $50 \mu \mathrm{g} / \mathrm{L}$ TVOC.

3. The six extraction wells in the Airport System were installed to address the leading edge of the plumes, which have migrated past the LIPA extraction wells and the North Street extraction wells. The sixth well was added in 2007 to address concentrations of VOCs observed to the west of extraction well RTW-1A. The Airport system wells were installed to prevent further migration of the plumes. They have a capture goal of $10 \mu \mathrm{g} / \mathrm{L}$ TVOC.

The water from the four LIPA wells is pumped to the treatment plant, about one mile south on Brookhaven [Town] Airport property, where it is combined with the water from the six airport extraction wells (RTW-1A through -6A) and treated via granular activated carbon. The treated water is released back to the ground via a series of shallow reinjection wells located on Brookhaven Airport and Dowling College property.

A more detailed description of this system is contained in the Operations and Maintenance Manual for the LIPA/ Airport Groundwater Treatment System (BNL 2004g).

\subsubsection{Groundwater Monitoring}

Well Network

The monitoring network consists of 50 wells. There are 16 wells associated with the LIPA Upper Glacial portion of the plume and was designed to monitor the VOC plume off site, south of the OU III Industrial Park System. The Airport System network has 28 monitoring wells, which monitor the portions of the plume south of the LIPA and the North Street systems. The Magothy extraction well on Stratler Drive has six monitoring wells associated with its operation. All of these wells are used to monitor and evaluate the effectiveness and progress of the cleanup associated with these three components of the system. Figure 1-2 identifies the monitoring wells for these plumes.

\section{Sampling Frequency and Analysis}

The monitoring wells for LIPA are currently on a quarterly and semi-annual schedule for VOCs. The Airport wells are quarterly.

\subsubsection{Monitoring Results}

The primary VOCs associated with these portions of the plume are carbon tetrachloride, TCA, TCE, and 1,1-dichloroethylene. Groundwater monitoring for these systems was initiated in 2004. Fourthquarter 2007 well data is posted on Figures 3.2-1 and 3.2.10-2. The complete results are in Appendix C and Table F-38 in Appendix F summarizes the data for the extraction wells. Results for key monitoring wells and extraction wells are as follows.

- Maximum TVOC concentrations during 2007 for the Magothy extraction well EW-4L on Stratler Drive ranged from $76 \mu \mathrm{g} / \mathrm{L}$ in January to $47 \mu \mathrm{g} / \mathrm{L}$ in December 2007. Carbon tetrachloride is the primary VOC detected in this well. All of the Magothy monitoring wells associated with this portion of the plume show concentrations below $50 \mu \mathrm{g} / \mathrm{L}$ TVOC, with well 000-130 showing the 
highest concentration, at $39 \mu \mathrm{g} / \mathrm{L}$ in May 2007. Figure 3.2.10.3 has the LIPA trend plots for the extraction wells.

- Two of the three Upper Glacial LIPA extraction wells, EW-1L and EW-3L were shutdown in October 2007 as per recommendations in last years annual report. Well EW-2L had a high concentration of TVOCs of $38 \mu \mathrm{g} / \mathrm{L}$ in January and a low of $22 \mu \mathrm{g} / \mathrm{L}$ in December 2007. Wells EW-1L and EW-3L continued to show VOC concentrations less then MCLs except for one detection of TCE in well EW-1L at $7 \mu \mathrm{g} / \mathrm{L}$ in October 2007.

- All monitoring wells near the extraction wells for the airport system are below MCLs except for well 800-96. However, upgradient monitoring wells 800-94 and -95, approximately 1,500 feet north of wells RTW-1A and -2A, have historically shown TVOC concentrations primarily composed of carbon tetrachloride ranging up to $100 \mu \mathrm{g} / \mathrm{L}$. This is an indication that higher concentrations should be expected at the extraction wells. Five of the six airport extraction wells had VOC concentrations below MCLs throughout 2007. Newly installed extraction well RTW6A showed concentrations as high as $86 \mu \mathrm{g} / \mathrm{L}$ in November during startup and concentrations had dropped to $12 \mu \mathrm{g} / 1$ in December.

- Well 800-96 is screened from 180 to 200 feet below grade. The well was installed as a western perimeter monitoring well for extraction well RTW-1A. Sampling of this well began in March 2004. No detections of carbon tetrachloride were found in this well until December 2005, when it was detected at $1.6 \mu \mathrm{g} / \mathrm{L}$. In June 2006 a concentration of carbon tetrachloride of $10 \mu \mathrm{g} / \mathrm{L}$ was detected in this well, and on August 31, 2006 the concentration increased to $40 \mu \mathrm{g} / \mathrm{L}$. Due to these VOC increases, the monitoring frequency for this well was changed from quarterly to monthly beginning in December 2006. Subsequent sampling showed concentrations of $100 \mu \mathrm{g} / \mathrm{L}$ in November 2006, $60 \mu \mathrm{g} / \mathrm{L}$ in December, and $51 \mu \mathrm{g} / \mathrm{L}$ in January 2007, with a maximum concentration of $122 \mu \mathrm{g} / \mathrm{L}$ in December 2007. During 2007 a new extraction well RTW-6A and five new monitoring wells $(800-126,800-127,800-128,800-129,800-130)$ were installed to monitor and capture the contaminants in well 800-96. See Figure 3.2.10.1 for locations. In addition, downgradient monitoring well 800-107, located several hundred feet south of extraction wells RTW-1A, had to be abandoned due to construction activities at Dowling College and was replaced with well 800-131, located just south of the original well.

\subsubsection{System Operations}

The extraction wells were sampled once per month in 2007. The influent, midpoint, and effluent of the carbon units were sampled once per week, along with weekly $\mathrm{pH}$ readings. All samples were analyzed for VOCs. The Airport extraction wells are being pulsed pumped one week per month except well RTW-1A and RTW-6A which are on a full time basis.

The following is a summary of the OU III Airport/LIPA operations for 2007.

\section{January-September}

The system operated normally during this period, with some down time other than for routine maintenance and repairs. The Airport System was down in August and September while a new extraction well (RTW-6) was installed and tied into the system. At this time additional controls were installed in the system to allow for the operation of the new extraction well. The Airport wells continued a pulse pumping schedule of one week of operation per month except for well RTW-1A, which operated on a full time basis.

\section{October-December}

The system was off for the last part of October and the entire month of November due to construction work. These problems were cleared up in December. New Extraction well RTW-6A began full time operations at this time. 


\section{Extraction Wells Operational Data}

During 2007, approximately 171 million gallons were pumped and treated by the OU III Airport/LIPA System, with an average flow rate of 498 gpm. Table F-37 shows the pumping data. VOC concentrations for the airport and LIPA extractions wells are provided in Table F-38. VOC levels in all airport extraction wells were below MCLs, except for well RTW-6A. Table 3.2.10-1 below shows maximum measured values and the values allowed under the SPDES equivalency permit.

\subsubsection{System Operational Data}

System Influent and Effluent

VOC concentrations in 2007 for the carbon influent and effluent are summarized in Tables F-39 and $\mathbf{F}-\mathbf{4 0}$.

The carbon vessels for the system effectively removed all contaminants from the influent groundwater. All effluent data were below the analytical method detection limit and below the regulatory limit specified in the SPDES equivalency permit.

\section{Cumulative Mass Removal}

The mass of VOCs removed from the aquifer by the OU III Airport/LIPA treatment system was calculated using the average flow rates for each monitoring period (Table F-37) in combination with the TVOC concentration in the carbon unit's influent, to calculate the pounds per month removed. The plot of cumulative mass of VOCs removed vs. time (Figure 3.2.10) shows that 35 pounds of VOCs were removed during 2007, with a total of 237 pounds removed since startup.

\section{Extraction Wells Data Evaluation}

Table F-38 in Appendix F summarizes the data for the extraction wells.

\subsubsection{System Evaluation}

The Airport Treatment System was designed to capture the leading edge of the OU III and OUI/IV VOC plumes. However, to date no concentrations of VOCs above MCLs have been detected in the original five extraction wells. The newly installed extraction well (RTW-6A) has shown carbon tetrachloride above MCLs since it was installed and began operations in November 2007. Some higher concentrations of VOCs have been detected upgradient of these wells. VOC concentrations in the LIPA wells are consistent with the groundwater modeling performed for the design of this system.

The OU III Airport/LIPA system performance can be evaluated based on the five major decision rules identified for this system resulting from the groundwater DQO process.

\section{Was the BNL Groundwater Contingency Plan} triggered?

No, however the Plan was triggered in 2006. This was due to the concentrations of VOCs observed in well 800-96, which is outside the capture zone of the treatment system. No unexpected VOC concentrations were observed in the monitoring wells of the LIPA/Airport Treatment System during 2007.

Table 3.2.10-1 OU III LIPA/Airport Pump \& Treat System 2007 SPDES Equivalency Permit Levels

\begin{tabular}{lcc}
\hline Parameters & $\begin{array}{c}\text { Permit } \\
\text { Level } \\
(\mu \mathrm{g} / \mathrm{L})\end{array}$ & $\begin{array}{c}\text { Max. } \\
\text { Measured } \\
\text { Value }(\mu \mathrm{g} / \mathrm{L})\end{array}$ \\
\hline $\mathrm{pH}$ & $5.5-7.5 \mathrm{SU}$ & $5.7-7.4 \mathrm{SU}$ \\
carbon tetrachloride & 5 & $\mathrm{ND}$ \\
chloroform & 7 & $\mathrm{ND}$ \\
1,1-dichloroethane & 5 & $\mathrm{ND}$ \\
1,1-dichloroethylene & 5 & $\mathrm{ND}$ \\
methylene chloride & 5 & $\mathrm{ND}$ \\
1,1,1-trichloroethane & 5 & $\mathrm{ND}$ \\
trichloroethylene & 10 & $\mathrm{ND}$ \\
\hline ND = Not detected above method detection limit of $0.50 \mu \mathrm{g} / \mathrm{L}$. \\
\hline
\end{tabular}




\section{Has the plume been controlled?}

Based on the results of the LIPA/Airport Pump Test Report (Holzmacher 2004), the plumes are being controlled. The capture zones clearly show that the capture goal of $50 \mu \mathrm{g} / \mathrm{L} \mathrm{TVOC}$ at the LIPA Upper Glacial and Magothy wells is being met. The leading edge of the plume has reached the airport. An additional extraction well was added and five additional monitoring wells to ensure its capture. This work was completed in November 2007.

3. Is the system operating as planned? Specifically, is the aquifer being restored at the planned rate? Yes, the system is operating as planned. These wells have not been operating long enough to evaluate the progress of aquifer restoration.

\section{Can the groundwater treatment system be shut down?}

No, the system has not met all shutdown requirements (see below).

4a. Have asymptotic TVOC concentrations been reached in core wells?

No, asymptotic concentrations have not been met.

4b. Is the TVOC concentration in the LIPA core wells less than $50 \mu \mathrm{g} / \mathrm{L})$ ?

Yes; however, extraction well EW-4L still shows concentrations greater then $50 \mu \mathrm{g} / \mathrm{L}$ during some of the months of operation. Since access in this area is limited the extraction well data is utilized to help in tracking the plume.

4c. Are the TVOC concentrations in the Airport core wells less than $10 \mu \mathrm{g} / \mathrm{L}$ ?

No, six airport core wells (800-63, -94, -95, -96, -99 and -106) have TVOC concentrations greater than $10 \mu \mathrm{g} / \mathrm{L}$.

4 d. During pulsed operation of the system, is there significant concentration rebound in core wells? The intent of the current pulse pumping is not to evaluate for rebound but to reduce pumping while the high-concentration segment continues to travel south toward the northern perimeter of the Airport extraction wells.

5. Have the groundwater cleanup goals been met? Have MCLs been achieved?

No, the cleanup goals have not been met. Based on model results, MCLs are expected to be achieved by 2030 for the Upper Glacial aquifer, and in the Magothy aquifer by 2070, as required by the OU III ROD and ESD.

\subsubsection{Recommendations}

The following recommendations are made for the LIPA/Airport Pump and Treat System and groundwater monitoring program:

- The extraction well sampling will be reduced from monthly to quarterly, except for the LIPA well EW-4L and Airport wells RTW-1A and 6A.

- Continue the airport extraction wells pulse-pumping of one week per month except for wells RTW-1A and 6A, which will continue with full-time operations. Pump well RTW-3A full time to intercept any VOCs migrating from the area of upgradient wells 800-99 and 800-106. If concentrations above the capture goal of $10 \mu \mathrm{g} / \mathrm{L}$ TVOCs are observed in any of the other extraction wells or the monitoring wells adjacent to them, the well(s) will be put back into fulltime operation. 
- Maintain LIPA wells EW-1L and EW-3L in standby mode. These extraction wells will be restarted if TVOC concentrations rebound in either the plume core monitoring wells or the extraction wells, greater than the $50 \mu \mathrm{g} / \mathrm{L}$ capture goal.

- Change well 800-96 from monthly to a quarterly sampling schedule since the new extraction well, EW-6A, is in operation.

- Install a temporary well 200 feet to the west of well RTW-3A and follow up with permanent monitoring well(s). This will be done to confirm the location of the western edge of the plume currently seen in upgradient monitoring wells 800-90 and 800-92. 
CHAPTER 3: ER GROUNDWATER MONITORING AND REMEDIATION

This page intentionally left blank. 


\subsubsection{Magothy Aquifer}

This section provides a brief summary of the Magothy Aquifer Groundwater Monitoring Program and the remedial approach for addressing the VOC contamination. The 41 monitoring wells used to characterize the Magothy are shown on Figure 3.2.11-1.

Detailed descriptions of the monitoring well data results and remediation progress are presented in the following sections of this report: Western South Boundary, Middle Road, Airport/LIPA, North Street, North Street East, OU III South Boundary, Industrial Park, Industrial Park East, and Central Monitoring. A brief summary of the results is provided in Table 3.2.11-1. Further details about these characterization results are in the Final Magothy Aquifer Characterization Report (Arcadis Geraghty \& Miller 2003).

Table 3.2.11-1. Magothy Aquifer Contamination (Historical and 2007).

\begin{tabular}{|c|c|c|c|c|}
\hline \multirow[b]{2}{*}{ Location } & \multicolumn{2}{|c|}{ Max. TVOC in $\mu \mathrm{g} / \mathrm{L}$} & \multirow[b]{2}{*}{$\begin{array}{r}\text { Primary } \\
\text { VOCs }\end{array}$} & \multirow[b]{2}{*}{ Results } \\
\hline & 2007 & Historical & & \\
\hline $\begin{array}{l}\text { Western boundary } \\
\text { on site }\end{array}$ & $<5.0$ & $<5.0$ & None & $\begin{array}{l}\text { Magothy not impacted. Two monitoring wells serve as } \\
\text { adequate outpost/sentinel wells for Suffolk County } \\
\text { Water Authority William Floyd well field. }\end{array}$ \\
\hline $\begin{array}{l}\text { Middle Road and } \\
\text { south boundary on } \\
\text { site }\end{array}$ & 117 & 340 & PCE, CCl4 & $\begin{array}{l}\text { VOCs identified in upper } 20 \text { to } 40 \text { feet of Magothy at } \\
\text { Middle Road area where brown clay is absent. A } \\
\text { temporary well installed in } 2006 \text { did not detect Magothy } \\
\text { contamination between the Middle Road and South } \\
\text { Boundary. VOCs not detected at South Boundary } \\
\text { beneath the clay. }\end{array}$ \\
\hline North Street off site & 48 & 50 & TCE & $\begin{array}{l}\text { Low VOC concentrations have been detected in } \\
\text { localized areas in the upper } 30 \text { feet of the Magothy } \\
\text { Aquifer and downgradient near Vita Drive. Leading } \\
\text { edge of contamination is around Moriches Middle Island } \\
\text { Road. }\end{array}$ \\
\hline $\begin{array}{l}\text { North Street East } \\
\text { off site }\end{array}$ & 8 & 30 & $\begin{array}{l}\text { 1,1-DCA; } \\
\text { 1,1-DCE }\end{array}$ & $\begin{array}{l}\text { Low VOC concentrations have been detected at the } \\
\text { BNL south boundary to North Street below the brown } \\
\text { clay at approximately } 40 \text { to } 150 \text { feet into the upper } \\
\text { Magothy }\end{array}$ \\
\hline $\begin{array}{l}\text { Industrial Park East } \\
\text { off site and south } \\
\text { boundary }\end{array}$ & 59 & 570 & TCA, CCl4 & $\begin{array}{l}\text { TVOCs currently less then } 60 \mu \mathrm{g} / \mathrm{L} \text { off site in the } \\
\text { Industrial Park, where brown clay is absent. Magothy } \\
\text { and Upper Glacial contamination is contiguous in } \\
\text { Industrial Park. }\end{array}$ \\
\hline $\begin{array}{l}\text { South of Carleton } \\
\text { Drive off site }\end{array}$ & 39 & 7,200 & $\mathrm{CCl} 4$ & $\begin{array}{l}\text { Historically high VOC concentrations just south of } \\
\text { Carleton Drive where brown clay is absent. Levels of } \\
\text { TVOCs are now less then } 50 \mu \mathrm{g} / \mathrm{L} \text {. Contamination is } \\
\text { contiguous between Magothy and Upper Glacial } \\
\text { aquifer. }\end{array}$ \\
\hline
\end{tabular}

The Magothy Remedy identified in the Explanation of Significant Differences (ESD) document calls for the following:

1. Continued operation of the five extraction wells as part of the Upper Glacial treatment systems that provide capture of Magothy VOC contamination (Middle Road, South Boundary, Airport, Industrial Park East, and LIPA) 
2. Data from the monitoring wells will continue to be evaluated to ensure protectiveness. Table 3.2.11-2 describes how each of the Magothy investigation areas is addressed by the DOE's selected Magothy aquifer remedy.

3. Institutional controls and 5-year reviews

Data for all Magothy monitoring wells are presented in Appendix C.

Table 3.2.11-2. Magothy Remedy.

\begin{tabular}{|c|c|}
\hline Area Investigated & Selected Remedy \\
\hline $\begin{array}{l}\text { Western boundary } \\
\text { onsite area }\end{array}$ & Continue monitoring and evaluate data. \\
\hline $\begin{array}{l}\text { Middle Road and } \\
\text { South Boundary } \\
\text { on-site area }\end{array}$ & $\begin{array}{l}\text { Continue operation of the Magothy extraction well at Middle Road, as well as the two Upper Glacial systems. } \\
\text { Continue to monitor the three Magothy monitoring wells at Middle Road and three at the south boundary. }\end{array}$ \\
\hline $\begin{array}{l}\text { North Street off- } \\
\text { site area }\end{array}$ & $\begin{array}{l}\text { Continue operation of the two existing Upper Glacial extraction wells on Sleepy Hollow Drive and North Street } \\
\text { until cleanup objectives are met. Continue monitoring and evaluate data. }\end{array}$ \\
\hline $\begin{array}{l}\text { North Street East } \\
\text { off-site area }\end{array}$ & Continue monitoring and evaluate data. \\
\hline $\begin{array}{l}\text { Industrial Park } \\
\text { East off-site area } \\
\text { and s. boundary }\end{array}$ & $\begin{array}{l}\text { Continue operation of the Industrial Park East Magothy extraction well until cleanup objectives are achieved. } \\
\text { Continue monitoring and evaluate data. }\end{array}$ \\
\hline $\begin{array}{l}\text { South of Carlton } \\
\text { Drive off-site area }\end{array}$ & $\begin{array}{l}\text { Continue operation of the LIPA Magothy extraction well on Stratler Drive until cleanup goals are achieved. This } \\
\text { will capture high concentrations of VOCs identified on Carleton Drive and prevent migration of high } \\
\text { concentrations of VOCs through the hole in the brown clay and into the Magothy aquifer. Continue monitoring and } \\
\text { data evaluation. }\end{array}$ \\
\hline
\end{tabular}

\subsubsection{Monitoring Well Results}

There are 41 monitoring wells in the Magothy monitoring program (Figure 3.2.11-1). Figure 3.2.11-2 shows trend plots of several of the key monitoring wells. A discussion of some of the key wells follows.

Well 000-130: This well is on Carleton Drive and has historically had the highest concentrations of carbon tetrachloride observed off site related to BNL: over 7,000 $\mu \mathrm{g} / \mathrm{L}$. Concentrations of VOCs have ranged from 31 to $39 \mu \mathrm{g} / \mathrm{L}$ in 2007 . The higher concentrations of carbon tetrachloride observed historically in this well are being captured by the LIPA extraction well on Stratler Drive. A more detailed discussion of this is available in Section 3.2.10, LIPA/Airport Pump \& Treat System.

Wells 000-249 and -250: These wells are in the Industrial Park near well UVB-1. Well 000-249 had VOC concentrations ranging from $59 \mu \mathrm{g} / \mathrm{L}$ in May 2007 to a low of $24 \mu \mathrm{g} / \mathrm{L}$ in November. Well $000-$ 250 had VOC concentrations below MCLs in 2007. Based on analytical data, the higher levels of contamination observed in well 000-249 are being captured by the UVB wells, even though 000-249 is on the edge of the capture zone for these wells. Any contaminants above the capture goal of 50 $\mu \mathrm{g} / \mathrm{L}$ TVOC that migrate beyond the capture of this system will be captured by the Stratler Drive extraction well.

Wells 000-425 and -460: These wells are adjacent to the LIPA Stratler Drive Magothy extraction well. Well 000-425 had concentrations of VOCs ranging from 10 to $26 \mu \mathrm{g} / \mathrm{L}$ during 2007. This well is immediately adjacent to the extraction well. Well 000-460, located east of the extraction well but within the capture zone, had concentrations of $26 \mu \mathrm{g} / \mathrm{L}$ in November 2007. The other three sampling events were below MCLs.

Well 122-05: located at the eastern edge of the OU III South Boundary System, showed concentrations of VOCs ranging from 19 to $25 \mu \mathrm{g} / \mathrm{L}$ in 2007. 
Well 000-343: south and between the OU I and OU III South Boundary systems, had VOC concentrations between 6 and $10 \mu \mathrm{g} / \mathrm{L}$ in 2006 .

Well 115-50: located south and between the OU I and OU III South Boundary systems, had concentrations up to $4 \mu \mathrm{g} / \mathrm{L}$ in 2007.

Wells 000-427 and -429: are just south of the Industrial Park East system on Carleton Drive. Well 000-427 had concentrations ranging from 4 to $14 \mu \mathrm{g} / \mathrm{L}$ in 2007 . Well $00-429$ had concentrations ranging from $<1 \mu \mathrm{g} / \mathrm{L}$ in January, to $59 \mu \mathrm{g} / \mathrm{L}$ in November.

Well 800-90: this well has historically not shown contaminants above MCLs. However, the sample in December shows TVOCs at $48 \mu \mathrm{g} / \mathrm{L}$. It is screened at about 255 feet below grade. This well is colocated with Well 800-92.

Well 800-92 (not a Magothy well), ( 200 feet) located about 2,500 feet north of the airport system, had VOC concentrations ranging from 43 to $50 \mu \mathrm{g} / \mathrm{L}$ in 2007 . The chemicals in both wells are similar. This is indicative of contamination that was already past the North Street extraction wells prior to operation and will eventually be captured by the Airport extraction wells.

\subsubsection{Recommendations}

Continue the current monitoring schedule for the Magothy monitoring program (see Table 1-5). 
SER VOLUME II: GROUNDWATER STATUS REPORT

This page intentionally left blank. 


\subsubsection{Central Monitoring}

The OU III RI identified several low-level (less than $50 \mu \mathrm{g} / \mathrm{L}$ ) TVOC source areas and nonpoint contaminant sources within the developed central areas of the BNL site. These sources include spills within the AGS Complex, the Bubble Chamber spill areas, and the Building 208 vapor degreaser. Because these sources are not large enough to warrant a dedicated monitoring program, they are monitored under the OU III Central Monitoring Program. In addition, this program includes wells 109-03 and 109-04, which are located near the BNL western site boundary. They were installed by the Suffolk County Department of Health Services (SCDHS) to serve as sentinel wells for the Suffolk County Water Authority (SCWA) William Floyd Parkway well field.

\subsubsection{Groundwater Monitoring}

Well Network

The monitoring well network is comprised of 20 wells (Figure 1-2). The locations aid in defining the VOC plumes, which extend downgradient from the central areas of the site. This network also is supplemented by data from Environmental Surveillance (ES) program wells that monitor active research and support facilities (Table 1-6). Results from the ES programs are provided in Section 4.

\section{Sampling Frequency and Analysis}

The wells are sampled and analyzed annually for VOCs, and wells 109-03 and 109-04 are analyzed quarterly for gamma spectroscopy, tritium, and Sr-90 (Table 1-5). Select ES wells in the AGS Complex are typically sampled annually for VOCs in order to complete the northern portion of the OU III VOC plume configuration.

\subsubsection{Monitoring Well Results}

VOC concentrations detected in most of the OU III Central wells are near or below NYS AWQS. The primary constituent in many of the wells in the north-central developed portion of the site is TCA. A discussion of some of the key wells follows.

- Wells 083-01 and 083-02 are near the intersection of Brookhaven Avenue and Upton Road, and are screened in the Upper Glacial aquifer. These wells consistently have contained 1 to $8 \mu \mathrm{g} / \mathrm{L}$ and 10 to $25 \mu \mathrm{g} / \mathrm{L}$ of chloroform since 1997, respectively. In November 2007, well 083-01 had a detection of chloroform of $7.8 \mu \mathrm{g} / \mathrm{L}$, barely exceeding the NYS AWQS of $7.0 \mu \mathrm{g} / \mathrm{L}$. Sources of this contamination may be in the water treatment plant chlorination process.

- SCDHS wells 109-03 and 109-04 serve as sentinel wells for the SCWA William Floyd Well Field and are near the western BNL property boundary. There have been no detections of VOCs in either well since early 2003, with the exception of chloroform and methylene chloride at concentrations less than $1 \mu \mathrm{g} / \mathrm{L}$ (the detection limit is $0.5 \mu \mathrm{g} / \mathrm{L}$ ) and one detection of trace levels of toluene in well 109-04 in March 2007. No radionuclides were detected in either well in 2007.

- Well 065-02, located near the AGS complex, had a detection of TCA at $17 \mu \mathrm{g} / \mathrm{L}$ in November 2007. This is consistent with historic results.

\subsubsection{Groundwater Monitoring Program Evaluation}

The evaluation of the OU III Central Monitoring Program is based on four major decision rules established for this program using the groundwater DQO process.

\section{Was the BNL Groundwater Contingency Plan triggered during 2007?}

No. There were no unusual or unexpected VOC or radionuclide concentrations in the monitoring wells associated with this program during 2007. 
2. Are there potential impacts to the SCWA William Floyd Parkway well field from on-site contamination?

No. There were no detections of contaminants in the sentinel monitoring wells during 2007, with the exception of low-level chloroform detections (below NYS AWQS).

\section{Are the performance objectives met?}

No. Since 1997 the VOC concentrations in the central portion of the site have significantly decreased as noted in TVOC plume comparison Figure 3.2-3. However, several individual wells continued to contain VOC concentrations exceeding the NYS AWQS during 2007; therefore, the OU III ROD objective of meeting MCLs by 2030 has not been met.

\section{If not, are observed conditions consistent with the attenuation model?}

Yes. The observed VOC concentrations generally agree with the model-predicted concentrations, with respect to both the plume extent and contaminant concentrations.

\subsubsection{Recommendation}

No changes to the monitoring program are warranted at this time. 


\subsubsection{Off-Site Monitoring}

The OU III Off-Site Groundwater Monitoring Program consists of 12 wells. They were installed to monitor contamination for the southwest portion of the OU III plume or were installed as part of the early BNL hydrogeologic characterization.

\subsubsection{Groundwater Monitoring}

Well Network

The network has 12 wells that monitor the off-site southwest downgradient extent of the OU III VOC plumes (Figure 1-2). Some wells downgradient of the leading edge of the plumes serve as sentinel wells. Their locations and screen depth, in the deep portions of the Upper Glacial aquifer.

Sampling Frequency and Analysis

The wells were sampled semiannually, and samples are analyzed for VOCs (Table 1-5). As per the 2006 Groundwater Status Report recommendations, the sampling frequency for this program will be changed to annually in 2008. Samples are to be collected in the fourth quarter of each year.

\subsubsection{Monitoring Well Results}

The complete results for the monitoring wells in this program can be found in Appendix C. The horizontal extent of the off-site segment of the OU III VOC plume is shown in Figure 3.2-1.

The monitoring wells in the OU III Off-Site Program are perimeter and sentinel wells. They continue to have VOC concentrations below the NYS AWQS.

\subsubsection{Groundwater Monitoring Program Evaluation}

There were no unexpected results during 2007 that would have triggered the BNL Groundwater Contingency Plan. All VOC detections were below NYS AWQS.

\subsubsection{Recommendation}

No changes to the monitoring program are warranted at this time. 
SER VOLUME II: GROUNDWATER STATUS REPORT

This page intentionally left blank. 


\subsubsection{South Boundary Radionuclide Monitoring Program}

The South Boundary Radionuclide Monitoring Program was initiated to confirm that groundwater impacted by radionuclides is not migrating off the south section of the BNL site. The sampling was conducted in conjunction with the OU III South Boundary, Western South Boundary, and OU VI Programs. The eastern portions of the site south boundary are monitored for radionuclides as part of the OU I South Boundary, OU VI, and OU V STP groundwater monitoring programs.

\subsubsection{Groundwater Monitoring}

A network of 59 monitoring wells is used to monitor radionuclides from the OU III South Boundary, OU III Western South Boundary, and OU VI programs. The well locations along the southern property boundary are shown in Figure 3.2.14-1.

\section{Sampling Frequency and Analysis}

The OU III South Boundary Radionuclide Monitoring Program wells were sampled annually for tritium, Sr-90, and gamma spectroscopy (Table 1-5).

\subsubsection{Monitoring Well Results}

The radionuclide analytical results for the wells can be found in Appendix C. There were no confirmed radionuclide detections during 2007. In April 2007 there were several reported low-level detections of radionuclides within the South Boundary Radionuclide Monitoring Program. A data usability review indicates that these results are most likely false positives. Therefore, the analytic results have been flagged to indicate this conclusion.

\subsubsection{Groundwater Monitoring Program Evaluation}

The OU III South Boundary Radionuclide Monitoring Program can be evaluated based on the decision rule identified for this program resulting from applying the groundwater DQO process.

\section{Was the BNL Groundwater Contingency Plan triggered?}

No. There were no unexpected results during 2007 to trigger the BNL Groundwater Contingency Plan.

\subsubsection{Recommendations}

No changes are recommended for the OU III South Boundary Radionuclide Monitoring Program. The wells will continue to be sampled on an annual basis for radionuclides. 
SER VOLUME II: GROUNDWATER STATUS REPORT

This page intentionally left blank. 


\subsubsection{BGRR/WCF Strontium-90 Treatment System}

The OU III Brookhaven Graphite Research Reactor (BGRR)/Waste Concentration Facility (WCF) Treatment System addresses the Sr-90 plumes in groundwater downgradient of these facilities. Some of the wells included in the OU III BGRR/WCF network are also monitored as part of the OU III AOC 29 HFBR and Building 801 programs (see Sections 3.2.17 and 4.11). These wells are sampled concurrently for all programs to avoid duplication of effort. The BGRR/WCF remedy consists of:

1. Installation of five extraction wells using ion exchange to remove Sr-90, with on-site discharge of the clean water to injection wells

2. Operation of the system to minimize plume growth and meet DWS within 70 years (by 2070)

3. Continued monitoring and evaluation of data to ensure protectiveness

4. Institutional controls and five-year reviews

The analytical results indicate three areas of elevated Sr-90: one from the WCF area, one in an area south of the BGRR Below Ground Ducts (BGD) and Canal House, and one that is south of the former Pile Fan Sump (PFS) area (Figure 3.2.15-1).

\subsubsection{System Description}

Construction of the Sr-90 BGRR/WCF groundwater treatment system was completed in December 2004. Startup testing for the new treatment system began in January of 2005. The Sr-90 BGRR/WCF/PFS Groundwater Treatment System Start-Up Report (BNL 2005d) was finalized in April 2005, and full operation of the treatment system began in July 2005. There are two extraction wells (SR-1 and SR-2) south of the WCF and three extraction wells (SR-3, SR-4, and SR-5) south of the BGRR. The treatment system typically operates at an average rate of $25 \mathrm{gpm}$ total from five extraction wells.

Groundwater from the five extraction wells is transported through pipelines to an ion exchange treatment system inside Building 855. The vessels of ion exchange media are designed to treat groundwater contaminated with $\mathrm{Sr}-90$ to below the $8 \mathrm{pCi} / \mathrm{L}$ DWS. In addition, the influent is also treated for low-level concentrations (less than $10 \mu \mathrm{g} / \mathrm{L}$ ) of VOCs using liquid phase activated carbon.

Effluent is recharged to the Upper Glacial aquifer via three drywells approximately 850 feet west of Building 855. A New York SPDES equivalency permit regulates this discharge. A complete description of the system is included in the Operation and Maintenance Manual for the Sr-90 BGRR/WCF/PFS Groundwater Treatment System (BNL 2005e).

\subsubsection{Groundwater Monitoring}

Well Network

A network of 86 monitoring wells monitor the Sr-90 plumes associated with the BGRR, WCF, and PFS areas. In late 2005, six monitoring wells $(085-299,-300,-302,-310,-311$, and -312) in the network were abandoned due to construction of the new Center for Functional Nanomaterials (CFN). Five new wells were installed in the fall of 2007 to replace the abandoned wells and enhance plume monitoring (BGRR07-A, through E). Two new monitoring wells (065-384 and -385), located just south of the WCF and downgradient of the g-2 area (Figures 1-2 and 3.2.1 5-1), were installed in January 2006 after tritium from the g-2 plume was captured by extraction well SR-2.

Sampling Frequency and Analysis

Through 2007, the monitoring well sampling frequency remained at the startup phase (semi-annual). The well samples are analyzed for Sr-90. As noted in Table 1-5, wells also serve duel purposes for other programs. 


\subsubsection{Monitoring Well/Temporary Well Data}

The Sr-90 plume distribution map is shown in Figure 3.2.15-1. The distribution of Sr-90 throughout the BGRR, WCF, and PFS areas is depicted based on groundwater data obtained from the fourth-quarter 2007 sampling of the monitoring well network and temporary wells.

Historically, the highest Sr-90 concentration $(3,150 \mathrm{pCi} / \mathrm{L})$ was collected in 2003 from a temporary well installed approximately 200 feet south of Building 701 and slightly upgradient of the current location of extraction well SR-3. The highest historical Sr-90 concentration in the WCF area $(1,560$ pCi/L) was in April 2003, from a temporary well installed immediately downgradient of the six former underground storage tanks (USTs A/B), approximately 25 feet north of the WCF (Building 811). This area within the WCF is upgradient of the current location of extraction well SR-1. The highest historical Sr-90 concentration in the former PFS area $(566 \mathrm{pCi} / \mathrm{L})$ was collected in March 1997 from a temporary well installed downgradient of the PFS.

The following is a summary of the 2007 monitoring well data for the three Sr-90 plumes:

WCF Plume (refer to Figure 3.2.15-4 for cross-sectional view of plume):

- In 2007, the highest Sr-90 monitoring well concentration from all three plumes was $302 \mathrm{pCi} / \mathrm{L}$ during October from plume core well $065-175$, which is immediately south of the WCF yard. This is a decrease from the 2006 high of $801 \mathrm{pCi} / \mathrm{L}$ in the same well. The historical high for this well was $821 \mathrm{pCi} / \mathrm{L}$ in 2000 . Figure 3.2.15-5 shows a gradually declining trend in this well since 1999. This contamination will be captured by extraction well SR-2.

- Plume perimeter well 075-662, previously located on the western portion of the plume just downgradient of the HFBR stack, was abandoned in August 2007 due to an obstruction in the well. The previous high for this well was $41 \mathrm{pCi} / \mathrm{L}$ in 2006. A replacement well, BGRR07-A, was installed in late 2007. Sr-90 was detected below the DWS in the December sample.

- Wells $075-47,-48$, and -87 , located on Temple Place, are sentinel wells for the WCF Sr-90 plume. In well $075-48$, the maximum Sr-90 detection was $0.5 \mathrm{pCi} / \mathrm{L}$ for 2007 . An additional sentinel well, BGRR07-E, was installed in late 2007 at this location. There was no Sr-90 detected.

- Sentinel wells 065-384 and 065-385 were installed in January 2006 to monitor the g-2 tritium plume concentrations immediately upgradient of SR-2. The highest tritium concentrations in these wells in 2007 was $11,700 \mathrm{pCi} / \mathrm{L}$ in October from well $065-384$, and 2,850 pCi/L from well $065-$ 385 in March. This is a significant reduction in tritium concentrations since the $150,000 \mathrm{pCi} / \mathrm{L}$ was identified in a temporary well at this location in January 2006. To maintain groundwater flow so as not to adversely affect the position of the g-2 tritium plume, the optimum pumping ratio between the western and eastern supply well field has been maintained at the goal of 75 to 25 percent split. During 2007, the western well field provided approximately 90 percent of the total water pumpage.

As recommended in the 2006 Groundwater Status Report, starting in June 2007 select wells were analyzed for Sr-90 during the installation of temporary wells just northwest of the HFBR as part of the characterization effort for the downgradient portion of the g-2 Tritium Plume. The two plumes are in close proximity in this area, which allowed for a number of data points to be collected to supplement the existing Sr-90 monitoring well network. Four sets of east-west temporary well transects were installed from June 2007 through March 2008. The 22 temporary well locations (i.e., g2-GP-62) are identified on Figure 3.2.15-1 and the complete data set is available in Table 3.2.15-2. The transects are located as follows:

- A - The northern-most transect situated in the parking lot just south of Rutherford Drive to the east of the BGRR

- B - Approximately 175 feet south of transect A and 250 feet north of the HFBR. 
- $\mathrm{C}$ - Immediately north of the HFBR

- D - The southern-most transect just south of the HFBR.

The following is a brief summary of the data for the four transects:

- Transect A - The data from the four temporary wells installed in August/September 2007 is consistent with the previous monitoring well data in this area. The maximum Sr-90 concentration was in temporary well g-2-GP-79 at $52 \mathrm{pCi} / \mathrm{L}$. The eastern-most temporary well detected 40 pCi/L of Sr-90.

- Transect B - Four temporary wells installed identified Sr-90 concentrations higher than was anticipated for this area. The maximum detection was $294 \mathrm{pCi} / \mathrm{L}$ in $\mathrm{g}-2-\mathrm{GP}-72$. The elevated concentrations $(\sim 200 \mathrm{pCi} / \mathrm{L})$ were consistently identified in all four temporary wells. The width of the $100 \mathrm{pCi} / \mathrm{L}$ isocontour in this area is significantly wider than previously determined based on the existing monitoring wells and the pre-design groundwater characterization efforts.

- Transect C - Six temporary wells were installed at this transect between October and December 2007, with the seventh (g-2-GP-68) in March 2008. The previous understanding of the plume in this general area was that $\mathrm{Sr}-90$ concentrations were less than $100 \mathrm{pCi} / \mathrm{L}$. It should be noted that no permanent monitoring wells exist in this area to monitor the center-line of the plume. Well 065-39, located approximately 300 feet northwest of the HFBR building, monitors the eastern edge of the plume. The maximum $2007 \mathrm{Sr}-90$ concentration at this location was $518 \mathrm{pCi} / \mathrm{L}$ in temporary well g-2-GP-63. This concentration was significantly higher than expected and prompted the BNL Groundwater Contingency Plan to be implemented (see Section 3.2.15.6). The adjacent temporary well to the east, g-2-GP-64, had $271 \mathrm{pCi} / \mathrm{L}$ of Sr-90. The width of the 100 $\mathrm{pCi} / \mathrm{L}$ isocontour in this area is greater than 300 feet. Based on the significantly higher $\mathrm{Sr}-90$ concentrations recently detected in this area, without active treatment the plume is not expected to naturally attenuate to below the drinking water standards within the required timeframe of 70 years as defined by the OU III ROD and ESD (see Section 3.2.15.6 for further discussion).

- Transect D - The data from the seven temporary wells installed in February/March 2008 in front of the HFBR building shows that the leading edge of the plume is slightly south of this area. The maximum Sr-90 detected in this southernmost transect is $83 \mathrm{pCi} / \mathrm{L}$, in westernmost temporary well g-2-GP-93. The remaining temporary wells to the east did not detect $\mathrm{Sr}-90$ above $28 \mathrm{pCi} / \mathrm{L}$. Sentinel monitoring wells on Temple Place only detected trace amounts of Sr-90.

\section{BGRR Plume:}

- The highest Sr-90 concentration downgradient of the BGRR in 2007 was from extraction well $\mathrm{SR}-3$, reaching a peak of $1,650 \mathrm{pCi} / \mathrm{L}$ in September. This is the historical high concentration for this well since its installation in 2005.

- Plume core well 075-664 is the closest upgradient well to SR-3, approximately 45 feet away. The highest concentration of Sr-90 detected in this well was 76 pCi/L in March 2007. As depicted on Figure 3.2.15-2, this well appears to be screened a few feet below the high area of Sr-90 contamination seen in SR-3.

- The highest Sr-90 concentration in a monitoring well downgradient of the BGRR: in 2007, 148 pCi/L in plume core well 075-669. Note: This value is not identified on Figure 3.2.15-1 since it was obtained in the second quarter.) This value is slightly less than the 2006 value in this well, $234 \mathrm{pCi} / \mathrm{L}$. This well, located south of Cornell Avenue, is approximately 200 feet downgradient of the southernmost extraction well, SR-4. This portion of the plume is not being actively remediated. Based on the monitoring data to date, it is expected to naturally attenuate on site to below the drinking water standards within 70 years. 
- Plume core wells 075-666 and 075-673 are immediately upgradient of extraction well SR-5. The concentrations in these wells, up to $9 \mathrm{pCi} / \mathrm{L}$ in both wells in 2007 , are less than the detections in 2005 and 2006.

- Plume perimeter wells $075-195,-196,-197$, and -200 , located west of the downgradient portion of the plume, are all less than the DWS.

- Sentinel wells, 075-670 and -671 are north of Brookhaven Avenue on the National Synchrotron Light Source (NSLS) lawn. Prior to 2007, these wells were located just downgradient of the leading edge of the plume. In 2007, both wells detected Sr-90 above the DWS, between $12 \mathrm{pCi} / \mathrm{L}$ and $14 \mathrm{pCi} / \mathrm{L}$.

Pile Fan Sump Plume:

- The highest Sr-90 concentration in the PFS plume is in core well 075-85, located just south of Cornell Avenue This well reached a high of $76 \mathrm{pCi} / \mathrm{L}$ in October 2007. The previous high was 25 $\mathrm{pCi} / \mathrm{L}$, in 2002 . This plume is not addressed by active pumping, but will naturally attenuate to below the DWS.

- Plume perimeter wells 075-46, 075-86, and 075-672 were previously located just downgradient of the leading edge of the plume. 2007 data from these wells were below the DWS. The highest $2007 \mathrm{Sr}-90$ concentration in these wells was $5.4 \mathrm{pCi} / \mathrm{L}$ in well $075-86$, in October.

- A new monitoring well, BGRR07-D, is located on the eastern downgradient perimeter of the plume. The Sr-90 detection in December 2007 was $30 \mathrm{pCi} / \mathrm{L}$.

- Plume core wells 075-193, -194, -674, and -675 are located on the south side of Cornell Avenue and monitor the western portion of the leading edge of the plume. The highest $2007 \mathrm{Sr}-90$ concentration in these wells was $19 \mathrm{pCi} / \mathrm{L}$, in well 075-675 in April.

- Plume perimeter well 065-37, located just downgradient of the PFS, detected up to $74 \mathrm{pCi} / \mathrm{L}$ in October 2007. As noted on Figure 3.2.15-5, this is a significant increase from the last seven years of data. See Section 4.11 for further discussion.

During 2007, TVOC concentrations for the monitoring wells were below $5 \mu \mathrm{g} / \mathrm{L}$, except for well 075 10 in October. This perimeter well for the BGRR plume detected $7 \mu \mathrm{g} / \mathrm{L}$ TVOCs, with chloroform at $2.4 \mu \mathrm{g} / \mathrm{L}$ and TCA at $1.9 \mu \mathrm{g} / \mathrm{L}$, both below the DWS.

The following cross-sectional views are also provided:

- Figure 3.2.15-2 (I-I') for the BGRR plume - A north-south cross section from the BGRR south to Brookhaven Avenue

- Figure 3.2.15-3 $\left(\mathrm{J}-\mathrm{J}^{\prime}\right)$ for the PFS plume - North-south cross section from Building 801 south to Cornell Avenue

- Figure 3.2.15-4 (K-K') for the WCF plume - North-south cross section from WCF south to Cornell Avenue

In addition, historical Sr-90 concentration trend plots for key wells are plotted on Figure 3.2.15-5.

\subsubsection{System Operations}

The required frequency for Sr-90 and VOC sampling is monthly in accordance with the SPDES equivalency permit. The $\mathrm{pH}$ measurement is weekly. However, samples from the influent, effluent, and midpoint locations of the treatment system were collected once a week through the second quarter 2007 in order to develop a history of resin usage. In the third quarter, the system monitoring frequency changed from weekly to two times per month. All samples were analyzed for Sr-90 and VOCs. The influent was analyzed for tritium, and both the influent and effluent were analyzed weekly 
for $\mathrm{pH}$. Sr-90 concentrations in 2007 for the extraction wells are summarized in Table F-41 in Appendix F. System influent and effluent concentrations are summarized in Tables F-42 and F-43. Table F-44 contains the monthly Sr-90 removal totals for the system.

Operation details are given in the $\mathrm{O} \& \mathrm{M}$ manual for this system. Below is a summary of the system operations for 2007:

January-September 2007

The treatment system was off from March 12 to March 30 for a resin vessel change-out. The entire system was off from June 1 to June 18 for electrical repairs. The treatment system was off again from July 7 through September 1 due to a lightning strike, which severely damaged the computer control center of the system. As recommended in the 2006 Groundwater Status Report, starting with the third quarter, gross beta was removed from the analyte list for the treatment system sampling.

October-December 2007

The treatment system ran normally for the entire period.

\subsubsection{System Operational Data}

The analytical data for the period January 1 through December 31, 2007 showed a Sr-90 influent range from 19 to $504 \mathrm{pCi} / \mathrm{L}$, with the highest concentration in June. The highest tritium concentration in the influent during 2007 was $874 \mathrm{pCi} / \mathrm{L}$, in January. Sr-90 was detected once in the effluent samples during 2007, with the concentration at $1.2 \mathrm{pCi} / \mathrm{L}$ in February, below the limit of $8.0 \mathrm{pCi} / \mathrm{L}$ (See Table 3.2.15-1). There were no VOCs detected in the influent or effluent in 2007 above the SPDES Equivalency Permit discharge limits. During 2007, approximately 7.6 million gallons of groundwater were processed through the system.

\section{Cumulative Mass Removal}

Average flow rates for each monitoring period were used, in combination with the Sr-90 influent concentration, to calculate the number of millicuries removed. During operation, the flow averaged 20 gpm from January 1 through December 31, 2007. Approximately $4.9 \mathrm{mCi}$ of $\mathrm{Sr}-90$ was removed during 2007, for a total removed since system startup in 2005 of $14.15 \mathrm{mCi}$ (Figure 3.2.15-6).

\section{Extraction Wells}

Maximum Sr-90 concentrations in each of the extraction wells during 2007 were as follows:

- SR-1 $94 \mathrm{pCi} / \mathrm{L}$ in September

- SR-2 $170 \mathrm{pCi} / \mathrm{L}$ in October

- SR-3 1,650 pCi/L in September

- SR-4 $27 \mathrm{pCi} / \mathrm{L}$ in December

- SR-5 $128 \mathrm{pCi} / \mathrm{L}$ in December

Table 3.2.15-1.

Sr-90 BGRR Treatment System 2007 SPDES Equivalency Permit Levels

\begin{tabular}{|c|c|c|}
\hline Parameter & $\begin{array}{l}\text { Permit } \\
\text { Level }\end{array}$ & $\begin{array}{l}\text { Max. Measured } \\
\text { Value }\end{array}$ \\
\hline $\mathrm{pH}$ range & 5.5-8.5 SU & $6.0-6.8 \mathrm{SU}$ \\
\hline Sr-90 & $8.0 \mathrm{pCi} / \mathrm{L}$ & 1.2 \\
\hline chloroform & $7.0 \mu \mathrm{g} / \mathrm{L}$ & $<0.5$ \\
\hline 1,1,1-trichloroethane & $5.0 \mu \mathrm{g} / \mathrm{L}$ & $<0.5$ \\
\hline \multicolumn{3}{|c|}{$\begin{array}{l}\text { ND = Not detected above minimum detectable activity. } \\
\text { SU = Standard Units } \\
\text { Required sampling frequency was originally weekly for Sr-90, VOCs, and } \\
\text { pH. In April 2006, the frequency changed to monthly for Sr-90 and } \\
\text { VOCs after } 6 \text { months of non-exceedances. pH is weekly. }\end{array}$} \\
\hline
\end{tabular}

Tritium concentrations in extraction well SR-2 decreased throughout 2007, from a high of 2,590 $\mathrm{pCi} / \mathrm{L}$ in January to a low of $300 \mathrm{pCi} / \mathrm{L}$ in May. The treatment system influent and extraction wells SR-1 and SR-2 continue to be monitored for Sr-90 and tritium. No VOCs above the drinking water standard were detected in the extraction wells during 2007. 


\subsubsection{Groundwater Monitoring Program Evaluation}

The OU III BGRR/WCF Strontium-90 Pump and Treat System and Monitoring Program can be evaluated in the context of four basic decisions established for this program using the groundwater DQO process:

\section{Was the BNL Groundwater Contingency Plan triggered?}

For WCF Plume: Yes. As discussed in Section 3.2.15.3 above, in October 2007 a temporary well sample at location g-2-GP-63 identified $\mathrm{Sr}-90$ at a maximum concentration of $518 \mathrm{pCi} / \mathrm{L}$. This concentration was significantly higher than expected for this location. The slow migration rate of Sr90 in the aquifer (approximately 20 to 40 feet per year) along with the location of this high concentration slug in the middle of the site and far from any sensitive receptors (e.g., potable supply wells) did not warrant any immediate actions. Preliminary groundwater modeling concluded that the recent characterization data concentrations would jeopardize meeting the OU III ESD cleanup goal of reaching DWS in 70 years. The regulators were briefed on the data during the February 14, 2008 IAG weekly teleconference.

For BGRR Plume: No.

For PFS Plume: No.

\section{Has the plume been controlled?}

For WCF Plume: No. Based on the monitoring well data, the area of high Sr-90 contamination near the WCF is controlled and captured by extraction wells SR-1 and SR-2. However, based on the additional temporary well data collected north of the HFBR in the fall of 2007, there are high Sr-90 concentrations that are not actively controlled. Preliminary groundwater modeling performed taking into account the recent data indicates that if left untreated, the OU III ESD cleanup objective would not be met.

For BGRR Plume: Yes. Based on the monitoring well data, the high concentration portion of the plume is being captured by extraction wells SR-3, SR-4, and SR-5. However, well 075-669 should continued to be monitored to ensure that the Sr-90 concentrations in this well do not continue to climb higher than the $272 \mathrm{pCi} / \mathrm{L}$ identified in October 2005. This portion of the plume is outside the extraction well's capture zone. Trends since 2005 show a gradual decline in Sr-90 concentrations in this well to $86 \mathrm{pCi} / \mathrm{L}$.

For PFS Plume: Yes. Based on the monitoring well data, the high concentration portion of the plume is expected to attenuate to below DWS.

3. Is the system operating as planned? Specifically, is the aquifer being restored at the planned rate identified in the Explanation of Significant Differences to the OU III Record of Decision?

For WCF Plume: The hydraulic capture performance of the system is operating as modeled in the system design. The system has been removing Sr-90 from the aquifer and the resin is effectively treating the Sr-90 to below MCLs. The system is operating as planned. However, based on current model projections on the long-term restoration of the aquifer, the elevated Sr-90 concentrations identified just north of the HFBR indicate that the ESD cleanup objective of meeting DWS within 70 years (by 2070) may not be met. Additional extraction wells will be necessary to reduce the high concentration slug identified as part of the recent characterization effort to levels that will attenuate in accordance with the cleanup goal. A complication to addressing the high concentration slug is that it is co-located with tritium from the g-2 plume, well in excess of the DWS. This will not allow for pumping of the Sr-90 high concentration slug for the next one to two years. The g-2 tritium slug has been well defined, and is moving at a rate five to 10 times faster than Sr-90 in the aquifer. Once the tritium slug has moved south of this area it will be possible to pump and treat the Sr-90. 
For BGRR Plume: The hydraulic capture performance of the system is operating as modeled in the system design, and the system has been removing Sr-90 from the aquifer. The resin is effectively treating the Sr-90 to below DWS. The ESD objectives are expected to be met.

For PFS Plume: Based on the Sr-90 concentrations detected this year in this plume it is attenuating as projected.

\section{Have the cleanup goals been met? Can the groundwater treatment system be shut down?}

For WCF Plume: No. The cleanup goal of meeting the DWS in the aquifer has not yet been met. However, the system is preventing and minimizing plume growth of the higher concentrations of Sr90 near the WCF portion of the plume. As noted above, based on the temporary well data from late 2007 , there are high concentration areas $(518 \mathrm{pCi} / \mathrm{L})$ of the plume near the HFBR that will slowly continue migrating if not actively addressed.

For BGRR Plume: No. The cleanup goal of meeting the DWS in the aquifer has not been met, but the system is preventing and minimizing plume growth of the higher concentrations of Sr-90.

For PFS Plume: No. The cleanup goal of meeting the DWS in the aquifer has not yet been met.

\subsubsection{Recommendations}

The following are recommendations for the BGRR/WCF Groundwater Treatment System and monitoring program:

- Install additional temporary wells during the fourth quarter of 2008 in the area of the high Sr-90 detected in late 2007 from the WCF plume near the HFBR. Also, continue to analyze select temporary wells for Sr-90 during their installation just near the HFBR in 2008 for the g-2 tritium plume. These data will be important both to track the hot spot Sr-90 concentrations as well as to determine when the high concentration portion of the g-2 tritium plume has migrated south of this area. This will allow for additional Sr-90 extraction and treatment. These are necessary to obtain sufficient data to accurately define the extent of the high concentration Sr-90 slug and design additional extraction wells.

- Install additional Sr-90 extraction wells to address the Sr-90 hot spot identified in the WCF plume. The modification to the existing Sr-90 treatment system will consist of several new extraction wells. The location and exact number of wells will depend on the distribution of the hot spot following the departure/attenuation of the g-2 tritium slug from this area. It is currently estimated that the modification will be implemented in late 2009/early 2010. Groundwater characterization over the next couple of years will determine the implementation time.

- Supplement existing sentinel monitoring wells along Temple Place as necessary to track the leading edge of the WCF Sr-90 plume. This will be determined based on the results of temporary wells to be installed during the second quarter of 2008 .

- For the BGRR plume, install temporary wells near 075-670 and 075-671 to determine the width of the downgradient portion of the plume.

- Raise the pump in BGRR plume core well 075-664 four feet to evaluate Sr-90 concentrations in a shallower portion of the aquifer.

- The monitoring well sampling frequency will be implemented in a phased approach starting in 2009:

- Change the frequency from startup (semi-annual) to the operations and maintenance phase (annually) for the BGRR and PFS plumes.

- Due to the additional extraction wells planned to be installed for the WCF plume in 2009/2010, the monitoring well frequency for this plume should remain at the startup phase. 
- Maintain the southerly groundwater flow direction by managing the pumping of the BNL supply wells, via the oversight of the BNL Water and Sanitary Planning Committee. 


\subsubsection{Chemical/Animal Holes Strontium-90 Treatment System}

This section summarizes the operational data from the OU III Chemical/Animal Holes Strontium90 Treatment System for 2007, and gives conclusions and recommendations for future operation. This system began operation in February 2003.

\subsubsection{System Description Background}

The Chemical/Animal Holes were located in the south-central portion of the BNL property (Figure 1-1 and 3.2.16-1). The area consisted of 55 pits east of the Former Landfill that were used for the disposal of a variety of laboratory chemicals and animal remains. The buried waste was excavated in 1997.

Following the excavation, a Sr-90 plume was characterized. As discussed in the 2006 Groundwater Status Report, 17 temporary wells were installed between April 2006 and February 2007 to collect additional data as a result of increasing Sr-90 concentrations downgradient of EW-1. Based on these data and the monitoring wells, the plume (as defined by the $8 \mathrm{pCi} / \mathrm{L}$ isocontour) is now approximately 650 feet long and 65 feet wide, with a maximum thickness of 15 feet. It is approximately 22 to 45 feet below ground surface. To date, the highest $\mathrm{Sr}-90$ concentration observed in groundwater in this area was $4,720 \mathrm{pCi} / \mathrm{L}$ at well $106-99$, in March 2005 . The areas of higher concentrations $(>100 \mathrm{pCi} / \mathrm{L})$ occurred in very narrow bands. The first is an area at and immediately upgradient of EW-1. The second area, approximately 25 feet wide, begins around the Princeton Avenue firebreak and continues south for approximately 325 feet (Figure 3.2.16-1).

The elements of the Sr-90 remediation at the Chemical/Animal Holes are:

1. Three extraction wells pumping into an ion exchange treatment system to remove Sr-90 from the extracted groundwater, and on-site discharge of the clean water into two dry wells. Extraction wells EW-2 and EW-3 were installed in August and became operational in November 2007.

2. Operation of the system to minimize plume growth and meet DWS within 40 years.

3. Continued monitoring and evaluation of the data to ensure protectiveness.

Details of operations are provided in the Strontium-90 Pilot Study Treatment System Operation and Maintenance Manual (BNL 2004b). This manual is in being updated to reflect the additional extraction wells.

\subsubsection{Groundwater Monitoring}

Well Network

The monitoring well network was enhanced in 2007 with the addition of five wells for a total of 41 . Figure 1-2 shows the monitoring well locations.

\section{Sampling Frequency and Analysis}

Per the recommendation in the 2006 Groundwater Status Report, starting in the third quarter of 2007 the monitoring well sampling frequency changed from startup (semi-annual and quarterly) to the O\&M phase (semi-annual and annual). Six of the 41 monitoring wells were sampled semi-annually for Sr-90; the remaining wells were sampled annually. All the wells are sampled annually for VOCs.

\subsubsection{Monitoring Well Results}

Figure 3.2.16-1 shows the Sr-90 plume distribution. The plume depiction is derived from the third and fourth-quarter monitoring well data and supplemented with the 17 temporary wells and five new monitoring wells. Note: The data from the temporary wells were previously included in the 2006 Groundwater Status Report and the 2007 Quarterly Operations Reports.

A summary of key monitoring well data for 2007 follows. 
- The highest Sr-90 concentration observed in 2007 was $589 \mathrm{pCi} / \mathrm{L}$ in plume core well 106-16. This well is approximately 50 feet upgradient of EW-1 and is beginning to increase following two previous years of lower values $(<360 \mathrm{pCi} / \mathrm{L})$. However, Sr-90 concentrations in plume core well 106-99, slightly downgradient of 106-16, continued to remain low over the past two years despite reaching a historic high for the plume in 2005 of $4,720 \mathrm{pCi} / \mathrm{L}$. This indicates that the slug near well 106-16 has not yet reached this location.

- Plume core well 106-49, located in the centerline of the plume approximately 170 feet downgradient of extraction well EW-1, detected Sr-90 up to $154 \mathrm{pCi} / \mathrm{L}$. As shown in Figure 3.2.16-2, the 2007 data for this well are the lowest since 2003. This may indicate that the trailing edge of the high Sr-90 portion of the plume between EW-1 and this location is now moving through this area. This hypothesis is also supported by the declining trends in upgradient wells 106-103 and 106-105.

- New plume core well 106-125, approximately 100 feet downgradient of well 106-49 and just upgradient of EW-2, is picking up the leading edge of the higher portion of the plume. This well detected $498 \mathrm{pCi} / \mathrm{L}$ of Sr-90 in October 2007 and dropped off slightly to $320 \mathrm{pCi} / \mathrm{L}$ in December. New plume core well 106-119, located upgradient of the southern-most extraction well EW-3, detected a maximum $\mathrm{Sr}-90$ concentration of $49 \mathrm{pCi} / \mathrm{L}$ also in October.

- Newly installed bypass wells 106-120, 106-121, and 106-122 are approximately 100 feet south of EW-3. No Sr-90 has yet been detected in these wells.

- Wells 106-43, 106-44, 106-45, and 106-64, approximately 500 feet west of the Chemical Holes plume, have not detected Sr-90 above the DWS since 2002. These wells are downgradient of the Former Landfill.

As noted earlier, there are two distinct portions of the plume greater than $50 \mathrm{pCi} / \mathrm{L}$ (see Figure 3.2.16-1). The smaller area extends approximately 85 feet upgradient of EW-1. There is then a break in the $50 \mathrm{pCi} / \mathrm{L}$ isocontour from EW-1 and downgradient approximately 100 feet. Based on the data from the temporary wells and new monitoring wells, the higher concentrations $(>50 \mathrm{pCi} / \mathrm{L})$ then continue for approximately 365 feet. The leading edge of the plume, as defined by the DWS of 8 $\mathrm{pCi} / \mathrm{L}$, is approximately 500 feet south of well EW-1. New extraction well EW-2 was installed in the middle of the high concentration segment of the plume, and EW-3 was installed just ahead of the leading edge of the $50 \mathrm{pCi} / \mathrm{L} \mathrm{Sr}-90$ isocontour.

All monitoring wells in this program are also analyzed annually for VOCs to monitor low-level VOC contamination originating from the Chemical/Animal Holes area Note: The five new monitoring wells were not yet sampled in 2007 for VOCs. There were no detections of VOCs above the DWS in 2007 in any well. The complete results are in Appendix C.

\subsubsection{System Operations}

The Strontium-90 Chemical/Animal Holes Treatment System influent, effluent, and midpoint locations were sampled once a week, in accordance with the SPDES equivalency permit. All samples were analyzed for Sr-90. In addition, the influent and effluent samples were analyzed for $\mathrm{pH}$ on a monthly basis (Table 3.2.16-1). As per the recommendations in the 2006 Groundwater Status Report, in the third quarter of 2007, gross beta was removed from the analyte list for the treatment system sampling, since this parameter is no longer needed. The SPDES Equivalency Permit, which expired in January 2008, was renewed in February 2008 and the Sr-90 sampling frequency was changed from weekly to monthly. In August, two new extraction wells (EW-2 and EW-3) were installed. The new extraction wells began operating November 5, 2007. The treatment system now consists of three extraction wells. Sr-90 concentrations in 2007 for the system influent and effluent are summarized in Tables F-45 and F-46 in Appendix F. Table F-47 contains a summary of the monthly Sr-90 mass removal for the system. 
Summarized below are the system operations data for 2007. Details for this system are given in the O\&M manual.

Table 3.2.16-1.

Sr-90 Chemical Holes Treatment System 2007 SPDES Equivalency Permit Levels

\begin{tabular}{lcc}
\hline Parameter & $\begin{array}{c}\text { Permit } \\
\text { Level }\end{array}$ & $\begin{array}{c}\text { Max. Measured } \\
\text { Value }\end{array}$ \\
\hline $\mathrm{pH}^{*}$ range (SU) & $5.0-8.5$ & $5.4-6.3$ \\
$\mathrm{Sr}-90$ (pCi/L) & 8.0 & $\mathrm{ND}$ \\
\hline * In May 2006, the permitted pH lower limit changed from 6.5 to $5.0 \mathrm{SU}$ \\
$\mathrm{ND}=$ Not detected above minimum detectable activity. \\
$\mathrm{SU}=$ Standard Units \\
$\begin{array}{l}\text { Required sampling frequencies are weekly and monthly for } \mathrm{Sr}-90 \text { and } \mathrm{pH}, \\
\text { respectively. }\end{array}$ \\
\hline
\end{tabular}

January-September 2007

In June 2007, a design report on the two additional extraction wells and additional monitoring wells was provided to the regulators. Construction was initiated in late June and was completed in August. The system was off for most of June and July due to a computer hardware problem. In August, the system was off for the last part of the month while the two new extraction wells were being connected. The system ran normally for September.

October-December 2007

The new extraction wells began operating November 5, 2007. The system operated normally the remainder of the quarter.

\subsubsection{System Operational Data}

The analytical data for the period January 1-December 31, 2007 show that Sr-90 in the influent ranged from $6 \mathrm{pCi} / \mathrm{L}$ to $79 \mathrm{pCi} / \mathrm{L}$. The increase noted in November 2007 is due to the start-up of both extraction wells. All effluent samples were well below the SPDES equivalency permit level of 8 pCi/L for Sr-90. During 2007, approximately 2.4 million gallons of groundwater were processed through the system.

\section{Cumulative Mass Removal}

Average flow rates for each monitoring period were used, in combination with the Sr-90 concentration, to calculate the number of millicuries $(\mathrm{mCi})$ removed. Flow averaged $6 \mathrm{gpm}$ during 2007. The cumulative total was approximately $0.27 \mathrm{mCi}$ of $\mathrm{Sr}-90$ removed during 2007, and a total since 2003 of approximately $2.60 \mathrm{mCi}$ (Figure 3.2.16-3).

\subsubsection{System Evaluation}

The Chemical/Animal Holes Treatment System performance can be evaluated based on the four major decisions identified for this system as part of the DQO process that was used to design the monitoring program.

\section{Was the BNL Groundwater Contingency Plan triggered?}

Not in 2007. Although based on the Contingency Plan being triggered in 2006, corrective measures were performed in 2007. These include:

- The installation of 17 temporary wells to further define the higher Sr-90 concentrations downgradient of EW-1

- The installation of two additional extraction wells to remediate the plume

- The installation of five additional monitoring wells to monitoring the effectiveness of the remediation system and plume reduction

\section{Has the plume been controlled?}

The monitoring data indicate the plume upgradient of the extraction EW-1 is controlled by the single extraction well pumping at $6 \mathrm{gpm}$. However, monitoring data collected downgradient of the extraction 
well in 2005 and 2006 showed significant Sr-90 concentrations (up to 1,530 pCi/L). Elevated Sr-90 concentrations, up to $356 \mathrm{pCi} / \mathrm{L}$, were detected in the additional temporary wells installed between April 2006 and February 2007. This area of Sr-90 contamination was already downgradient of the pilot study extraction well when the well went into operation (Figure 3.2.16-1). Since the two additional extraction wells were installed in late 2007 the downgradient portion of the plume should be controlled. Continued monitoring of the wells over time will provide verification.

\section{Is the system operating as planned? Specifically, is the aquifer being restored at the planned rate} identified in the Explanation of Significant Differences to the OU III Record of Decision?

The system was designed to meet the ROD and ESD cleanup goal of reaching the maximum contaminant level (MCL) within 40 years. The design expected that the one extraction well would need to operate approximately 10 years to actively treat the Sr-90 plume, followed by 30 years of natural attenuation and radioactive decay. Based on increased Sr-90 concentrations identified in monitoring wells further downgradient, two additional extraction wells were installed in 2007 to ensure the cleanup goals would be met. The additional two extraction wells are also expected to operate approximately 10 years as originally designed.

\section{Have the cleanup goals been met? Can the groundwater treatment system be shut down?}

No. Based on groundwater monitoring data discussed in Section 3.2.16.3 above, significant contamination remains upgradient of extraction wells EW-1, EW-2, and EW-3. If this were left untreated, the cleanup goal of meeting the MCL within 40 years would not be met.

\subsubsection{Recommendations}

The following are the recommendations for the Chemical/Animal Holes Strontium-90 Treatment System and groundwater monitoring program:

- Continue to operate extraction wells EW-2 and EW-3 between 5 to 7 gpm.

- Due to the low influent concentrations, implement pulse pumping of EW-1 (cycle of 1 month on, 1 month off) beginning in January 2008. If concentrations in this extraction well increase significantly, then EW-1 will be put back into full-time operation

- Due to the increase of Sr-90 concentrations in monitoring well 106-16, install temporary wells upgradient of this location to verify that there is no continuing source of contamination. This work will be performed in mid 2008. Based on a review of the data, a monitoring well may also be installed.

- Maintain the operations and maintenance phase monitoring well sampling frequency started in 2007. Change the frequency for the five new monitoring wells from quarterly to semi-annually. Also, change the sampling frequency for well 106-99 from annual to semi-annual.

- Starting in the third quarter of 2008, drop VOC analysis from the monitoring wells, since VOCs have not been detected above the DWS since 2004.

- Transfer monitoring wells 106-20, 106-21, 106-43, 106-44, 106-45, and 106-64 to the Former Landfill groundwater monitoring program. The data will be discussed in the annual Landfill Monitoring Report. 


\subsubsection{HFBR Tritium Pump and Recharge System}

In late 1996, tritium was detected in monitoring wells near the HFBR. The source of the release was traced to the HFBR spent fuel pool. In response, the fuel rods were removed and the spent fuel pool was drained. In May 1997, a three-well groundwater pump and recharge system was constructed on Princeton Avenue firebreak road approximately 3,700 feet downgradient of the HFBR, to capture tritium and assure that the plume would not move off site. Extracted water was recharged at the RA V recharge basin. Groundwater modeling projected that the tritium plume would attenuate naturally to below DWS $(20,000 \mathrm{pCi} / \mathrm{L})$ before reaching the site boundary. The extraction system was placed on standby status in September 2000, as groundwater monitoring data demonstrated that the plume was attenuating to concentrations well below DWS in the vicinity of the Pump and Recharge System.

As described in the OU III ROD, the selected remedy to address the HFBR tritium plume included implementing monitoring and low-flow extraction programs to prevent or minimize the plume's growth. Beginning in June 2000 and ending April 2001, 20 low-flow extraction events removed 95,000 gallons of tritiated water with concentrations greater than $750,000 \mathrm{pCi} / \mathrm{L}$. This water was sent off site for disposal. The OU III ROD contingencies are defined as either a detection of tritium above $25,000 \mathrm{pCi} / \mathrm{L}$ in monitoring wells at the Chilled Water Facility Road, or above 20,000 pCi/L in monitoring wells along Weaver Drive. The OU III ROD contingency of exceeding $20,000 \mathrm{pCi} / \mathrm{L}$ at Weaver Drive was triggered with a detection of $21,000 \mathrm{pCi} / \mathrm{L}$ in $\mathrm{GP}-297$ on November 2, 2006. A new extraction well EW-16 was installed in 2007 to supplement the three existing pump and recharge wells and the system was restarted in November 2007 as per the ROD contingency.

Groundwater flow in the vicinity of the HFBR is primarily to the south (Figures 2-2 and 2-3). Evaluation of groundwater flow and quality data indicates that the downgradient portion of the tritium plume (south of Brookhaven Avenue) has shifted east since 1997 in response to decreased cooling water discharges to the HO recharge basin, the OU III recharge basin, and the reduced pumping of BNL's eastern supply wells 10,11 , and 12 . The eastward shift can also be seen by observing the sharp declines in tritium concentration for monitoring wells $075-294,075-418,085-287$, and 085-78 in Figure 3.2.17-3.

\subsubsection{HFBR Pump and Recharge System}

Operation of the system resumed in November 2007 as a result of the implementation of the ROD contingency described above and included the pumping of wells EW-16 and EW-11. Extraction well EW-16 was installed in 2007 approximately 400 feet north of the existing pump and recharge wells located on the Princeton Avenue firebreak road (Figure 3.2.17-1). Extraction wells EW-9, EW-10, and EW-11 are being sampled quarterly and EW-16 is being sampled at a monthly frequency. A prestartup sample obtained on November 28, 2007 showed tritium at 6,580 pCi/L. Since that time the tritium concentrations in EW-16 have ranged from $970 \mathrm{pCi} / \mathrm{L}$ to $2,530 \mathrm{pCi} / \mathrm{L}$. Complete system operations and system evaluation reporting will resume in the 2008 Groundwater Status Report.

\subsubsection{System Description}

For a complete description of the HFBR Tritium Pump and Recharge System, see the Operation and Maintenance Plan for the High Flux Beam Reactor Tritium Plume Pump and Recharge System (BNL 1998). The O\&M Plan is currently being updated to incorporate the modifications to the system.

\subsubsection{Groundwater Monitoring}

\section{Well Network}

A monitoring well network of 116 wells is used to evaluate the extent of the plume, monitor the source area, and verify the predicted attenuation of the plume (Figure 1-2 ). The permanent monitoring well network is being supplemented with a semi-annual temporary well characterization. A total of 27 temporary wells were installed and sampled in 2007 and the first quarter of 2008. Eight 
temporary wells were installed between July 17 and August 2, and 19 temporary wells were installed between January 14 and February 27, 2008 (Figure 3.2.17-1) and Table 3.2.17-1.

Sampling Frequency and Analysis

Sampling details for the well network are contained in Table 1-5. Select wells are also analyzed for VOCs as part of the Carbon Tetrachloride and Middle Road programs.

\subsubsection{Monitoring Well Data}

The extent of the tritium plume is shown on Figure 3.2.17-1. This figure summarizes data collected from monitoring wells during the fourth quarter of 2007, supplemented with data obtained from 27 temporary wells at 20 locations installed from December 2007 through March 2008. The temporary wells were undertaken to fill in data gaps along key segments of the plume. The temporary wells were installed east of the existing monitoring well network along transects established at Temple Place, east of Bell Avenue, east of the Chilled Water Facility Road, east of Weaver Drive, and immediately north of EW-16, as shown in Figure 3.2.17-1. Appendix $\mathbf{C}$ has the complete set of monitoring well data. Data from temporary wells installed from July 2007 through March 2008 are summarized in Table 3.2.17-1. A north-south cross-sectional view of the plume centerline is shown in Figure 3.2.17-2. Tritium concentration trends for key monitoring wells are shown in Figure 3.2.17-3.

\section{Background}

Samples are collected from a network of seven monitoring wells north of the HFBR. These wells serve as early detection points if groundwater flow shifts to a more northerly direction and toward supply wells 10, 11, and 12. Groundwater flow during 2007 was consistently to the south. Supply well 10 remained in standby mode the entire year, while wells 11 and 12 operated minimally. As a result there was no northward migration of tritium in groundwater. It should be noted that tritium was detected in well $065-39$ at a concentration of $31,700 \mathrm{pCi} / \mathrm{L}$ in 2007 . This well is approximately 400 feet northwest of the HFBR. The tritium observed in this well originates from the g-2 source area. A characterization of the downgradient extent of the g-2 tritium plume was conducted in 2007 and is summarized in Section 4.2. This plume is present in the vicinity of the HFBR, approximately 10 to 20 feet deeper than the HFBR plume.

\section{HFBR to Brookhaven Avenue}

Tritium concentrations directly downgradient from the HFBR have been observed to correlate with peak water table elevations in response to water table flushing of the unsaturated zone beneath the HFBR (Figure 3.2.17-4. There is an approximate nine- to 12-month lag time between peak water table conditions and observed tritium concentration increases in wells immediately downgradient of the HFBR. The tritium concentrations detected in monitoring wells that are immediately downgradient of the HFBR and associated with the periodic water table rises that are mobilizing tritium beneath the source area are trended in Figure 3.2.17-5. A steady decrease is observed with respect to these peak tritium concentrations over time. Based on the trend, it is anticipated that peak tritium concentrations in these wells will be less than the $20,000 \mathrm{pCi} / \mathrm{L}$ DWS within the next several years.

The centerline of the tritium plume from the HFBR to Brookhaven Avenue shifted to the east along Cornell Avenue in early 2006 and has remained relatively steady since that time, as can be seen in the tritium concentration in wells $075-240$ and $075-245$, which are at the east end of the monitoring well network on Cornell Avenue (Figure 3.2.17-3).

The peak tritium concentration in this area, $200,000 \mathrm{pCi} / \mathrm{L}$ in well $075-240$ in July 2007, probably resulted from the water table rise in June 2006. Tritium concentrations in this well steadily decreased to $9,700 \mathrm{pCi} / \mathrm{L}$ in December of 2007 . Based on the declining water table elevation in late 2007 and early 2008, the tritium concentrations observed immediately downgradient of the HFBR are expected to continue decreasing in 2008. 


\section{Brookhaven Avenue to Weaver Drive}

The monitoring well network in this area was supplemented with 10 temporary wells during 2007/2008. Locations 095-278 and 095-272 were sampled twice during this period. The only significant change to the plume in this area was the migration of the break in the $20,000 \mathrm{pCi} / \mathrm{L}$ contour to an area between Temple Place and just north of Brookhaven Avenue, as shown in Figure 3.2.17-1. This break was created by the intermittent nature of tritium flushing in the vadose zone beneath the HFBR over the past several years.

In the first quarter of 2008, the highest concentration segment of the HFBR tritium plume continues to be located at and just south of Chilled Water Facility Road. The highest tritium concentration detected was $118,000 \mathrm{pCi} / \mathrm{L}$, in temporary well GP-282, in August 2007. This was similar to the high concentration at this location in 2006 of $97,000 \mathrm{pCi} / \mathrm{L}$. The trailing edge of the higher concentration slug should be approaching this location, which is scheduled to be sampled again in July 2008.

\section{Weaver Drive to Princeton Avenue Firebreak Road}

A temporary well characterization effort was conducted in this area during the second quarter of 2007 and the first quarter of 2008 to supplement the monitoring well network. The highest detection observed along Weaver Drive was $65,800 \mathrm{pCi} / \mathrm{L}$ in GP-300 in late January 2008 . Temporary well GP349 was installed mid-way between Weaver Drive and EW-16 in March 2008 and detected 82,300 $\mathrm{pCi} / \mathrm{L}$ tritium (Figure 3.2.17-1). Temporary well GP-340, located approximately 100 feet north of EW-16, detected 10,000 pCi/L in March 2008. Based on these characterization data, the leading edge of the plume, as defined by concentrations greater than $20,000 \mathrm{pCi} / \mathrm{L}$, is approaching the vicinity of EW-16. EW-16 is being sampled on a monthly basis, and concentrations to date have not reflected the plume reaching this well. Table F-48 in Appendix F presents the VOC and tritium 2007 detections in the extraction wells.

\subsubsection{Groundwater Monitoring Program Evaluation}

The OU III HFBR Tritium Monitoring Program can be evaluated based on five major decision rules established for this program using the groundwater DQO process.

\section{Was the BNL Groundwater Contingency Plan triggered?}

No. The were no unusual or unexpected concentrations of contaminants observed in the monitoring wells or the extraction wells associated with the HFBR Tritium Pump and Recharge System during 2007. EW-16 was installed and the Pump and Recharge system restarted in 2007 in response to triggering the ROD contingency of 20,000 pCi/L at Weaver Drive in 2006.

\section{Is the tritium plume growing?}

Based on the position of the $20,000 \mathrm{pCi} / \mathrm{L}$ isocontour line, the high concentration segment of the plume has migrated to a location immediately north of EW-16, which is positioned to capture the plume. See Figure 3.2.17-6 for the plume distribution comparison between 1997 and 2007.

\section{Are observed conditions consistent with the attenuation model?}

Yes. The BNL groundwater model 2003 update predicted that the remnants of the hot spot would reach Weaver Drive in approximately the late 2005 time frame at concentrations between 30,000 and $60,000 \mathrm{pCi} / \mathrm{L}$. Observed conditions with respect to both tritium concentrations and hot-spot position matched the model predictions reasonably well. The observed concentration of $82,300 \mathrm{pCi} / \mathrm{L}$ between Weaver Drive and EW-16 in 2008 is slightly higher the model predicted concentration $(20,000-$ $40,000 \mathrm{pCi} / \mathrm{L}$ ), but within an acceptable error range for a 5-year prediction.

4. Is the tritium plume migrating toward the zone of influence of water supply wells 10,11, and 12? No. Groundwater flow from this area was to the south during 2007 (Figure 2-2). 
5. Has any segment of the plume migrated beyond the current monitoring network?

No. The plume is monitored by a combination of permanent wells supplemented with temporary wells, where necessary, to ensure that the plume extent is characterized.

\subsubsection{Recommendations}

The following are recommendations for the HFBR tritium Pump and Recharge System and monitoring program:

- Continue monitoring well sampling schedule initiated in 2006.

- Continue to install and sample temporary wells twice per year over the next several years to characterize the location of the high tritium concentration area, and results will be communicated to the regulators via the IAG conference call and quarterly/annual reports.

- Continue operating EW-16 and EW-11 in 2008. Monitor tritium concentrations in EW-16 on a monthly basis.

- The pump and recharge well(s) will be operated until the tritium concentrations from Weaver Drive to the new extraction well drop below 20,000 pCi/L. The estimated operational duration of 2 to 4 years is based on the length of the high concentration area slug and the time it would take to be completely captured by the new extraction well. The decision to turn the wells back to standby will be based on; 1) concentrations of tritium being less than $20,000 \mathrm{pCi} / \mathrm{L}$ in the monitoring wells at Weaver Drive as well as the extraction wells, and 2) verification that the new extraction well has captured concentrations of tritium in this area greater than $20,000 \mathrm{pCi} / \mathrm{L}$. This decision to turn the wells back to standby will be supported with data from additional permanent and temporary wells, as needed. 


\subsection{OPERABLE UNIT IV}

\subsubsection{Post Closure Monitoring (Former OU IV AS/SVE System)}

The OU IV Air Sparge System was shut down in August 2001, and further monitoring was continued as per OU IV Remediation Area 1 Proposed Supplemental Remedial Effort - Work Plan (BNL 2001b). The Petition for Closure and Termination of Formal Post Closure Monitoring of OU IV Air Sparge/Soil Vapor Extraction Remediation System (BNL 2002c) was submitted to the regulatory agencies in June 2002. BNL received regulatory approval in July 2003 and decommissioned the system in December 2003.

A Five-Year Review Report for OU IV was submitted to the regulators in June 2002. Following revisions made based on regulator comments, a final report was approved in September 2003. This report included changes to the continued groundwater monitoring program.

\subsubsection{Groundwater Monitoring}

Well Network

The Final CERCLA Five Year Review Report for OU IV (BNL 2003b) stated that monitoring under this program should continue for three monitoring wells: 076-04, 076-06, and 076-185.

Monitoring wells 076-18 and 076-19 continue to be monitored under the BNL Facility Monitoring Program for the Central Steam Facility. The remaining monitoring wells were either included under the radionuclide monitoring under the OU IV AOC 6 Program or abandoned as per the final report (BNL 2003b) (Figure 1-2).

Sampling Frequency and Analysis

The sampling frequency for these wells is semi-annually for VOCs and SVOCs.

\subsubsection{Monitoring Well Results}

Post-closure sampling of monitoring wells was conducted for 2007. The complete groundwater data are given in Appendix C. There were no detections of SVOCs in any of the samples collected. No samples exceeded the NYS AWQS for VOCs during 2007.

\subsubsection{Post-Closure Monitoring Evaluation}

The system can be evaluated based on the decision rule identified during the groundwater DQO process.

\section{Was the BNL Contingency Plan triggered?}

No. There were no unexpected VOC concentrations in groundwater during 2007.

\subsubsection{Recommendations}

The following are recommendations for the OU IV AS/SVE Post Closure Monitoring program:

- Reduce frequency of sampling from semiannual to annual due to the lack of detections of VOCs and SVOCs. 
SER VOLUME II: GROUNDWATER STATUS REPORT

This page intentionally left blank. 


\subsubsection{Building 650 Strontium-90 Monitoring Program}

The Building 650 Strontium-90 Monitoring Program monitors a Sr-90 plume emanating from a former source area known as the former Building 650 Sump Outfall Area. This former source consisted of a depression at the terminus of a discharge pipe from the building. The pipe conveyed discharges from a concrete pad located approximately 1,200 feet to the west, where radioactively contaminated clothing and equipment were decontaminated, beginning in 1959.

Remediation (by excavation) of the contaminated soils associated with the Building 650 sump outfall and removal of the pipe leading to the outfall, as well as soil, concrete, and asphalt associated with the former decontamination pad behind Building 650, were completed in 2002.

\subsubsection{Groundwater Monitoring}

Well Network

The network consists of 29 wells used to monitor the Sr-90 concentrations originating from the former Building 650 sump and sump outfall area. (Figure 1-2).

Sampling Frequency and Analysis

During 2007, the wells were monitored either annually or semi-annually and the samples were analyzed for Sr-90 (Table 1-5).

\subsubsection{Monitoring Well Results}

The complete results from radionuclide sampling can be found in Appendix C. The overall extent of the Sr-90 plume originating from the Building $650 \mathrm{sump}$ outfall has not changed significantly over the past several years, as it continues to migrate slowly southward while attenuating in the vicinity of well 076-24 (Figure 3.3.2-1). The leading edge of the plume is presently located just to the southwest of well 076-24. The highest Sr-90 concentrations were detected in well 076-169, at $25 \mathrm{pCi} / \mathrm{L}$, in January 2007. In general, the concentrations in wells associated with the Building 650 sump and sump outfall plume displayed declining trends during 2007 (Figure 3.3.2-2).

Sr-90 concentrations in well 076-28 are shown in Figure 3.3.2-2. This well is immediately north of Building 650, adjacent to the former decontamination pad where contaminated soils were removed in 2002. Periodic increases in Sr-90 concentrations have been observed in this well over the past several years. The Sr-90 data from this well, which dates back to 1997, was compared to water table elevation data to identify whether the increases may be in response to periodic water table rises that flush out residual Sr-90 residing in the unsaturated zone in the vicinity of the pad/building. This water table flushing process has been observed in several former source areas across the site, including the HFBR, BGRR, and g-2. Based on an analysis of the data there does not appear to be a direct correlation between water table elevation and Sr-90 concentration in this well. Sr-90 concentrations were also compared to precipitation data over the history of the well with no observable correlation.

\subsubsection{Groundwater Monitoring Program Evaluation}

The system can be evaluated based on the three decision rules identified from the groundwater DQO process.

\section{Was the BNL Groundwater Contingency Plan triggered?}

No. There were no unexpected Sr-90 concentrations in groundwater during 2007.

\section{Were performance objectives met?}

No. The performance objective for this project is to achieve Sr-90 concentrations below the DWS of 8 $\mathrm{pCi} / \mathrm{L}$. There were four monitoring wells exceeding this limit in 2007. Therefore, the performance objectives have yet to be achieved. The removal of contaminated soils in 2002 addressed the 
predominate source of groundwater contamination. The groundwater plume continues to degrade due to natural attenuation (i.e., radioactive decay).

\section{If not, are observed conditions consistent with the attenuation model?}

Yes. The observed data are consistent with the attenuation model in terms of the extent of Sr-90 contamination.

\subsubsection{Recommendation}

The following recommendation is made for the Building 650 Strontium-90 Groundwater Monitoring Program:

- Reduce the sampling frequency for monitoring wells 076-25, 076-26, 076-314, 076-317, 076-373, 066-189, and 066-190 to annual. There have been no significant detections of Sr-90 in these wells over the past several years. Several of these wells (076-314, 066-189, and 066-190) are no longer downgradient of the source area due to changes in groundwater flow resulting from the diminished water table mounding at Basin HO. The sampling frequencies can be increased if warranted by future changes in groundwater flow conditions. 


\subsection{OPERABLE UNIT V}

\subsubsection{Sewage Treatment Plant Monitoring Program}

The Sewage Treatment Plant (STP) processes sanitary wastewater from BNL's research and support facilities. Treated effluent from the STP is discharged to the Peconic River under a NYSDEC SPDES permit. Historically, BNL's STP received discharges of contaminants from routine operations. Releases of low-level contaminants to groundwater (in particular, VOCs, metals, and radionuclides) occurred via the STP sand filter beds and discharges to the Peconic River. The OU V project monitors the identified groundwater contamination downgradient of the STP. Groundwater quality in the immediate vicinity of the STP is being monitored under the Facility Monitoring Program, which is discussed in Section 4.6 of this document.

\subsubsection{Groundwater Monitoring}

\section{Well Locations}

A network of 34 monitoring wells was designed to track groundwater contamination downgradient of the STP, at the boundary, and off site (Figure 1-2). BNL's Groundwater Model was used to aid in placing these wells.

\section{Sampling Frequency and Analysis}

Wells are sampled semi-annually and samples are analyzed for VOCs, perchlorate, and tritium (Table 1-5). Sample frequency will be reduced to annual in 2008 based on the 2006 Groundwater Status Report recommendation.

\subsubsection{Monitoring Well Results}

The OU V wells were sampled during two rounds in 2007. Appendix $\mathbf{C}$ contains the complete data. The VOC plume consists of an area of less than $8 \mu \mathrm{g} / \mathrm{L}$ TVOCs that extends from south and east of the STP southeast to the vicinity of the Long Island Expressway (Figure 3.4-1). During 2007, the highest TVOC concentration was $8 \mu \mathrm{g} / \mathrm{L}$ in well $000-122$, located just north of the expressway. In general, VOC concentrations in on-site plume core wells continued to decline. The TVOC concentrations in off-site plume core well 000-122 have shown a decreasing trend since early 2005 (Figure 3.4-2). The only individual VOC detected at levels exceeding NYS AWQS was TCE, at 5.2 $\mu \mathrm{g} / \mathrm{L} .2007$ was the first year since 1998 that 1,2-dichloropropane has not been detected in shallow off-site sentinel well 600-25 at concentrations exceeding the NYS AWQS of $1 \mu \mathrm{g} / \mathrm{L}$. It is believed that the previous detections in this well originated from an off-site source, based on the shallow depth and distance from the site (approximately 4,000 feet) at which it was detected. There have been no significant changes to the VOC plume over the past several years, other than the gradual decline in concentrations (Figure 3.4-2). A comparison of the plume from 1997 to 2008 is shown on Figure 3.4-3.

In August 2004, the 34 OU V monitoring wells were sampled and analyzed for perchlorate in response to a request from SCDHS. In June of that year, perchlorate had been detected in SCDHS monitoring well EG-A (off site and east of BNL) in a sample from the deep section of the Upper Glacial aquifer. Perchlorate was detected during the August 2004 sampling event in four of the 34 BNL wells (049-06, 050-02, 061-04, and 061-05), with concentrations ranging between 5.0 and 12.7 $\mu \mathrm{g} / \mathrm{L}$. The NYSDOH Action Level for perchlorate in drinking water supply wells is $18 \mu \mathrm{g} / \mathrm{L}$. The US EPA published a new Drinking Water Equivalent Level for perchlorate of $24.5 \mu \mathrm{g} / \mathrm{L}$ in January 2006.

In 2007, eight OU V wells (000-122, 000-123, 049-05, 049-06, 050-01, 050-02, 061-04, and 061$05)$ were analyzed for perchlorate during two sampling rounds. The compound was detected in wells 049-06 and 061-05, which monitor the deep portion of the Upper Glacial aquifer. Well 049-06 is near the eastern firebreak road and well 061-05 is at the eastern site boundary. The maximum perchlorate concentration, detected in well $061-05$, was $4.6 \mu \mathrm{g} / \mathrm{L}$, which is significantly below the NYSDOH 
action level. Concentrations in wells 049-06 and 061-05 continue the steady decline observed over the past several years. The same eight OU V wells will be sampled for perchlorate again in 2008.

Tritium has historically been detected at low concentrations in monitoring wells 049-06, 050-02, and 061-05. The maximum tritium concentration during 2007 was $1,260 \mathrm{pCi} / \mathrm{L}$, in well $061-05$; this is approximately one-twentieth the DWS of $20,000 \mathrm{pCi} / \mathrm{L}$. Tritium was not detected in the off-site monitoring wells.

\subsubsection{Groundwater Monitoring Program Evaluation}

\section{Was the BNL Groundwater Contingency Plan triggered?}

No. There were no unexpected contaminant concentrations in groundwater during 2007.

\section{Were the performance objectives met?}

No. The performance objective for this program is to attain NYS AWQS for VOCs in groundwater in the Upper Glacial aquifer within 30 years, through monitored natural attenuation. These standards continue to be exceeded in only one of the monitoring wells in early 2008.

\section{Is the extent of the plume still defined by the existing monitoring well network?}

Yes. The leading edge of the plume is in the vicinity of well 000-122 (south of the Long Island Expressway). Currently, two well clusters serve as sentinel wells for this plume along South Street and Wading River Road.

\subsubsection{Recommendations}

The following recommendation is made for the OU V plume groundwater monitoring program:

- Due to the low concentrations of perchlorate being detected, reduce the frequency of this analysis from semi-annual to annual for the eight monitoring wells. 


\subsection{OPERABLE UNIT VI EDB PUMP AND TREAT SYSTEM}

The OU VI EDB Program monitors the extent of an ethylene dibromide (EDB) plume in groundwater extending from just south of the site boundary to south of North Street. EDB was used during the 1970s as a fumigant for the BNL Biology Department's agricultural fields located in the southeastern portion of the site. In 1995 and 1996, low levels of EDB were detected in groundwater near the fields. Higher levels were found migrating toward the southern site boundary and off site to the south. In addition, the depth of the plume increased within the Upper Glacial aquifer to the south. Currently, only trace levels of EDB are detected on the site property.

\subsubsection{System Description}

A groundwater remediation system to address the off-site EDB plume began routine operations in August 2004. The OU VI Treatment System consists of two extraction wells and two recharge wells. A complete description of the system is included in the Operation and Maintenance Manual for the OU VI EDB Groundwater Treatment System (BNL 2004e).

\subsubsection{Groundwater Monitoring}

Well Locations

A network of 30 wells monitor the EDB plume from the former source area in the Biology Department's agricultural fields to locations on private property south of North Street (Figure 3.5-1).

\section{Sampling Frequency and Analysis}

Beginning with the third quarter of 2006, the OU VI plume monitoring program moved into the O\&M phase (see Table 1-7). The sampling frequency for plume core and perimeter wells (Table 1-5) was reduced from quarterly to semi-annually. The exception to this was perimeter well $000-498$, which remained at a quarterly sampling frequency for the year. The wells are analyzed for EDB by EPA Method 504. Samples are also analyzed annually for VOCs. Several wells were incorporated into the OU III South Boundary Radionuclide monitoring program and analyzed for tritium annually. The inclusion of these wells will allow for radionuclide monitoring across the entire downgradient site boundary. (Table 1-5).

\subsubsection{Monitoring Well Results}

Appendix C contains the complete results of the sampling program. The distribution of the EDB plume is shown for the fourth quarter of 2007 (Figure 3.5-1). The leading edge of the plume is currently being captured by extraction wells EW-1E and -2E. The plume is located in the deep Upper Glacial aquifer and is generally moving horizontally, as depicted on cross section M-M' (Figure 3.52). A summary of key monitoring well data for 2007 follows:

- The highest EDB concentration observed in the plume during 2007 was $2.3 \mu \mathrm{g} / \mathrm{L}$, in core well 000-283. This is less than the maximum EDB concentrations reported in 2004, 2005, and 2006 of $4.1 \mu \mathrm{g} / \mathrm{L}, 3.4 \mu \mathrm{g} / \mathrm{L}$, and $2.9 \mu \mathrm{g} / \mathrm{L}$, respectively, in well 000-284. As seen in trend Figure 3.5-3, EDB in this well has remained stable over the past several years. The federal DWS for EDB is $0.05 \mu \mathrm{g} / \mathrm{L}$.

- The trailing edge of the EDB plume is moving south, as evidenced by the reduction in concentrations over the past few years in upgradient plume core wells 000-110,000-175, and 000-209. Plume core wells 000-283 and 000-284 have remained stable. They contained the highest plume concentrations over the past 2 years. Core well 000-507 has detected gradually increasing levels of EDB since it was installed in 2005.

- Well 000-178, also installed in 2005, is upgradient of EW-2E. This well has also been detecting increased values since late 2006 . 
- Plume perimeter well 000-500, in the eastern portion of the plume, has increased to above the DWS in 2007 with detections of $0.071 \mu \mathrm{g} / \mathrm{L}$ and $0.23 \mu \mathrm{g} / \mathrm{L}$. The last detection previously above the DWS in this well was in 2005 , at $0.087 \mu \mathrm{g} / \mathrm{L}$. This portion of the plume will be captured by EW-2E.

- Plume bypass well 000-508 has not detected any EDB since the system began operations.

As noted above, the southward migration of the plume can be observed by analyzing the trends in Figure 3.5-3. Over the past three years, EDB has increased in well 000-507, indicating that the core of the plume is located between well 000-507 and wells 000-283 and 000-284. Comparing the plume's distribution from 1999 to 2007 in Figure 3.5-4, as well as the EDB concentrations in monitoring wells just south of North Street, also helps to illustrate the southward movement of the plume. Overall, peak EDB concentrations have been reduced from $7.6 \mu \mathrm{g} / \mathrm{L}$ in 2001 (in well 000-283) to $2.3 \mu \mathrm{g} / \mathrm{L}$ (also in well $000-283$ ) in 2007 .

EDB was the only VOC detected above the MCL in any well in 2007 (Appendix C).

\subsubsection{System Operational Data}

The extraction wells are currently sampled monthly. In conformance with the SPDES equivalency permit, the sampling frequency for the influent and effluent is now monthly. All samples were analyzed for VOCs and EDB. The effluent sample is analyzed weekly for $\mathrm{pH}$. Table 3.5-1 provides the effluent limitations for meeting the requirements of the SPDES permit equivalency.

Table 3.5-1

OU VI EDB Pump \& Treat System 2007 SPDES Equivalency Permit Levels

\begin{tabular}{lcc}
\hline Parameters & $\begin{array}{c}\text { Permit } \\
\text { Limit }\end{array}$ & $\begin{array}{c}\text { Max. Measured } \\
\text { Value }\end{array}$ \\
\hline $\mathrm{pH}$ (range) & $5.0-8.5 \mathrm{SU}$ & $5.3-7.2 \mathrm{SU}$ \\
ethylene dibromide & $5.0 \mu \mathrm{g} / \mathrm{L}$ & $<0.50 \mu \mathrm{g} / \mathrm{L}$ \\
chloroform & $7.0 \mu \mathrm{g} / \mathrm{L}$ & $1.3 \mu \mathrm{g} / \mathrm{L}$ \\
& & \\
1,1-dichloroethene & $5.0 \mu \mathrm{g} / \mathrm{L}$ & $<0.50 \mu \mathrm{g} / \mathrm{L}$ \\
1,1,1-trichloroethane & $5.0 \mu \mathrm{g} / \mathrm{L}$ & $<0.50 \mu \mathrm{g} / \mathrm{L}$ \\
\hline
\end{tabular}

Required sampling frequency is monthly for VOCs and weekly for $\mathrm{pH}$.

\section{January through September}

The system operated with EW-1E and EW$2 \mathrm{E}$ running at $150 \mathrm{gpm}$ each for almost this entire period. EW-2E was off from March 15 to April 16 for repairs to the flow meter. EW-1E was off for a half month in June for repairs to the flow meter. During this period approximately 115 million gallons of water were pumped and treated.

\section{October through December} EW-1E was off from November 6 to November 26 for repairs. The system operated normally for the remainder of this period.

\section{Extraction Wells}

During 2007, 138 million gallons were pumped and treated by the OU VI EDB System, with an average flow rate of approximately $300 \mathrm{gpm}$. Table $\mathbf{2 - 3}$ contains the monthly pumping data for the two extraction wells. VOC concentrations for EW-1E (000-503) and EW-2E (000-504) are provided in Table F-49 in Appendix F. There were several low-level detections of EDB in extraction well EW-1E during 2007, with a maximum of $0.045 \mu \mathrm{g} / \mathrm{L}$. There were no EDB detections in EW-2E. No other VOCs were detected in the extraction wells above the MCLs.

\section{System Influent and Effluent}

All discharge parameters were below the regulatory limit specified in the SPDES equivalency permit. Influent and effluent results are reported in Tables F-50 and F-51, respectively. There were several detections of EDB in the influent throughout 2007, with a maximum concentration of 0.032 $\mu \mathrm{g} / \mathrm{L}$. These detections were below the federal DWS of $0.05 \mu \mathrm{g} / \mathrm{L}$. 


\section{Cumulative Mass Removal}

No cumulative mass calculations were performed, based on the low detections of EDB below the federal DWS in the system influent. Several low-level VOCs not attributable to BNL were detected; the results are potentially due to analytical lab contamination and were all below the DWS.

\subsubsection{System Evaluation Data}

The OU VI EDB System was designed to capture and remediate the EDB plume as it travels off site south of BNL with the regional groundwater flow. Startup of the system was initiated in August 2004, and it is planned to run for approximately 10 years. The system is operating as designed; no operating difficulties were experienced beyond normal maintenance, and no permit equivalencies have been exceeded.

The OU VI EDB System performance can be evaluated based on the four major decisions identified in the groundwater DQO process.

\section{Was the BNL Groundwater Contingency Plan triggered?}

No. There were no unusual or unexpected concentrations of contaminants observed in monitoring wells associated with the OU VI EDB plume treatment system.

\section{If not, has the plume been controlled?}

Yes. An analysis of data from the plume perimeter and bypass wells shows no detections of EDB above the DWS in 2007 except in perimeter well 000-500, located just upgradient and slightly east of extraction well EW-2E. As noted above, this well had two detections of EDB in 2007, with a maximum of $0.23 \mu \mathrm{g} / \mathrm{L}$. Extraction well EW-2E is expected to capture this portion of the plume.

3. Is the system operating as planned? Specifically, is the aquifer being restored at the planned rate? The hydraulic capture of the system is operating as designed. In 2006, EDB was only detected twice in the system influent; however, in 2007 EDB was detected in the system influent monthly. These detections were at concentrations below the federal DWS. Based on the location of the trailing edge of the plume, the aquifer is being restored at the planned rate.

\section{Can the groundwater treatment system be shut down?}

No, the system has not met all shutdown requirements.

4a. Have asymptotic EDB concentrations been reached in plume core wells?

No. Asymptotic conditions have not yet been achieved.

4b. Are there individual plume core wells above $0.05 \mu \mathrm{g} / \mathrm{L}$ EDB?

There are currently seven of eight plume core wells with concentrations greater than the $0.05 \mu \mathrm{g} / \mathrm{L}$ federal DWS.

4c. During pulsed operation of the system, is there significant concentration rebound in core wells? The OU VI EDB system has not been pulsed to date.

4d. Have the groundwater cleanup goals been met? Are MCLs expected to be achieved by 2030? No. The federal DWS has not been achieved for EDB in plume core wells. It is expected to be achieved by 2030, as required by the OU VI ROD. 


\subsubsection{Recommendations}

The following recommendations are made for the OU VI EDB Pump and Treat System and groundwater monitoring program:

- Add another plume bypass well east of well 000-508 and slightly deeper, to verify that EDB is being captured by extraction well EW-2E.

- Maintain the routine operation and maintenance monitoring frequency that began in third-quarter 2006.

- Since there were no detections above the DWS for EDB in well 000-498 for 2006 and 2007, change the sampling frequency for this well from quarterly (system start-up phase) to semiannually (O\&M phase). Also change the frequency for on-site wells 058-02, 089-13, 089-14, 09906, 099-10, 099-11, 100-12, 100-13, and 100-14 to annual, since there have been no detections of EDB above the federal DWS since mid 2003. 


\subsection{SITE BACKGROUND MONITORING}

Background water quality has been monitored since 1990. Historically, low levels of VOCs were routinely detected in several background wells that are screened in the deeper portions of the Upper Glacial aquifer.

\subsubsection{Groundwater Monitoring}

Well Network

The 2007 program included 10 wells in the northwestern portion of the BNL property (Figure 1-2). Background quality is defined as the quality of groundwater that is completely unaffected by BNL operations.

\section{Sampling Frequency and Analysis}

The samples were collected annually and analyzed for VOCs (Table 1-5).

\subsubsection{Monitoring Well Results}

The complete groundwater data for 2007 is provided in Appendix C. There were detections of low levels of several VOCs in the site background wells. All VOC detections were below NYS AWQS. The highest concentration detected was chloroform, at $0.95 \mu \mathrm{g} / \mathrm{L}$ in well 017-01.

While radionuclides are no longer analyzed in background wells, historic results are presented for reference purposes. Table 3.6-1 summarizes the range of radionuclide values detected in background wells from 1996 through 2001.

\subsubsection{Monitoring Program Evaluation}

The program can be evaluated using the decision rule developed as part of the groundwater DQO process.

1. Is groundwater quality at BNL being impacted by off-site, upgradient source(s) of contamination? No. There were no VOCs detected in site background wells above NYS AWQS during 2007. Based on these results, there is no current impact to BNL groundwater quality from upgradient contaminant sources.

\subsubsection{Recommendations}

No changes to the monitoring program are warranted at this time

Table 3.6-1.

Radiological Background Monitoring, 1996 - 2001

\begin{tabular}{lcc}
\hline Parameter & $\begin{array}{c}\text { Activity Range } \\
\text { (pCi/L) }\end{array}$ & $\begin{array}{c}\text { Contract-Required } \\
\text { Detection Limit }\end{array}$ \\
\hline Cesium-137 & $<$ MDA to 7.24 & 12 \\
Gross alpha & $<$ MDA to 2.66 & 1.5 \\
Gross beta & $<$ MDA to 6.41 & 4.0 \\
Strontium-90 & $<$ MDA to 3.84 & 0.8 \\
Tritium & $<$ MDA & 1,000 \\
\hline Notes: & \\
$<$ MDA = Less than minimum detectable activity & \\
\hline
\end{tabular}


SER VOLUME II: GROUNDWATER STATUS REPORT

This page intentionally left blank. 


\subsection{CURRENT AND FORMER LANDFILL GROUNDWATER MONITORING}

Groundwater monitoring data from both the Current and Former Landfills are discussed in detail in the BNL 2007 Environmental Monitoring Report, Current and Former Landfill Areas (BNL 2008a). This report can be found in Appendix H. The complete groundwater monitoring results for these programs are included in Appendix C.

\subsubsection{Current Landfill Summary}

Data show that, in general, contaminant concentrations have been decreasing following the capping of the landfill in 1995. By the end of 2007 the landfill had been capped for 12 years. Groundwater quality has been slowly improving. The trend in the data suggests that the cap is effective in mitigating contamination. The following is a summary of the results from the samples collected during 2007:

- VOCs, such as benzene and chloroethane, continue to be detected in downgradient wells 087-11, 087-23, 087-27, 088-109, and 088-110 at concentrations above NYS AWQS. These wells are screened in the upper 20 feet of the aquifer. The maximum VOC concentration (chloroethane) in 2007 was $36.1 \mu \mathrm{g} / \mathrm{L}$, in well $088-109$. TVOC concentrations in these five wells ranged between $2.29 \mu \mathrm{g} / \mathrm{L}$ to $38 \mu \mathrm{g} / \mathrm{L}$ during 2007 , indicating that low-level VOCs continue to emanate from the landfill. The continued presence of these compounds is expected.

- Landfill water chemistry parameters and metals (which include total dissolved solids, total suspended solids, alkalinity, ammonia, iron and manganese) evaluated during the year suggest that leachate continues to emanate from the landfill. The continued presence of these leachate indicators is expected.

- Tritium and Sr-90 continue to be detected in the wells downgradient of the Current Landfill, but at concentrations well below the drinking water standards. These concentrations, up to $673 \mathrm{pCi} / \mathrm{L}$ and $2.91 \mathrm{pCi} / \mathrm{L}$ of tritium and Sr-90, respectively, were consistent with those observed in 2006.

- Since 1998, there have been no detections of VOCs, metals, water chemistry parameters, or radionuclides exceeding NYS AWQS in wells 087-24, 088-22, and 088-23. These wells are all screened in the mid-to deep-Upper Glacial aquifer to monitor the vertical extent of contamination from the Current Landfill.

\subsubsection{Current Landfill Recommendation}

No changes to the monitoring program are warranted at this time

\subsubsection{Former Landfill Summary}

Data show that contaminant concentrations have been decreasing following the capping of the landfill in 1996. Contaminant concentrations downgradient of this landfill were relatively low prior to capping, primarily due to it being approximately 50 years old. The trend in the data suggests that the cap is effective in mitigating the remaining contamination from entering the groundwater. Based on the declining VOC and Sr-90 concentration trends in downgradient wells, it appears that the landfill cap is performing as planned. The following is a summary of the results from the samples collected during 2007:

- The Former Landfill is not a significant source of VOC contamination. No VOCs were detected above NYS AWQS in 2007. VOC concentrations in the downgradient wells were at or near the minimum detection limits.

- The Former Landfill no longer appears to be a source of Sr-90 contamination to groundwater. The approximated Sr-90 plume (as defined by concentrations exceeding $8 \mathrm{pCi} / \mathrm{L}$ ) has migrated south 
of well 097-64 and continues to attenuate below $8 \mathrm{pCi} / \mathrm{L}$. The Sr-90 concentration in well 097-64 reached a historic high of $12 \mathrm{pCi} / \mathrm{L}$ in January 1998 and has been below $8 \mathrm{pCi} / \mathrm{L}$ since January 2000 .

- Landfill-leachate indicators such as sulfate, nitrite, nitrate, chloride, and alkalinity in downgradient wells were detected at concentrations consistent with background, indicating that leachate generation is minimal to nonexistent. The implemented landfill controls are effective, as evidenced by the improving quality of groundwater downgradient of the landfill.

\subsubsection{Former Landfill Recommendation}

No changes to the monitoring program are warranted at this time 


\subsection{ENVIRONMENTAL SURVEILLANCE PROGRAM SUMMARY}

During 2007, the Environmental Surveillance (ES) Program at BNL monitored the groundwater quality at 10 active research and support facilities. New York State operating permits require groundwater monitoring at two support facilities (the Major Petroleum Facility and the Waste Management Facility); the remaining eight research and support facilities are monitored in accordance with DOE Order 450.1, Environmental Protection Program. This Order requires the Laboratory to establish environmental monitoring programs at facilities that can potentially impact environmental quality, and to demonstrate compliance with DOE requirements and the applicable federal, state, and local laws and regulations. BNL is implementing this part of the Environmental Management System to collect information on groundwater quality, and will use the data to determine whether current engineered and administrative controls effectively protect groundwater quality and whether additional corrective actions are needed.

During 2007, 125 groundwater surveillance wells were monitored during approximately 240 individual sampling events. Information on groundwater quality at each of the monitored research and support facilities is described below. Table 1-6 summarizes the ES Groundwater Monitoring Program by project. Complete analytical results from groundwater samples collected in 2007 can be found in Appendix D.

\subsection{Alternating Gradient Synchrotron (AGS) Complex}

The structures that constitute the AGS Complex include the AGS Ring, Linear Accelerator (Linac), Building 912, AGS Booster Beam Stop, 914 Transfer Tunnel, g-2 experimental area, E-20 Catcher, former U-Line Target, and the J-10 Beam Stop. Activated soil has been created near a number of these areas as the result of secondary particles (primarily neutrons) produced at beam targets and beam stops. A number of radionuclides can be produced by the interaction of secondary particles with the soil that surrounds these experimental areas. Once produced in the soils, some of these radionuclides can be leached from the soils by rainwater, and carried to the groundwater. Of the radionuclides formed in the soil, only tritium (half-life $=12.3$ years) and sodium-22 (half-life $=2.6$ years) are detected in groundwater. Of these two radionuclides, tritium is more easily leached from the activated soils by rainwater and does not bind to soil particles. When tritium enters the water table, it migrates at the same rate as groundwater flow (approximately 0.75 feet per day). Sodium-22 does not leach out of the soil as readily as tritium, and migrates at a slower rate in the aquifer. The drinking water standard (DWS) for tritium is $20,000 \mathrm{pCi} / \mathrm{L}$, and $400 \mathrm{pCi} / \mathrm{L}$ for sodium- 22 .

To prevent rainwater from leaching these radionuclides from the soil, impermeable caps have been constructed over many of the soil activation areas. Specifications for evaluating potential impacts to groundwater quality and the need for impermeable caps over beam loss areas are defined in the Standards Based Management System (SBMS) subject area entitled Accelerator Safety. BNL uses 56 groundwater monitoring wells to evaluate the impact of current and historical operations at the AGS beam stop and target areas. The locations of permanent monitoring wells are shown on Figure 4-1. During 2007, all 56 AGS monitoring wells were used to evaluate groundwater quality within the AGS Complex. The wells are routinely monitored for tritium. Routine analysis for sodium-22 was dropped from the groundwater surveillance program in 2002 because tritium is the best indicator of possible cap failure.

Following the 1999 installation of an improved monitoring well network at the AGS, BNL detected three tritium plumes that originated from activated soil shielding at the g-2 experimental area, the former U-Line beam stop, and the former E-20 Catcher. The subsequent installation of impermeable caps over these soil activation areas has resulted in a reduction of tritium levels to less than the 20,000

pCi/L DWS in the Former U-Line and E-20 Catcher areas. As discussed below, tritium concentrations 
greater than $20,000 \mathrm{pCi} / \mathrm{L}$ continue to be detected downgradient of the g-2 (VQ-12 magnet) soil activation area (see Section 4.2).

Historical surface spills and discharges of solvents to several cesspools and recharge basins near the AGS contaminated the groundwater with volatile organic compounds (VOCs). VOC contaminated groundwater within the AGS complex is monitored under the Long Term Response Actions (LTRA) program’s Operable Unit III Central monitoring program (see Section 3.2.12).

\subsubsection{AGS Building 912}

Building 912 consists of five interconnected structures that have been used to house as many as four experimental beam lines (A, B, C, and D lines). A typical beam line consists of bending and focusing electromagnets, vacuum pipes, instrumentation, high-voltage electrostatic devices, beam targets, radiation shielding, cooling water systems, and experimental detectors. Although these beam lines stopped operations in 2002, plans are being developed to reconfigure the experiment area for new experiments.

Beam loss and the production of secondary particles at proton target areas result in the activation of adjacent equipment, the floor, and probably the soil beneath the floor. The highest levels of soil activation beneath Building 912 are expected at the former B-Line target cave. Stormwater infiltration around the building is controlled by paving and stormwater drainage systems that direct most of the water to recharge basins north of the AGS complex. Therefore, it is believed that the potentially activated soil underlying the beam targets and stops is adequately protected from surface water infiltration.

\subsubsection{AGS Building 912 Groundwater Monitoring}

Well Network

Seventeen shallow Upper Glacial aquifer wells are positioned upgradient and downgradient of Building 912 (Figure 4-1). Upgradient wells are positioned to monitor potential tritium contamination from sources such as the g-2 area and the former U-Line experimental area. The downgradient wells are positioned to monitor significant beam stop and target areas in Building 912. Six of the downgradient wells are also used to track a section of the g-2 tritium plume that has migrated below Building 912 (see Section 4.2).

\section{Sampling Frequency and Analysis}

During 2007, the six Building 912 wells that are used to track the g-2 tritium plume were sampled three times, whereas the remaining wells were sampled annually. The groundwater samples were analyzed for tritium (Table 1-6). Analytical results for 2007 are presented in Appendix D.

\subsubsection{AGS Building 912 Monitoring Well Results}

Other than low level tritium contamination that is traceable to the g-2 source area, groundwater surveillance data for 2007 indicate that tritium is not being released from activated soil beneath the experimental floor of Building 912. The g-2 tritium plume has been tracked from the VQ-12 magnet source, beneath a portion of Building 912, to the High Flux Beam Reactor (HFBR) facility (Figure 48). Tritium from this plume was detected in five wells downgradient of Building 912, with a maximum concentration of 16,400 pCi/L in the January 2007 sample from well 065-123. As described in Section 4.2, remedial actions for the g-2 source area and tritium plume are described in the Record of Decision signed in May 2007 (BNL 2007b).

\subsubsection{AGS Building 912 Groundwater Monitoring Program Evaluation}

As noted above, in areas not impacted by the g-2 tritium plume, tritium was not detected in the Building 912 area groundwater monitoring wells. These results indicate that the building and associated stormwater management operations are effectively preventing rainwater from infiltrating activated soil below the experimental hall. For 2008, the Building 912 wells used to track the g-2 tritium plume will 
be sampled semiannually, whereas the remainder of the Building 912 monitoring wells will be sampled annually.

\subsubsection{AGS Booster Beam Stop}

The AGS Booster is a circular accelerator with a circumference of nearly 660 feet. It is connected to the northwest portion of the main AGS Ring and to the Linear Accelerator (Linac). The AGS Booster, which has been in operation since 1994, receives either a proton beam from the Linac or heavy ions from the Tandem Van de Graaff generator. The booster accelerates protons and heavy ions before injecting them into the main AGS ring. In order to dispose of the beam during studies, a beam stop system was originally constructed at the 10 to 11 o'clock portion of the booster. In 1999, the beam stop was repositioned to the south side (6 o'clock section) of the Booster ring to accommodate the construction of the NASA Space Radiation Laboratory (NSRL) tunnel in the original beam stop location.

Although internal shielding around the beam stop was designed to keep secondary particle interactions with the soil to very low levels, a landfill-type geomembrane cap was constructed over the original beam stop region to prevent stormwater infiltration into the activated soil. When the beam stop was repositioned to the 6 o'clock region of the Booster, a coated concrete cap was constructed over the new beam stop area to prevent stormwater infiltration.

\subsubsection{AGS Booster Groundwater Monitoring}

Well Network

Two shallow Upper Glacial aquifer monitoring wells (064-51 and 064-52) are approximately 50 feet downgradient of the current beam stop (Figure 4-1).

Sampling Frequency and Analysis

The Booster area wells were scheduled to be sampled one time during 2007, with the samples being analyzed for tritium (Table 1-6). However, access to the wells was prevented during 2007 due to beam line operations.

\subsubsection{AGS Booster Monitoring Well Results}

Although low levels (up to $1,340 \mathrm{pCi} / \mathrm{L}$ ) of tritium were detected downgradient of the AGS Booster stop during 2001 and 2002, tritium has not been detected since that time (Figure 4-2). As noted previously, the Booster area wells were not sampled during 2007, due to access limitations.

\subsubsection{AGS Booster Groundwater Monitoring Program Evaluation}

The low-levels of tritium detected during 2001 and 2002 near the Booster beam stop were related to a short-term uncovering of activated soil shielding near the former booster beam stop area during the construction of the tunnel leading from the Booster to the NSRL facility. This work, which began in September 1999 and was completed by October 1999, allowed rainwater to infiltrate the low-level activated soil shielding. ${ }^{1}$ Tritium has not been detected in the Booster area monitoring wells since 2003. No changes to the monitoring frequency for these wells are proposed for 2008.

\footnotetext{
${ }^{1}$ Before construction of the NSRL tunnel commenced, soil samples were collected by drilling through the tunnel wall near the booster beam stop to verify that the tritium and sodium-22 levels were within acceptable limits for worker safety and environmental protection.
} 
Figure 4-2.

Maximum Tritium Concentrations Downgradient of AGS Booster Beam Stop (Wells 064-51 and 064-52).

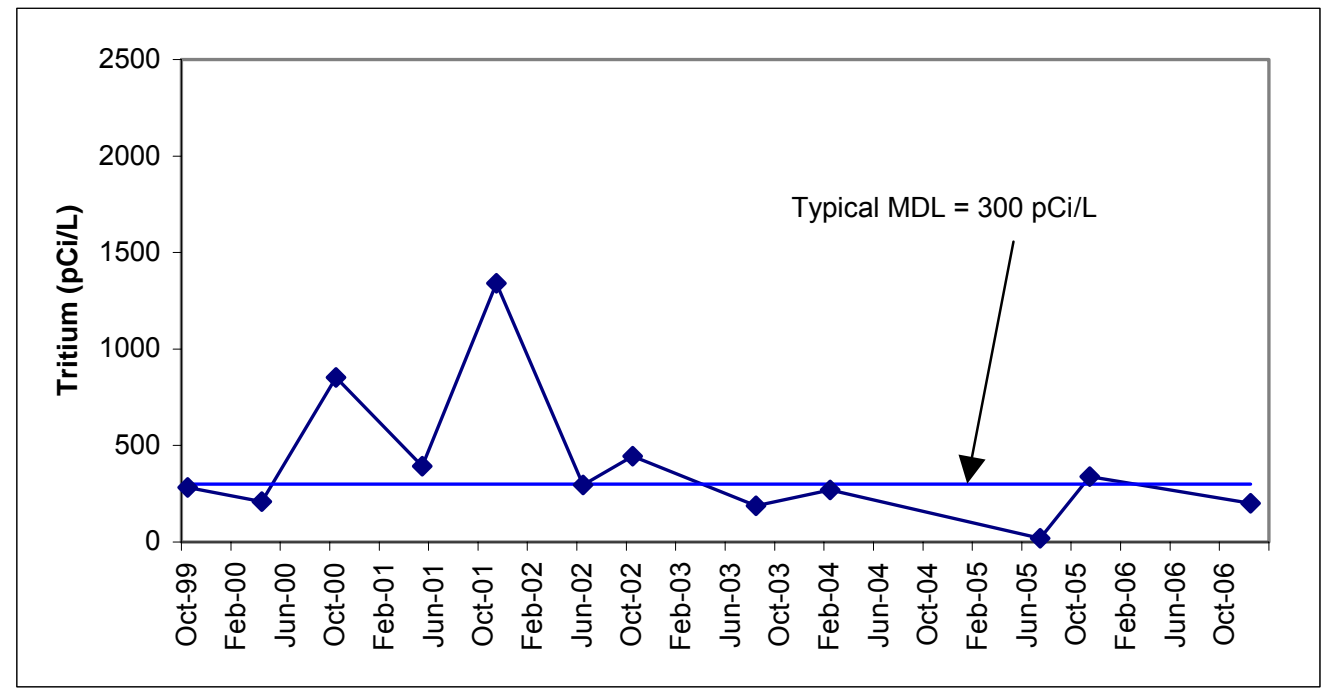

\subsubsection{NASA Space Radiation Laboratory Facility}

The NSRL facility is jointly managed by the U.S. Department of Energy's Office of Science and NASA's Johnson Space Center. The NSRL facility employs beams of heavy ions extracted from Brookhaven's Booster accelerator for radiobiology studies. NSRL became operational during summer 2003. Although the secondary particle interactions with the surrounding soil shielding are expected to result in only a minor level of soil activation, geomembrane caps were constructed over the entire length of the beam line and the beam stop region to prevent stormwater infiltration into potentially activated soil.

\subsubsection{NSRL Facility Groundwater Monitoring}

Well Network

Two shallow Upper Glacial aquifer monitoring wells (054-08 and 054-191) are located immediately downgradient of the NSRL facility (Figure 4-1).

\section{Sampling Frequency and Analysis}

The NSRL area wells were scheduled to be monitored one time during 2007 with the sampled being analyzed for tritium (Table 1-6). However, access to the wells was prevented during 2007 due to beam line operations.

\subsubsection{NSRL Facility Monitoring Well Results}

Groundwater monitoring at the NSRL facility began in late 2002. Since that time, tritium has not been detected in any of the groundwater samples.

\subsubsection{NSRL Groundwater Monitoring Program Evaluation}

Based on monitoring conducted to date, NSRL beam line operations have not impacted groundwater quality. 


\subsubsection{AGS E-20 Beam Catcher}

The E-20 beam catcher was used from 1984 to 1999, and was located at the 5 o'clock position of the AGS ring (Figure 4-1). The E-20 Catcher was a minimum aperture area of the AGS ring, and was used to pick up or "scrape" protons that move out of acceptable pathways. The E-20 Catcher picked up about 80 to 90 percent of all losses resulting from beam injection, transition, and ejection in the AGS Ring.

Like other beam loss areas in the AGS complex, the soil surrounding the E-20 Catcher became activated by the interaction with secondary particles. In late 1999 and early 2000, tritium and sodium-22 levels in groundwater were found to exceed the DWS, with concentrations of 40,400 pCi/L and 704 pCi/L, respectively. In April 2000, a temporary impermeable cap was installed over the E-20 Catcher soil activation area. A permanent cap was constructed by October 2000. Tritium and sodium-22 concentrations dropped to below their applicable DWS soon after the cap was installed.

\subsubsection{AGS E-20 Catcher Groundwater Monitoring}

Well Network

To verify the effectiveness of the impermeable cap over the E-20 Catcher, the area is monitored by three shallow Upper Glacial aquifer wells 064-55, -56, and -80. These wells are approximately 100 feet downgradient of the source area (Figure 4-1).

Sampling Frequency and Analysis

During 2007, the E-20 Catcher wells were monitored one time, and the samples were analyzed for tritium (Table 1-6). Analytical results for 2007 are presented in Appendix D.

\subsubsection{AGS E-20 Catcher Monitoring Well Results}

Following the installation of the cap in 2000, tritium and sodium-22 concentrations decreased to levels below applicable DWS (Figure 4-3). During 2007, the maximum observed tritium concentration was $4,140 \mathrm{pCi} / \mathrm{L}$, detected in well 064-80.

\subsubsection{AGS E-20 Catcher Monitoring Program Evaluation}

The reduction in tritium concentrations since the impermeable cap was constructed over the E-20 Catcher area in 2000 indicates that the cap has been effective in preventing rainwater infiltration into the activated soil that surrounds this portion of the AGS tunnel. For 2008, the monitoring frequency for the E-20 Catcher wells will continue to be annual.

Figure 4-3.

Maximum Tritium and Sodium-22 Concentrations in Temporary and Permanent Monitoring Wells Downgradient of the Former E-20 Catcher.

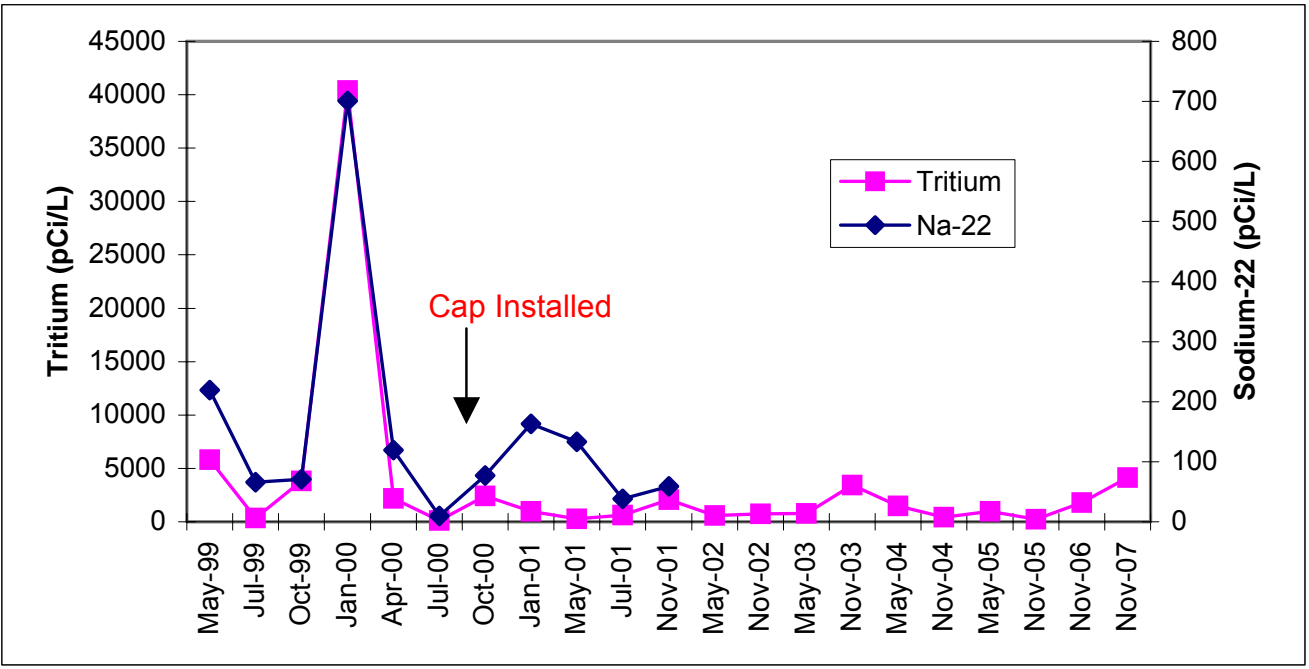




\subsubsection{AGS Building 914}

Building 914 houses the transfer line between the AGS Ring and the Booster. Due to beam loss near the extraction (kicker) magnet, the extraction area of Building 914 is heavily shielded with iron. Because the extraction area is housed in a large building, most soil activation is expected to be below the floor of the building, where it will be protected from water infiltration.

\subsubsection{AGS Building 914 Groundwater Monitoring}

Well Network

Groundwater quality downgradient of the Building 914 transfer line area is monitored by three shallow Upper Glacial aquifer wells (Figure 4-1).

Sampling Frequency and Analysis

During 2007, the Building 914 area wells were monitored one time and samples were analyzed for tritium (Table 1-6). Analytical results for 2007 are presented in Appendix D.

\subsubsection{AGS Building 914 Monitoring Well Results}

Low levels of tritium were detected intermittently in groundwater downgradient of the Building 914 transfer tunnel during 2000 - 2005 (Figure 4-4). During 2006 and 2007, tritium was not detected in any of the groundwater samples.

\subsubsection{AGS Building 914 Groundwater Monitoring Program Evaluation}

Groundwater monitoring downgradient of Building 914 continues to indicate that the building structure and associated stormwater controls are effectively preventing significant rainwater infiltration into activated soil below the building. However, the periodic detection of trace levels of tritium since 2000 suggests that some rainwater may be infiltrating the activated soil. Continued monitoring is required. For 2008, the monitoring frequency for the Building 912 area wells will continue to be annual.

Figure 4-4.

Maximum Tritium Concentrations Downgradient of the 914 Transfer Tunnel (Wells 064-03, -53, and -54).

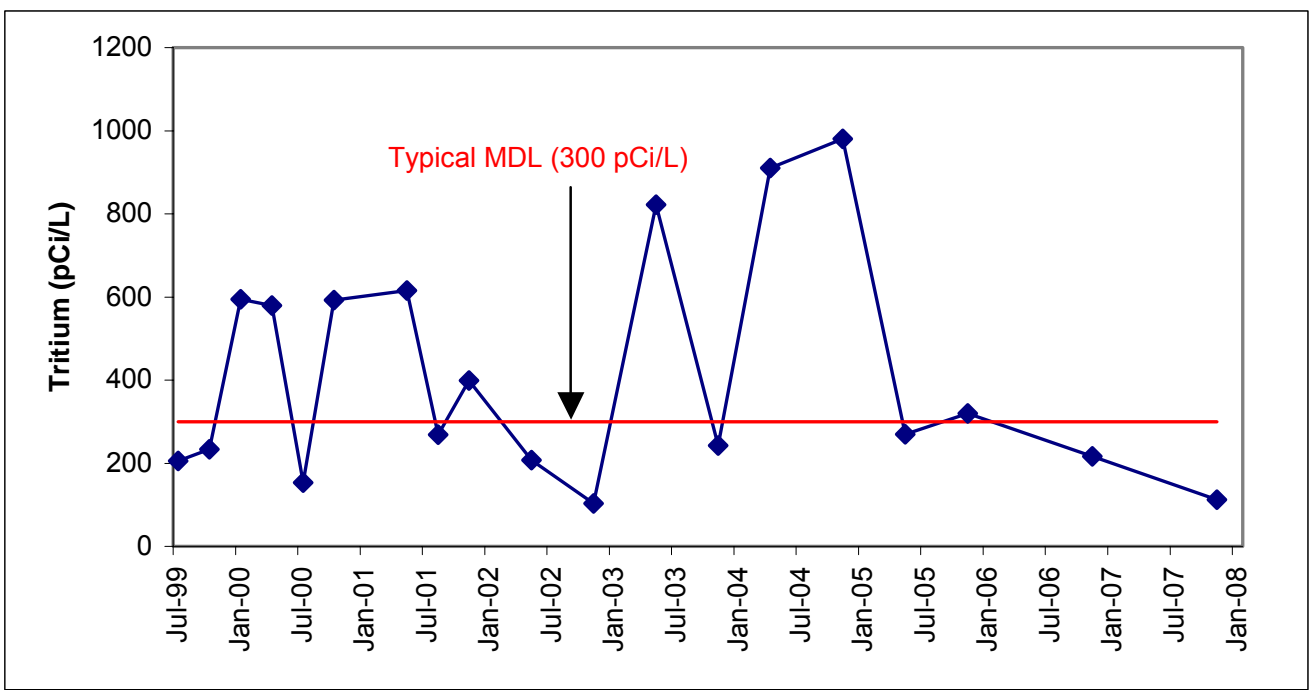




\subsection{6 g-2 Beam Stop}

The g-2 experiment operated from April 1997 until April 2001. The g-2 beam stop is composed of iron, and is covered by soil. Like other beam loss areas in the AGS complex, the g-2 beam stop was an area where the soil surrounding the stop would have become activated by the interaction with secondary particles. To prevent rainwater from infiltrating the soil surrounding the beam stop, BNL installed a gunite cap over the stop area before the start of beam line operations.

In November 1999, monitoring wells approximately 250 feet downgradient of the g-2 experimental area detected the presence of tritium and sodium-22 in the groundwater. A groundwater investigation conducted during November and December 1999 revealed a narrow plume of tritium with a maximum tritium concentration of $1,800,000 \mathrm{pCi} / \mathrm{L}$. Sodium-22 was also detected, but at a concentration of only $60 \mathrm{pCi} / \mathrm{L}$, or 15 percent of the $400 \mathrm{pCi} / \mathrm{L}$ DWS.

Following the discovery, an investigation into the source of the contamination revealed that the tritium originated from activated soil shielding adjacent to the g-2 experiment's VQ-12 Magnet. There was no evidence that any of the tritium originated from the beam stop area. The VQ-12 magnet section of the beam line was not a designed beam loss area, and the gunite cap installed over the nearby beam stop did not protect the VQ-12 area. In December 1999, an impermeable cap was installed over the VQ12 soil activation area. This cap was joined to the existing beam stop cap. In September 2000, the activated soil shielding and associated tritium plume were designated as new sub-Area of Concern 16T. The selected remedial actions for the $\mathrm{g}-2$ tritium source area and plume are documented in a Record of Decision, which was signed in May 2007 (BNL 2007b). The monitoring program for the VQ12 source area and g-2 tritium plume are described in Section 4.2, below.

\subsubsection{1 g-2 Beam Stop Groundwater Monitoring}

\section{Well Network}

Groundwater quality downgradient of the g-2 beam stop is monitored using three downgradient wells, (Figure 4-1).

\section{Sampling Frequency and Analysis}

During 2007, the g-2 beam stop wells were monitored annually, and the samples were analyzed for tritium (Table 1-6). Analytical results for 2007 are presented in Appendix D.

\subsubsection{2 g-2 Beam Stop Monitoring Well Results}

During 2007, tritium was not detected in any samples from the three monitoring wells located downgradient of the g-2 beam stop.

\subsubsection{3 g-2 Beam Stop Groundwater Monitoring Program Evaluation}

Monitoring of wells downgradient of the $\mathrm{g}-2$ beam stop indicates that the cap is effectively preventing rainwater from infiltrating the activated soil shielding. During 2008, the g-2 beam stop area wells will continue to be monitored on an annual basis.

\subsubsection{AGS J-10 Beam Stop}

In 1998, BNL established a new beam stop at the J-10 (12 o'clock) section of the AGS Ring, replacing E-20 as the preferred repository for any beam that might be lost in the AGS Ring (Figure 41). The J-10 beam stop is subject to the same injection, transition, ejection and studies losses that occurred at the former E-20 Catcher, discussed earlier. Because the J-10 stop area of the AGS Ring is covered by layers of soil-crete (a sand and concrete mixture), the ability of rainwater to infiltrate the potentially activated soil has been reduced. BNL also constructed a gunite cap over a small section of the J-10 region that did not have a soil-crete cover before beam stop operations began. 


\subsubsection{AGS J-10 Beam Stop Groundwater Monitoring}

Well Network

The monitoring well network for the J-10 beam stop consists of one upgradient (054-62) and two downgradient wells (054-63 and -64) (Figure 4-1).

\section{Sampling Frequency and Analysis}

During 2007, the three J-10 beam stop wells were monitored one time and the samples were analyzed for tritium (Table 1-6). Analytical results for 2007 are presented in Appendix D.

\subsubsection{AGS J-10 Beam Stop Monitoring Well Results}

Since 2001, low levels of tritium have been routinely detected in groundwater downgradient of the J10 beam stop (Figure 4-5). During 2007, the maximum tritium concentration was $490 \mathrm{pCi} / \mathrm{L}$ in well 054-63.

\subsubsection{AGS J-10 Beam Stop Monitoring Program Evaluation}

Groundwater monitoring data suggest that the engineered controls in place at J-10 are preventing significant rainwater infiltration into the activated soil shielding. However, the occasional detection of low levels of tritium (up to $1,000 \mathrm{pCi} / \mathrm{L}$ ), suggests that some rainwater may be infiltrating the activated soil. During 2008, the monitoring frequency for the J-10 Beam Stop area wells will continue to be annual.

Figure 4-5.

Maximum Tritium Concentrations in Wells 054-63 and 054-64, Downgradient of the J-10 Beam Stop.

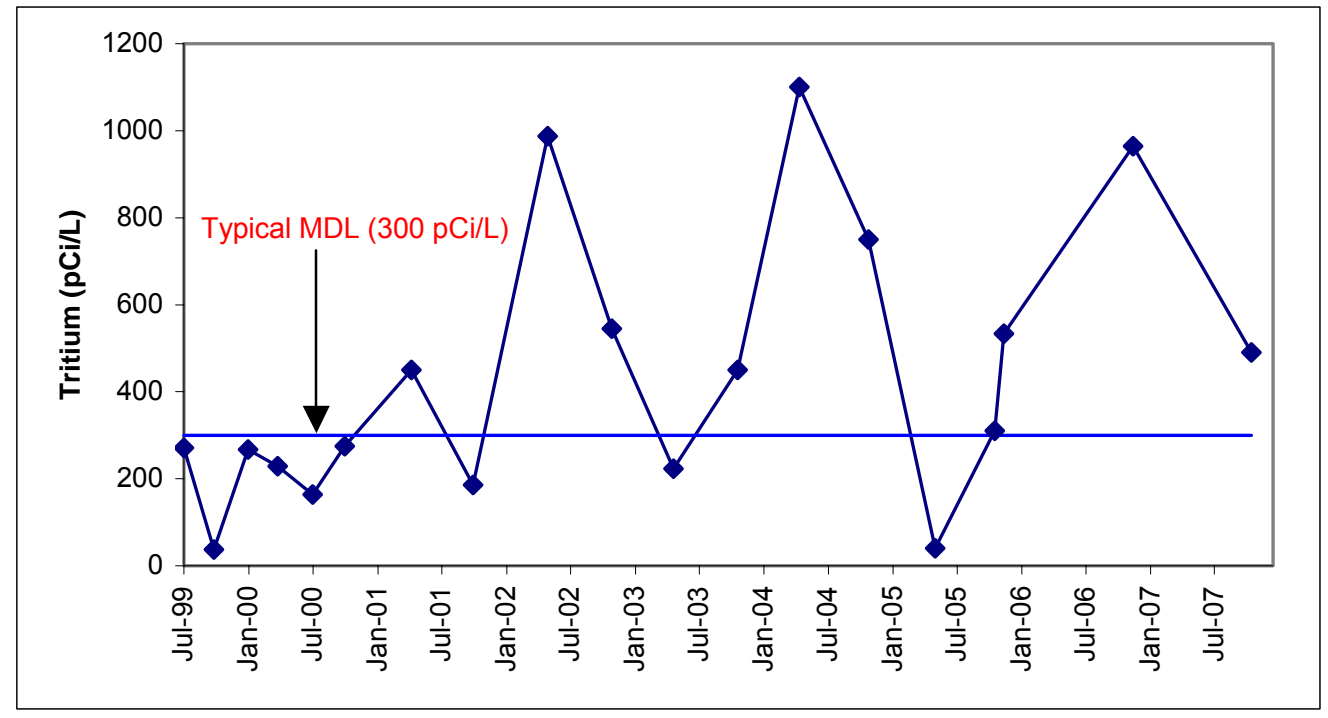

\subsubsection{Former AGS U-Line Beam Target and Stop Areas}

The U-Line beam target area was in operation from 1974 through 1986. During its operation, a proton beam from the AGS would first strike a target and the resulting secondary particles would be selected by an arrangement of two magnetic "horns" and collimators immediately downstream of the target. Secondary particles desired for research would be focused by the horns, and other particles would either strike the collimators or be de-focused and enter the surrounding shielding. The entire assembly was in a ground-level tunnel covered with an earthen berm. Internal shielding was stacked around the horns. Although the U-Line beam target has not been in operation since 1986, the associated tunnel, shielding, and overlying soil remain in place. The former U-Line beam target, horns, and beam stop are areas 
where the interaction of secondary particles with soil surrounding the tunnel resulted in production of tritium and sodium-22.

In late 1999, BNL installed monitoring wells downgradient of the target area to evaluate whether residual activated soil shielding was impacting groundwater quality. Subsequent monitoring found low levels of tritium and sodium-22, but at concentrations well below the applicable DWS. In early 2000, BNL installed four temporary wells downgradient of the former U-Line beam stop, which is approximately 200 feet north of the target area. Tritium was detected at concentrations up to 71,600 pCi/L. Sodium-22 was not detected in any of the samples. In May 2000, a temporary impermeable cap was installed over the U-Line beam stop soil activation area to prevent rainwater infiltration and the continued leaching of radionuclides out of the soil and into groundwater. By October 2000, a permanent geotextile cap was constructed over the U-Line beam stop area, and two additional permanent wells were installed to provide improved long-term monitoring of this source area.

\subsubsection{Former AGS U-Line Groundwater Monitoring}

Well Network

The former U-Line area is monitored by one upgradient and six downgradient wells. Three of the downgradient wells monitor the target area, and three wells monitor the beam stop area (Figure 4-1).

\section{Sampling Frequency and Analysis}

During 2007, the former U-Line area wells were monitored one time, and the samples were analyzed for tritium (Table 1-6). Analytical results for 2007 are presented in Appendix D.

\subsubsection{Former AGS U-Line Groundwater Monitoring Well Results}

\section{U-Line Target Area}

Low levels of tritium have been routinely detected in wells downgradient of the former U-Line beam target since monitoring began in 2000 (Figure 4-6). The highest tritium concentration during 2007 was $1,980 \mathrm{pCi} / \mathrm{L}$, in well 054-129 located approximately 200 feet downgradient of the target area.

\section{U-Line Beam Stop Area}

Since the cap was installed over the former U-line stop in 2000, tritium concentrations in downgradient wells have been well below the 20,000 pCi/L DWS (Figure 4-7). During 2007, only a trace level of tritium $(280 \mathrm{pCi} / \mathrm{L})$ was detected in one well downgradient of the U-Line target area.

\subsubsection{Former U-Line Groundwater Monitoring Program Evaluation}

Although low levels of tritium continue to be detected downgradient of the former U-Line target, these concentrations are well below the $20,000 \mathrm{pCi} / \mathrm{L}$ DWS. Furthermore, the significant decrease in tritium concentrations since 2000 indicates that the impermeable cap has been effective in stopping rainwater infiltration into the residual activated soil. For 2008, the monitoring frequency for the U-line area wells will continue to be annual. 
Figure 4-6.

Maximum Tritium Concentrations in Well 054-129,

Downgradient of the Former U-Line Beam Target.

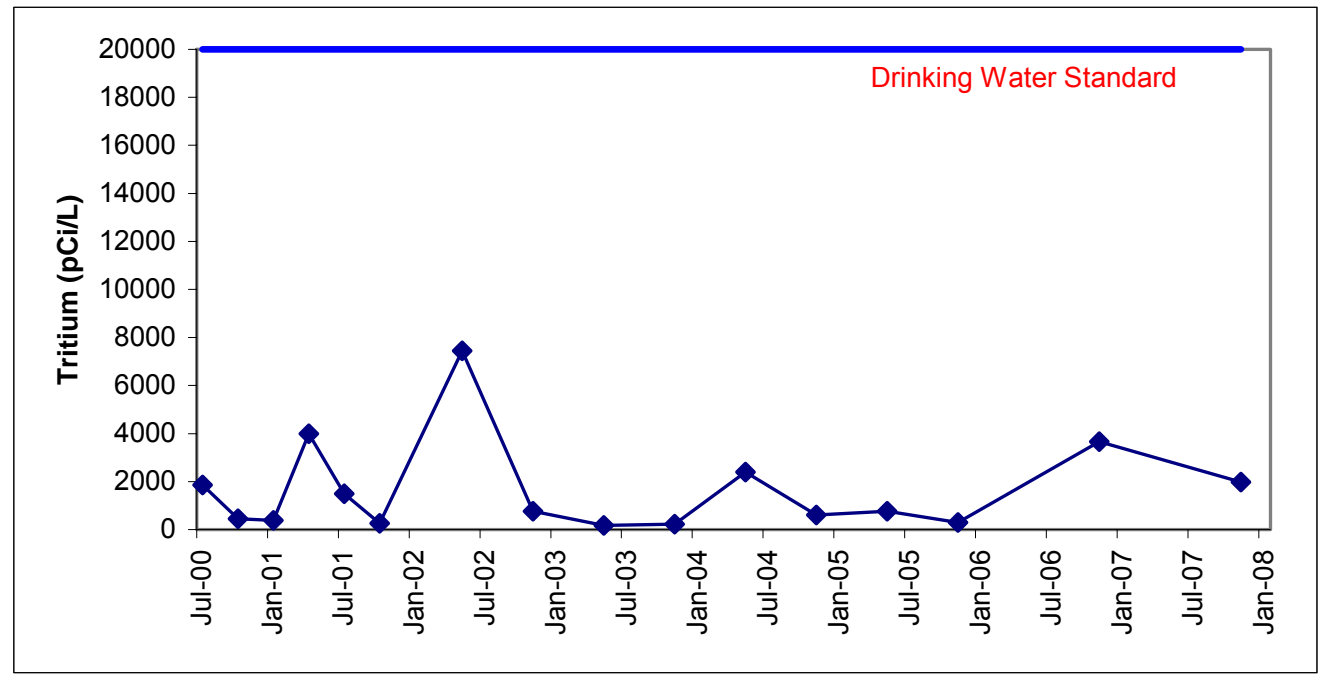

Figure 4-7.

Maximum Tritium Concentrations in Temporary and Permanent Wells Downgradient of U-Line Beam Stop.

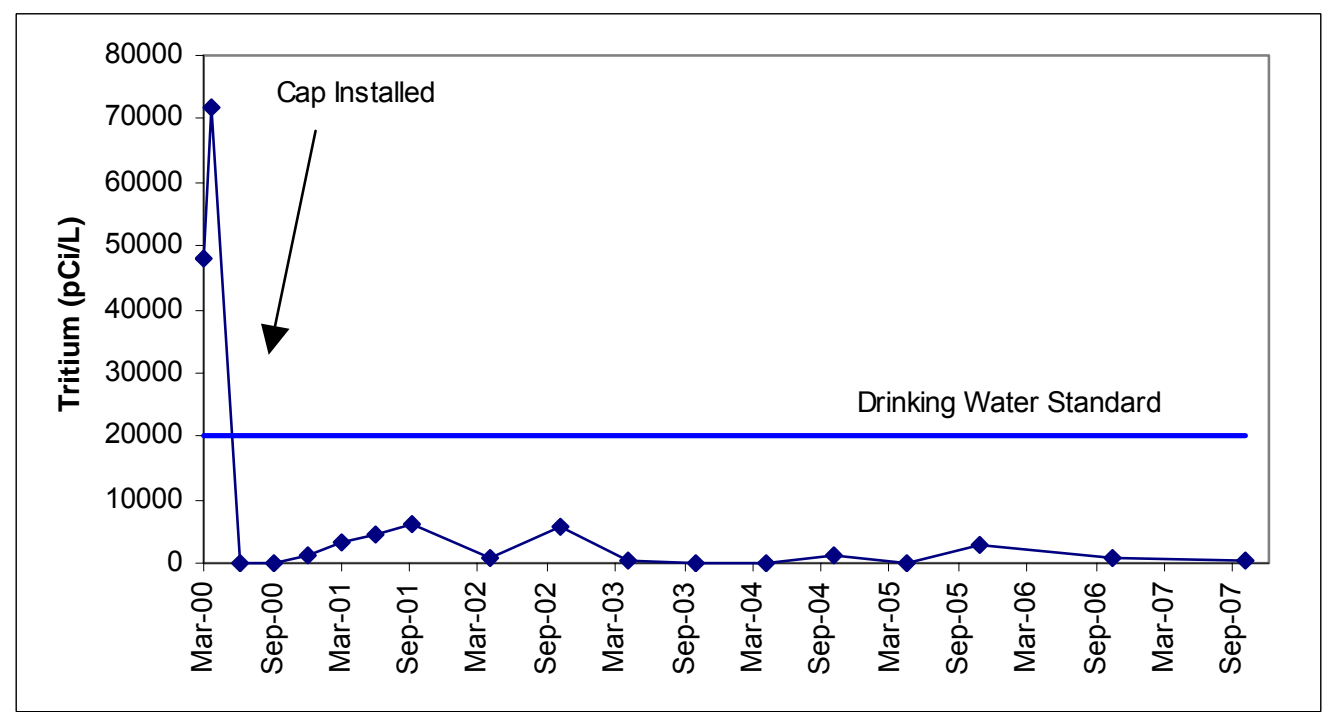

\section{2 g-2 Tritium Source Area and Groundwater Plume}

In November 1999, tritium was detected in the groundwater near the g-2 experiment at concentrations above the $20,000 \mathrm{pCi} / \mathrm{L}$ DWS. Sodium-22 was also detected in the groundwater, but at concentrations well below the $400 \mathrm{pCi} / \mathrm{L}$ DWS. An investigation into the source of the contamination revealed that the tritium and sodium-22 originated from activated soil shielding located adjacent to the g-2 target building, where approximately 5 percent of the beam was inadvertently striking one of the beam line magnets (magnet VQ-12). Rainwater was able to infiltrate the activated soils and carry the tritium and sodium-22 into the groundwater. To prevent additional rainwater infiltration into the activated soil 
shielding, a concrete cap was constructed over the area in December 1999. Other corrective actions included refocusing the beam and improved beam loss monitoring to reduce additional soil activation, stormwater management improvements, and additional groundwater monitoring.

Following the concurrence from the NYSDEC, a Record of Decision (ROD) was signed by the U.S. DOE and U.S. EPA in early 2007 (BNL 2007b). This ROD requires continued routine inspection and maintenance of the impermeable cap, groundwater monitoring of the source area to verify the continued effectiveness of the storm water controls, and monitoring the tritium plume until it attenuates to less than the $20,000 \mathrm{pCi} / \mathrm{L}$ DWS. Monitoring of the source area will continue for as long as the activated soils remain a threat to groundwater quality. Contingency actions have been developed if tritium levels exceeding 1,000,000 $\mathrm{pCi} / \mathrm{L}$ are detected within the plume, or if the tritium plume does not attenuate as predicted by the groundwater model.

\subsection{1 g-2 Tritium Source Area and Plume Groundwater Monitoring}

Well Network

Since the discovery of the g-2 tritium plume, BNL has been monitoring the source area surveillance wells quarterly. Monitoring of the downgradient sections of the tritium plume is accomplished using a combination of permanent and temporary wells (Figures 4-8 and 4-9).

\section{Sampling Frequency and Analysis}

During 2007, the g-2 VQ12 source area monitoring wells were monitored quarterly, and the samples were analyzed for tritium (Table 1-6). Analytical results for 2007 are presented in Appendix D. The downgradient sections of the tritium plume were monitored using a combination of permanent and temporary wells. The permanent wells located near Building 912 and the AGS parking lot/Waste Concentration Facility areas were sampled three times during the year. From June 2007 to March 2008, 19 temporary wells were installed to track the leading edge of the g-2 tritium plume (Figure 4-8). Sample results for the temporary wells are summarized in Table 4-1.

\subsection{2 g-2 Tritium Source Area and Plume Monitoring Well Results}

\section{Source Area Monitoring Results}

Monitoring data indicate that the high levels of tritium have entered the groundwater as a series of slug releases (Figure 4-10). Following the initial releases of tritium that occurred prior to cap installation in December 1999, subsequent periodic slug releases, characterized by short-term spikes in tritium concentrations, appear to be related to changes in the water table elevation. As the water table rises, residual tritium is flushed from the vadose (unsaturated) zone close to the water table. Water levels in the central BNL area in mid-2000, mid-2001, and mid-2003 were near the highest observed in almost 50 years of record for the BNL site, to a level of approximately 49 feet above mean sea level. Approximately 1 year after each of these periods of high water table elevations, elevated tritium concentrations were observed in the first set of source area surveillance wells. Over time, the amount of tritium remaining in the vadose zone near the water table is expected to decrease by this flushing mechanism and by natural radioactive decay. Although the water table increased to nearly 49 feet above mean sea level during three periods since 2004, tritium levels in all but two sets of quarterly samples from source area surveillance wells have been less than $100,000 \mathrm{pCi} / \mathrm{L}$. Tritium concentrations were less than $50,000 \mathrm{pCi} / \mathrm{L}$ during the second half of 2007 , but then increased to $186,000 \mathrm{pCi} / \mathrm{L}$ in January 2008 (in well 054-07). Well 054-07 was sampled again in February 2008, and the tritium concentration in the well dropped to $21,800 \mathrm{pCi} / \mathrm{L}$. The overall reductions in tritium concentrations suggest that the amount of residual tritium that is available to be flushed out of the deep vadose zone is decreasing. 
Figure 4-10. Maximum Tritium Concentrations Downgradient of the g-2 Tritium Source Area. A: Maximum tritium concentrations observed during 1999 through 2007 in groundwater downgradient of the $\mathrm{VQ}-12$ source area. Red arrows represent approximately 1 year of travel time from the source area to the first set of downgradient monitoring wells.

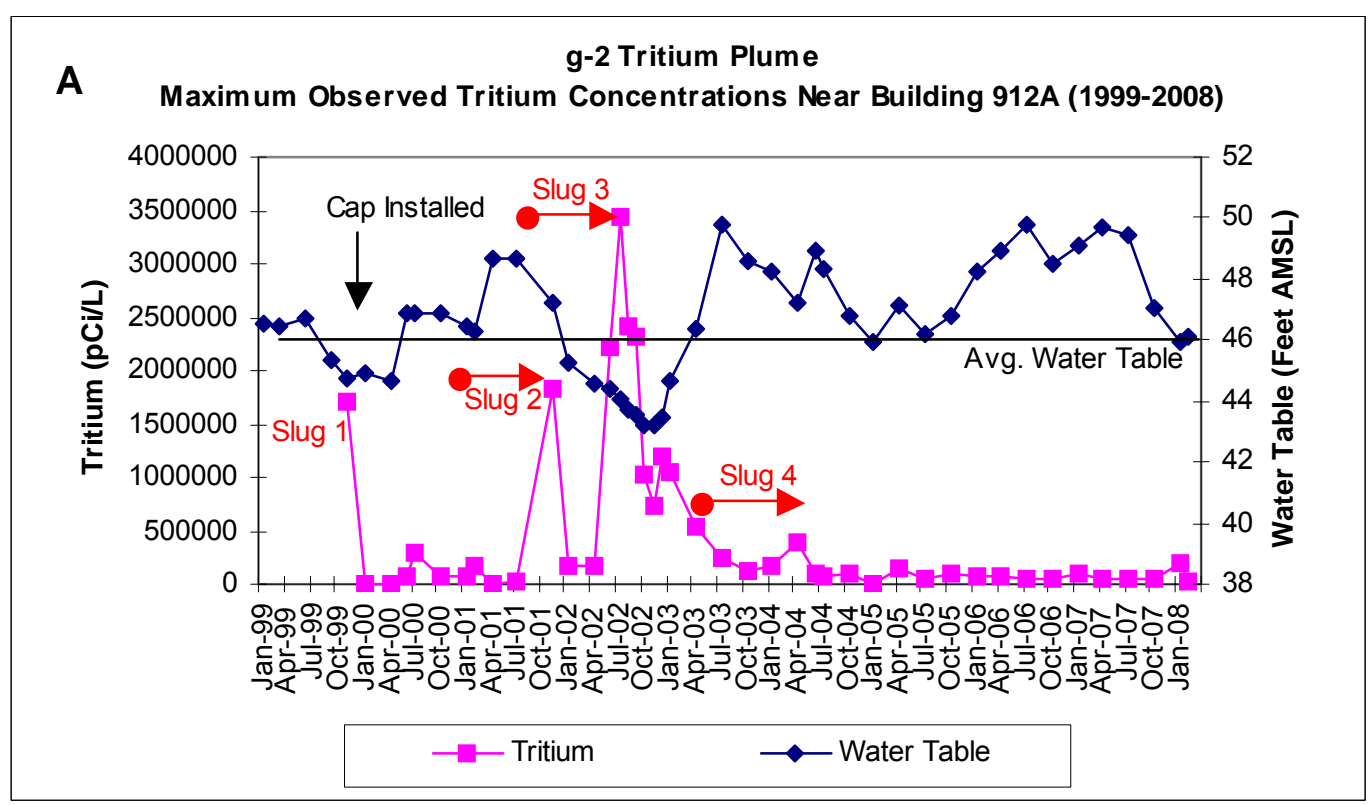

B: Comparison of 2003-2007 results to the ROD trigger level. Red arrows represent approximately 1 year of travel time from the source area to the first set of downgradient monitoring wells.

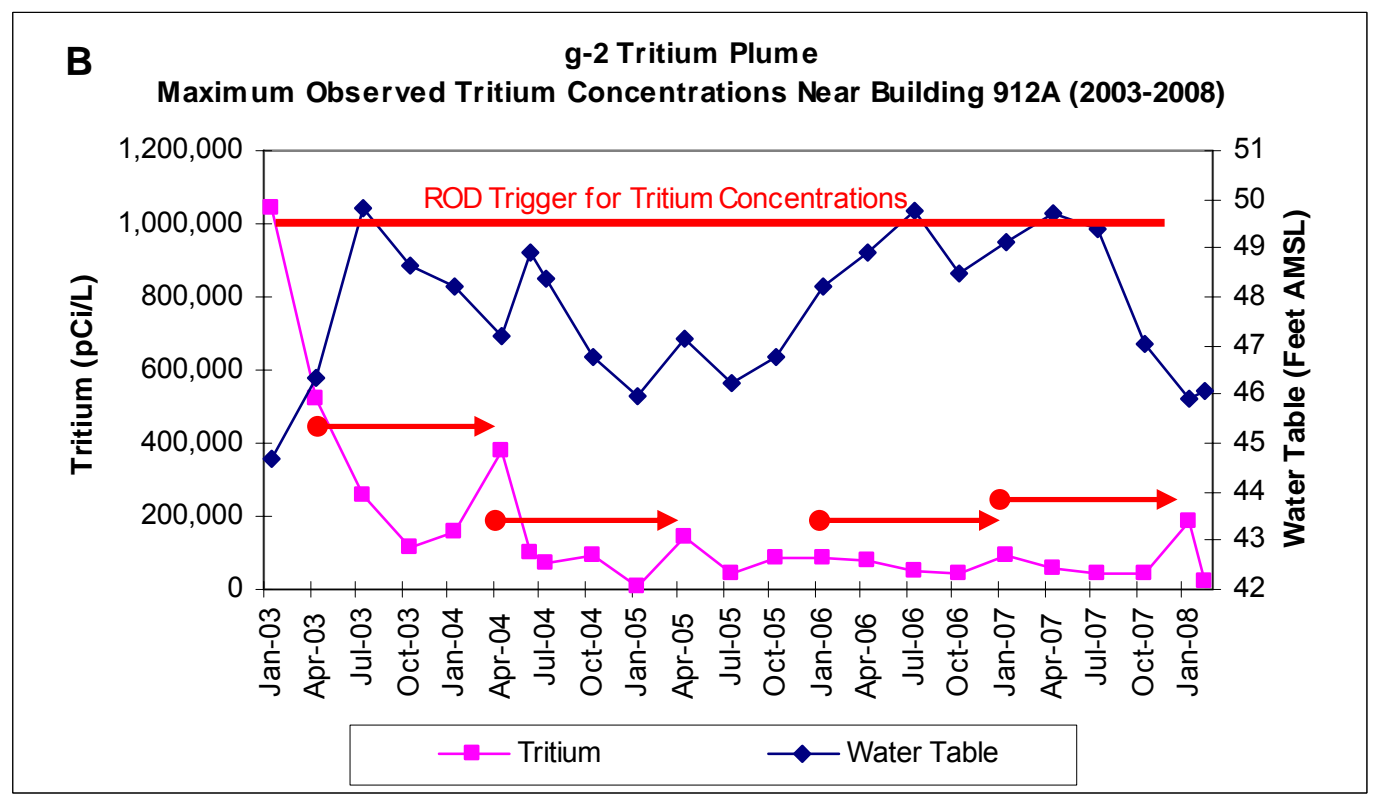

\section{Downgradient Areas of the Plume}

The extent of the g-2 tritium plume during the first quarter of 2008 is depicted on Figure 4-8. Figure 49 provides a cross-section view of the plume. Monitoring of the downgradient areas of the plume is accomplished using a combination of permanent and temporary wells. During June 2007 through March 2008, 19 temporary wells were installed along four east-west transects (Transects A, B, C and D). The highest tritium concentration was $198,000 \mathrm{pCi} / \mathrm{L}$, observed along Transect B in temporary well GP-73. 
This tritium concentration is consistent with g-2 Engineering Evaluation/Cost Analysis (EE/CA) model predictions of decay and dispersion effects on the high concentration plume segments (i.e., slugs) with distance from the source area. Along Transect $\mathrm{C}$ located immediately north of the HFBR, the highest tritium concentration was $53,900 \mathrm{pCi} / \mathrm{L}$, in temporary well GP-66. Along Transect $\mathrm{D}$, installed immediately south of the HFBR, the maximum tritium concentration was $83,000 \mathrm{pCi} / \mathrm{L}$ in temporary well GP-84. As a result of natural radioactive decay and dispersion in the aquifer, the tritium plume (as defined by concentrations $>20,000 \mathrm{pCi} / \mathrm{L} \mathrm{MCL}$ ) appears to be breaking up into discrete segments.

\subsection{3 g-2 Tritium Source Area and Plume Groundwater Monitoring Program Evaluation}

Although tritium continues to be detected in the groundwater downgradient of the g-2 VQ12 source area at concentrations that exceed the $20,000 \mathrm{pCi} / \mathrm{L}$ DWS, the reduction in tritium concentrations since 2003 indicates that the cap is effectively preventing rainwater from infiltrating the activated soil shielding. As discussed previously, a comparison of tritium levels in the source area monitoring wells and the water table elevation data suggests that the periodic natural fluctuations in the water table have released residual tritium from the deep vadose zone (i.e., unsaturated soil immediately above the water table). It is believed that this tritium was mobilized to the soil close to the water table before the cap was constructed in December 1999. Once the cap was in place, the lack of additional rainwater infiltration kept the tritium in the vadose zone from migrating into the groundwater until the significant rise in water table mobilized it. There appears to be good correlation between high tritium concentrations detected in monitoring wells immediately downgradient of the source area, and the groundwater table elevation about 1 year before the sampling (Figure 4-10). Over time, the amount of tritium remaining in the vadose zone near the water table is expected to decrease by this flushing mechanism and by natural radioactive decay. To fulfill the monitoring requirements defined in the ROD, BNL will continue to monitor groundwater quality in the source area until the activated soils are no longer a threat to groundwater quality.

During 2008, source area monitoring wells will continue to be sampled quarterly. The downgradient sections of the tritium plume will continue to be monitored using a combination of permanent wells near Building 912 and the AGS parking lot, and temporary wells will be used to track the leading segments of the plume. The permanent wells will be monitored semiannually. During the summer of 2008, additional temporary wells will be installed immediately south of the HFBR to track the leading edge of the g-2 plume. To fulfill the monitoring requirements defined in the ROD, BNL will continue to track the plume until the tritium concentrations drop below the $20,000 \mathrm{pCi} / \mathrm{L}$ DWS.

\subsection{Brookhaven Linac Isotope Producer (BLIP)}

When the Brookhaven Linac Isotope Producer (BLIP) is operating, the Linac delivers a beam of protons that strike a series of targets in the BLIP target vessel, positioned at the bottom of a $30-\mathrm{ft}$ underground tank. The targets rest inside a water-filled 18-in. diameter shaft that runs the length of the tank, and they are cooled by a 300-gal closed loop primary cooling system. During irradiation, several radionuclides are produced in the cooling water, and soil immediately outside the tank is activated by the production of secondary particles at the target.

As part of a 1985 redesign of the vessel, leak detection devices were installed and the open space between the water-filled shaft and the vessel's outer wall became a secondary containment system for the primary vessel. The BLIP target vessel system conforms to Suffolk County Article 12 requirements, and is registered with the Suffolk County Department of Health Services (SCDHS). The BLIP facility also has a 500-gal underground storage tank (UST) for liquid radioactive waste (change-out water from the BLIP primary system). The waste tank and its associated piping system conform to Article 12 requirements and are registered with SCDHS.

In 1998, BNL conducted an extensive evaluation of groundwater quality near the BLIP facility. Tritium concentrations of $52,000 \mathrm{pCi} / \mathrm{L}$ and sodium-22 up to $151 \mathrm{pCi} / \mathrm{L}$ were detected in the 
groundwater approximately 50 feet downgradient of the BLIP target vessel. Due to the activation of the soil shielding surrounding the BLIP target vessel and the detection of tritium and sodium-22 in groundwater, the BLIP facility was designated as sub-AOC $16 \mathrm{~K}$ under the IAG.

In 1998, BNL made improvements to the stormwater management program at BLIP in an effort to prevent additional rainwater infiltration into the activated soil below the building. The BLIP building's roof drains were redirected away from the building, existing paved areas on the south side of the building were resealed, and a gunite cap was installed on the remaining three sides of the building. In May and June 2000, BNL undertook additional protective measures by injecting colloidal silica grout (also known as a Viscous Liquid Barrier) into the activated soil. The grout reduces the permeability of the soil, thus further reducing the ability of rainwater to leach tritium and sodium-22 from the activated soils should the stormwater controls fail.

In late 2004, BNL also constructed a new protective cap over the beam line that runs from the Linac to the BLIP facility. The new cap was installed because direct soil measurements and beam loss calculations indicated that the tritium and sodium-22 concentrations in soils surrounding these beam lines could result in stormwater leachate concentrations that exceed the " 5 percent" criteria described in the Accelerator Safety SBMS (Standards Based Management System) subject area. ${ }^{2}$

Following the concurrence from the NYSDEC, a ROD was signed by the U.S. DOE and U.S. EPA in early 2007 (BNL 2007b). This ROD requires continued routine inspection and maintenance of the impermeable cap, and groundwater monitoring to verify the continued effectiveness of the storm water controls. Maintenance of the cap and groundwater monitoring will continue for as long as the activated soils remain a threat to groundwater quality.

\subsubsection{BLIP Groundwater Monitoring}

\section{Well Network}

The monitoring well network for the BLIP facility consists of two upgradient and five downgradient wells. These wells provide a means of verifying that the engineered and administrative controls described above are effective in protecting groundwater quality (Figure 4-1).

\section{Sampling Frequency and Analysis}

During 2007, the three wells located immediately downgradient of BLIP were monitored quarterly (wells 064-47,-48, and -67). The two upgradient wells and remaining two downgradient wells were sampled semiannually. All samples were analyzed for tritium, and one set of samples from the three immediately downgradient wells were analyzed for sodium-22 (Table 1-6). Analytical results for 2007 are presented in Appendix D.

\subsubsection{BLIP Monitoring Well Results}

Monitoring data collected from January 1999 to July 2000 indicated that the corrective actions taken during 1998 were highly effective in preventing the release of tritium and sodium-22 from the activated soil surrounding the BLIP target vessel. Prior to May 2000, tritium and sodium-22 concentrations in wells directly downgradient of BLIP were $<3,000 \mathrm{pCi} / \mathrm{L}$ and $<5 \mathrm{pCi} / \mathrm{L}$, respectively. However, significant increases in tritium concentrations were observed in groundwater samples collected after the silica grout injection that took place in late May and early June 2000 (Figure 4-11). It was determined that tritium in the soil pore water near the target vessel was displaced by the grout. Tritium concentrations in the groundwater immediately downgradient of BLIP increased to $56,500 \mathrm{pCi} / \mathrm{L}$ by October 2000. By December 2000, tritium concentrations dropped to below 20,000 pCi/L, and remained below this level throughout all of 2001 and 2002. From 2003 through 2006, there were

\footnotetext{
${ }^{2}$ The BNL Accelerator Safety SBMS subject area requires stormwater controls where rainwater infiltration into activated soil shielding could result in leachate concentrations that exceed 5 percent of the drinking water standard (i.e., $>1,000 \mathrm{pCi} / \mathrm{L}$ for tritium and $20 \mathrm{pCi} / \mathrm{L}$ for sodium-22).
} 
several short-duration periods when tritium concentrations once again exceeded 20,000 pCi/L (Figure 4-12). Since January 2006, tritium levels have remained below the 20,000 pCi/L DWS. During 2007, the maximum tritium concentration was $13,100 \mathrm{pCi} / \mathrm{L}$. During the first two sample quarters of 2008, tritium levels have remained less than $2,000 \mathrm{pCi} / \mathrm{L}$.

Figure 4-11.

Maximum Tritium Concentrations in Wells $\sim 40$ feet Downgradient of the BLIP Target Vessel.

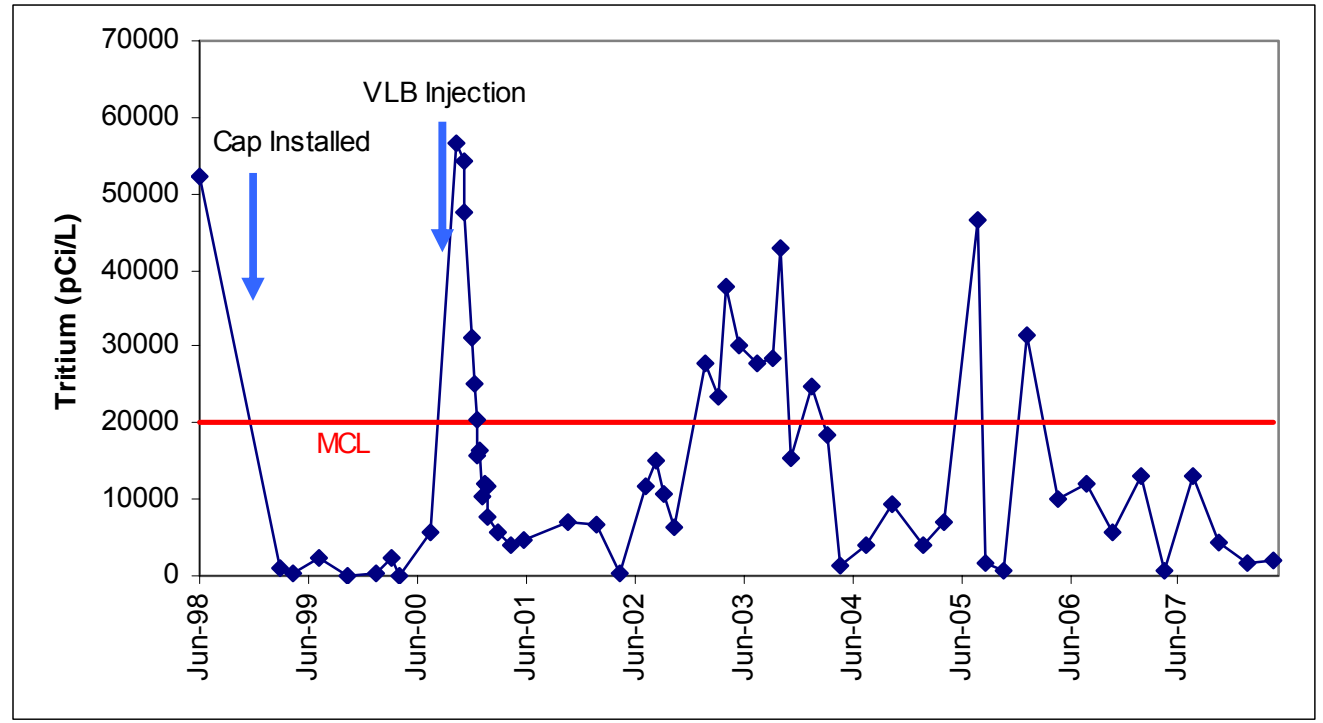

Figure 4-12.

Tritium Concentrations vs. Water Table Position, 40 Feet Downgradient of the BLIP Target Vessel.

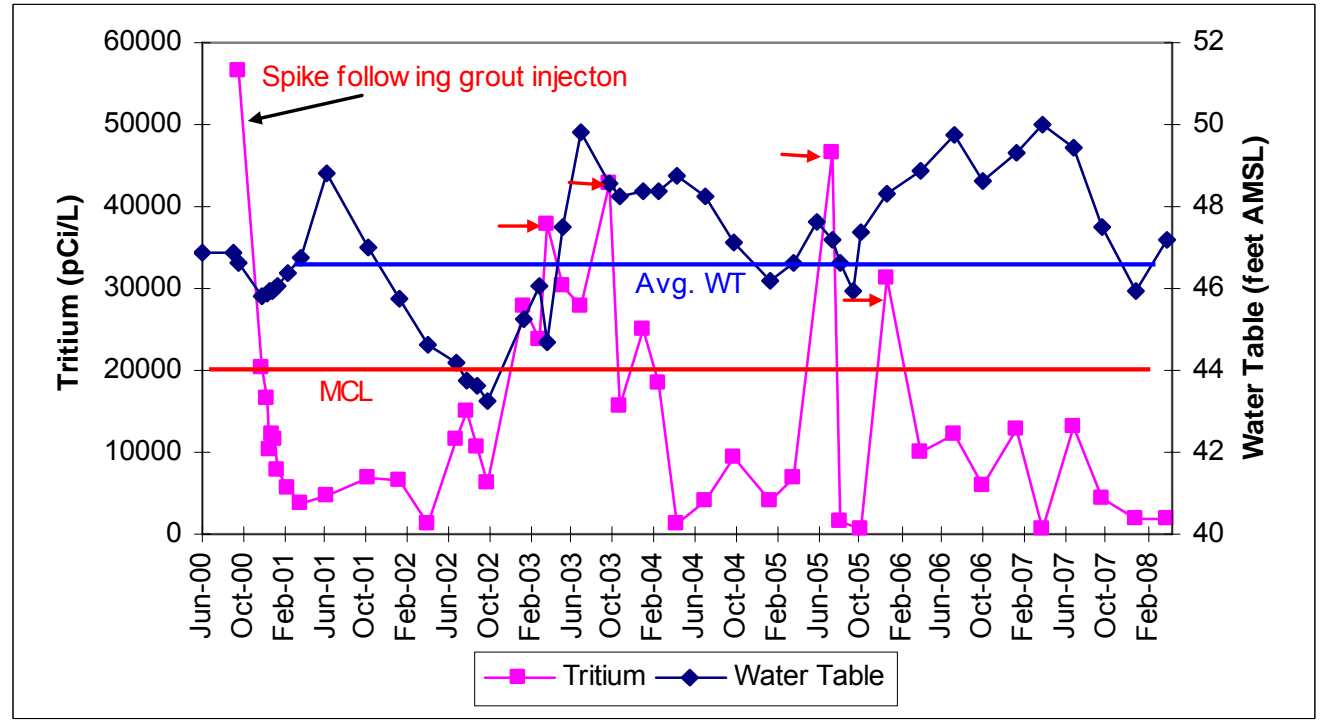

Note 1: Arrows indicate approximate groundwater travel time from directly below the BLIP target to the first set of monitoring wells (e.g., well 064-67). Travel time is approximately 89 days, based on a distance of 40 feet and groundwater velocity of $0.45 \mathrm{ft} / \mathrm{day}$. 


\subsubsection{BLIP Groundwater Monitoring Program Evaluation}

The gunite cap, paved areas, and roof drains at BLIP are in good condition and are effectively controlling stormwater infiltration. Although direct inspection of the silica grout is not possible, it is expected to be in good condition and would be effective in preventing significant leaching of tritium from the activation zone should the primary stormwater controls fail. A comparison of tritium concentrations to changes in water table position suggests that the periodic increases in tritium concentrations are probably associated with seasonal increases in water table elevation (Figure 4-12). As the water table rises, older tritium that had leached from the soil before the cap was installed in 1998 or that was released during the grout injection project is flushed from the soil close to the water table. The amount of tritium remaining in the vadose zone close to the water table is expected to decline over time, due to this flushing mechanism and by natural radioactive decay. The short-term concentration increases observed in 2005 and 2006 also appear to be correlated to increases in the position of the water table.

As required by the ROD, BNL will continue to conduct routine inspections of the cap, and to monitor groundwater quality downgradient of the BLIP facility. Until the tritium levels in groundwater routinely remain below the $20,000 \mathrm{pCi} / \mathrm{L}$ DWS, BNL will continue to monitor the BLIP wells quarterly.

\subsection{Relativistic Heavy Ion Collider (RHIC)}

Beam line interaction with the Relativistic Heavy Ion Collider (RHIC) collimators and beam stops produces secondary particles that interact with soil surrounding the 8 o'clock and 10 o'clock portions of the RHIC tunnel and the W-Line stop (Figure 4-13). These interactions result in the production of tritium and sodium-22, which can be leached out of the soil by rainwater. Although the level of soil activation was expected to be minor, before RHIC operations began in 2000 BNL installed impermeable caps over these beam loss areas to prevent the potential impact to groundwater quality.

\subsubsection{RHIC Groundwater Monitoring}

Well Network

Thirteen shallow wells are used to verify that the engineered impermeable caps and operational controls implemented at the RHIC beam stops and collimators are effective in protecting groundwater quality. Six of the monitoring wells are located in the 10 o'clock beam stop area, six wells in the collimator area, and one well is downgradient of the W-Line beam stop (Figure 4-13). As an extension to the groundwater monitoring program, surface water samples are also collected from the Peconic River both upstream (location HY) and downstream (location HV) of the beam stop area to verify that potentially contaminated groundwater is not being discharged into the Peconic River stream bed during high water table conditions.

\section{Sampling Frequency and Analysis}

During 2007, groundwater samples were collected from the RHIC monitoring wells on a semiannual schedule, and the samples were analyzed for tritium (Table 1-6). Analytical results for 2007 are presented in Appendix D . Routine analysis for sodium-22 was dropped from the groundwater surveillance program in 2002 because tritium is the best indicator of possible cap failure (i.e., tritium is more leachable than sodium-22, and it migrates at the same rate as groundwater). Surface water samples were collected quarterly and analyzed for tritium and sodium-22.

\subsubsection{RHIC Monitoring Well Results}

As in past years, no tritium was detected in any groundwater samples. No tritium or sodium-22 was detected in surface water samples from downstream location HV. 


\subsubsection{RHIC Groundwater Monitoring Program Evaluation}

Groundwater and surface water monitoring data continue to demonstrate that the impermeable caps installed over the RHIC beam stop and collimator areas are effectively preventing rainwater infiltration into the activated soil shielding. During 2008, groundwater samples will continue to be collected on a semiannual basis. Surface water samples will also be collected periodically as part of the surveillance program.

\subsection{Brookhaven Medical Research Reactor (BMRR)}

The Brookhaven Medical Research Reactor (BMRR) was a 3-megawatt light water reactor that was used for biomedical research. Research operations at the BMRR stopped in December 2000. All spent fuel was removed in 2003 and the primary cooling water system has been drained. BNL is preparing plans to permanently decommission the facility.

The BMRR primary cooling water system consisted of a recirculation piping system that contained 2,550 gallons of water. The cooling water contained approximately $5 \mathrm{Ci}$ of tritium. Unlike the High Flux Beam Reactor, the BMRR does not have a spent fuel storage canal or pressurized imbedded piping systems that contained radioactive liquids. Historically, fuel elements that required storage were either stored within the reactor vessel, or they were transferred to the HFBR spent fuel canal. The BMRR primary cooling water system piping is fully exposed in the containment structure and is accessible for routine visual inspections. When the BMRR was operational, excess heat was transferred by means of heat exchangers with once-through (secondary) cooling water, which was obtained from nearby process supply wells or the BNL Chilled Water System. This secondary water was discharged to recharge basin HP, 800 feet south of the Medical Department complex, and was monitored as part of the SPDES program. All cooling water discharges from the BMRR stopped in December 2000.

In 1997, tritium was detected in wells installed directly downgradient (within 30 feet) of the BMRR. The maximum tritium concentration observed during 1997 was $11,800 \mathrm{pCi} / \mathrm{L}$, almost one-half of the $20,000 \mathrm{pCi} / \mathrm{L}$ DWS. The highest observed tritium concentration since the start of groundwater monitoring was $17,100 \mathrm{pCi} / \mathrm{L}$ in October 1999 . The tritium currently detected in groundwater is believed to have originated from the historical discharge of small amounts of BMRR primary cooling water to a basement floor drain and sump system that may have leaked. Although the last discharge of primary cooling water to the floor drain system occurred in 1987, the floor drains continued to be used for secondary (nonradioactive) cooling water until 1997. The infiltration of this water may have promoted the movement of residual tritium from the soil surrounding the floor drain piping system to the groundwater. The floor drains were permanently sealed in 1998 to prevent any accidental future releases to the underlying soil.

\subsubsection{BMRR Groundwater Monitoring}

Well Network

The monitoring well network for the BMRR facility consists of one upgradient and three downgradient wells (Figure 4-14). Samples collected from the four groundwater monitoring wells are used to determine whether residual tritium in the soils below the BMRR is impacting groundwater quality.

\section{Sampling Frequency and Analysis}

Starting in 2007, the sampling frequency for the BMRR wells was changed from annual to once every 2 years. The next set of samples will be collected in 2008, and the samples will be analyzed for tritium, gamma emitting radionuclides, gross alpha, and gross beta (Table 1-6). 


\subsubsection{BMRR Monitoring Well Results}

Monitoring results for the last set of samples collected in 2006 indicated that tritium concentrations continued to be well below the $20,000 \mathrm{pCi} / \mathrm{L}$ DWS. Detectable levels of tritium were observed in all three downgradient wells, with the maximum value of 1,570 pCi/L detected in well 084-27 (Figure 415). As in past years, gamma, gross alpha, and gross beta results did not indicate the presence of any other reactor-related radionuclides.

\subsubsection{BMRR Groundwater Monitoring Program Evaluation}

Tritium concentrations in groundwater have never exceeded the $20,000 \mathrm{pCi} / \mathrm{L} \mathrm{DWS}$, and have remained $<5,000 \mathrm{pCi} / \mathrm{L}$ since 2001 . The $\mathrm{BMRR}$ structure is effectively reducing rainwater infiltration into the underlying soils, and therefore reducing the movement of any residual tritium from the soil to the groundwater.

Starting in 2007, the monitoring frequency for the BGRR wells was reduced to once every 2 years, with the next set of samples being collected in 2008 .

Figure 4-15.

Tritium Concentrations Downgradient of the BMRR from 1997-2007.

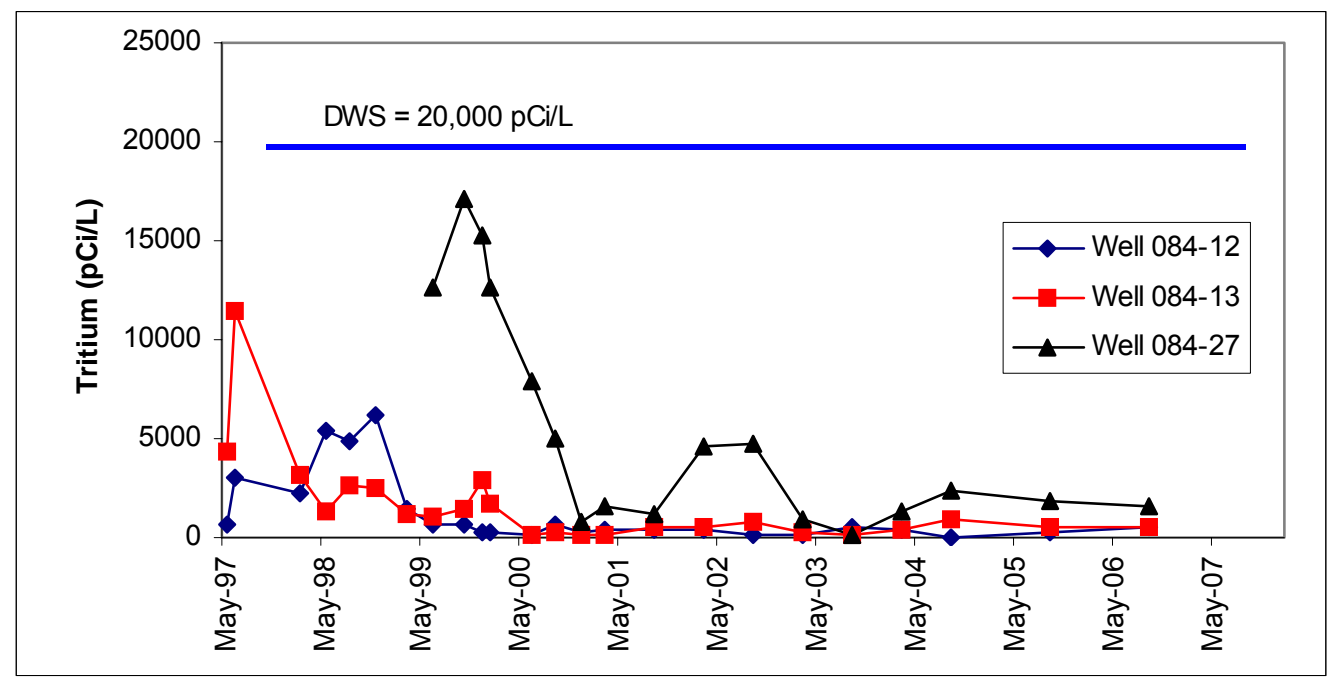

\subsection{Sewage Treatment Plant (STP)}

The Sewage Treatment Plant (STP) processes sanitary wastewater from BNL research and support facilities. Treated effluent from the STP is discharged to the Peconic River under a NYSDEC SPDES permit (NY-0005835). On average, 1.25 million gallons per day (MGD) are processed during the summer and $0.72 \mathrm{MGD}$ are processed daily during the rest of the year. Before discharge into the Peconic River, the sanitary waste stream is fully treated by 1) primary clarification to remove settleable solids and floatable materials, 2) aerobic oxidation for secondary removal of the biological matter and nitrification of ammonia, 3) secondary clarification, 4) sand filtration for final effluent polishing, and 5) ultraviolet disinfection for bacterial control. Oxygen levels are regulated during the treatment process to remove nitrogen biologically, using nitrate-bound oxygen for respiration.

Wastewater from the STP clarifier is released to the sand filter beds, where water percolates through 3 feet of sand before being recovered by an underlying clay tile drain system, which transports the water to the discharge point at the Peconic River (SPDES Outfall 001). Approximately 15 percent of the water released to the filter beds is either lost to evaporation or to direct groundwater recharge. At the present time, six sand filter beds are used in rotation. 
Two emergency hold-up ponds are located east of the sand filter bed area. The hold-up ponds are used to store sanitary waste in the event of an upset condition or if the influent contains contaminants in concentrations exceeding BNL administrative limits and/or SPDES permit effluent release criteria. The hold-up ponds have a combined holding capacity of nearly 8 million gallons of water, and provide the Laboratory with the ability to divert all sanitary system effluent for approximately 1 week. The hold-up ponds are equipped with fabric-reinforced plastic liners that are heat-welded along all seams. As part of the Phase III Sewage Treatment Plant Upgrades project in 2001, the liners were enhanced by the addition of new primary liners and a leak detection system. The older liners now serve as secondary containment.

\subsubsection{STP Groundwater}

Well Network

In addition to the comprehensive influent and effluent monitoring program at the STP, the groundwater monitoring program is designed to provide a secondary means of verifying that STP operations are not impacting environmental quality. Six wells are used to monitor groundwater quality in the filter bed area and three wells are monitored in the holding pond area (Figure 4-16).

\section{Sampling Frequency and Analysis}

During 2007, the six STP filter bed area wells were monitored semiannually and the three holding pond area wells were sampled annually. The samples were analyzed for VOCs, anions, metals, tritium, gross alpha, gross beta, and gamma emitting radionuclides (Table 1-6). Analytical results for 2007 are presented in Appendix D.

\subsubsection{STP Monitoring Well Results}

\section{Radiological Analyses}

Radioactivity levels in samples collected from most of the STP wells during 2007 were generally typical of ambient (background) levels. As in previous years, higher than normal gross alpha and gross beta levels were detected in the samples from filter bed area monitoring well 038-02, at maximum concentrations of $93 \mathrm{pCi} / \mathrm{L}$ and $109 \mathrm{pCi} / \mathrm{L}$, respectively. This well is screened in fine-grained material above a localized low permeability (silt and clay) deposit, and the elevated gross alpha and gross beta values are believed to be related to the naturally occurring radionuclides common to these deposits. Low levels of tritium were detected in filter bed area wells 039-86 and 039-87, at concentrations of $1,190 \mathrm{pCi} / \mathrm{L}$ and $660 \mathrm{pCi} / \mathrm{L}$, respectively. No BNL-related gamma emitting radionuclides were detected in any of the STP groundwater monitoring wells.

\section{Nonradiological Analyses}

During 2007, all water quality and most metals concentrations were below the applicable NYS AWQS or DWS. In filter bed area well 039-86 sodium was detected at a concentration of $27 \mathrm{mg} / \mathrm{L}$, slightly above the $20 \mathrm{mg} / \mathrm{L}$ NYS AWQS. Low levels of nitrates continue to be detected in many of the STP filter bed area wells, with a maximum concentration of $5.2 \mathrm{mg} / \mathrm{L}$ detected in filter bed area monitoring well 039-86. The NYS AWQS for nitrate is $10 \mathrm{mg} / \mathrm{L}$. No VOCs were detected above the NYS AWQS in any of the STP monitoring wells.

\subsubsection{STP Groundwater Monitoring Program Evaluation}

Monitoring results for 2007 indicate that STP operations are not having a significant impact on groundwater quality, and that the BNL administrative and engineered controls designed to prevent the discharge of chemicals and radionuclides to the sanitary system continue to be highly effective. No changes to the monitoring frequency are proposed for 2008. 


\subsection{Motor Pool Maintenance Area}

The Motor Pool (Building 423) and Site Maintenance facility (Building 326) are attached structures located along West Princeton Avenue (Figure 4-17). The Motor Pool area consists of a five-bay automotive repair shop, which includes office and storage spaces. The Site Maintenance facility provides office space, supply storage, locker room, and lunchroom facilities for custodial, grounds, and heavy equipment personnel. Both facilities have been used continuously since 1947.

Potential environmental concerns at the Motor Pool include 1) the historical use of USTs to store gasoline, diesel fuel, and waste oil, 2) hydraulic fluids used for lift stations, and 3) the use of solvents for parts cleaning. In August 1989, the gasoline and waste oil USTs, pump islands, and associated piping were upgraded to conform to Suffolk County Article 12 requirements for secondary containment, leak detection devices, and overfill alarms. Following the removal of the old USTs, there were no obvious signs of soil contamination. The present tank inventory includes two 8,000-gallon USTs used to store unleaded gasoline, one 260-gallon aboveground storage tank used for waste oil, and one 3,000-gal UST for No. 2 fuel oil. The Motor Pool facility has five vehicle lift stations. The hydraulic fluid reservoirs for the lifts are located above ground.

Since 1996, several small-scale hydraulic oil and diesel oil spills have been remediated at the Motor Pool. The only known environmental concern associated with the Site Maintenance facility (Building 326) was the December 1996 discovery of an old oil spill directly south of the building. In an effort to investigate the potential impact that this spill had on groundwater quality, four wells were installed downgradient of the spill site. Although the solvent TCA was detected in the groundwater at concentrations above NYS AWQS, petroleum hydrocarbons were not detected.

\subsubsection{Motor Pool Maintenance Area Groundwater Monitoring}

Well Network

The Motor Pool facility's groundwater monitoring program for the UST area is designed to confirm that the engineered and institutional controls are effective in preventing contamination of the aquifer and to evaluate continued impacts from historical spills. Two shallow Upper Glacial aquifer wells (10205 and -06) are used to monitor for potential contaminant releases from the UST area (Figure 4-17).

Groundwater quality downgradient of Building 423 and Building 326 is monitored using four wells (102-10, 102-11, 102-12, and 102-13). The program is designed to periodically assess existing solvent contamination that resulted from historical vehicle maintenance operations, and to confirm that the current engineered and institutional controls are effective in preventing additional contamination of the aquifer.

Sampling Frequency and Analysis

During 2007, the UST area wells were monitored semiannually and the samples were analyzed for VOCs (Table 1-6). Analytical results for 2007 are presented in Appendix D. The wells were also checked for the presence of floating petroleum hydrocarbons during these sample periods. The Building $423 / 326$ area wells were monitored annually, and the samples were analyzed for VOCs.

\subsubsection{Motor Pool Monitoring Well Results}

Underground Storage Tank Area

During 2007, no gasoline related products (including MTBE) were detected in groundwater downgradient of the gasoline UST area (Figure 4-18). Although MTBE concentrations had reached a maximum of nearly $34 \mu \mathrm{g} / \mathrm{L}$ (the NYS AWQS is $10 \mu \mathrm{g} / \mathrm{L}$ ) during 2003, MTBE concentrations decreased to non-detectable levels by 2006. As in past years, low levels of the solvent TCA were also detected, but at concentrations that continued to be well below the NYS AWQS of $5 \mu \mathrm{g} / \mathrm{L}$. Wells 10205 and 102-06 were also tested for the presence of floating petroleum hydrocarbons. As in previous years, no floating product was observed. 


\section{Building 423/326 Area}

For the first time in 7 years of groundwater surveillance in this area, all concentrations of the solvents TCA and DCA decreased to less than their applicable NYS AWQS (Figure 4-19). Levels of the former gasoline additive MTBE has been less than the $10 \mu \mathrm{g} / \mathrm{L}$ NYS AWQS since 2005. It is believed that the TCA, DCA, and MTBE originated from historical vehicle maintenance operations.

Figure 4-18.

VOC Concentration Trends Downgradient of the Gasoline UST Area.
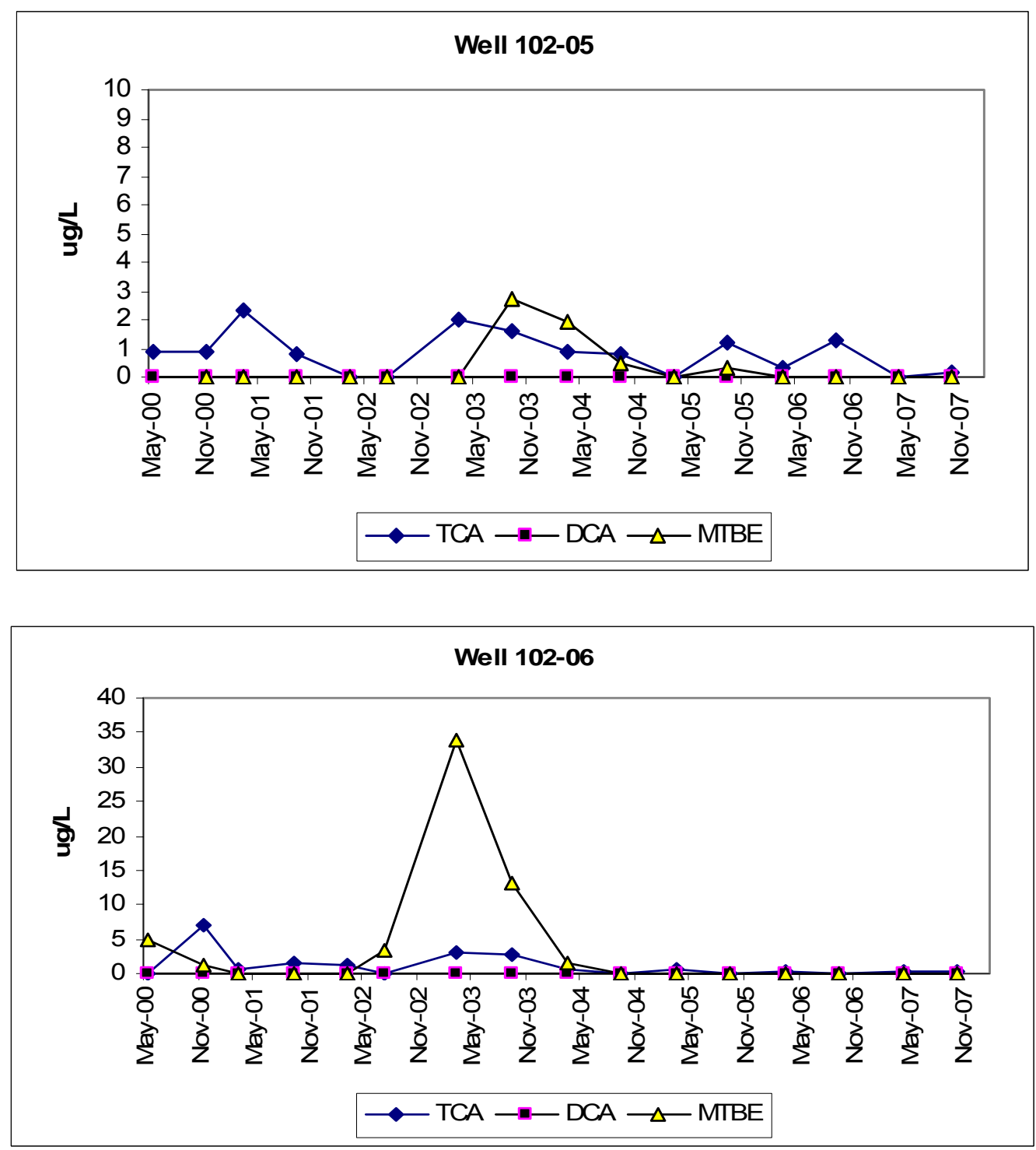
Figure 4-19.

VOC Concentration Trends in Wells Downgradient of Building 323/326.
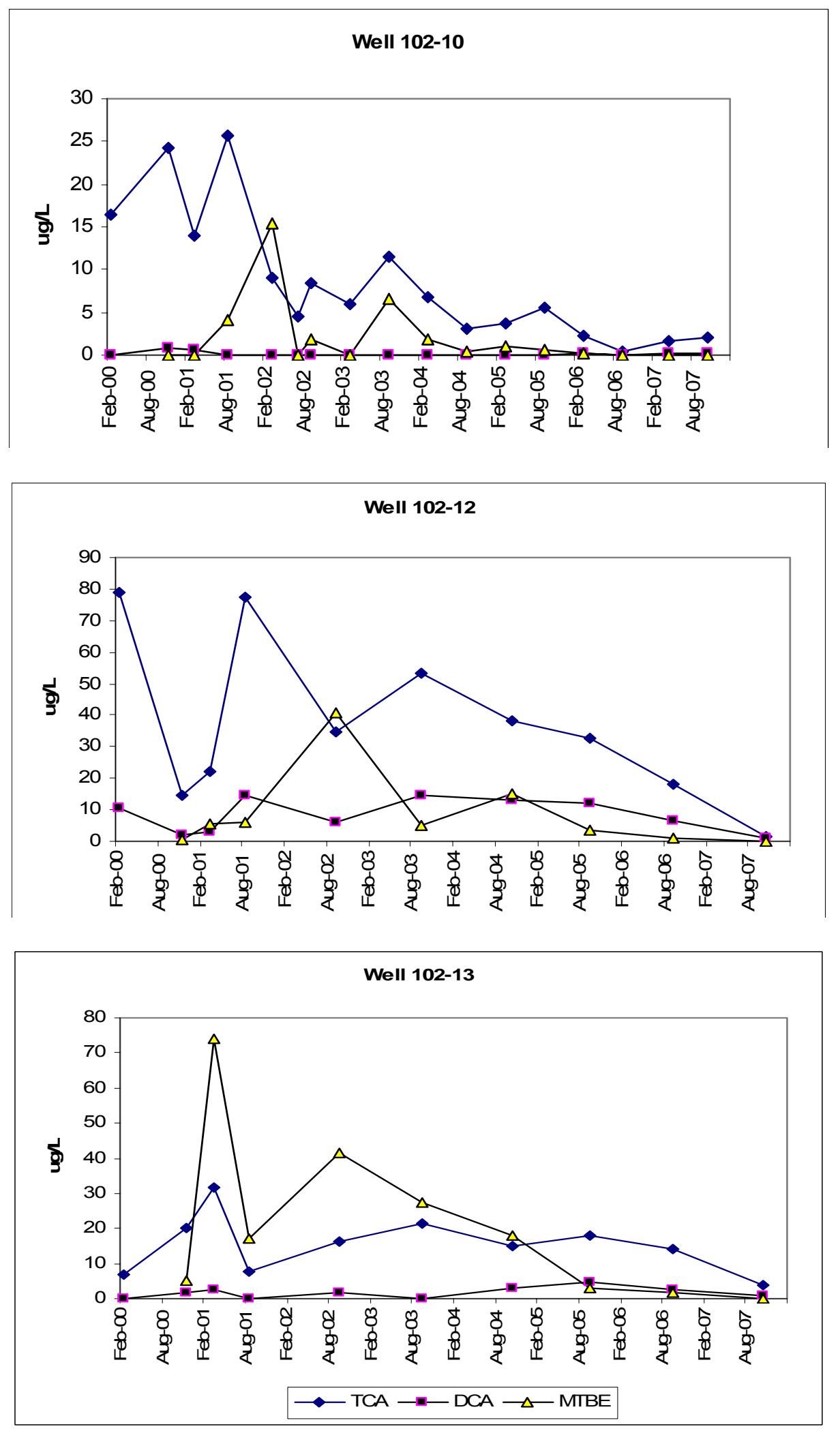


\subsubsection{Motor Pool Monitoring Program Evaluation}

Although small-scale solvent and gasoline releases from vehicle maintenance operations have impacted groundwater quality in the Motor Pool area, there has been a steady decrease in VOC concentrations over the past several years. During 2007 there were no reported gasoline or motor oil losses or spills that could affect groundwater quality, and all waste oils and used solvents generated from current operations are being properly stored and recycled. The gasoline USTs have electronic leak detection systems, and there is a daily product reconciliation (i.e., an accounting of the volume of gasoline stored in USTs and volume of gasoline sold). The MTBE and TCA that is periodically detected in the groundwater near the UST area is likely to have originated from historical spills. No changes to the monitoring program are proposed for 2008.

\subsection{On-Site Service Station}

Building 630 is a commercial automobile service station, privately operated under a contract with BNL. The station was built in 1966, and is used for automobile repair and gasoline sales.

Potential environmental concerns at the service station include the historical use of USTs for the storage of gasoline and waste oil, hydraulic fluids used for lift stations, and the use of solvents for parts cleaning. When the service station was built in 1966, the UST inventory consisted of one 6,000-gal and two 8,000-gal tanks for storing gasoline, and one 500-gal tank for used motor oil. In August 1989, the USTs, pump islands, and associated piping were upgraded to conform to Suffolk County Article 12 requirements for secondary containment, leak detection devices, and overfill alarms. During the removal of the old USTs, there were no obvious signs of soil contamination.

The current tank inventory includes three 8,000-gal USTs for storing unleaded gasoline, and one 500gal UST used for waste oil. The facility has three hydraulic vehicle lift stations.

Groundwater quality in the service station area has been impacted by historical small-scale spills of oils, gasoline, and solvents, and by carbon tetrachloride contamination associated with a nearby UST that was used as part of a science experiment conducted in the 1950s. In April 1998, BNL removed a UST from an area approximately 200 feet northwest (upgradient) of the service station. Although there are indications that the tank was releasing small quantities of carbon tetrachloride before its removal, a significant increase in carbon tetrachloride concentrations in groundwater indicated that additional amounts of this chemical were inadvertently released during the excavation and removal process. BNL started to remediate the carbon tetrachloride plume in October 1999 (see Section 3.2.1).

\subsubsection{Service Station Groundwater Monitoring}

Well Network

The service station's groundwater monitoring program is designed to confirm that the engineered and institutional controls in place are effective in preventing contamination of the aquifer and to evaluate continued impacts from historical spills. Five wells are used to monitor for potential contaminant releases (Figure 4-20).

\section{Sampling Frequency and Analysis}

During 2007, the service station facility wells were monitored three times, primarily by the LTRA program as part of the Carbon Tetrachloride plume monitoring project. The samples were analyzed for VOCs (Tables 1-5 and 1 -6). Analytical results for 2007 are presented in Appendix D. Three of the wells near the gasoline USTs were also checked semiannually for the presence of floating petroleum hydrocarbons.

\subsubsection{Service Station Monitoring Well Results}

During 2007, carbon tetrachloride (and its breakdown product, chloroform) continued to be observed in the service station monitoring wells (Figure 4-21 ). The maximum carbon tetrachloride and 
chloroform concentrations were $24 \mu \mathrm{g} / \mathrm{L}$ and $16 \mu \mathrm{g} / \mathrm{L}$, respectively. The levels of carbon tetrachloride currently detected in the groundwater is considerably less than those observed during 2000, when carbon tetrachloride concentrations approached 4,500 $\mu \mathrm{g} / \mathrm{L}$. The reduction in carbon tetrachloride levels reflects the effectiveness of the groundwater remediation system (see Section 3.2.1), which achieved its cleanup objectives and was shut down in August 2004.

Historically, groundwater quality at the Service Station has been affected by a variety of VOCs that appeared to be related to historical service station operations. During 2007, high levels of VOCs were detected in well 085-17 during the October sample round, with total xylenes detected at $140 \mu \mathrm{g} / \mathrm{L}$, ethylbenzene at $15 \mu \mathrm{g} / \mathrm{L}, 1,2,4$-trimethylbenzene at $35 \mu \mathrm{g} / \mathrm{L}$, and the solvent PCE at a concentration of $14 \mu \mathrm{g} / \mathrm{L}$ (Figure 4-22). Compared to 2006, there was a significant drop in VOC concentrations in well 085-236, to nearly non-detectable levels (Figure 4-23). VOC levels remained nearly non-detectable in well 085-237 (Figure 4-24). As in previous years, no floating product was detected in the wells.

Figure 4-21.

Carbon Tetrachloride Concentration Trends in Service Station Monitoring Wells.

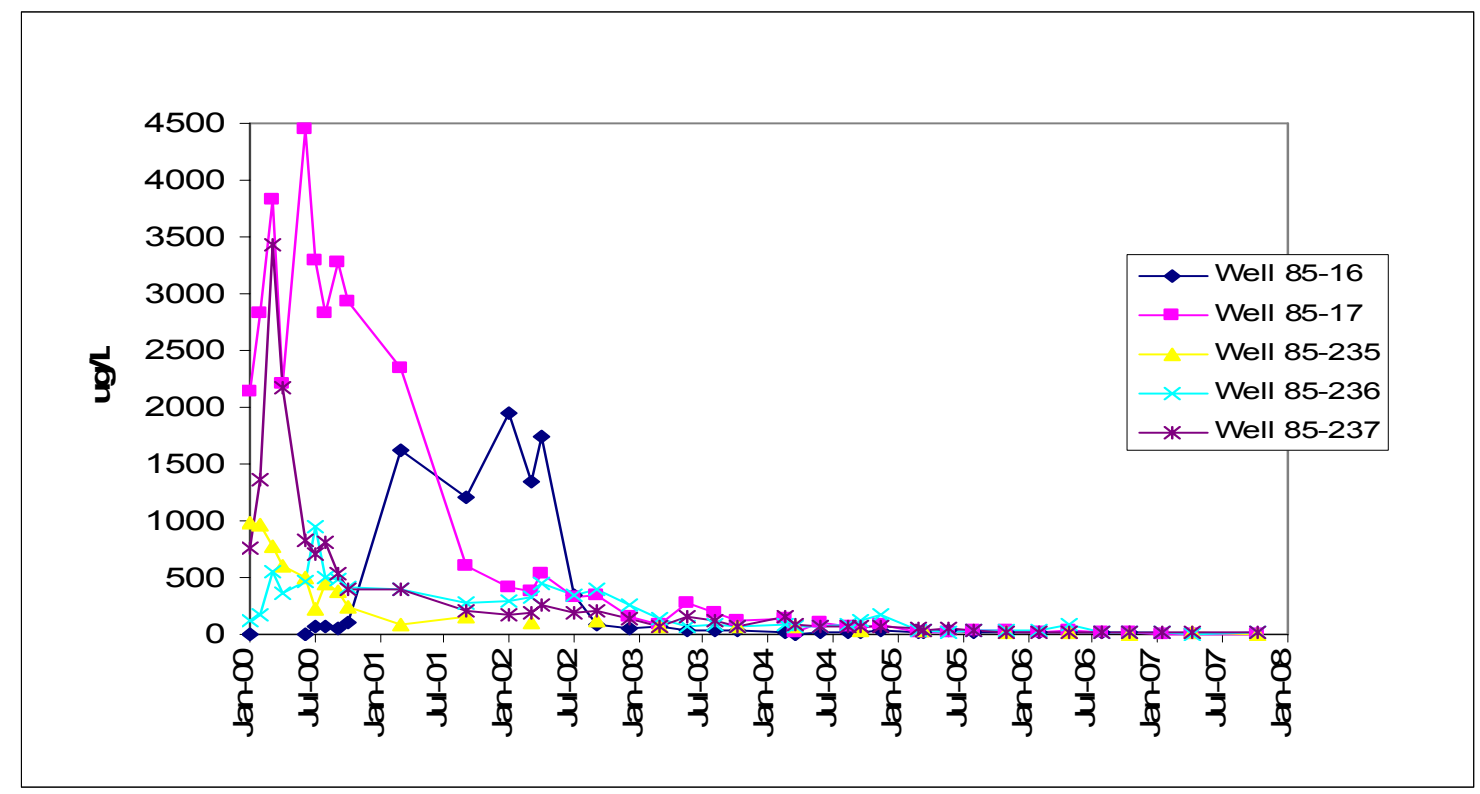

\subsubsection{Service Station Groundwater Monitoring Program Evaluation}

Analysis of groundwater samples collected at the service station facility during 2007 indicates that VOCs continue to be detected at concentrations greater than the applicable NYS AWQS. There were no reported gasoline or motor oil losses or spills that could affect groundwater quality, and all waste oils and used solvents generated from current operations are being properly stored and recycled. The gasoline USTs have electronic leak detection systems, and there is a daily product reconciliation (i.e., an accounting of the volume of gasoline stored in USTs and volume of gasoline sold). It is believed that the petroleum hydrocarbon-related compounds and solvents that have been detected in groundwater originated from historical vehicle maintenance operations before improved chemical storage and handling controls were implemented in the 1980s. No changes to the monitoring program are proposed for 2008 . 
Figure4-22.

Downgradient Well 085-17: Trend of Service Station-Related VOCs. Carbon tetrachloride originating from the upgradient carbon tetrachloride UST source area is not included.

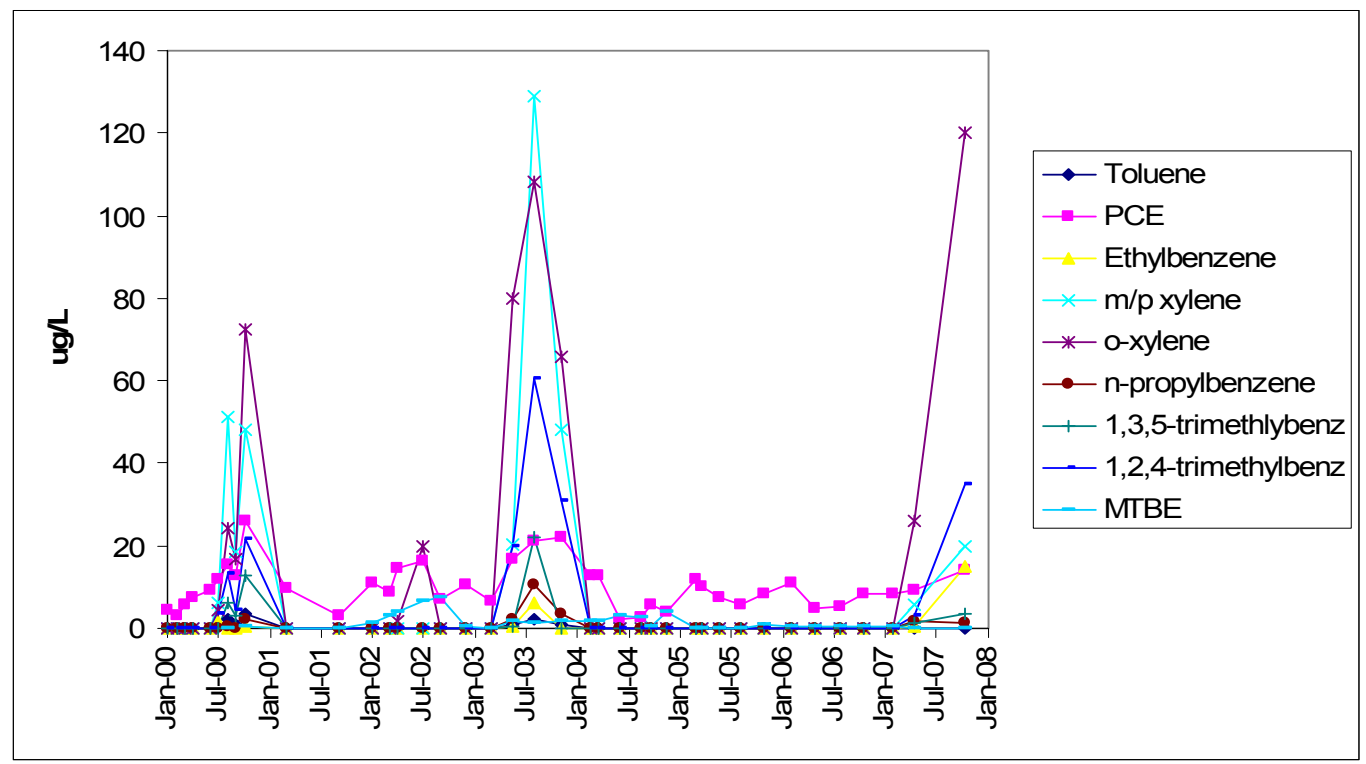

Figure 4-23.

Downgradient Well 085-236: Trend of Service Station-Related VOCs. Carbon tetrachloride from the upgradient carbon tetrachloride UST source area is not included.

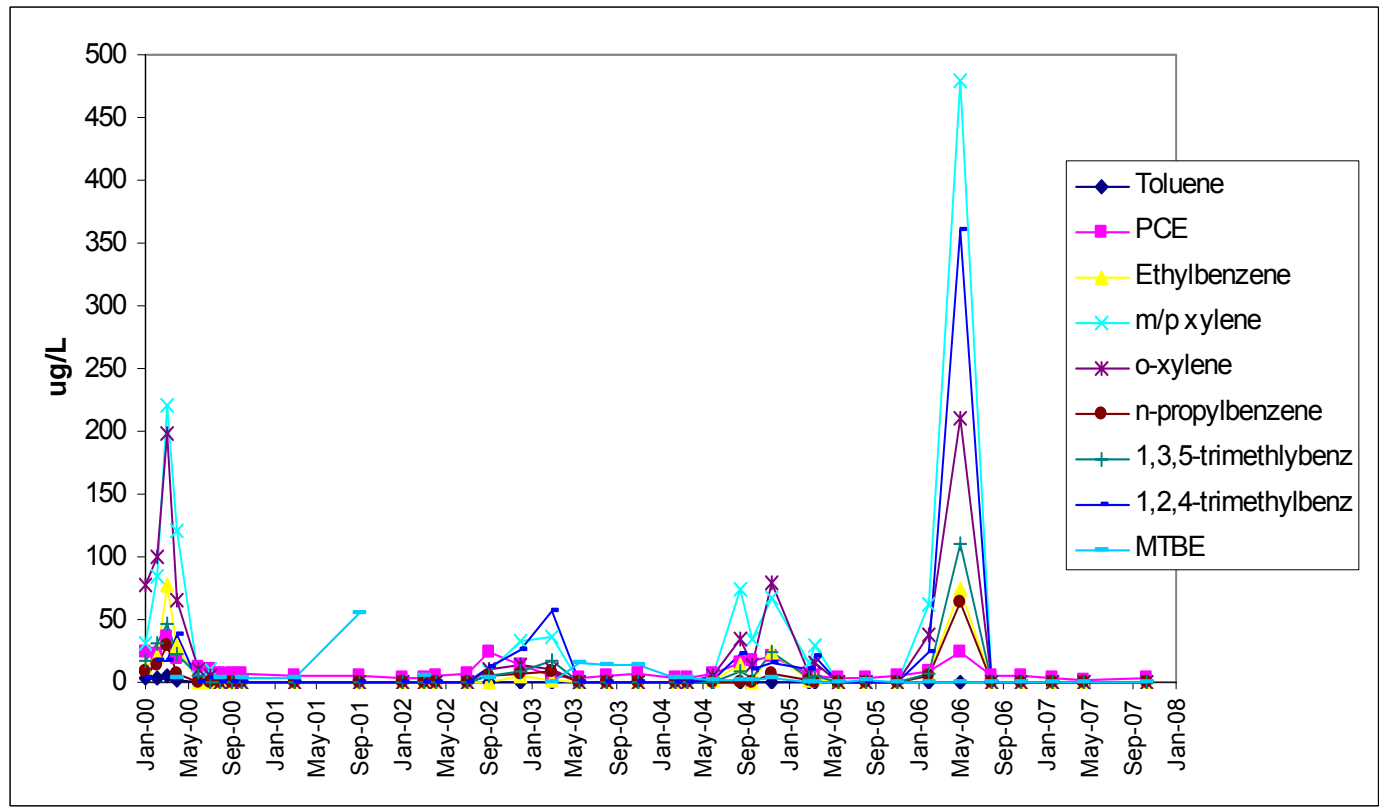


Figure 4-24. Downgradient Well 085-237: Trend of Service Station-Related VOCs. Carbon tetrachloride originating from the upgradient carbon tetrachloride UST source area is not included.

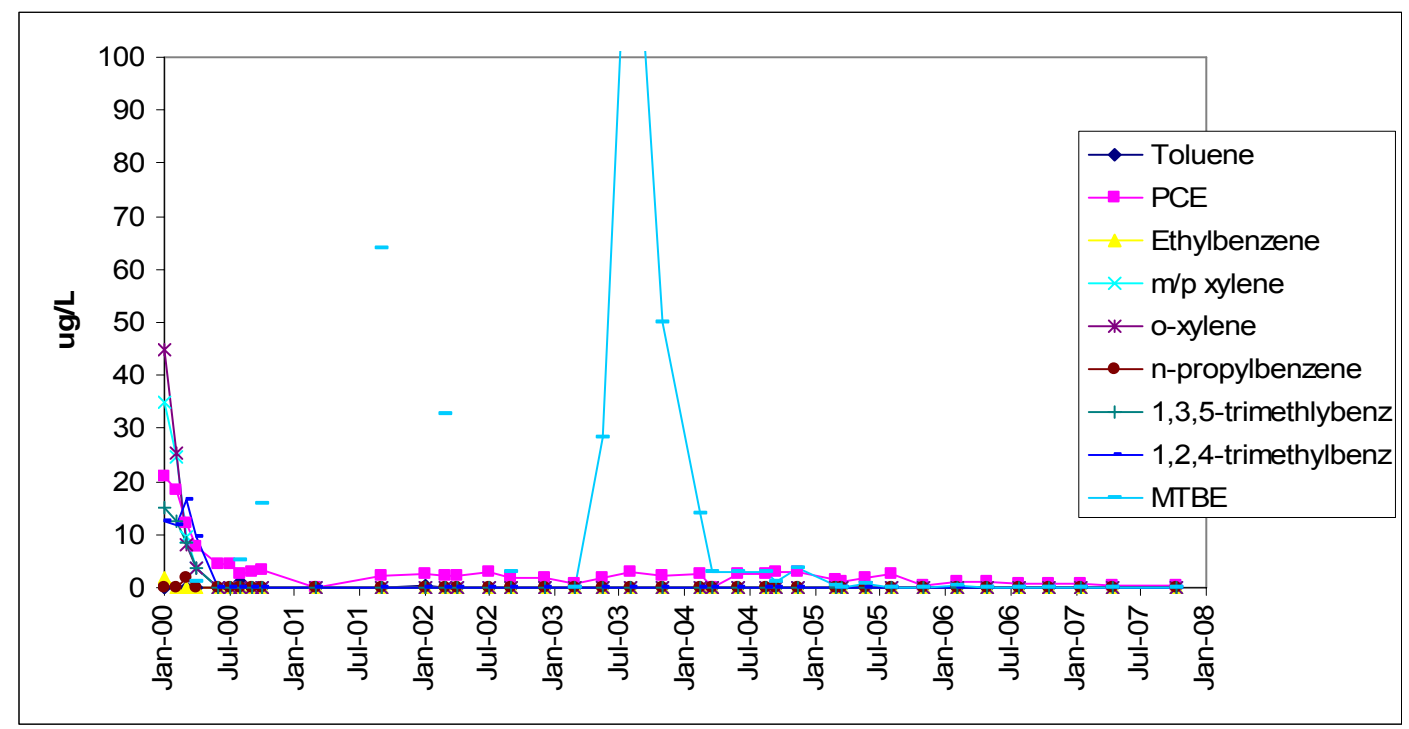

\subsection{Major Petroleum Facility Area}

The Major Petroleum Facility (MPF) is the holding area for fuel oil used at the Central Steam Facility (CSF). The fuel oil is held in a network of seven aboveground storage tanks, which have a combined capacity of up to 1.7 million gallons of No. 6 fuel oil and 60,000 gallons of No. 2 fuel oil. The tanks are connected to the CSF by aboveground pipelines that have secondary containment and leak detection devices. All of the fuel storage tanks are positioned in bermed containment areas that have a capacity to hold $>110$ percent of the volume of the largest tank located there. The bermed areas have bentonite clay liners consisting of either Environmat ${ }^{\mathrm{TM}}$ (bentonite clay sandwiched between geotextile material) or bentonite clay mixed into the native soil to form an impervious soil/clay layer. As of December 1996, all fuel-unloading operations were consolidated to one centralized building that has secondary containment features. The MPF is operated under NYSDEC Permit \#1-1700 and, as required by law, a Spill Prevention and Countermeasures (SPCC) Plan and a Facility Response Plan have been developed for the facility. Groundwater quality near the MPF has been impacted by several oil and solvent spills: 1) the 1977 fuel oil/solvent spill east of the MPF that was remediated under the Interagency Agreement (see Section 3.3.1); and 2) solvent spills near the CSF.

\subsubsection{MPF Groundwater Monitoring}

Well Network

Eight shallow Upper Glacial aquifer wells are used to confirm that the engineered and institutional controls in place are effective in preventing contamination of the aquifer (Figure 4-25).

\section{Sampling Frequency and Analysis}

Groundwater contaminants from the fuel oil products stored at the MPF can travel both as free product and in dissolved form with advective groundwater flow. Historically, the Special License Conditions for the MPF required semiannual sampling for SVOCs and monthly monitoring for floating petroleum. Samples were also periodically tested for VOCs as part of the Environmental Surveillance Program. In 2002, NYSDEC expanded the required list of routine analyses to include VOCs, including testing for MTBE (Table 1-6). MTBE was a common gasoline additive until January 2004, and it was 
occasionally introduced to fuel oil as a contaminant during the storage and transportation process. Analytical results for 2007 are presented in Appendix D.

\subsubsection{MPF Monitoring Well Results}

BNL sampled the MPF wells in April and October 2007. The wells were also tested monthly for the presence of floating petroleum. The samples were tested for SVOCs and VOCs. As in the past, no SVOCs were detected, and no floating product was observed. Trace to low levels of TCA (up to 0.8 $\mu \mathrm{g} / \mathrm{L}$ ), tetrachloroethylene (up to $6.5 \mu \mathrm{g} / \mathrm{L}$ ), and chloroform (up to $1.2 \mu \mathrm{g} / \mathrm{L}$ ) continued to be detected in upgradient well 075-25. These compounds are related to historical spills near building 650. As in past years, several solvents continued to be detected in downgradient well 076-380. Trace levels of TCA and TCE were detected $(<1 \mu \mathrm{g} / \mathrm{L})$, and PCE was detected at concentrations up to $7.9 \mu \mathrm{g} / \mathrm{L}$, slightly above NYS AWQS of $5 \mu \mathrm{g} / \mathrm{L}$. Levels of the PCE breakdown product trans-1,2-dichloroethene dropped to nondetectable levels by the end of 2005, and remained at non-detectable levels during all of 2006 and 2007 (Figure 4-26). These solvents are believed to have originated from documented historical spills near the CSF building; their presence in groundwater is not the result of recent CSF or MPF operations.

\subsubsection{MPF Monitoring Program Evaluation}

Groundwater monitoring at the MPF continues to show that fuel storage and distribution operations are not impacting groundwater quality. The low levels of PCE and TCE detected in the groundwater originated from historical solvent spills near Building 610. The historical nature of this contamination is supported by: 1) degreasing agents such as PCE have not been used at the CSF in many years, 2) PCE has been detected in several MPF area wells since the early 1990s, and 3) trans-1,2-dichloroethene is a breakdown product of PCE. A number of historical spill sites near the CSF were identified in the late 1990 s, and the contaminated soil was excavated in accordance with regulatory requirements. For 2008, monitoring will continue as required by the NYS operating permit.

Figure 4-26.

VOC Concentrations Downgradient of the Major Petroleum Facility, in Well 076-380.

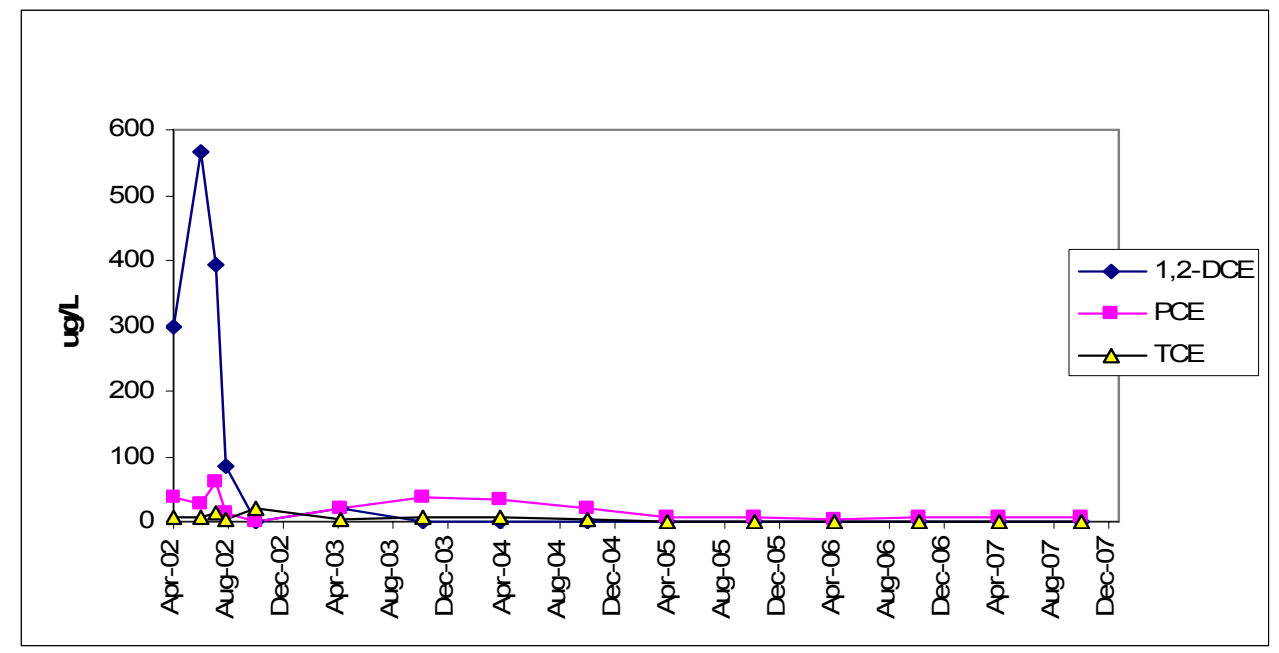

\subsection{Waste Management Facility (WMF)}

The Waste Management Facility (WMF) is designed to safely handle, repackage, and temporarily store BNL-derived wastes prior to shipment to off-site disposal or treatment facilities. The WMF is a 
state-of-the-art facility, with administrative and engineered controls that meet all applicable federal, state, and local environmental protection requirements. The WMF consists of four buildings: the Operations Building, Reclamation Building (for radioactive waste), RCRA Waste Building, and the Mixed Waste Building.

Groundwater monitoring is a requirement of the RCRA Part B permit issued for WMF operations. The groundwater monitoring program for the WMF is designed to supplement the engineered and institutional controls by providing additional means of detecting potential contaminant releases from the facility. Because of the close proximity of the WMF to BNL potable supply wells 11 and 12, it is imperative that the engineered and institutional controls implemented at the WMF are effective in ensuring that waste handling operations do not degrade the quality of the soil and groundwater in this area.

\subsubsection{WMF Groundwater Monitoring}

Well Network

Eight wells are used to monitor groundwater quality near the WMF (Figure 4-27). Three wells are used to assess background water quality, and five wells are positioned downgradient of the three waste handling and storage buildings. When the monitoring wells were originally installed in the mid 1990s, groundwater flow directions in the WMF area were predominantly to the north-northeast; with flow directions being strongly influenced by a groundwater mound below Basin HO (located immediately south of the WMF) and water pumpage from supply wells 11 and 12 (located immediately to the north). Subsequent water conservation efforts have resulted in significant reductions in water supply pumpage from wells 11 and 12 and reduced recharge at Basin HO. When supply wells 11 and 12 are not in operation, the groundwater flow direction in the WMF area is predominantly to the southeast. To effectively use the existing monitoring wells, supply wells 11 and 12 are operated continuously for a 2week period prior to sampling the monitoring wells, in order to establish the necessary northward flow patterns. A complete set of monitoring data and groundwater flow maps are provided in the 2007 Groundwater Monitoring Report for the Waste Management Facility (BNL 2008c).

\section{Sampling Frequency and Analysis}

During 2007, the WMF wells were sampled in February and August. Groundwater samples were analyzed twice for VOCs, tritium, gamma spectroscopy, gross alpha, and gross beta, and one time for metals and anions (e.g., chlorides, sulfates, and nitrates) (Table 1-6). Analytical results for 2007 are presented in Appendix D.

\subsubsection{WMF Monitoring Well Results}

\section{Radiological Analyses}

Gross alpha and beta concentrations in samples from both upgradient and downgradient monitoring wells are consistent with background concentrations, and no BNL-related gamma-emitting radionuclides were identified. As in past years, a trace level of tritium $(660 \mathrm{pCi} / \mathrm{L})$ was detected in Reclamation Building area monitoring well 056-23 (Figure 4-28). In October 2007, a trace level of tritium $(700 \mathrm{pCi} / \mathrm{L})$ was detected in nearby supply well 12 . 
Figure 4-28.

Tritium Concentration Trends in Well 056-23,

Downgradient of Waste Management Facility.

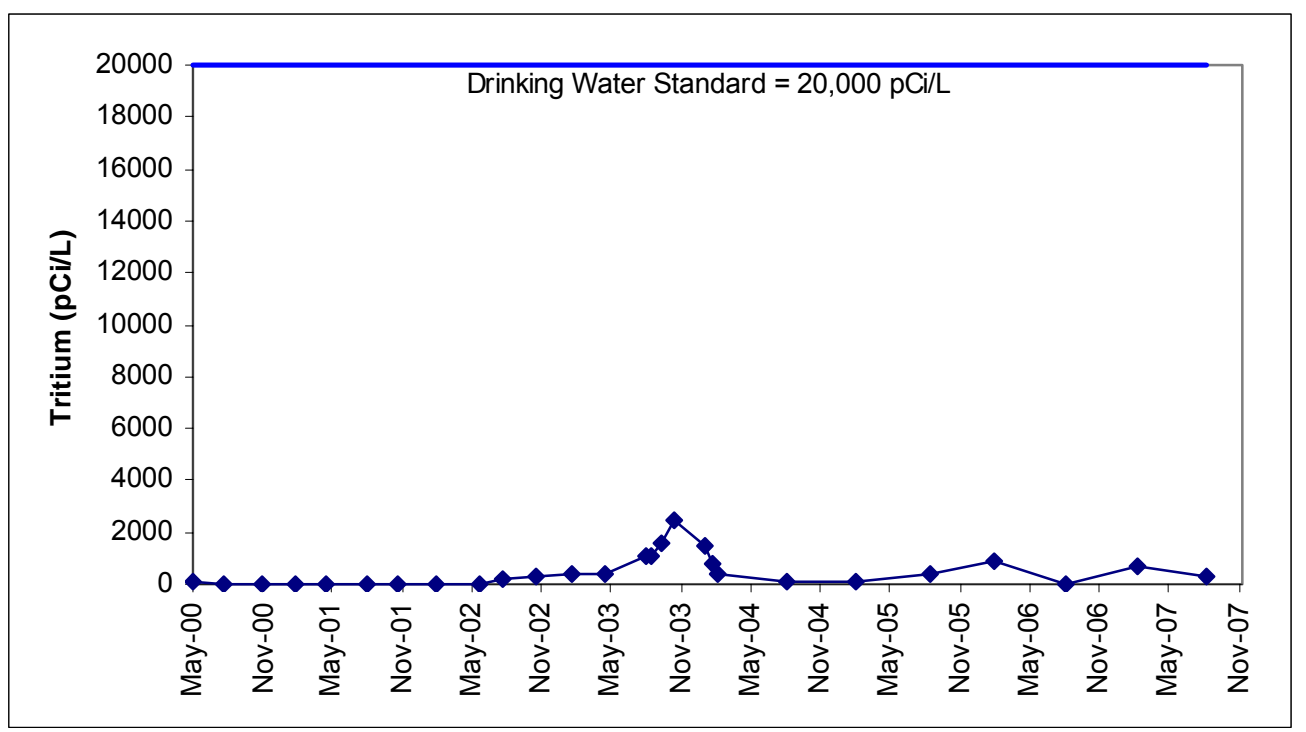

\section{Nonradiological Analyses}

All anions (chlorides, sulfates, and nitrates) and most metals concentrations were below applicable NYS AWQS. As in past years, sodium continued to be detected above the $20 \mathrm{mg} / \mathrm{L} \mathrm{NYS} \mathrm{AWQS} \mathrm{in} \mathrm{a}$ number of upgradient and downgradient wells, with a maximum concentration of $32 \mathrm{mg} / \mathrm{L}$ detected in downgradient well 056-22. The elevated sodium concentrations are likely due to road salting operations. During 2007, no VOCs were detected at concentrations above NYS AWQS. Low levels of chloroform continued to be detected in many of the WMF wells, with the highest level of $1.3 \mu \mathrm{g} / \mathrm{L}$ detected in upgradient well 066-83, which is located close to recharge basin HO. Because this basin receives secondary cooling water that was supplied from the potable water system, it is likely that the chloroform detected in the WMF monitoring wells is a chlorination by-product. A trace level of TCA $(0.13 \mu \mathrm{g} / \mathrm{L})$ was detected in downgradient well 066-84. The NYS AWQS for TCA and chloroform are 5 $\mu \mathrm{g} / \mathrm{L}$ and $7 \mu \mathrm{g} / \mathrm{L}$, respectively.

\subsubsection{WMF Groundwater Monitoring Program Evaluation}

Groundwater monitoring results for 2007 were consistent with previous years' monitoring, and continued to show that WMF operations were not affecting groundwater quality. There were no outdoor or indoor spills at the facility that could have impacted soil or groundwater quality. Except for sodium detected in one well, all chemical and radionuclide concentrations were below NYS AWQS or DWS. Although there continue to be periodic detections of trace levels of tritium in the groundwater, a thorough review of Waste Management operations suggests that the tritium was not released from the WMF.

For 2008, monitoring will continue as required by the RCRA Part B Permit. In late 2007, five new downgradient groundwater monitoring wells were installed at the WMF. The new wells were positioned downgradient of the buildings based on the current southeast groundwater flow direction. As a result, supply wells 11 and 12 will not have to be operated continuously for a two-week period prior to sampling the monitoring wells. These new wells will be incorporated into the monitoring program starting in February 2008. The older wells will be maintained for the collection of water level data, and the possible future collection of groundwater samples. 


\subsection{Building 801}

In early December 2001, approximately 8,000 gallons of stormwater seeped into the basement of Building 801. Analysis of the floodwater indicated that the water contained Cs-137 (up to $784 \mathrm{pCi} / \mathrm{L}$ ), $\mathrm{Sr}-90(594 \mathrm{pCi} / \mathrm{L})$, and tritium $(25,000 \mathrm{pCi} / \mathrm{L})$. It is believed that the floodwater became contaminated when it came into contact with the basement floor, which contains significant residual contamination from historical radiological spills. When the floodwater was pumped from the basement on March 8, 2002, approximately 4,950 gallons of contaminated water were removed. Taking into account possible losses due to evaporation, estimates were that between 1,350 and 2,750 gallons of contaminated floodwater might have seeped into the soil below Building 801. To evaluate the potential impact to groundwater quality of such a release, BNL installed a new surveillance well immediately downgradient of the building and monitored several nearby wells.

\subsubsection{Building 801 Groundwater Monitoring}

\section{Well Network}

From May through October 2002, three existing downgradient wells were sampled. Well 065-169 is approximately 10 feet south of Building 801, whereas wells 065-37 and 065-170 are approximately 80 feet downgradient of the building (see Figure 3.2.15). These wells were installed in 1999 to monitor historical releases from the Waste Concentration Facility and the former Pile Fan Sump area. Well 06537 is screened close to the water table, whereas wells 065-169 and 065-170 are screened approximately 10 feet below the water table. Because well $065-37$ is not ideally screened at the water table to properly monitor a nearby contaminant source area, a new shallower well, 065-325, was installed in early October 2002.

\section{Sampling Frequency and Analysis}

During 2007, Building 801 monitoring well 065-325 was sampled two times under the Environmental Surveillance Program (Table 1-6). Analytical results for 2007 are presented in Appendix D. The samples were analyzed for gross alpha, gross beta, Sr-90, Cs-137, and tritium. Monitoring wells 065-37, -169 , and -170 were sampled one to two times under the LTRA program, and the samples were analyzed for Sr-90 and Cs-137 (Table 1-5).

\subsubsection{Building 801 Monitoring Well Results}

The April and October 2007 samples from well 065-325 had Sr-90 concentrations of $56 \mathrm{pCi} / \mathrm{L}$ and $31.7 \mathrm{pCi} / \mathrm{L}$, respectively (Figure 4-29). Cs-137 was not detected in any of the samples. Sr-90 concentrations in the slightly deeper well $065-37$ increased from $21.3 \mathrm{pCi} / \mathrm{L}$ in 2006 to $73.3 \mathrm{pCi} / \mathrm{L}$ in October 2007. Only low levels of Sr-90 were detected in deeper wells 065-169 and 065-170, with maximum concentrations of $1.3 \mathrm{pCi} / \mathrm{L}$ and $1.2 \mathrm{pCi} / \mathrm{L}$, respectively.

\subsubsection{Building 801 Monitoring Program Evaluation}

Sr-90 concentrations in samples collected during 2007 from shallow groundwater well 065-325 are consistent with pre-December 2001 values. Additionally, Cs-137 has not been detected in any of the groundwater samples. It is estimated that it could take approximately 3 to 8 years for Sr-90, and approximately 100 years for Cs-137, from the December 2001 Building 801 floodwater release to migrate to the closest downgradient well (065-325). Furthermore, detecting any new groundwater impacts from this release will be difficult to identify, as the local groundwater is already contaminated with radioactivity from legacy releases from Building 801 or the nearby former Pile Fan Sump (see Section 3.2.15). 
The monitoring frequency for well $065-325$ for 2008 will continue to be semiannual, and the monitoring will be conducted as close as possible with planned semiannual sampling of wells 065-37, 065-169, and 065-170 by the LTRA program.

Figure 4-29.

Sr-90 Concentration Trends in Downgradient Wells 065-37 and 065-325 at Building 801.

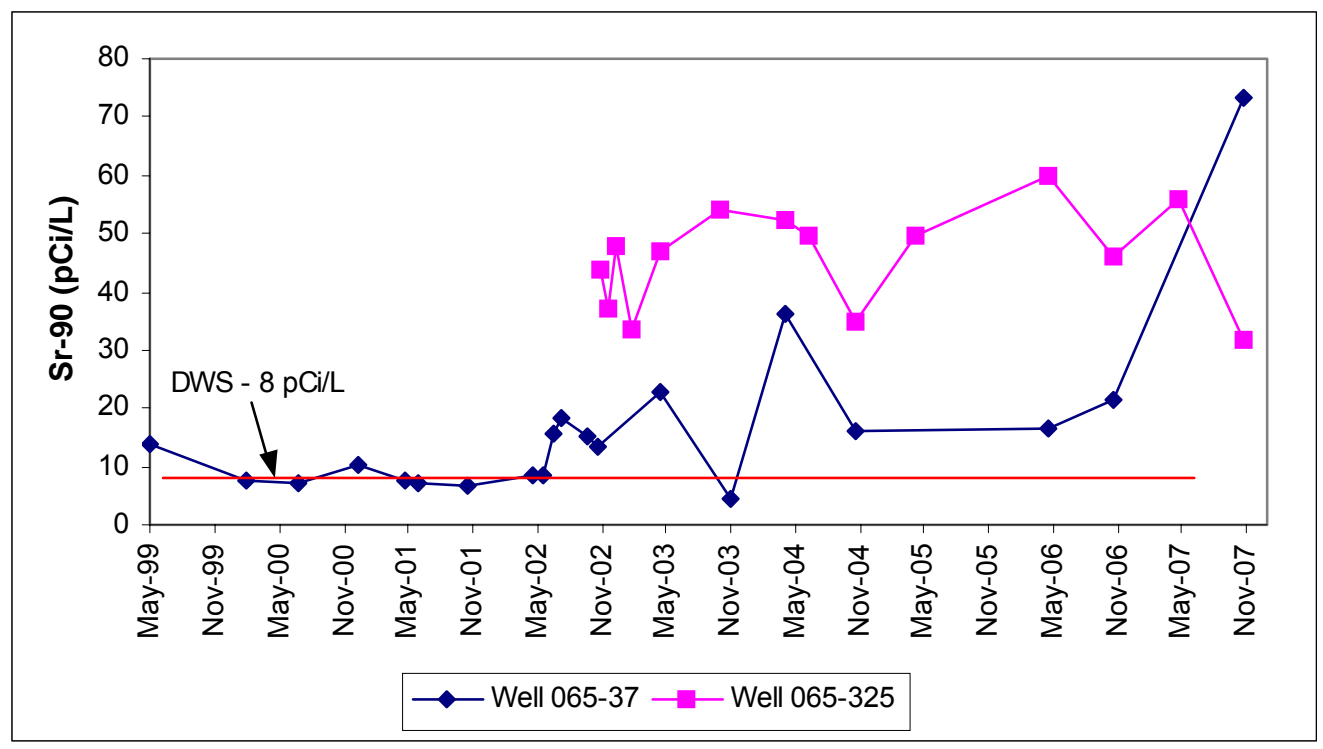


SER VOLUME II: GROUNDWATER STATUS REPORT

This page intentionally left blank. 


\subsection{SUMMARY OF RECOMMENDATIONS}

This section, a summary of all of the recommendations from Sections 3 and 4, is provided as a quick reference. The recommendations are sequenced as they appear in Sections 3 and 4.

\subsection{OU I South Boundary Pump and Treat System}

The following are recommendations for the OU I South Boundary Pump and Treat System and groundwater monitoring program:

- Based on TVOC concentration increases in upgradient plume core well 107-40 the leading edge of the high concentration segment of the VOC plume is approaching the south boundary and should arrive in the near future. As a result, full-time operation of extraction wells EW-1 and EW2 will continue until further notice.

- Install a vertical profile well approximately 500 feet north of well 107-40 along the Princeton Avenue Firebreak Road to locate the centerline of the VOC high concentration slug. Install a monitoring well if TVOCs are greater than $50 \mu \mathrm{g} / \mathrm{L}$.

- The routine operation and maintenance monitoring frequency implemented in the fourth quarter of 2004 should be continued. Plume core and perimeter wells are monitored on a semiannual frequency. Sentinel and bypass wells are sampled at a quarterly frequency. Maintain a quarterly sampling frequency for well 107-40 to monitor the hot spot.

- Reduce frequency of Sr-90 sampling for wells 107-34, 107-35, 108-43, 108-44, 115-41, and 11542 from quarterly to semi-annually, due to the absence of Sr-90 in these wells. Drop Sr-90 analysis for all other off-site wells due to absence of Sr-90. Reduce tritium sampling in bypass wells 115-41 and 115-42 from quarterly to semi-annually.

\subsection{Carbon Tetrachloride Pump and Treat System}

The following are recommendations for the OU III Carbon Tetrachloride Groundwater Remediation System and monitoring program:

- Maintain the system in standby mode. If significant concentrations of carbon tetrachloride are detected in monitoring or extraction wells, the system will be turned on.

- Move monitoring well 095-92 to the Middle Road Pump and Treat System well network.

- Perform two to four temporary wells in the center of the plume north of extraction well EW-15 and south of well 85-17. These data will be used to help perform the recommended modeling evaluation below.

- Perform groundwater modeling to evaluate if the remaining levels of contaminants in this area can meet the cleanup objectives through natural attenuation. If it can be demonstrated by the model that the current levels will achieve these objectives, then a petition for closure of this system will be submitted to the regulators.

\subsection{Building 96 Air Stripping System}

The following are recommendations for the OU III Building 96 groundwater remediation system and monitoring program:

- In the spring of 2008 implement the modification to recirculation well RTW-1 to work as a 
pumping well with $\mathrm{Cr}(\mathrm{VI})$ treatment, and discharge to the nearby surface drainage culvert. In addition to the existing air stripping treatment for VOCs, this will involve the installation of ionexchange treatment vessels for $\mathrm{Cr}(\mathrm{VI})$, and running a discharge line to the culvert about 300 feet away. Effluent sampling frequency will be performed as per the approved SPDES equivalency permit. Once $\mathrm{Cr}(\mathrm{VI})$ concentrations drop below allowable discharge levels and all monitoring wells in the vicinity of the pumping well are below these levels, treatment for chromium will be eliminated.

- Continue monitoring well sampling at the current quarterly frequency, and add total $\mathrm{Cr}$ and $\mathrm{Cr}(\mathrm{VI})$ to the analysis.

- Maintain operation of downgradient recirculation wells RTW-2, RTW-3, and RTW-4. Continue operation until TVOC concentrations $<50 \mu \mathrm{g} / \mathrm{L}$ are seen in the recirculation wells' influent and adjacent monitoring wells. Maintain a monthly sampling frequency of the influent and effluent for each well when they are operating. When in standby mode reduce the sampling to quarterly.

- In the spring of 2008, perform soil borings at the location of the highest VOC contamination and analyze the silt zone soil cores for VOCs. Geophysical logs and soil cores will be obtained to determine detailed lithology. These data will aid in precisely defining the nature and extent of the source area, which is critical to determine the most cost-effective remedial alternative for this area. In addition, one well will be installed to help evaluate the effectiveness of using soil vapor extraction technology in this area.

- Following the collection of the source area analytical and geological data, complete an evaluation of alternative methods for remediating the contamination in the silt zone upgradient of extraction well RTW-1. This evaluation will include excavation of the source area, adding an additional extraction well in the source area, and evaluating other remedial technologies. The evaluation will be prepared in 2008 .

- Following the determination of the remedial action to address the VOCs in the silt zone, update the project DQOs.

- Add a core monitoring well west of well 095-172 to determine VOC concentrations just upgradient of RTW-2.

\subsection{Middle Road Pump and Treat System}

The following recommendations are made for the OU III Middle Road Pump and Treat System and groundwater monitoring program:

- Maintain the routine operation and maintenance monitoring frequency that began in 2003.

- Maintain extraction wells RW-4, RW-5, and RW-6 in standby mode during 2008. Restart the wells if extraction or monitoring well data indicate that TVOC concentrations exceed the $50 \mu \mathrm{g} / \mathrm{L}$ capture goal.

- Install a temporary well about 100 feet to the west of well 113-09 to confirm the western edge of the OU III plume in this area. Based on the results of this temporary well, additional sampling or another permanent monitoring well may be required.

- Install a temporary well several hundred feet upgradient of RW-1 to locate a permanent well(s) in this area to provide for monitoring of VOCs migrating toward RW-1.

\subsection{OU III South Boundary Pump and Treat System}

The following are recommendations for the OU III South Boundary Pump and Treat System and 
groundwater monitoring program:

- Maintain the routine operations and maintenance monitoring frequency that began in 2003.

- Maintain wells EW-6, EW-7, EW-8 and EW-12 in standby mode. All extraction wells will continue to be sampled on a quarterly basis. The wells will be restarted if extraction or monitoring well data indicate TVOC concentrations exceed the $50 \mu \mathrm{g} / \mathrm{L}$ capture goal.

\subsection{Western South Boundary Pump and Treat System}

The following are recommendations for the OU III Western South Boundary Treatment System and groundwater monitoring program:

- Based on increasing TVOC concentrations (i.e., $>20 \mu \mathrm{g} / \mathrm{L}$ ) in core well 126-11 in 2007, return extraction well WSB-1 to on full-time operation. Continue pulse pumping WSB-2 at the schedule of one month on and two months off. This process will continue and any changes to the VOC concentrations in the influent and the monitoring wells will be evaluated.

- If any of the three bypass detection wells starts showing increasing trends, the need to take further action will be evaluated.

- As there have been no detections of VOCs exceeding NYS AWQS for plume perimeter wells 119-03 and 125-01 since they were installed in 2002, VOC analysis will be discontinued. These wells monitor the groundwater quality in the vicinity of the OU III Western South Boundary recharge basin. Also, since background well 124-02 has not had any detections of VOC above the NYS AWQS, this parameter will be dropped.

- Maintain the routine O\&M monitoring frequency that began in 2005.

\subsection{Industrial Park In-Well Air Stripping System}

The following are recommendations for the Industrial Park In-Well Air Stripping System and groundwater monitoring program:

- The current routine operations and maintenance monitoring frequency will be maintained during 2008.

- The system will continue operations at 60 gpm per well except for well UVB-1, which is to remain in a standby mode. It is recommended that well UVB-4 be placed back in operation to address VOCs being observed in monitoring well 000-262, which is located between UVB-4 and UVB-5. Monthly recovery well sampling will continue, and if TVOC concentrations greater than $50 \mu \mathrm{g} / \mathrm{L}$ are observed, well UVB-1 will be restarted.

\subsection{Industrial Park East Pump and Treat System}

The following are recommendations for the Industrial Park East Pump and Treat System and groundwater monitoring program:

- Continue pulse pumping for one year and if in November 2008 no rebound is seen (i.e., TVOC concentrations exceeding $50 \mu \mathrm{g} / \mathrm{L}$ ) in extraction or monitoring wells, then petition for shutdown of this system.

\subsection{North Street Pump and Treat System}

The following is recommended for the North Street Pump and Treat System and groundwater monitoring program: 
- Maintain the operations and maintenance sampling frequency for monitoring wells initiated in 2006.

- Eliminate the Sr-90, gamma spectroscopy, and gross alpha/beta analysis for monitoring well samples due to the absence of any detections for radionuclides over the past several years.

\subsection{North Street East Pump and Treat System}

The following is recommended for the North Street East Pump and Treat System and groundwater monitoring program:

- Maintain the routine operations and maintenance monitoring frequency for the monitoring wells that began in third quarter 2006. However, plume core wells 000-481, 000-482, 000-483, and 000-484 should be maintained at the quarterly sampling frequency since they are immediately upgradient of extraction well NSE-2.

- Delete Sr-90, gross alpha/beta, and gamma spectroscopy from the analyte, list since there have been no detections above the standards.

- Continue pulse pumping of both extraction wells, since the system influent concentrations have remained very low over the past two years and all of the monitoring wells are already below the capture goal of $50 \mu \mathrm{g} / \mathrm{L}$ TVOC. The pulse pumping consists of having the system on for one month, then off in standby mode for the next month. The extraction well sampling frequency will change from a monthly schedule to only sampled during the months the system is in operation (every other month) If concentrations above the capture goal of $50 \mu \mathrm{g} / \mathrm{L} \mathrm{TVOCs}$ are observed in either the core monitoring wells or the extraction wells, the well(s) will be put back into full-time operation. If no rebound is observed in 2008, then petition for shutdown of the system.

- As of the first quarter 2008, lower the pump location four feet in monitor wells 000-482, 000-483, and 000-484 to obtain data from a slightly deeper portion of the aquifer.

\subsection{LIPA/Airport Pump and Treat System}

The following are recommendations for the LIPA/Airport Groundwater Treatment System and groundwater monitoring program:

- The extraction well sampling will be reduced from monthly to quarterly, except for the LIPA well EW-4L and Airport wells RTW-1A and 6A.

- Continue the airport extraction wells pulse-pumping of one week per month except for wells RTW-1A and 6A, which will continue with full-time operations. Pump well RTW-3A full time to intercept any VOCs migrating from the area of upgradient wells 800-99 and 800-106. If concentrations above the capture goal of $10 \mu \mathrm{g} / \mathrm{L}$ TVOCs are observed in any of the other extraction wells or the monitoring wells adjacent to them, the well(s) will be put back into fulltime operation.

- Maintain LIPA wells EW-1L and EW-3L in standby mode. These extraction wells will be restarted if TVOC concentrations rebound in either the plume core monitoring wells or the extraction wells, greater than the $50 \mu \mathrm{g} / \mathrm{L}$ capture goal.

- Change well 800-96 from monthly to a quarterly sampling schedule since the new extraction well, EW-6A, is in operation.

- Install a temporary well 200 feet to the west of well RTW-3A and followup with permanent monitoring well(s). This will be done to confirm the location of the western edge of the plume currently seen in upgradient monitoring wells 800-90 and 800-92. 


\subsection{Magothy Monitoring}

No changes to the monitoring program are warranted at this time.

\subsection{Central Monitoring}

No changes to the monitoring program are warranted at this time.

\subsection{Off-Site Monitoring}

No changes to the monitoring program are warranted at this time.

\subsection{South Boundary Radionuclide Monitoring Program}

No changes to the monitoring program are warranted at this time.

\subsection{BGRR/WCF Strontium-90 Treatment System}

The following are recommendations for the BGRR/WCF groundwater treatment system and monitoring program:

- Install additional temporary wells during the fourth quarter of 2008 in the area of the high Sr-90 detected in late 2007 from the WCF plume near the HFBR. Also, continue to analyze select temporary wells for Sr-90 during their installation just near the HFBR in 2008 for the g-2 tritium plume. These data will be important both to track the hot spot Sr-90 concentrations as well as to determine when the high concentration portion of the g-2 tritium plume has migrated south of this area. This will allow for additional Sr-90 extraction and treatment. These are necessary to obtain sufficient data to accurately define the extent of the high concentration Sr-90 slug and design additional extraction wells.

- Install additional Sr-90 extraction wells to address the Sr-90 hot spot identified in the WCF plume. The modification to the existing Sr-90 treatment system will consist of several new extraction wells. The location and exact number of wells will depend on the distribution of the hot spot following the departure/attenuation of the g-2 tritium slug from this area. It is currently estimated that the modification will be implemented in late 2009/early 2010. Groundwater characterization over the next couple of years will determine the implementation time.

- Supplement existing sentinel monitoring wells along Temple Place as necessary to track the leading edge of the WCF Sr-90 plume. This will be determined based on the results of temporary wells to be installed during the second quarter of 2008.

- For the BGRR plume, install temporary wells near 075-670 and 075-671 to determine the width of the downgradient portion of the plume.

- Raise the pump in BGRR plume core well 075-664 four feet to evaluate Sr-90 concentrations in a shallower portion of the aquifer.

- The monitoring well sampling frequency will be implemented in a phased approach starting in 2009:

- Change the frequency from startup (semi-annual) to the operations and maintenance phase (annually) for the BGRR and PFS plumes.

- Due to the additional extraction wells planned to be installed for the WCF plume in 2009/2010, the monitoring well frequency for this plume should remain at the startup phase. 
- Maintain the southerly groundwater flow direction by managing the pumping of the BNL supply wells, via the oversight of the BNL Water and Sanitary Planning Committee.

\subsection{Chemical/Animal Holes Strontium-90 Treatment System}

The following are the $\mathrm{r}$ ecommendations for the $\mathrm{Ch}$ emical/Animal Holes Strontium -90 Treat ment System and groundwater monitoring program:

- Continue to operate extraction wells EW-2 and EW-3 between 5 to $7 \mathrm{gpm}$.

- Due to the low influent concentrations, implement pulse pumping of EW-1 (cycle of 1 month on, $1 \mathrm{~m}$ onth off ) beginni ng in Januar y 2 008. If conc entrations in this extraction well incr ease significantly, then EW-1 will be put back into full-time operation

- Due to the increas e of Sr- 90 concentrations in monitoring well 10 6-16, install tem porary wells upgradient of this location to verify that there is n o continuing source of contam ination. This work will be performed in mid 2008. Based on a revi ew of the dat a, a monitoring well may also be installed.

- Maintain the operations and $\mathrm{m}$ aintenance phase monitoring well sa mpling frequency started in 2007. Change the frequency for the fiv e new monitoring wells from quarterly to sem i-annually. Also, change the sampling frequency for well 106-99 from annual to semi-annual.

- Starting in the third quarter of 2008, drop VOC analysis from the monitoring wells, since VOCs have not been detected above the DWS since 2004.

- Transfer monitoring wells $106-20,106-21,106-43,106-44,106-45$, and 106-64 to the For mer Landfill groundwater monitoring progr am. The dat a will b e discussed in th e annual Landfill Monitoring Report.

\subsection{HFBR Tritium Pump and Recharge System}

The following are reco mmendations for the HF BR tritium P ump and Recharge Sy stem and monitoring program:

- Continue the monitoring well sampling schedule initiated in 2006.

- Continue to i nstall and sam ple tem porary wells twice per y ear over the next several y ears to characterize the location of the high tritium concen tration area, and results will be communicated to the regulators via the IAG conference call and quarterly/annual reports.

- Continue operating EW-16 and EW-11 in 2008. Mo nitor tritium concentrations in EW-16 on a monthly basis.

- The pump and recharge well(s) will be operated until the tritium concentrations in the wells in the area of Weaver Drive to the new ex traction well drop below $20,000 \mathrm{pCi} / \mathrm{L}$. The estimated operational duration of 2 to 4 years is based on the length of the high concentration area slug and the time it would take to be completely captured by the new extraction well. The decision to turn the wells back to standby will be based on; 1) concentrations of tritium decreasing to less than $20,000 \mathrm{pCi} / \mathrm{L}$ in the $\mathrm{m}$ onitoring wells at Weaver Drive as well as the extraction wells, and 2) verification that the new extraction well has capture $d$ concentrations of tritium in this area greater than $20,000 \mathrm{pCi} / \mathrm{L}$. This decision to turn the wells back to stan dby will be supported wit $\mathrm{h}$ data from additional permanent and temporary wells, as needed. 


\subsection{OU IV AS/SVE System Post Closure Monitoring}

The following are recommendations for the OU IV AS/SVE Post Closure Monitoring program:

- Reduce frequency of sampling from semiannual to annual due to the lack of detections of VOCs and SVOCs.

\subsection{Building 650 (Sump Outfall) Strontium-90 Monitoring}

The following recommendation is made for the Build ing 650 Strontium-90 Groundwater Monitoring Program:

- Reduce the sampling frequency for monitoring wells 076-25, 076-26, 076-314, 076-317, 076-373, 066-189, and 066-190 to annual. There have been no significant detections of Sr-90 in these wells over the past several years. Several of these wells (076-314, 066-189, and 066-190) are no longer downgradient of the source area due to cha nges in groun dwater flow resulting from the diminished water table mounding at Basin HO. The sam pling frequencies can be incr eased if warranted by future changes in groundwater flow conditions.

\subsection{Operable Unit V}

The following recommendation is made for the OU V plume groundwater monitoring program:

- Due to the low concentrations of perchlorate being detected, reduce the frequency of this analysis from semi-annual to annual for the eight monitoring wells.

\subsection{Operable Unit VI Pump and Treat System}

The following reco mmendations are made for th e OU VI E DB Pu mp a nd Treat Syste $\mathrm{m}$ and groundwater monitoring program:

- Add another plum e bypass well east of well 000-508 and slightly deeper, to verify that EDB i s being captured by extraction well EW-2E.

- Maintain the routine operation and maintenance monitoring frequency that began in third-quarter 2006.

- Since there were no detections above the DW S for EDB in well 000- 498 for 2006 and 2007 , change the sa mpling frequency for this well fro $m$ quarterly (s ystem start-up phase) to se miannually (O\&M phase). Also change the frequency for on-site wells 058-02, 089-13, 089-14, 09906, 099-10, 099-11, 100-12, 100-13, and 100-14 to annual, since there have been no detections of EDB above the federal DWS since mid 2003.

\subsection{Site Background Monitoring}

No changes to the monitoring program are warranted at this time.

\subsection{Current Landfill Groundwater Monitoring}

No changes to the monitoring program are warranted at this time.

\subsection{Former Landfill Groundwater Monitoring}

No changes to the monitoring program are warranted at this time. 


\subsection{Alternating Gradient Synchrotron (AGS) Complex}

In accordance with g-2/BLIP/UST ROD requirements, BNL will continue to monitor groundwater quality downgradient of $\mathrm{g}-2$ source area until the source is no longer a threat to groundwater quality. Furthermore, the downgradient sections of the g-2 plume will be monitored until the plume attenuates to less than the $20,000 \mathrm{pCi} / \mathrm{L}$ DWS. For 2008 , BNL will continue to monitor the $\mathrm{g}-2$ source area wells on a quarterly basis. BNL will also continue to track the downgradient sections of the tritium plume using a combination of permanent and temporary wells.

The remaining areas of the AGS Complex will continue to be monitored on an annual basis.

\subsection{Brookhaven Linac Isotope Producer Facility}

In accordance with g-2/BLIP/UST ROD requirements, BNL will continue to monitor groundwater quality downgradient of BLIP until the source is no longer a threat to groundwater quality. For 2008, BNL will continue to monitor the BLIP wells on a quarterly basis.

\subsection{Relativistic Heavy Ion Collider Facility}

For 2008, groundwater samples will continue to be collected on a semi-annual basis.

\subsection{Brookhaven Medical Research Reactor Facility}

Starting in 2007, BNL reduced the monitoring frequency for the BMRR wells to once every two years. The next set of samples will be collected in 2008 .

\subsection{Sewage Treatment Plant}

No changes to the STP groundwater monitoring program are proposed for 2008.

\subsection{Motor Pool Maintenance Area}

No changes to the Motor Pool groundwater monitoring program are proposed for 2008.

\subsection{On-Site Service Station}

No changes to the Service Station groundwater monitoring program are proposed for 2008.

\subsection{Major Petroleum Facility Area}

No changes to the Service Station groundwater monitoring program are proposed for 2008.

\subsection{Waste Management Facility}

During 2008, groundwater monitoring at the WMF will be conducted in accordance with the RCRA Part B Permit. The five new downgradient groundwater monitoring wells installed at the WMF in late 2007 will be incorporated into the monitoring program starting in February 2008.

\subsection{Building 801}

The monitoring frequency for well $065-325$ for 2008 will continue to be semi-annual, and the monitoring will be conducted as close as possible with planned semi-annual sampling of wells 065- 
CHAPTER 5: SUMMARY OF RECOMMENDATIONS

37, 065-169, and 065-170 by the LTRA Program. 
SER VOLUME II: GROUNDWATER STATUS REPORT

This page intentionally left blank. 


\section{REFERENCE LIST}

Arcadis Ge raghty \& Mill er. 2003 . Magothy Aquifer Characterization Report, Broo khaven National Laboratory, Upton, NY. May 2003.

Aronson, D.A., and Seaburn, G.E. 1974. Appraisal of the operating efficiency of recharge basins on Long Island, NY in 1969. USGS Supply Paper 2001-D.

BNL 1998. Operation and Maintenance Plan for the High Flux Beam Reactor Tritium Plume Pump and Recharge System Brookhaven National Laboratory, Upton, NY, May 1998.

BNL. 2000a. Carbon Tetrachloride Groundwater Removal Action Operations and Maintenance Manual. Brookhaven National Laboratory, Upton, NY. January 26, 2000.

BNL. 2000b. Operations and Maintenance Manual for the OU III Offsite Removal Action. Brookhaven National Laboratory, Upton, NY. February 11, 2000.

BNL. 2001a. BNL Spill Prevention, Control and Countermeasures Plan. Brookhaven National Laboratory, Upton, NY.

BNL. 2001b. OU IV Remediation Area 1 Proposed Supplemental Remedial Effort - Work Plan, Brookhaven National Laboratory, Upton, NY, May 2001.

BNL. 2002a. Building 96 Groundwater Source Control Treatment System Operations and Maintenance Manual. Brookhaven National Laboratory, Upton, NY. April 2002.

BNL. 2002b. Operations and Maintenance Manual for the Western South Boundary Treatment System. Brookhaven National Laboratory, Upton, NY. December 2002.

BNL. 2002c. Petition For Closure and Termination of Formal Post Closure Monitoring of OU IV Air Sparge/Soil Vapor Extraction Remediation System Brookhaven National Laboratory, Upton, NY, June 2002.

BNL. 2003a. Operations and Maintenance Manual for the OU III Middle Road and South Boundary Groundwater Treatment System, Revision 1. Brookhaven National Laboratory, Upton, NY. July 18, 2003.

BNL. 2003b. Final CERCLA Five Year Report for OU IV. Brookhaven National Laboratory, Upton, NY.

BNL. 2004a. Strontium-90 Pilot Study Report. Brookhaven National Laboratory, Upton, NY. April 2004.

BNL. 2004b. Strontium-90 Pilot Study Treatment System Operations and Maintenance Manual Modification. Brookhaven National Laboratory, Upton, NY. June 2004.

BNL. 2004c. OU III Building 96 Operations and Maintenance Manual Modification. Brookhaven National Laboratory, Upton, NY. June 2004.

BNL. 2004d. Building 96 Site Source Reduction Chemical Oxidation Scope of Work. Brookhaven National Laboratory, Upton, NY. November 2004.

BNL 2004e. Operations and Maintenance Manual for the OU IV EDB Groundwater Treatment System. Brookhaven National Laboratory, Upton, NY. Sept. 16, 2004.

BNL. 2004f. Operations and Maintenance Manual for the North Street/North Street East Offsite Groundwater Treatment Systems. Brookhaven National Laboratory, Upton, NY. August 24, 2004. 
BNL. 2004g. Operations and Maintenance Manual for the LIPA/Airport Groundwater Treatment System, Revision 2. Brookhaven National Laboratory, Upton, NY. August 23, 2004.

BNL. 2004h. LIPA/Airport System Discharge Monitoring Report. Brookhaven National Laboratory, Upton, NY. December 2004.

BNL. 2004i. Operations and Maintenance Manual for the Industrial Park East Offsite Groundwater Remediation System. Brookhaven National Laboratory, Upton, NY. September 3, 2004.

BNL. 20 04j. Petition to Shutdown the OU III Carbon Tetrachloride Treatment System. Broo khaven National Laboratory, Upton, NY. April 2004.

BNL 2005a. OU III Explanation of Significant Differences. Brookhaven National Laboratory, Upton, NY.

BNL. 2005b. Operations and Maintenance Manual for the RA V Treatment Facility. Brookhaven National Laboratory, Upton, NY. October 7, 2005.

BNL. 2005c. OU III Building 96 Groundwater Treatment Shutdown Petition (AOC 26B). Brookhaven National Laboratory, Upton, NY. April 2005.

BNL 2005d. Sr-90 BGRR/WCF/PFS Groundwater Treatment System Start-Up Report. Brookhaven National Laboratory, Upton, NY.

BNL 2005e. Operations and Maintenance Manual for the Sr-90 BGRR/WCF/PFS Groundwater Treatment System. Brookhaven National Laboratory, Upton, NY.

BNL. 20 06a. BNL 2006 Environmental Monitoring Plan, Brookhaven Nation al Laboratory, Upton, NY. January 2006.

BNL. 2006b. BNL 2006. g-2 Source Area and Tritium Plume - AOC 16T Focused Feasibility Study. BNL, October 1, 2006.

BNL 200 6c. BNL 200 6. The Proposed Remedial Action Plan for the g-2 Tritium Source area and Groundwater Plume, Brookhaven Linac Isotope Producer Soils, and Former Underground Storage Tanks at Brookhaven National Laboratory. BNL, Released for Public Comment October 12, 2006.

BNL. 200 7a. 2006 Environmental Monitoring Report, Current and Former Landfill Areas Broo khaven National Laboratory, Upton, NY. March 2007

BNL 2007b. Record of Decision for Area of Concern $16 T \mathrm{~g}-2$ Tritium Source Area and Groundwater Plume, Area of Concern 16K Brookhaven Linac Isotope Producer, and Area of Concern 12 Former Underground Storage Tanks. BNL. May 10, 2007.

BNL. 200 7c. 2006 Groundwater Monitoring Report for the Waste Management Facility. Brookhave $\mathrm{n}$ National Laboratory, Upton, NY.

BNL. 200 8a. 2007 Environmental Monitoring Report, Current and Former Landfill Areas Broo khaven National Laboratory, Upton, NY. March 2008

deLaguna, W. 1963. Geology of Brookhaven National Laboratory and Vicinity, Suffolk County NY.

DOE. 1990. Order 5400.5, Radiation Protection of the Public and the Environment. February 1990.

DOE. 2003. Order 450.1, Environmental Protection Program, 2003. 
Franke, O.L. and McClym onds, P. 1972. Summary of the hydrologic situation on Long Island, NY, as a guide to water management alternatives. USGS Professional Paper 627-F.

Paquette, D.E.; Bennett, D.B, and Dorsch, W.R. 2002. Brookhaven National Laboratory Groundwater Protection Management Description. BNL Report 52664. May 31, 2002.

Scorca, M.P., W.R. Dorsch, and D.E. Paquette. 1999. Stratigraphy and Hydraulic Conditions at the Brookhaven National Laboratory and Vicinity, Suffolk County, NY, 1994-97. U.S. Geological Survey Water Resources Investigations Report 99-4086.

U.S. Environmental Protec tion Agenc y (EPA). 1992. Interagenc y Agreement, Administrative Doc ket Number: II-CERCLA-FFA-00201, May 1992. 